\title{
$\therefore$ catalysts
}

\section{Novel Enzyme \\ and Whole-cell}

\section{Biocatalysts}

Edited by

Anwar Sunna and Richard Daniellou Printed Edition of the Special Issue Published in Catalysts 
Novel Enzyme and Whole-Cell Biocatalysts 



\section{Novel Enzyme and Whole-Cell Biocatalysts}

Editors

Anwar Sunna

Richard Daniellou 
Editors

Anwar Sunna

Macquarie University

Australia
Richard Daniellou

Université d'Orléans UMR-CNRS 7311

France

Editorial Office

MDPI

St. Alban-Anlage 66

4052 Basel, Switzerland

This is a reprint of articles from the Special Issue published online in the open access journal Catalysts (ISSN 2073-4344) (available at: https://www.mdpi.com/journal/catalysts/special_issues/enzyme_ whole_cell_biocataly).

For citation purposes, cite each article independently as indicated on the article page online and as indicated below:

LastName, A.A.; LastName, B.B.; LastName, C.C. Article Title. Journal Name Year, Article Number, Page Range.

ISBN 978-3-03943-464-0 (Hbk)

ISBN 978-3-03943-465-7 (PDF)

(C) 2020 by the authors. Articles in this book are Open Access and distributed under the Creative Commons Attribution (CC BY) license, which allows users to download, copy and build upon published articles, as long as the author and publisher are properly credited, which ensures maximum dissemination and a wider impact of our publications.

The book as a whole is distributed by MDPI under the terms and conditions of the Creative Commons license CC BY-NC-ND. 


\section{Contents}

About the Editors $\ldots \ldots \ldots \ldots \ldots \ldots \ldots \ldots \ldots \ldots \ldots \ldots \ldots \ldots$

Anwar Sunna and Richard Daniellou

Editorial Catalysts: Special Issue on Novel Enzyme and Whole-Cell Biocatalysts

Reprinted from: Catalysts 2020, 10, 1088, doi:10.3390/catal10091088 . . . . . . . . . . . . . . 1

Huixia Yang and Weiwei Zhang

Surfactant Imprinting Hyperactivated Immobilized Lipase as Efficient Biocatalyst for Biodiesel

Production from Waste Cooking Oil

Reprinted from: Catalysts 2019,9,914, doi:10.3390/catal9110914 . . . . . . . . . . . . . . 5

Fatima Shafiq, Muhammad Waseem Mumtaz, Hamid Mukhtar, Tooba Touqeer, Syed Ali Raza, Umer Rashid, Imededdine Arbi Nehdi and Thomas Shean Yaw Choong

Response Surface Methodology Approach for Optimized Biodiesel Production from Waste Chicken Fat Oil

Reprinted from: Catalysts 2020, 10,633, doi:10.3390/catal10060633 . . . . . . . . . . . . . .

Juan Pinheiro De Oliveira Martinez, Guiqin Cai, Matthias Nachtschatt, Laura Navone, Zhanying Zhang, Karen Robins and Robert Speight

Challenges and Opportunities in Identifying and Characterising Keratinases for Value-Added Peptide Production

Reprinted from: Catalysts 2020, 10, 184, doi:10.3390/catal10020184 . . . . . . . . . . . . . 31

Dominik Kopp, Robert Willows and Anwar Sunna

Characterisation of the First Archaeal Mannonate Dehydratase from Thermoplasma acidophilum and Its Potential Role in the Catabolism of D-Mannose

Reprinted from: Catalysts 2019,9, 234, doi:10.3390/catal9030234 . . . . . . . . . . . . . 55

Christin Burkhardt, Christian Schäfers, Jörg Claren, Georg Schirrmacher and Garabed Antranikian

Comparative Analysis and Biochemical Characterization of Two Endo- $\beta$-1,3-Glucanases from the Thermophilic Bacterium Fervidobacterium sp.

Reprinted from: Catalysts 2019,9,830, doi:10.3390/catal9100830 . . . . . . . . . . . . . 6

Hiryahafira Mohamad Tahir, Raja Noor Zaliha Raja Abd Rahman, Adam Thean Chor Leow and Mohd Shukuri Mohamad Ali

Expression, Characterisation and Homology Modelling of a Novel Hormone-Sensitive Lipase (HSL)-Like Esterase from Glaciozyma antarctica

Reprinted from: Catalysts 2020, 10, 58, doi:10.3390/catal10010058

David Aregger, Christin Peters and Rebecca M. Buller

Characterization of the Novel Ene Reductase Ppo-Er1 from Paenibacillus Polymyxa

Reprinted from: Catalysts 2020, 10, 254, doi:10.3390/catal10020254 . . . . . . . . . . . . . . . 105

Mihir V. Shah, James Antoney, Suk Woo Kang, Andrew C. Warden, Carol J. Hartley,

Hadi Nazem-Bokaee, Colin J. Jackson and Colin Scott

Cofactor $\mathrm{F}_{420}$-Dependent Enzymes: An Under-Explored Resource for Asymmetric

Redox Biocatalysis

Reprinted from: Catalysts 2019,9,868, doi:10.3390/catal9100868 . . . . . . . . . . . . . . . . 119 
Anamya Ajjolli Nagaraja, Philippe Charton, Xavier F. Cadet, Nicolas Fontaine, Mathieu Delsaut, Birgit Wiltschi, Alena Voit, Bernard Offmann, Cedric Damour, Brigitte Grondin-Perez and Frederic Cadet

A Machine Learning Approach for Efficient Selection of Enzyme Concentrations and Its Application for Flux Optimization

Reprinted from: Catalysts 2020, 10, 291, doi:10.3390/catal10030291 . . . . . . . . . . . . . . 137

Immobilization of $\beta$-Galactosidases on the Lactobacillus Cell Surface Using the Peptidoglycan-Binding Motif LysM

Reprinted from: Catalysts 2019, 9,443, doi:10.3390/catal9050443 . . . . . . . . . . . . . . . 161

Paula Bracco, Nelleke van Midden, Epifanía Arango, Guzman Torrelo, Valerio Ferrario, Lucia Gardossi and Ulf Hanefeld

Bacillus subtilis Lipase A-Lipase or Esterase?

Reprinted from: Catalysts 2020, 10, 308, doi:10.3390/catal10030308

Laure Guillotin, Zeinab Assaf, Salvatore G. Pistorio, Pierre Lafite, Alexei V. Demchenko and Richard Daniellou

Hydrolysis of Glycosyl Thioimidates by Glycoside Hydrolase Requires Remote Activation for Efficient Activity

Reprinted from: Catalysts 2019, 9, 826, doi:10.3390/catal9100826 . . . . . . . . . . . . . . . 197

Zhihai Liu, Alessandra Piccirilli, Dejun Liu, Wan Li, Yang Wang and Jianzhong Shen

Deciphering the Role of V88L Substitution in NDM-24 Metallo- $\beta$-Lactamase

Reprinted from: Catalysts 2019, 9,744, doi:10.3390/catal9090744 . . . . . . . . . . . . . . . . 209

Lynn Sophie Schwardmann, Sarah Schmitz, Volker Nölle and Skander Elleuche

Decoding Essential Amino Acid Residues in the Substrate Groove of a Non-Specific Nuclease from Pseudomonas syringae

Reprinted from: Catalysts 2019,9,941, doi:10.3390/catal9110941 . . . . . . . . . . . . . . . . . 221

Giuseppe Perugino, Andrea Strazzulli, Marialuisa Mazzone, Mosè Rossi and Marco Moracci Effects of Random Mutagenesis and In Vivo Selection on the Specificity and Stability of a Thermozyme

Reprinted from: Catalysts 2019, 9,440, doi:10.3390/catal9050440 . . . . . . . . . . . . . . 237

Christian Sonnendecker and Wolfgang Zimmermann

Change of the Product Specificity of a Cyclodextrin Glucanotransferase by Semi-Rational Mutagenesis to Synthesize Large-Ring Cyclodextrins

Reprinted from: Catalysts 2019, 9, 242, doi:10.3390/catal9030242 . . . . . . . . . . . . . . . 253

Yan Yang, Min-Zhi Liu, Yun-Song Cao, Chang-Kun Li and Wei Wang

Low-Level Organic Solvents Improve Multienzyme Whole-Cell Catalytic Synthesis of Myricetin-7-O-Glucuronide

Reprinted from: Catalysts 2019, 9, 970, doi:10.3390/catal9110970

Thais S. Milessi-Esteves, Felipe A.S. Corradini, Willian Kopp, Teresa C. Zangirolami,

Rautordioli, Roberto C. Giordano and Raquel L.C. Giordano

An Innovative Biocatalyst for Continuous 2G Ethanol Production from Xylo-Oligomers by Saccharomyces cerevisiae through Simultaneous Hydrolysis, Isomerization, and Fermentation (SHIF)

Reprinted from: Catalysts 2019, 9, 225, doi:10.3390/catal9030225 . . . . . . . . . . . . . . . . . 277 
Ran Cang, Li-Qun Shen, Guang Yang, Zhi-Dong Zhang, He Huang and Zhi-Gang Zhang Highly Selective Oxidation of 5-Hydroxymethylfurfural to 5-Hydroxymethyl2-Furancarboxylic Acid by a Robust Whole-Cell Biocatalyst

Reprinted from: Catalysts 2019, 9, 526, doi:10.3390/catal9060526 . . . . . . . . . . . . . . . 291

Najme Gord Noshahri, Jamshid Fooladi, Christoph Syldatk, Ulrike Engel, Majid M. Heravi, Mohammad Zare Mehrjerdi and Jens Rudat

Screening and Comparative Characterization of Microorganisms from Iranian Soil Samples Showing $\omega$-Transaminase Activity toward a Plethora of Substrates

Reprinted from: Catalysts 2019, 9, 874, doi:10.3390/catal9100874 307 



\section{About the Editors}

Anwar Sunna received his $\mathrm{PhD}$ in Technical Microbiology from the Hamburg University of Technology (TUHH) in Germany and has held research and teaching positions at the TUHH and Potsdam University. He joined Macquarie University (MQ) in 2005 at the Department of Molecular Sciences. He was manager of the Environmental Biotechnology Cooperative Research Centre at $\mathrm{MQ}$ and later was the recipient of the prestigious MQ Vice-Chancellor's Innovation Fellowship. His research is strongly driven by industrial and biomedical applications using Synthetic Biology and NanoBiotechnology to address current biotechnological and biomedical challenges. His current research integrates enzyme technology and biomolecule-inorganic interactions with synthetic biology for the construction of multi-enzyme biocatalytic modules and the assembly of synthetic pathways. His research is aimed at addressing current relevant issues including valorization of organic waste, and biomanufacturing bulk and specialty chemicals. He is currently the Director of the MQ Biomolecular Discovery Research Centre, one of the Directors of Synthetic Biology Australasia, and the Director of the Master of Biotechnology and Master of Biotechnology and Business programs at Macquarie University.

Richard Daniellou, An internationally recognized expert in Glycosciences, Prof. Richard Daniellou received a BSc in Biochemistry and a PhD (2003) in Organic Chemistry from Paris XI. After two years as a postdoctoral researcher at the University of Saskatchewan (Canada), he was offered an Assistant Professor position at the ENSC of Rennes (France). In 2010, he was promoted Full Professor of Biochemistry at ICOA (France). His main interest for carbohydrate-active enzymes as biocatalysts for chemo-enzymatic synthesis of glycoconjugates led him to the creation of the research group named Enzymology and Glycobiochemistry. He is currently the co-author of 75 publications and 3 patents. 



\title{
Editorial \\ Editorial Catalysts: Special Issue on Novel Enzyme and Whole-Cell Biocatalysts
}

\author{
Anwar Sunna ${ }^{1, *}$ and Richard Daniellou ${ }^{2, *}$ \\ 1 Department of Molecular Sciences, Macquarie University, Sydney, NSW 2109, Australia \\ 2 ICOA UMR CNRS 7311, University of Orleans, rue de Chartres, BP 6759, CEDEX 2, 45067 Orléans, France \\ * Correspondence: anwar.sunna@mq.edu.au (A.S.); richard.daniellou@univ-orleans.fr (R.D.)
}

Received: 16 September 2020; Accepted: 17 September 2020; Published: 20 September 2020

Keywords: chemo-enzymatic synthesis; glycosyl transferases; protein engineering; carbohydrates; biocatalysis; synthetic biology; industrial enzymes; thermostable enzymes; glycoside hydrolases; cell-free biocatalysis; natural and non-natural multi-enzyme pathways; bio-based chemicals

Global trends emphasizing the reduction of organic waste, carbon capture and landfill avoidance are driving the demand for greener products with improved properties. Recent advances in synthetic biology, molecular biology, computational tools and metabolic engineering have promoted the discovery of new enzymes and the rational design of whole-cell biocatalysts. Accordingly, with increased demand for sustainable and environmentally-friendly biomanufacturing, the field of enzyme technology and biocatalysis (multi-enzymes and whole-cells) has become a primary focus for the synthesis of bio-based chemicals and high-value compounds.

In this Special Issue, we would like to highlight these current advances in the field of biocatalysis, with special emphasis on novel enzymes and whole-cell biocatalysts for applications in industry, health, or cosmetics.

Over the past decades, biodiesel has attracted great interest as a sustainable alternative for fossil fuels. Two research papers focused on this important challenge. The enzymatic production of biodiesel from waste cooking oil that could contribute to resolve the problems of energy demand and environment pollution. Yang et al. [1] report on the activation of Burkholderia cepacia lipase by surface imprinting and its immobilization in magnetic cross-linked enzyme aggregates, thus exhibiting a significant increase in biodiesel yield and tolerance to methanol. Shafiq et al. [2] describe the use of response surface methodology to optimize the reaction parameters of bioproduction of biodiesel from waste chicken fat oil and demonstrated that optimal yield can be obtained in their conditions using immobilized Aspergillus terreus lipase on $\mathrm{Fe}_{3} \mathrm{O}_{4}$ nanoparticles with a methanol-to-oil ratio of 6:1 at $42{ }^{\circ} \mathrm{C}$ for $36 \mathrm{~h}$.

However, bioproduction is certainly not limited to solving energy and environmental troubles and there is also a challenging area in the field of biomass valorization, as depicted by an excellent review from Martinez et al. [3]. The authors outlined the challenges and opportunities in the discovery of original keratinases for value-added peptide production. Indeed, keratins represent millions of tons of protein wastes and their enzymatic hydrolysates can generate valuable industrial applications. To do so, the search for original, innovative and robust biocatalysts is a key step, and extremophile sources are a good starting point. Therefore, a large part of this special issue has been devoted to this immense field of research. First, Kopp et al. [4] identify and characterize the first archaeal mannonate dehydratase from Thermoplasma acidophilum and demonstrate it to have an original physiological role in this extremophile. Then, Burkhardt et al. [5] show interest in two endo- $\beta-1,3$-glucanases from the thermophilic bacterium Fervidobacterium sp. These two enzymes proved to be highly specific to laminarin and tolerant to high temperature, and are good candidates for application in biomass conversion. In addition, Tahir et al. [6] clone and overexpress a novel hormone-sensitive lipase-like 
esterase from Glaciozyma antartica. Unlike other known enzymes, this protein demonstrates higher activity towards medium-chain ester substrates, rather than shorter chain esters, and increased stability at $60{ }^{\circ} \mathrm{C}$, as well as alkaline $\mathrm{pH}$ conditions. In addition, asymmetric catalysis is evoked by the article of Aregger et al. [7], in which the authors report the characterization of the novel ene reductase Ppo-Er1 from Paenibacillus polymyxa. This biocatalyst exhibits enantioselective activity towards a large panel of substrates, a large range of temperature and co-solvents, making it a promising tool for industrial bioconversions. Finally, an excellent review from Shah et al. [8] presents the cofactor F420 both (i) as an alternative to nicotinamide cofactors implicated in asymmetric reduction of enoates, imines and ketones, and (ii) as an underexplored resource for asymmetric redox biocatalysis at the industrial level.

Besides revealing their original activities, many processes also can be improved so to increase industrial applications of enzymes. One elegant and powerful example relies in the machine learning approach described by Nagaraja et al. [9] for the efficient selection of enzyme concentration and its application for flux optimization. Pham et al. [10] demonstrate the immobilization of $\beta$-galactosidase on the Lactobacillus cell surface using LysM, the common peptidoglycan-binding motif, thus facilitating many uses of the biocatalyst and showing its potential for applications in the synthesis of prebiotic galacto-oligosaccharides.

Understanding the intrinsic mechanism of the enzyme also can help in improvement of the biocatalyst. Bracco et al. [11] demonstrated one decisive criterion to differentiate between esterase and lipase, with the latter being the only one active in dry organic solvents. Substrates also can give important clues on the mechanism, as demonstrated by Guillotin and co-workers [12] when using glycosyl thioimidates with biologically-relevant glycoside hydrolases. Fine tuning of amino acids is another level of improvement. Liu et al. [13] show the role of V88L substitution in increasing the enzyme activity and decreasing the protein stability in the New Dehli metallo- $\beta$-lactamase- 1 family. Mutagenesis of enzymes is a further powerful tool as shown by Schwardmann et al. [14]. The authors studied the well-defined outer ring of the substrate groove of a non-specific nuclease from Pseudomonas syringae and defined it as a potential target for modulation of the enzymatic performance. Perugino et al. [15] demonstrated that random mutagenesis and biological selection allowed the identification of residues that are critical in determining thermal activity, stability and substrate recognition of a $\beta$-glycosidase from the thermoacidophile Saccharolobus solfataricus. Cyclodextrin transferase's product specificity was changed finally by Sonnendecker et al. [16] by semi-rational mutagenesis, obtaining larger cyclodextrin's rings of up to 12 units.

Whole-cell biocatalysed reactions are also discussed broadly. First, the impact of low-level organic solvents on engineered Escherichia coli strains was studied in a model reaction of multi-enzyme whole-cell biocatalysts by Yang and co-workers [17]. Secondly, Milessi-Esteves et al. [18] described the production of ethanol from xylo-oligomers by native Saccharomyces cerevisiae. The authors investigate a new concept of biocatalysts to overcome the ease of the contamination of the bioreactor by bacteria that metabolize xylose. In addition, Cang et al. [19] showed that the extremely radiation resistant Deinococcus wulumquiensis R12 was a new and robust biocatalyst for selective oxidation of 5-hydroxymethylfurfural to 5-hydroxymethyl-2-furancaroxylic acid. In the final contribution, Noshahri et al. [20] examined the Iranian soil to locate robust microorganisms with $\omega$-transaminase activities.

In conclusion, this Special Issue showcases a large panel of techniques and tools in biocatalysis, so as to transform biomass into valuable energy and other bioproducts. 
Funding: This research received no external funding.

Conflicts of Interest: The authors declare no conflict of interest.

\section{References}

1. Yang, H.; Zhang, W. Surfactant imprinting hyperactivated immobilized lipase as efficient biocatalyst for biodiesel production from waste cooking oil. Catalysts 2019, 9, 914. [CrossRef]

2. Shafiq, F.; Mumtaz, M.W.; Mukhtar, H.; Touqeer, T.; Raza, S.A.; Rashid, U.; Nehdi, I.A.; Choong, T.S.Y. Response surface methodology approach for optimized biodiesel production from waste chicken fat oil. Catalysts 2020, 10, 633. [CrossRef]

3. De Oliveira Martinez, J.P.; Cai, G.; Nachtschatt, M.; Navone, L.; Zhang, Z.; Robins, K.; Speight, R. Challenges and opportunities in identifying and characterising keratinases for value-added peptide production. Catalysts 2020, 10, 184. [CrossRef]

4. Kopp, D.; Willows, R.; Sunna, A. Characterisation of the first archaeal mannonate dehydratase from Thermoplasma acidophilum and its potential role in the catabolism of D-Mannose. Catalysts 2019, 9, 234. [CrossRef]

5. Burkhardt, C.; Schäfers, C.; Claren, J.; Schirrmacher, G.; Antranikian, G. Comparative analysis and biochemical characterization of two endo- $\beta$-1,3-glucanases from the thermophilic bacterium Fervidobacterium sp. Catalysts 2019, 9, 830. [CrossRef]

6. Tahir, H.M.; Raja Abd Rahman, R.N.Z.; Leow, A.T.C.; Ali, M.S.M. Expression, characterisation and homology modelling of a novel hormone-sensitive lipase (HSL)-like esterase from Glaciozyma antarctica. Catalysts 2020, 10, 58. [CrossRef]

7. Aregger, D.; Peters, C.; Buller, R.M. Characterization of the novel ene reductase Ppo-Er1 from Paenibacillus polymyxa. Catalysts 2020, 10, 254. [CrossRef]

8. Shah, M.V.; Antoney, J.; Kang, S.W.; Warden, A.C.; Hartley, C.J.; Nazem-Bokaee, H.; Jackson, C.J.; Scott, C. Cofactor $\mathrm{F}_{420}$-dependent enzymes: An under-explored resource for asymmetric redox biocatalysis. Catalysts 2019, 9, 868. [CrossRef]

9. Nagaraja, A.A.; Charton, P.; Cadet, X.F.; Fontaine, N.; Delsaut, M.; Wiltschi, B.; Voit, A.; Offmann, B.; Damour, C.; Grondin-Perez, B.; et al. A machine learning approach for efficient selection of enzyme concentrations and its application for flux optimization. Catalysts 2020, 10, 291. [CrossRef]

10. Pham, M.L.; Tran, A.M.; Kittibunchakul, S.; Nguyen, T.T.; Mathiesen, G.; Nguyen, T.H. Immobilization of $\beta$-galactosidases on the Lactobacillus cell surface using the peptidoglycan-binding motif LysM. Catalysts 2019, 9, 443. [CrossRef] [PubMed]

11. Bracco, P.; van Midden, N.; Arango, E.; Torrelo, G.; Ferrario, V.; Gardossi, L.; Hanefeld, U. Bacillus subtilis lipase A-Lipase or esterase? Catalysts 2020, 10, 308. [CrossRef]

12. Guillotin, L.; Assaf, Z.; Pistorio, S.G.; Lafite, P.; Demchenko, A.V.; Daniellou, R. Hydrolysis of glycosyl thioimidates by glycoside hydrolase requires remote activation for efficient activity. Catalysts 2019, 9, 826 . [CrossRef]

13. Liu, Z.; Piccirilli, A.; Liu, D.; Li, W.; Wang, Y.; Shen, J. Deciphering the role of V88L substitution in NDM-24 metallo- $\beta$-lactamase. Catalysts 2019, 9, 744. [CrossRef]

14. Schwardmann, L.S.; Schmitz, S.; Nölle, V.; Elleuche, S. Decoding essential amino acid residues in the substrate groove of a non-specific nuclease from Pseudomonas syringae. Catalysts 2019, 9, 941. [CrossRef]

15. Perugino, G.; Strazzulli, A.; Mazzone, M.; Rossi, M.; Moracci, M. Effects of random mutagenesis and in vivo selection on the specificity and stability of a thermozyme. Catalysts 2019, 9, 440. [CrossRef]

16. Sonnendecker, C.; Zimmermann, W. Change of the product specificity of a cyclodextrin glucanotransferase by semi-rational mutagenesis to synthesize large-ring cyclodextrins. Catalysts 2019, 9, 242. [CrossRef]

17. Yang, Y.; Liu, M.Z.; Cao, Y.S.; Li, C.K.; Wang, W. Low-level organic solvents improve multienzyme whole-cell catalytic synthesis of myricetin-7-O-glucuronide. Catalysts 2019, 9, 970. [CrossRef]

18. Milessi-Esteves, T.S.; Corradini, F.A.S.; Kopp, W.; Zangirolami, T.C.; Tardioli, P.W.; Giordano, R.C.; Giordano, R.L.C. An innovative biocatalyst for continuous $2 \mathrm{G}$ ethanol production from xylo-oligomers by Saccharomyces cerevisiae through simultaneous hydrolysis, isomerization, and fermentation (SHIF). Catalysts 2019, 9, 225. [CrossRef] 
19. Cang, R.; Shen, L.Q.; Yang, G.; Zhang, Z.D.; Huang, H.; Zhang, Z.G. Highly selective oxidation of 5-hydroxymethylfurfural to 5-hydroxymethyl-2-furancarboxylic acid by a robust whole-cell biocatalyst. Catalysts 2019, 9, 526. [CrossRef]

20. Noshahri, N.G.; Fooladi, J.; Syldatk, C.; Engel, U.; Heravi, M.M.; Mehrjerdi, M.Z.; Rudat, J. Screening and comparative characterization of microorganisms from iranian soil samples showing $\omega$-transaminase activity toward a plethora of substrates. Catalysts 2019, 9, 874. [CrossRef]

(C) 2020 by the authors. Licensee MDPI, Basel, Switzerland. This article is an open access article distributed under the terms and conditions of the Creative Commons Attribution (CC BY) license (http://creativecommons.org/licenses/by/4.0/). 
Article

\title{
Surfactant Imprinting Hyperactivated Immobilized Lipase as Efficient Biocatalyst for Biodiesel Production from Waste Cooking Oil
}

\author{
Huixia Yang and Weiwei Zhang * \\ State Key Laboratory of High-efficiency Utilization of Coal and Green Chemical Engineering, School of \\ Chemistry and Chemical Engineering, Ningxia University, Yinchuan 750021, China; yhx6668297@sina.com \\ * Correspondence: zhangww@nxu.edu.cn; Tel.: +86-0951-2062004
}

Received: 12 October 2019; Accepted: 29 October 2019; Published: 1 November 2019

\begin{abstract}
Enzymatic production of biodiesel from waste cooking oil (WCO) could contribute to resolving the problems of energy demand and environment pollutions.In the present work, Burkholderia cepacia lipase (BCL) was activated by surfactant imprinting, and subsequently immobilized in magnetic cross-linked enzyme aggregates (mCLEAs) with hydroxyapatite coated magnetic nanoparticles (HAP-coated MNPs). The maximum hyperactivation of BCL mCLEAs was observed in the pretreatment of BCL with $0.1 \mathrm{mM}$ Triton X-100. The optimized Triton-activated BCL mCLEAs was used as a highly active and robust biocatalyst for biodiesel production from WCO, exhibiting significant increase in biodiesel yield and tolerance to methanol. The results indicated that surfactant imprinting integrating mCLEAs could fix BCL in their active (open) form, experiencing a boost in activity and allowing biodiesel production performed in solvent without further addition of water. A maximal biodiesel yield of $98 \%$ was achieved under optimized conditions with molar ratio of methanol-to-WCO 7:1 in one-time addition in hexane at $40^{\circ} \mathrm{C}$. Therefore, the present study displays a versatile method for lipase immobilization and shows great practical latency in renewable biodiesel production.
\end{abstract}

Keywords: biodiesel; waste cooking oil; lipase immobilization; interfacial activation; functionalized magnetic nanoparticles

\section{Introduction}

Over the past decades, biodiesel has attracted great interest as a sustainable alternative for fossil fuels in virtue of the depletion of fossilized fuel resources and their environmental impacts [1]. Biodiesel is a renewable and clean energy, and possess favorable advantages in combustion emission like low emissions of $\mathrm{CO}$, sulfur free, low hydrocarbon aroma, high cetanenumber, and high flash point [2].

The conventional chemical technologies for biodiesel production involve the use of acid or basic catalysts (i.e., $\mathrm{NaOH}, \mathrm{KOH}$, and $\mathrm{H}_{2} \mathrm{SO}_{4}$ ), thus numerous disadvantages are inescapable, for example, high corrosive procedure, high energy consumption, high quantities of waste pollution, and costly in efficient product separation processes [3]. Furthermore, in order to prevent the hydrolysis reaction and saponification, high quality oils are required, with low contents of water and free fatty acids [4].

Feedstocks used for biodiesel can be allocated five categories, including edible vegetable oils, non-edible plant oils, animal fats, microalgae oils, and waste oils [5]. The global application of first-generation biodiesel produced by using edible oils, was restricted due to food scarcity and high cost of the edible oils [6]. Biodiesel production from waste cooking oils (WCO) could be a promising and cost effective candidate in handling issues associated with energy crisis, environmental concerns, and total cost reduction of biodiesel production [7]. Moreover, 15 million tons of WCO are produced annually throughout the world [8], bringing great challenge in reasonable management 
of such oils on account of environment concerns [9]. However, using WCO as raw material is quite challenging as it contains a high amount of free fatty acids (FFAs) and water which could hinder the homogeneous alkaline-catalyzed transesterification in conventional biodiesel production processes [10]. Complete conversion of these low-quality feedstocks like WCO could be accomplished in enzymatic biodiesel production without saponification. Therefore, enzyme-catalyzed transesterification has become a laudable potential alternative for biodiesel synthesis.

Particularly, lipases are foremost and efficient enzymes implemented in biodiesel production. Lipase-catalyzed process exhibits key advantages such as no soap formation, high-purity products, easy product removal, adaptable to different biodiesel feedstock, environmentally friendly, and mild operating conditions [5]. However, the commercialization of enzymatic biodiesel production remains complicated, because of high price and low stability of lipases as well as low reaction rate of biocatalysis. Heterogeneous enzyme-catalyzed transesterification using immobilized lipases is a possible solution to these problems [11].

Immobilization of enzymes has been investigated for many years, and lipase can generally be immobilized by various techniques such as cross-linking, adsorption, entrapment and encapsulation [12,13]. Thereinto, cross-linked enzyme aggregates (CLEAs) is a cheap and efficient strategy for enzyme immobilization, which has broad applicability over numerous enzyme classes. Owing to its outstanding resistance to organic solvents, extreme $\mathrm{pH}$, and high temperatures, CLEAs has attracted growing attention in cost effective biocatalysis [14]. Nevertheless, small particle size and low mechanical stability of CLEAs could directly affect mass transfer and stability under operational conditions, thus accordingly cause problems in practical use [15]. An alternative approach for circumventing compressed construction of CLEAs is to use "smart" magnetic CLEAs (mCLEAs). Magnetic nanoparticles (MNPs) could provide enhanced stability over repeated uses, especially for enzymes having low amount of lysine residues on their surface. Besides, mCLEAs could perform easily separation using a permanent magnet, affording novel combinations of bioconversions and down-streaming processes, thus provide the necessary reduction in enzymecosts to enable commercial viability.

Among various types of nanomaterials, MNPs have attracted substantial attention in enzyme immobilizations. However, bare MNPs tend to aggregate due to their high surface energy and are easily oxidized in the air leading to loss of magnetism and dispersibility, thus limiting their exploitation in practical applications [16]. The surface modification with an organic or an inorganic shell is an appropriate strategy to address these issues. Due to their excellent biocompatibility, slow biodegradation, high surface area-to-volume-ratio, and unique mechanical stability, Hydroxyapatite (HAP) could be a proper inorganic surface coating for MNPs [17]. Moreover, HAP-coated MNPs can be easily functionalized with organosilanes, and consequently has great application potential in enzyme immobilization.

Burkholderia cepacia lipase (BCL)is one of the most widely used lipases in biocatalysis [18]. On account of its versatility to accommodate a wide variety of substrates, high heat resistance, and good tolerance to polar organic solvents, BCL has been extensively used in various biotechnological processes, especially for biodiesel production. The active site of BCL is shielded by a mobile element, called the lid or flap [19]. The displacement of lid or flap to closed or open position, which directly impacts the accessibility of active site, determines the enzyme in an in active or active conformation. In general, substrate access to the underlying active site is prohibited in its closed configuration. As the stabilization of the open conformation of all lipases could remarkably increase their catalytic activity, a favorable method to obtain highly active biocatalysts should try to immobilize lipases in their most active form (open conformation).

Generally, the preparation of immobilized enzyme with enhanced activity and stability is a persistent goal of the biotechnology industry to seek maximum profit. Therefore, developing a simple and efficient approach for lipase interfacial activation in immobilization is highly desirable. Bioimprinting is a commonly used method for achieving hyperactivation of lipases in organic media. 
The principle of bioimprinting is to "anchor" the enzyme in its active form, which could be achieved by binding with imprint molecules (such as surfactants, natural substrates, substrate analogs etc.). From an applied point of view, the dramatic hyperactivation of lipases by low concentrations of surfactants is an expeditious and facile method for lipase interfacial activation [20].

To develop an efficient and environmentally benign process for the biodiesel production from waste cooking oils, in the present study surfactant imprinting strategy on BCL was implemented in combination with mCLEAs immobilization using HAP-coated MNPs. Subsequent cross-linking could "lock" BCL in its favorable conformation, while HAP-coated MNPs could facilitate the recovery of immobilized BCL and simplify the biodiesel purification. To the best of our knowledge, this is the first report on BCL immobilization integrating surfactant imprinting and mCLEAs. The optimal conditions for mCLEAs preparation, along with the effect of different surfactants (anionic, cationic, and non-ionic) on the catalytic activity of BCL mCLEAs in transesterification were studied. The optimized surfactant-activated BCL mCLEAs was further used in transesterification of waste cooking oils to biodiesel. In addition, a detailed analysis of solvents, methanol-to-oil molar ratio, and temperatures on the yield of biodiesel production was presented. The results obtained in the research are expected to provide a reliable basis for further exploration of lipase immobilization and efficient biodiesel production in industry.

\section{Results and Discussion}

\subsection{Preparation and Characterization of Immobilized Lipase}

In this study, the prepared MNPs encapsulated by hydroxyapatite (HAP) were used as immobilization supports. The amino functionalization of HAP-coated MNPs was carried out using 3-aminopropyltrimethoxysilane (APTES) for efficient enzyme attachment. Typically, the preparation procedure of immobilization supports and surfactant-activated BCL mCLEAs were performed according to the scheme shown in Scheme 1. The prepared magnetic supports and immobilized BCL were characterized by fourier transform infrared spectroscopy (FT-IR), transmission electron microscope (SEM) and vibrating sample magnetometer (VSM).

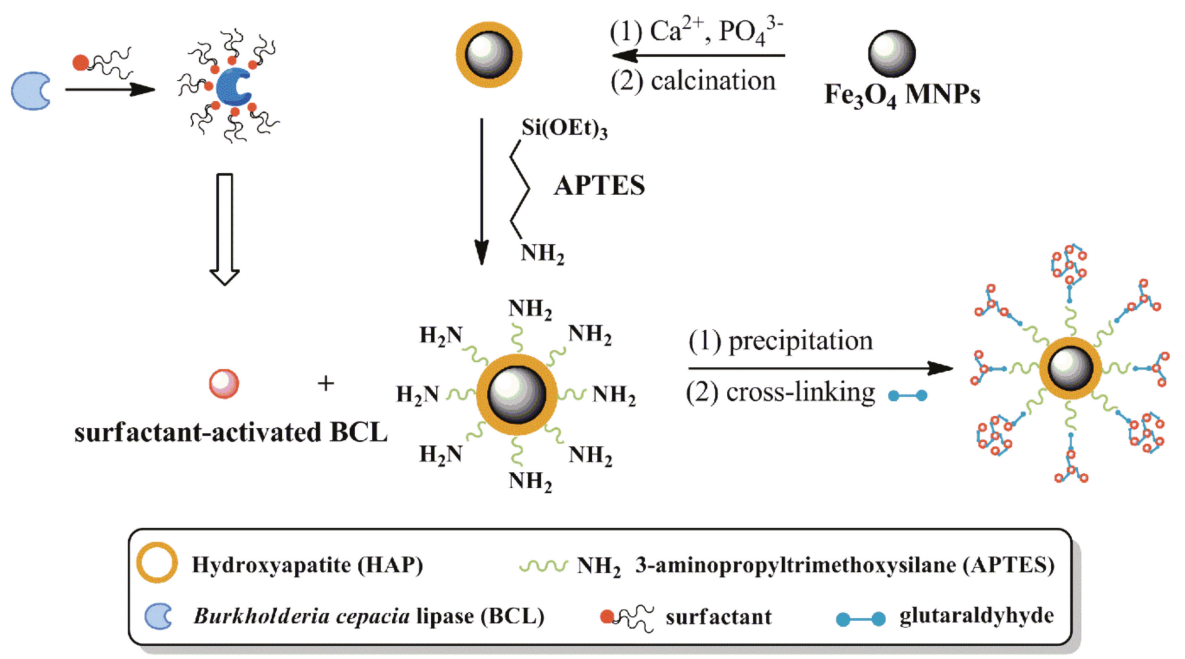

Scheme 1. Preparation procedure of immobilization supports and surfactant-activated Burkholderia cepacia lipase (BCL) magnetic cross-linked enzyme aggregates (mCLEAs).

FTIR characterization was performed to investigate the chemical composition of functionalized MNPs and immobilized BCL. Spectra were recorded on over the region from 4000 to $400 \mathrm{~cm}^{-1}$. 
As shown in Figure 1, the strong peak at 588 and $639 \mathrm{~cm}^{-1}$ corresponds to the stretching vibration of Fe-O bond. The characteristic absorption bands related to the HAP appease at 565 and $1044 \mathrm{~cm}^{-1}$, which are assigned to phosphate groups [21]. In the IR spectrum of modified MNPs and BCL mCLEAs, the characteristic absorption bands related to the functional groups of HAP emerged clearly, which demonstrated the successful incorporation of MNPs with HAP. For all immobilized lipases, including BCL CLEAs, BCL mCLEAs and surfactant-activated BCL mCLEAs, the typical IR bands responsible for the lipase that were chemically covalent-bonded to the functionalized MNPs were observed at $1642 \mathrm{~cm}^{-1}$ for amide I (C=O stretching vibration) and at $1539 \mathrm{~cm}^{-1}$ for amide II (N-H bending vibration), respectively. Besides, compared with the results shown in Figure 1, aliphatic $\mathrm{C}-\mathrm{H}$ stretch band at 2859 and $2927 \mathrm{~cm}^{-1}$, corresponding to C-H stretching vibrations, are clearly observed in all immobilized lipases, which also indicated the successful loading of lipase.

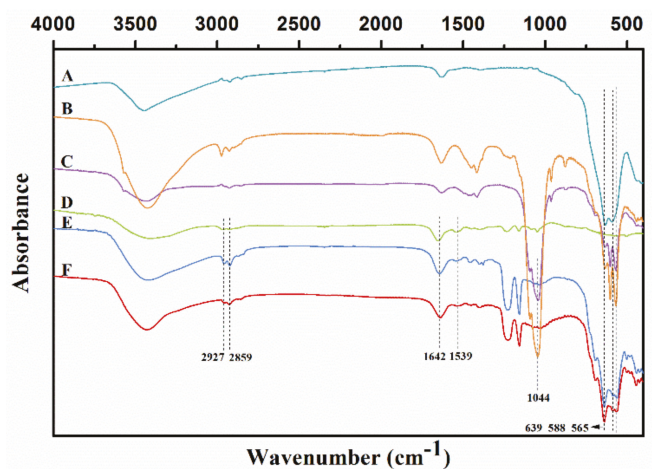

Figure 1. Spectra of (A) $\mathrm{Fe}_{3} \mathrm{O}_{4} \mathrm{MNPs}$, (B) hydroxyapatite coated magnetic nanoparticles (HAP-coated MNPs), (C) 3-aminopropyltrimethoxysilane (APTES)-HAP-coated MNPs, (D) BCL CLEAs, (E) BCL mCLEAs, (F) Triton-activated BCL mCLEAs.

In order to assess morphology, size and composition of functionalized MNPs and immobilized BCL, SEM images were collected and illustrated in Figure 2. As seen in Figure 2, bare $\mathrm{Fe}_{3} \mathrm{O}_{4} \mathrm{MNPs}$ formed significantly dense agglomeration, because of their high surface energy and strong dipole-dipole interactions. It is obvious that the structure of $\mathrm{Fe}_{3} \mathrm{O}_{4} \mathrm{MNPs}$ becomes looser and more evenly distributed after being functionalized with HAP (Figure 2B) and APTES (Figure 2C), suggesting that surface modification is favorable for preventing aggregation of $\mathrm{Fe}_{3} \mathrm{O}_{4} \mathrm{MNPs}$. At the same time, the rough surface of $\mathrm{Fe}_{3} \mathrm{O}_{4}$ MNPs also increased the surface area for attachment of enzyme.

The crucial structure factors in aggregated-based enzyme immobilization, including morphological topographies, structural arrangement and size, play an important role in affecting substrate affinity and stability of biocatalyst [22]. Besides, the particle size of enzymes is an important property of any heterogeneous catalysis since it can directly affect the diffusion of substrates and catalytic efficiency, especially in the internal enzymes of highly compact aggregates [23]. SEM images (Figure 2D) of standard BCL CLEAs revealed no defined morphologies and large size particles. Moreover, standard BCL CLEAs presented a uniform and compact surface with the presence of few tiny pores. On the contrary, after the incorporation of functionalized MNPs, BCL mCLEAs formed spherical structures and small particle sizes, which could reduce inner steric hindrance in closely packed CLEAs. It is noteworthy that the presence of functionalized MNPs displayed large active surface available for lipase immobilization, therefore were important for development of a stabilized enzyme-matrix. Furthermore, a loose and homodispersed structure of Triton-activated BCL mCLEAs was found in Figure $2 \mathrm{~F}$, suggesting that the formation of large aggregates were forbidden by the imprinting of surfactants. From the SEM outcomes, it can be discerned that, thanks to the coating of surfactants, lipase could be uniformly dispersed on functionalized MNPs, which could contribute to a wider 
surface area with more catalytic sites and decrease the diffusion limit. Consequently, compared with standard BCL CLEAs, Triton-activated BCL mCLEAs could perform superior catalytic efficiency.

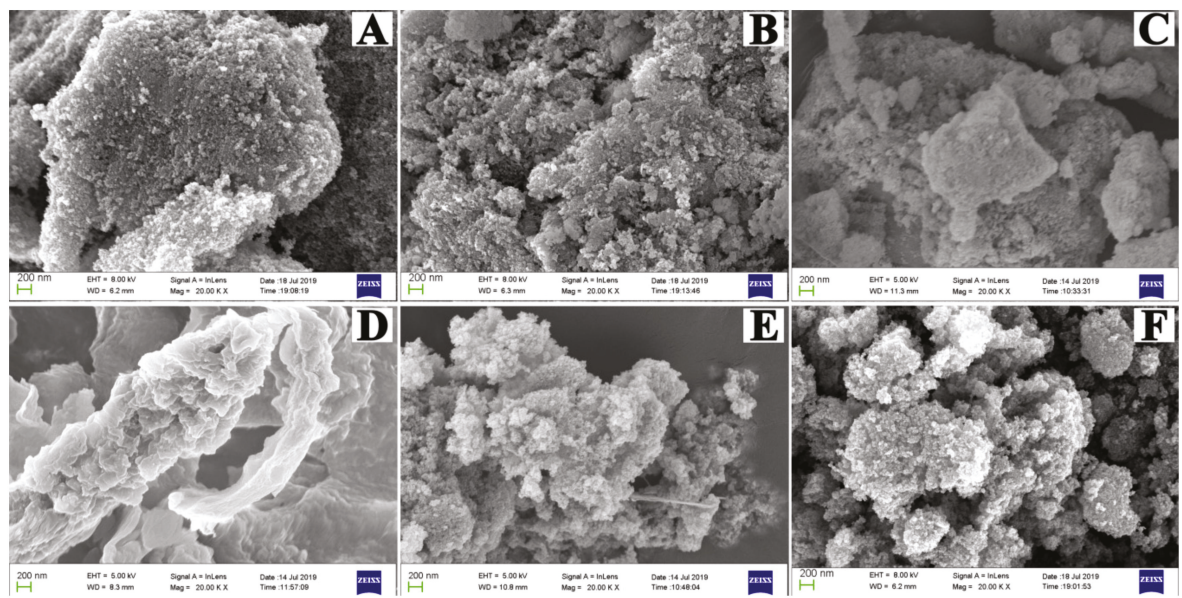

Figure 2. Images of(A) $\mathrm{Fe}_{3} \mathrm{O}_{4}$ MNPs, (B) HAP-coated MNPs, (C) APTES-HAP-coated MNPs, (D) BCL CLEAs, (E) BCL mCLEAs, (F) Triton-activated BCL mCLEAs.

The magnetic property of functionalized MNPs and immobilized BCL were measured using VSM. The hysteresis curves of the $\mathrm{Fe}_{3} \mathrm{O}_{4}$ MNPs, HAP-coated MNPs, APTES-HAP-coated MNPs, BCL mCLEAs and Triton-activated BCL mCLEAs shown in Figure 3, exhibited a perfect sigmoidal behavior, corresponding to a typical superparamagnetism.

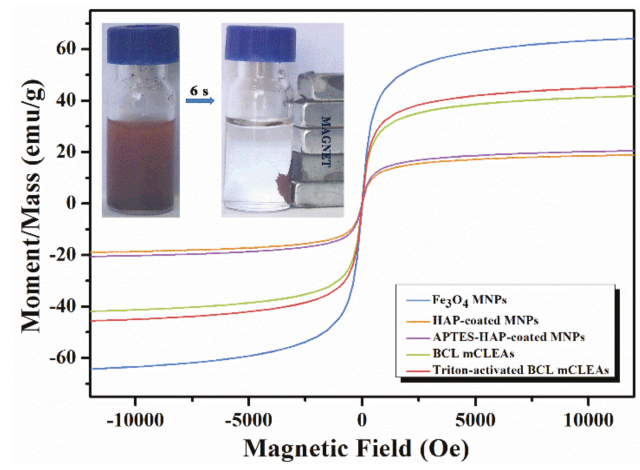

Figure 3. Hysteresis loops of $\mathrm{Fe}_{3} \mathrm{O}_{4}$ MNPs, HAP-coated MNPs, APTES-HAP-coated MNPs, BCL mCLEAs and Triton-activated BCL mCLEAs. The inner shows the easy magnetic separation of Triton-activated BCL mCLEAs in reaction mixture.

With further functionalization of MNPs, the saturation magnetization value decreased and correlated with the increase of the core-shell layer. Interestingly, it is obviously observed that the saturation magnetization value of Triton-activated BCL mCLEAs increased visibly compared to BCL mCLEAs. It might be due to the uniform dispersion of lipase on MNPs and availability of large surface area which decreased the shielding-effect of the out layer substances. As seen in Figure 3 (inner), Triton-activated BCL mCLEAs showed fast response (6s) to the external magnetic field andcould be easily recovered from the reaction mixture. After removing the external magnetic field, the magnetic 
immobilized BCL redispersed rapidly by a slight shake, indicating good dispersion and efficient recyclability in industrial application.

\subsection{Optimization of the Immobilization Conditions}

In this study, the enzymes were precipitated by adding water-miscible organic solvents (acetone, ethanol and 2-propanol), PEG 800 and ammonium sulfate. The optimum precipitant was selected by measuring the transesterification activity of the corresponding BCL mCLEAs. Compared with free BCL, all BCL mCLEAs prepared using different precipitants performed higher transesterification activity in organic solvent. Among the protein precipitants evaluated, ammonium sulfate showed maximum recovery of activity (Figure 4a), therefore was further used in BCL immobilization.
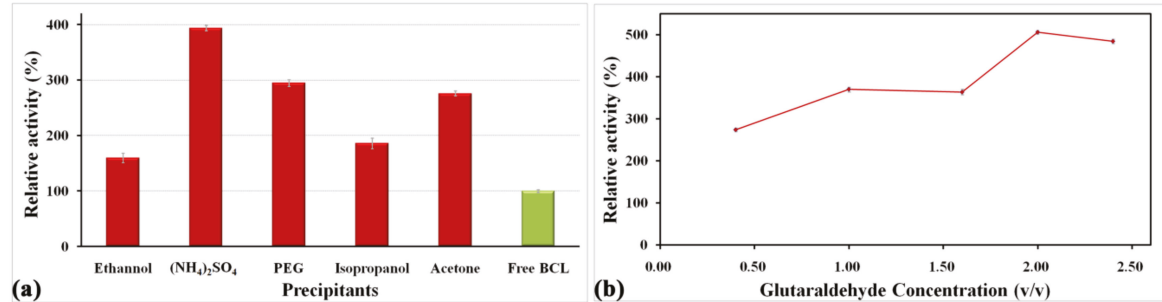

Figure 4. (a) Precipitant type and (b) glutaraldehyde concentration on the activities of BCL mCLEAs.

Traditionally, glutaraldehyde has been extensively used as the cross-linking agent to prepare CLEAs of various enzymes and exhibited a strong effect on activity and particle size of enzyme aggregates. The activity recovery of CLEAs greatly depends on the type of enzyme and the concentration of glutaraldehyde [24]. Lower glutaraldehyde concentration affects the cross-linking efficiency, which might result in enzyme leakage in immobilization, while excessive glutaraldehyde can induce the flexibility of enzymes and the active site availability, consequently, decreasing the activity recovery of CLEAs [25,26]. In this study, the influence of glutaraldehyde concentration on activity of BCL mCLEAs was investigated by using various concentrations of glutaraldehyde in cross-linking. As shown in Figure $4 \mathrm{~b}$, the optimum glutaraldehyde concentration of BCL mCLEAs was $2.0 \%$ (v/v).

\subsection{Hyperactivation of BCL $m C L E A$ s with Surfactants}

A pivotal challenge in lipase immobilization is to open the lid of lipases and fix their open form for the exposure of active site. Surfactant imprinting is an efficient approach to activate lipases by facilitating lid-opening. Like other lipases, BCL also consists of a mobile element at the surface, which composed of two helical elements (a5- and a9-helices) and covers the active site [18]. To improve the catalytic performance of BCL mCLEAs, BCL was imprinted in the presence of surfactants prior to immobilization. Thus, four different surfactants with different properties (cationic, anionic and non-ionic) were investigated for modulating the activity of BCL mCLEAs in biodiesel production. As seen in Figure 5, Triton X-100 exhibited maximum effect on the enhancement of lipase activity in low surfactant concentration, while the addition of sodium bis-2-(ethylhexyl) sulfosuccinate (AOT) showed the least influence. The optimal surfactant in proper concentration acting as a bipolar agent, could simulate the amphiphilic environment to benefit the exposure of hydrophobic regions in the active site. Meanwhile, surfactants may also promote the dissociation of large aggregates formed, thus slightly increase the enzymatic activity of lipase (Figure 2). 


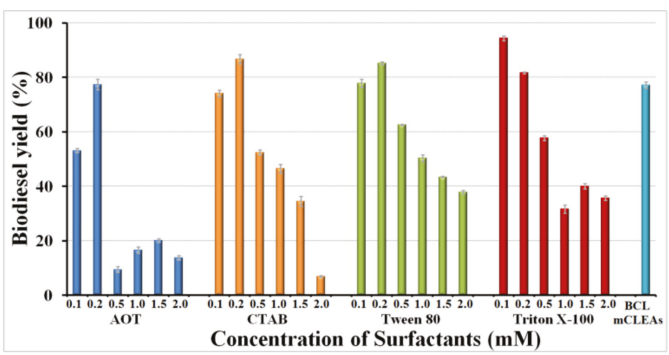

Figure 5. Four different surfactants activation on activity of surfactant-activated BCL mCLEAs in biodiesel production.

However, the increase of surfactant concentration led to gradual decrease of biodiesel yield in all cases, indicating that surfactants showed positive and negative effect on the activity of lipase. Additional detergent molecules may bind to the active site region of lipase, blocking the substrate access, inducing inhibition [27]. Compared with ionic surfactants (AOT and cetrimonium bromide $(\mathrm{CTAB})$ ), nonionic surfactants (Triton X-100 and Tween 80 ) were preferred aiming at regulating the activity of BCL (Figure 5). As the main interaction between the enzyme and nonionic surfactants is hydrophobic interaction while anionic or cationic surfactants perform electrostatic interactions [28], mild hydrophobic interaction between BCL and the surfactant might be important to trigger the interfacial activation mechanism. Therefore, nonionic Triton X-100 and Tween 80 were further studied to confirm the optimal amphiphile and surfactant concentration. As performed in Figure 6, the maximum hyperactivation of BCL mCLEAs was observed in the pretreatment of BCL with $0.1 \mathrm{mM}$ Triton X-100, and the optimal Triton-activated BCL mCLEAs were used for further experiments.

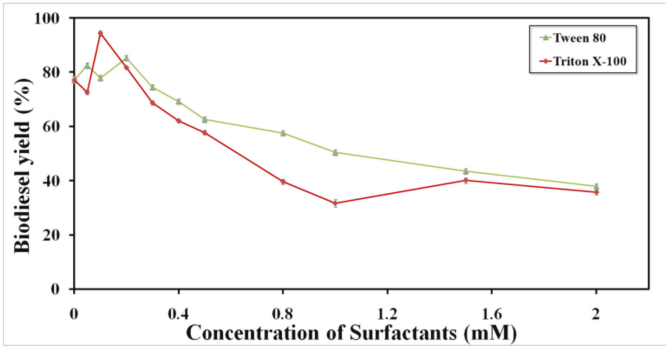

Figure 6. Surfactants (Triton X-100 and Tween 80) concentration in surfactant-activated BCL mCLEAs preparation.

\subsection{Biodiesel Production}

For the economic feasibility of biodiesel production, solvents, methanol-to-oil molar ratio, and reaction temperature are important variables to optimize for transesterification step. As a result of oxidative reactions occurring during cooking and long-term storage in air, WCO generally exhibits a dramatic increase in viscosity and saponification value [7]. Compared to the fresh oil, high viscose WCO is not favored in biodiesel production. Using solvents could reduce the viscosity of the reaction medium and decrease the diffusion limitations, while it might also directly affect the enzyme structure and activity. In general, hydrophobic solvents could promote the interface and stabilize lipases on their open assembly, causing the hyperactivation of these enzymes. To select the most suitable medium, five hydrophobic solvents commonly used in transesterification were tested in biodiesel production (Figure 7a). It can be clearly seen that biodiesel yield is remarkably dependent on the type of solvent. Overall, Triton-activated BCL mCLEAs exhibited higher activity than BCL mCLEAs and free BCL in all the solvents tested, and the changing trend of their activity in various solvents was accord with 
BCL mCLEAs and free BCL. In case of Triton-activated BCL mCLEAs, the best results were achieved using n-hexane with a yield of up to $94 \%$ biodiesel, which was 3.3-fold higher than that in free BCL catalyzed reaction. Interestingly, surfactant hyperactivation in combination with immobilization could fasten lipase in their active conformation, allowing biodiesel production performed in solvent without further addition of water, which was in accordance with earlier reports $[29,30]$.
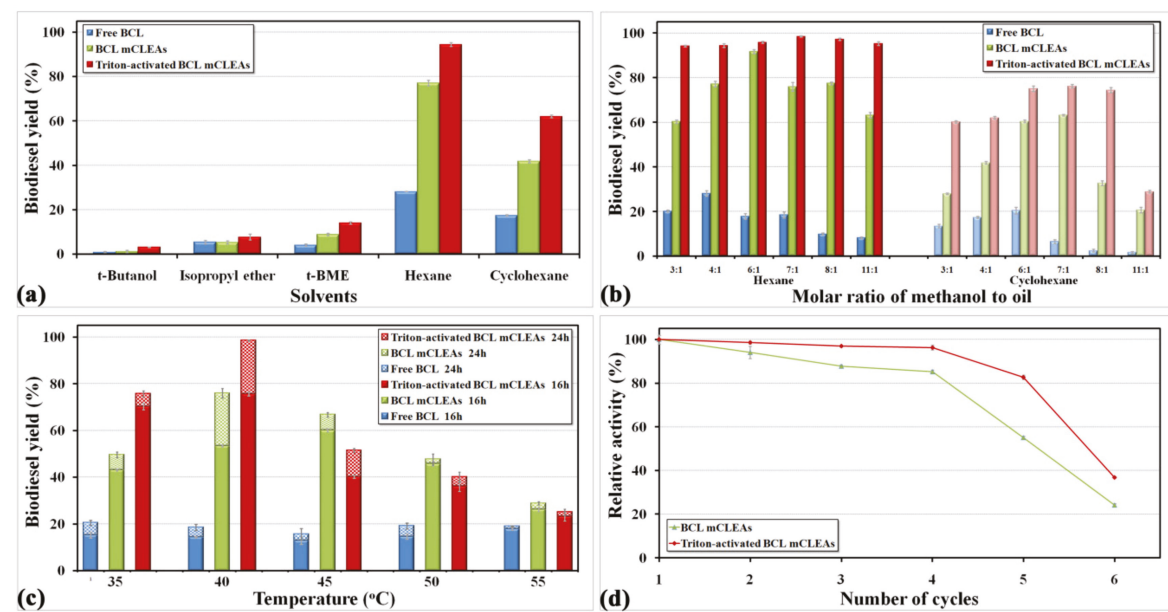

Figure 7. Reaction parameters on biodiesel production catalyzed by free BCL, BCL mCLEAs and Trion-activated BCL mCLEAs and reusability of immobilized BCL. (a) Solvents, (b) molar ratio of methanol to oil, (c) temperature, (d) reusability.

The methanol:oil molar ratio can have a significant effect on the reaction yield because excess methanol increases the reaction rate and drives high yield of biodiesel, while a high concentration of methanol leads to inactivation of lipases. In this study, experiments were performed at different molar ratios of methanol to WCO ranging from 3:1 (stoichiometric ratio) to 11:1 both in hexane and cyclohexane with methanol added only once. As shown in Figure 7b, Triton-activated BCL mCLEAs exhibited higher biodiesel yields in one-time addition of methanol under all the experimental conditions, especially when hexane was used as solvent. Meanwhile, owing to the significant inhibitory effect of excess methanol in one time addition, free BCL showed low activity in biodiesel production. It is worth noting that yields of Triton-activated BCL mCLEAs catalyzed reactions in hexane exceeded $90 \%$ in a wide range of methanol-to-WCO ratio, while the reaction yield of BCL mCLEAs catalyzed reaction decreased with methanol-to-WCO ratio exceeding 6:1. Consequently, it can be confirmed that surfactants pretreatment provided not only hyperactivation but also protection to lipases from denaturation in excess methanol. In addition, the maximum biodiesel yield was observed at a methanol-to-WCO ratio of 7:1 for Triton-activated BCL mCLEAs. Consequently, the minimal stoichiometric methanol-to-WCO ratio of 7:1 was chosen in further experiments.

Most of the enzymatic transesterification depends on temperature, which could enhance reaction rate and improve the dispersion of immobilized particles in reaction medium with better mass transfer between the reactants [31]. However, thermal denaturation of the enzyme might occur with elevation of temperature, typically according to the property of enzyme and immobilized methods. The effect of temperature on the yield of biodiesel during the transesterification of WCO has been investigated over a temperature range from 35 to $55^{\circ} \mathrm{C}$. According to Figure $7 \mathrm{c}$, the optimum operational temperature for Triton-activated BCL mCLEAs and BCL mCLEAs was $40{ }^{\circ} \mathrm{C}$, with biodiesel yields of $98 \%$ and $76 \%$ respectively after $24 \mathrm{~h}$, and further increase of temperature will result in decrease of biodiesel yields simultaneously. Besides, Triton-activated BCL mCLEAs showed better activity below $40{ }^{\circ} \mathrm{C}$, while BCL mCLEAs performed higher biodiesel yield over $40^{\circ} \mathrm{C}$. The suitable covalent cross-linking 
with functionalized MNPs provided extra structure stabilization in mCLEAs, requiring much more energy to the disruption of this stable structure than free enzyme [32]. Nevertheless, the accessible active site of lipases achieved by surfactants pretreatment might be more sensitive to high temperature denaturation [33].

In summary, the optimal reaction conditions for Triton-activated BCL mCLEAs catalyzed transesterification of WCO are as follows: hexane used as solvent, molar ratio of methanol-to-WCO 7:1 in one-time addition, reaction temperature $40^{\circ} \mathrm{C}$. To verify the feasibility of the whole process at a larger scale, transesterification of WCO were performed under optimal conditions adding proper amount of Triton-activated BCL mCLEAs (the initial content of BCL was $240 \mathrm{mg}$ in immobilization) to a mixture of $1 \mathrm{~g}$ WCO in $20 \mathrm{~mL}$ hexane. The biodiesel yield reached $94 \%$ after shaking at $40{ }^{\circ} \mathrm{C}$ for $48 \mathrm{~h}$. Triton-activated BCL mCLEAs showed good activity and stability under higher oil content, indicating the possibility of its scale-up application in bioreactor systems.

\subsection{Reusability}

Reusability of immobilized enzyme is a chief criterion for its cost-effective use for potential industry applications. The utilization of functionalized MNPs facilitates the consequent reuse of immobilized enzyme. To investigate the reusability of BCL mCLEAs and Triton-activated BCL mCLEAs, the immobilized lipases were recovered by magnetic separation, and applied in the consecutive batches of biodiesel reactions under optimized conditions. Assessments of the operational stability were analyzed for 6 cycles and presented in Figure 7d. As observed, Triton-activated BCL mCLEAs showed no significant loss in the catalytic activity after subsequent consecutive reuse for 4 cycles, and kept $82 \%$ relative activity after continuous running 5 cycles. Meanwhile, the relative activity of BCL mCLEAs was $55 \%$ after 5 cycles, implying that BCL could possess good long-term stability with surfactant pretreatment. The protein denaturation in one time addition of methanol and byproduct inhibition might be account for the decrease in biodiesel yield in long-term reuses [34].

\section{Materials and Methods}

\subsection{Materials}

Burkholderia cepacia lipase (powder, Amano Lipase PS, $\geq 3000 \mathrm{U} / \mathrm{g}$ ) and fatty acid methyl ester standards were purchased from Sigma-Aldrich (St. Louis, MO, USA). Also, 3-aminopropyl triethoxysilane (APTES), glutaraldehyde $(25 \%, \mathrm{v} / \mathrm{v})$ and 2-phenyl ethanol $(>98 \%, \mathrm{CP})$ were supplied by Aladdin (Shanghai, China). Sodium bis-2-(ethylhexyl) sulfosuccinate (AOT) were procured from Acros (USA). Waste cooking oil (WCO) was obtained from local restaurant around Ningxia University campus (Yinchuan, China) with the following fatty acid compositions: $10.48 \%$ palmitic acid, $15.04 \%$ stearicacid, $38.44 \%$ oleic acid, $23.76 \%$ linoleic acid, and $1.72 \%$ linolenic acid. The WCO sample was filtered to separate impurities and solids in the oil. The physical properties of WCO are saponification value of $197.3 \mathrm{mg} \mathrm{KOH} / \mathrm{g}$, acid value of $4.37 \mathrm{mg} \mathrm{KOH} / \mathrm{g}$, and average molecular weight of $870.9 \mathrm{~g} / \mathrm{mol}$. All other chemicals were of analytical or chromatographical grade and used as purchased.

\subsection{Preparation of Magnetic Support}

Preparation of HAP-coated MNPs was carried out according to the previously reported method [35] Initially, MNPs cores were prepared by the conventional co-precipitation method. Typically, $\mathrm{FeCl}_{2} \cdot 4 \mathrm{H}_{2} \mathrm{O}$ $(1.1 \mathrm{~g})$ and $(3.0 \mathrm{~g})$ of $\mathrm{FeCl}_{3} \cdot 6 \mathrm{H}_{2} \mathrm{O}$ were dissolved in $90 \mathrm{~mL}$ deionized water under the protection of argon, with subsequent addition of $25 \%$ ammonia solution $(30 \mathrm{~mL})$ under vigorous stirring at room temperature. After stirring for $30 \mathrm{~min}$, a $60 \mathrm{~mL}$ aqueous solution composed of $\mathrm{Ca}\left(\mathrm{NO}_{3}\right)_{2} \cdot 4 \mathrm{H}_{2} \mathrm{O}$ $(7.1 \mathrm{~g})$ and $\left(\mathrm{NH}_{4}\right)_{2} \mathrm{HPO}_{4}(2.3 \mathrm{~g})$ adjusted to $\mathrm{pH}=11$ was added drop wise to the above suspension under continuous stirring. Subsequently, the resultant mixture was heated to $90{ }^{\circ} \mathrm{C}$ and stirred for $2 \mathrm{~h}$. After cooling to room temperature and aging in the mother solution overnight, the obtained 
precipitates were washed several times with deionized water until neutral and lyophilized for $12 \mathrm{~h}$. The HAP-coated MNPs were obtained by calcining the materials in air at $300{ }^{\circ} \mathrm{C}$ for $3 \mathrm{~h}$.

To obtain 3-aminopropyl trimetoxysilane functionalized HAP-coated MNPs (APTES-HAP-coated MNPs), HAP-coated MNPs (1.0 g) were suspended in a solution composed of $30 \mathrm{~mL}$ anhydrous toluene and $0.44 \mathrm{~g}$ of APTES. The mixture was refluxed under Ar atmosphere for $12 \mathrm{~h}$, and then washed several times with ethanol, magnetically separated, and subsequently lyophilized prior to use.

\subsection{Lipase Immobilization}

BCL mCLEAs were produced according to the procedure described in Scheme 1. Firstly, $10 \mathrm{mg}$ of APTES-HAP-MNPs were dispersed in $1 \mathrm{~mL}$ of BCL solution $(10 \mathrm{mg} / \mathrm{mL}, 0.1 \mathrm{M}$ phosphate buffer, $\mathrm{pH}$ 7.0) and shaken for $15 \mathrm{~min}$ at $30{ }^{\circ} \mathrm{C}$. Then $5 \mathrm{~mL}$ of precipitant was added with stirring at $4{ }^{\circ} \mathrm{C}$ for $30 \mathrm{~min}$. After precipitation, glutaraldyhyde was added drop wise into the suspension and stirred for $3 \mathrm{~h}$ at $30^{\circ} \mathrm{C}$. Afterwards, BCL mCLEAs were collected by centrifugation and washed thrice with phosphate buffer and deionized water, lyophilized and finally stored at $4{ }^{\circ} \mathrm{C}$.

During optimization of the immobilization conditions, the effects of precipitants (acetone, ethanol, isopropanol, PEG 800 (1 g/mL), and saturated ammonium sulfate solution) and concentration of glutaraldehyde on the activity recovery of BCL mCLEAs were investigated.

The surfactant-activated BCL mCLEAs was prepared using cationic (CTAB), anionic (AOT) and nonionic (Tween 80 and Triton Triton X-100) surfactants at various concentrations. Then, $1 \mathrm{~mL}$ of BCL solution and appropriate amount of surfactant were mixed and stirred at $4{ }^{\circ} \mathrm{C}$ for $30 \mathrm{~min}$. After incubated for $24 \mathrm{~h}$ at $4{ }^{\circ} \mathrm{C}$, the suspended solution was sequentially used for BCL mCLEAs preparation under optimal conditions.

\subsection{Characterization}

The prepared support matrix and immobilized lipase described above were characterized using FTIR, SEM and VSM. The Fourier transform infrared (FTIR) spectra were acquired using a Perkin Elmer Frontier spectrometer (Spectrum Two, Waltham, MA, USA) equipped with an Attenuate Total Reflection (ATR) accessory. Samples were analyzed as KBr pellets in the range of 400 to $4000 \mathrm{~cm}^{-1}$ at a resolution of $0.5 \mathrm{~cm}^{-1}$. The morphology of the particle surface was observed using a scanning electron microscope (SEM, Sigma HD, ZEISS, Germany), with deposition of a thin coating of gold onto the samples prior to analyses. The magnetic properties were detected by a vibrating sample magnetometer (VSM, MicroSense EZ9, Lowell, MA, USA) at room temperature.

\subsection{Activity Assay}

In studying the optimal conditions for BCL mCLEAs preparation, the enzymatic transesterification activities of free lipase and immobilized BCLs were assayed via transesterification reaction of 2-phenyl ethanol with vinyl acetate according to the method introduced previously [36]. The reaction mixture contained $10 \mathrm{mg}$ of 2-phenylethanol, $1 \mathrm{~mL}$ of vinyl acetate and $10 \mathrm{mg}$ of lipase (the initial content of BCL was $10 \mathrm{mg}$ in preparing BCL CLEAs and BCL mCLEAs), and the reactions were carried out at $30{ }^{\circ} \mathrm{C}$ with continuous shaking at $220 \mathrm{rpm}$. After $24 \mathrm{~h}$ of reaction, samples were withdrawn and analyzed by high-performance liquid chromatography (HPLC). All experiments were repeated at least three times. The relative activity of BCL mCLEAs was calculated with the following equation:

$$
\text { Relative activity }(\%)=\frac{\text { Transesterification yield of immobilized BCL }}{\text { Trasesterification yield of free BCL }} \times 100
$$

\subsection{Enzymatic Transesterification for Biodiesel Production}

The transesterification of WCO were carried out at $40{ }^{\circ} \mathrm{C}$ in a $10 \mathrm{~mL}$ screw-capped vessel for $24 \mathrm{~h}$ with continuous shaking at $220 \mathrm{rpm}$. Unless otherwise stated, a typical reaction mixture consisted of $50 \mathrm{mg}$ WCO, $2.0 \mathrm{~mL}$ hexane, $10 \mathrm{mg}$ of lipase (the initial content of BCL was $10 \mathrm{mg}$ in preparing 
BCL CLEAs and BCL mCLEAs) and methanol using methanol: oil molar ratio of 4:1. Single factor optimization was conducted to determine optimal reaction parameters for transesterification of WCO to biodiesel. Various conditions including kinds and concentration of surfactants, solvents, molar ratio of methanol to oil and temperature $\left({ }^{\circ} \mathrm{C}\right)$ were investigated. The transesterification reaction of large scale with $1 \mathrm{~g} \mathrm{WCO}$ were carried out as described in Section 2.4. All biodiesel reactions were performed in dried solvents without any water added. The yield of biodiesel $(20 \mu \mathrm{L})$ was analyzed in different time intervals using gas chromatography.

\subsection{Analytical Methods}

HPLC was conducted with Shimadzu LC-2010A HT apparatus using C18 column (UltimateXB-C18, $5 \mu \mathrm{m}, 4.6 \times 150 \mathrm{~mm}$, Welch). The samples were analyzed with a mixture of $\mathrm{MeOH} / \mathrm{water}=80: 20(\mathrm{v} / \mathrm{v})$ as eluent at $0.8 \mathrm{~mL} / \mathrm{min}$ for $9 \mathrm{~min}$ at $254 \mathrm{~nm}$.

Fatty acid methyl esters (FAMEs) were analyzed by a Fuli9790 plus gas chromatography (Fuli, Zhejiang, China) fitted with a flame ionization detectorcity (FID, Zhejiang, China), and a KB-FFAP column $(30 \mathrm{~m} \times 0.32 \mathrm{~mm} \times 0.25 \mu \mathrm{m})$. Nitrogen gas was a carrier at continues flow of $1.0 \mathrm{~mL} / \mathrm{min}$. The oven (Zhejiang, China) temperature was set and at $160{ }^{\circ} \mathrm{C}$ maintained for $2 \mathrm{~min}$, then a heating ramp was applied up to $240{ }^{\circ} \mathrm{C}$ at a rate of $10{ }^{\circ} \mathrm{C} / \mathrm{min}$, and the temperature of the oven was maintained at $240{ }^{\circ} \mathrm{C}$ for $15 \mathrm{~min}$. The temperatures of the injector (Zhejiang, China) and the detector (Zhejiang, China) were set at 270 and $280^{\circ} \mathrm{C}$, respectively. Methyl tridecanoate was used as internal standard, and the biodiesel yield (\%) was calculated by peaks area of standard FAME peaks.

\subsection{Reusability}

The reusability of Triton-activated BCL mCLEAs and BCL mCLEAs for the transesterification of WCO were also investigated under optimal conditions. After each batch reaction, immobilized BCL was recovered by magnetic separation and washed with $n$-hexane. The washed biocatalyst was reused consecutively in repetitive cycles. The biodiesel yield of the first reaction was set as $100 \%$ and the FAMEs yield in the subsequent reactions was calculated accordingly.

\section{Conclusions}

A facile and effectual surfactant imprinting method to expose the lipase active site integrating amino functionalized HAP-coated MNPs was established to immobilize CLEAs of BCL attaining enhanced activity and stability. The as-prepared Triton-activated BCL mCLEAs was subsequent processed in enzymatic transesterification of waste cooking oil for biodiesel production, and showed $98 \%$ biodiesel yield under optimal conditions, which was 5.3-fold higher than the free lipase. This study proved that hyperactivation with surfactant could significantly improve the resistance of lipase to methanol in one-time addition, when compared to BCL mCLEAs and free BCL. In addition, surfactant imprinting in combination with immobilization could fasten lipase in their active conformation, allowing biodiesel production performed in solvent without further addition of water, and thus displayed priority in downstream purification of biodiesel over ordinary immobilization methods. Besides, the green immobilization with functionalized MNPs facilitates fast and easy recovery of lipase, and the corresponding immobilized BCL was reused for 4 cycles without significant loss in the catalytic activity. Furthermore, this work provides a promising approach for immobilization of other lipases, which can be used with success in green and clean production processes.

Author Contributions: Conceptualization, W.Z.; Investigation, H.Y.; supervision, funding acquisition, writing - original draft preparation and review and editing, W.Z.

Funding: This research was funded by the National Natural Science Foundation of China (No. 21865023), the Natural Science Foundation of Ningxia (No. 2019AAC03022), Scientific Research Foundation of the Higher Education Institutions of Ningxia (No. NGY2017045), Major Innovation Projects for Building First-class Universities in China's Western Region (No. ZKZD2017003), and the Scientific Research Start Funds of Ningxia University Talent Introduction (No. BQD2015012). 
Acknowledgments: The help from Fu Zheng (School of Physics \& Electronic-Electrical Engineering, Ningxia University) for magnetization measurements is gratefully recognized.

Conflicts of Interest: The authors declare no conflict of interest.

\section{References}

1. Mahmudul, H.M.; Hagos, F.Y.; Mamat, R.; AbdulAdam, A.; Ishak, W.F.W.; Alenezi, R. Production, characterization and performance of biodiesel as an alternative fuel in diesel engines-a review. Renew. Sustain. Energy Rev. 2017, 72, 497-509. [CrossRef]

2. Laesecke, J.; Ellis, N.; Kirchen, P. Production, analysis and combustion characterizationof biomass fast pyrolysis oil-biodiesel blends for use in diesel engines. Fuel 2017, 199, 346-357. [CrossRef]

3. Jamil, F.; Alhaj, L.; Almuhtaseb, A.H.; Baawain, M.; Rashid, U.; Ahmad, M.N.M. Current scenario of catalysts for biodieselproduction: A critical review. Rev. Chem. Eng. 2018, 34, 267-297. [CrossRef]

4. Banković-Ilić, I.B.; Stamenković, O.S.; Veljković, V.B. Biodiesel production fromnon-edible plant oils. Reneww. Sustain. Energy Rev. 2012, 16, 3621-3647. [CrossRef]

5. Hama, S.; Noda, H.; Kondo, A. How lipase technology contributes to evolution ofbiodiesel production using multiple feedstocks. Curr. Opin. Biotechnol. 2018, 50, 57-64. [CrossRef]

6. Gebremariam, S.N.; Marchetti, J.M. Economics of biodiesel production: Review. Energy Convers. Manag. 2018, 168, 74-84. [CrossRef]

7. Moazeni, F.; Chen, Y.-C.; Zhang, G. Enzymatic transesterification for biodiesel production from usedcooking oil, a review. J. Clean. Prod. 2019, 216, 117-128. [CrossRef]

8. Lopresto, C.; Naccarato, S.; Albo, L.; De Paola, M.; Chakraborty, S.; Curcio, S.; Calabro, V. Enzymatic transesterification of waste vegetable oil to producebiodiesel. Ecotoxicol. Environ. Saf. 2015, 121, 229-235. [CrossRef]

9. Chhetri, A.; Watts, K.; Islam, M. Waste cooking oil as an alternate feedstock forbiodiesel production. Energies 2008, 1, 3-18. [CrossRef]

10. Sabudak, T.; Yildiz, M. Biodiesel production from waste frying oils and itsquality control. Waste Manag. 2010, 30, 799-803. [CrossRef]

11. Kim, K.H.; Lee, O.K.; Lee, E.Y. Nano-immobilized biocatalysts for biodiesel production from renewable and sustainable resources. Catalysts 2018, 8, 68. [CrossRef]

12. Facin, B.R.; Melchiors, M.S.; Valério, A.; Oliveira, J.V.; Oliveira, D. Driving immobilized lipases as biocatalysts: 10 years state of the art and future prospects. Ind. Eng. Chem. Res. 2019, 58, 5358-5378. [CrossRef]

13. Filho, D.G.; Silva, A.G.; Guidini, C.Z. Lipases: Sources, immobilization methods, and industrial applications. Appl. Microbiol. Biotechnol. 2019, 103, 7399-7423. [CrossRef]

14. Xu, M.-Q.; Wang, S.-S.; Li, L.-N.; Gao, J.; Zhang, Y.-W. Combined cross-linked enzyme aggregatesas biocatalysts. Catalysts 2018, 8, 460. [CrossRef]

15. Sheldon, R.A. CLEAs, combi-CLEAs and 'smart' magnetic CLEAs: Biocatalysis in a bio-based economy. Catalysts 2019, 9, 261. [CrossRef]

16. Liu, D.-M.; Chen, J.; Shi, Y.-P. Advances on methods and easy separated support materials forenzymes immobilization. TrAC-Trends Anal. Chem. 2018, 102, 332-342. [CrossRef]

17. Izadia, A.; Meshkinia, A.; Entezari, M.H. Mesoporous superparamagnetic hydroxyapatite nanocomposite: Amultifunctional platform for synergistic targeted chemo-magnetotherapy. Mater. Sci. Eng. C Mater. 2019, 101, 27-41. [CrossRef]

18. Sánchez, D.A.; Tonetto, G.M.; Ferreira, M.L. Burkholderia cepacia lipase: A versatile catalyst in synthesisreactions. Biotechnol. Bioeng. 2018, 115, 6-24. [CrossRef]

19. Barbe, S.; Lafaquiere, V.; Guieysse, D.; Monsan, P.; Remaud-Siméon, M.; Andre, I. Insights into lid movements of Burkholderia cepacialipase inferred from molecular dynamics simulations. Proteins 2009, 77, 509-523. [CrossRef]

20. Gabriele, F.; Spreti, N.; Giacco, T.D.; Germani, R.; Tiecco, M. Effect of surfactant structure on the superactivity of Candida rugosalipase. Langmuir 2018, 34, 11510-11517. [CrossRef]

21. Zhang, N.; Gao, T.; Wang, Y.; Wang, Z.; Zhang, P.; Liu, J. Environmental pH-controlledloading and release of protein on mesoporous hydroxyapatite nanoparticles forbone tissue engineering. Mater. Sci. Eng. C Mater. 2015, 46, 158-165. [CrossRef] 
22. Kannan, S.; Marudhamuthu, M. Development of chitin cross-linked enzyme aggregates of L-methioninase for upgraded activity, permanence andapplication as efficient therapeutic formulations. Int. J. Biol. Macromol. 2019, 141, 218-231. [CrossRef]

23. Shaarani, S.M.; Jahim, J.M.; Rahman, R.A.; Idris, A.; Murad, A.M.A.; Illias, R.M. Silanized maghemite for cross-linked enzyme aggregates of recombinantxylanase from Trichoderma reesei. J. Mol. Catal. B Enzym. 2016, 133, 65-76. [CrossRef]

24. Rehman, S.; Bhatti, H.N.; Bilal, M.; Asgher, M. Cross-linked enzyme aggregates (CLEAs) of Pencilluim notatum lipaseenzymewith improved activity, stability and reusabilitycharacteristics. Int. J. Biol. Macromol. 2016, 91, 1161-1169. [CrossRef]

25. Cui, J.; Lin, T.; Feng, Y.; Tan, Z.; Jia, S. Preparation of spherical cross-linked lipaseaggregates with improved activity, stabilityand reusability characteristic in water-in-ionicliquid microemulsion. J. Chem. Technol. Biotechnol. 2017, 92, 1785-1793. [CrossRef]

26. Yamaguchi, H.; Kiyota, Y.; Miyazaki, M. Techniques for preparation of cross-linked enzyme aggregates and their applications in bioconversions. Catalysts 2018, 8, 174. [CrossRef]

27. Bañó, M.C.; González-Navarro, H.; Abad, C. Long-chain fatty acyl-CoA esters induce lipase activation in the absence of a water-lipid interface. BBA Mol. Cell Biol. Lipids 2003, 1632, 55-61. [CrossRef]

28. Delorme, V.; Dhouib, R.; Canaan, S.; Fotiadu, F.; Carriere, F.; Cavalier, J.F. Effects of surfactants on lipase structure, activity, and inhibition. Pharm. Res. 2011, 28, 1831-1842. [CrossRef]

29. Mukherjee, J.; Gupta, M.N. Molecular bioimprinting of lipases with surfactantsand its functional consequences in low water media. Int. J. Biol. Macromol. 2015, 81, 544-551. [CrossRef]

30. Zhang, W.-W.; Yang, X.-L.; Jia, J.Q.; Wang, N.; Hu, C.-L.; Yu, X.-Q. Surfactant-activated magnetic cross-linked enzyme aggregates (magnetic CLEAs) of Thermomyces lanugunosus lipase for biodiesel production. J. Mol. Catal. B Enzym. 2015, 115, 83-89. [CrossRef]

31. Lee, H.V.; Yunus, R.; Juan, J.C.; Taufiq-Yap, Y.H. Process optimization design forjatropha-based biodiesel production using response surface methodology. Fuel Process. Technol. 2011, 92, 2420-2428. [CrossRef]

32. Dong, T.; Zhao, L.; Huang, Y.; Tan, X. Preparation of cross-linked aggregates ofaminoacylase from Aspergillus melleus by using bovine serum albumin as aninert additive. Bioresour. Technol. 2010, 101, 6569-6571. [CrossRef]

33. Rehm, S.; Trodler, P.; Pleiss, J. Solvent-induced lid opening in lipases: A molecular dynamics study. Protein Sci. 2010, 19, 2122-2130. [CrossRef]

34. Xie, W.; Huang, M. Immobilization of Candida rugosa lipase onto graphene oxide Fe3O4nanocomposite: Characterization and application for biodiesel production. Energy Convers. Manag. 2018, 159, 42-53. [CrossRef]

35. Xie, W.; Zang, X. Covalent immobilization of lipase onto aminopropyl-functionalizedhydroxyapatiteencapsulated- $\gamma-\mathrm{Fe}_{2} \mathrm{O}_{3}$ nanoparticles: A magneticbiocatalyst for interesterification of soybean oil. Food Chem. 2017, 227, 397-403. [CrossRef]

36. Zhang, W.-W.; Yang, H.-X.; Liu, W.-Y.; Wang, N.; Yu, X.-Q. Improved performance of magnetic cross-linked lipase aggregates by interfacial activation: A robustand magnetically recyclable biocatalyst for transesterification of Jatropha oil. Molecules 2017, 22, 2157. [CrossRef]

(C) 2019 by the authors. Licensee MDPI, Basel, Switzerland. This article is an open access article distributed under the terms and conditions of the Creative Commons Attribution (CC BY) license (http://creativecommons.org/licenses/by/4.0/). 

Article

\title{
Response Surface Methodology Approach for Optimized Biodiesel Production from Waste Chicken Fat Oil
}

\author{
Fatima Shafiq ${ }^{1}$, Muhammad Waseem Mumtaz ${ }^{1, *}$, Hamid Mukhtar ${ }^{2}$, Tooba Touqeer ${ }^{1}$, \\ Syed Ali Raza ${ }^{3}$, Umer Rashid ${ }^{4, *}$, Imededdine Arbi Nehdi ${ }^{5,6}$ and Thomas Shean Yaw Choong ${ }^{7}$ \\ 1 Department of Chemistry, University of Gujrat, Gujrat 50700, Pakistan; fatimashafiq369@gmail.com (F.S.); \\ tuba.toqir@gmail.com (T.T.) \\ 2 Institute of Industrial Biotechnology, Government College University, Lahore 54000, Pakistan; \\ hamidwaseer@yahoo.com \\ 3 Department of Chemistry, Government College University, Lahore 54000, Pakistan; chemstone@yahoo.com \\ 4 Institute of Advanced Technology, Universiti Putra Malaysia, UPM Serdang, Selangor 43400, Malaysia \\ 5 Chemistry Department, College of Science, King Saud University, Riyadh 1145, Saudi Arabia; \\ inahdi@ksu.edu.sa \\ 6 Laboratoire de Recherche LR18ES08, Chemistry Department, Science College, Tunis El Manar University, \\ Tunis 2092, Tunisia \\ 7 Department of Chemical and Environmental Engineering, Universiti Putra Malaysia, UPM Serdang, \\ Selangor 43400, Malaysia; csthomas@upm.edu.my \\ * Correspondence: muhammad.waseem@uog.edu.pk (M.W.M.); umer.rashid@upm.edu.my (U.R.); \\ Tel.: +60-3-9769-7393 (U.R.)
}

Received: 1 February 2020; Accepted: 26 February 2020; Published: 6 June 2020

\begin{abstract}
Biodiesel is gaining acceptance as an alternative fuel in a scenario where fossil fuel reserves are being depleted rapidly. Therefore, it is considered as the fuel of the future due to its sustainability, renewable nature and environment friendly attributes. The optimal yield of biodiesel from cheap feed stock oils is a challenge to add cost effectiveness without compromising the fuel quality. In the current experiment, waste chicken fat oil was taken as the feedstock oil to produce biodiesel through the chemical and enzymatic route of transesterification. The process of chemical transesterification was performed using $\mathrm{KOH}$ and sodium methoxide, while enzymatic transesterification was done by using free Aspergillus terreus lipase and Aspergillus terreus lipase immobilized on functionalized $\mathrm{Fe}_{3} \mathrm{O}_{4}$ nanoparticles ( $\mathrm{Fe}_{3} \mathrm{O}_{4}$ PDA_Lipase) as biocatalysts. The physico-chemical properties of the understudy feedstock oil were analyzed to check the feasibility as a feedstock for the biodiesel synthesis. The feedstock oil was found suitable for biodiesel production based upon quality assessment. Optimization of various reaction parameters (the temperature and time of reaction, catalyst concentration and methanol-to-oil mole ratio) was performed based on the response surface methodology (RSM). The maximum yield of biodiesel (90.6\%) was obtained from waste chicken fat oil by using $\mathrm{Fe}_{3} \mathrm{O}_{4}{ }_{-} \mathrm{PDA} \_$Lipase as an immobilized nano-biocatalyst. Moreover, the above said optimum yield was obtained when transesterification was done using $6 \% \mathrm{Fe}_{3} \mathrm{O}_{4}$ PDD_Lipase with a methanol-to-oil ratio of $6: 1$ at $42{ }^{\circ} \mathrm{C}$ for $36 \mathrm{~h}$. Biodiesel production was monitored by FTIR spectroscopic analysis, whereas compositional profiling was done by GC-MS. The measured fuel properties—cloud point, pour point, flash point, fire point and kinematic viscosity—met the biodiesel specifications by American Society for Testing and Materials (ASTM).
\end{abstract}

Keywords: biodiesel; transesterification; immobilized lipase; RSM; fuel properties 


\section{Introduction}

The rapid industrial growth and population explosion have built an immense pressure on natural resources, including fossil fuels. The whole world is determined to find suitable solutions in context with the forthcoming energy crisis. The world is in search of alternate sources of fuel to reduce its dependency on conventional fuels. Biodiesel has emerged as a promising alternative fuel in recent years due to its renewable nature and environment friendly attributes. Biodiesel may be characterized as alkyl esters of fatty acids and may be utilized easily in diesel engines without major alterations [1]. The emissions of $\mathrm{CO}$ and NOx from diesel burning are issues of keen interest as both are greenhouse gases and responsible for tropospheric ozone formation. It is an established fact based on the work of many researchers that, comparative to conventional diesel, combustion of biodiesel produces less CO and unburnt hydrocarbons but higher NOx emissions, probably due to a higher oxygen content in biodiesel [2,3].

Initially, synthesis of biodiesel was extensively carried out using vegetable oils and seed oils of non-edible origin. Usually, the production of biodiesel from edible oils is not cost-effective and these vegetable oils are used in food, hence are valuable. To avoid the problems associated with cost, edibility and food shortage, biodiesel production from non-edible fractions of food and related wastes is gaining sound gravity. Similarly, the biodiesel preparation from non-edible seeds like Jatropha is not completely feasible as the cultivation of non-edible seed oil plants may create competition with edible crops on shrinking fertile agriculture land [4]. Recently many studies were carried out for biodiesel synthesis from low cost vegetal and animal-based feed stocks like waste cooking oils and animal fats by reducing their viscosity through the transesterification process [5]. The chemical and enzymatic transesterification processes are adopted to convert fatty acids of feedstock into their alkyl esters. Both transesterification modes have their own modalities and advantages but may be optimized for high quality biodiesel [6].

Chicken fat is a poultry waste that can be used to produce biodiesel. The fat content in chicken is about $10 \%$ by weight, which is very high, and its cost is low. Commercial broiler chicken meat was reported to have relatively high contents of polyunsaturated lipids as compared with organic chicken [7]. Researchers have reported that chicken fat constitute about $25 \%$ to $35 \%$ saturated and $40 \%$ to $75 \%$ unsaturated fatty acids. Palmitic acid, along with stearic acid, linoleic acid and oleic acid, are major fatty acids in chicken fat $[8,9]$. The fats can be converted into alkyl esters by the process of transesterification. In an alkali-catalyzed transesterification reaction, both the glyceride and alcohol should be extensively free of water contents as the water compels the reaction to partly change into a saponification reaction, resulting in soap formation [6]. Sodium hydroxide and potassium hydroxide are commonly used as alkali catalysts, but they result in water formation during transesterification, that is why sodium and potassium methoxides are preferred for biodiesel production. Alkali catalysts are good especially for those feed stocks that contain minimal acid value. However, if the acid value of the feed stock is high, then it is recommended to perform pre-treatment acid esterification to reduce the free fatty acid contents before performing base-catalyzed transesterification of the feedstock [10].

On the other hand, enzyme-catalyzed transesterification is gaining acceptance and is considered technically comparable to alkali transesterification. This method normally employs lipase as a catalyst. Lipase-catalyzed transesterification of feedstock oils with a relatively higher free fatty acid content can be carried out without performing any pre-treatment acid esterification step that is normally required in case of alkaline transesterification [11]. However enzymatic transesterification is a high-cost process, because enzymes can be denatured easily in the presence of short-chain alcohols and it is difficult to recover [12]. To cope with these problems, enzymes are immobilized on various supports to enhance their durability. Immobilized enzymes are adoptable to harsh conditions as compared to the free enzymes and are easy to recover. Immobilization of enzymes on the matrix and beads may reduce the enzyme activity by blocking its active site and lowering the mass transfer. However, due to very small size and Brownian movement of nanoparticles, these are a potent choice for enzyme immobilization [13]. There are few reports on enzymatic transesterification of chicken fat oil $[14,15]$. 
In the present work the transesterification process was optimized to synthesize biodiesel from a cheaper source in the form of waste chicken fat. The relative effects of various catalysts and their concentration were studied and optimized for improved yields of biodiesel by involving the methanol-to-oil ratio along with reaction time and temperature. The synthesized biodiesel was also analyzed for fuel properties to check its feasibility for use in a compression ignition (CI) engine.

\section{Results and Discussion}

\subsection{Physico-Chemical Characterization of Waste Chicken Fat Oil (WCFO)}

The pre-analysis tests of WCFO revealed that the acid value of the oil was $6.56 \pm 0.05 \mathrm{mg} \mathrm{KOH} / \mathrm{g}$, saponification value $200 \pm 7.50 \mathrm{mg} \mathrm{KOH} / \mathrm{g}$, refractive index $1.46 \pm 0.01$, density $0.85 \pm 0.07 \mathrm{~g} / \mathrm{cm}^{3}$, iodine number $75 \pm 10.70 \mathrm{~g}$ iodine $/ 100 \mathrm{~g}$ and the peroxide value was computed as $\left(5.5 \pm 0.50 \mathrm{meqO}_{2} / \mathrm{kg}\right)$. These values were depicted comparable with that reported by previous studies [16]. Chicken fat oil has a high acid value, which is why the acid esterification of the feedstock was done prior to the alkaline transesterification to reduce the free fatty acid content and avoid saponification.

\subsection{Optimization of Biodiesel Production Process}

The experimental results obtained after performing reactions as per CCRD were statistically analyzed to select the most appropriate model from the linear, $2 \mathrm{~F} 1$, cubical and quadratic models. The model that was best suited was chosen by considering the $p$-values, $\mathrm{R}^{2}$ values, lack-of-fit tests and adjusted $R^{2}$ values. It was observed that the quadratic model was most suited for both the chemical and enzymatic routes of biodiesel production (Table 1).

Table 1. Summary of selected quadratic models.

\begin{tabular}{|c|c|c|c|c|c|c|}
\hline Feedstock & \multicolumn{2}{|c|}{ Catalysts/Biocatalysts } & \multirow{2}{*}{$\begin{array}{c}\begin{array}{c}\text { Selected } \\
\text { Models }\end{array} \\
\text { Quadratic }\end{array}$} & \multirow{2}{*}{$\begin{array}{c}\begin{array}{c}\text { Sequential } \\
p \text {-Value }\end{array} \\
<0.0001\end{array}$} & \multirow{2}{*}{$\begin{array}{c}\begin{array}{c}\text { Lack-of-Fit } \\
p \text {-Value }\end{array} \\
0.0701\end{array}$} & \multirow{2}{*}{$\begin{array}{c}\begin{array}{c}\text { Adjusted } \\
\text { R-Squared }\end{array} \\
0.9713\end{array}$} \\
\hline WCFO & & $\mathrm{Fe}_{3} \mathrm{O}_{4}$ PDA_Lipase & & & & \\
\hline WCFO & & Aspergillus terreus lipase & Quadratic & $<0.0001$ & 0.1276 & 0.9679 \\
\hline WCFO & & $\mathrm{CH}_{3} \mathrm{ONa}$ & Quadratic & $<0.0001$ & 0.4021 & 0.9519 \\
\hline WCFO & & $\mathrm{KOH}$ & Quadratic & $<0.0001$ & 0.0916 & 0.9518 \\
\hline
\end{tabular}

The summary statistics clearly determined the fitness of quadratic models for chemical as well as enzymatic biodiesel production process for WCFO.

\subsection{Graphs of Predicted vs. Actual Values}

The predicted vs. actual value graphs for biodiesel yield depicts the fitness of the selected quadratic model. The graphs of predicted vs. actual values are shown in Figure 1, where Figure 1a-d describes the predicted vs. actual graphs based on experimental data about yield of biodiesel obtained through the transesterification of waste chicken fat oil by $\mathrm{Fe}_{3} \mathrm{O}_{4}$ PDA_Lipase (Figure 1a), Aspergillus terreus lipase (Figure 1b), sodium methoxide (Figure 1c) and $\mathrm{KOH}$ (Figure 1d). The distribution of the data along the straight line and the small difference between the predicted and actual value reveals the fitness of the quadratic model for all four experimental designs. 

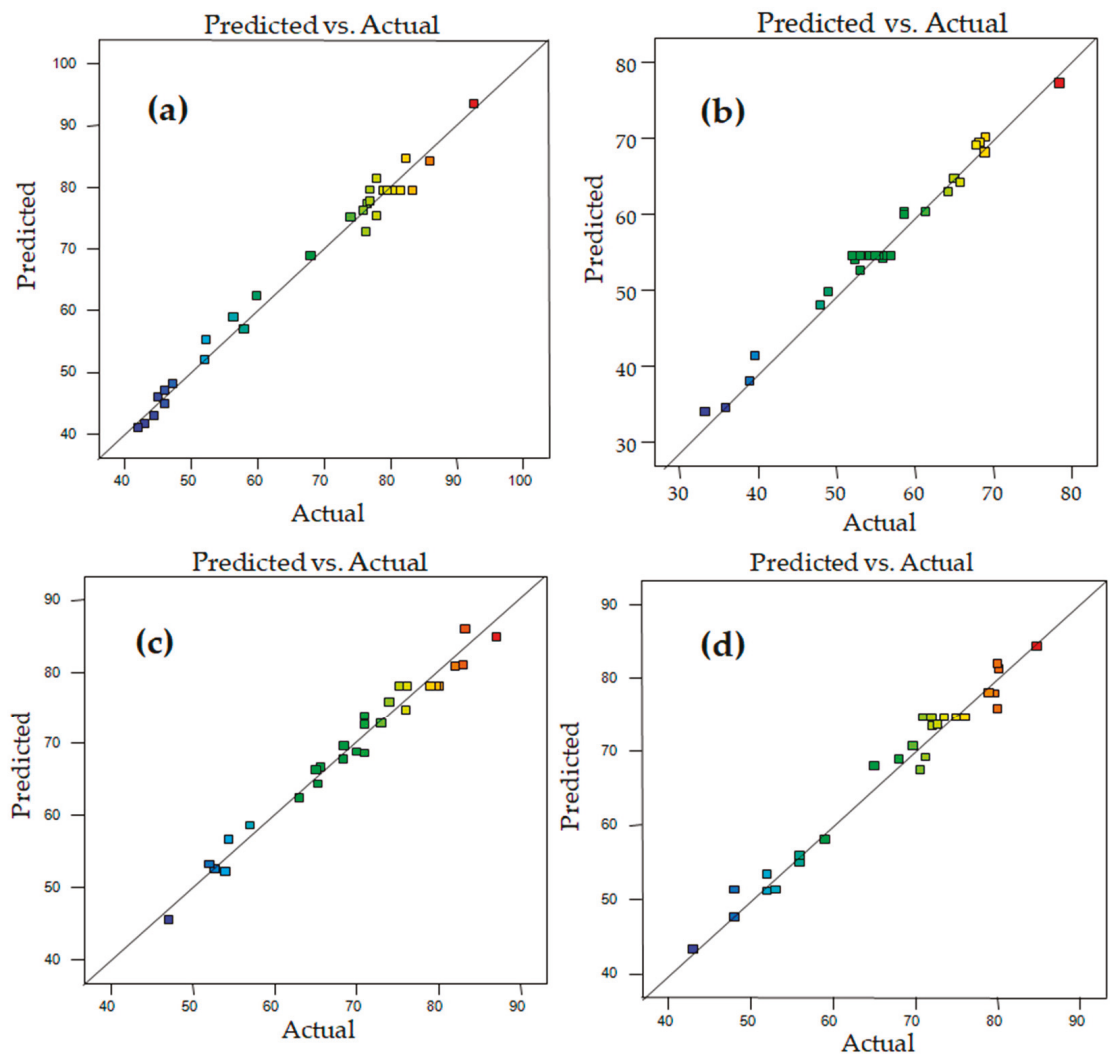

Figure 1. Graphs of predicted vs. actual yield for waste chicken fat oil-based biodiesel by $\mathrm{Fe}_{3} \mathrm{O}_{4} \_\mathrm{PDA} \_$Lipase (a), Aspergillus terreus lipase (b), Sodium methoxide (c) and $\mathrm{KOH}(\mathbf{d})$.

\subsection{Optimization of Reaction Parameters for Manufacturing of Biodiesel Using Chicken Fat Oils}

The enzymatic transesterification of waste chicken oil using $\mathrm{Fe}_{3} \mathrm{O}_{4}$ PDA_Lipase as a bio-catalyst resulted in optimal biodiesel yield when transesterification reactions were performed by employing $6 \% \mathrm{Fe}_{3} \mathrm{O}_{4}$ PPDA_Lipaseconcentration with a $6: 1$ molar ratio of methanol to oil, at $42{ }^{\circ} \mathrm{C}$ for $36 \mathrm{~h}$. While in case of enzymatic transesterification by Aspergillus terreus lipase, a $1 \%$ enzyme concentration, methanol-to-oil ratio of $6: 1$ and reaction temperature of $35{ }^{\circ} \mathrm{C}$ for $36 \mathrm{~h}$ were the optimal process conditions. However, when the sodium methoxide-catalyzed transesterification of WCFO was conducted, the optimum conditions for the reaction were a 1\% catalyst level and a 6:1 methanol:oil mole ratio at $60{ }^{\circ} \mathrm{C}$ for a $1.25 \mathrm{~h}$ reaction time (Table 2). The optimum biodiesel yield in case of a potassium hydroxide $(\mathrm{KOH})$-catalyzed reaction was obtained at a $1 \%$ catalyst concentration, $1 \mathrm{~h}$ of reaction time, a methanol-to-oil ratio of $6: 1$ and $60^{\circ} \mathrm{C}$. Highest biodiesel yield was obtained for the nano-biocatalyst ( $\mathrm{Fe}_{3} \mathrm{O}_{4}$ PDA_Lipase), which might be due to the high stability and activity of the immobilized enzyme at an elevated temperature and adoptability towards harsh conditions [17]. Moreover, the lipase can also convert the free fatty acids present in the feedstock to FAMEs. Lower yield obtained by the free lipase can be explained by the reduction of enzyme activity due to denaturation of the free enzymes at a higher temperature, which is required for biodiesel production from chicken fat oil, and the presence of short-chain alcohol [18]. For chemical transesterification, sodium methoxide was proven to be better than $\mathrm{KOH}$, because sodium methoxide did not produce water, which might be responsible for saponification, and the separation of glycerol from biodiesel could be difficult, thus reducing process 
efficiency. Comparable results for enzymatic and chemical transesterification of waste chicken fat oil have been reported in the published literature. Coppini et al. has reported a $90.61 \%$ biodiesel yield from chicken fat by using a $0.3 \mathrm{wt} \%$ NS-40116 enzyme, 1.5 of methanol:oil and $1.5 \mathrm{wt} \%$ water at $45^{\circ} \mathrm{C}$ for $24 \mathrm{~h} \mathrm{[11].} \mathrm{Da} \mathrm{Silva} \mathrm{et} \mathrm{al.} \mathrm{has} \mathrm{reported} \mathrm{a} \mathrm{77 \%} \mathrm{esterification} \mathrm{yield} \mathrm{by} \mathrm{using} 0.3 \mathrm{wt} \%$ lipase, 1:4.5 methanol:oil and $2 \mathrm{wt} \%$ water at $30^{\circ} \mathrm{C}$ in $24 \mathrm{~h}$ [15]. Alptekin et al. has reported an $87.4 \%$ biodiesel yield from waste chicken fat using a $1 \%$ concentration of a $\mathrm{KOH}$ catalyst and a 6:1 methanol-to-oil ratio at $60{ }^{\circ} \mathrm{C}$ [19]. Mata et al. has reported a $76.8 \%$ biodiesel yield by transesterification of chicken fat using a $0.8 \% \mathrm{KOH}$ catalyst, $6: 1$ methanol:oil at $60^{\circ} \mathrm{C}$ for $2 \mathrm{~h}$ [20]. The few variations in the results are probably due to the different fatty acid profiles of chicken fats and different enzyme sources.

Table 2. Optimized factors for biodiesel synthesis via enzymatic and chemical modes of transesterification of chicken fat oil.

\begin{tabular}{|c|c|c|c|c|c|c|}
\hline Feedstock Oil & Catalysts/Biocatalysts & $\begin{array}{l}\text { Reaction } \\
\text { Time } \\
\text { (Hours) }\end{array}$ & $\begin{array}{c}\text { Reaction } \\
\text { Temperature } \\
{ }^{\circ} \mathrm{C}\end{array}$ & $\begin{array}{l}\mathrm{CH}_{3} \mathrm{OH}: \mathrm{Oil} \\
\text { Molar Ratio }\end{array}$ & $\begin{array}{c}\text { Catalyst's } \\
\text { Concentration } \\
(\%)\end{array}$ & $\begin{array}{l}\text { Biodiesel } \\
\text { Yield (\%) }\end{array}$ \\
\hline WCFO & Aspergillus terreus Lipase & 36 & 35 & $6: 1$ & 1 & 78.4 \\
\hline WCFO & $\mathrm{CH}_{3} \mathrm{ONa}$ & 1.25 & 60 & $6: 1$ & 1 & 87.1 \\
\hline WCFO & $\mathrm{KOH}$ & 1 & 60 & $6: 1$ & 1 & 84.8 \\
\hline
\end{tabular}

\subsection{ANOVA for Transesterification Data of WCFO}

The influence of various reaction parameters such as linear factors, 1st order interactions and quadratic expressions on percentage biodiesel yield are described in the ANOVA table (Table 3). The terms (a)-(d) represents the quadratic models based on findings of $\mathrm{Fe}_{3} \mathrm{O}_{4}$ PDA_Lipase, Aspergillus terreus lipase, sodium methoxide and $\mathrm{KOH}$-catalyzed transesterification of WCFO, respectively. The statistical analysis depicted that the linear term, A-reaction time, had a significant impact for models $\mathrm{a}, \mathrm{b}$ and $\mathrm{c}$ on biodiesel yield $(p<0.0001,0.0003$ and 0.0003 , respectively), which were $<0.05$, while for model $\mathrm{d}$ it was not significant. The linear term B-reaction temperature, showed $p$ values of $0.1743,<0.0001,0.0004$ and $<0.0001$ for models $\mathrm{a}, \mathrm{b}, \mathrm{c}$ and d, respectively. The $\mathrm{Fe}_{3} \mathrm{O}_{4} \_$PDA_Lipase catalyzed transesterification was not affected significantly by temperature change in the selected range. Reaction temperature significantly affected the biodiesel yield for Aspergillus terreus lipase, which was temperature sensitive. The $p$ values for the linear term $\mathrm{C}-\mathrm{CH}_{3} \mathrm{OH}$ :Oil, was $<0.05$ for model (a) and (c) but it was 0.1524 for model (b) and 0.7970 for model (d), which is $>0.05$. D—catalysts/biocatalysts concentration, was proven to have a significant effect on biodiesel yield for all the four models. A previous report on Jatropha curcas seed oil transesterification showed the significant impact of catalyst concentration, methanol-to-oil molar ratio, reaction temperature and reaction time on biodiesel yields [21] In case of Model (a), the 1st order interaction terms AC, AD and CD were found to be significant having $p$-values of $0.0007,0.0001$ and 0.0018 , respectively, which were less than 0.05 ; however, for Model (b) only BD and CD were found significant. In case of Model (c), the 1st order interaction variables, i.e., $\mathrm{AD}$ and $\mathrm{CD}$, were significant with $p$-values of 0.0065 and 0.0017 being less than 0.05 ; for Model (d), only AC 1st order interactions were imparting a significant impact on biodiesel yield with p-values lower than 0.05 . Where the quadratic terms $\mathrm{C}^{2}$ and $\mathrm{D}^{2}$ were significant for Models (a) having a $p<0.05$, for Model (b) the statistical significance was noted among the quadratic terms $\mathrm{B}^{2}$, $C^{2}$ and $D^{2}$. In Model (c), $B^{2}$ and $C^{2}$ were significant, while in the case of Model (d), $A^{2}$ and $D^{2}$ were significantly affecting the biodiesel yield with $p<0.05$. 
Table 3. RSM-based ANOVA for transesterification of waste chicken fat oil (WCFO).

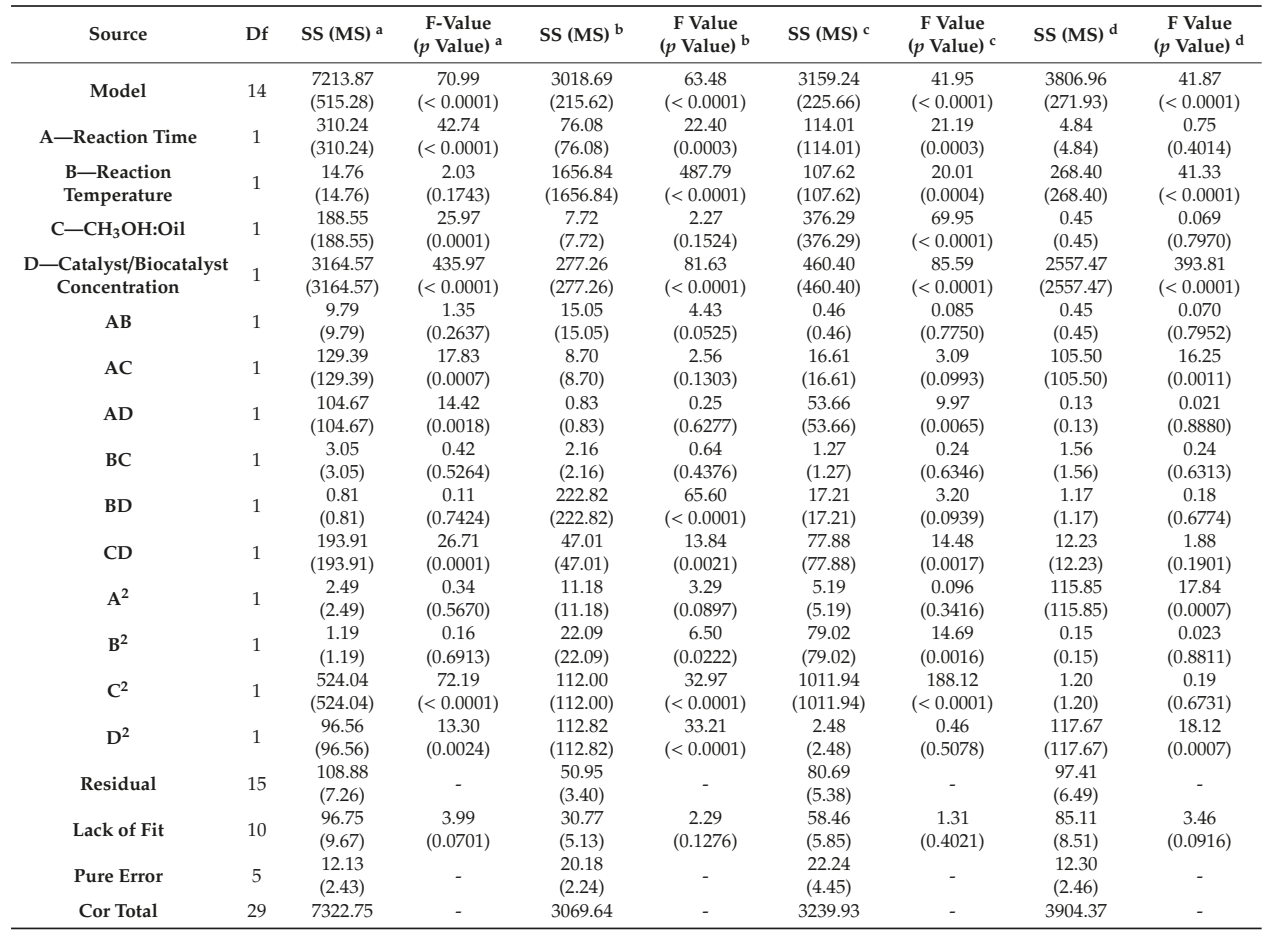

Note: $\mathrm{Fe}_{3} \mathrm{O}_{4}$ PDA_Lipase (a), Aspergillus terreus lipase (b), sodium methoxide (c) and $\mathrm{KOH}$ (d). SS stands for sum of squares and MS is mean square.

The 3D surface plots of the significant 1st order interaction terms are presented in Figure 2. Figure 2a-c presents the significant 1st order interaction terms of Model (a). Figure 2a shows the 3D surface plot between the methanol-to-oil ratio and reaction time; it reveals that the yield increases with an increase in reaction time and methanol:oil, but further increases in the methanol-to-oil ratio resulted in a decreased biodiesel yield. The joint impact of time and concentration to increase the biodiesel yield is given in Figure 2b. Figure 2c presents the 3D plot between bio-catalyst/enzyme concentration and methanol:oil for Model (a). The plot shows that enzyme concentration directly increases the biodiesel yield but the increase of metahonl:oil after a specific limit decreases the biodiesel yield.

Figure 2d,e presents the 3D response surface plots for Model (b). Figure 2d reveals the relation between catalyst concentration and reaction temperature; an increase in temperature decreases the biodiesel yield probably due to the denaturation of free enzyme. Figure 2e presents possible impact of methanol:oil and bio-catalyst/enzyme concentration on biodiesel yield.

Figure 2f,g are the 3D plots of the significant 1st order interaction terms of Model (c). Figure $2 \mathrm{f}$ presents the relation between catalyst concentration and reaction time. It is observed that increase in both parameters increases the biodiesel yield. Figure $2 \mathrm{~g}$ shows the relation between the methanol-to-oil ratio and catalyst concentration. The catalyst concentration increased the biodiesel yield but by further increasing the methanol-to-oil ratio up to certain level, however beyond optimal level, a decrease in biodiesel yield was noted.

Figure $2 \mathrm{~h}$ presents the response of surface plot on the only significant interaction term of Model (d), which is between the reaction time and methanol-to-oil ratio. It showed that biodiesel yield increased with time but after a specific period any further increase in time was not effective. 

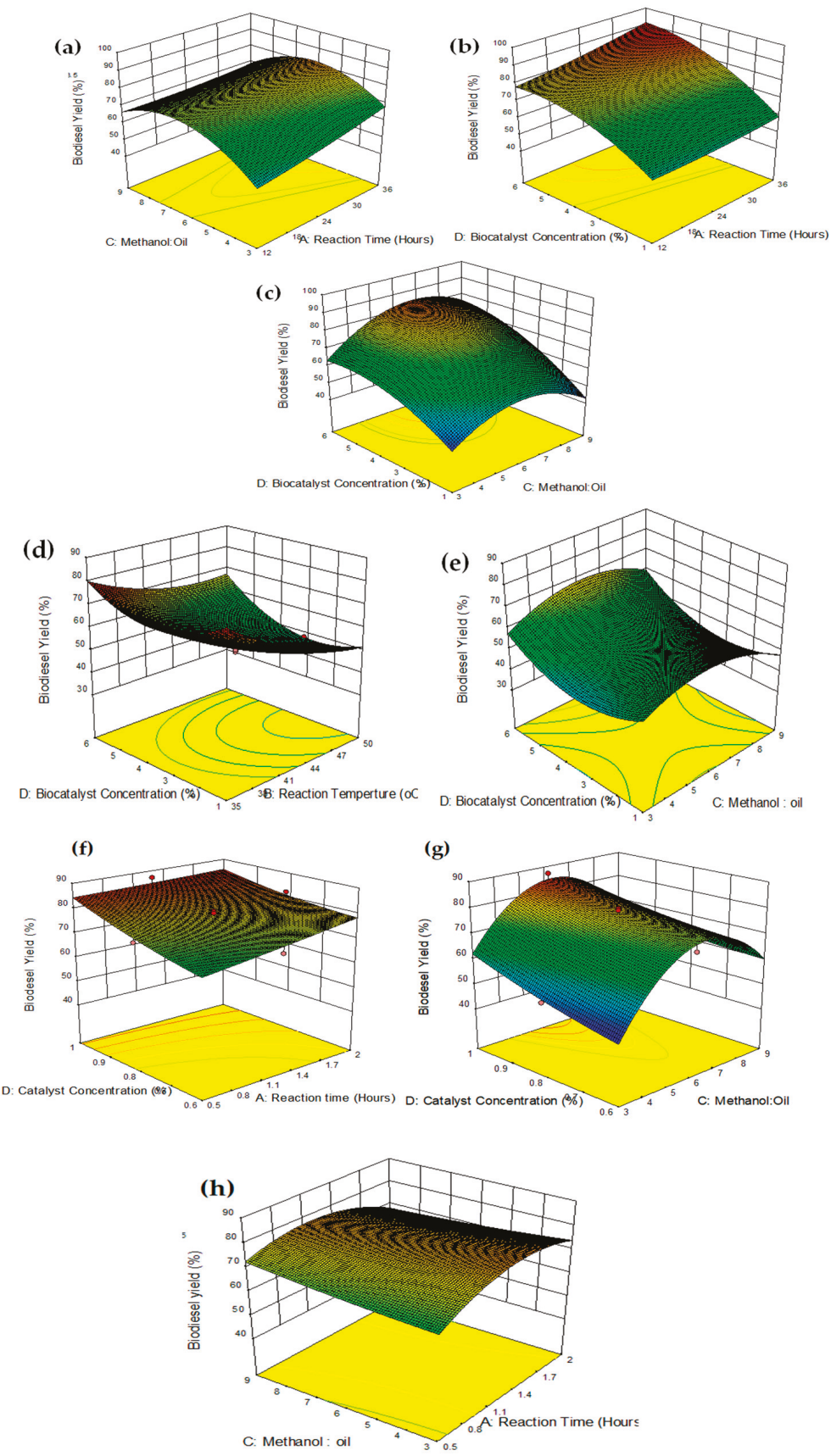

Figure 2. Response surface graphs for the significant 1st order interaction terms of Model (a) $(A \times C)$, (b) $(\mathrm{A} \times \mathrm{D}),(\mathrm{c})(\mathrm{C} \times \mathrm{D})$; $\operatorname{Model}(\mathrm{b}),(\mathrm{d})(\mathrm{B} \times \mathrm{D}),(\mathbf{e})(\mathrm{C} \times \mathrm{D})$; $\operatorname{Model}(\mathrm{c}),(\mathrm{f})(\mathrm{A} \times \mathrm{D}),(\mathrm{g})(\mathrm{C} \times \mathrm{D})$; Model $(\mathrm{d})$, (h) $(\mathrm{A} \times \mathrm{C})$. 


\subsection{FTIR Spectroscopic Analysis of Feedstock Oil, Biodiesel and Composition of Fatty Acid Methyl Esters}

Asymmetric bending of the $\mathrm{CH}_{3}$ group was observed in the region between 1425 and $1447 \mathrm{~cm}^{-1}$ and in the region ranging from 1188 to $1200 \mathrm{~cm}^{-1}$ which were basic characteristic peaks of biodiesel. While the $\mathrm{C}=\mathrm{O}$ stretch vibrations observed in the region between 1700 and $1800 \mathrm{~cm}^{-1}$ and $\mathrm{CH}_{2}$ asymmetric and symmetric stretching vibrations appeared at $2900-3100 \mathrm{~cm}^{-1}$ were present in FTIR spectra of both feedstock oil and synthesized biodiesel samples. However, signals in the $1390-1400 \mathrm{~cm}^{-1}$ region confirmed the $\mathrm{O}-\mathrm{CH}_{2}$ group and in the $1095-1101 \mathrm{~cm}^{-1}$ region defined the asymmetric axial stretching of $\mathrm{O}-\mathrm{CH}_{2}-\mathrm{C}$ for WCFO in FTIR spectra; however, these bands were absent in their respective biodiesel spectra. The above spectroscopic observations were according with the findings of a previous study [22]. The palmitic acid methyl ester (C16:0) 17.96\%, stearic acid methyl ester (C18:0) 20.85\%, oleic acid methyl ester (C18:1) 42.92\% and linoleic acid methyl ester (C18:2) 16.54\%, respectively, were the major FAMEs (Table 4). The current findings were found comparable with those reported by a previous study [16].

Table 4. The fatty acid methyl ester (ME) composition of the synthesized biodiesel.

\begin{tabular}{lllll}
\hline Biodiesel Type & $\begin{array}{l}\text { Palmitic Acid } \\
\text { (C16:0) ME \% }\end{array}$ & $\begin{array}{l}\text { Stearic Acid } \\
\text { (C18:0) ME \% }\end{array}$ & $\begin{array}{l}\text { Oleic Acid } \\
\text { (C18:1, cis) ME \% }\end{array}$ & $\begin{array}{l}\text { Linoleic Acid } \\
\text { (C18:2, cis) }\end{array}$ \\
\hline WCFAO & 17.96 & 20.85 & 42.92 & 16.54 \\
\hline
\end{tabular}

\subsection{Fuel Characteristics of WCFO Biodiesel}

Fuel analysis plays a vital role in the evaluation of the manufactured biodiesel for its technical compatibility with conventional diesel. Fuel analysis of the understudy biodiesel samples was carried out in accordance with ASTM standard methods and the findings are mentioned below.

Kinematic viscosity is considered as one of the most significant fuel properties, as it is related to the resistance of flow that mainly occurs due to internal friction. If a biofuel contains greater values of kinematic viscosity, it will result in poor fuel atomization or incomplete combustion. Flash point and fuel volatility are inversely related to each other. Similarly, high values of cloud point generally result in problems such as fuel-line clogging. The kinematic viscosity $\left(\mathrm{mm}^{2} / \mathrm{s}\right)$, flash point $\left({ }^{\circ} \mathrm{C}\right)$, fire point $\left({ }^{\circ} \mathrm{C}\right)$, pour point $\left({ }^{\circ} \mathrm{C}\right)$ and cloud point $\left({ }^{\circ} \mathrm{C}\right)$ values for WCFO biodiesel are given in Table 5 . The mentioned fuel-quality parameters were found comparable with those from previous studies $[19,20]$.

Table 5. Fuel characteristics of WCFO biodiesel.

\begin{tabular}{lc}
\hline \multicolumn{1}{c}{ Properties } & WCFOB \\
\hline Kinematic viscosity $\left(\mathrm{mm}^{2} / \mathrm{s}\right)$ at $40{ }^{\circ} \mathrm{C}$ & $4.9 \pm 0.55$ \\
Flash point ${ }^{\circ} \mathrm{C}$ & $171 \pm 2.51$ \\
Fire point ${ }^{\circ} \mathrm{C}$ & $187 \pm 3.51$ \\
Pour point ${ }^{\circ} \mathrm{C}$ & $3.0 \pm 2.0$ \\
Cloud point $^{\circ} \mathrm{C}$ & $6.3 \pm 2.37$ \\
\hline
\end{tabular}

\section{Materials and Methods}

Chemicals and reagents of analytical grade were utilized during study and were procured from Sigma-Aldrich (Saint Louis, MO, USA) and Merck (Darmstadt, Germany). Lipase from Aspergillus terreus was produced through fermentation at the Institute of Industrial Biotechnology, GC University, Lahore, Pakistan. The nano-biocatalyst $\left(\mathrm{Fe}_{3} \mathrm{O}_{4} \_\right.$PDA_Lipase) prepared and characterized in our previous work has been used as the immobilized lipase for biodiesel production from chicken fat oil [17]. The chicken fat was collected from the local market of Gujrat City, Pakistan. 


\subsection{Pre-Treatment of Feedstock}

The collected waste chicken fat was heated at $100{ }^{\circ} \mathrm{C}$ to convert it into liquid. The liquid was then filtered to remove the solid waste. Since the chicken fat oil contains a high free fatty acid (FFA) content, alkaline catalysts are not suitable for un-treated chicken fat oil. In this case, acid esterification was used to reduce the acid value before alkaline transesterification. For this purpose, the chicken fat oil was taken in three neck flasks equipped with a thermometer and a glass condenser. The third neck was used to withdraw the sample. Oil was homogenized by heating and stirring at $600 \mathrm{rpm}$. Briefly, $50 \mathrm{mg}$ concentrated sulfuric acid and $2.25 \mathrm{~g}$ methanol for each gram of FFA present in the oil was mixed in a beaker. The acid value of the sample was checked after specific time intervals by taking small aliquots. The process was carried out till the acid number reduced to the desired value. After completion of the process, the mixture was put in a separating funnel. Three layers were formed after some time. The top layer consisted of unreacted methanol and the lower layer was water while the middle layer was fatty acid methyl esters (FAMEs) and oil. The middle layer was collected for chemical transesterification [23]. The enzymatic transesterification, however, was done without pre-acid esterification. The collected oil was subjected to analysis for some basic parameters, including saponification value, acid value (AV) and peroxide value. The degree of unsaturation of feedstock oil was determined by iodine number. Similarly, the specific gravity was also determined along with density and the refractive index.

\subsection{Experimental Design}

The Central Composite Response Surface Methodology (CCRD-RSM) was used to evaluate the impact of the different conditions, namely A) reaction time, B) reaction temperature, C) $\mathrm{CH}_{3} \mathrm{OH}$ : oil and D) the catalyst/biocatalyst's concentration on percentage biodiesel yield, for different transesterification routs using catalysts $\left(\mathrm{KOH}, \mathrm{CH}_{3} \mathrm{ONa}\right.$, free Aspergillus terreus lipase and $\mathrm{Fe}_{3} \mathrm{O}_{4}$ _PDA_Lipase). The ranges of the selected parameters for the four models are presented in Table 6.

Table 6. The ranges of reaction parameters: reaction time, temperature, $\mathrm{CH}_{3} \mathrm{OH}$-to-oil ratio and enzyme concentration used for optimization studies of enzymatic and chemical transesterification.

\begin{tabular}{|c|c|c|c|c|c|}
\hline Design & Catalysts/Biocatalysts & $\begin{array}{c}\text { A-Reaction } \\
\text { Time (h) }\end{array}$ & $\begin{array}{c}\text { B-Reaction } \\
\text { Temp }\left({ }^{\circ} \mathrm{C}\right)\end{array}$ & $\mathrm{C}-\mathrm{CH}_{3} \mathrm{OH}:$ oil & $\begin{array}{c}\text { D-Catalyst/Biocatalyst } \\
\text { Concentration (\%) (with } \\
\text { Respect to Substrate) }\end{array}$ \\
\hline (a) & $\mathrm{Fe}_{3} \mathrm{O}_{4}$ PDA_Lipase & $12-36$ & $35-50$ & $3: 1-9: 1$ & $1-6$ \\
\hline (b) & Aspergillus terreus lipase & $12-36$ & $35-50$ & $3: 1-9: 1$ & $1-6$ \\
\hline (c) & $\mathrm{CH}_{3} \mathrm{ONa}$ & $0.5-2$ & $40-60$ & $3: 1-9: 1$ & $0.6-1$ \\
\hline (d) & $\mathrm{KOH}$ & $0.5-2$ & $40-60$ & $3: 1-9: 1$ & $0.6-1$ \\
\hline
\end{tabular}

In each case, thirty experiments were carried out as per CCRD factorial design. Chemically, this process was performed in three neck flasks equipped with a temperature regulator. A stirrer and reflux condenser were also attached with the flask. The reactions were accomplished at 500 RPM.

\subsubsection{Chemical Transesterification}

Briefly, $50 \mathrm{~g}$ of pre-treated waste chicken fat oil (WCFO) in a flat-bottom three-neck flask was subjected to pre-heating for moisture removal. The molecular weight of the understudy chicken fat oil $(873.72 \mathrm{~g} / \mathrm{mol})$ was calculated as per a previously reported method [24]. The next step involved the mixing of known amounts of methanol and catalysts, respectively. The resultant mixture was transferred gently to the flask. The whole mixture present in the flask was kept for heating with stirring. According to the CCRD design, the reaction conditions were maintained. The reaction was allowed to proceed, and on completion the mixture was separated into two layers. The upper layer was taken and further processed to obtain the refined biodiesel. 


\subsubsection{Enzymatic Transesterification}

For enzymatic biodiesel production, firstly waste chicken oil was mixed with methanol. A specific amount of immobilized lipase ( $\mathrm{Fe}_{3} \mathrm{O}_{4}$ PDA_Lipase) for design (a) and free Aspergillus terreus lipase for design (b) was introduced to the oil/methanol solution and the reaction mixture was subjected to orbital shaking at $200 \mathrm{rpm}$ with a $0.5 \%$ water content (with respect to oil), for a specific time period [25]. The CCRD was followed to set the alcohol to oil molar ratio, enzyme concentration, reaction temperature and time. After completion of the reaction, the glycerol was removed to obtain crude biodiesel, which was purified to get refined biodiesel. Magnetic nano-biocatalyst was separated from biodiesel and glycerol by magnetic decantation.

For the optimization studies, suitable statistical models based on experimental data were employed. Linear, 2FI, cubical and quadratic models were tested. The lack-of-fit test values, model significance ( $p$-value), the $\mathrm{R}^{2}$ and adjusted $\mathrm{R}^{2}$ values provided the base to select most appropriate statistical model. Finally, the response surface graphs were utilized to check the influence of the studied reaction conditions on the yield of biodiesel.

\subsection{Quantification and Characterization of Synthesized Biodiesel}

For the FTIR spectroscopic study, a Carry660 FTIR spectrophotometer (Agilent Technologies, Santa Clara, CA, United States) was used and FTIR spectra were drawn over $400-4000 \mathrm{~cm}^{-1}$ scanning range.

The biodiesel from waste chicken oil was subjected to GC-MS analysis in order to evaluate the fatty acid methyl esters content (FAMEs). For this purpose, the GC-MS (QP 2010) instrument with a dB 5 column (Shimadzu, Japan) having diameter of $0.15 \mathrm{~mm}$ was used. The sample size $(1.0 \mu \mathrm{L})$ was taken with a split ratio of 1:100, while a source of carrier gas, helium, was used having a $1.20 \mathrm{ml} / \mathrm{min}$ flow rate. The oven temperature was kept at 160.0 to $260.0^{\circ} \mathrm{C}$ with a ramp rate of $4{ }^{\circ} \mathrm{C}$ per minute. The scanning of mass was done from 40.0 to $560.0 \mathrm{~m} / \mathrm{z}$. The detection of FAMEs was ascertained by comparing the relative retention time of each discrete FAMEs with reliable standards of FAMEs and by comparison with the NIST mass spectral library.

Fuel characteristics of the biodiesel were evaluated by some test experiments utilizing the ASTM standard procedure, i.e., cloud point (ASTM D 2500), viscosity (ASTM D 455), pour point (ASTM D 97) and flash point (ASTM D 93) [19]. The measurements were made in triplicate and the results were analyzed with the help of statistical tools.

\section{Conclusions}

The waste chicken fat oil was transformed into biodiesel by alkaline and enzymatic transesterifications. The reaction time, temperature, methanol:oil ratio and catalyst concentration were selected for the process optimization. Among all the catalysts and enzymes used, $\mathrm{Fe}_{3} \mathrm{O}_{4}$ _PDA_Lipase-catalyzed transesterification of the studied feedstock oil was proved to be the most efficient to give maximum biodiesel yield. On the other hand, in case of chemical catalysis, $\mathrm{CH}_{3} \mathrm{ONa}$ was proved to be better than $\mathrm{KOH}$ when chicken fat oil was used as the feedstock. FTIR spectroscopy and GC/MS characterization further confirmed biodiesel formation. The compositional profiles and fuel characteristics of the synthesized biodiesel showed a promising compatibility of WCFO as a potential candidate for biodiesel production for future fuel regimes.

Author Contributions: The idea and concept for the current research was floated by, F.S., T.T., M.W.M., H.M. and U.R.; the methodology was also designed by F.S., M.W.M. and U.R.; the enzyme production was carried out by H.M.; the writing of the original draft was prepared by F.S. with the help and supervision of M.W.M., H.M., S.A.R., T.S.Y.C.; and I.A.N. reviewed the manuscript for improvement of the final version. All authors have read and agreed to the published version of the manuscript.

Funding: This research received no external funding.

Acknowledgments: One of the authors acknowledges his gratitude to King Saud University (Riyadh, Saudi Arabia) for the support/technical assistance of this research through Researchers Supporting Project number (RSP-2019/80). 
Conflicts of Interest: The author declares no conflict of interest.

\section{References}

1. Berchmans, H.J.; Hirata, S. Biodiesel production from crude Jatropha curcas L. seed oil with a high content of free fatty acids. Bioresour. Technol. 2008, 99, 1716-1721. [CrossRef] [PubMed]

2. Niculescu, R.; Clenci, A.; Iorga-Siman, V. Review on the use of diesel-biodiesel-alcohol blends in compression ignition engines. Energies 2019, 12, 1194. [CrossRef]

3. Rehan, M.; Gardy, J.; Demirbas, A.; Rashid, U.; Budzianowski, W.M.; Pant, D.; Nizami, A.S. Waste to biodiesel: A preliminary assessment for Saudi Arabia. Bioresour. Technol. 2018, 250, 17-25. [CrossRef]

4. Talebian-Kiakalaieh, A.; Amin, N.A.S.; Mazaheri, H. A review on novel processes of biodiesel production from waste cooking oil. Appl. Energy 2013, 104, 683-710. [CrossRef]

5. Jamil, F.; Al-Muhtaseb, A.H.; Al-Haj, L.; Al-Hinai, M.A.; Hellier, P.; Rashid, U. Optimization of oil extraction from waste "Date pits" for biodiesel production. Energ. Conver. Manag. 2016, 117, 264-272. [CrossRef]

6. Lotero, E.; Goodwin, J.G., Jr.; Bruce, D.A.; Suwannakarn, K.; Liu, Y.; Lopez, D.E. The catalysis of biodiesel synthesis. Catalysis 2006, 19, 41-83.

7. Gürü, M.; Koca, A.; Can, Ö.; Çınar, C.; Şahin, F. Biodiesel production from waste chicken fat based sources and evaluation with $\mathrm{Mg}$ based additive in a diesel engine. Renew. Energy 2010, 35, 637-643. [CrossRef]

8. Chiu, M.C.; Gioielli, L.A. Solid fat content of abdominal chicken fat, its stearins and its binary mixtures with bacon. Food Sci. Technol. 2002, 22, 151-157.

9. Gugule, S.; Fatimah, F.; Rampoh, Y. The utilization of chicken fat as alternative raw material for biodiesel synthesis. Anim. Prod. 2011, 13, 115-121.

10. Liu, K.S. Preparation of fatty acid methyl esters for gas-chromatographic analysis of lipids in biological materials. J. Am. Oil Chem. Soc. 1994, 71, 1179-1187. [CrossRef]

11. Coppini, M.; Magro, J.D.; Martello, R.; Valério, A.; Zenevicz, M.C.; Oliveira, D.D.; Oliveira, J.V. Production of methyl esters by enzymatic hydroesterification of chicken fat industrial residue. Braz. J. Chem. Eng. 2019, 36, 923-928. [CrossRef]

12. Christopher, L.P.; Kumar, H.; Zambare, V.P. Enzymatic biodiesel: Challenges and opportunities. Appl. Energy 2014, 119, 497-520. [CrossRef]

13. Dumri, K.; Hung Anh, D. Immobilization of lipase on silver nanoparticles via adhesive polydopamine for biodiesel production. Enzym. Res. 2014, 2014, 389739. [CrossRef]

14. Aryee, A.N.; Simpson, B.K.; Cue, R.I.; Phillip, L.E. Enzymatic transesterification of fats and oils from animal discards to fatty acid ethyl esters for potential fuel use. Biomass Bioenergy 2011, 35, 4149-4157. [CrossRef]

15. da Silva, J.R.P.; Nürnberg, A.J.; da Costa, F.P.; Zenevicz, M.C.; Lerin, L.A.; Zanetti, M.; Valério, A.; de Oliveira, J.V.; Ninow, J.L.; de Oliveira, D. Lipase NS40116 as catalyst for enzymatic transesterification of abdominal chicken fat as substrate. Bioresour. Technol. Rep. 2018, 4, 214-217. [CrossRef]

16. Feddern, V.; Kupski, L.; Cipolatti, E.P.; Giacobbo, G.; Mendes, G.L.; Badiale, F.E.; de Souza-Soares, L.A. Physico-chemical composition, fractionated glycerides and fatty acid profile of chicken skin fat. Eur. J. Lipid Sci. Technol. 2010, 112, 1277-1284. [CrossRef]

17. Touqeer, T.; Mumtaz, M.W.; Mukhtar, H.; Irfan, A.; Akram, S.; Shabbir, A.; Rashid, U.; Nehdi, I.A.; Choong, T.S.Y. $\mathrm{Fe}_{3} \mathrm{O}_{4}$-PDA-Lipase as surface functionalized nano biocatalyst for the production of biodiesel using waste cooking oil as feedstock: Characterization and process optimization. Energies 2019, 13, 177. [CrossRef]

18. Andrade, M.F.; Parussulo, A.L.; Netto, C.G.C.M.; Andrade, L.H.; Toma, H.E. Lipase immobilized on polydopamine-coated magnetite nanoparticles for biodiesel production from soybean oil. Biofuel Res. J. 2016, 3, 403-409. [CrossRef]

19. Alptekin, E.; Canakci, M. Optimization of pretreatment reaction for methyl ester production from chicken fat. Fuel 2010, 89, 4035-4039. [CrossRef]

20. Mata, T.M.; Cardoso, N.; Ornelas, M.; Neves, S.; Caetano, N.S. Evaluation of two purification methods of biodiesel from beef tallow, pork lard, and chicken fat. Energy Fuels 2011, 25, 4756-4762. [CrossRef]

21. Kamel, D.A.; Farag, H.A.; Amin, N.K.; Zatout, A.A.; Ali, R.M. Smart utilization of jatropha (Jatropha curcas Linnaeus) seeds for biodiesel production: Optimization and mechanism. Ind. Crops. Prod. 2018, 111, 407-413. [CrossRef] 
22. Mumtaz, M.W.; Mukhtar, H.; Anwar, F.; Saari, N. RSM based optimization of chemical and enzymatic transesterification of palm oil: Biodiesel production and assessment of exhaust emission levels. Sci. World J. 2014, 2014. [CrossRef] [PubMed]

23. Chai, M.; Tu, Q.; Lu, M.; Yang, Y.J. Esterification pretreatment of free fatty acid in biodiesel production, from laboratory to industry. Fuel Process. Technol. 2014, 125, 106-113. [CrossRef]

24. Marulanda, V.F.; Anitescu, G.; Tavlarides, L.L. Investigations on supercritical transesterification of chicken fat for biodiesel production from low-cost lipid feedstocks. J. Supercrit. Fluids 2010, 54, 53-60. [CrossRef]

25. Katiyar, M.; Ali, A. Onepot lipase entrapment within silica particles to prepare a stable and reusable biocatalyst for transesterification. J. Am.OilChem. Soc. 2015, 92, 623-632. [CrossRef]

(C) 2020 by the authors. Licensee MDPI, Basel, Switzerland. This article is an open access article distributed under the terms and conditions of the Creative Commons Attribution (CC BY) license (http://creativecommons.org/licenses/by/4.0/). 


\title{
Review \\ Challenges and Opportunities in Identifying and Characterising Keratinases for Value-Added Peptide Production
}

\author{
Juan Pinheiro De Oliveira Martinez ${ }^{1}$, Guiqin Cai ${ }^{1}$, Matthias Nachtschatt ${ }^{1}$, Laura Navone ${ }^{1}$, \\ Zhanying Zhang ${ }^{1}$, Karen Robins ${ }^{1,2}$ and Robert Speight ${ }^{1, *}$ \\ 1 Science and Engineering Faculty, Queensland University of Technology, Brisbane, QLD 4000, Australia; \\ j5.martinez@hdr.qut.edu.au (J.P.D.O.M.); guiqin.cai@qut.edu.au (G.C.); m.nachtschatt@qut.edu.au (M.N.); \\ laura.navone@qut.edu.au (L.N.); jan.zhang@qut.edu.au (Z.Z.); sustainbiotech@iinet.net.au (K.R.) \\ 2 Sustain Biotech, Sydney, NSW 2224, Australia \\ * Correspondence: robert.speight@qut.edu.au; Tel.: +61-7-3138-0373
}

Received: 8 January 2020; Accepted: 24 January 2020; Published: 3 February 2020

\begin{abstract}
Keratins are important structural proteins produced by mammals, birds and reptiles. Keratins usually act as a protective barrier or a mechanical support. Millions of tonnes of keratin wastes and low value co-products are generated every year in the poultry, meat processing, leather and wool industries. Keratinases are proteases able to breakdown keratin providing a unique opportunity of hydrolysing keratin materials like mammalian hair, wool and feathers under mild conditions. These mild conditions ameliorate the problem of unwanted amino acid modification that usually occurs with thermochemical alternatives. Keratinase hydrolysis addresses the waste problem by producing valuable peptide mixes. Identifying keratinases is an inherent problem associated with the search for new enzymes due to the challenge of predicting protease substrate specificity. Here, we present a comprehensive review of twenty sequenced peptidases with keratinolytic activity from the serine protease and metalloprotease families. The review compares their biochemical activities and highlights the difficulties associated with the interpretation of these data. Potential applications of keratinases and keratin hydrolysates generated with these enzymes are also discussed. The review concludes with a critical discussion of the need for standardized assays and increased number of sequenced keratinases, which would allow a meaningful comparison of the biochemical traits, phylogeny and keratinase sequences. This deeper understanding would facilitate the search of the vast peptidase family sequence space for novel keratinases with industrial potential.
\end{abstract}

Keywords: keratinase; serine protease; metalloprotease; peptidase; keratin hydrolysis; keratin waste; valorisation; bioactive peptides

\section{Introduction}

Millions of tonnes of waste keratin are produced every year in the poultry, meat processing, leather and wool textile industries. The global poultry meat processing industry alone produces $40 \times 10^{6}$ tonnes of waste feathers annually [1]. With the transition away from the fossil fuel-centric economy to a sustainable circular economy, the valorisation of keratin materials addresses the waste problem and facilitates the integration of waste keratin into new value chains to enable a circular economy.

Traditionally, keratin waste has been sent to landfill or rendering, or used as fertilizer, feather meal or incinerated [2,3]. There is, however, an opportunity for livestock industries to produce higher value products from waste keratin. There are multiple thermochemical methods available to prepare hydrolysed keratin for various value-adding opportunities [4]. However, the use of peptidases with keratinolytic activity for keratin hydrolysis protects the integrity of the keratin amino acids in 
most cases and allows control over the peptide size in the hydrolysate that is not readily achievable with other methods [5]. This degree of control allows the production of bespoke medical biomaterials, smart biocomposites, protein feed supplements with enhanced nutritional and bioactive properties as well as personal care products with enhanced functional and bioactive properties.

Identifying peptidases with keratinolytic activity is an inherent problem associated with the search for new enzymes. Keratinase activity however appears to be dependent on the accessibility of the keratin substrate to the enzyme [6,7]. Thermochemical or biochemical treatment of the keratin, with emphasis on the reduction of the disulphide bond and disruption of other important bonds involved in the structural stability of keratin like isopeptide, hydrogen and glycolytic bonds [6,8-10], appears to be the prerequisite for enzymatic hydrolysis. Sulphitolysis, which involves reduction of the disulphide bond in keratin, often acts synergistically with keratinases in nature [6,7]. Although destabilization of the keratin structure is a prerequisite for keratin hydrolysis, not all peptidases can hydrolyse keratin. Peptidases like trypsin, papain and pepsin cannot hydrolyse keratin as efficiently as peptidases with keratinolytic activity, even if the reduction of disulphide bond has already occurred [11]. The elucidation of the unique characteristics of peptidases with keratinolytic activity that differentiate them from the other peptidases, would be an important breakthrough in the search for new and robust keratinases for the valorisation of keratin waste.

This paper reviews twenty sequenced peptidases with keratinolytic activity from the serine protease and metalloprotease families by comparing their biochemical characteristics and will highlight the difficulties associated with the interpretation of these data.

\section{Keratin: A Complex and Strong Structure}

Keratins are important structural proteins produced by vertebrate epithelia that have various physiological function. Keratins can act as a protective barrier to water, against infection or cushion tissue from mechanical impact. The two main types of keratins proteins are $\alpha$-keratin and $\beta$-keratins. These two types are further divided into acidic or basic, soft or hard, and have different molecular weights $[4,9,12,13]$. The following section describes the complexity of the keratin structure, which provides insight into the resistance of keratin to hydrolysis. This review will concentrate on hard $\alpha$-keratin and $\beta$-keratin, $\gamma$-keratins and the keratin-associated proteins, which are common to mammalian hair, bristles, wool, hooves, horns and feathers.

$\alpha$-Keratin has an $\alpha$-helix structure, which is stabilized by hydrogen bonding and the presence of multiple cysteines forming disulphide bridges. $\alpha$-Keratin is characterized by a lower sulphur content compared to other keratins and a molecular mass of $60-80 \mathrm{kDa}$ [4]. Hard $\alpha$-keratin is the major protein of mammalian fibres, nails, hooves and horns. In contrast, hard $\beta$-keratins are characteristic of the hard, cornified epidermis of reptiles and birds, e.g., feathers, claws and scales, and have a twisted $\beta$-sheet-like structure. They also form the major component of the fibre cuticle. The $\beta$-keratin pleated sheets consist of $\beta$-strands, which are laterally packed and can have a parallel or antiparallel orientation. The $\beta$-sheets are held together by hydrogen bonds and the planar nature of the peptide bond, which results in the stable pleated $\beta$-sheet [13]. $\beta$-Keratins have a molecular mass of 10-22 kDa. A third type of keratin, $\gamma$-keratin, is a globular protein with a high sulphur content and a molecular weight of about $15 \mathrm{kDa}$. This keratin, along with keratin-associated proteins, form the matrix between the microfibrils and microfibrils of the fibre cortex of mammalian fibres and stabilize the structure of the cortex via extensive disulphide bridge formation.

The complex structural organization of all mammalian fibres is very similar [8]. The hair fibre consists of an outermost cuticle layer, which is composed of overlapping flattened scale-like cells that form a protective sheath around the cortex [8]. The major protein of the fibre cuticle is $\beta$-keratin [4]. The cortex is composed of hard $\alpha$-keratin intermediate filaments embedded in a sulphur-rich matrix. These filaments surround the medulla when present, as is the case for coarser fibres. The cell membrane complex binds the cuticle and cortical cells. 
The cuticle layer is laminated and consists of the following layers-the cuticle filament-associated surface membrane, the cystine-rich exocuticular $a$-layer, the lower exocuticle and the endocuticle, which contains only low levels of sulphur-containing amino acids and constitutes the inner lining of the cuticle [8]. The outermost layer of the cuticle provides a hydrophobic barrier, which protects the fibre surface from water and chemical compounds. This cuticle filament-associated surface membrane is $2-7 \mathrm{~nm}$ thick and composed of highly cross-linked proteins and lipids. The major fatty acid of the cuticle surface lipids found in human and animal hair is 18-methyleicosanoic acid [14]. It is covalently linked to the protein matrix below by a thioester linkage and the protein matrix is cross-linked by isopeptide bonds [15]. An isopeptide bond results from the transglutaminase-catalysed formation of an amide bond between the amino acid side chains of the amino acid residues in the keratin protein, for example, lysine and glutamine [9].

The cortical cells are assembled as keratin intermediate filaments and have a diameter of 7-8 nm in all mammalian fibres [8]. These intermediate filaments form ordered aggregates or microfibrils and macrofibrils depending on species and function (Figure 1). The hard $\alpha$-keratin intermediate filaments are assembled from tetramers, a pair of laterally aligned and antiparallel dimeric molecules. On average, keratin intermediate filaments contain eight tetramers. In the case of wool, the cortex region is composed of an orthocortex and paracortex with different intermediate filament/matrix packing. The proportion of ortho- and paracortex in the wool fibre determines the degree of crimping [13].

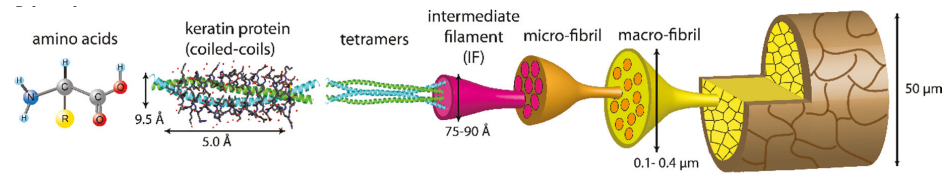

Figure 1. Structure of keratin. Adapted from work in [12] under the Creative Commons Attribution 4.0 International license (https://creativecommons.org/licenses/by/4.0/deed.en).

Keratin peptide heterodimers are formed when a type I (acidic) polypeptide chain and a type II (basic) polypeptide chain align in parallel. Each polypeptide chain is composed of a central $\alpha$-helical region (about $46 \mathrm{~nm}$ in length) with non-helical head and tail domains [13]. The head and tail domains are rich in cysteine, glycine and tyrosine amino acids. Disulphide and isopeptide bonds are formed with other keratin intermediate filaments, cysteine-rich matrix proteins and keratin associated proteins, which stabilize the fibre [8-10]. The disulphide bonds along with the N-acetyl glucosamine-glycosylated serine and threonine in the head and tail domains also stabilize the heterodimers [6].

\section{Thermochemical Methods of Keratin Degradation}

There are multiple thermochemical methods available to prepare hydrolysed keratin for various value-adding opportunities, with specific processes chosen depending on the end-use [4]. Thermochemical methods include solubilization of keratin in organic solvents, ionic liquids or by hydrothermal methods; oxidation or reduction of the disulphide bridges; disruption of the hydrogen bonds with compounds like urea; and acid or base hydrolysis.

The composition of the final hydrolysate will depend on the method used to hydrolyse the keratin. Some of the thermochemical processes result in a hydrolysate containing a highly diverse mix of keratin-derived peptides and free amino acids and others are more specific. However, in most cases, the amino acid composition is modified. The processes and hydrolysate products will be described in more detail in the following section.

After solubilization of keratin with solvents like with $N, N$-dimethylformamide or dimethyl sulfoxide, precipitation is required with acetone and drying to produce a powder of keratin [16]. The major drawback of this method is the use of large quantities of solvents, which need to be recycled or incinerated. Solubilization can also be achieved with ionic liquids. Xie et al. used the ionic liquid, 1-butyl-3-methylimidazolium chloride for the solubilization of wool keratin, which disrupted 
the hydrogen bonds in the keratin macromolecules [17]. The keratin peptides were precipitated from the resulting hydrolysate with methanol. Ionic liquids are more expensive than traditional solvents and extraction of the keratins from the ionic liquid can be difficult.

Hydrothermal treatment is usually carried out at temperatures of $80-140{ }^{\circ} \mathrm{C}$ and steam pressures of 10-15 psi. Acid or base can be added to speed up the process of solubilization [18]. Under conditions of high temperature and pressure, the thermally unstable amino acids, glutamine and asparagine are degraded [19]. If base is added to this process then lysine, methionine and tryptophan are also destroyed [20,21]. Modified amino acids, lysinoalanine and lanthionine are also formed from lysine and cystine, respectively. Heating of proteins leads to a degree of racemization of the free and bound L-amino acids [22-24].

Reduction with reducing agents like thioglycolate [4], dithiothreitol [25], 2-mercaptoethanol [26], sodium sulphite [27], bisulphites [28] or cysteine [29] combined with high concentrations of compounds like urea, thiourea or surfactants, which disrupt the hydrogen bonds stabilising the keratin structure, results in the production of kerateine [30]. Kerateine contains cysteine thiol and cysteine sulfonate in place of the disulphide bonds. Kerateine is less soluble in water and can be re-cross-linked if exposed to an oxidant [4].

The microstructure of wool keratin after treatment for $4 \mathrm{~h}$ at $65^{\circ} \mathrm{C}$ with 2-mercaptoethanol, EDTA, high concentrations of urea and $\mathrm{pH} 9$ was investigated by Cardamone [31]. Analysis of the hydrolysate revealed a defined mixture of microfibrillar and intermediate filaments. This mixture of subunits was suitable for producing self-assembling biomaterials.

Oxidation of keratin by oxidants like peracetic acid [32] or peroxycarboximidic acid [33] leads to the formation of keratose. Keratose contains sulfonic acid groups and cysteic acid instead of the disulphide bonds [4]. These keratoses are hydroscopic, water soluble and the disulphide bridges cannot spontaneously re-form under oxidative conditions. Keratoses are not as stable as kerateines.

Oxidative sulphitolysis has been patented and commercialized to produce three functional keratin protein and peptide products. These products are based on S-sulphonated keratin intermediate filaments, S-sulphonated keratin high-sulphur proteins and keratin peptides [34]. The process aims at maintaining the structural integrity of the keratin proteins. The cystine groups in the wool keratin are converted to S-sulfocysteine using sodium sulphite or sodium metabisulfite and then oxidized with cupraammonium hydroxide. The intermediate filaments and peptides can undergo crosslinking by reductive desulfonation of the cysteines in the filaments and peptides and subsequent reformation of the intermolecular disulphide bonds.

One of the disadvantages of alkaline hydrolysis of keratins is the modification or degradation of amino acids (Table 1). Alkaline hydrolysis of keratins at higher temperatures results in the degradation of the thermally unstable amino acids, asparagine, glutamine, arginine, serine, threonine and cysteine [5]. Lysinoalanine and 8-aminoalanine are formed under alkaline conditions [35,36]. Another modification that occurs is the racemization of free or bound L-amino acids to the D-enantiomers $[23,37,38]$. Free amino acids racemize ten times slower than bound amino acids [24]. Following, for example, prolonged treatment of wool keratin at $70{ }^{\circ} \mathrm{C}$ and $\mathrm{pH}$ 9-11, lanthionyl residues [31] and dehydroalanine [39] are formed from cystine. Cystine and hydroxy amino acids were destroyed if the alkaline treatment was performed in the presence of reducing agents [40].

Table 1. Amino acid modification during alkaline treatment.

\begin{tabular}{ccc}
\hline Amino Acid & Degradation Products & Reference \\
\hline Asparagine & Aspartate, ammonia & {$[41]$} \\
Glutamine & Glutamate, ammonia & {$[41]$} \\
Arginine & Ornithine, citrulline, 3-aminopiperidin-2-one & {$[42]$} \\
Serine & Glycine, alanine, oxalic acid, lactic acid, ammonia & {$[43]$} \\
Threonine & Glycine, alanine, $\alpha$-aminobutyric acid, ammonia & {$[44]$} \\
Cysteine & Pyruvic acid, sodium sulfide, ammonia & {$[45]$} \\
$*$ Cystine, lysine, arginine & Lanthionine, lysinoalanine, ornithinalanine; ${ }^{*}$ dehydroalanine $[39]$ & {$[35,36]$} \\
L-amino acids & D-amino acids & {$[37]$} \\
\hline
\end{tabular}

Note: * Dehydroalanine is probably formed from the cleavage of the C-S bond in cystine. 
Acid hydrolysis of keratins leads to the loss of some amino acids like serine, threonine, tyrosine and cystine and the conversion of asparagine, glutamine, methionine and tryptophan into other compounds $([5,19,46]$ Table 2$)$. Polypeptides, resulting from the acid hydrolysis of keratin, have a more amorphous structure than alkaline hydrolysates, because most of the hydrogen bonds are broken during this process [47]. A typical acid hydrolysis of keratin uses hydrochloric acid [48,49] or sulphuric acid [50] at high temperatures.

Zhang et al. showed that acid hydrolysis was not as effective as other treatments mentioned above [49]. Wool keratin was hydrolysed with $4 \mathrm{M}$ hydrochloric acid at $95^{\circ} \mathrm{C}$ for $24 \mathrm{~h}$, resulting in $33 \%$ solubilization of the wool keratin. Increasing the treatment time had no effect on the yield, suggesting that there is a recalcitrant portion of the keratin resistant to acid hydrolysis.

Thermochemical methods offer cheap and versatile processes for hydrolysing keratin for a variety of applications. However, the use of harsh chemicals and conditions, the lack of ability to control the processes in most cases and the often unfavourable modification of the amino acids or peptides present environmental problems and peptide mixes that would be unsuitable for some applications. Using enzymes working under mild conditions to catalyse the hydrolysis offers a favourable alternative.

Table 2. Amino acid modification during acid treatment.

\begin{tabular}{ccc}
\hline Amino Acid & Degradation Products & Reference \\
\hline Asparagine & Aspartate, ammonia & {$[19,41]$} \\
Glutamine & Glutamate, ammonia & {$[19,41]$} \\
Methionine & Methionine sulfoxide & {$[19]$} \\
Tryptophan & Oxindolylalanine, dioxindolylalanine & {$[46]$} \\
\hline
\end{tabular}

\section{Microbial Degradation of Keratin}

The first peptidases with keratinolytic activity were found in Bacillus sp. and Streptomyces sp. and belong to the serine peptidase family [51]. The ability to degrade keratin is widespread and has been identified in bacteria and fungi [4,52]. Keratin-degrading microorganisms have been isolated from many sources like skin, feathers, hair, nails, soil, geothermal hot stream and wastewater, which is reflected in the optimum $\mathrm{pH}$ and temperature of the keratinase activity of these microorganisms. The $\mathrm{pH}$ optimums of keratinases range from $\mathrm{pH} 5.5$ for the fungal keratinase from Trichophyton mentagrophytes [53] to $\mathrm{pH} 12.5$ for the keratinase from Brevibacillus sp. AS-S10-11 [54]. Although, temperature optimums vary from $30^{\circ} \mathrm{C}$ for the keratinase from Brevibacterium luteolum [55] to $100^{\circ} \mathrm{C}$ for the keratinase from Fervidobacterium islandicum AW-1 [56].

Publications from 2018 and 2019 report the isolation of diverse species of bacteria like Streptomyces sp. [57], Aeromonas hydrophila FB3 [58], Pseudomonas putida KT2440 [59] and Serratia marcescens EGD-HP20 [60,61] with keratinolytic activity. However, the number of Bacillus strains with keratinolytic activity prevailed over any other genus of bacteria [62-86]. Valorisation of waste feathers $[5,65,66,87]$ and the replacement of the traditional, highly polluting hide dehairing step used in the leather industry with a more environmentally friendly enzymatic step using keratinases $[2,55,79,88]$ were the dominant themes of these papers.

Despite the interest in the enzymatic hydrolysis of keratin, mechanisms of keratin degradation in microorganisms are not fully understood. There is evidence that microbial degradation of keratin proceeds via a consortium of enzymes (Figure $2[6,7,89]$ ).

Disruption of the keratin structure is an essential step in the breakdown of keratin by keratinases. Various mechanisms have been suggested for fungal systems. Disulphide bond reductases and the intracellular cysteine dioxygenase can break the structure-stabilizing disulphide bridges in keratin $[6,7,90]$. Cysteine dioxygenase in conjunction with aspartate aminotransferase produces the reducing agent, sulphite, from cysteine, which is secreted into the surroundings and contributes to the chemical reduction of the disulphide bond. The reduction of the disulphide bonds aids access of the endoproteases (serine protease family), exoproteases (metalloprotease family) and 
oligopeptidase (metalloprotease family) to the keratin fibres or feathers. It has also been found that the membrane-bound redox system of the cell can cleave the disulphide bonds in keratin. The mechanical pressure exerted by fungal mycelia penetrating the keratin structure can also contribute to the disruption of this structure, facilitating access of the keratinase to the substrate. In nature, these mechanisms act synergistically with keratinases and speed up the degradation of keratin. Auxiliary proteins, like lytic polysaccharide monooxygenases (LPMOs), have been found associated with keratin degradation [6]. It is thought that they contribute to $\alpha$ - and $\beta$-keratin degradation. Until now LPMOs were thought to be associated with cellulose, chitin, hemicellulose and starch degradation only. It is possible that these enzymes hydrolyse the glycolytic bond between $\mathrm{N}$-acetylglucosamine and serine and threonine in the head and tail region of the intermediate filaments, which contributes to the destabilization of the keratin structure.

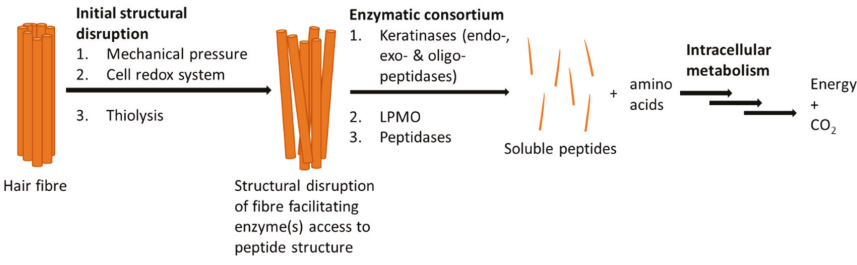

Figure 2. Possible mechanisms for microbial degradation of keratin (LPMO = lytic polysaccharide monooxygenase).

However, examples of peptidases with keratinolytic activity that do not need the assistance of disulphide reducing enzymes or agents have also been reported. Pillai et al. isolated a serine protease from Bacillus subtilis P13 with reductase and keratinase activities [91]. The isolated enzyme was able to decompose feathers and dehair hides.

He et al. analysed the enzyme consortium involved in the hydrolysis of feathers by a specific strain of Bacillus subtilis and identified four of the enzymes involved in keratin hydrolysis [74]: a serine protease with keratinase and disulphide bond-reducing activity; a peptidase T; a $\gamma$-glutamyltransferase, which generates a free cysteinyl group from glutathionine; and a cystathionine $\gamma$-synthase, which catalyses the production of L-cystathionine from homoserine ester and cysteine. The L-cystathionine is further converted to methionine and ammonia is released.

\section{Characterisation and Comparison of Keratinases from S1, S8 and M4 Peptidase Families}

Many articles characterising organisms capable of degrading keratin and their possible industrial applications have been published. Yet, there are few articles that report enzyme sequences and investigate the molecular and biochemical characteristics of the enzymes produced by these organisms [92,93]. The first paper that explored the molecular aspects of a keratinase produced by Bacillus licheniformis was published by Lin et al., 1995. Since then, more than 40 keratinases have been sequenced. To date, peptidases with keratinolytic activity from six different peptidase families have been identified: S1, S8, M4, M5, M14 and M28. Most of the characterized keratinases are produced by Bacilli and are members of the S8 serine peptidase family. There are currently over 127,000 peptidase sequences from the S1 (70919), S8 (38270), M4 (6403), M5 (145), M14 (11202) and M28 (904) families deposited on the MEROPS peptidases database. These 127,000 peptidase sequences represent an enormous unmined potential for the discovery of new peptidases with keratinolytic activity if the requisite properties of a peptidase with keratinolytic activity can be identified.

The S1 family sequences, when pairwise aligned, show a minimum value of $27.27 \%$ and a maximum of $97.22 \%$ identity, with an average of $61.48 \%$ for the four available sequences. The S8 family has a minimum of $13.69 \%$ and a maximum of $99.72 \%$ identity, with an average of $63.29 \%$ for the 13 available sequences, and the M4 family has $25.56 \%$ identity between the two available sequences. Although many of the characterized enzymes have been produced by the native unmodified organism [94-98], several 
examples involve heterologous expression. Different organisms have been used for recombinant production, including yeast such as Komagataella Pastoris (Pichia Pastoris) [99] and bacteria such as Escherichia coli [100-110] and Streptomyces lividans [111]. Including the pre-pro-domains with the catalytic domain in heterologous systems have been shown to maintain enzyme activity and secretion $[99,102,107,110]$ and inclusion of C-domains, when present, is important for substrate binding and recognition [105]. Replacing the native signal peptide for the E. coli signal peptide when expressing in E. coli has also led to higher levels of expression [101].

In this section the biochemical data of twenty sequenced peptidases with keratinolytic activity from the S1 and S8 peptidase families (serine proteases) and the M4 peptidase family (metalloprotease) are compared (Table 3). Difficulties associated with the interpretation of these data are also highlighted. The selection is based on the availability of sequence and biochemical data. The M5, M14 and M28 peptidase families were excluded because each family had only one biochemically characterized example with full sequence data available.

Table 3. Keratinolytic microorganisms and their keratinases from the S1, S8 and M4 keratinases selected for this study.

\begin{tabular}{|c|c|c|c|c|}
\hline Organism & Strain & Keratinase Name & Accession No. ${ }^{1}$ & Reference \\
\hline \multicolumn{5}{|l|}{ S1A Peptidases } \\
\hline Actinomadura viridilutea & DZ50 & KERDZ & KU550701 & [94] \\
\hline Actinomadura keratinilytica & Cpt29 & KERAK-29 & ASU91959 & [95] \\
\hline Streptomyces fradiae & Var. k11 & SFP2 & AJ784940 & [99] \\
\hline Nocardiopsis sp. & TOA-1 & NAPase & AY151208 & [111] \\
\hline \multicolumn{5}{|l|}{ S8A Peptidases } \\
\hline Bacillus circulans & DZ100 & SAPDZ & AGN91700 & [100] \\
\hline Bacillus licheniformis & RPk & KerRP & EU502844 & [96] \\
\hline Stenotrophomonas maltophilia & BBE11-1 & KerSMD & KC814180 & [101] \\
\hline Stenotrophomonas maltophilia & BBE11-1 & KerSMF & KC763971 & [101] \\
\hline Bacillus pumilus & A1 & KerA1 & ACM47735 & [97] \\
\hline Bacillus pumilus & CBS & SAPB & CAO03040 & [102] \\
\hline Bacillus pumilus & KS12 & $\mathrm{rK}_{27}$ & HM219183 & [103] \\
\hline Bacillus tequilensis & Q7 & KerQ7 & AKN20219 & [104] \\
\hline Bacillus cereus & DCUW & Vpr & ACC 94305 & {$[105,112]$} \\
\hline Bacillus altitudinis & RBDV1 & KBALT & APZ77034 & [63] \\
\hline Thermoactinomyces sp. & YT06 & YT06 Protease & WP_037995056 & [98] \\
\hline Thermoactinomyces $s p$. & $\mathrm{CDF}$ & Protease C2 & ADD51544 & [106] \\
\hline Meiothermus taiwanensis & WR-220 & rMtaKer & 5WSL & [107] \\
\hline Brevibacillus sp. & WF146 & WF146 Protease & AAQ82911 & [108] \\
\hline \multicolumn{5}{|l|}{ M4 Peptidases } \\
\hline Geobacillus stearothermophilus & AD-11 & RecGEOker & KJ783444 & [109] \\
\hline Pseudomonas aeruginosa & KS-1 & KerP & HM452163 & [110] \\
\hline
\end{tabular}

Note: ${ }^{1}$ NCBI GenBank nucleotide accession number.

\subsection{S1, S8 and M4 Peptidase Families}

The S1 family is the largest family of serine proteases. The active site of S1 peptidases contains the catalytic triad, His, Asp and Ser. All enzymes characterized in this family are endopeptidases. The four peptidases in Table 3 belong to the S1A family represented by chymotrypsin as the type-example. The hydrophobic amino acid at the P1 site determines the specificity of these peptidases [113,114].

The S8 family is currently the second largest serine protease family and the most widely characterized to date $[114,115]$. Most of the keratinases are found in the subfamily S8A including the 14 keratinases in Table 3. They are represented by subtilisin as the type-example. Their active site contains the catalytic triad of Asp, His and Ser. In general, these enzymes are endopeptidases [116], active between neutral and moderately alkaline $\mathrm{pH}$ and many are thermostable [117]. Most enzymes in this family are not specific, usually cleaving after a hydrophobic residue in the peptide substrate $[114,117]$. S1 and S8 families are examples of convergent evolution as they catalyse the same reaction but have no sequence homology. Two calcium-binding sites contribute to thermal stability in many members of these families [114,117]. 
Two keratinases in Table 3 belong to the M4 family. They are characterized by a catalytic zinc ion tetrahedrally coordinated in the active site by a histidine and glutamate present in a HEXXH motif, another glutamate residue and water [118]. Most members of this family are endopeptidases and active at neutral $\mathrm{pH}$. The preferred cleavage site occurs at a hydrophobic residue followed by leucine, phenylalanine, isoleucine or valine. These peptidases are stabilized by $\mathrm{Ca}^{2+}[119]$.

Independent of their families, keratinases usually cleave aromatic and hydrophobic amino acid residues at the $\mathrm{P} 1$ position. Keratins are composed of 50 to $60 \%$ aromatic and hydrophobic residues, which could partially explain the keratinase specificity for keratin [120-122]. Most of these peptidases are stabilized by divalent cations like $\mathrm{Ca}^{2+}$ and are extracellular $[119,123,124]$.

\subsection{Problems Associated with Keratinase Assays}

There are several issues with the current methods used to characterize keratinases. The assays are not standardized in the literature in terms of reaction conditions and substrates. The most common method used to measure keratinase activity is a colorimetric assay that uses the commercially available derivative of wool, keratin azure [125] or azokeratin (sulfanilic acid-azokeratin [126]). However, batch variability and the fact that the chromogenic agents are only bound to the outer portion of the substrate compromises reproducibility. Quantification of the soluble peptides generated by hydrolysis of keratin has also been used to determine the effectiveness of keratinases on keratin substrates. Common quantification methods used are Bradford [95,127], Lowry [128,129] or measurement of absorption at $280 \mathrm{~nm}[106,111]$ (see Table 4). Each of these methods have several limitations. The Coomassie Blue dye used in the Bradford method preferentially reacts with arginine and lysine in the peptide mix and alkaline $\mathrm{pH}$ and detergents interfere with the reaction. The Folin-Ciocalteu dye used in the Lowry method oxidizes the aromatic amino acids residues in the protein and is affected by reducing agents. Only tyrosine, tryptophan and cysteine absorb at $280 \mathrm{~nm}$ and other compounds like DNA in the solution can interfere with the measurement [130]. The simplest and probably most accurate method for quantifying keratinase activity is the measurement of weight loss when the insoluble keratin substrates like mammalian hair fibres, feathers or wool are solubilised through hydrolysis [96,127].

Table 4 describes a variety of substrates that have been used to assay keratinase activity in the literature. The substrates that were used include keratin azure (wool), keratin powder, soluble keratin, keratin (undefined), feathers and feather meal powder. It was not possible to ascertain the source and integrity of most of these keratin substrates from the papers. The pretreatment of these substrates is also an important aspect in determining the keratinase activity. Keratin powder and solubilized keratin were generally obtained from commercial sources; however, the sources and preparation were not described. Pretreatments like autoclaving and milling [103,107], or treating with solvents at high temperatures [106], are known methods for keratin powder preparation from the literature. In the case of the $\mathrm{rK}_{27}$ keratinase, the feather powder used in the assay was autoclaved and dried at $60{ }^{\circ} \mathrm{C}$ [103]. These preparation methods, as already described in Section 3, would compromise the keratin structure. The keratinases, KerRP [96], Ker-A1 [97] and SAPB [102] were assayed on keratins of unknown source. In the WF146 protease assay, the feather substrate was washed with ethanol prior to use in the assay, which would likely remove the protective lipid layer [108].

Co-treatment can also affect the integrity of the keratin substrates during enzymatic hydrolysis [125,131,132]. Except for KerQ7 [104], all assays in Table 4 were carried under alkaline conditions between $\mathrm{pH} 8$ and $\mathrm{pH} 12.5$ and temperatures ranging from 50 to $80^{\circ} \mathrm{C}$. These conditions would most likely contribute to the weakening the keratin structure. Keratinase assays with SAPDZ [100], KerQ7 [104], KERDZ [94], and KERAK-29 [95] were supplemented with the divalent cations $\mathrm{Ca}^{2+}$ or $\mathrm{Mn}^{+}$. Divalent cations are known to stabilize serine proteases [114,117]. Other keratinase studies added reducing agents, like $\beta$-mercaptoethanol (protease C2 [106], WF146 protease [108]) or dithiothreitol (SFP2 [99]) to the assay mixture. Reducing agents are known to break the disulphide bond leading to disruption of the keratin. 
Table 4. Keratinase $\mathrm{pH}$ and temperature optimums of the selected S1, S8 and M4 keratinases with associated assay conditions. See text for further details of the assays.

\begin{tabular}{|c|c|c|c|c|c|}
\hline Protein & ${ }^{*} \mathrm{pH}$ & ${ }^{*} \operatorname{Temp}\left({ }^{\circ} \mathrm{C}\right)$ & Conditions & PT & CT \\
\hline \multicolumn{6}{|c|}{ S1A Peptidases } \\
\hline KERDZ & 11 & 80 & $\begin{array}{l}10 \mathrm{~g} / \mathrm{L} \text { keratin azure, } 50 \mathrm{mM} \\
\text { bicarbonate- } \mathrm{NaOH} \text { buffer, } \mathrm{pH} 11 \text { mixed } \\
1: 1 \text { with the enzyme, } 30 \mathrm{~min}, 80^{\circ} \mathrm{C}, 200 \\
\mathrm{rpm}\left(\mathrm{Abs}_{595 \mathrm{~nm}}\right) .\end{array}$ & - & $2 \mathrm{mM} \mathrm{CaCl}_{2}$ \\
\hline KERAK-29 & 10 & 70 & $\begin{array}{l}1 \mathrm{~mL} \text { of } 10 \mathrm{~g} / \mathrm{L} \text { keratin azure, } 100 \mathrm{mM} \\
\text { Glycine- } \mathrm{NaOH} \text { buffer mixed } 1: 1 \text { with the } \\
\text { enzyme, } \mathrm{pH} 10,20 \mathrm{~min}, 70^{\circ} \mathrm{C}\left(\mathrm{Abs}_{595 \mathrm{~nm}}\right) .\end{array}$ & - & $5 \mathrm{mM} \mathrm{MnSO}_{4}$ \\
\hline SFP2 & 10 & 60 & $\begin{array}{l}5 \mathrm{mg} \text { keratin azure, } 50 \mathrm{mM} \text { Tris- } \mathrm{HCl}, \mathrm{pH} \\
8.5,1 \mathrm{~h}, 37^{\circ} \mathrm{C}\left(\text { Abs }_{595 \mathrm{~nm}}\right) .\end{array}$ & - & $10 \mathrm{mM}$ DTT \\
\hline NAPase & 12.5 & 60 & $\begin{array}{l}60 \text { mg wool keratin powder, } \\
\text { Glycine-NaOH, } \mathrm{pH} 10 \text { or } 50 \mathrm{mM} \\
\mathrm{KCl}-\mathrm{NaOH}, \mathrm{pH} 12.5,30^{\circ} \mathrm{C}, 2 \mathrm{~h} \\
\left(\mathrm{Abs}_{280 \mathrm{~nm}}\right) .\end{array}$ & Not specified & - \\
\hline \multicolumn{6}{|c|}{ S8A Peptidases } \\
\hline SAPDZ & 12.5 & 85 & $\begin{array}{l}10 \mathrm{~g} / \mathrm{L} \mathrm{keratin} \text { azure, } 100 \mathrm{mM} \mathrm{KClNaOH} \text {, } \\
250 \mathrm{rpm}, 20 \mathrm{~min} \text { incubation, } 85^{\circ} \mathrm{C} \\
\left(\mathrm{Abs}_{595 \mathrm{~nm}}\right) .\end{array}$ & - & $5 \mathrm{mM} \mathrm{CaCl}_{2}$ \\
\hline KerRP & $9(11)$ & $60(65-70)$ & $\begin{array}{l}0.8 \% \mathrm{w} / \mathrm{v} \text { keratin diluted } 1: 1 \mathrm{in} \text { enzyme, } \\
1 \mathrm{~h} \text { incubation, } 60{ }^{\circ} \mathrm{C}\left(\mathrm{Abs}_{280 \mathrm{~nm}}\right) .\end{array}$ & Not specified & - \\
\hline KerSMD & 8 & 60 & $\begin{array}{l}1 \% \text { w/v soluble keratin, } 50 \mathrm{mM} \\
\mathrm{Gly}-\mathrm{NaOH}, 20 \mathrm{~min}, 50^{\circ} \mathrm{C} \\
\text { (Folin-Ciocalteu). }\end{array}$ & Not specified & - \\
\hline KerSMF & 9 & 60 & $\begin{array}{l}1 \% \text { w/v soluble keratin, } 50 \mathrm{mM} \\
\text { Gly-NaOH, } 20 \mathrm{~min}, 50^{\circ} \mathrm{C} \\
\text { (Folin-Ciocalteu). }\end{array}$ & Not specified & - \\
\hline KerA1 & $9(10)$ & $60(65)$ & $\begin{array}{l}0.8 \% \text { w/v keratin diluted } 1: 1 \text { in enzyme } \\
\text { solution, } 1 \mathrm{~h}, 50{ }^{\circ} \mathrm{C}\left(\mathrm{Abs}_{280 \mathrm{~nm}}\right) .\end{array}$ & Not specified & - \\
\hline SAPB & 10.6 & 65 & $\begin{array}{l}1 \% \text { keratin w/v, on } 100 \mathrm{mM} \\
\text { glycine- } \mathrm{NaOH} \text { Buffer, } \mathrm{pH} 10.6,30 \mathrm{~min} \text {, } \\
55^{\circ} \mathrm{C} .2 \mathrm{mM} \mathrm{CaCl}_{2} \text { supplemented. }\end{array}$ & Not specified & - \\
\hline $\mathrm{rK}_{27}$ & 9 & 70 & $\begin{array}{l}20 \text { mg feather powder, Gly-NaOH } 50 \text { mM, } \\
1 \mathrm{~h}\left(\mathrm{Abs}_{280 \mathrm{~nm}}\right) \text {. }\end{array}$ & $\begin{array}{l}\text { Washed with Triton } \mathrm{X}-100 \\
(1 \%) \text {, rinsed with water, } \\
\text { autoclaved, dried in an oven } \\
\text { at } 60^{\circ} \mathrm{C} \text { for } 1 \mathrm{~h} \text {, milled then } \\
\text { sieved with } 2 \mathrm{~mm} \text { pore size. }\end{array}$ & - \\
\hline KerQ7 & 7 & 30 & $\begin{array}{l}10 \mathrm{~g} / \mathrm{L} \text { keratin azure, } 50 \mathrm{mM} \text { HEPES } \\
\text { buffer, } 30 \mathrm{~min}, 200 \mathrm{rpm}\left(\mathrm{Abs}_{595 \mathrm{~nm}}\right) .\end{array}$ & - & $1 \mathrm{mM} \mathrm{CaCl}_{2}$ \\
\hline Vpr & 8.5 & 50 & $\begin{array}{l}2 \% \text { w/v chopped feather keratin, } 50{ }^{\circ} \mathrm{C} \text {, } \\
15 \mathrm{~min}, \mathrm{pH} 7.5 \text {. }\end{array}$ & - & - \\
\hline KBALT & 8 & 85 & $\begin{array}{l}5 \mathrm{mg} \text { keratin azure, } 0.8 \mathrm{~mL} \text { buffer, } 15 \mathrm{~min} \\
\text { incubation, } \mathrm{pH} 6 \text { to } 12,25 \text { to } 95^{\circ} \mathrm{C} \\
\left(\mathrm{Abs}_{595 \mathrm{~nm}}\right) \text {. }\end{array}$ & - & - \\
\hline YT06 protease & $8-9$ & 65 & $\begin{array}{l}1 \% \text { soluble keratin, } 50 \mathrm{mM} \text { Gly-NaOH, } \\
\text { pH 9, } 20 \text { min (Folin-Ciocalteu). }\end{array}$ & Not specified & - \\
\hline Protease C2 & 11 & $60-80$ & $\begin{array}{l}5 \% \text { keratin powder, } 50 \mathrm{mM} \text { Tris- } \mathrm{HCl} \mathrm{pH} 8 \text {, } \\
60 \mathrm{~min} 60^{\circ} \mathrm{C}\left(\mathrm{Abs}_{280 \mathrm{~nm}}\right) .\end{array}$ & $\begin{array}{l}100^{\circ} \mathrm{C} \text { incubation in DMSO } \\
\text { for } 2 \mathrm{~h} \text {. Protein precipitated } \\
\text { with acetone } 2: 1 \mathrm{v} / \mathrm{v}[133]\end{array}$ & $0.5 \% \beta-\mathrm{ME}$ \\
\hline rMtaKer & 10 & 65 & $\begin{array}{l}1 \% \text { feather powder on } 50 \text { mM HEPES, } \\
\text { pH8.0, } 25-95^{\circ} \mathrm{C} \text {. Supplemented with } 10 \\
\mathrm{mM} \mathrm{CaCl} 2,150 \mathrm{mM} \mathrm{NaCl} \text { (Ninhydrin). }\end{array}$ & $\begin{array}{l}\text { Chicken feathers rinsed, } \\
\text { air-dried, ground by ball mill. }\end{array}$ & - \\
\hline WF146 protease & - & 80 & $\begin{array}{l}10 \mathrm{mg} \text { of feathers, } 50{ }^{\circ} \mathrm{C} \text { or } 80{ }^{\circ} \mathrm{C}, 1 \mathrm{ml} \\
\text { Tris- } \mathrm{HCl} 50 \mathrm{mM} \text { buffer, } \mathrm{pH} 8.0,10 \mathrm{mM} \\
\mathrm{CaCl}_{2} \text {, multiple time points from } 0 \text { to } 20 \mathrm{~h} \\
\left(\mathrm{Abs}_{280 \mathrm{~nm}}\right) .\end{array}$ & $\begin{array}{l}70 \text { Ethanol wash, rinse water, } \\
\text { dry, cut } 2-3 \mathrm{~mm} \text { long }\end{array}$ & $1 \% \beta-\mathrm{ME}$ \\
\hline \multicolumn{6}{|c|}{ M4 Peptidases } \\
\hline RecGEOker & 9 & 60 & $\begin{array}{l}4 \mathrm{mg} \text { keratin azure, } 50 \mathrm{mM} \text { Tris- } \mathrm{HCl}, \mathrm{pH} \\
\left.7.8,1 \mathrm{~h} \text { (Wool-Folin-Ciocalteu; } \mathrm{Abs}_{595 \mathrm{~nm}}\right)\end{array}$ & - & - \\
\hline KerP & 9 & 50 & $\begin{array}{l}20 \mathrm{mg} \text { chicken feathers, Glycine- } \mathrm{NaOH} \\
\text { buffer, } \mathrm{pH} 10,60^{\circ} \mathrm{C}, 60 \mathrm{~min}\left(\mathrm{Abs}_{280 \mathrm{~nm}}\right)\end{array}$ & - & - \\
\hline
\end{tabular}

Note: Source organism, accession numbers and references can be found in Table 3 ; ${ }^{*}$ in some cases $\mathrm{pH}$ and temperature optimums were determined on both casein and keratin substrates. The casein optimums are in brackets; Temp = temperature; PT $=$ pretreatment; $\mathrm{CT}=$ co-treatment; $\beta$-ME $=\beta$-mercaptoethanol; $\mathrm{DTT}=$ dithiothreitol.

Quantification methods, where available, are in brackets after the assay condition description. 
The challenges with the keratinase assays discussed above highlight the need for standardized assays and substrates used to test keratinases and the challenges faced in attempting to compare and analyse data from the literature when the assays are not comparable.

\subsection{The Effect of Additives on Selected S1, S8 and M4 Keratinases}

Various additives were tested on the selected S1, S8 and M4 keratinases-cationic, anionic and neutral detergents, oxidizing agents, reducing agents, mono- and divalent metals. Table 5 contains a summary of additives that had a positive effect on keratinase activity. A positive effect was defined as $\geq 110 \%$ activity compared to the control without additive. Some of the papers used keratin as the assay substrate, some used casein and in some cases, both were tested.

Table 5. Influence of additives on the activity of selected S1, S8 and M4 keratinases. Numbers in brackets correspond to the $\%$ activity compared to $100 \%$ in the absence of the additive.

\begin{tabular}{|c|c|c|c|c|c|}
\hline Protein & Metal ions (\%) & \multicolumn{2}{|c|}{ Detergents (\%) } & Reducing Agents (\%) & Solvents/Others (\%) \\
\hline \multicolumn{6}{|l|}{ S1A Peptidases } \\
\hline KERDZ & $\begin{array}{l}\mathrm{Ca}^{2+}(270) \\
\mathrm{Mg}^{2+}(180) \\
\mathrm{Fe}^{2+}(145) \\
\end{array}$ & & & & \\
\hline KERAK-29 & $\begin{array}{l}\mathrm{Ca}^{2+}(150) \\
\mathrm{Mg}^{2+}(110) \\
\mathrm{Mn}^{2+}(210)\end{array}$ & $\begin{array}{l}\text { Zwittergent (114) } \\
\text { Tween-20 (130) } \\
\text { Triton X-100 (132) } \\
\text { Tween-80 (145) } \\
\text { TTAB }(116) \\
\text { CHAPS (140) }\end{array}$ & $\begin{array}{l}\text { Sulfobetaine (135) } \\
\text { LAS (118) } \\
\overline{\text { SDS }(115)} \\
\overline{\text { CTAB }(110)}\end{array}$ & $\beta-\mathrm{ME}(102)$ & $\mathrm{H}_{2} \mathrm{O}_{2}(170)$ \\
\hline SFP2 & $\begin{array}{l}\mathrm{Cu}^{2+}(149) \\
\mathrm{Ni}^{2+}(116)\end{array}$ & & & $\begin{array}{l}\text { DTT (278) } \\
\beta \text {-ME (235) }\end{array}$ & \\
\hline NAPase & & & & & Isopropanol (130) \\
\hline \multicolumn{6}{|l|}{ S8A Peptidases } \\
\hline SAPDZ & $\begin{array}{ll}\mathrm{Ca}^{2+}(450) & \mathrm{Zn}^{2+}(180) \\
\mathrm{Mg}^{2+}(195) & \mathrm{Cu}^{2+}(110) \\
\mathrm{Mn}^{2+}(280) & \mathrm{Co}^{2+}(113)\end{array}$ & & & & \\
\hline KerRP & ${ }^{*} \mathrm{Ca}^{2+}$ & & & & \\
\hline KerSMD & $\mathrm{Ca}^{2+}(112)$ & & & $\mathrm{Na}_{2} \mathrm{SO}_{3}(116)$ & \\
\hline KerSMF & $* * \mathrm{Ca}^{2+}(105)$ & Tween-20 (112) & & $\begin{array}{l}\mathrm{Na}_{2} \mathrm{SO}_{3}(115) \\
\text { DTT (115) }\end{array}$ & \\
\hline KerA1 & $\begin{array}{l}\mathrm{Ca}^{2+}(123) \\
\mathrm{Mg}^{2+}(199) \\
\mathrm{Na}^{+}(135)\end{array}$ & Tween 80 (113) & & $\begin{array}{l}\beta-\mathrm{ME} \text { (Casein 100) } \\
\text { (Keratin 192) }\end{array}$ & \\
\hline SAPB & $\begin{array}{l}\mathrm{Ca}^{2+}(157) \\
\mathrm{Mg}^{2+}(112) \\
\mathrm{Na}^{+}(118)\end{array}$ & $\begin{array}{l}\text { LAS }(114) \\
\text { Tween } 80(119)\end{array}$ & $\begin{array}{l}\text { Tween } 20(117) \\
\text { SDS (119) }\end{array}$ & $\beta-\mathrm{ME}$ (192) & $\begin{array}{l}\text { Urea (165) } \\
\mathrm{H}_{2} \mathrm{O}_{2}(168)\end{array}$ \\
\hline $\mathrm{rK}_{27}$ & Stability only tested & $\begin{array}{l}\text { Triton X-100 (677) } \\
\text { Tween-80 (242) } \\
\text { Saponin }(461) \\
\text { Sodium Cholate (2 } \\
\text { SDS (186) }\end{array}$ & & $\begin{array}{l}\text { DTT (267) } \\
\beta-M E ~(323)\end{array}$ & $\begin{array}{l}\mathrm{NaClO}(276) \\
\mathrm{H}_{2} \mathrm{O}_{2}(275)\end{array}$ \\
\hline KerQ7 & $\begin{array}{ll}\mathrm{Ca}^{2+}(417) & \mathrm{Ba}^{2+}(121) \\
\mathrm{Mg}^{2+}(175) & \mathrm{Sn}^{2+}(115) \\
\mathrm{Mn}^{2+}(250) & \end{array}$ & & & & \\
\hline KBALT & $\begin{array}{ll}\mathrm{Ca}^{2+}(127) & \mathrm{Zn}^{2+}(129) \\
\mathrm{Mg}^{2+}(134) & \mathrm{Ba}^{2+}(115)\end{array}$ & SDS (128) & & $\beta$-ME (102.5) & \\
\hline YT06 Protease & $\begin{array}{ll}\mathrm{Mg}^{2+}(118) & \mathrm{Ni}^{2+}(120) \\
\mathrm{Mn}^{2+}(196) & \mathrm{Ba}^{2+}(115)\end{array}$ & Tween-20 (170) & & $\beta-\mathrm{ME}$ (623) & \\
\hline \multicolumn{6}{|l|}{ M4 Peptidases } \\
\hline RecGEOker & $\begin{array}{l}\mathrm{Mg}^{2+}(112) \\
\mathrm{Mn}^{2+}(116) \\
\mathrm{Zn}^{2+} 1 \mathrm{mM}(58) ; 10 \mathrm{mM}(52) \\
\mathrm{Ca}^{2+} 1 \mathrm{mM}(101) ; 10 \mathrm{mM}(66)\end{array}$ & $\begin{array}{l}\text { Triton X-100 (115) } \\
\text { Tween } 40(180) \\
\text { Tween } 60(133)\end{array}$ & $\begin{array}{l}\text { Tween } 80 \text { (122) } \\
\text { Triton X-305 (153) }\end{array}$ & DTT (139) & \\
\hline
\end{tabular}

Note: Source organism, accession numbers and references can be found in Table 3; Bold = tested on a keratinous substrate; Not bold = tested on casein; * = Only tested for binding; ${ }^{*}$ included for comparison with KerSMD; underlined = denaturing detergents; DTT = dithiothreitol; $\beta$-ME $=\beta$-mercaptoethanol; LAS $=$ linear alkylbenzene sulfonate; SDS = sodium dodecyl sulfate; TAED = tetraacetylethylenediamine; TTAB = tetradecyltrimethylammonium bromide; CHAPS = 3-[(3-cholamidopropyl)dimethylammonio]-1-propanesulfonate; $\mathrm{CTAB}=$ cetrimonium bromide. 
Despite there being large differences in concentrations of metals additives, incubation time and temperature, in general, supplementation with $\mathrm{Ca}^{2+}$ showed the largest increase in activity except for KerSMF [101] and kerA1 [97]. In the case of KerSMF, $\mathrm{Ca}^{2+}$ had no effect on activity and in the case of kerA1, $\mathrm{Mg}^{2+}$ addition increased activity by $199 \%$ compared to $123 \%$ for $\mathrm{Ca}^{2+}$. In general, $\mathrm{Ca}^{2+}$ $>\mathrm{Mg}^{2+}>\mathrm{Mn}^{2+}$ had a positive effect on all the S1 and S8 keratinases (Table 5). The effect of these divalent metals on M4 metalloproteases is discrete compared to serine proteases. Only the addition of magnesium and manganese ions resulted in keratinase activity slightly above the control without additives. These divalent ions have been described to stabilize the active structure of the peptidases by binding to the metal-binding sites [100]. Other explanations for the higher activity are possible stabilization of enzyme/substrate complex [101] or formation of salt or ion bridges that maintain the enzyme conformation $[97,122,128]$. Furthermore, these metal ions reduce thermal denaturation [134]. Lin et al. observed that aqualysin, a thermostable peptidase from the S8 family, was only stable at high temperatures in the presence of $1 \mathrm{mM} \mathrm{Ca}^{2+}[135]$.

Several studies were carried out on the keratinase activity in the presence of metal ions $\left(\mathrm{Zn}^{2+}, \mathrm{Cu}^{2+}\right.$, $\mathrm{Co}^{2+}, \mathrm{Ba}^{2+}, \mathrm{Sn}^{2+}$ and $\mathrm{Ni}^{2+}$ ) were carried out (Table 5). The addition of the metal ions improved activity between $10 \%$ and $29 \%$ except for SAPDZ [100], where $\mathrm{Zn}^{2+}$ addition increased activity by $80 \%$ and $\mathrm{Cu}^{2+}$ addition increased activity of SFP2 [99] by $49 \%$. Li et al. characterized SFP1, a non-keratinolytic peptidase similar to SFP2 and produced by the same organism [99]. It showed increased activity with copper ions, possibly due to the stabilization of the enzyme. Copper ions acting as a stabilizer has rarely been described in previous serine protease studies, and it is not known whether there is a copper-binding site stabilizing the enzyme [136]. In another example, peptidases were more stable in the presence of copper ions, which resulted in a reduction in both autolysis and thermal inactivation rates [137].

Detergents, in general, enable the disruption or formation of hydrophobic and hydrophilic bonds and assist in the extraction of proteins into aqueous media [138]. Detergents can act as denaturing agents on enzymes. Denaturing detergents are anionic (SDS, LAS) or cationic (CTAB, TTAB). They denature proteins by breaking protein-protein interactions. Non-denaturing detergents are non-ionic (Triton X-100, Tweens, cholate, saponin) or zwitterionic (CHAPS, sulfobetaine, zwittergent), and their action is milder and enzyme function is usually maintained. In most cases the addition of denaturing and non-denaturing detergents resulted in an increase in activity (110-150\%). However, the addition of the non-ionic detergents to the assay mixture with keratin as substrate of $\mathrm{rK}_{27}$ had a dramatic effect on activity compared to the control without detergent [103]. Activities of $677 \%$ (Triton X-100), $242 \%$ (Tween 80 ), $461 \%$ (saponin) and $276 \%$ (cholate) were achieved. The addition of the anionic denaturing detergent, SDS to the assay increased the keratinase activity to $186 \%$. The addition of the non-ionic detergents, Tween 40, Tween 60 , Tween 80 and Triton X-305 to the assay mixture with keratin as substrate for the M4 keratinase, RecGEOker [109], showed increased activity to $180 \%$, $133 \%, 122 \%$ and $153 \%$, respectively. This example showed a definite trend of increasing activity with decreasing Tween 80 (monounsaturated C18 derivative) < Tween 60 (saturated C18 derivative) < Tween 40 (saturated C16 derivative). The partial solubilizing action of detergents on the insoluble keratin substrate might explain why both denaturing and non-denaturing detergents have a positive effect on keratin hydrolysis. There are insufficient examples to confirm this Tween effect on keratinases in general.

The reduction of disulphide bonds, destabilizes keratins and acts synergistically with keratin hydrolysis in nature [6,8-10]. Sodium sulphite, dithiothreitol (DTT) and $\beta$-mercaptoethanol were tested on some of the keratinases in Table 5. The reducing agents had a positive effect on all S8 keratinases tested with keratin as the substrate. The increase in activity ranged from $115 \%$ for $\mathrm{Na}_{2} \mathrm{SO}_{3}$ (KerSMF [101]) to $623 \%$ for $\beta$-mercaptoethanol (YT06 protease [98]) except in the case of KBALT [63], where $\beta$-mercaptoethanol had no effect on the activity. $\beta$-Mercaptoethanol doubled the activity of SAPB [102] when tested with casein as substrate. DTT also increased the activity of the M4 keratinase, RecGEOker (139\% [109]), when tested with keratin as substrate. None of the S1 enzymes were tested 
with keratin and reducing agents. However, the two assays with casein and reducing agent showed on one hand, no effect from $\beta$-mercaptoethanol on KERAK-29, [95] and on the other hand, a considerable effect on SFP2 (DTT, 278\%; $\beta$-mercaptoethanol, 235\% [99]). It should be noted that where disulphide bonds present in the enzyme are essential for function the inclusion of reducing agents may negatively affect activity.

Chaotropic agents are comparable to detergents, breaking non-covalent interactions and allowing protein denaturation [139-141]. Urea and isopropanol are chaotropic agents (Table 5). The activity of SAPB [102] was increased to $165 \%$ in the presence of urea compared to the control and the activity of NAPase [111] was increased to $130 \%$ in the presence of isopropanol [111].

The effect of the oxidizing agents, $\mathrm{H}_{2} \mathrm{O}_{2}$ and sodium hypochlorite, was also studied on three $\mathrm{S} 8$ and S1 keratinases, SAPB [102], $\mathrm{rK}_{27}$ [103] and KERAK-29 [95]. Activity was significantly increased in all cases (Table 5).

In most cases the effect of additives like divalent cations, detergents, reducing agents, chaotropic agents and oxidizing agents have a positive effect on keratinase activity. Nearly all compounds capable of disrupting the integrity of the keratin structure without inactivating the keratinase appear to have a positive effect on keratinase activity. The effect of compounds disrupting the keratin structure was, in some cases like $\mathrm{rK}_{27}$ [103], significant.

\subsection{Substrate Specificity}

Table 6 summarizes the substrate specificity data of the selected keratinases from the literature. In general, a variety of keratins and other proteins like gelatin, casein and albumin were tested. To compare the selected keratinases, the values in Table 6 have been normalized using the activity of designated keratin substrates (keratin azure, keratin, feather or wool) as 100\% activity.

KerQ7 [104] was the only keratinase in Table 6 tested on multiple types of keratins. KerQ7 showed a preference for the $\beta$-keratin-rich feather meal and feathers. The activity on feather meal was only $16 \%$ higher than feathers. The activity on rabbit hair, goat hair and bovine hair was $88 \%, 74 \%$ and $50 \%$ of the activity on feathers, respectively, whereas activity on wool was only $12 \%$. These substrates are rich in $\alpha$-keratins $[4,9,12,13]$. Substrate fibre thickness and fibre surface area may also contribute to the variations in enzyme activity. Nonetheless, the keratinase activity toward various substrates is likely to be multifactorial. KerSMD and KerSMF, from Stenotrophomonas maltophilia, showed less activity towards feather powder and wool than keratin azure [101]. KerSMD and KerSMF had similar activity on feather powder (54\% and 71\%, respectively) and wool (59\% and $78 \%$, respectively). However, KerSMD showed an activity of $1589 \%$ towards soluble keratin compared to an activity of $126 \%$ for KerSMF on the same substrate.

No trends were observable on non-keratin substrates. For example, SAPDZ [100] showed 81\% activity on gelatin compared to keratin, whereas the activity of kerA1 [97] and SAPB [102] on gelatin was $22 \%$ and $146 \%$ compared to keratin, respectively. The same inconsistencies can be seen with casein. The activities of SAPB [102] and KerSMD [101] on casein are 153\% and 2800\%, respectively, compared to keratin azure, whereas KerSMF [101] has only slightly lower activity on casein (91\%) compared to keratin azure.

Keratinases are known for their activity on "hard-to-degrade" proteinogenic substrates. Most of the characterized keratinases in the literature are also capable of degrading collagen, which is an example of another complex and hard-to-degrade substrate [142]. A study in 2008 characterized the first keratinase without collagenase activity [143]. Only three enzymes from the S8 family were tested on collagen or azocoll (azocollagen). Vpr [105] presented collagenase activity (129\%) and while SAPDZ [100] did not. Protease C2 [106] showed a surprisingly high activity (24000\%) on azocoll compared to keratin azure (100\%). KERDZ [94], from the S1 peptidase family, had no activity on collagen, whereas RecGEOker [109], belonging to the M4 metallopeptidase family, was able to hydrolyse collagen. The differences in activity between substrates may be attributed to the specific peptide sequences in the substrates and the sequence specificity of the enzymes. 
Table 6. Substrate specificity of the selected S1, S8 and M4 keratinases. Numbers in brackets correspond to the $\%$ activity relative to other substrates.

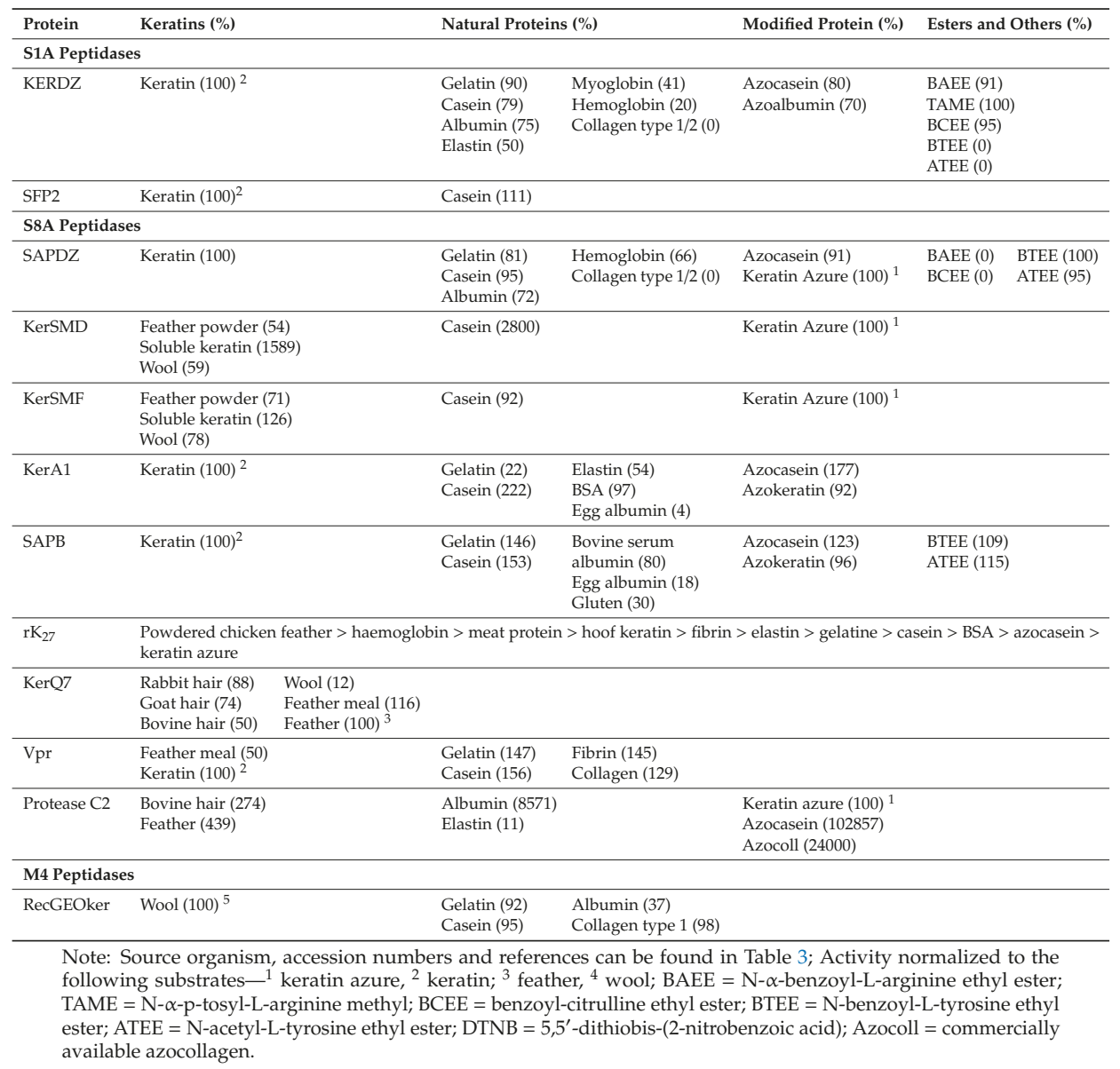

Some enzymes also showed esterase activity, which may be of importance for facilitating enzyme access to the substrate. Fatty acids of the cuticle surface are linked via a thioester to the protein matrix below in keratin fibres and feathers [14]. Only three enzymes in Table 6 have been characterized on ester substrates. The two S8 family peptidases-SAPDZ [100] and KerRP [96] - appear to have similar ester substrate affinity with both showing activity against N-benzoyl-L-tyrosine ethyl ester (BTEE) and $\mathrm{N}$-acetyl-L-tyrosine ethyl ester (ATEE). In contrast, KERDZ (S1 family) had no activity towards these substrates but was active towards $\mathrm{N}$ - $\alpha$-benzoyl-L-arginine ethyl ester (BAEE), $\mathrm{N}$ - $\alpha$-p-tosyl-L-arginine methyl (TAME) and benzoyl-citrulline ethyl ester (BCEE) [94]

In general, the peptidases from $\mathrm{S1}, \mathrm{S} 8$ and $\mathrm{M} 4$ families (Table 6) present varied substrate specificities. There are limited examples in the S1 and M4 families to detect trends but even within the S8 peptidases examples there were no obvious substrate preferences.

\section{Potential Applications of Keratinases}

New keratinases with improved properties for commercialization and the keratin hydrolysates they produce represent an opportunity for adding value to keratin waste. 
Commercial keratinases are sold for a variety of applications (Table 7) such as the degradation of infectious prions, as supplements for animal feed to improve its nutritional value, removal of corns and calluses from skin, treatment of acne and nail fungi and, they are also incorporated into cosmetic skin peeling and depilatory creams $[6,52,144]$. Other applications include the use in cleaning products for unblocking drainpipes and septic tanks.

Table 7. Some examples of commercial keratinases.

\begin{tabular}{|c|c|c|c|c|}
\hline Trade Name & Source & EC Number & Substrate or Function & Supplier \\
\hline Versazyme $^{1,3}$ & Bacillus licheniformis & 3.4.21.62/ S8 family & $\begin{array}{l}\text { Improving nutritional value of } \\
\text { poultry feed \& prions } \\
\text { degradation }\end{array}$ & $\begin{array}{l}\text { Bioresource Int'l, } \\
\text { Inc. }\end{array}$ \\
\hline Ronozyme ProAct ${ }^{2}$ & Nocardiopsis prasina & $\begin{array}{l}\text { 3.4.21.-/serine } \\
\text { protease }\end{array}$ & $\begin{array}{l}\text { Improving nutritional value } \\
\text { animal feed }\end{array}$ & DSM/Novozymes \\
\hline Pure Keratinase $100^{3}$ & $\begin{array}{l}\text { Bacillus } \\
\text { licheniformis PWD-1 }\end{array}$ & - & $\begin{array}{l}\text { Prion degradation from } \\
\text { medical \& dental instruments }\end{array}$ & Proteus Biotech \\
\hline BioGuard Plus ${ }^{3}$ & $\begin{array}{l}\text { Proprietary blend } \\
\text { of microorganisms- } \\
\text { incl. keratinase } \\
\text { producer }\end{array}$ & - & $\begin{array}{l}\text { Cleaning drainpipes, septic } \\
\text { tanks \& digesters }\end{array}$ & RuShay Inc. \\
\hline $\begin{array}{l}\text { Keratoclean Hydra } \\
\mathrm{PB}^{3}\end{array}$ & Bacillus licheniformis & - & $\begin{array}{l}\text { Removal of corns \& call uses, } \\
\text { acne, Hirsutism, peeling }\end{array}$ & Proteus Biotech \\
\hline FixaFungus $^{3}$ & - & - & $\begin{array}{l}\text { Treatment of toenail fungal } \\
\text { infections }\end{array}$ & Proteus Biotech \\
\hline
\end{tabular}

There are also a number of promising applications of keratinases that have not been commercialized to date: dag or manure balls removal from cattle hides and tails [145]; extraction of glucocorticoids from chicken feathers to monitor the stress level in poultry breeding and production programmes [146] extraction of chicken feather cholesterol as a precursor to bile salts that can be used to produce bio-emulsifiers and biosurfactants in the cosmetic industry [18]; selective hydrolysis of wool from wool/polyester or mixed textiles to facilitate textile recycling [147]; and dehairing of hides in the leather industry $[64,65,82]$.

The use of keratinases for the processing of keratinous waste might be advantageous for high value products. The use of enzymes instead of thermochemical methods for keratin hydrolysis reduces chemical modification arising from harsh chemical hydrolysis and might allow a degree of control of the peptide composition that is produced. Keratin hydrolysates are widely used in protein feed supplements [18]. Feather waste, for example, is hydrolysed with saturated steam under high pressure (sometimes with the addition of lime) to produce feather meal, which is used as a feed supplement [148]. These conditions lead to the loss or modification of some of the amino acids, which impacts the nutritional value and digestibility of the feather meal. Hydrolysis with keratinases might offer an alternative, which reduces the energy requirements of the process and enhances the nutritional value of the supplement.

Keratin-derived bioactive peptides have been reported in the literature. These peptides have a range of activities like antimicrobial [149], antihypertensive [150], anti-inflammatory [151-154], antioxidant [149,150,155], inhibition of early stage amyloid aggregation [156], antidiabetic [157] or anti-aging [158-160] depending on the keratin source and the method of preparation. Producing protein feed supplements with antioxidant or anti-inflammatory properties as well as skin and hair 
products with antioxidant, anti-inflammatory, antimicrobial or anti-aging properties would most likely increase the value of these products.

Keratin peptides and subunits can spontaneously self-assemble [161]. This property can be exploited to form biomaterials like hydrogels, films, sponges, scaffolds and nanofibres for tissue engineering, wound healing, fibroblast cultivation and treatment of burns [161-164]. The production of smart biocomposites is also of interest. An example is the production of transparent plastic film containing citric acid from wool hydrolysate [165]. The plastic has excellent biocidal activity and could be used as a functional packaging for food.

The examples described above demonstrate the commercial potential of keratinases and the large number of opportunities they offer for adding value to keratin waste by producing bioactive protein feed supplements, personal care products and biomaterials from keratin hydrolysates.

\section{Discovery and Future Research}

The standout problem with the characterization of keratinases, demonstrated by the analysis of the assay conditions in this review, is lack of standardization of the keratinase assay combined with the small number of sequenced peptidases with keratinolytic activity that have been biochemically characterized. Both of these issues hamper the identification and comparison of true keratinases. Current experimental conditions vary in temperature, $\mathrm{pH}$, buffer types and concentration, additives, substrates and their pretreatment biasing possible conclusions. It is unclear whether some proteases are keratinases or whether pretreatment or co-treatment influences their keratinolytic activity to some degree.

The uncertainty in defining keratinases and highly variable characterization of keratinases in the literature increases the challenge of finding new keratinases based on literature data or from sequence databases. However, the discovery of new keratinases is critical for expanding the opportunities for waste keratin valorisation. It would be desirable to identify new keratinases with high activities and specificities enabling control over cleavage sites, peptide molecular weights and amino acid side chain modifications.

Standardized experiments combined with phylogenetic studies and sequence analyses are needed. Standardized experiments, which avoid pre- or co-treatments, would determine the true protease activity on keratin substrates and reduce possible experimental biases. An in-depth phylogenetic analysis would help to clarify the position of keratinases within the phylogenetic trees of the peptidase families in which they are found and may help focus the search for new peptidases with keratinolytic activity. A comprehensive sequence analyses, aimed at the identification of conserved sites between peptidases with keratinolytic activity, as well as the presence of specific domains that possibly contribute to their ability to hydrolyse keratin, may assist in the development of algorithms to search the vast sequence space of the peptidase families.

Author Contributions: Conceptualization, R.S., K.R., J.P.D.O.M., L.N., M.N., G.C. and Z.Z.; investigation, J.P.D.O.M. and K.R.; writing—original draft preparation, J.P.D.O.M. and K.R.; writing-review and editing, R.S., L.N., M.N. and G.C.; supervision, R.S.; project administration, R.S.; funding acquisition, R.S. All authors have read and agreed to the published version of the manuscript.

Funding: This research was funded by the Australian Government Department of Agriculture, grant number RnD4Profit-16-03-002.

Acknowledgments: This project is supported by Meat and Livestock Australia through funding from the Australian Government Department of Agriculture as part of its Rural R\&D for Profit program and the partners.

Conflicts of Interest: The authors declare no conflicts of interest. This manuscript was approved for publishing by Meat and Livestock Australia and the Australian Government Department of Agriculture.

\section{References}

1. Tesfaye, T.; Sithole, B.; Ramjugernath, D. Valorisation of chicken feathers: A review on recycling and recovery route-current status and future prospects. Clean Technol. Environ. Policy 2017, 19, 2363-2368. [CrossRef] 
2. Thyagarajan, D.; Barathi, M.; Sakthivadivu, R. Scope of poultry waste utilization. IOSR-JAVS 2013, 6, 29-35.

3. Gooding, C.H.; Meeker, D.L. Review: Comparison of 3 alternatives for large-scale processing of animal carcasses and meat by-products. PAS 2016, 32, 259-270. [CrossRef]

4. Sinkiewicz, I.; Staroszczyk, H.; Sliwinska, A. Solubilization of keratins and functional properties of their isolates and hydrolysates. J. Food Biochem. 2018, 42, e12494. [CrossRef]

5. Chojnacka, K.; Gorecka, H.; Michalak, I.M.; Gorecki, H. A review: Valorization of keratinous materials. Waste Biomass Valoriz. 2011, 2, 3017-3021. [CrossRef]

6. Lange, L.; Huang, Y.; Busk, P.K. Microbial decomposition of keratin in nature-A new hypothesis of industrial relevance. Appl. Microbiol. Biotechnol. 2016, 100, 2083-2096. [CrossRef]

7. Peng, Z.; Zhang, J.; Du, G.; Chen, J. Keratin waste recycling based on microbial degradation: Mechanisms and prospects. ACS Sustain. Chem. Eng. 2019, 7, 9727-9736. [CrossRef]

8. Jones, L.N. Hair structure anatomy and comparative anatomy. Clin. Dermatol. 2001, 19, 95-103. [CrossRef]

9. Bragulla, H.H.; Homberg, D.G. Structure and functions of keratin proteins in simple, stratified, keratinized and cornified epithelia. J. Anat. 2009, 214, 516-559. [CrossRef]

10. Plowman, J.E. Proteomic database of wool components. J. Chromatog. B. 2003, 787, 63-76. [CrossRef]

11. Da Silva, R.R. Different processes for keratin degradation: The ways for the biotechnological application of keratinases. J. Agric. Food Chem. 2018, 66, 9377-9378. [CrossRef] [PubMed]

12. Yang, F.; Zhang, Y.; Rheinstädter, M.C. The structure of people's hair. PeerJ 2014, 2, e619. [CrossRef] [PubMed]

13. Wang, B.; Yang, W.; McKittrick, J.; Meyers, M.A. Keratin: structure, mechanical properties, occurrence in biological organisms, and efforts of bioinspiration. Prog. Mater. Sci. 2016, 76, 229-318. [CrossRef]

14. Ganske, F.; Meyer, H.H.; Deutz, H.; Bornscheuer, U. Enzyme-catalysed hydrolysis of 18-methyleicosanoic acid-cysteine thioester. Eur. J. Lipid Sci. Technol. 2003, 105, 627-632. [CrossRef]

15. Koepke, V.; Nilssen, B. Wool surface properties and their influence on dye uptake-A microscopical study. J. Text. Inst. 1960, 51, T1398-T1413. [CrossRef]

16. Wolski, T. Modified Keratin Proteins, Their Physiochemical Properties, Analysis and Application; Medical Academy: Lublin, Poland, 1985.

17. Xie, H.; Li, S.; Zhang, S. Ionic liquids as novel solvents for the dissolution of and blending of wool keratin fibers. Green Chem. 2005, 7, 606-608. [CrossRef]

18. Ningthoujam, D.S.; Tamreihao, K.; Mukherjee, S.; Khunjamayum, R.; Devi, L.J.; Asem, R.S. Keratinaceous Wastes and Their Valorization Through Keratinolytic Microorganisms. In Keratin; Blumenberg, M., Ed.; IntechOpen: London, UK, 2018; Volume 1, pp. 129-148.

19. Wu, G. Amino Acids: Biochemistry and Nutrition, 1st ed.; CRC Press: Boca Raton, FL, USA, 2013.

20. Papadopoulis, M.C. Effect of processing on high-protein feedstuffs: a review. Biol. Wastes 1989, 29, 123-138. [CrossRef]

21. Latshaw, J.D.; Musharaf, N.; Retrum, R. Processing of feather meal to maximize its nutritional value for poultry. Animal Feed Sci. Technol. 1994, 47, 179-188. [CrossRef]

22. Schwass, D.E.; Finley, J.W. Heat and alkaline damage to proteins: Racemization and lysinoalanine formation. J. Ag. Food Chem. 1984, 32, 1377-1382. [CrossRef]

23. Liardon, R.; Hurrell, R.F. Amino acid racemization in heated and alkali-treated proteins. J. Ag. Food Chem. 1983, 31, 432-437. [CrossRef]

24. Liardon, R.; Ledermann, S. Racemization kinetics of free and protein-bound amino acids under moderate alkaline treatment. J. Agric. Food Chem. 1986, 34, 557-565. [CrossRef]

25. Vasconcelos, A.; Freddi, G.; Cavaco-Paulo, A. Biodegradable materials based on silk fibroin and keratin. Biomacromolecules 2008, 9, 1299-1305. [CrossRef] [PubMed]

26. Yamauchi, K.; Yamauchi, A.; Kusonoki, T.; Kohda, A.; Konishi, Y. Preparation of stable aqueous solution of keratins, and physiochemical and degradational properties of films. J. Biomed. Mater. Res. Part Res. 1996, 31, 439-444. [CrossRef]

27. Wang, S.; Taraballi, F.; Tan, L.P.; Ng, K.W. Human keratin hydrogels support fibroblast attachment and proliferation in vitro. Cell Tissue Res. 2012, 347, 795-802. [CrossRef]

28. Tonin, C.; Aluigi, A.; Vineis, C.; Varesano, A.; Montarsolo, A.; Ferrero, F. Thermal and structural characterizationof poly (ethylene-oxide)/keratin blend films. J. Therm. Anal. Calorim. 2007, 89, 601-608. [CrossRef]

29. Wang, K.; Li, R.; Ma, J.H.; Jian, Y.K.; Che, J.N. Extracting keratin from wool using cysteine. Green Chem. 2016, 18, 476-481. [CrossRef] 
30. Torchinski, Y.M. Sulfur in Proteins; Pergamon Press: Oxford, UK, 1981.

31. Cardamone, J.M. Investigating the microstructure of keratin extracted from wool: Peptide sequence (MALDI-TOF/TOF) and protein conformation (FTIR). J. Mol. Struct. 2010, 969, 97-105. [CrossRef]

32. De Guzman, R.C.; Merrill, M.R.; Richter, J.R.; Hamzi, R.I.; Greengauz-Roberts, O.K.; Van Dyke, M.E. Mechanical and biological properties of keratose biomaterials. Biomaterials 2011, 32, 8205-8217. [CrossRef]

33. Cardamone, J.M.; Nunez, A.; Garcia, R.A.; Aldema-Ramos, M. Characterizing wool keratin. Lett. Mater. Sci. 2009, 2009, 147175. [CrossRef]

34. Kelly, R.J.; Worth, G.H.; Roddick-Lanzilotta, A.D.; Rankin, D.A.; Ellis, G.D.; Mesman, P.J.R.; Summers, C.G.; Singleton, D.J. The Production of Soluble Keratin Derivatives. U.S. 7148327B2, 2001.

35. Cornfield, M.C.; Robson, A. The amino acid composition of wool. Biochem. J. 1955, 59, 62-68.

36. Mellet, P. The influence of alkali treatment on native and denatured proteins. Tex. Res. J. 1968, 38, 977-983. [CrossRef]

37. Masters, P.M.; Friedman, M. Racemization of amino acids in alkali-treated food proteins. J. Agric. Food Chem. 1979, 27, 507-511. [CrossRef]

38. Provansal, M.M.P.; Cug, J.L.A.; Cheftal, J.C. Chemical and nutritional modifications of sunfower proteins due to alkaline processing. Formation of amino acid cross-links and isomerization of lysine residues. J. Agric. Food Chem. 1975, 23, 938-943. [CrossRef]

39. Gaidau, C.; Epure, D.-G.; Enascuta, C.E.; Carsote, C.; Sendrea, C.; Proietti, N.C.W.; Gu, H. Wool keratin total solubilisation for recovery and reintegration-An ecological approach. J. Clean. Prod. 2019, 236, 117586. [CrossRef]

40. Koleva, M.; Danalev, D.; Ivanova, D.; Vezenkov, L.; Vassiliev, N. Synthesis of two peptide mimetics as markers for chemical changes of wool's keratin during skin unhairing process and comparison the wool quality obtaianed by ecological methods for skin unhairing. Bulg. Chem. Commun. 2009, 41, 160-164.

41. Banga, A.K. Therapeutic Peptides and Proteins: Formulation, Process and Development Systems; CRC Press: Boca Raton, FL, USA, 1997.

42. Murray, K.; Rasmussen, P.; Neustaedter, J.; Luck, J.M. The hydrolysis of arginine. J. Biol. Chem. 1965, 240, 705-709.

43. Daft, F.S.; Coghill, R.D. The alkaline decomposition of serine. J. Biol. Chem. 1931, 90, 341-350.

44. Hunt, S. The non-protein amino acids. In Chemistry and Biochemistry of the Amino Acids; Barrett, G.C., Ed.; Springer: Dordrecht, Germany, 1985.

45. Stapleton, I.; Swan, J. Amino acids and peptides. VI. Studies on cystine and $\alpha \alpha^{\prime}$-dimethylcystine in relation to the alkaline degradation of protein disulphides. Aust. J. Chem. 1960, 13, 416-425. [CrossRef]

46. Ohta, T.; Suzuki, S.; Todo, M.; Kurechi, T. The decomposition of tryptophan in acid solutions: specific effect of hydrochloric acid. Chem. Pharm. Bull. 1981, 29, 1767-1771. [CrossRef]

47. Tung, W.S.; Daoud, W.A. Photocatalytic self-cleaning keratins: A feasibility study. Acta Biomater. 2009, 5, 50-56. [CrossRef]

48. Kurbanoglu, E.B.; Kurbanoglu, N.I. A new process for the utilization of ram horn waste. J. Biosci. Bioeng. 2002, 94, 202-206. [CrossRef]

49. Zhang, J.; Li, Y.; Li, J.; Zhao, Z.; Liu, X.; Li, Z.; Han, Y.; Hu, J. Isolation and characterization of biofunctional keratin particles extracted from wool waste. Powder Technol. 2013, 246, 356-362. [CrossRef]

50. Kurbanoglu, E.B.; Kurbanoglu, N.I. Ram horn hydrolysate as enhancer of xanthan production in batch culture of Xanthomonas campestris EBK-4 isolate. Process Biochem. 2007, 42, 1146-1149. [CrossRef]

51. Brandelli, A. Bacterial keratinases: useful enzymes for bioprocessing agroindustrial wastes and beyond. Food Bioproc. Technol. 2008, 1, 105-116. [CrossRef]

52. Sharma, R.; Devi, S. Versatility and commercial status of microbial keratinases: A review. Rev. Environ. Sci. Biotechnol. 2018, 17, 19-45. [CrossRef]

53. Muhsin, T.H.; Aubaid, A.H. Partial purification and some biochemical characteristics of exocellular keratinase from Trichophyton mentagrophytes var erinacei. Mycopathologia 2001, 150, 121-125. [CrossRef]

54. Rai, S.K.; Mukherjee, A.K. Optimization of the production of an oxidant and detergent-stable alkaline beta-keratinase from Brevibacillus sp. strain AS-S10-11: application of enzyme in laundry detergent formulations and in the leather industry. Biochem. Eng. J. 2011, 54, 47-56. [CrossRef] 
55. Thankaswamy, S.R.; Sundaramoorthy, S.; Palanivel, S.; Ramudu, K.N. Improved microbial degradation of animal hair waste from leather industry using Brevibacterium luteolum (MTCC 5982). J. Clean. Prod. 2018, 189, 701-708. [CrossRef]

56. Nam, G.-W.; Lee, D.-W.; Lee, H.-S.; Lee, N.-J.; Kim, B.-C.; Choe, E.-A.; Hwang, J.-K.; Suhartono, M.T.; Pyun, Y.-R. Native feather-degradation by Fervidobacterium islandicum AW-1, a newly isolated keratinase-producing thermophilic anaerobe. Arch. Microbiol. 2002, 178, 538-547. [CrossRef]

57. Kshteri, P.; Roy, S.S.; Sharma, S.K.; Singh, T.S.; Ansari, M.A.; Sailo, B.; Singh, S. Feather degrading, phytostimulating, and biocontrol potential of actinobacteria from North Easatern Himalayan Region. J. Basic Microbiol. 2018, 58, 730-738. [CrossRef]

58. Mamangkey, J.; Suryanto, D.; Munir, E.; Mustopa, A.Z. Isolation, molecular identification and verification of gene encoding bacterial keratinase from crocodile (crocodylus porosus) feces. IOP Conf. Ser. Earth Environ. Sci. 2019, 305, 012085. [CrossRef]

59. Pernicova, I.; Enev, V.; Marova, I.; Obruca, S. Interconnection oof waste chicken feather biodegradation and keratinase and mcl-PHA prooduction employing Pseudomonas putida KT2440. Appl. Food Biotechnol. 2019, 6, 83-90.

60. Fuke, P.; Gujar, V.V.; Khardenavis, A. Genome annotation and vlidation of keratin hydrolyzing proteolytic enzymes from Serratia marcescens EGD-HP20. Appl. Biochem. Biotechnol. 2018, 18, 970-986. [CrossRef] [PubMed]

61. Fuke, P.; Pal, R.R.; Khardenavis, A.A.; Purohit, H. In silico characterization of broad range proteases produced by Serratia marcescens EGD-HP20. J. Basic Microbiol. 2018, 58, 492-500. [CrossRef]

62. Bhari, R.; Kaur, M.; Singh, R.S. Thermostable and halotolerant keratinae from Bacillus aerius NSMk2 with remarkable dehairing and laundry applications. J. Basic Microbiol. 2019, 59, 555-558. [CrossRef]

63. Pawar, V.A.; Prajapati, A.S.; Akhani, R.C.; Patel, D.H.; Subramanian, R.B. Molecular and biochemical characteriztion of a thermostable keratinase from Bacillus altitudinis RBDV1. 3 Biotech 2018, 8, 107-113. [CrossRef]

64. Cao, S.; Li, D.; Ma, X.X.Q.; Song, J.; Lu, F.; Li, Y. A novel unhairing enzyme produced by heterolgous expression of keratinase gene (kerT) in Bacillus subtilis. World J. Microbiol. Biotechnol. 2019, 35, 122-131. [CrossRef]

65. Kumar, M.; Bhatia, D.; Khatak, S.; Kumar, R.; Sharma, A.; Malik, D.K. Optimization and purification of keratinase from Bacillus anthracis with dehairing application. J. Pure Appl. Microbiol. 2019, 13, 585-590. [CrossRef]

66. Kalaikumari, S.S.; Vennila, T.; Monika, V.; Chandraraj, K.; Gunasekaran, P. Bioutilization of poultry feather for keratinase production and its application in leather industry. J. Clean. Prod. 2019, 208, 44-45. [CrossRef]

67. Hamiche, S.; Mechri, S.; Khelouia, L.; Annane, R.; El Hattab, M.; Badis, A.; Jaouadi, B. Purification and biochemical characterization of two keratinases from Bacillus amyloliquefaciens S13 isolated from marine brown algae Zonaria tournefortii with potential keratin-biodegradation and hide-unhairing activities. Int. J. Biol. Macromol. 2019, 122, 758-769. [CrossRef]

68. Devi, C.S.; Shankar, R.S.; Kumar, S.; Mohanasrinivasan, B. Production of keratinase from a newly isolates feather degrading Bacillus cereus VITSDVM4 from poultry waste. Natl. Acad. Sci. Lett. 2018, 41, 307-311. [CrossRef]

69. Arokiyaraj, S.; Varghese, R.; Ahmed, B.A.; Duraipandiyan, V.; Al-Dhabi, N.A. Optimizing the fermentation conditions and enhanced production of keratinase from Bacillus cereus isolated from halophilic environment. Saudi J. Biol. Sci. 2019, 26, 378-381. [CrossRef] [PubMed]

70. Abdel-Fattah, A.M.; El-Gamal, M.S.; Ismail, S.A.; Emran, M.A. Biodegradation of feather waste by keratinase produced from newly isolated Bacillus licheniformis ALW1. JGEB 2018, 16, 311-318. [CrossRef]

71. Cavello, I.; Urbieta, M.S.; Segretin, A.B.; Giaveno, A.; Cavalitto, S.; Donati, E.R. Assessment of keratinase and other hydrolytc enzymes in thermophilic bacteria isolated from geothermal areas in Patagonia Argentina. Geomicrobiol. J. 2018, 35, 156-165. [CrossRef]

72. Adetunji, C.O.; Adejumo, I.O. Efficacy of crude and immobilized enzymes from Bacillus licheniformis for production of biodegraded feather meal and their assessment. Environ. Technol. Inno. 2018, 11, 116-124. [CrossRef] 
73. Hashem, A.M.; Abdel-Fattah, A.M.; Ismail, S.A.; El-Gamal, M.S.; Esawy, M.A.; Emran, M.A. Optimization, characterization and thermodynamic studies on B. licheniformis ALW1 keratinase. Egypt J. Chem. 2018, 61, 591-607. [CrossRef]

74. He, Z.; Sun, R.; Tang, Z.; Bu, T.; Wu, Q.; Li, C.; Chen, H. Biodegradation of feather waste keratin by keratin-degrading strain Bacillus subtilis 8. J. Microbiol. Biotechnol. 2018, 28, 314-322. [CrossRef]

75. Oluwaseun, A.C.; Phazang, P.; Sarin, N.B. Production of ecofriendly biofertilizers produced from crude and immobilized enzymes from Bacillus subtilis $\mathrm{CH} 008$ and their effect on the growth of Solanum lycopersicum. Plant Arch. 2018, 18, 1455-1462.

76. Nagarajan, S.; Eswaran, P.; Masilamani, R.P.; Natarajan, H. Chicken feather compost to promote the plant growth activity by using keratinolytic bacteria. Waste Biomass Valor. 2018, 9, 531-538. [CrossRef]

77. Imtiaz, A.; Rehman, A. Bacillus subtilis BML5 isolated from soil contaminated with poultry waste has keratinolytic activity. Pakistan J. Zool. 2018, 50, 143-148. [CrossRef]

78. De Paiva, D.P.; De Oliveira, S.S.A.; Mazotto, A.M.; Vermehlo, A.B.; De Oliveira, S.S. Keratinolytic activity of Bacillus subtilis LFB-FIOCRUZ 1266 enhanced by whole-cell mutagenesis. 3 Biotech 2019, 9, 2-13. [CrossRef] [PubMed]

79. Sharma, S.; Prasad, R.K.; Chatterjee, S.; Sharma, A.; Variable, M.G.; Yadav, K.K. Characterization of Bacillus species with keratinase and cellulase properties isolated from feather dumping and cockroach gut. Proc. Natl. Acad. Sci. India. Sect. B Biol. Sci 2019, 89, 1079-1086. [CrossRef]

80. Suharti, D.R.T.; Nilamsari, N.R. Isolation and characterization of newly keratinase producing Bacillus sp. N1 from tofu liquid waste. IOP Conf. Ser. Earth Environ. Sci. 2019, 230, 012088. [CrossRef]

81. Jin, M.; Chen, C.; He, X.; Zeng, R. Characterization of an extreme alkaline-stable keratinase from the draft genome of feather-degrading Bacillus sp. JM7 from deep-sea. Acta Oceanol. Sin. 2019, 38, 87-95. [CrossRef]

82. Tian, J.; Xu, Z.; Long, X.; Tian, Y.; Shi, B. High-expression keratinase by Bacillus subtilis SCK6 for enzymatic dehairing of goatskins. Int. J. Biol. Macromol. 2019, 135, 119-126. [CrossRef]

83. Koentjoro, M.P.; Prasetyo, E.N.; Rahmatullah, A.M. Optimization of keratinase production by Bacillus SLII-I bacteria in chicken feather waste medium. ARPN J. Engin. Appl. Sci. 2018, 13, 482-488.

84. Nurkhasanah, U.; Suharti. Preliminary study on keratinase fermentation by Bacillus sp. MD24 under solid state fermentation. IOP Conf. Ser. Earth Environ. Sci. 2019, 276, 012016. [CrossRef]

85. Suharti, S.; Riesmi, M.T.; Hidayati, A.; Zuhriyah, U.F.; Wonorahardjo, S.; Susanti, E. Enzymatic dehairing of goat skin using keratinase from Bacillus sp. MD24, a newly isolated soil bacterium. Pertanika J. Trop. Agric. Sci. 2018, 41, 1449-1461.

86. Ashokkumar, M.; Irudayaraj, G.; Yellapu, N.; Manonmani, A.M. Molecular characterization of $b m y C$ gene of the mosquito pupicidal bacterial, Bacillus amyloliquefaciens (VCRC B483) and in silico analysis of bacillomycin D snthetase C protein. World J. Microbiol. Biotechnol. 2018, 34, 116-126. [CrossRef]

87. Yusuf, I.; Ahmad, S.A.; Pang, L.Y.; Yasid, N.A.; Shukor, M.Y. Effective production of keratinase by gellum gum-immobilised Alcaligenes sp. AQ05-001 using heavy metal-free and polluted feather wastes as substrates. 3 Biotech 2019, 9, 32-43. [CrossRef]

88. Sultana, N.; Saha, P. Studies on potential application of crude keratinase enzyme from Stenotrophomonas sp. for dehairing in leather processing industry. J. Environ. Biol. 2018, 39, 324-330. [CrossRef]

89. Kang, D.; Herschend, J.; Al-Soud, W.A.; Mortensen, M.S.; Gonzalo, M.; Jacquiod, S.; Sorensen, S.J. Enrichment and characterization of an environmental microbial consortium displaying efficient keratinolytic acitivty. Bioresour. Technol. 2018, 270, 303-310. [CrossRef] [PubMed]

90. Mercer, D.K.; Stewart, C.S. Keratin hydrolysis by dermophytes. Med. Mycol. J. 2019, 57, 13-22. [CrossRef]

91. Pillai, P.; Mandge, S.; Archana, G. Statistical optimization of production and tannery application of a keratinolytic serine protease from Bacillus subtilis P13. Process Biochem. 2011, 46, 1110-1117. [CrossRef]

92. Purchase, D. Microbial Keratinases: Characteristics, Biotechnological Applications and Potential; CABI: Wallingford, UK, 2016.

93. Gupta, R.; Sharma, R.; Beg, Q.K. Revisiting microbial keratinases: Next generation proteases for sustainable biotechnology. Crit. Revs. Biotechnol. 2013, 33, 216-228. [CrossRef]

94. Elhoul, M.B.; Jaouadi, N.Z.; Rekik, H.; Benmrad, M.O.; Mechri, S.; Moujehed, E.; Kourdali, S.; Hattab, M.E.; Badis, A.; Bejar, S.; et al. Biochemical and molecular characterization of new keratinoytic protease from Actinomadura viridilutea DZ50. Int. J. Biol. Macromol. 2016, 92, 299-315. [CrossRef] [PubMed] 
95. Habbeche, A.; Saoudi, B.; Jaouadi, B.; Haberra, S.; Kerouaz, B.; Boudelaa, M.; Badis, A.; Ladjama, A. Purification and biochemical characterization of a detergent-stable keratinase from a newly thermophilic actinomycete Actinomadura keratinilytica strain Cpt29 isolated from poultry compost. J. Biosci. Bioeng. 2014, 117, 413-421. [CrossRef]

96. Fakhfakh, N.; Kanoun, S.; Manni, L.; Nasri, M. Production and biochemical and molecular characterization of a keratinolytic serine protease from chicken feather-degrading Bacillus licheniformis RPk. Can. J. Microbiol. 2009, 55, 427-436. [CrossRef]

97. Fakhfakh-Zouari, N.; Hmidet, N.; Haddar, A.; Kanoun, S.; Nasri, M. A novel serine metalloprotease from a newly isolated Bacillus pumilus A1 grown on chicken feather meal: biochemical and molecular characterization. Appl. Biochem. Biotechnol. 2010, 162, 329-344. [CrossRef]

98. Wang, L.; Qian, Y.; Cao, Y.; Huang, Y.; Chang, Z.; Huang, H. Production and characterization of keratinolytic proteases by a chicken feather-degrading thermophilic strain, Thermoactinomyces sp. YT06. J. Microbiol. Biotechnol. 2017, 27, 2190-2198. [CrossRef]

99. Li, J.; Shi, P.-J.; Han, X.-Y.; Meng, K.; Yang, P.-L.; Wang, Y.-R.; Luo, H.-Y.; Wu, N.-F.; Yao, B.; Fan, Y.-L. Functional expression of the keratinolytic serine protease gene sfp2 from Streptomyces fradiae var. k11 in Pichia pastoris. Protein Expres. Purif. 2007, 54, 79-86. [CrossRef] [PubMed]

100. Benkiar, A.; Nadia, Z.J.; Badis, A.; Rebzani, F.; Soraya, B.T.; Rekik, H.; Naili, B.; Ferradji, F.Z.; Bejar, S.; Jaouadi, B. Biochemical and molecular characterization of a thermo- and detergent-stable alkaline serin keratinolytic protease from Bacillus circulans strain DZ100 for detergent formulations and feather-biodegradation process. Int. Biodeterior. Biodegradation 2013, 83, 129-138. [CrossRef]

101. Fang, Z.; Zhang, J.; Liu, B.; Jiang, L.; Du, G.; Chen, J. Cloning, heterologous expression and characterization of two keratinases from Stenotrophomonas maltophilia BBE11-1. Proc. Biochem. 2014, 49, 647-654. [CrossRef]

102. Jaouadi, B.; Ellouz-Chaabouni, S.; Rhimi, M.; Bejar, S. Biochemical and molecular characterization of a detergent-stable serine alkaline protease from Bacillus pumilus CBS with high catalytic efficiency. Biochimie 2008, 90, 1291-1305. [CrossRef]

103. Rajput, R.; Sharma, R.; Gupta, R. Cloning and characterization of a thermostable detergent-compatible recombinant keratinase from Bacillus pumilus KS12. IUBMB 2011, 58, 109-118.

104. Jaouadi, N.Z.; Rekik, H.; Elhoul, M.B.; Rahem, F.Z.; Hila, C.G.; Aicha, H.S.B.; Badis, A.; Toumi, A.; Bejar, S.; Jaouadi, B. A novel keratinase from Bacillus tequilensis strain Q7 with promising potential for the leather bating process. Int. J. Biol. Macromol. 2015, 79, 952-964. [CrossRef]

105. Ghosh, A.; Chakrabarti, K.; Chattopadhyay, D. Cloning of feather-degrading minor extracellular protease from Bacillus cereus DCUW: dissection of the structural domains. Microbiology 2009, 155, 2049-2057. [CrossRef]

106. Wang, L.; Cheng, G.; Ren, Y.; Dai, Z.; Zhao, Z.-S.; Liu, F.; Li, S.; Wei, Y.; Xiong, J.; Tang, X.-F.; et al. Degradation of intact chicken feathers by Thermoactinomyces sp. CDF and characterization of its keratinolytic protease. Appl Microbiol. Biotechnol. 2015, 99, 3949-3959. [CrossRef]

107. Wu, W.-L.; Chen, M.-Y.; Tu, I.-F.; Lin, Y.-C.; Kumar, N.E.; Chen, M.-Y.; Ho, M.-C.; Wu, S.-H. The discovery of novel heat-stable keratinases from Meiothermus taiwanensis WR-220 and other extremophiles. Sci. Rep. 2017, 7, 4658-4669. [CrossRef]

108. Liang, X.; Bian, Y.; Tang, X.-F.; Xiao, G.; Tang, B. Enhancement of keratinolytic activity of a thermophilic subtilase by improving its autolysis resistance and thermostability under reducing conditions. Appl. Microbiol. Biotechnol. 2010, 87, 999-1006. [CrossRef]

109. Gegeckas, A.; Gudiukaite, R.; Debski, J.; Citavicius, D. Keratinous waste decomposition and peptide production by keratinase from Geobacillus stearothermophilus AD-11. Int. J. Biol. Macromol. 2015, 75, 158-165. [CrossRef] [PubMed]

110. Sharma, R.; Murty, N.A.R.; Gupta, R. Molecular characterization of N-terminal pro-sequence of keratinase ker P from Pseudomonas aeruginosa: identification of region with chaperone activity. Appl. Biochem. Biotechnol. 2011, 165, 892-901. [CrossRef] [PubMed]

111. Mitsuiki, S.; Ichikawa, M.; Oka, T.; Sakai, M.; Moriyama, Y.; Sameshima, Y.; Goto, M.; Furukawa, K. Molecular characterization of a keratinolytic enzyme from an alkaliphilic Nocardiopsis sp. TOA-1. Enzyme Microb. Technol. 2004, 34, 482-489. [CrossRef]

112. Ghosh, A.; Chakrabarti, K. Degradtion of raw feather by a novel high molecular weight extracellular protease from newly isolated Bacillus cereus DCUW. J. Ind. Microbiol. Biotechnol. 2008, 35, 825-834. [CrossRef] 
113. Tripathi, L.P.; Sowdhamini, R. Genome-wide survey of prokaryotic serine proteases: analysis of distribution and domain architectures of five serine protease families in prokaryotes. BMC Genomics 2008, 9, 549-576. [CrossRef]

114. Rawlings, N.D.; Waller, M.; Barrett, A.J.; Bateman, A. MEROPS: the database of proteolytic enzymes, their substrates and inhibitors. Nucleic Acids Res. 2014, 42, D503-D509. [CrossRef]

115. Siezen, R.J. Homology modelling and protein engineering strategy of subtilases, the family of subtilisin-like serine proteinases. Protein Eng. 1991, 4, 719-737. [CrossRef]

116. Page, M.J.; Di Cera, E. Serine peptidases: classification, structure and function. Cell Mol. Life Sci. 2008, 65, 1220-1236. [CrossRef]

117. Donlon, J.; Polaina, J.; MacCabe, A.P. (Eds.) Industrial Enzymes; Springer: Dordrecht, Germany, 2007.

118. Jongeneel, C.V.; Bouvier, J.; Bairoch, A. A unique signature identifies a family of zinc-dependent metallopeptidases. FEBS Lett. 1989, 242, 211-214. [CrossRef]

119. De Kreij, A.; Venema, G.; Van den Burg, B. Substrate specificity in the highly heterogeneous M4 peptidase family is determined by a small subset of amino acids. JBC 2000, 275, 31115-31120. [CrossRef]

120. Gregg, K.A. A comparison of genomic coding sequences for feather and scale keratins: Structural and evolutionary implications. EMBO J. 1984, 3, 175-178. [CrossRef] [PubMed]

121. Gradisar, H.; Friedrich, J.; Krizaj, I.; Jerala, R. Similarities and specificities of fungal keratinolytic proteases: comparison of keratinases of Paecilomyces marquandii and Doratomyces microsporus to some known proteases. Appl. Environ. Microbiol. 2005, 71, 3420-3426. [CrossRef]

122. Brandelli, A.; Daroit, D.J.; Riffel, A. Biochemical features of microbial keratinases and their production and applications. Appl Microbiol. Biotechnol. 2010, 85, 1735-1750. [CrossRef] [PubMed]

123. Di Cera, E. Serine proteases. IUBMB Life 2009, 61, 510-515. [CrossRef] [PubMed]

124. Wu, J.W.; Chen, X.L. Extracellular metalloproteases from bacteria. Appl. Microbiol. Biotechnol. 2011, 92, 253-262. [CrossRef]

125. Wainwright, M. A new method for determining the microbial degradation of keratin in soils. Experientia 1982, 38, 243-244. [CrossRef]

126. Riffel, A.; Lucas, F.; Heeb, P.; Brandelli, A. Characterization of a new keratinolytic bacterium that completely degrades native feather keratin. Arch. Microbiol. 2003, 179, 258-265. [CrossRef]

127. Navone, L.; Speight, R. Understanding the dynamics of keratin weakening and hydrolysis by proteases. PLoS ONE 2018, 13, e0202608. [CrossRef]

128. Farag, A.M.; Hassan, M.A. Purification, characterization and immobilization of a keratinase from Aspergillus orizae. Enzyme Microb. Technol. 2004, 34, 85-93. [CrossRef]

129. Grazziotin, A.; Pimentel, F.A.; De Jong, E.V.; Brandelli, A. Nutritional improvement of feather protein by treatment with microbial keratinase. Animal Feed Sci. Technol. 2006, 126, 135-144. [CrossRef]

130. Gill, S.C.; Von Hippel, P.H. Calculation of protein extinction coefficients from amino acid sequence data. Anal. Biochem. 1989, 182, 319-326. [CrossRef]

131. Daroit, D.J.; Corrêa, A.P.F.; Brandelli, A. Keratinolytic potential of a novel Bacillus sp. P45 isolated from the Amazon basin fish Piaractus mesopotamicus. Int. Biodeter. Biodegr. 2009, 63, 358-363. [CrossRef]

132. Pereira, J.Q.; Lopes, F.C.; Petry, M.V.; Da Costa Medina, L.F.; Brandelli, A. Isolation of three novel Antarctic psychrotolerant feather-degrading bacteria and partial purification of keratinolytic enzyme from Lysobacter sp. A03. Int. Biodeter. Biodegr. 2014, 88, 1-7. [CrossRef]

133. Wawrzkiewicz, K.; Wolski, T.; Lobarzewski, J. Screening the keratinoltic activity of dermatophytes in vitro. Mycopathologia 1991, 114, 1-8. [CrossRef] [PubMed]

134. Bressollier, P.; Letourneau, F.; Urdaci, M.; Verneuil, B. Purification and characterization of a keratinolytic serine proteinase from Streptomyces albidoflavus. Appl. Environ. Microbiol. 1999, 65, 2570-2576. [CrossRef] [PubMed]

135. Lin, S.J.; Yoshimura, E.; Sakai, H.; Wakagi, T.; Matsuzawa, H. Weakly bound calcium ions involved in the thermostability of aqualysin I, a heat-stable subtilisin-type protease of Thermus aquaticus YT-1. BBA-Protein Struct. M. 1999, 133, 132-138. [CrossRef]

136. Meng, K.; Li, J.; Cao, Y.; Shi, P.; Wu, B.; Han, X.; Bai, Y.; Wu, N.-F.; Yao, B. Gene cloning and heterologous expression of a serine protease from Streptomyces fradiae var.k11. Can. J. Microbiol. 2007, 53, 186-195. [CrossRef] 
137. Öztürk, N.Ç.; Kazan, D.; Denizci, A.A.; Erarslan, A. The influence of copper on alkaline protease stability toward autolysis and thermal inactivation. Eng. Life Sci. 2012, 12, 662-671. [CrossRef]

138. Walker, J.M. The Proteins Protocols Handbook, 2nd ed.; Humana Press: Totowa, NJ, USA, 1996.

139. Fershi, A.R. Structure and Mechanism in Protein Science: A Guide to Enzyme Catalysis and Protein Folding; Freeman W. H. \& Co.: New York, NY, USA, 1999.

140. Kunugi, S.; Tanaka, N. Cold denaturation of proteins under high pressure. Biochim. Biophys. Acta 2002, 1595, 309-314. [CrossRef]

141. Salvi, G.; De Los Rios, P.; Vendruscolo, M. Effective interactions between chaotropic agents and proteins. Proteins Struct. Funct. Bioinf. 2005, 61, 429-499. [CrossRef]

142. Suzuki, Y.; Tsujimoto, Y.; Matsui, H.; Watanabe, K. Decomposition of extremely hard-to-degrade animal proteins by thermophilic bacteria. J. Biosci. Bioeng. 2006, 102, 73-81. [CrossRef] [PubMed]

143. Macedo, A.J.; Beys da Silva, W.O.; Termignoni, C. Properties of a non collagen-degrading Bacillus subtilis keratinase. Can. J. Microbiol. 2008, 54, 180-188. [CrossRef] [PubMed]

144. Gupta, R.; Rajput, R.; Sharma, R.; Gupta, N. Biotechnological applications and prospective market of microbial keratinases. Appl. Microbiol. Biotechnol. 2013, 97, 9931-9940. [CrossRef] [PubMed]

145. Navone, L.; Speight, R.E. Enzyme systems for effective dag removal from cattle hides. Anim. Prod. Sci. 2019, 59, 1387-1398. [CrossRef]

146. Alba, A.C.; Strauch, T.A.; Keisler, D.H.; Wells, K.D.; Kesler, D.C. Using a keratinase to degrade chicken feathers for improved extraction of glucocorticoids. Gen. Comp. Endocr. 2019, 270, 35-40. [CrossRef]

147. Navone, L.; Moffitt, K.; Hansen, K.-A.; Blinco, J.; Payne, A.; Speight, R. Closing the textile loop: enzymatic fibre spearation and recycling of wool/polyester fabric blends. J. Waste Manag. 2020, 102, 149-160. [CrossRef]

148. El Boushy, A.R.Y.; Van der Poel, F.B. Poultry by-Products. In Handbook of Poultry Feed from Waste; Springer: Dordrecht, Germany, 2000; pp. 90-152. [CrossRef]

149. Sundaram, M.; Legadavi, R.; Banu, N.A.; Gayathri, V.; Palanisammy, A. A study of antibacterial activity of keratin nanoparticles from chicken feather waste against Staphylococcus aureus (Bovine mastitis bacteria) and its antioxidant activity. Eur. J. Biotechnol. Biosci. 2015, 6, 1-5.

150. Ohba, R.; Deguchi, T.; Kishikawa, M.; Arsyad, F.; Morimura, S.; Kida, K. Physiological function of enzymatic hydrolysates of collagen or keratin contained in livestock or fish waste. Food Sci. Technol. Res. 2003, 9, 91-93. [CrossRef]

151. Li, L.; Wang, W.; Shi, B.-H.; Li, J.-C.; Zhang, R.-Z.; Liu, S.-T.; Chen, R.-M.; Gao, W.-H.; Chen, G.-R.; Zheng, Y.-Q.; et al. Anti-Inflammatory Activity of Antelope Horn Keratin and its Tryptic Hydrolysate; Nutrition Press Inc.: Trumbull, CT, USA, 1999.

152. Kelly, R.; Ellis, G.; Macdonald, R.; McPherson, R.; Middlewood, P.; Nuthall, M.; Rao, G.-F.; RoddickLanzilotta, A.; Sigurjonsson, G.; Singleton, D. Keratin and Soluble Derivatives Thereof for a Nutraceutical and to Reduce Oxidative Stress and to Reduce Inflammation and to Promote Skin Health. U.S. Patent 0065506, 22 March 2007.

153. Kelly, R.J.; Ellis, G.D.; Macdonald, R.J.; McPherson, R.A.; Middlewood, P.G.; Nuthall, M.G.; Rao, G.-F.; Roddick-Lanzilotta, A.D.; Sigurjonsson, G.F.; Singleton, D.J. Nutraceutical Composition Comprising Soluble Keratin or Derivatives Thereof. U.S. Patent 7579317, 25 August 2009.

154. Cutler, P. Protein Purification Protocols; Humana Press: Totowa, NJ, USA, 2004.

155. Zeng, W.-C.; Zhang, W.-C.; Zhang, W.-H.; Shi, B. Antioxidant activity and characterization of bioactive polypeptides from bovine hair. Funct. Polym. 2013, 73, 573-578. [CrossRef]

156. Jones, L.N.; Sinclair, R.D.; Ecroyd, H.; Lui, Y.; Bennett, L.E. Bioprospecting keratinous material. Int. J. Trichol. 2010, 2, 47-49. [CrossRef]

157. Fontoura, R.; Daroit, D.J.; Correa, A.P.F.; Meira, S.M.M.; Mosquera, M.; Brandelli, A. Production of feather hydrolysates with antioxidant, angiotensin-1 converting enzyme- and dipeptidyl peptidase-IVinhibitory activities. New Biotechnol. 2014, 31, 506-513. [CrossRef] [PubMed]

158. Yeo, I.; Lee, Y.-J.; Song, K.; Jin, H.-S.; Lee, J.-E.; Kim, D.; Lee, D.-W.; Kang, N.J. Low molecular weight keratins with anti-skin aging activity produced by anaerobic digestion of poultry feathers with Fervidobacterium islandicum AW-1. J. Biotechnol. 2018, 271, 17-25. [CrossRef]

159. Jin, H.-S.; Song, K.; Baek, J.-H.; Lee, J.-E.; Kim, D.J.; Nam, G.-W.; Kang, N.J.; Lee, D.-L. Identification of matrix metalloproteinasae-1-suppressive peptides in feather hydrolysates. J. Agric. Food Chem. 2018, 66, 12719-12729. [CrossRef] [PubMed] 
160. Jin, H.-S.; Park, S.Y.; Kim, J.-Y.; Lee, J.-E.; Lee, H.-S.; Kang, N.J.; Lee, D.-W. Fluorescence-based quantification of bioactive keratin peptides from feathers for optimising large-scale anaerobic fermentation and purification. Biotechnol. Bioproc. Eng. 2019, 2, 240-249. [CrossRef]

161. Rouse, J.G.; Van Dyke, M.E. A review of keratin-based biomaterials for biomedical applications. Materials 2010, 3, 999-1014. [CrossRef]

162. Tachibana, A.; Furuta, Y.; Takesima, H.; Tanabe, T.; Yamauchi, K. Fabrication of wool keratin sponge scaffolds for long-term cell cultivation. J. Biotechnol. 2002, 93, 165-170. [CrossRef]

163. Tang, L.; Ollague, S.J.; Kelly, R.; Kirsner, R.S.; Li, J. Wool-derived keratin stimulates uman keratinocyte migration and types IV and VIIcollagen expression. Exp. Dermatol. 2012, 21, 458-460. [CrossRef]

164. Loan, F.; Marsh, C.; Cassidy, S.; Simcock, J. Keratin-based products for effective wound care management in superficial and partial thickeness burns injuries. Burns 2016, 4, 541-547. [CrossRef]

165. Sanchez Ramirez, D.O.; Carletto, R.A.; Tonetti, C.; Giachet, F.T.; Varesano, A.; Vineis, C. Wool keratin film plasticized by citric acid for food packaging. Food Pack. Shelf Life 2017, 12, 100-110. [CrossRef]

(C) 2020 by the authors. Licensee MDPI, Basel, Switzerland. This article is an open access article distributed under the terms and conditions of the Creative Commons Attribution (CC BY) license (http://creativecommons.org/licenses/by/4.0/). 

Article

\title{
Characterisation of the First Archaeal Mannonate Dehydratase from Thermoplasma acidophilum and Its Potential Role in the Catabolism of D-Mannose
}

\author{
Dominik Kopp ${ }^{1}$, Robert Willows ${ }^{1,2}$ and Anwar Sunna ${ }^{1,2, *}$ \\ 1 Department of Molecular Sciences, Macquarie University, Sydney, New South Wales 2109, Australia; \\ dominik.kopp@hdr.mq.edu.au (D.K.); robert.willows@mq.edu.au (R.W.) \\ 2 Biomolecular Discovery and Design Research Centre, Macquarie University, \\ Sydney, New South Wales 2109, Australia \\ * Correspondence: anwar.sunna@mq.edu.au; Tel.: +61-2-9850-4220
}

Received: 13 February 2019; Accepted: 24 February 2019; Published: 3 March 2019

\begin{abstract}
Mannonate dehydratases catalyse the dehydration reaction from mannonate to 2-keto-3-deoxygluconate as part of the hexuronic acid metabolism in bacteria. Bacterial mannonate dehydratases present in this gene cluster usually belong to the xylose isomerase-like superfamily, which have been the focus of structural, biochemical and physiological studies. Mannonate dehydratases from archaea have not been studied in detail. Here, we identified and characterised the first archaeal mannonate dehydratase (TaManD) from the thermoacidophilic archaeon Thermoplasma acidophilum. The recombinant TaManD enzyme was optimally active at $65^{\circ} \mathrm{C}$ and showed high specificity towards D-mannonate and its lactone, D-mannono-1,4-lactone. The gene encoding for TaManD is located adjacent to a previously studied mannose-specific aldohexose dehydrogenase (AldT) in the genome of T. acidophilum. Using nuclear magnetic resonance (NMR) spectroscopy, we showed that the mannose-specific AldT produces the substrates for TaManD, demonstrating the possibility for an oxidative metabolism of mannose in T. acidophilum. Among previously studied mannonate dehydratases, TaManD showed closest homology to enzymes belonging to the xylose isomerase-like superfamily. Genetic analysis revealed that closely related mannonate dehydratases among archaea are not located in a hexuronate gene cluster like in bacteria, but next to putative aldohexose dehydrogenases, implying a different physiological role of mannonate dehydratases in those archaeal species.
\end{abstract}

Keywords: mannonate dehydratase; mannose metabolism; Thermoplasma acidophilum; mannono-1,4-lactone; 2-keto-3-deoxygluconate; aldohexose dehydrogenase

\section{Introduction}

Mannonate dehydratases (EC 4.2.1.8) catalyse the conversion of mannonate to 2-keto-3-deoxygluconate (KDG) and have been studied as part of the hexuronic acid gene cluster in several organisms, such as Escherichia coli, Bacillus stearothermophilus, Bacillus subtilis and Erwinia chrysanthemi [1-4]. The hexuronate gene cluster encodes enzymes involved in the metabolism of glucuronate and galacturonate [5]. Glucuronate is a common sugar acid present in glucuronoxylan, a constituent of plant cell walls which can serve as the only carbon source for growth of some bacteria $[3,6,7]$. Glucuronate is also present in the mucus layer of mammals, providing a carbon source for anaerobic gut bacteria, such as E. coli $[8,9]$. As part of the hexuronate metabolism, mannonate dehydratase converts mannonate to KDG (Figure 1A). In E. coli, and some species of Erwinia, KDG is phosphorylated and cleaved into pyruvate and 3-phosphoglycerate, which can be further metabolised in the tricarboxylic acid cycle, or the Entner-Doudoroff pathway [4,5]. 
Mannonate dehydratases are represented in different enzyme families, such as the xylose isomerase-like superfamily or the enolase superfamily. Mannonate dehydratases encoded in the bacterial hexuronate gene clusters usually belong to the xylose isomerase-like superfamily. Crystal structures have been solved for xylose isomerase-like mannonate dehydratases from Streptococcus suis, E. coli $\mathrm{K} 12$ and Enterococcus faecalis in native form and in complex with $\mathrm{Mn}^{2+}$ ions $[10,11]$. His 311 and Tyr325 in the binding pocket were identified as crucial for the activity of the mannonate dehydratases from Gram-positive bacteria, such as S. suis. However, in Gram-negative bacteria (e.g., E. coli K12), an additional inserted sequence in the binding pocket rendered the dehydratase less active [11]. Members of the enolase superfamily show a conserved structure and reaction mechanism, but differ in their physiological functions. Within their conserved barrel structure, mannonate dehydratases of this family share conserved ligand-binding sites for $\mathrm{Mg}^{2+}$, which are essential for the stabilisation of the enediolate intermediate [12]. Among mannonate dehydratases of the enolase superfamily, some representatives with diverse functions have been found, which are involved in the catabolism of sugar acids other than glucuronate or galacturonate [13]. Several crystal structures have been solved for mannonate dehydratases from the enolase superfamily, including enzymes from Chromohalobacter salexigens and Novosphingobium aromaticivorans [12,14]. However, to the best of our knowledge, no archaeal mannonate dehydratase has been investigated so far.

Here, we used genomic analysis to identify the first functional mannonate dehydratase from the thermoacidophilic archaeon Thermoplasma acidophilum (TaManD). The archaeal mannonate dehydratase was recombinantly-expressed in E. coli, purified and functionally characterised. TaManD showed high amino acid sequence identity to bacterial mannonate dehydratases from the xylose isomerase-like superfamily. In the genome of T. acidophilum, the gene encoding for TaManD is located adjacent to an aldohexose dehydrogenase (AldT), which has been shown previously to catalyse the oxidation of mannose to mannonate with high specificity $[15,16]$. However, the physiological significance of the oxidation and its products were not investigated further. We identified the products of an AldT-mediated oxidation of D-mannose using NMR spectroscopy and confirmed that TaManD is able to convert the products to KDG. This demonstrates that in principle, a mannose metabolism based on AldT and ManD is possible in T. acidophilum (Figure 1B).

A

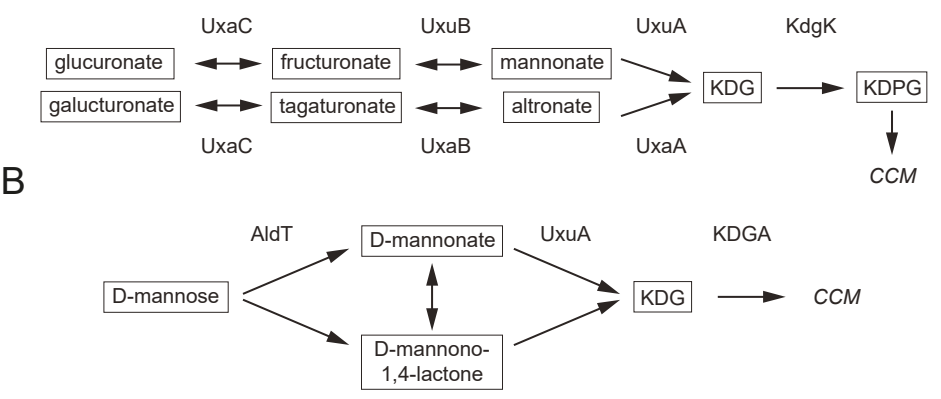

Figure 1. Hexuronate metabolism in E. coli and possible mannose catabolism in T. acidophilum. (A) Role of uxuA mannnonate dehdyratase in dissimilation of hexuronates in E. coli adapted from Peekhaus and Conway [8]. (B) Role of uxuA mannonate dehydratase in a possible mannose metabolism in T. acidophilum. UxaC: hexuronate isomerase, UxuB: mannonate oxidoreductase, UxaB: altronate oxidoreductase, UxuA: mannonate dehydratase, UxaA: altronate dehydratase, KdgK: 2-keto-3-deoxygluconate kinase, KDG: 2-keto-3-deoxygluconate, KDPG: 2-keto-3-deoxy-6-phosphogluconate, AldT: aldose dehydrogenase, KDGA: 2-keto-3-deoxygluconate aldolase, CCM: central carbon metabolism. 


\section{Results and Discussion}

\subsection{Screening for a Functional Mannonate Dehydratase in T. acidophilum}

Based on the previously identified mannose-specific AldT, we searched the genomic neighbourhood of its gene locus (Ta0754) for enzymes which could display activity towards mannonate. In the proximity of Ta0754, several genes are located that encode for hypothetical dehydratases, suggesting their potential to convert mannonate to KDG (Table S1). We identified the protein product of the Ta0753 gene as a functional mannonate dehydratase from T. acidophilum by heterologous expression in E. coli, and compared its properties and genomic context to other previously studied mannonate dehydratases.

Among previously characterised mannonate dehydratases, TaManD shares highest protein sequence identity (31.5\%) with enzymes in the xylose isomerase-like superfamily, such as the mannonate dehydratase from S. suis [10]. Key amino acid residues for substrate binding (His311 and Tyr325) and binding of the cofactor $\mathrm{Mn}^{2+}$ (Asp310, Cys237, His199 and His266) in S. suis are conserved in the amino acid sequence of TaManD. A much higher amino acid sequence identity $(62.9 \%)$ is shared between TaManD and putative mannonate dehydratases from closely related archaeal species, Ferroplasma acidarmanus and Ferroplasma acidiphilum, suggesting an archaeal clade of mannonate dehydratases.

Phylogenetic analysis showed that mannonate dehydratases from T. acidophilum, F. acidarmanus and $F$. acidiphilum are more closely related to bacterial mannonate dehydratases from the xylose isomerase-like superfamily than to bacterial or archaeal mannonate dehydratases of the enolase superfamily (Figure 2). Mannonate dehydratases of the enolase superfamily have a substantially different structure from those in the xylose isomerase-like superfamily, and therefore, are only distantly related to TaManD. Despite fulfilling a similar function, the dihydroxy-acid dehydratase from $S$. solfataricus, which belongs to the IlvD/EDD superfamily, is rather unrelated to the xylose isomerase-like and enolase superfamilies [17].

For bacterial xylose isomerase-like mannonate dehydratases, a physiological function of the enzyme in the catabolism of hexuronates has been demonstrated $[18,19]$. Although TaManD is annotated as uxuA mannonate dehydratase, which implies a role in the metabolism of hexuronates, it is not present in a classical hexuronate gene cluster known from bacteria such as E. coli, B. subtilis or $B$. stearothermophilus (Figure 3) [2,3]. In contrast, the gene encoding for TaManD is located adjacent to AldT in the genome of T. acidophilum. Similarly, the two closely related putative mannonate dehydratases in F. acidarmanus and F. acidiphilum are also located adjacent to putative aldohexose dehydrogenases. Therefore, a different physiological role can be proposed for these mannonate dehydratases. In the following, we functionally characterise TaManD and show that AldT is able to produce the substrate needed for a subsequent conversion to KDG mediated by TaManD. 


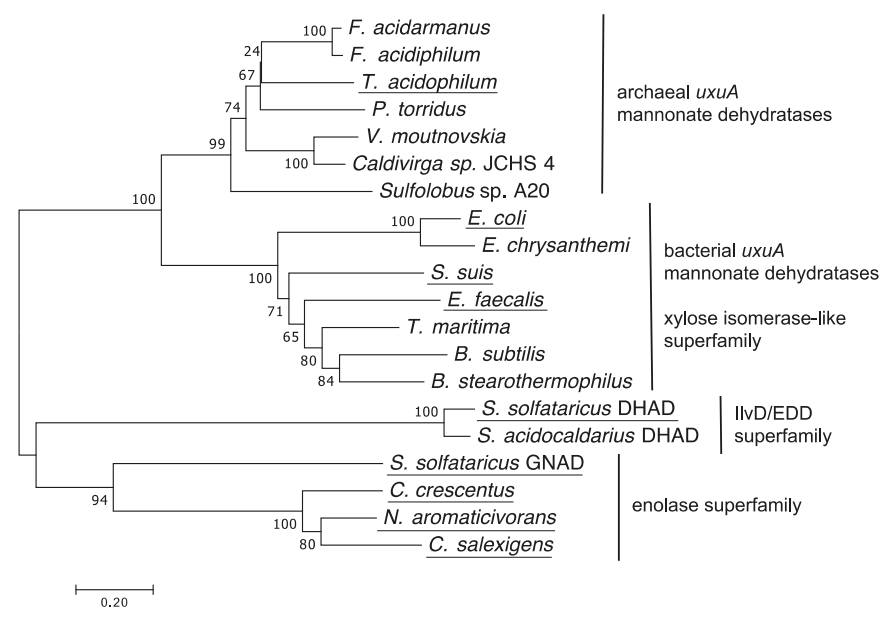

Figure 2. Phylogenetic relationship of different putative and confirmed dehydratases belonging to different enzyme families. Characterised enzymes are underlined. Evolutionary analyses were conducted in MEGA 7. 20 protein sequences were aligned using MUSCLE. The phylogenetic tree was inferred using the neighbour-joining method. The scale bar indicates an evolutionary distance of 0.20 nucleotide per position in the sequence. The number next to the nodes represent bootstrap confidence values estimated from 500 replicates. Protein sequences were retrieved from the Uniprot database and their entry codes are as follows. Ferroplasma acidarmanus: S0AL33, Ferroplasma acidiphilum: A0A1V0N416, Thermoplasma acidophilum: Q9HK52, Picrophilus torridus: Q6L2R9, Vulcanisaeta moutnovskia: F0QYL3, Caldivirga sp. JCHS 4: A0A101XEY7, Sulfolobus sp. A20: A0A1C8ZTN0, Escherichia coli K12: P24215, Erwinia chrysanthemi/Dickeya dadantii: E0SEP1, Streptococcus suis: A0A142UME2, Enterococcus faecalis: Q82ZC9, Thermotoga maritima: Q9WXS4, Bacillus subtilis: O34346, Bacillus stearothermophilus: A0A087LHB3, Sulfolobus solfataricus DHAD: Q97UB2, Sulfolobus acidocaldarius DHAD: Q4J860, Sulfolobus solfataricus GNAD: Q97U27, Caulobacter crescentus/Caulobacter vibroides: Q9AAR4, Novosphingobium aromaticivorans: A4XF23, Chromohalobacter salexigens: Q1QT89.

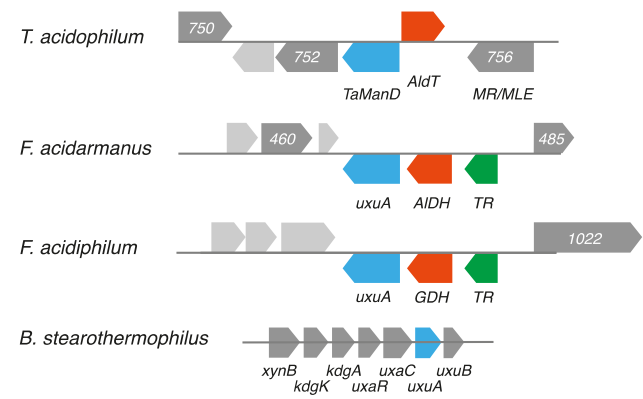

Figure 3. Schematic maps of uxuA mannonate dehydratases and their genomic neighbourhoods in T. acidophilum, F. acidarmanus, F. acidiphilum and B. stearothermophilus. Genes are annotated in the NCBI database as follows: In blue, TaManD/uxuA: T. acidophilum mannonate dehydratase/uxuA D-mannonate dehydratases; in orange, AldT/AlDH/GDH: aldohexose dehydrogenase/aldose dehydrogenase/glucose-1-dehydrogenase; in green, TR: transcriptional regulator; in light grey, annotated as hypothetical protein. Note: 750: FAA hydrolase family protein, 752: L-rhamnonate dehydratase, 756: mandelate racemase/muconate lactonizing enzyme family protein, 460: transposase, 485: acetyl-coenzyme A synthetase, 1022: acetate-CoA ligase, $x y n B: \beta$-xylosidase, $k d g K$ : 2-keto-3-deoxygluconate kinase, $k d g A$ : 2-keto-3-deoxy-6-phosphogluconate aldolase, uxaR: regulatory protein, $u x a C$ : hexuronate isomerase, $u x u B$ : mannonate oxidoreductase. 


\subsection{Substrate Conformation for TaManD Activity}

Before acquiring enzyme kinetics and studying the characteristics of TaManD, we investigated which substrate conformation is encountered by TaManD under physiological conditions. In aqueous solutions, free sugar acids coexist with their lactone in an equilibrium, which is defined by the stability of the lactone, the temperature and the $\mathrm{pH}$ of the solution. Many lactones hydrolyse spontaneously in water, although several lactones, including D-arabinonolactone [20], L-rhamnonolactone [21] and D-xylonolactone [22], have been reported to be hydrolysed by lactonases. Mannonate is able to form a lactone by covalent bond formation between carbon 1 and carbon 5 ( $\delta$-lactone) or carbon 1 and carbon 4 ( $\gamma$-lactone) (Figure 4A). The equilibrium of the two different envelope forms has been studied by NMR spectroscopy and it was found that the $\gamma$-lactone is strongly favoured over the $\delta$-lactone [23]. However, these studies do not describe equilibria between lactone and free acid form in a physiological buffer. In a cellular environment mannonate can either be produced by a mannonate oxidoreductase (UxuB) as part of the catabolism of hexuronic acids or by an aldohexose dehydrogenase, such as AldT, in a hypothetical oxidative mannose catabolism (Figure 1). In order to study the conformation of the substrate for TaManD in a physiological environment, we first acquired decoupled ${ }^{13} \mathrm{C}$ NMR spectra for D-mannono-1,4-lactone in physiological buffer at $\mathrm{pH}$ 7, in its lactone form (incubated with $\mathrm{HCl}$ ) and after hydrolysis to the free sugar acid (incubated with $\mathrm{NaOH}$ ) (Figure $4 \mathrm{~B}$ ). The spectra obtained indicated that the lactone and the free sugar acid can be distinguished by their chemical shifts. In the free sugar acid form, carbon 6 yields a chemical shift at 63.51 ppm, whereas in D-mannono-1,4-lactone, carbon 6 displays a chemical shift at $63.02 \mathrm{ppm}$. D-mannono-1,4-lactone in buffer shows both chemical shifts, indicating that D-mannono-1,4-lactone and D-mannonate are present in an equilibrium at $\mathrm{pH} 7$.

A

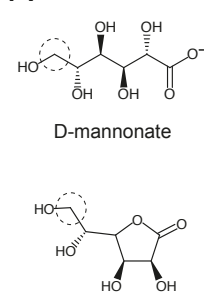

D-mannono-1,4-lactone
B

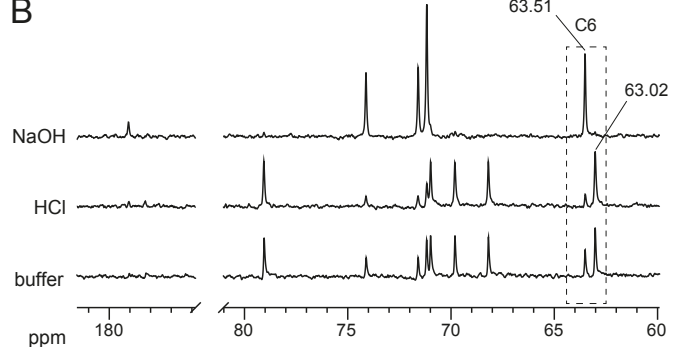

C

D-[1,6-13 $\left.\mathrm{C}_{2}\right]$ mannose

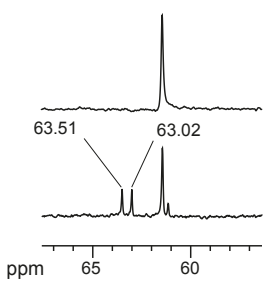

Figure 4. Analysis of D-mannono-1,4-lactone under different conditions and products of AldT-mediated oxidation of isotope labelled D-mannose. (A) Chemical structures of the free sugar acid, D-mannonate, and its lactone, D-mannono-1,4-lactone. Carbon 6, which was used to differentiate the two different substrate forms in NMR spectra, is circled for both structures. (B) Decoupled $1 \mathrm{D}^{13} \mathrm{C}$ NMR spectra of D-mannono-1,4-lactone after incubation in $1 \mathrm{M} \mathrm{NaOH}, 1 \mathrm{M} \mathrm{HCl}$ and in $0.1 \mathrm{M}$ sodium phosphate $(\mathrm{NaP})$ buffer $\mathrm{pH}$ 7. Chemical shift for carbon 6 is shown by a dashed rectangle. Characteristic chemical shifts for the lactone (63.02 ppm) and for the free sugar acid $(63.51 \mathrm{ppm})$ are indicated. (C) Decoupled $1 \mathrm{D}^{13} \mathrm{C}$ NMR spectra before (top) and after (bottom) oxidation of labelled D-mannose with AldT. Chemical shifts of carbon 6 for lactone and free sugar acid are indicated. 
Next, we oxidised isotope-labelled D-[1,6- $\left.{ }^{13} \mathrm{C}_{2}\right]$ mannose using recombinantly-expressed AldT and acquired $1 \mathrm{D}{ }^{13} \mathrm{C}$ NMR spectra of the reaction product. The chemical shifts for carbon 6 of mannono-1,4-lactone and D-mannonate were used to analyse the reaction products of the mannose oxidation with AldT, as these were close together but well resolved and will have similar relaxation rates in both forms. The spectrum after partial AldT oxidation of D- $\left[1,6-{ }^{13} \mathrm{C}_{2}\right]$ mannose (Figure $4 \mathrm{C}$ ) shows that equal quantities of D-mannono-1,4-lactone and D-mannonate are produced for the subsequent dehydration by TaManD.

\subsection{Expression and Purification of TaManD}

For the further biochemical characterisation, TaManD was expressed together with a tobacco etch virus (TEV) sequence, which allowed the proteolytic cleavage of the His-tag after the first metal affinity purification. In order to study the effect of bivalent metal cofactors on enzyme activity, cleavage of the His-tag from the recombinant enzyme was necessary, since cations $\left(\mathrm{Ni}^{2+}, \mathrm{Mg}^{2+}\right)$ might influence enzyme activity assays of a His-tagged enzyme. After His-tag cleavage, the recombinant enzyme showed a single band on sodium dodecyl sulfate polyacrylamide gel electrophoresis (SDS-PAGE) with an apparent mass of $38 \mathrm{kDa}$ (Figure S1). Peptide mass fingerprinting was performed with liquid chromatography-electrospray ionisation-tandem mass spectrometry (LC ESI MS/MS) and the National Center for Biotechnology Information (NCBI) database searches using the mascot software confirmed the identity of the purified protein as uxuA mannonate dehydratase from T. acidophilum. In addition, the apparent native molecular mass of the protein was estimated from size exclusion chromatography to be $225 \mathrm{kDa}$, indicating a hexameric structure of the protein.

\subsection{Enzyme Characterisation}

Initial tests showed that TaManD lost almost its complete activity after purification, suggesting that essential cofactors for activity were removed during the purification process. Accordingly, the effect of several additives was tested for their influence on the activity of TaManD with D-mannono-1,4-lactone. TaManD showed strongly enhanced activity in the presence of $\beta$-mercaptoethanol and the metal ions $\mathrm{Mn}^{2+}, \mathrm{Ni}^{2+}, \mathrm{Mg}^{2+}, \mathrm{Ca}^{2+}$ and $\mathrm{Co}^{2+}$ (Figure 5). The highest activation (100\%) was observed in the presence of $\beta$-mercaptoethanol, which was significantly higher than the activating bivalent cation $\mathrm{Ni}^{2+}$ (71.5\% of maximum enzyme activity, $\mathrm{p}$-value: 0.0022$) . \mathrm{Mn}^{2+}, \mathrm{Mg}^{2+}$ and $\mathrm{Co}^{2+}$ also activated TaManD and resulted in 50-60\% increase in maximum activity when compared to the TaManD control (without any additive). No significant difference in activity was observed in the presence of $\mathrm{Fe}^{2+}, \mathrm{Zn}^{2+}, \mathrm{Cu}^{2+}$, EDTA, DTT and glutathione.

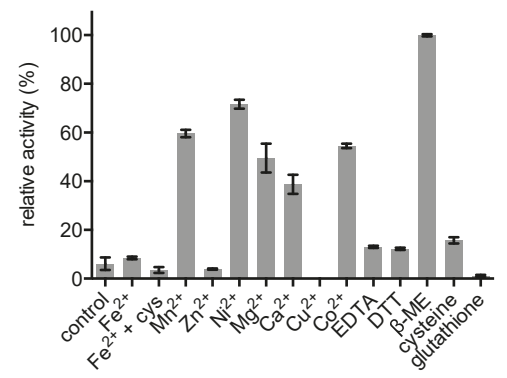

Figure 5. Effect of metal ions, chelating and reducing agents on the activity of TaManD. Purified enzyme $(0.6 \mu \mathrm{g})$ was pre-incubated for $1 \mathrm{~h}$ with $1 \mathrm{mM}$ of each additive in $50 \mathrm{mM}$ HEPES pH 7. Activity was then determined in reactions containing $10 \mathrm{mM}$ D-mannono-1,4-lactone in $50 \mathrm{mM}$ HEPES pH 7 incubated for $1 \mathrm{~h}$ at $55^{\circ} \mathrm{C}$ before analysis with the semicarbazide assay. Activity is expressed in relation to the maximum enzyme activity. $\mathrm{Fe}^{2+}+$ cys: $\mathrm{Fe}^{2+}$ was prepared with $1 \mathrm{mM}$ cysteine. DTT: dithioerythritol, EDTA: ethylendiaminetetraacetate, $\beta$-ME: $\beta$-mercaptoethanol. 
TaManD was activated by similar bivalent ions and reducing factor, as previously studied bacterial mannonate dehydratases from the xylose isomerase-like superfamily. However, none of the bacterial mannonate dehydratases described so far have been shown to have an equally strong activation with both metal ions, $\mathrm{Co}^{2+}$ and $\mathrm{Ni}^{2+}$, as observed with TaManD. Early investigations of mannonate dehydratases focused on $E$. coli and showed different strengths in activation after incubation with bivalent cations [1,24-26]. In summary, most studies showed that $\beta$-mercaptoethanol, $\mathrm{Fe}^{2+}$ and $\mathrm{Mn}^{2+}$ resulted in highest enzyme activity (90-100\% of maximum enzyme activity). Incubation with other bivalent cations resulted in less activity compared to the enzyme's maximum activity $\left(\mathrm{Co}^{2+}: 27-80 \%\right.$, $\mathrm{Ni}^{2+}: 5-40 \%$ and $\mathrm{Zn}^{2+}: 5-25 \%$, depending on the study). More recently, crystal structures of xylose isomerase-like mannonate dehydratases from $S$. suis and E. coli have been solved and revealed the presence of primarily $\mathrm{Mn}^{2+}$ and lower amounts of $\mathrm{Mg}^{2+}, \mathrm{Ni}^{2+}$ and $\mathrm{Zn}^{2+}$ in their binding sites [10,11].

T. acidophilum was originally isolated from a hot and acidic environment and accordingly this archaeon displays optimal temperature and $\mathrm{pH}$ for growth at $59{ }^{\circ} \mathrm{C}$ and $\mathrm{pH} 1-2$, respectively [27]. The purified TaManD was active between $35^{\circ} \mathrm{C}$ and $70^{\circ} \mathrm{C}$, with an optimal temperature for activity at $65{ }^{\circ} \mathrm{C}$ (Figure 6A). Thermostability of the enzyme in the absence of substrate was studied at temperatures between $55^{\circ} \mathrm{C}$ and $95^{\circ} \mathrm{C}$ (Figure 6B). The enzyme retains its full activity at $55^{\circ} \mathrm{C}$ for at least an hour, whereas complete inactivation was observed at $75^{\circ} \mathrm{C}, 85^{\circ} \mathrm{C}$ and $95^{\circ} \mathrm{C}$ within $90 \mathrm{~min}$, $60 \mathrm{~min}$ and $15 \mathrm{~min}$, respectively. The difference in the relatively high optimal temperature of the enzyme to the comparably low thermostability indicated that the enzyme is more prone to inactivation in the absence of substrate. Other enzymes obtained from this organism have been shown to display optimal temperatures in the range of $55^{\circ} \mathrm{C}$ to $70^{\circ} \mathrm{C}$ [15,28-30].
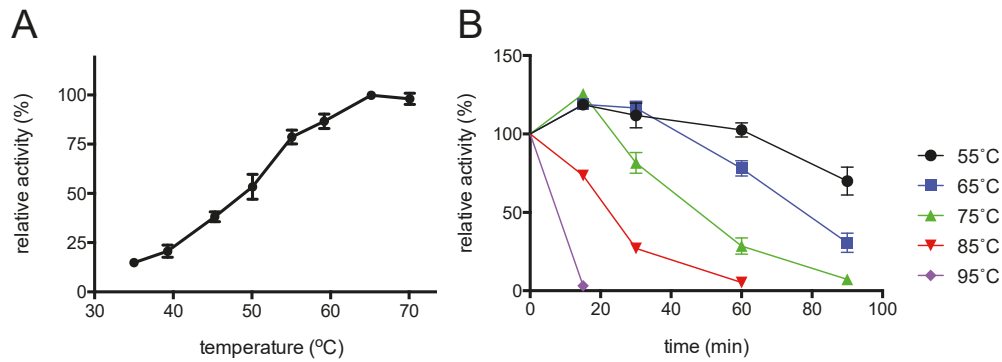

Figure 6. Effect of temperature on TaManD activity. (A) Optimum temperature of TaManD.

(B) Thermostability of purified TaManD enzyme $(1 \mu \mathrm{g})$ incubated over $90 \mathrm{~min}$ at various temperatures.

Following the identification of the crucial metal cofactors required for TaManD activity and determination of its optimal reaction temperature, we acquired enzyme kinetic data for the purified enzyme. Considering the fact that under physiological conditions an equilibrium of both lactone and free sugar acid exists, the kinetic data was acquired in reactions with substrate provided in these two different forms. The substrate was either hydrolysed with $\mathrm{NaOH}$ to obtain free sugar acid, D-mannonate, or the lactone was prepared in buffer, equaling an equilibrium of lactone and free sugar acid. TaManD displayed a higher activity in reactions with D-mannonate compared to reactions with D-mannono-1,4-lactone prepared in buffer at $\mathrm{pH} 7$ (Table 1). The maximal velocity of the reaction, $\mathrm{V}_{\max }$, with D-mannonate as substrate was slightly higher (24-27\%) compared to reactions with the lactone prepared in buffer (p-value: 0.06), whereas no difference in the affinity between the two different forms of the substrate could be observed (Table 1, Figure S2).

The $\mathrm{pH}$ optimum of TaManD was dependent on the form of the substrate. TaManD displayed highest activity between pH 5 and 7 with mannonate, while with D-mannono-1,4-lactone in buffer, the enzyme displayed overall lower activities with an apparent optimum at pH 7 (Figure 7). Unlike previously studied enzymes from T. acidophilum (e.g., AldT), TaManD did not retain maximum activity above $\mathrm{pH} 7$ with both substrates [15]. 
Table 1. TaManD kinetic data with D-mannonate (prepared by hydrolysis with $\mathrm{NaOH}$ ) and with D-mannono-1,4-lactone prepared in buffer ( $\mathrm{pH}$ 7). Non-linear fitting was performed (Figure S2).

\begin{tabular}{ccccc}
\hline Substrate & $\boldsymbol{K}_{\mathbf{m}}(\mathbf{m M})$ & $\mathbf{V}_{\max }(\mathbf{U} / \mathbf{m g})$ & $\boldsymbol{k}_{\text {cat }}\left(\mathbf{s}^{-\mathbf{1}}\right)$ & $\boldsymbol{k}_{\text {cat }} / \boldsymbol{K}_{\mathbf{m}}\left(\mathbf{m M}^{-\mathbf{1}} \mathbf{s}^{-\mathbf{1}}\right)$ \\
\hline D-mannonate & $5.37 \pm 0.90$ & $2.39 \pm 0.11$ & 1.64 & 0.30 \\
D-mannono-1,4-lactone in buffer & $4.90 \pm 0.53$ & $1.90 \pm 0.06$ & 1.33 & 0.26 \\
\hline
\end{tabular}

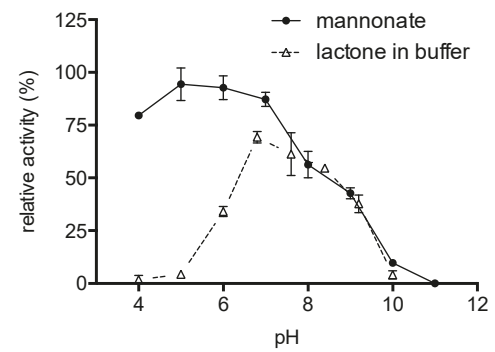

Figure 7. The $\mathrm{pH}$ optima of reactions with D-mannono-1,4-lactone prepared in buffer $\mathrm{pH} 7$ (lactone in buffer) and with D-mannonate (prepared by hydrolysis with $\mathrm{NaOH}$ ). Activity values are expressed as relative activity (\%) normalised to the highest overall activity observed in the assay.

Based on the observations from experiments with different forms of substrate, we assume that D-mannonate is either the only form, or at least more accessible to TaManD than its lactone. At low $\mathrm{pH}$, TaManD shows low activity with D-mannono-1,4-lactone, supposedly because the lactone does not hydrolyse to the free acid. In contrast, if D-mannono-1,4-lactone was hydrolysed to D-mannonate and used as substrate at low $\mathrm{pH}$, high enzyme activity should be observed. Similarly, the difference in $\mathrm{V}_{\max }$ for D-mannonate and D-mannono-1,4-lactone in buffer can be explained by slow hydrolysis of the lactone to the free acid. Reactions with hydrolysed D-mannonate occur faster compared to the lactone in buffer, since more substrate is readily available.

\subsection{Product Identification and Substrate Specificity}

In order to identify the product of the TaManD reaction with mannonate, reactions containing the substrate and $\mathrm{Co}^{2+}$ were analysed at several time points by high-performance liquid chromatography (HPLC) (Figure 8A). Although a complete separation of the product KDG and mannonate could not be achieved on different organic acid columns, an increase of KDG was observed. In order to test for substrate promiscuity, 11 different sugar acids (Figure 8B) were incubated with purified TaManD and tested for the formation of 2-keto-3-deoxy analogues using the semicarbazide assay. D-mannonate and D-mannono-1,4-lactone were the only substrates that showed a positive reaction after incubation for $16 \mathrm{~h}$. This is in contrast to other dehydratases, including members of the enolase superfamily and the IlvD/EDD superfamily, such as the L-fuconate dehydratase from Xanthomonas campestris [31] or the dihydroxy-acid dehydratase from Sulfolobus solfataricus [17,32], which have been shown to be active with a multitude of different sugar acids. 
A

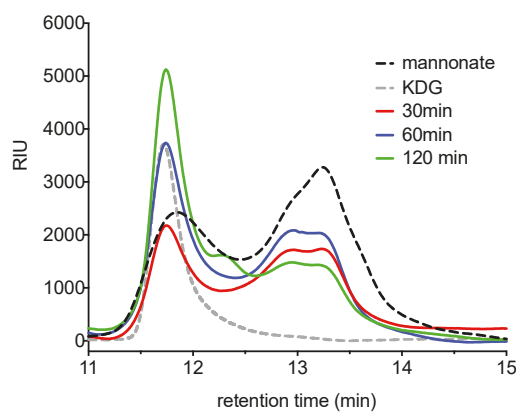

B

\begin{tabular}{ll} 
tested sugar acids & $\begin{array}{l}\text { relative } \\
\text { activity }\end{array}$ \\
\hline D-mannonate & $100 \%$ \\
D-mannono-1,4-lactone & $79 \%$ \\
D-gluconic acid sodium salt & n.d. \\
D-galactono-1,4-lactone & n.d. \\
D-glucuronic acid & n.d. \\
D-galacturonic acid sodium salt & n.d. \\
L-gulonic acid-y-lactone & n.d. \\
D-arabinoic acid sodium salt & n.d. \\
D-fuconic acid lithium salt & n.d. \\
L-fuconic acid sodium salt & n.d. \\
L-rhamnonic acid lithium salt & n.d.
\end{tabular}

Figure 8. Substrate specificity and product analysis of reactions with TaManD. (A) Reactions with TaManD and $10 \mathrm{mM}$ mannonate analysed by HPLC equipped with a refractive index detector. Standards: $10 \mathrm{mM}$ mannonate (dashed black line), $2.5 \mathrm{mM} \mathrm{KDG}$ (dashed grey line). Reactions: stopped after $30 \mathrm{~min}$ (red line), stopped after $60 \mathrm{~min}$ (blue line), stopped after $120 \mathrm{~min}$ (green line). RIU: refractive index units. (B) List of sugar acids that were tested as substrates for TaManD. Activity is expressed relative (\%) to the maximal activity obtained in the assay; n.d.: no signal detected after $16 \mathrm{~h}$ of incubation. Lactones except for D-mannono-1,4-lactone were hydrolysed by incubation in $1 \mathrm{M} \mathrm{NaOH}$ for $1 \mathrm{~h}$ at room temperature and then diluted in $50 \mathrm{mM}$ HEPES $\mathrm{pH} 7$ to obtain free sugar acids. All sugar acids were tested at a concentration of $10 \mathrm{mM}$ in duplicate experiments.

\section{Materials and Methods}

\subsection{Cloning, Expression and Purification of Enzymes}

All plasmids were constructed by amplification of genes from T. acidophilum DSM 1728 genomic DNA (DSMZ, Braunschweig, Germany) using PCR, restriction and ligation into vectors according to standard protocols [33]. Primer pairs and restriction enzymes used for the construction of each expression plasmid are summarised in Table S2. E. coli strain $\alpha$-select (Bioline, Sydney, Australia) was used in all initial cloning procedures. The expression plasmid pProEX HTa-Ta0753 was then used to transform BL21-CodonPlus (DE3)-RIL competent cells (Agilent Technologies, Santa Clara, CA, USA). Plasmid pETDuet-1-AldT was used to transform BL21 (DE3) cells (NEB, Ipswitch, Burlington, MA, USA). BL21-CodonPlus (DE3)-RIL strains containing the respective expression plasmid were grown in $500 \mathrm{~mL}$ Luria-Bertani medium (LB) supplemented with carbenicillin $(100 \mu \mathrm{g} / \mathrm{ml})$ and chloramphenicol $(35 \mu \mathrm{g} / \mathrm{ml})$ at $37^{\circ} \mathrm{C}$ to an $\mathrm{OD}_{600}$ of 0.6 before induction was performed with $0.4 \mathrm{mM}$ isopropyl $\beta$-D-1-thiogalactopyranoside (IPTG) at $20^{\circ} \mathrm{C}$ for $16-18 \mathrm{~h}$. The BL21 (DE3) cells carrying the expression plasmid pETDuet-1-AldT were grown in $500 \mathrm{~mL}$ LB medium containing carbenicillin $(100 \mu \mathrm{g} / \mathrm{ml})$ to an $\mathrm{OD}_{600}$ of 0.5 at $37{ }^{\circ} \mathrm{C}$ before induction was performed with $0.4 \mathrm{mM}$ IPTG at $37^{\circ} \mathrm{C}$ for $4 \mathrm{~h}$. All cultures were harvested by centrifugation at $5000 \times g$ for $20 \mathrm{~min}$, resuspended in $50 \mathrm{mM}$ 4-(2-hydroxyethyl)-1-piperazineethanesulfonic acid (HEPES) pH 7 and lysed by three passages through a French pressure cell. Soluble fractions of the lysates were obtained by centrifugation at $15,000 \times g$ for $20 \mathrm{~min}$. His-tagged enzymes were purified by subjecting the soluble extracts to a $5 \mathrm{~mL}$ nickel-nitrilotriacetic acid (Ni-NTA) affinity column (GE Healthcare) equilibrated with buffer containing $50 \mathrm{mM}$ sodium phosphate (NaP), $300 \mathrm{mM} \mathrm{NaCl}$ and $20 \mathrm{mM}$ imidazole. The proteins were eluted isocratically with a final concentration of $400 \mathrm{mM}$ imidazole. The buffer of the eluates was exchanged to $50 \mathrm{mM}$ HEPES pH 7 by three rounds of centrifugation in Amicon Ultra centrifugal filters (Millipore) with a $30 \mathrm{kDa}$ molecular weight cut-off.

In order to obtain TaManD without a N-terminal His-tag, the enzyme obtained after pProEX HTa-Ta0753 expression and first His-tag purification was incubated with a TEV Protease (Promega, 
Madison, WI, USA). Digestion was performed according to the manufacturer's protocol with addition of $10 \%$ glycerol (v/v, final concentration) and incubation for $1.5 \mathrm{~h}$ at $30^{\circ} \mathrm{C}$ followed by incubation at $4{ }^{\circ} \mathrm{C}$ overnight. Removal of the His-tag and the TEV Protease was achieved by a second Ni-NTA purification using a $1 \mathrm{~mL}$ ZetaSep Ni-NTA affinity column (emp Biotech, Berlin, Germany). The flow-through contained the pure protein and cleavage of the His-tag was verified by SDS-PAGE.

\subsection{Protein Analysis}

Purified proteins were separated by SDS-PAGE using 4-15\% Tris-glycine polyacrylamide gels (Bio-Rad Laboratories, Hercules, USA) and visualised with Coomassie Brilliant Blue. For the identification of TaManD, the single protein band at $38 \mathrm{kDa}$ was excised from the gel and analysed by LC ESI MS/MS at the Australian Proteome Analysis Facility (APAF, Macquarie University), as described elsewhere [34]. Protein identification was performed using the mascot software (2.4.1, Matrixscience, Boston, MA, USA). The native molecular mass of the recombinant protein was determined by size exclusion chromatography on an ÄKTA pure FPLC system using a Superdex Increase 200 10/300 GL column (GE Healthcare) equilibrated with $10 \mathrm{mM} \mathrm{NaP}$ buffer, $140 \mathrm{mM} \mathrm{NaCl}$, $\mathrm{pH}$ 7. A calibration curve was obtained with molecular weight markers thyroglobulin $(669 \mathrm{kDa})$, ferritin $(440 \mathrm{kDa})$, aldolase $(158 \mathrm{kDa})$, conalbumin $(75 \mathrm{kDa})$ and ovalbumin $(43 \mathrm{kDa})$.

\subsection{Nuclear Magentic Resonance (NMR) Analysis}

D-Mannono-1,4-lactone ( $>95 \%$ ) was purchased from TCI Chemicals Co. (Tokyo, Japan). For NMR spectra of the sugar acid in different substrate forms, $1 \mathrm{M}$ D-Mannono-1,4-lactone solutions were prepared in $1 \mathrm{M} \mathrm{NaOH}, 1 \mathrm{M} \mathrm{HCl}$ and in ultrapure water. All solutions were incubated for $1 \mathrm{~h}$ at room temperature, before each solution was diluted to $100 \mathrm{mM}$ using ultrapure water. Then, $300 \mu \mathrm{L}$ of each $100 \mathrm{mM}$ solution (equivalent to $5 \mathrm{mg}$ sugar acid) was freeze-dried and resuspended in $500 \mu \mathrm{L} 0.1 \mathrm{M}$ $\mathrm{NaP}$ buffer, $\mathrm{pH}$ 7. The $\mathrm{pH}$ of all three samples was evaluated prior to NMR analysis. The substrate incubated in $\mathrm{HCl}$ displayed $\mathrm{pH}$ 6, while the substrate in water or $\mathrm{NaOH}$ displayed $\mathrm{pH}$ 7. After transfer of each sample to $5 \mathrm{~mm}$ NMR tubes, $10 \% \mathrm{D}_{2} \mathrm{O}$ and $40 \mu \mathrm{M}$ 3-(trimethylsilyl)propionic-2,2,3,3-d4 acid (TMSP) chemical shift standard was added. The 1D decoupled ${ }^{13} \mathrm{C}$ NMR spectra of non-isotopically labelled samples were acquired on a $500 \mathrm{MHz}$ Bruker Avance III HD NMR equipped with a BBFO probe at $50{ }^{\circ} \mathrm{C}(323 \mathrm{~K})$, using power-gated proton decoupling with a $90^{\circ}$ pulse with 512 scans and a $3 \mathrm{~s}$ relaxation delay between scans. Oxidation of D-[1,6- $\left.{ }^{13} \mathrm{C}_{2}\right]$ mannose was performed in reactions containing $5 \mathrm{mM}$ of the substrate, $5 \mathrm{mM} \mathrm{NAD}+20 \mathrm{mM} \mathrm{NaP}$ buffer at $\mathrm{pH} 7$ and $13.5 \mu \mathrm{g}$ purified AldT. Prior to the addition of purified enzyme and after $30 \mathrm{~min}$ of reaction at $50{ }^{\circ} \mathrm{C}, 1 \mathrm{D}$ power-gated proton decoupled ${ }^{13} \mathrm{C}$ NMR spectra were acquired using a $90^{\circ}$ pulse with 4 scans and a $3 \mathrm{~s}$ relaxation delay between scans. Visualisation of all spectra was performed with iNMR 6.0 (http:/ /www.inmr.net). After Fourier transformation and automatic phase correction, an exponential visual weighting factor of 1.5 and a smoothing factor of 10 were applied to all spectra.

\subsection{Enzyme Activity}

D-mannono-1,4-lactone was either used after preparation in 50 mM HEPES at pH 7 (indicated as "lactone in buffer") or after hydrolysis to its free acid form (indicated as "mannonate" or "free sugar acid"). Hydrolysis was performed according to Lamble et al. by preparing $1 \mathrm{M}$ stock solutions of D-mannono-1,4-lactone in $1 \mathrm{M} \mathrm{NaOH}$ and incubation at room temperature for $1 \mathrm{~h}$ before dilutions were prepared in $50 \mathrm{mM}$ HEPES $\mathrm{pH} 7$ [35]. For temperature optimum, $\mathrm{pH}$ optimum and thermostability, activity was quantified using the thiobarbituric acid (TBA) assay, according to a modification by Buchanan et al. [36,37]. Unless stated otherwise, reactions $(60 \mu \mathrm{L})$ contained $0.5-1.5 \mu \mathrm{g}$ pure enzyme, $10 \mathrm{mM}$ mannonate, $50 \mathrm{mM}$ HEPES $\mathrm{pH} 7$ (adjusted at $55^{\circ} \mathrm{C}$ ) and $1 \mathrm{mM} \mathrm{CoSO}_{4}$. Reactions were stopped by incubation on ice or if needed by addition of $6 \mu \mathrm{L} 12.5 \%$ trichloracetic acid (TCA). Next, $50 \mu \mathrm{L}$ of the reaction mixture was oxidised using $125 \mu \mathrm{L}$ of $25 \mathrm{mM}$ periodic acid in $0.25 \mathrm{M} \mathrm{H}_{2} \mathrm{SO}_{4}$ at room temperature for $20 \mathrm{~min}$. The oxidation was stopped by addition of $250 \mu \mathrm{L}$ of $2 \%(\mathrm{w} / \mathrm{v})$ sodium arsenite 
in $0.5 \mathrm{M} \mathrm{HCl}$. Finally, $1 \mathrm{~mL}$ of $0.3 \%$ TBA in water was added to the samples and the reaction mixture was boiled for $10 \mathrm{~min}$. The formation of 2-keto-3-deoxy sugar acid was determined by reading $A_{549 \mathrm{~nm}}$ using 96-well microtiter plates in a Spectrostar Nano plate reader (BMG Labtech, Ortenberg, Germany) and quantified using the molar extinction coefficient of $67.8 \times 10^{3} \mathrm{M}^{-1} \times \mathrm{cm}^{-1}$.

The effect of $\mathrm{pH}$ on enzyme activity was analysed in duplicate reactions with $1 \mu \mathrm{g}$ enzyme and $120 \mathrm{mM}$ universal buffer [38]. Reactions were incubated for $2 \mathrm{~h}$ at $55^{\circ} \mathrm{C}$ before they were analysed with the TBA Assay. In reactions with D-mannono-1,4-lactone in buffer, $\mathrm{pH}$ decreased during the course of the experiment, which was accounted for in the analysis by measurement of the $\mathrm{pH}$ after the reaction. The optimal temperature for enzyme activity was determined in duplicate reactions containing $1 \mu \mathrm{g}$ enzyme. Duplicate reactions were performed for $1 \mathrm{~h}$ at different temperatures before being analysed with the TBA Assay. For thermostability assays, $120 \mathrm{mM}$ universal buffer was used and purified enzyme $(1 \mu \mathrm{g})$ was incubated in duplicates at temperatures between $55^{\circ} \mathrm{C}$ and $95{ }^{\circ} \mathrm{C}$ in the absence of substrate. Samples were removed at different times and the residual activity was measured in reactions with $10 \mathrm{mM}$ mannonate for $45 \mathrm{~min}$ at $55^{\circ} \mathrm{C}$.

The semicarbazide assay was used according to Wichelecki et al. [12] to determine the effect of metal ions, chelators and reducing agents, and the acquisition of Michalis-Menten kinetics $\left(K_{\mathrm{m}}\right.$, $\left.\mathrm{V}_{\max }\right)$. Each reaction $(60 \mu \mathrm{L})$ was incubated with $240 \mu \mathrm{L}$ semicarbazide reagent at room temperature for $1 \mathrm{~h}$. $A_{250 \mathrm{~nm}}$ was read in a UV transparent microtiter plate (Thermo Scientific, Waltham, MA, USA) using a Spectrostar Nano plate reader. Product formation was quantified using a standard curve of 2-keto-3-deoxygluconate (Sigma-Aldrich, St. Louis, MO, USA) prepared in the same assay buffer. $K_{\mathrm{m}}$, $\mathrm{V}_{\max }$ values were estimated using non-linear fitting in Prism 6 (6.0c, GraphPad software, San Diego, CA, USA). For the effect of metals, chelators and reducing agents, pure enzyme $(0.6 \mu \mathrm{g})$ was incubated with $1 \mathrm{mM}$ of each additive in $50 \mathrm{mM}$ HEPES $\mathrm{pH} 7$ for $1 \mathrm{~h}$ at room temperature. Activity was measured in duplicate reactions containing $10 \mathrm{mM}$ D-mannono-1,4-lactone in $50 \mathrm{mM}$ HEPES $\mathrm{pH}$ 7, incubated for $1 \mathrm{~h}$ at $55^{\circ} \mathrm{C}$ and then analysed with the semicarbazide assay. Kinetic data for the determination of $K_{\mathrm{m}}$ and $\mathrm{V}_{\max }$ were performed in duplicate reactions $(60 \mu \mathrm{L})$, containing $1 \mu \mathrm{g}$ purified TaManD, $50 \mathrm{mM}$ HEPES pH 7, $1 \mathrm{mM} \mathrm{CoSO}_{4}$ and different substrate concentrations (1-50 mM). Linear increase of reaction product was assured over $1 \mathrm{~h}$ reaction time. Reactions were performed for $45 \mathrm{~min}$ at $55{ }^{\circ} \mathrm{C}$ before product formation was determined using the semicarbazide assay and the KDG standard curve. Substrate specificity was analysed using 11 different sugar acids (Figure 8B). Reactions were performed in duplicate and contained $0.5 \mu \mathrm{g}$ enzyme, $50 \mathrm{mM}$ HEPES pH 7, $1 \mathrm{mM} \mathrm{CoSO}_{4}$ and $10 \mathrm{mM}$ of each sugar acid. Reactions were incubated for $16 \mathrm{~h}$ at $55^{\circ} \mathrm{C}$ before they were analysed using the semicarbazide assay.

\subsection{High Performance Liquid Chromatography (HPLC) Analysis}

Reactions catalysed by TaManD and standards of mannonate and KDG were analysed using an Agilent 1290 HPLC system connected to a refractive index detector (RID) G1362A (Agilent Technologies, Santa Clara, CA, USA). Samples were analysed on an organic acid column (Agilent HiPlex $\mathrm{H}^{+}$) with $10 \mathrm{mM} \mathrm{H}_{2} \mathrm{SO}_{4}$ as a mobile phase at a flow rate of $0.6 \mathrm{ml} / \mathrm{min}$. The column was heated to $80^{\circ} \mathrm{C}$ and the RID was set to $55^{\circ} \mathrm{C}$. Reactions were stopped by addition of $7 \mu \mathrm{L} 12.5 \%$ TCA to a $60 \mu \mathrm{L}$ reaction. After short centrifugation, $10 \mu \mathrm{L}$ of the supernatant was used for HPLC analysis.

\subsection{Statistical Analysis}

Statistical analysis was performed for enzyme kinetics and effect of different metals and additives on enzyme activity, by two-tailed unpaired t-tests using Prism 6.

\section{Conclusions}

In this study, we present the first purification and characterisation of a functional archaeal mannonate dehydratase. The gene encoding for the mannonate dehydratase was found adjacent to a previously described aldohexose dehydrogenase (AldT) gene in the genome of T. acidophilum [15]. 
Previously, it has been shown that AldT from T. acidophilum selectively oxidises mannose, but the physiological function behind that oxidation was not investigated. Using NMR spectroscopy, we were able to show that mannonate and mannono-1,4-lactone are produced via oxidation of D-mannose by AldT. Kinetic assays confirmed that TaManD was able to convert both the sugar acid and its lactone to the central intermediate KDG at neutral $\mathrm{pH}$, without further help of a lactonase. This resembles the second step of many oxidative pathways studied in archaea, including those for sugars like glucose, galactose, rhamnose, arabinose and xylose [39]. The amino acid sequence of TaManD and those of the putative mannonate dehydratases from F. acidarmanus and F. acidiphilum share high amino acid sequence identity. Although the gene annotations for those mannonate dehydratases indicate a role in the hexuronate metabolism $(u x u A)$, they are all located adjacent to (putative) aldohexose dehydrogenases. It remains to be seen whether a non-phosphorylative pathway starting from mannose, similar to the non-phosphorylative Entner-Doudoroff pathway from glucose and galactose, exists in thermophilic archaea like T. acidophilum, F. acidarmanus and F. acidiphilum.

Supplementary Materials: The following are available online at http:/ /www.mdpi.com/2073-4344/9/3/234/s1, Figure S1: Purification of the Ta0753 gene product (TaManD) after expression in E. coli, Figure S2: TaManD kinetic data Table S1: Overview of genes, potentially encoding for mannonate dehydratases located in the genomic neighbourhood of AldT (Ta0754), Table S2: Oligonucleotides used in this study.

Author Contributions: Conceptualization, D.K. and A.S.; methodology, experimental design, D.K., R.W., and A.S.; data collection, D.K.; data analysis, D.K.; writing-original draft preparation, D.K. and A.S.; writing-review and editing, D.K., R.W., and A.S.; supervision, A.S.; project administration, A.S.

Funding: D.K. is supported by an international Macquarie University Research Excellence Scholarship (iMQRES).

Acknowledgments: We thank the Australian Proteome Analysis Facility (Macquarie University, Sydney, Australia) for their support in performing LC ESI MS/MS experiments and Nicole Cordina from the Macquarie University NMR facility from the Department of Molecular Sciences for her help in performing NMR studies.

Conflicts of Interest: The authors declare no conflict of interest.

\section{References}

1. Robert-Baudouy, J.; Jimeno-Abendano, J.; Stoeber, F. D-Mannonate and D-altronate dehydratases of Escherichia coli K12. Methods Enzymol. 1982, 90, 288-294. [PubMed]

2. Shulami, S.; Gat, O.; Sonenshein, A.L.; Shoham, Y. The glucuronic acid utilization gene cluster from Bacillus stearothermophilus T-6. J. Bacteriol. 1999, 181, 3695-3704. [PubMed]

3. Mekjian, K.R.; Bryan, E.M.; Beall, B.W.; Moran, C.P. Regulation of hexuronate utilization in Bacillus subtilis. J. Bacteriol. 1999, 181, 426-433. [PubMed]

4. Hugouvieux-Cotte-Pattat, N.; Robert-Baudouy, J. Hexuronate catabolism in Erwinia Chrysanthemi. J. Bacteriol. 1987, 169, 1223-1231. [CrossRef] [PubMed]

5. Mandrand-Berthelot, M.-A.; Condemine, G.; Hugouvieux-Cotte-Pattat, N. Catabolism of hexuronides, hexuronates, aldonates, and aldarates. EcoSal Plus 2004, 1, 1-21. [CrossRef] [PubMed]

6. Reis, D.; Vian, B.; Roland, J.C. Cellulose-glucuronoxylans and plant cell wall structure. Micron 1994, 25, 171-187. [CrossRef]

7. Lawford, H.G.; Rousseau, J.D. Fermentation of biomass-derived glucuronic acid by pet expressing recombinants of E. coli B. Appl. Biochem. Biotechnol. 1997, 63-65, 221-241. [CrossRef]

8. Peekhaus, N.; Conway, T. What's for dinner?: Entner-Doudoroff metabolism in Escherichia coli. J. Bacteriol. 1998, 180, 3495-3502. [PubMed]

9. Chang, D.-E.; Smalley, D.J.; Tucker, D.L.; Leatham, M.P.; Norris, W.E.; Stevenson, S.J.; Anderson, A.B.; Grissom, J.E.; Laux, D.C.; Cohen, P.S.; et al. Carbon nutrition of Escherichia coli in the mouse intestine. Proc. Natl. Acad. Sci. USA 2004, 101, 7427-7432. [CrossRef] [PubMed]

10. Zhang, Q.; Gao, F.; Peng, H.; Cheng, H.; Liu, Y.; Tang, J.; Thompson, J.; Wei, G.; Zhang, J.; Du, Y.; et al. Crystal structures of Streptococcus suis mannonate dehydratase (ManD) and its complex with substrate: Genetic and biochemical evidence for a catalytic mechanism. J. Bacteriol. 2009, 191, 5832-5837. [CrossRef] [PubMed] 
11. Qiu, X.; Tao, Y.; Zhu, Y.; Yuan, Y.; Zhang, Y.; Liu, H.; Gao, Y.; Teng, M.; Niu, L. Structural insights into decreased enzymatic activity induced by an insert sequence in mannonate dehydratase from Gram negative bacterium. J. Struct. Biol. 2012, 180, 327-334. [CrossRef] [PubMed]

12. Wichelecki, D.J.; Balthazor, B.M.; Chau, A.C.; Vetting, M.W.; Fedorov, A.A.; Fedorov, E.V.; Lukk, T.; Patskovsky, Y.V.; Stead, M.B.; Hillerich, B.S.; et al. Discovery of function in the enolase superfamily: D-mannonate and D-gluconate dehydratases in the D-mannonate dehydratase subgroup. Biochemistry 2014, 53, 2722-2731. [CrossRef] [PubMed]

13. Wichelecki, D.J.; Alyxa, J.; Vendiola, F.; Jones, A.M.; Al-obaidi, N.; Almo, S.C.; Gerlt, J.A. Investigating the physiological roles of low-efficiency D-mannonate and D-gluconate dehydratases in the enolase superfamily: pathways for the catabolism of L-gulonate and L-idonate. Biochemistry 2014, 53, 5692-5699. [CrossRef] [PubMed]

14. Rakus, J.F.; Fedorov, A.A.; Fedorov, E.V.; Glasner, M.E.; Vick, J.E.; Babbitt, P.C.; Almo, S.C.; Gerlt, J.A. Evolution of enzymatic activities in the enolase superfamily: D-mannonate dehydratase from Novosphingobium aromaticivorans. Biochemistry 2007, 46, 12896-12908. [CrossRef] [PubMed]

15. Nishiya, Y.; Tamura, N.; Tamura, T. Analysis of bacterial glucose dehydrogenase homologs from thermoacidophilic archaeon Thermoplasma acidophilum: finding and characterization of aldohexose dehydrogenase. Biosci. Biotechnol. Biochem. 2014, 68, 2451-2456. [CrossRef] [PubMed]

16. Yasutake, Y.; Nishiya, Y.; Tamura, N.; Tamura, T. Structural Insights into unique substrate selectivity of Thermoplasma acidophilum D-aldohexose dehydrogenase. J. Mol. Biol. 2007, 367, 1034-1046. [CrossRef] [PubMed]

17. Kim, S.; Lee, S.B. Catalytic promiscuity in dihydroxy-acid dehydratase from the thermoacidophilic archaeon Sulfolobus solfataricus. J. Biochem. 2006, 139, 591-596. [CrossRef] [PubMed]

18. Ashwell, G. [21] Enzymes of glucuronic and galacturonic acid metabolism in bacteria. In Methods in enzymology; Academic Press: Cambridge, MA, USA, 1962; Volume 5, pp. 190-208, ISBN 0076-6879.

19. Portalier, R.; Robert-Baudouy, J.; Stoeber, F. Regulation of Escherichia coli K-12 hexuronate system genes: exu regulon. J. Bacteriol. 1980, 143, 1095-1107. [PubMed]

20. Palleroni, N.J.; Duodoroff, M. Metabolism of Carbohydrate by Pseudomonas Saccharophila III. Oxidation of Arabinose. J. Bacteriol. 1957, 74, 180-185. [PubMed]

21. Watanabe, S.; Saimura, M.; Makino, K. Eukaryotic and bacterial gene clusters related to an alternative pathway of nonphosphorylated L-rhamnose metabolism. J. Biol. Chem. 2008, 283, 20372-20382. [CrossRef] [PubMed]

22. Stephens, C.; Christen, B.; Fuchs, T.; Sundaram, V.; Watanabe, K.; Jenal, U. Genetic analysis of a novel pathway for D-xylose metabolism in Caulobacter crescentus. J. Bacteriol. 2007, 189, 2181-2185. [CrossRef] [PubMed]

23. Wałaszek, Z;; Horton, D. Conformational studies on aldonolactones by NMR spectroscopy. Conformations of d-glucono-, D-mannono, D-gulono-, D-galactono-1,4-lactone in solution. Carbohydr. Res. 1982, 105, 131-143. [CrossRef]

24. Dreyer, J. The role of iron in the activation of mannonic and altronic acid hydratases, two Fe-requiring hydro-lyases. Eur. J. Biochem 1987, 166, 623-630. [CrossRef] [PubMed]

25. Robert-Baudouy, J.M.; Jimeno-Abendano, J.; Stoeber, F.R. Individualité des hydrolyases mannonique et altronique chez E. coli K-12. Biochimie 1975, 57, 1-8. [CrossRef]

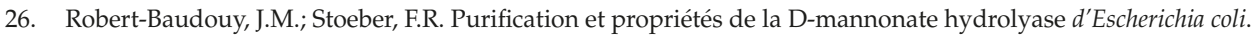
Biochim. Biophys. Acta-Enzymology 1973, 309, 473-485. [CrossRef]

27. Darland, G.; Brock, T.D.; Samsonoff, W.; Conti, S.F. A thermophilic, acidophilic mycoplasma isolated from a coal refuse pile. Science 1970, 170, 1416-1418. [CrossRef] [PubMed]

28. Jung, J.H.; Lee, S.B. Identification and characterization of Thermoplasma acidophilum 2-keto-3-deoxy-D-gluconate kinase: A new class of sugar kinases. Biotechnol. Bioprocess Eng. 2005, 10, 535-539. [CrossRef]

29. Kim, S.M.; Paek, K.H.; Lee, S.B. Characterization of $\mathrm{NADP}^{+}$-specific L-rhamnose dehydrogenase from the thermoacidophilic Archaeon Thermoplasma acidophilum. Extremophiles 2012, 16, 447-454. [CrossRef] [PubMed] 
30. Reher, M.; Schönheit, P. Glyceraldehyde dehydrogenases from the thermoacidophilic euryarchaeota Picrophilus torridus and Thermoplasma acidophilum, key enzymes of the non-phosphorylative Entner-Doudoroff pathway, constitute a novel enzyme family within the aldehyde dehydrogenase superfamily. FEBS Lett. 2006, 580, 1198-1204. [PubMed]

31. Yew, W.S.; Fedorov, A.A.; Fedorov, E.V.; Rakus, J.F.; Pierce, R.W.; Almo, S.C.; Gerlt, J.A. Evolution of enzymatic activities in the enolase superfamily: L-fuconate dehydratase from Xanthomonas campestris. Biochemistry 2006, 45, 14582-14597. [CrossRef] [PubMed]

32. Carsten, J.M.; Schmidt, A.; Sieber, V. Characterization of recombinantly expressed dihydroxy-acid dehydratase from Sulfobus solfataricus-A key enzyme for the conversion of carbohydrates into chemicals. J. Biotechnol. 2015, 211, 31-41. [CrossRef] [PubMed]

33. Sambrook, J.; Russell, D.W.; Russell, D.W. Molecular Cloning: A Laboratory Manual; Cold Spring Harbor Laboratory Press: New York, NY, USA, 2001; Volume 49, ISBN 978-1-936113-42-2.

34. Atack, J.M.; Srikhanta, Y.N.; Fox, K.L.; Jurcisek, J.A.; Brockman, K.L.; Clark, T.A.; Boitano, M.; Power, P.M.; Jen, F.E.C.; McEwan, A.G.; et al. A biphasic epigenetic switch controls immunoevasion, virulence and niche adaptation in non-typeable Haemophilus influenzae. Nat. Commun. 2015, 6, 1-12. [CrossRef] [PubMed]

35. Lamble, H.J.; Milburn, C.C.; Taylor, G.L.; Hough, D.W.; Danson, M.J. Gluconate dehydratase from the promiscuous Entner-Doudoroff pathway in Sulfolobus solfataricus. FEBS Lett. 2004, 576, 133-136. [CrossRef] [PubMed]

36. Buchanan, C.L.; Connaris, H.; Danson, M.J.; Reeve, C.D.; Hough, D.W. An extremely thermostable aldolase from Sulfolobus solfataricus with specificity for non-phosphorylated substrates. Biochem. J. 1999, 343, 563-570. [CrossRef] [PubMed]

37. Skoza, L.; Mohos, S. Stable thiobarbituric acid chromophore with dimethyl sulphoxide. Application to sialic acid assay in analytical de-O-acetylation. Biochem. J. 1976, 159, 457-462. [CrossRef] [PubMed]

38. Britton, H.T.S.; Robinson, R.A. CXCVIII.-Universal buffer solutions and the dissociation constant of veronal. J. Chem. Soc. 1931, 1456-1462. [CrossRef]

39. Bräsen, C.; Esser, D.; Rauch, B.; Siebers, B. Carbohydrate metabolism in archaea: current insights into unusual enzymes and pathways and their regulation. Microbiol. Mol. Biol. Rev. 2014, 78, 89-175. [CrossRef] [PubMed]

(c) 2019 by the authors. Licensee MDPI, Basel, Switzerland. This article is an open access article distributed under the terms and conditions of the Creative Commons Attribution (CC BY) license (http:/ / creativecommons.org/licenses/by/4.0/). 
Article

\title{
Comparative Analysis and Biochemical Characterization of Two Endo- $\beta-1,3-$ Glucanases from the Thermophilic Bacterium Fervidobacterium sp.
}

\author{
Christin Burkhardt ${ }^{1}$, Christian Schäfers ${ }^{1}$, Jörg Claren ${ }^{2}$, Georg Schirrmacher ${ }^{2}$ and \\ Garabed Antranikian 1,* \\ 1 Institute of Technical Microbiology, Hamburg University of Technology (TUHH), Kasernenstr. 12, \\ 21073 Hamburg, Germany; christin.burkhardt@tuhh.de (C.B.); christian.schaefers@tuhh.de (C.S.) \\ 2 Group Biotechnology, Clariant Produkte (Deutschland) GmbH, Semmelweisstr. 1, 82152 Planegg, Germany; \\ joerg.claren@clariant.com (J.C.); georg.schirrmacher@eitfood.eu (G.S.) \\ * Correspondence: antranikian@tuhh.de; Tel.: +49-4042-878-3117
}

Received: 3 September 2019; Accepted: 29 September 2019; Published: 1 October 2019

\begin{abstract}
Laminarinases exhibit potential in a wide range of industrial applications including the production of biofuels and pharmaceuticals. In this study, we present the genetic and biochemical characteristics of FLamA and FLamB, two laminarinases derived from a metagenomic sample from a hot spring in the Azores. Sequence comparison revealed that both genes had high similarities to genes from Fervidobacterium nodosum Rt17-B1. The two proteins showed sequence similarities of $62 \%$ to each other and belong to the glycoside hydrolase $(\mathrm{GH})$ family 16 . For biochemical characterization, both laminarinases were heterologously produced in Escherichia coli and purified to homogeneity. FLamA and FLamB exhibited similar properties and both showed highest activity towards laminarin at $90{ }^{\circ} \mathrm{C}$ and $\mathrm{pH}$ 6.5. The two enzymes were thermostable but differed in their half-life at $80^{\circ} \mathrm{C}$ with $5 \mathrm{~h}$ and $1 \mathrm{~h}$ for FLamA and FLamB, respectively. In contrast to other laminarinases, both enzymes prefer $\beta$-1,3-glucans and mixed-linked glucans as substrates. However, FLamA and FLamB differ in their catalytic efficiency towards laminarin. Structure predictions were made and showed minor differences particularly in a kink adjacent to the active site cleft. The high specific activities and resistance to elevated temperatures and various additives make both enzymes suitable candidates for application in biomass conversion.
\end{abstract}

Keywords: Fervidobacterium; endo- $\beta$-1,3-glucanase; laminarinase; glycoside hydrolase; thermostable; gene duplication

\section{Introduction}

$\beta-1,3-$ Glucans are non-cellulosic carbohydrates that are widespread in nature. They can be found in the cell walls of fungi (pachyman), in reproductive structures of plants (callose) or as exopolysaccharide from bacteria (curdlan) [1]. $\beta-1,3$-Glycosidic linkages are also present in mixed-linked $\beta$-glucans from cereals (e.g., barley) or lichens [2]. Moreover, $\beta$-1,3-glucans are one of the most abundant carbohydrates in marine ecosystems [3]. In micro- and macroalgae, $\beta$-1,3-glucans are structurally diverse and serve as storage glucans. In brown algae, the $\beta-1,3$-glucan is named laminarin and represents up to $25 \%$ of the dry weight, depending on species, season, and growing conditions [4]. Due to the significantly higher production yields than terrestrial biomass, a high carbohydrate content, and the lack of hemicellulose and lignin, macroalgae biomass is a promising feedstock for new biorefinery concepts $[5,6]$. For industrial utilization of this feedstock, robust and efficient enzymes like laminarinases are required [7]. Furthermore, laminarinases could be applied for yeast extract production, as a biocontrol agent against fungal plant pathogens [8], and for partial hydrolysis of $\beta$-1,3-glucans for the production of antiviral and antitumor therapeutics [9]. 
For the complete enzymatic hydrolysis of $\beta$-1,3-glucans endo-acting $\beta$-1,3-glucanases (EC 3.2.1.39) and $\beta-1,3(4)$-glucanases (EC 3.2.1.6), both known as laminarinases, exo- $\beta$-1,3-glucosidases (EC 3.2.1.58) are required. These enzymes and their corresponding substrates have in common that they both are widely distributed among plants, fungi, and bacteria from many different habitats. On the basis of amino acid sequence similarities, all endo-acting laminarinases from plants can be assigned to the glycoside hydrolase family GH 17, whereas most of the bacterial laminarinases belong to GH 16 [10]. According to the Carbohydrate-Active Enzymes database (CAZy), around $40 \beta$-1,3-glucanases from bacteria are already characterized (August 2019). Nevertheless, laminarinases with high stability at varying conditions and temperatures are desired for industrial applications [11]. To obtain highly stable and efficient enzymes for industrial application, thermophilic organisms represent an excellent resource. Moreover, these enzymes allow reactions at elevated process temperatures, which do not only reduce microbial contamination, but also increase the solubility and diffusion rates of the catalysts for complex polymeric substrates [12].

In this study, an environmental sample from an Azorean hot spring (São Miguel, Portugal) was used as a source for novel laminarinase-encoding genes. Recently, this environmental sample has been proven to be an excellent source for unique thermo-active enzymes [13]. By sequence-based screening, two putative genes were identified with sequence similarities to parts of the genomic sequence of the thermophilic bacterium Fervidobacterium nodosum Rt17-B1, which was completely sequenced in 2007 [14]. Fervidobacterium nodosum which was isolated from a hot spring in New Zealand, is able to ferment a wide range of carbohydrates [15] and is considered as a good source for novel carbohydrate degrading enzymes. So far, only one highly active and thermostable cellulase from this bacterium has been characterized [16].

Here, we describe the recombinant production and purification of the two thermoactive laminarinases FLamA and FLamB originating from Fervidobacterium sp. To estimate their potential relevance for industrial applications, both recombinant enzymes were characterized in detail.

\section{Results}

\subsection{Sequence Analysis of FLamA and FLamB}

By sequence-based screening, two new putative laminarinase encoding genes were identified. Metagenomic DNA from a hot spring of the Azores, which was known to contain genomic DNA of a Fervidobacterium strain, was used as template DNA for PCR. The primers for the amplification of the two genes encoding for FLamA and FLamB were based on two putative laminarinase genes of the complete genome sequence of Fervidobacterium nodosum Rt17-B1 (GenBank: CP000771). The amplified DNA fragment for flamA showed $99 \%$ sequence similarity to putative laminarinase genes from the genomes of F. nodosum Rt17-B1 and F. pennivorans DSM 9078 (GenBank: NC_017095). The corresponding amino acid sequence is annotated as a multispecies endo- $\beta$ - 1,3 -glucanase found in various Fervidobacterium species (GenBank: WP_011994743). In comparison to that, the amplified DNA fragment for flamB showed $95 \%$ and $67 \%$ sequence similarity to GenBank sequences of two other putative laminarinase genes from F. nodosum Rt17-B1 and F. pennivorans DSM 9078, respectively. Due to the $99 \%$ similarity of the amino acid sequence to next hits in the database, flamB was annotated in GenBank with the accession number LT882624.

In the genome of F. nodosum Rt17-B1, the highly similar genes of flamA and flamB are embedded in two different operons. By comparing these operons, we identified putative open reading frames for proteins with the same predicted functions (Figure 1). Among both gene clusters, the related proteins revealed high sequence similarities of $62-89 \%$ on amino acid level (100\% query coverage). Flam $A$ and flamB showed $62 \%$ sequence similarity to each other. Adjacent to the putative laminarinase encoding genes, we identified genes for putative proteins involved in ABC transporter system and genes for putative alanine racemases and GH 3 proteins. Moreover, a truncated gene encoding a 
Transposase_20 and a repeat region nearby one of the predicted operons indicated that the two related operons originate from a gene duplication event of a DNA cassette around $20 \mathrm{~kb}$ in size.

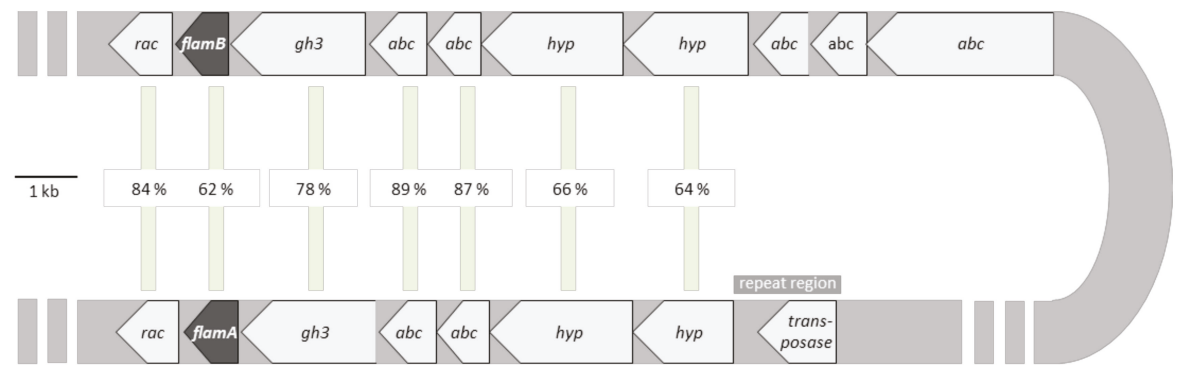

Figure 1. Predicted structural organization of the two operons containing flam $A$ and flamB based on the highly similar genes in the genome of Fervidobacterium nodosum. Sequence identities of similar genes are shown in the center. Predicted genes: rac — putative gene for alanine racemase; flam $A$ and flamB — genes for $\beta$-1,3-glucanases; gh3 - putative genes for glycoside hydrolase of family GH 3; abc-putative genes for ABC transporter proteins; transposase - truncated gene of a Transposase_20 with a repeat region; hyp-hypothetical genes.

Structure predictions for FLamA and FLamB revealed a sandwich-like $\beta$-jelly roll fold, which is characteristic for laminarinases of class GH 16 (Figure S1). The structural prediction of both proteins was based on the catalytic residue of Thermotoga maritima, with $58 \%$ and $60 \%$ sequence identity to flam $A$ and $f l a m B$, respectively. The comparison of both predictions demonstrated the high structural similarities of FLamA and FLamB with only small differences in a loop adjacent to the cleft of the active site (highlighted in color).

The sequences of both proteins showed similarities to those of laminarinases from other thermophilic bacteria. Indeed, FLamA and FLamB were similar to catalytic domains of experimentally verified $\beta$-1,3-glucanases from T. maritima, T. petrophila, and T. neapolitana with a 54-55\% and 58-59\% identity, respectively. Moreover, FLamA and FLamB were $55 \%$ and $58 \%$ similar to the catalytic domain of a $\beta$-1,3-glucanase from the hyperthermophilic Archaeon Pyrococcus furiosus. The phylogenetic relationship among both enzymes and other biochemically characterized GH 16 family members of bacteria is shown in Figure 2. Concerning the predicted tree based on the homologous region of the catalytic domain, FLamA and FLamB form a solid clade with the $\beta$-1,3-glucanases of the Archaeon $P$. furiosus and members of the same eubacterial order Thermotogales, which includes some of the most extremely thermophilic species currently known.

\subsection{Recombinant Production of FLamA and FLamB}

Both genes were expressed in E. coli C43(DE3) at $37^{\circ} \mathrm{C}$ over $4 \mathrm{~h}$ of induction. The obtained proteins harboring a C-terminal 6xHis affinity tag were purified via affinity chromatography and size exclusion chromatography. Both FLamA and FLamB were purified to homogeneity with a factor of 178 and 593 and a final yield of $30 \%$ and $18 \%$, respectively (Table S1). The SDS-PAGE revealed a molecular weight of approximately $30 \mathrm{kDa}$ for both proteins, which was slightly smaller than the predicted molecular size of $34.9 \mathrm{kDa}$ and $34.1 \mathrm{kDa}$ for FLamA and FLamB, respectively (Figure 3). Domain prediction revealed that FLamA and FLamB consisted, in each case, of one single GH 16 domain without any further known structural elements. 


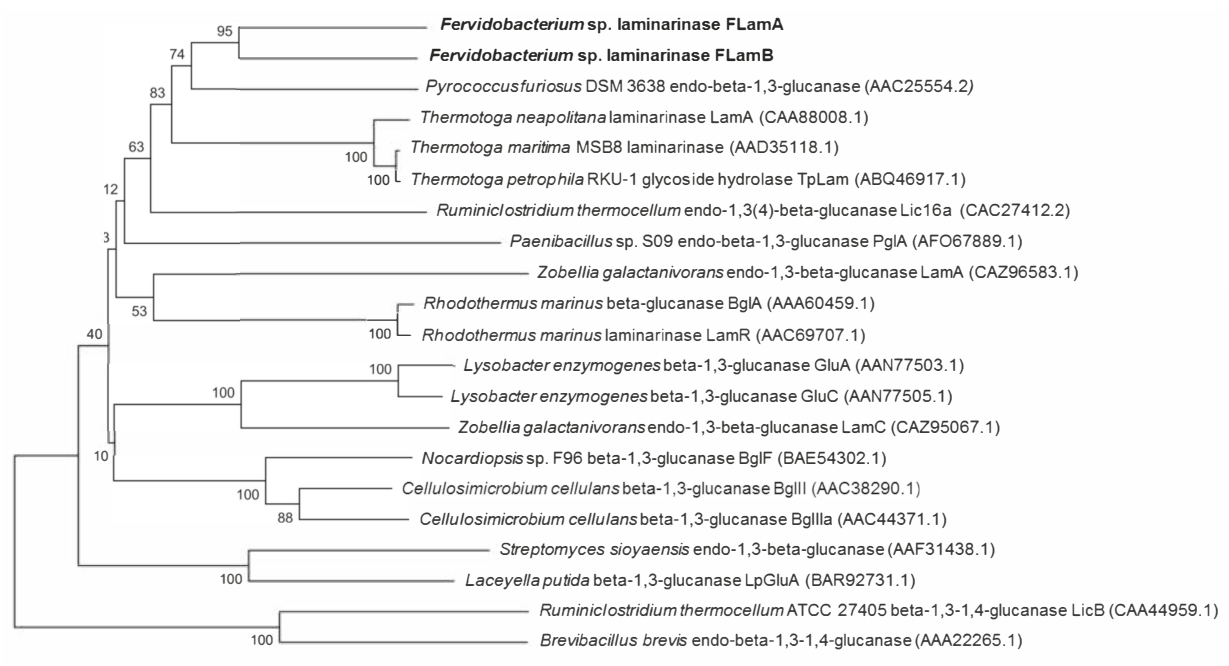

$\stackrel{\Gamma .05}{r}$

Figure 2. Phylogenetic tree of biochemically characterized GH 16 enzymes. For construction of the tree, sequences of the catalytic domains were used. GenBank accession numbers are indicated in brackets. Bootstrap values are designated on each branch of the tree.
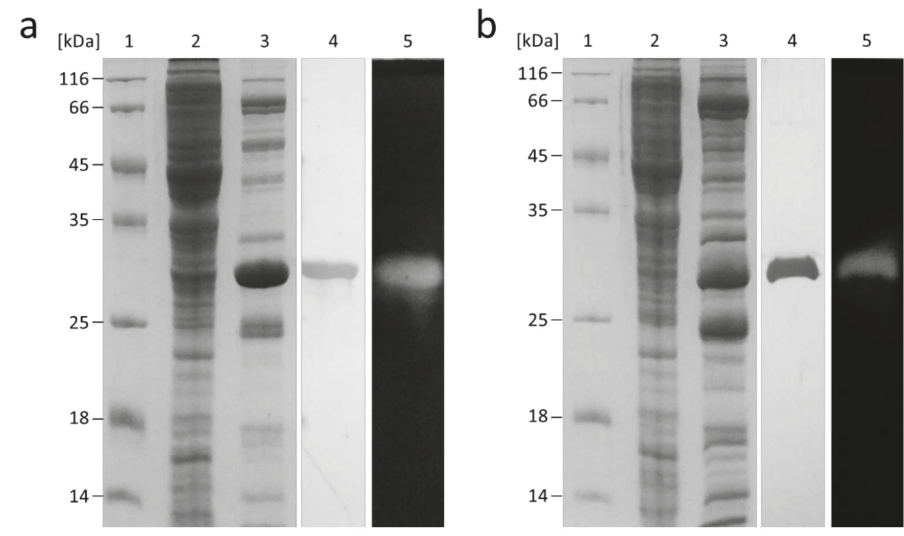

Figure 3. SDS-PAGE analysis of the His-tagged $\beta$-1,3-glucanases FLamA (a) and FLamB (b). Line 1, molecular weight marker; line 2, crude extract; line 3, eluate after the Ni-NTA affinity chromatography; line 4, purified enzymes after size exclusion chromatography; line 5, zymogram for activity staining of the purified enzyme.

\subsection{Substrate Specificity of FLamA and FLamB}

The substrate specificity of FLamA and FLamB was tested towards a number of complex carbohydrates in a range from 40 to $100{ }^{\circ} \mathrm{C}$ (Figure 4, Table 1). Significant differences between FLamA and FLamB were detected in the specific activities towards $\beta$-1,3-glucans. Highest activities of both enzymes were measured at $90^{\circ} \mathrm{C}$ towards laminarin, whereby FLamB showed a higher specific activity than FLamA, with $876 \mathrm{U} / \mathrm{mg}$ and $609 \mathrm{U} / \mathrm{mg}$, respectively. Compared to that, highest activities towards amorphous curdlan were revealed at $70{ }^{\circ} \mathrm{C}$ with $78 \%$ and $94 \%$ relative activity. For undissolved curdlan, the highest activity was determined at $80{ }^{\circ} \mathrm{C}$, with even lower relative activities of $44 \%$ and $50 \%$ for FLamA and FLamB, respectively. 

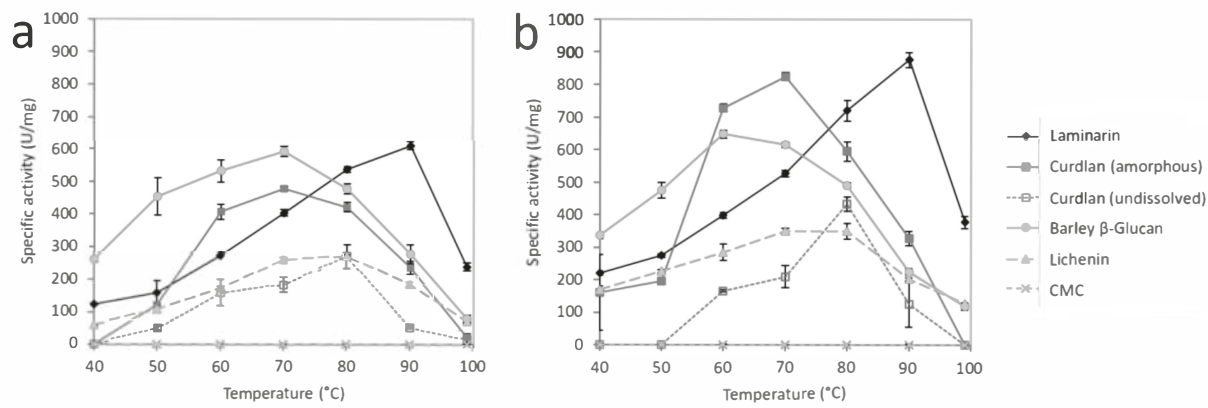

Figure 4. The temperature profiles of recombinant FLamA (a) and FLamB (b) depending on substrates laminarin, amorphous curdlan, unsolved curdlan, barley $\beta$-glucan, lichenin, and carboxymethyl cellulose (CMC).

Table 1. Substrate specificity of FLamA and FLamB at the optimal temperatures for each substrate.

\begin{tabular}{lrrrrrr}
\hline \multirow{3}{*}{ Substrate } & \multicolumn{3}{c}{ FLamA } & \multicolumn{3}{c}{ FLamB } \\
\cline { 2 - 7 } & T $\left({ }^{\circ} \mathbf{C}\right)$ & $\begin{array}{r}\text { Specific } \\
\text { Activity } \\
\mathbf{( U / m g )}\end{array}$ & $\begin{array}{r}\text { Relative } \\
\text { Activity } \\
(\mathbf{\%})\end{array}$ & $\mathbf{T}\left({ }^{\circ} \mathbf{C}\right)$ & $\begin{array}{r}\text { Specific } \\
\text { Activity } \\
(\mathbf{U} / \mathbf{m g})\end{array}$ & $\begin{array}{r}\text { Relative } \\
\text { Activity } \\
(\%)\end{array}$ \\
\hline Laminarin & 90 & $609 \pm 12$ & 100 & 90 & $876 \pm 23$ & 100 \\
Curdlan * & 70 & $478 \pm 07$ & 78 & 70 & $825 \pm 13$ & 94 \\
Curdlan & 80 & $270 \pm 37$ & 44 & 80 & $434 \pm 22$ & 50 \\
Barley $\beta$-glucan & 70 & $592 \pm 16$ & 97 & 60 & $648 \pm 12$ & 74 \\
Lichenin & 80 & $271 \pm 5$ & 45 & 70 & $350 \pm 8$ & 40 \\
CMC $^{+}$ & - & 0 & 0 & - & 0 & 0 \\
\hline
\end{tabular}

${ }^{*}$ Amorphous curdlan, diluted in $\mathrm{NaOH}$ and neutralized; ${ }^{+}$between $40-99^{\circ} \mathrm{C}$, no activity was detectable.

In comparison to $\beta-1,3$-glucans, the specific activities towards mixed-linked glucans did not differ substantially between FLamA and FLamB. The specific activities of FLamA and FLamB towards barley $\beta$-glucan from barley were in the same range with $592 \mathrm{U} / \mathrm{mg}$ and $648 \mathrm{U} / \mathrm{mg}$, respectively. This was determined at optimal temperatures of $70{ }^{\circ} \mathrm{C}$ (FLamA) and $60{ }^{\circ} \mathrm{C}$ (FLamB). For both enzymes, $44 \%$ and $52 \%$ residual activities towards barley $\beta$-glucan were detected at $40^{\circ} \mathrm{C}$. Moreover, both enzymes showed, at $40{ }^{\circ} \mathrm{C}$, higher activities towards mixed-linked $\beta$-glucan $(262 \mathrm{U} / \mathrm{mg}$ and $336 \mathrm{U} / \mathrm{mg})$ than towards laminarin $(124 \mathrm{U} / \mathrm{mg}$ and $220 \mathrm{U} / \mathrm{mg})$. The specific activities towards lichenin at optimal conditions $\left(80^{\circ} \mathrm{C}\right.$ and $70{ }^{\circ} \mathrm{C}$ ) were with $271 \mathrm{U} / \mathrm{mg}$ and $350 \mathrm{U} / \mathrm{mg}$ for FLamA and FLamB, lower than towards the other tested substrates. Hydrolysis of the $\beta-1,4$-glucan CMC was not observed.

\subsection{Degradation Pattern and Enzyme Kinetics}

The hydrolysis products of laminarin and barley $\beta$-glucan were investigated by HPLC analysis. The FLamA and FLamB produced similar degradation patterns. Hydrolysis of laminarin (Figure 5a) mainly results in laminaribiose, glucose-mannitol units (DP2), and glucose (DP1) and to a lesser extent laminaritriose (DP3) and higher oligosaccharides. The degradation pattern of barley $\beta$-glucan was different (Figure $5 b$ ). Laminaritriose was the major product and to a lesser extent DP1 and DP2 were detected. The produced oligosaccharides indicated that FLamA and FLamB are $\beta-1,3$-glucanases with endo-acting mode. Moreover, the shifted product variation with barley $\beta$-glucan suggested that both enzymes hydrolyzed the $\beta-1,3$-glycosidic linkages in mixed-linked glucans and to a lesser extent the $\beta-1,4$-building blocks. 

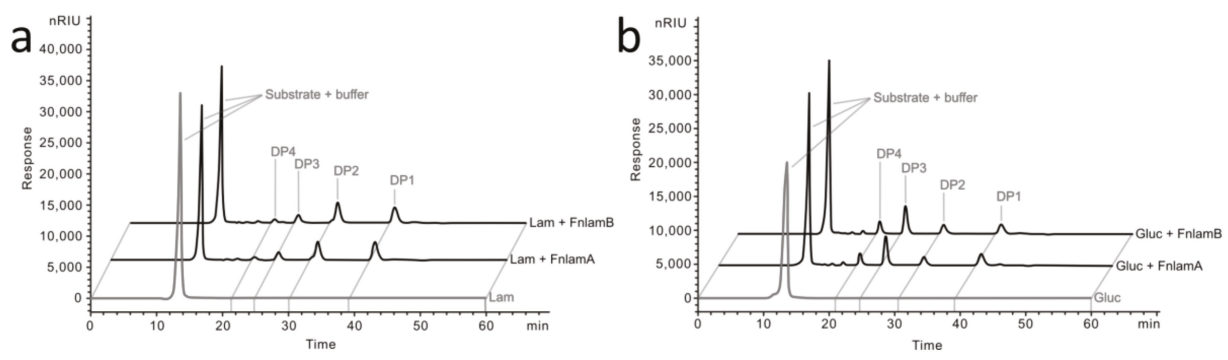

Figure 5. HPLC analysis of products from polysaccharide degradation. Hydrolysis products from laminarin (a) and barley $\beta$-glucan (b) after $18 \mathrm{~h}$ of incubation at $70^{\circ} \mathrm{C}$. DP: degree of polymerization. DP1: glucose. Lam: laminarin. Gluc: barley $\beta$-glucan.

The kinetic parameters were determined in the presence of laminarin. At optimal conditions $(90$ ${ }^{\circ} \mathrm{C}$, $\mathrm{pH}$ 6.5) the $\mathrm{K}_{\mathrm{m}}$ value of FLamA was $2.01 \mathrm{mg} \mathrm{ml}^{-1}$ and with that higher than that of FLamB (1.64 $\left.\mathrm{mg} \mathrm{ml}^{-1}\right)$. Moreover, the catalytic efficiency values $\left(\mathrm{k}_{\mathrm{cat}} / \mathrm{K}_{\mathrm{m}}\right)$ were $494.3 \mathrm{ml} \mathrm{s}^{-1} \mathrm{mg}^{-1}$ and $806.3 \mathrm{ml} \mathrm{s}^{-1}$ $\mathrm{mg}^{-1}$ for FLamA and FLamB, respectively. The results indicated that FLamB has a $61 \%$ higher catalytic efficiency on laminarin than FLamA, which is in agreement with the determined substrate specificities.

\subsection{Effects of $\mathrm{pH}$ and Temperature}

The effect of $\mathrm{pH}$ was analyzed in a range of $\mathrm{pH} 2$ to 12 . Measurements revealed similar $\mathrm{pH}$ spectra for FLamA and FLamB (Figure 6). Both enzymes showed activity in a range between pH 5 and 9. Optimal activity was detected at $\mathrm{pH}$ 6.5. Concerning the stability of FLamA, there was a decrease by approximately $8 \%$ in activity over the entire $\mathrm{pH}$ range after $24 \mathrm{~h}$ (Figure S3). In the same $\mathrm{pH}$ range, FLamB showed at least $82 \%$ residual activity.

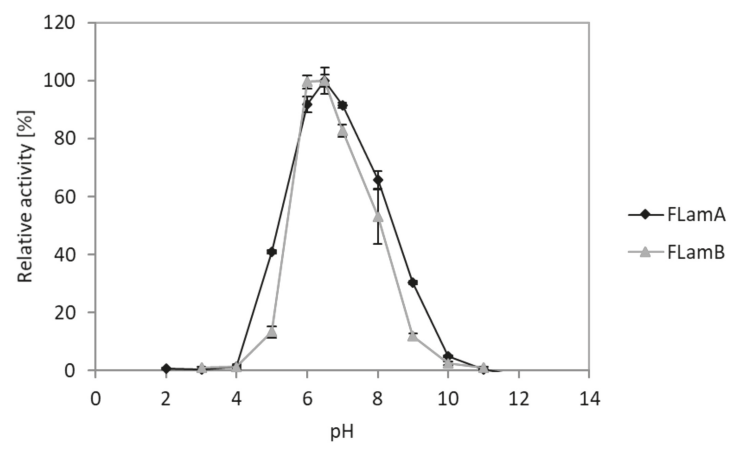

Figure 6. Influence of $\mathrm{pH}$ on the activity of recombinant FLamA and FLamB towards laminarin.

To examine the temperature stability of the two thermoactive enzymes, the residual activities after heat incubation at 70, 80, and $90^{\circ} \mathrm{C}$ were measured (Figure 7). FLamA and FLamB exhibited more than $80 \%$ and $40 \%$ residual activity over $24 \mathrm{~h}$ at $70{ }^{\circ} \mathrm{C}$, respectively. At $80^{\circ} \mathrm{C}$, the enzymes had a half-life time of $5 \mathrm{~h}$ (FLamA) and $1 \mathrm{~h}$ (FLamB). By incubating the enzymes at $90^{\circ} \mathrm{C}$ after $30 \mathrm{~min}$, no residual activity was detected. FLamA was, in the tested temperature range, more stable than FLamB. 

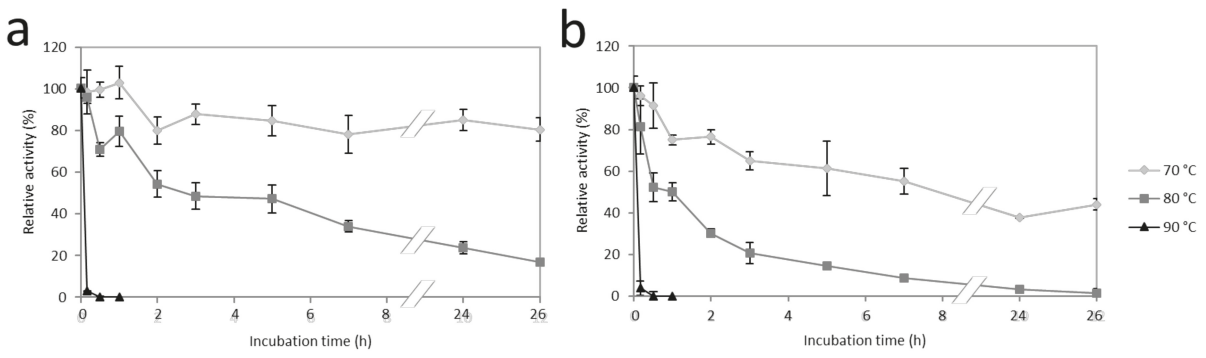

Figure 7. Influence of temperature on the stability of FLamA (a) and FLamB (b).

\subsection{Effects of Metal Ions and Chemical Additives}

The effect of various additives on the activities of FLamA and FLamB was investigated. For both enzymes, the examined additives had similar influences. Among the tested metal ions ( $5 \mathrm{mM}), \mathrm{Ag}^{+}$, $\mathrm{Al}^{3+}, \mathrm{Cr}^{3+}, \mathrm{Cu}^{2+}, \mathrm{Zn}^{2+}$, and $\mathrm{Fe}^{2+}$ completely inhibited FLamA and FLamB (Table 2a). Both $\mathrm{Co}^{2+}$ and $\mathrm{Ni}^{2+}$ significantly reduced the activity of the enzymes. The same effect was observed by the addition of $5 \mathrm{mM}$ SDS, cetyltrimethylammonium bromide (CTAB), and Pefabloc (Table 2b). In contrast, the reducing agents dithiothreitol (DTT) and $\beta$-mercaptoethanol had positive effects on enzyme activities.

Table 2. Influence of metal ions (a) and different reagents (b) on laminarinase activity of FLamA and FLamB.

\begin{tabular}{|c|c|c|c|c|c|}
\hline \multirow{2}{*}{$\begin{array}{c}\text { a } \\
\text { Metal ion }\end{array}$} & \multicolumn{2}{|c|}{ Relative Residual Activity (\%) * } & \multirow[b]{2}{*}{ at } & \multicolumn{2}{|c|}{ Relative Residual Activity (\%) * } \\
\hline & FLamA & FLamB & & FLamA & FLamB \\
\hline $\mathrm{AgNO}_{3}$ & $0.65 \pm 0.00$ & $3.29 \pm 0.58$ & CHAPS & $78.95 \pm 3.64$ & $80.11 \pm 2.36$ \\
\hline $\mathrm{AlCl}_{3}$ & $4.98 \pm 2.31$ & $4.73 \pm 0.27$ & SDS & $29.10 \pm 1.08$ & $36.70 \pm 6.61$ \\
\hline $\mathrm{CaCl}_{2}$ & $89.85 \pm 8.46$ & $87.79 \pm 1.60$ & Triton X-100 & $89.42 \pm 4.03$ & $89.77 \pm 0.61$ \\
\hline $\mathrm{CoCl}_{2}$ & $9.31 \pm 0.33$ & $16.64 \pm 1.30$ & Tween 20 & $91.83 \pm 1.67$ & $91.18 \pm 2.20$ \\
\hline $\mathrm{CrCl}_{3}$ & $2.50 \pm 0.04$ & $1.32 \pm 4.80$ & Tween 80 & $95.41 \pm 3.85$ & $92.52 \pm 1.60$ \\
\hline $\mathrm{CuCl}_{2}$ & $0.66 \pm 0.40$ & $0.84 \pm 4.18$ & Guanidine- $\mathrm{HCl}$ & $91.14 \pm 7.34$ & $84.70 \pm 0.68$ \\
\hline $\mathrm{FeCl}_{2}$ & $1.05 \pm 0.17$ & $3.29 \pm 1.14$ & Urea & $100.14 \pm 1.41$ & $93.30 \pm 1.06$ \\
\hline $\mathrm{KCl}$ & $93.78 \pm 1.00$ & $91.08 \pm 1.39$ & DTT & $119.04 \pm 1.16$ & $124.61 \pm 1.88$ \\
\hline $\mathrm{MgCl}_{2}$ & $92.48 \pm 2.42$ & $95.15 \pm 1.57$ & $\beta$-Mercaptoethanol & $125.03 \pm 2.88$ & $124.12 \pm 3.42$ \\
\hline $\mathrm{NaCl}$ & $92.41 \pm 1.53$ & $86.42 \pm 1.17$ & EDTA & $109.32 \pm 3.01$ & $95.28 \pm 2.20$ \\
\hline $\mathrm{NiCl}_{2}$ & $4.67 \pm 0.16$ & $7.06 \pm 0.10$ & Na-Iodoacetate & $105.34 \pm 1.19$ & $92.45 \pm 2.57$ \\
\hline $\mathrm{RbCl}$ & $90.79 \pm 1.76$ & $97.47 \pm 1.01$ & Pefabloc & $37.79 \pm 5.67$ & $76.94 \pm 12.14$ \\
\hline $\mathrm{SrCl}_{2}$ & $93.15 \pm 1.84$ & $96.20 \pm 2.63$ & СТАВ & $24.85 \pm 1.69$ & $30.68 \pm 2.60$ \\
\hline $\mathrm{ZnCl}_{2}$ & $1.85 \pm 0.20$ & $3.67 \pm 0.29$ & Na-Azide & $102.37 \pm 2.14$ & $103.81 \pm 6.97$ \\
\hline
\end{tabular}

* Laminarinase activity without additives was defined as $100 \%$.

\section{Discussion}

The two genes flam $A$ and flamB revealed high sequence similarities of $62 \%$ (100\% query coverage) with each other. Two highly similar genes within the genome of Fervidobacterium nodosum were located in two different operons. The pattern of the operons and adjacent genes as well as the presence of a truncated transposase gene suggest that these structures were generated by a duplication of an around $20 \mathrm{~kb}$ genome section. Moreover, it has been shown that flam $A$ and flamB encode for active laminarinases possessing nearly the same biochemical characteristics, indicating that both genes form a multigene family.

There are other bacterial species which express more than one gene encoding for laminarinases. Nevertheless, these genes contain various modular architectures and the proteins possess different domains and functions like in the marine bacterium Zobellia galactanivorans [17]. In Lysobacter enzymogenes, two laminarinases are present which have high sequence identities in part of the catalytic 
domain (86\%) but differentiate in an additional carbohydrate binding module (CBM) in one of the proteins [18]. Similar relationships were also observed for related laminarinases from Streptomyces sioyaensis [19]. So far, however, only members of the family Fervibacteriaceae are known to harbor two similar genes, such as flam $A$ and flamB, which encode for laminarinases with similar sequence and function.

It has been shown that gene duplication probably generates no benefit by enhanced gene dosage of laminarinases or adjacent genes, such as those for the ABC transporter system. The increase of gene dosages may cause higher energy consumption leading to significant reduced fitness of the organism $[20,21]$. Therefore, it is more likely that gene duplication leads to redundancy and, thus, facilitates mutations in one of the copies and possibly results in new benefiting gene functions [22]. A similar operon composition occurs in the closely related F. pennivorans, where two genes exist with $100 \%$ and $70 \%$ sequence identity to flam $A$ and flamB, respectively. This demonstrates that flam $A$ is highly conserved in both species, whereas differences in flam $B$ were probably generated by point mutations. This may lead to beneficial properties, like obviously higher catalytic activities of FLamB towards $\beta$-1,3-glucans. If there is no selective advantage, duplicated genes normally become inactivated by mutations and these pseudogenes will disappear from the genome [23].

Phylogenetic analysis of the catalytic residues of FLamA, FLamB, and other characterized laminarinases revealed a solid clade with close a relationship between enzymes from the bacterial order Thermotogales, including FLamA and FLamB, and the Archaeon Pyrococcus furiosus (Figure 2). Thermotogales are assumed to have interchanged large numbers of genes with Archaea and Firmicutes by horizontal gene transfer (HGT) [14]. An extraordinarily high number of insertion sequence elements for example in the genome of $F$. nodosum demonstrate the great influence of foreign genes. The high sequence similarity of FLamA, FLamB, and the laminarinases of the bacterium Thermotoga to one from the Archaeon P. furiosus suggests that an ancestral gene was exchanged by HGT.

Regarding the temperature optima of these enzymes, FLamA and FLamB are both thermoactive enzymes showing highest activity at $90{ }^{\circ} \mathrm{C}$. This optimum is similar to that of the other examined laminarinases from the phylum Thermotogae $[24,25]$ which are to our knowledge the ones with the highest temperature optima among reported $\beta$-1,3-glucanases from eubacteria and plants. However, LamA from the Archaeon P. furiosus showed among all characterized laminarinases activity at the highest temperatures of $100-105^{\circ} \mathrm{C}$ (Table 3) [26]. Both FLamA and FLamB showed high storage stabilities at $4{ }^{\circ} \mathrm{C}$ in a broad $\mathrm{pH}$ range of 3 to 11 which enables an easy handling of both laminarinases. Their stability at 70 to $90^{\circ} \mathrm{C}$ is also comparable to those of the other laminarinases operating at high temperatures (Table 3). All in all, FLamA and FLamB have significantly high temperature stabilities, which are a decisive criterion for industrial application.

The investigation of the substrate specificities of FLamA and FLamB revealed different temperature optima for the tested substrates (Figure 4). Schwarz et al. [27] observed related characteristics of a laminarinase of Clostridium thermocellum. The optimal temperature towards curdlan is lower in consideration to the fact that curdlan forms at temperatures above $80^{\circ} \mathrm{C}$ irreversible high-set gels [28], which might be less accessible for enzymes. Nevertheless, the reasons for the different temperature optima can only be speculated. 
Table 3. Comparison of biochemically characterized laminarinases from thermophilic bacteria and Archaea.

\begin{tabular}{|c|c|c|c|c|c|c|c|c|c|c|}
\hline \multirow{2}{*}{$\begin{array}{l}\text { Organism and } \\
\text { Enzyme }\end{array}$} & \multirow{2}{*}{$\mathrm{T}_{\text {opt }}\left({ }^{\circ} \mathrm{C}\right)$} & \multicolumn{3}{|c|}{ Thermal Stability } & \multirow{2}{*}{$\mathrm{pH}_{\mathrm{opt}}$} & \multicolumn{4}{|c|}{ Activity (U/mg) ${ }^{+}$} & \multirow{2}{*}{ Reference } \\
\hline & & $\mathrm{T}\left({ }^{\circ} \mathrm{C}\right)$ & $t(h)$ & $A *(\%)$ & & Lam & Curd & Glu & Lich & \\
\hline Caldicellulosiruptor sp. & 75 & 65 & 42 & 72 & 6.5 & 172 & ND & 2961 & ND & [29] \\
\hline $\begin{array}{l}\text { Fervidobacterium sp., } \\
\text { FLamA }\end{array}$ & 90 & 80 & 5 & 50 & 6.5 & 609 & 270 & 592 & 271 & $\begin{array}{l}\text { Present } \\
\text { study }\end{array}$ \\
\hline $\begin{array}{l}\text { Fervidobacterium sp., } \\
\text { FLamB }\end{array}$ & 90 & 80 & 1 & 50 & 6.5 & 876 & 434 & 648 & 350 & $\begin{array}{l}\text { Present } \\
\text { study }\end{array}$ \\
\hline $\begin{array}{l}\text { Laceyella putida, } \\
\text { LpGluA }\end{array}$ & 80 & 75 & 0.5 & 45 & 4.2 & $48 \%$ & $100 \%$ & ND & ND & [30] \\
\hline $\begin{array}{l}\text { Nocardiopsis sp. F96, } \\
\text { BglF }\end{array}$ & 70 & ND & ND & ND & 9.0 & $100 \%$ & $159 \%$ & ND & $815 \%$ & [31] \\
\hline $\begin{array}{l}\text { Pyrococcus furiosus, } \\
\text { LamA }\end{array}$ & $100 / 105$ & 80 & 80 & 100 & $6-6.5$ & 922 & ND & 99 & 95 & [26] \\
\hline $\begin{array}{l}\text { Rhodothermus marinus } \\
\text { 21, BglA }\end{array}$ & 85 & 80 & 16 & 100 & 7.0 & 542 & ND & 1568 & 1445 & [32] \\
\hline $\begin{array}{l}\text { Rhodothermus marinus } \\
\text { ITI278, LamR }\end{array}$ & 88 & 90 & 0.45 & 50 & 5.5 & 656 & ND & 2199 & 3111 & [33] \\
\hline $\begin{array}{l}\text { Ruminiclostridium } \\
\text { thermocellum, CelC }\end{array}$ & 65 & 70 & 10 & 30 & 6.5 & 86 & ND & 504 & 245 & [27] \\
\hline $\begin{array}{l}\text { Ruminiclostridium } \\
\text { thermocellum, Lic16A }\end{array}$ & 70 & 70 & 0.17 & 50 & 6.0 & 340 & 29 & 268 & 2404 & [34] \\
\hline $\begin{array}{l}\text { Thermotoga maritima, } \\
\operatorname{Tm} \beta \mathrm{G}\end{array}$ & 80 & ND & $\mathrm{ND}$ & ND & 5.0 & \multicolumn{4}{|c|}{ Efficient on $\beta$-1,3-glucans } & [35] \\
\hline $\begin{array}{l}\text { Thermotoga } \\
\text { neapolitana, LamA }\end{array}$ & 95 & 95 & 0.5 & 82 & 6.3 & 3100 & ND & ND & 90 & [25] \\
\hline $\begin{array}{l}\text { Thermotoga petrophila, } \\
\text { TpLam }\end{array}$ & 91 & 80 & 16 & 60 & 6.2 & 48 & ND & 41 & 21 & [24] \\
\hline
\end{tabular}

${ }^{*}$ Residual activity detected after incubation at the given temperature and time. ${ }^{+}$If available, specific activity (U/mg); otherwise relative activities (\%) towards laminarin (Lam), Curdlan (Curd), barley $\beta$-glucan (Gluc) or lichenin (Lich).

So far, published thermostable $\beta$-1,3-linkage hydrolyzing enzymes generally possessed strong preferences either for $\beta$-1,3-glucans or mixed-linked glucans (Table 3). Both FLamA and FLamB take an intermediate position between those groups by degrading approximately both types of substrates with activity in the same range. Additionally, FLamA and FLamB exhibit higher substrate affinities towards mixed-linked glucans in comparison to similar enzymes from Thermotoga neapolitana [25] and P. furiosus [26]. Ilari et al. [36] investigated a deletion mutant and were able to show that the loss of a five amino acid kink at the entrance of the catalytic cleft leads to higher activity towards mixed-linked glucans. This effect was also observed in other laminarinases missing these residues [34,37]. Even in FLamA and FLamB, these amino acid residues are missing (Figure S2). Thus, differences in the kink possibly explain the altered substrate preferences between those enzymes.

The described substrate spectra and hydrolysis products suggest that FLamA and FLamB are able to cleave $\beta-1,3$ glycosidic bonds in an endo-acting mode. Nevertheless, the hydrolysis of $\beta-1,4$ glycosidic bonds in mixed-linked glucans is also possible. Similar product patterns of laminarin and barley $\beta$-glucan were observed with a laminarinase form Caldicellulosiruptor sp., when the authors proved that the enzyme was able to degrade $\beta-1,4$ glyosidic bonds adjacent to 3 -O-substituted glucopyranose units [32].

For industrial application, detection of inhibitory effects and comparison with other enzymes the influences of different metal ions and additives were tested. For FLamA and FLamB similar effects were observed. The inhibitory effects of metal ions observed in this study are well known for many glucosidases, probably due to the redox effects on the amino acids [38]. The SDS had a negative influence on the activity of the enzymes by disturbing hydrophobic interactions and generating protein denaturation. Moreover, the detergent CTAB blocked the catalytic cleft of a related laminarinase by hydrophobic interactions [38], which may lead to reduced activities of FLamA and FLamB as well. Pefabloc, a serine protease inhibitor, negatively influenced the enzyme activity probably by binding irreversiblely to serine residues nearby the catalytic cleft. In contrary, the reducing properties of DTT 
and $\beta$-mercaptoethanol might positively influence a cysteine residue adjacent to the nucleophile of the active site and therefore increase the laminarinase activity.

Although FLamA and FLamB share many biochemical properties, the two enzymes exhibit differences in substrate specificities, particularly towards $\beta$-1,3-glucans. In comparison to the specific activities of FLamA, FLamB exhibits approximately $40 \%$ and more than $70 \%$ higher activity towards laminarin and amorphous curdlan, respectively (Table 1). These differences were reflected in the kinetic parameters as well. In the analysis of Labourel et al. [39], significant differences in substrate specificity were caused by an additional loop in protein structure which leads to higher affinities towards mixed-linked glucans. Nevertheless, according to structural predictions, those considerable differences were not observed between FLamA and FLamB (Figure S1). Only minor structural modifications particularly in a loop adjacent to the catalytic cleft possibly result in an upwardly more opened cleft of FLamB. Based on the observations of Labourel et al. [39] and Jeng et al. [40] concerning the enzyme-substrate complexes, the enlarged opening might improve the access for $\beta$-1,3-glucans that possess helical conformation, whereas the affinity of FLamB towards mixed-linked glucans with linear conformation is not affected. These results and further investigations will help to improve activities of $\beta$-1,3-glucananases towards $\beta$-1,3-glucans.

\section{Materials and Methods}

\subsection{Cloning of the Endo- $\beta-1,3-$ Glucanase Encoding Genes flam A and flamB}

Metagenomic DNA was extracted from environmental samples taken from different locations at the hot spring Caldeirão at Furnas Valley (Azores, Portugal) followed by the production and sequencing of a 454 shotgun library as described previously [41]. For the two genes flamA and flamB, encoding for endo- $\beta$-1,3-glucanases from Fervidobacterium, no signal peptides were predicted by SignalP [42]. For cloning into the StarGate system (IBA Lifesciences) the two genes were amplified by PCR using the metagenomic DNA as a template and the following primers (primer extending sequences are indicated in boldface):

\section{- $\quad$ flamA-for: AGCGGCTCTTCAATGAAAGTTAAATATTTCTCAAATATT \\ - flamA-rev: AGCGGCTCTTCTCCCCTCATTTTCAAGCTTGTATAC \\ - flamB-for: AGCGGCTCTTCAATGAGAGAAAAGTTGCTGT \\ - flamB-rev: AGCGGCTCTTCTCCCCTCTTCATCTAATGTATACAC}

The PCR products were cloned into the destination vector pASG-IBA33 according to the producer instructions resulting in recombinant fusion genes with C-terminal sequences encoding for hexahistidine tags. After transformation of Escherichia coli TOP10 and selection on LB medium containing $100 \mu \mathrm{g} / \mathrm{mL}$ ampicillin and $50 \mu \mathrm{L} / \mathrm{mL}$ X-gal, plasmids of recombinant clones were isolated. The inserts were sequenced for verification. Subsequently, the vectors were used to transform E. coli C43(DE3) for protein production.

\subsection{Sequence Comparison and Phylogenetic Analysis}

From the GenBank database, amino acid sequences of characterized $\beta$-1,3-glucanases and $\beta-1,3(4)$-glucanases of the family GH 16 were selected. Multiple sequence alignment was performed using ClustalX. Homologous sequence regions were selected and applied in a second multiple sequence alignment. Using MEGA6, a phylogenetic tree was calculated by the neighbor joining method. Bootstrap analysis with resampling of the dataset was performed $(n=100)$ to test the reliability of the tree. Structure prediction of both proteins were done by SWISS-MODEL using the crystal structure of the laminarinase from Thermotoga maritima (PDB ID: 3azx) as a template. Structures of FLamA and FLamB were visualized and compared in the UCFS Chimera program by applying the Needleman-Wunsch algorithm and the scoring matrix Blosum62. 


\subsection{Heterologous Expression of the flamA and flamB Genes and Purification of the Endo- $\beta-1,3-$ Glucanases}

Escherichia coli C43(DE3) harboring the plasmids pASG-IBA33::flamA or pASG-IBA33::flamB were grown in LB media ( $100 \mu \mathrm{g} / \mathrm{mL}$ ampicillin) at $37^{\circ} \mathrm{C}$ and $160 \mathrm{rpm}$. Gene expression was induced at $\mathrm{OD}_{600} 0.6$ by adding anhydrotetracycline to a final concentration of $200 \mathrm{ng} / \mu \mathrm{L}$. After four hours of induction cells were harvested by centrifugation at $9000 \times g$ at $4{ }^{\circ} \mathrm{C}$ for $20 \mathrm{~min}$. The resulting cell pellet was stored at $-20{ }^{\circ} \mathrm{C}$.

For purification, $0.2 \mathrm{~g}$ cells were resuspended per $1 \mathrm{~mL}$ lysis buffer $(50 \mathrm{mM} \mathrm{NaH} 2 \mathrm{PO} 4,300$ $\mathrm{mM} \mathrm{NaCl}, 10 \mathrm{mM}$ imidazole, $\mathrm{pH}$ 8) and disrupted by three passages through a French pressure cell with constant pressure of 1,000 psi (French Pressure Cell Press, SLM-Aminco). Cell debris was removed by centrifugation $\left(20,000 \times g, 4{ }^{\circ} \mathrm{C}, 30 \mathrm{~min}\right)$ and supernatant was loaded onto a $1 \mathrm{ml} \mathrm{Ni}$-NTA Superflow column (Qiagen). Proteins were eluted by an increasing imidazole gradient according to the manufacturer's instructions. Eluted fractions were pooled, washed three times with buffer G (50 $\mathrm{mM}$ Na-phosphate buffer, $\mathrm{pH} 7.2,150 \mathrm{mM} \mathrm{NaCl}$ ) by ultrafiltration in an Amicon filter unit (Amicon Ultra-15, 1000 MWCO, Merck Millipore). For final purification via size exclusion chromatography, protein solutions were loaded onto a Superose 12 column (GE Healthcare) previously equilibrated with buffer $\mathrm{G}$. Protein fractions containing the purified $\beta$-1,3-glucanases were pooled and stored at $4{ }^{\circ} \mathrm{C}$.

Protein samples were analyzed on a $12.5 \%$ SDS-PAGE (12.5\%) [43]. Additionally, $\beta-1,3$-glucanase activity was determined by zymogram technique. For this, proteins were applied to a denaturing SDS-PAGE and were subsequently renaturated by incubation for $1 \mathrm{~h}$ in $1 \%(v / v)$ Triton X-100 and three successive washings for $5 \mathrm{~min}$ in $50 \mathrm{mM}$ sodium phosphate buffer ( $\mathrm{pH}$ 6.5). Then, the gel slices were incubated for $20 \mathrm{~min}$ at $80^{\circ} \mathrm{C}$ on an agarose gel containing $0.1 \%(w / v)$ curdlan. For visualization agarose slides were stained for $1 \mathrm{~h}$ with $1 \%(w / v)$ Congo Red and destained in $1 \mathrm{M} \mathrm{NaCl}$. To increase the contrast, the slides were finally overlaid with $0.1 \mathrm{M}$ acetic acid.

Protein concentrations were determined according to Bradford [44], with bovine serum albumin as the standard.

\section{4. $\beta$-Glucanase Activity Assay}

The standard assay was carried out at $90{ }^{\circ} \mathrm{C}$ for $7 \mathrm{~min}$ in $500 \mu \mathrm{L}$ reaction mixture using $0.25 \%(w / v)$ laminarin from Laminaria digitata (Merck) as substrate in $20 \mathrm{mM}$ sodium phosphate buffer (pH 6.5) and $50 \mu \mathrm{L}$ enzyme sample. In advance, it was ensured that product formation per min was constant in the time interval and with a linear correlation to preclude instability effects of the enzymes. Additionally, blank experiments without enzymes were performed by default for all measurement series. The hydrolytic activities of the purified enzymes FLamA and FLamB were detected by measuring the reducing sugars with 3,5-dinitrosalicylic acid (DNS) according to Miller [45] with glucose as the standard. In brief, after enzyme reaction $500 \mu \mathrm{l}$ reaction mixture were mixed with $500 \mu \mathrm{L}$ DNS reagent $(1 \%(w / v)$ DNS, $30 \%(w / v)$ potassium sodium tartrate, $0.4 \mathrm{M} \mathrm{NaOH})$ and were incubated for $5 \mathrm{~min}$ at $100{ }^{\circ} \mathrm{C}$. Samples were subsequently cooled on ice to room temperature and absorption was measured at $546 \mathrm{~nm}$. All measurements were done in triplicates. One unit of enzyme activity was defined as the amount of enzyme required to release $1 \mu \mathrm{mol}$ of reducing sugars per minute.

The influence of temperature was examined by performing the standard assay at temperatures from 20 to $100{ }^{\circ} \mathrm{C}$. To investigate the temperature stability of FLamA and FLamB, the enzymes were preincubated with a concentration of $0.1 \mathrm{mg} / \mathrm{mL}$ in $20 \mathrm{mM}$ sodium phosphate buffer $(\mathrm{pH} 6.5)$ at 70, 80, and $90{ }^{\circ} \mathrm{C}$. Samples were taken in time intervals up to $26 \mathrm{~h}$ and residual activities were measured by using the standard assay.

To investigate the influence of the $\mathrm{pH}$ on enzyme activity, a standard assay was performed using Britton-Robinson buffer $(50 \mathrm{mM})$ in a range of $\mathrm{pH} 2-11$ in the reaction mixture [46]. The $\mathrm{pH}$ stabilities of both enzymes were tested by preincubation of the enzymes with a concentration of $0.01 \mathrm{mg} / \mathrm{mL}$ in $50 \mathrm{mM}$ Britton-Robinson buffer $\mathrm{pH} 3-11$ for $24 \mathrm{~h}$ at $4{ }^{\circ} \mathrm{C}$. Residual activity was determined with the standard assay by dilution the incubation mixtures in Britton-Robinson buffer at $\mathrm{pH} 6$. Enzyme activity previous to incubation was defined as $100 \%$. 
Additionally, the influences of metal ions on enzyme activity were analyzed by using a standard assay, but with $20 \mathrm{mM}$ maleate buffer ( $\mathrm{pH}$ 6.5) and the addition of $5 \mathrm{mM} \mathrm{AgNO}, \mathrm{AlCl}_{3}, \mathrm{CaCl}_{2}$, $\mathrm{CoCl}_{2}, \mathrm{CrCl}_{3}, \mathrm{CuCl}_{2}, \mathrm{FeCl}_{2}, \mathrm{KCl}, \mathrm{MgCl}_{2}, \mathrm{NaCl}, \mathrm{NiCl}_{2}, \mathrm{RbCl}, \mathrm{SrCl}_{2}$ or $\mathrm{ZnCl}_{2}$. Furthermore, the influences of 3-((3-cholamidopropyl)dimethylammonio)-1-propanesulfonate (CHAPS), SDS, Triton X-100, Tween 20, Tween 80, guanidine hydrochloride, urea, dithiothreitol (DTT), $\beta$-mercaptoethanol, EDTA, iodoacetic acid, Pefabloc, cetyltrimethylammonium bromide (CTAB) and sodium azide were examined by the standard assay procedure. All additives were tested in a concentration of $5 \mathrm{mM}$ under standard conditions.

To measure the specific activities of FLamA and FLamB, substrates were used in a final concentration of $0.25 \%(w / v)$. The CMC and lichenin were obtained from Merck and $\beta$-glucan (barley) and curdlan (Alcaligenes faecalis) from Megazyme. In case of curdlan an undissolved and a dissolved (amorphous) form was tested. To achieve an amorphous type of curdlan, $0.2 \mathrm{~g}$ were first solubilized in $6 \mathrm{~mL}$ alkaline solution $(0.6 \mathrm{M} \mathrm{NaOH})$ and subsequently neutralized with $\mathrm{HCl}$ to a concentration of $0.5 \%(w / v)$ and $\mathrm{pH} 6.5$ in $20 \mathrm{mM}$ sodium phosphate buffer.

Kinetic parameters were determined by performing the standard assay with twelve different substrate concentrations varying from 0 to $25 \mathrm{mM}$. The Michaelis constant $\mathrm{K}_{\mathrm{m}}$ and the maximum reaction rate at maximum substrate concentration $\mathrm{v}_{\max }$ were calculated by non-linear regression applying the Michaelis-Menten equation.

\subsection{Determination of the Hydrolysis Products}

For determination of the hydrolysis products of laminarin and barley $\beta$-glucan, $0.25 \%(w / v)$ substrate were incubated with FLamA or FLamB in standard reaction mixtures at $70{ }^{\circ} \mathrm{C}$ for $18 \mathrm{~h}$. After the inactivation of the enzymes at $100{ }^{\circ} \mathrm{C}$ for $10 \mathrm{~min}$, samples were centrifuged $(20.000 \times g, 10 \mathrm{~min})$ and the supernatant was filtered using a $0.22 \mu \mathrm{m}$ membrane filter unit. Hydrolysis products were analyzed by high-performance liquid chromatography (HPLC) under the following conditions: Hi-Plex $\mathrm{Na}$ column (Agilent Technologies), $80^{\circ} \mathrm{C}, 0.2 \mathrm{~mL} / \mathrm{min}$ flow rate, water as mobile phase, RI detector (Agilent Technologies). Laminaritetraose, laminaritriose, laminaribiose (all from Megazymes) and glucose (Merck) were used as standards.

\section{Conclusions}

Laminarinases are enzymes which could be applied in diverse fields, from biomass conversion, over yeast extract production, agents against fungal plant pathogens to the production of antiviral and antitumor therapeutics from $\beta$-1,3-glucans. The biochemical characterization of the two laminarinases FLamA and FLamB derived from a Fervidobacterium species revealed high specific activities and resistance to elevated temperatures and various additives which make both enzymes suitable candidates for application under harsh conditions. Moreover, the comparative analysis of both enzymes showed differences in their thermal stability and catalytic efficiency towards $\beta$-1,3-glucans, like laminarin and curdlan. In conclusion, these results will contribute to our knowledge of sequence-function correlations and will potentially help to improve activity and stability of laminarinases and other related glucanases.

Supplementary Materials: The following are available online at http://www.mdpi.com/2073-4344/9/10/830/s1, Figure S1: Structural models of FLamA and FLamB, Figure S2: Amino acid alignment of the catalytic domains of FLamA and FLamB with other members of GH 16, Figure S3: Laminarinase activity of FLamA and FLamB after incubation at $\mathrm{pH} 3-11$ and $4{ }^{\circ} \mathrm{C}$ for $24 \mathrm{~h}$, Table S1: Purification of the recombinant FLamA and FLamB from E. coli.

Author Contributions: C.B. designed the study and performed the experimental work. C.S., G.S. and G.A. supervised this study. C.B. prepared the manuscript. C.S., J.C. and G.A. reviewed and edited the manuscript before submission.

Funding: This research was funded by BMBF (Bundesministerium für Bildung und Forschung, Germany) in the project LIPOMAR (Lipids and surfactants from marine biomass), FKZ 031A261.

Conflicts of Interest: The authors declare no conflict of interest. 


\section{References}

1. Stone, B.A. Chemistry, biochemistry, and biology of (1-3)- $\beta$-glucans and related polysaccharides. In Chemistry of $\beta$-Glucans, 1st ed.; Bacic, A., Fincher, G.B., Stone, B.A., Eds.; Elsevier Academic Press: Amsterdam, The Netherlands, 2009; pp. 5-46.

2. Ebringerová, A.; Hromádková, Z.; Heinze, T. Hemicellulose. In Polysaccharides, I. Structure, Characterisation and Use; Heinze, T.T., Ed.; Springer-Verlag GmbH: Berlin/Heidelberg, Germany, 2005; pp. 1-67.

3. Painter, T.J. Algal polysaccharides. In The Polysaccharides; Aspinall, G.O., Ed.; Academic Press (Molecular biology): New York, NY, USA, 1983; pp. 195-285. Volume 2.

4. Schiener, P.; Black, K.D.; Stanley, M.S.; Green, D.H. The seasonal variation in the chemical composition of the kelp species Laminaria digitata, Laminaria hyperborea, Saccharina latissima Alaria esculenta. J. Appl. Phycol. 2015, 27, 363-373. [CrossRef]

5. Wei, N.; Quarterman, J.; Jin, Y.-S. Marine macroalgae: an untapped resource for producing fuels and chemicals. Trends Biotechnol. 2013, 31, 70-77. [CrossRef] [PubMed]

6. Jung, K.A.; Lim, S.-R.; Kim, Y.; Park, J.M. Potentials of macroalgae as feedstocks for biorefinery. Bioresour. Technol. 2013, 135, 182-190. [CrossRef] [PubMed]

7. Hehemann, J.-H.; Boraston, A.B.; Czjzek, M. A sweet new wave: structures and mechanisms of enzymes that digest polysaccharides from marine algae. Curr. Opin. Struct. Biol. 2014, 28, 77-86. [CrossRef] [PubMed]

8. Shi, P.; Yao, G.; Yang, P.; Li, N.; Luo, H.; Bai, Y.; Wang, Y.; Yao, B. Cloning, characterization, and antifungal activity of an endo-1,3- $\beta$-D-glucanase from Streptomyces sp. S27. Appl. Microbiol. Biotechnol. 2010, 85, 1483-1490. [CrossRef] [PubMed]

9. Vetvicka, V. Glucan-immunostimulant, adjuvant, potential drug. World J. Clin. Oncol. 2011, 2, 115-119. [CrossRef]

10. Cantarel, B.L.; Coutinho, P.M.; Rancurel, C.; Bernard, T.; Lombard, V.; Henrissat, B. The Carbohydrate-Active EnZymes database (CAZy): an expert resource for Glycogenomics. Nucleic Acids Res. 2009, 37, D233-D238. [CrossRef]

11. Sarmiento, F.; Peralta, R.; Blamey, J.M. Cold and Hot Extremozymes: Industrial Relevance and Current Trends. Front. Bioeng. Biotechnol. 2015, 3, 348. [CrossRef]

12. Krahe, M.; Markl, H.; Antranikian, G. Fermentation of extremophilic microorganisms. FEMS Microbiol. Rev. 1996, 18, 271-285. [CrossRef]

13. Schroeder, C.; Elleuche, S.; Blank, S.; Antranikian, G. Characterization of a heat-active archaeal beta-glucosidase from a hydrothermal spring metagenome. Enzyme Microb. Technol. 2014, 57, 48-54. [CrossRef]

14. Zhaxybayeva, O.; Swithers, K.S.; Lapierre, P.; Fournier, G.P.; Bickhart, D.M.; DeBoy, R.T.; Nelson, K.E.; Nesbø, C.L.; Doolittle, W.F.; Gogarten, J.P.; et al. On the chimeric nature, thermophilic origin, and phylogenetic placement of the Thermotogales. Proc. Natl. Acad. Sci. USA 2009, 106, 5865-5870. [CrossRef] [PubMed]

15. Patel, B.K.C.; Morgan, H.W.; Daniel, R.M. Fervidobacterium nodosum gen. nov. and spec. nov., a new chemoorganotrophic, caldoactive, anaerobic bacterium. Arch. Microbiol. 1985, 141, 63-69. [CrossRef]

16. Wang, Y.; Wang, X.; Tang, R.; Yu, S.; Zheng, B.; Feng, Y. A novel thermostable cellulase from Fervidobacterium nodosum. J. Mol. Catal. B: Enzym. 2010, 66, 294-301. [CrossRef]

17. Labourel, A.; Jam, M.; Legentil, L.; Sylla, B.; Hehemann, J.H.; Ferrières, V.; Czzzek, M.; Michel, G. Structural and biochemical characterization of the laminarinase ZgLamCGH16 from Zobellia galactanivorans suggests preferred recognition of branched laminarin. Acta Crystallogr. D 2015, 71 Pt 2, 173-184. [CrossRef]

18. Palumbo, J.D.; Sullivan, R.F.; Kobayashi, D.Y. Molecular Characterization and Expression in Escherichia coli

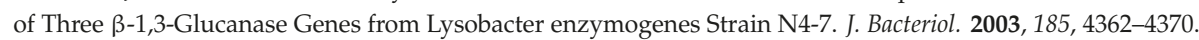
[CrossRef] [PubMed]

19. Hong, T.-Y.; Huang, J.-W.; Meng, M.; Cheng, C.-W. Isolation and biochemical characterization of an endo-1,3- $\beta$-glucanase from Streptomyces sioyaensis containing a C-terminal family 6 carbohydrate-binding module that binds to 1,3- $\beta$-glucan. Microbiology 2002, 148 Pt 4, 1151-1159. [CrossRef]

20. Qian, W.; Zhang, J. Gene dosage and gene duplicability. Genetics 2008, 179, 2319-2324. [CrossRef]

21. Wagner, A. Energy Constraints on the Evolution of Gene Expression. Mol. Boil. Evol. 2005, 22, 1365-1374. [CrossRef] 
22. Francino, M.P. An adaptive radiation model for the origin of new gene functions. Nat. Genet. 2005, 37, 573-578. [CrossRef]

23. Bratlie, M.S.; Johansen, J.; Sherman, B.T.; Huang, D.W.; Lempicki, R.A.; Drabløs, F. Gene duplications in prokaryotes can be associated with environmental adaptation. BMC Genom. 2010, 11, 588. [CrossRef]

24. Cota, J.; Alvarez, T.M.; Citadini, A.P.; Santos, C.R.; Neto, M.D.O.; Oliveira, R.R.; Pastore, G.M.; Ruller, R.; Prade, R.A.; Murakami, M.T.; et al. Mode of operation and low-resolution structure of a multi-domain and hyperthermophilic endo- $\beta-1,3$-glucanase from Thermotoga petrophila. Biochem. Biophys. Res. Commun. 2011, 406, 590-594. [CrossRef] [PubMed]

25. Zverlov, V.V.; Volkov, I.Y.; Velikodvorskaya, T.V.; Schwarz, W.H. Thermotoga neapolitana bglB gene, upstream of lamA, encodes a highly thermostable beta-glucosidase that is a laminaribiase. Microbiology 1997, 143 Pt 11, 3537-3542. [CrossRef]

26. Gueguen, Y.; Voorhorst, W.G.B.; van der Oost, J.; de Vos, W.M. Molecular and biochemical characterization of an endo- $\beta$-1,3-glucanase of the hyperthermophilic archaeon Pyrococcus furiosus. J. Biol. Chem. 1997, 272, 31258-31264. [CrossRef] [PubMed]

27. Schwarz, W.H.; Schimming, S.; Staudenbauer, W.L. Isolation of a Clostridium thermocellum gene encoding a thermostable $\beta$-1,3-glucanase (laminarinase). Biotechnol. Lett. 1988, 10, 225-230. [CrossRef]

28. Kasai, N.; Harada, T. Ultrastructure of Curdlan. In Fiber Diffraction Methods; French, A.D., Ed.; American Chemical Society (ACS symposium series): Washington, DC, USA, 1980; pp. 363-383. Volume 141.

29. Meng, D.D.; Wang, B.; Ma, X.Q.; Ji, S.Q.; Lu, M.; Li, F.L. Characterization of a thermostable endo-1,3(4)-beta-glucanase from Caldicellulosiruptor sp. strain F32 and its application for yeast lysis. Appl. Microbiol. Biotechnol. 2016, 100, 4923-4934. [CrossRef] [PubMed]

30. Kobayashi, T.; Uchimura, K.; Kubota, T.; Nunoura, T.; Deguchi, S. Biochemical and genetic characterization of beta-1,3 glucanase from a deep subseafloor Laceyella putida. Appl. Microbiol. Biotechnol. 2016, 100, $203-214$. [CrossRef]

31. Masuda, S.; Endo, K.; Koizumi, N.; Hayami, T.; Fukazawa, T.; Yatsunami, R.; Fukui, T.; Nakamura, S. Molecular identification of a novel beta-1,3-glucanase from alkaliphilic Nocardiopsis sp. strain F96. Extremophiles 2006, 10, 251-255. [CrossRef] [PubMed]

32. Spilliaert, R.; Hreggvidsson, G.O.; Kristjansson, J.K.; Eggertsson, G.; Palsdottir, A. Cloning and Sequencing of a Rhodothermus marinus Gene, bglA, Coding for a Thermostable beta-Glucanase and its Expression in Escherichia coli. JBIC J. Boil. Inorg. Chem. 1994, 224, 923-930. [CrossRef]

33. Krah, M.; Misselwitz, R.; Politz, O.; Thomsen, K.K.; Welfle, H.; Borriss, R. The laminarinase from thermophilic eubacterium Rhodothermus marinus. Conformation, stability, and identification of active site carboxylic residues by site-directed mutagenesis. Eur. J. Biochem. 1998, 257, 101-111. [CrossRef]

34. Fuchs, K.-P.; Zverlov, V.V.; Velikodvorskaya, G.A.; Lottspeich, F.; Schwarz, W.H. Lic16A of Clostridium thermocellum, a non-cellulosomal, highly complex endo-beta-1,3-glucanase bound to the outer cell surface. Microbiology 2003, 149 Pt 4, 1021-1031. [CrossRef]

35. Woo, C.-B.; Kang, H.-N.; Lee, S.-B. Molecular cloning and anti-fungal effect of endo- $\beta$-1,3-glucanase from Thermotoga maritima. Food Sci. Biotechnol. 2014, 23, 1243-1246. [CrossRef]

36. Ilari, A.; Fiorillo, A.; Angelaccio, S.; Florio, R.; Chiaraluce, R.; Van Der Oost, J.; Consalvi, V. Crystal structure of a family 16 endoglucanase from the hyperthermophile Pyrococcus furiosus- structural basis of substrate recognition. FEBS J. 2009, 276, 1048-1058. [CrossRef] [PubMed]

37. Gaiser, O.J.; Piotukh, K.; Ponnuswamy, M.N.; Planas, A.; Borriss, R.; Heinemann, U. Structural basis for the substrate specificity of a Bacillus 1,3-1,4-beta-glucanase. J. Mol. Biol. 2006, 357, 1211-1225. [CrossRef] [PubMed]

38. Pereira, J.D.C.; Giese, E.C.; Moretti, M.M.D.S.; Gomes, A.C.D.S.; Perrone, M.B.O.M.; Da Silva, R.; Martins, D.A.B. Effect of Metal Ions, Chemical Agents and Organic Compounds on Lignocellulolytic Enzymes Activities. In Enzyme Inhibitors and Activators; IntechOpen: London, UK, 2017; pp. 139-164.

39. Labourel, A.; Jam, M.; Jeudy, A.; Hehemann, J.-H.; Czjzek, M.; Michel, G. The $\beta$-glucanase ZgLamA from Zobellia galactanivorans evolved a bent active site adapted for efficient degradation of algal laminarin. J. Biol. Chem. 2014, 289, 2027-2042. [CrossRef] [PubMed]

40. Jeng, W.-Y.; Wang, N.-C.; Lin, C.-T.; Shyur, L.-F.; Wang, A.H.-J. Crystal structures of the laminarinase catalytic domain from Thermotoga maritima MSB8 in complex with inhibitors: essential residues for $\beta-1,3-$ and $\beta$-1,4-glucan selection. J. Biol. Chem. 2011, 286, 45030-45040. [CrossRef] [PubMed] 
41. Sahm, K.; John, P.; Nacke, H.; Wemheuer, B.; Grote, R.; Daniel, R.; Antranikian, G. High abundance of heterotrophic prokaryotes in hydrothermal springs of the Azores as revealed by a network of 16S rRNA gene-based methods. Extremophiles 2013, 17, 649-662. [CrossRef] [PubMed]

42. Petersen, T.N.; Brunak, S.; Von Heijne, G.; Nielsen, H. SignalP 4.0: discriminating signal peptides from transmembrane regions. Nat. Methods 2011, 8, 785-786. [CrossRef] [PubMed]

43. Laemmli, U.K. Cleavage of Structural Proteins during the Assembly of the Head of Bacteriophage T4. Nature 1970, 227, 680-685. [CrossRef] [PubMed]

44. Bradford, M.M. A rapid and sensitive method for the quantitation of microgram quantities of protein utilizing the principle of protein-dye binding. Anal. Biochem. 1976, 72, 248-254. [CrossRef]

45. Miller, G.L. Use of Dinitrosalicylic Acid Reagent for Determination of Reducing Sugar. Anal. Chem. 1959, 31, 426-428. [CrossRef]

46. Britton, H.T.S.; Robinson, R.A. CXCVIII.-Universal buffer solutions and the dissociation constant of veronal. J. Chem. Soc. 1931, 1456-1462. [CrossRef]

(C) 2019 by the authors. Licensee MDPI, Basel, Switzerland. This article is an open access article distributed under the terms and conditions of the Creative Commons Attribution (CC BY) license (http://creativecommons.org/licenses/by/4.0/). 

Article

\title{
Expression, Characterisation and Homology Modelling of a Novel Hormone-Sensitive Lipase (HSL)-Like Esterase from Glaciozyma antarctica
}

\author{
Hiryahafira Mohamad Tahir 1,2, Raja Noor Zaliha Raja Abd Rahman 1,3, \\ Adam Thean Chor Leow ${ }^{1,4}$ and Mohd Shukuri Mohamad Ali ${ }^{1,2, *}$ \\ 1 Enzyme and Microbial Technology Research Center, Faculty of Biotechnology and Biomolecular Sciences, \\ Universiti Putra Malaysia, Serdang, Selangor 43400, Malaysia; firatahir3@gmail.com (H.M.T.); \\ rnzaliha@upm.edu.my (R.N.Z.R.A.R.); adamleow@upm.edu.my (A.T.C.L.) \\ 2 Department of Biochemistry, Faculty of Biotechnology and Biomolecular Science, Universiti Putra Malaysia, \\ Serdang Selangor 43400, Malaysia \\ 3 Department of Microbiology, Faculty of Biotechnology and Biomolecular Sciences, Universiti Putra Malaysia, \\ Serdang Selangor 43400, Malaysia \\ 4 Department of Cell and Molecular Biology, Faculty of Biotechnology and Biomolecular Sciences, \\ Universiti Putra Malaysia, Serdang Selangor 43400, Malaysia \\ * Correspondence: mshukuri@upm.edu.my; Tel.: +603-9769-6721
}

Received: 2 October 2019; Accepted: 5 November 2019; Published: 1 January 2020

\begin{abstract}
Microorganisms, especially those that survive in extremely cold places such as Antarctica, have gained research attention since they produce a unique feature of the protein, such as being able to withstand at extreme temperature, salinity, and pressure, that make them desired for biotechnological application. Here, we report the first hormone-sensitive lipase (HSL)-like esterase from a Glaciozyma species, a psychrophilic yeast designated as GlaEst12-like esterase. In this study, the putative lipolytic enzyme was cloned, expressed in E. coli, purified, and characterised for its biochemical properties. Protein sequences analysis showed that GlaEst12 shared about 30\% sequence identity with chain A of the bacterial hormone-sensitive lipase of E40. It belongs to the H group since it has the conserved motifs of Histidine-Glycine-Glycine-Glycine (HGGG)and Glycine-Aspartate-Serine-Alanine-Glycine (GDSAG) at the amino acid sequences. The recombinant GlaEst12 was successfully purified via one-step Ni-Sepharose affinity chromatography. Interestingly, GlaEst12 showed unusual properties with other enzymes from psychrophilic origin since it showed an optimal temperature ranged between 50-60 ${ }^{\circ} \mathrm{C}$ and was stable at alkaline $\mathrm{pH}$ conditions. Unlike other HSL-like esterase, this esterase showed higher activity towards medium-chain ester substrates rather than shorter chain ester. The 3D structure of GlaEst12, predicted by homology modelling using Robetta software, showed a secondary structure composed of mainly $\alpha / \beta$ hydrolase fold, with the catalytic residues being found at $\operatorname{Ser}^{232}$, $\mathrm{Glu}^{341}$, and $\mathrm{His}^{371}$.
\end{abstract}

Keywords: psychrophilic yeast; hormone-sensitive lipase; Glaciozyma antarctica; Antarctica and homology modelling

\section{Introduction}

The lipolytic enzyme consists of esterases (EC 3.1.1.1) and lipases (EC 3.1.1.3) that catalyse both the cleavage and formation of ester bonds [1]. Although they have similar secondary structures, i.e., $\alpha / \beta$ hydrolase fold, esterase prefers to hydrolyse fatty-acids esters with acyl chain with less than 10 carbon atoms, whereas lipase is able to hydrolyse long-chain fatty acids with more than 10 carbon atoms [2]. Based on the sequence similarity, these protein have been classified into four groups, namely, C (cholinesterases and fungal lipase), L (lipoprotein and bacterial lipase), H (mammalian 
hormone-sensitive lipase and hormone-sensitive lipase (HSL)-like family), and X ( $\alpha / \beta$ hydrolase and does not belong to any of the other groups) [3].

The H group consists of two members that are HSL and HSL-like, in which both of them having conserved motifs, such as GDSAG or Glycine-Threonine-Serine-Alanine-Glycine (GTSAG) and HGGG motifs. Hormone-sensitive lipase is an enzyme that is mostly found in mammalian tissue and stimulated by several hormones, such as catecholamines, ACTH, and glucagon, to hydrolyse the triglyceride into free fatty acids and glycerol, which makes it play a pivotal role in providing the major source of energy for most tissues [4,5]. Another member of the H group is HSL-like, which is mostly originated from microbial sources that have similar protein sequences with HSL, especially at the C-terminal catalytic domain [6]. Although the mechanism of catalysis and the function of $\mathrm{N}$-terminal domain HSL-like in microorganisms is still scarcely explored, the discovery of this new enzyme provides biotechnological application, such as in biosensors to detect foodborne bacteria and organophosphate pesticides $[7,8]$. Besides that, HSL-like enzymes also have potential to be used in the pharmaceutical, biodiesel, and detergents industry $[6,9,10]$.

Several HSL-like enzymes have been reported from microbial sources, such as RmEstB from the thermophilic fungus Rhizomucor miehei [11], PMGL2 from a permafrost bacterium Psychrobacter cryohalolentis [12], and E25 HSL esterase from a surface sediment sample E505 collected from the South China Sea [13]. Even though there are many reported HSL-like esterase from psychrophilic microorganisms on heterologous expression and biochemical characterisation, there are few reports on HSL-like esterase specifically from psychrophilic yeast. Discovery of the new HSL-like esterase from psychrophilic yeast not only provides an opportunity in biotechnology application but also gives crucial information on novel sequence, characterisation, and the structure-function relationship.

Glaciozyma antarctica strain PI12 is a member of the phylum Basidiomycota that was previously known as the Leucosporidium antarcticum [14]. This psychrophilic yeast was isolated from sea ice near the Casey Research Station in Antarctica and had optimum temperature growth at $12{ }^{\circ} \mathrm{C}$ but can grow at up to $18{ }^{\circ} \mathrm{C}$ [15]. A few reported proteins have been successfully expressed from G. antarctica such as proteases, antifreeze protein, $\alpha$-amylase, and chitinase [16-19]. In this work, we report the heterologous expression, purification, biochemical characterisation, and structural prediction of the first HSL-like esterase from the Glaciozyma Antarctica species, and we also believe this enzyme is the first HSL-like esterase from psychrophilic basidiomycete yeast.

\section{Results and Discussion}

\subsection{Sequence Analysis of GlaEst12}

The amino acid sequence of Glaciozyma antarctica hormone-sensitive lipase (GlaEst12) esterase was searched for similarity against the protein data bank at the National Centre of Biotechnology (NCBI) (https://blast.ncbi.nlm.nih.gov/Blast.cgi) using BLASTP. The search results showed that GlaEst12 had low sequence similarity (about 30\% identity) with chain A of the crystal structure of esterase 40 from the bacterial HSL family and apparently no homology to the HSL-like esterase from psychrophilic yeast or bacteria. No similarity of the GlaEst12 sequence with psychrophilic microorganism may have two possible explanations. Firstly, there is less discovery of this type of enzyme from a cold environment, so the possibility of this GlaEst12 sequence being similar to other mesophiles and thermophiles is quite high. Hormone-sensitive lipase from Psycrobacter sp. that has been isolated from Antarctic seawater also showed similar reports in that the enzyme is closely related to the HSL-like esterase from the mesophilic enzyme [20]. Another explanation is because GlaEst12 showed mesophilic or thermophilic characteristics rather than psychrophilic features. The limited sequence of the GlaEst12 to the known HSL-like esterase sequences indicated less conserved residues, which provide novelty properties. The nucleotide sequence of GlaEst12 revealed an open reading frame (ORF) of 1200 nucleotide, which encoded 399 amino acids with a predicted molecular weight of $44.5 \mathrm{kDa}$. This esterase lacks signal peptide and has a theoretical isoelectric point (pI) value of 7.72. 
The multiple sequence alignment was performed using ENDscript with the other seven proteins that have higher percentage of sequence similarity with GlaEst12 esterase, in which they are chain A of esterase from the bacterial HSL family (PDB ID: 4XVC A); chain A of mutant S202w/203f of the Esterase E40 (PDB ID: 5GMS A); chain C of mutant M3+s202w/i203f of Esterase E40 (PDB ID: 5GMR C); chain A of esterase/lipase from uncultured bacterium (PDB ID: 3V9A A); chain A of Hormone-sensitive lipase-like Este5 (PDB ID: 3FAK A), chain A of hyper-thermophilic carboxylesterase from archaeon Archaeoglobus fulgidus (PDB ID: 1JJI A), and chain A of MGS-MT1, an alpha/beta hydrolase enzyme from a Lake Matapan deep-sea metagenome library. Surprisingly, the GlaEst12 sequence is closely related to the mesophilic and thermophilic esterase. None of them are from either a psychrophilic or Antarctica environment. This finding might give new insight into the highly similar protein sequences that are not usually from the same environment.

Multiple sequence alignment showed that GlaEst12 belongs to the H group of the lipolytic group, which consists of a type of protein that has sequence similarity with the HSL subfamily. Most of the members of the $\mathrm{H}$ group have two highly conserved motifs, which are also present in the GlaEst12 sequence, such as His-Gly-Gly-Gly at upstream of the catalytic triad and the residue of serine at GDSAG motif [3]. Figure 1 shows GlaEst12 adhered to the characteristic of the H group, which is indicated by the red residue for HGGG and GDSAG motifs. The alignment with other proteins showed the possibility of the catalytic residue of GlaEst12 at position $\mathrm{Ser}^{232}, \mathrm{Glu}^{341}$, and His ${ }^{371}$. The hormone-sensitive lipase-like family (HSL-like) can be widely found in microorganisms, animals, and plants. Most of the microbial HSL-like family consists of two subfamilies, GDSAG and GTSAG [21]. Since the serine residue was located at the pentapeptide motif, which is in the middle between aspartate acid and alanine, we proposed that GlaEst12 is a new member of the GDSAG subfamily of the HSL family.

Furthermore, the phylogenetic tree was constructed based on the amino acid sequence that aligned with closely related proteins and with the other members of HSL-like esterase from prokaryotic and eukaryotic microorganisms (PDB ID: 4QO5; 4Q30; 4WY8; 4WY5; Accession number: WP_012330536.1, ADH59412, QBH67630.1, KX580963.1). The results showed that GlaEst12 is grouped under the GDSAG motif subfamily (Figure 2) together with other proteins containing a GDSAG conserved sequence. Interestingly, GlaEst12 was assigned at a different sub-branch with other GDSAG subfamily members, indicating the differences of this sequence with the other esterases. The contrast may be due to the presence of extra $\alpha$-helix at the $\mathrm{N}$-terminal region, which was absent in all other esterases. Apart from that, this esterase is mostly related to eukaryotic proteins, such as RmEsTA (PDB 4WY5) and RmEsTB (PDB 4WY8), since they come from fungi species. 

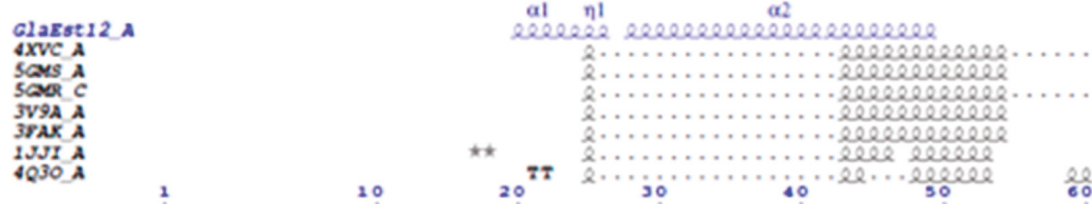

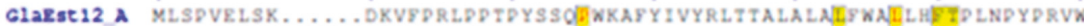

4XVC A
SQTS

Sats A

SQR C $\quad$...........

3V9A A

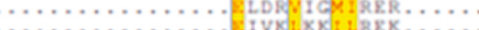

3rax

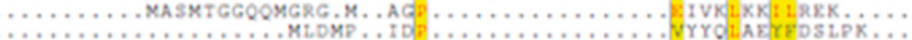
acc a

Glagst 2 A BB Ba B

$\alpha^{3}$

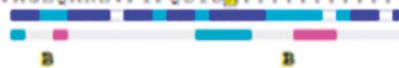

a

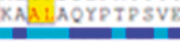

Glasst2

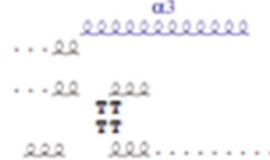

.

Axve a

5 CONS A

IVPA A

IFAK A

$1 J J I A$

22

200

$20222 \ldots \cdots$

\section{ZQQQQQ2QQ2QS

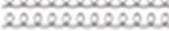 202020222028} 2202020202 2222222228

$4 Q 30 A$ -...22229222222222220292

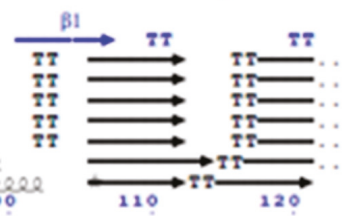

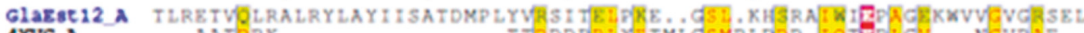

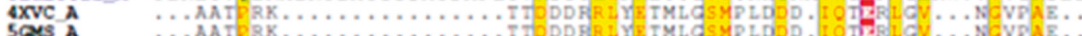

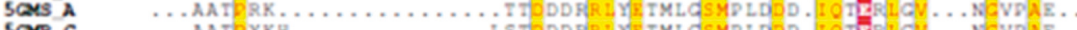

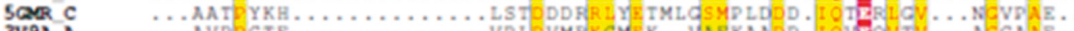

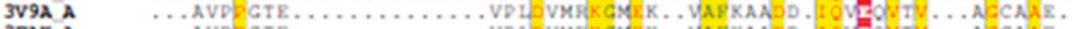

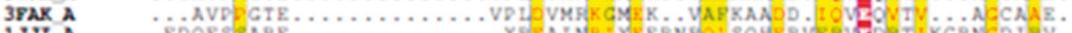

IJUT A

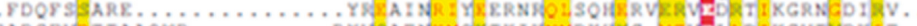

4Q30 A EARSFVRTTAAOKR......... DYVQATAKYOKTKIYNYRKHYG.VTVELLOIKGVTVRKIT.

$$
\begin{array}{r}
2 c c \\
\text { byd }
\end{array}
$$
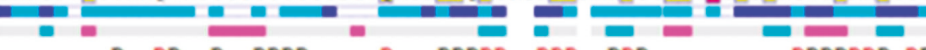

Glasst2 A

$4 x$ V A

save A

5 GN

3V9A A

IFAX A

$1 J J I$ A

4830 A
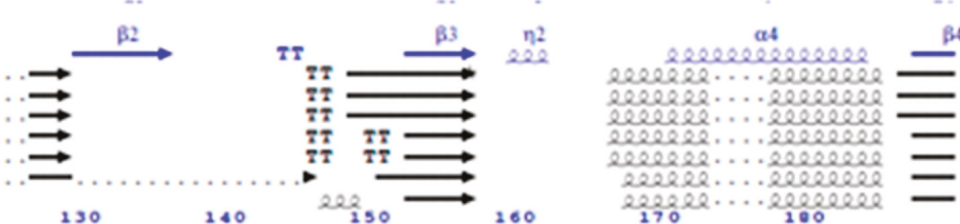

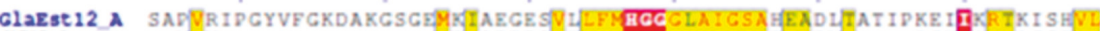
$4 \times V C$ A

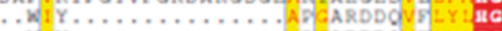

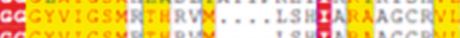

$\operatorname{son} A$

3 T 9 A A

3 Fax a

$\sin$ a

4030 A

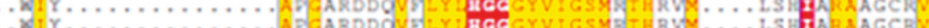

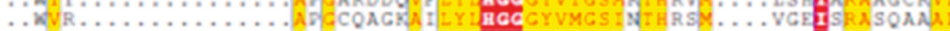

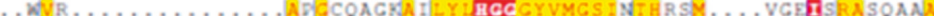

- EvY ....

acc

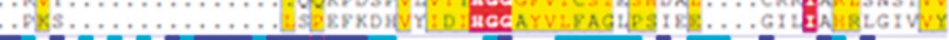
Glagsti2 a

Figure 1. Cont. 

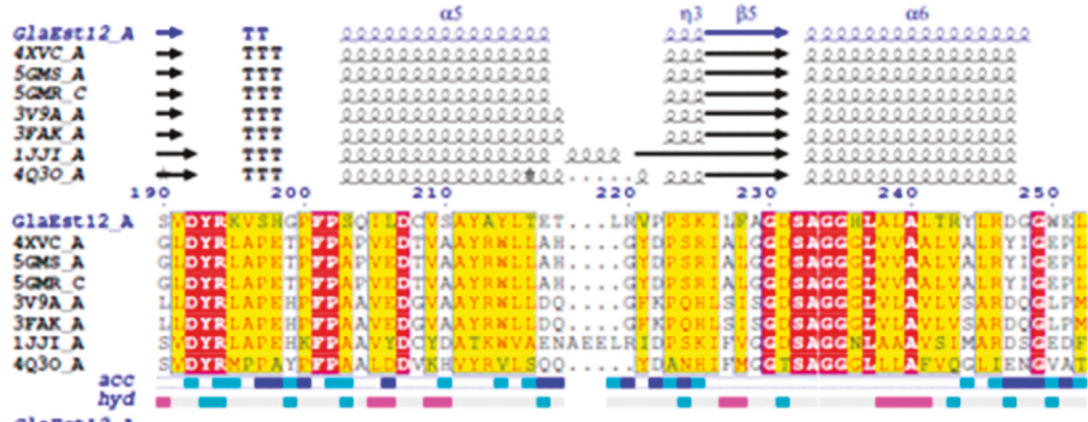
Glarst 12 A
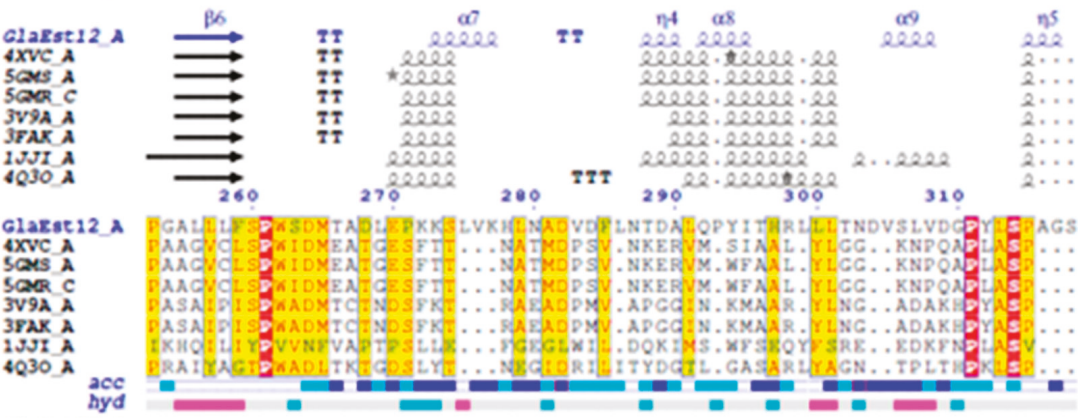

Glaxst:2 A

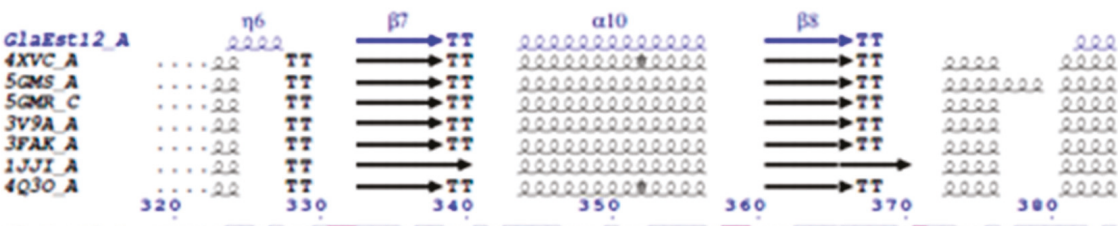

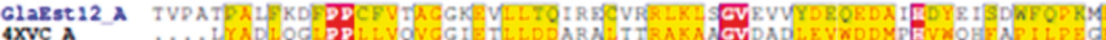

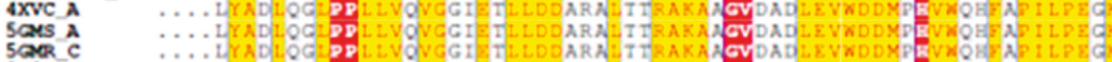

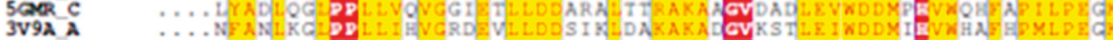

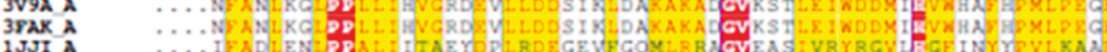

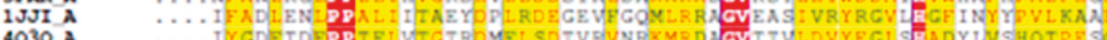

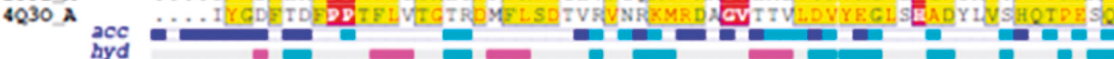

Glasst 12 A

GlaEst12_A eecellecelee

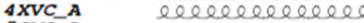

5GMSAA lelelelelelel

5GMRCA lelelelelelel

3FAKA bebelebelebel

IJJI_A leeleededed

4030 A eleereele

GlaEst12_A ERIWKTTALWVDGKF

4XVC_A $-A$ AIARIGEFIRKQIG

4XVC_A

5GMS_A 5 GMR_C AIARIGEFIRKQIG

SGMR_C A A ARIGEFLRKQIG

3FAK_A A A ARVGEFMREOWA

1JJIA DAINOIAAL VED

1JJI_A 4030 A

acc

GlaEst12 A

Figure 1. Multiple alignments of amino acid and secondary structure protein sequences from Glaciozyma Antarctica of hormone-sensitive lipase (GlaEst12) esterase with other related proteins. Squiggles indicate helices, arrows indicate $\beta$-strands, TT letters indicate a turn, $\eta$ letters indicate random coil and the catalytic triad are indicated by an arrow symbol. The identical and highly conserved residues are indicated by red and yellow colour, respectively. 


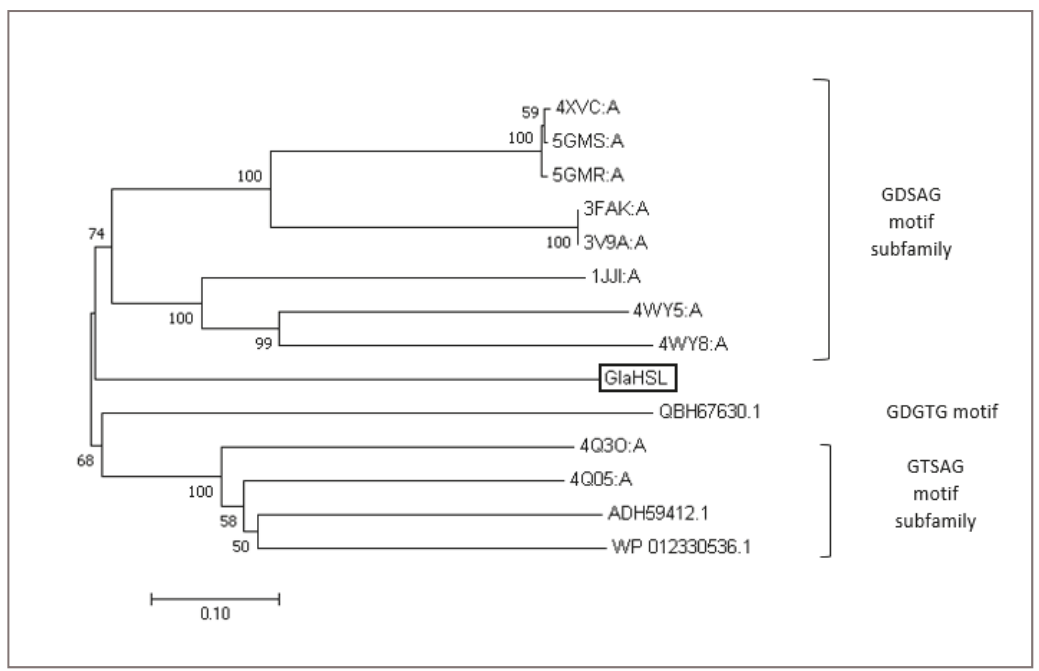

Figure 2. Phylogenetic tree of representative esterase sequences from microbial hormone-sensitive lipase (HSL) family generated using MEGA 7.0. The amino acid sequences were retrieved from the National Centre of Biotechnology (NCBI) and Research Collaboratory for Structural Bioinformatics Protein Data Bank (RCSB PDB) database. The neighbour-joining method was built with a Jones-Taylor-Thornton matrix-based model to estimate the phylogenetic tree. The black box indicates GlaEst12.

\subsection{Expression and Purification of Recombinant GlaEst12}

GlaEst12-like esterase was cloned and expressed in an E. coli BL21(De3)/pET32b(+) expression system, which resulted in the accumulation of expressed GlaEst12 in the form of inclusion bodies. It is well known that high-level expression recombinant protein in E. coli is usually formed of partially folded or misfolded protein. HSL-like esterases from Psychrobacter sp. TA144 [20] and Mycobacterium tuberculosis LIPY [22] were also expressed as inclusion bodies. In the case of recombinant GlaEst12, the active enzyme was successfully renatured (Figure 2). A protein band corresponding to GlaEst12-like esterase with an expected size of $63 \mathrm{kDa}$ was obtained as visualised by sodium dodecyl sulphate-polyacrylamide gel electrophoresis (SDS-PAGE). High expression of GlaEst12 in inclusion bodies leads to solubilisation and refolding to recover the bioactive protein. The proper protein folding of the aggregated protein in inclusion bodies was achieved by solubilising it with a high concentration of urea and then refolded by dilution. The refolded GlaEst12 esterase showed the highest esterase activity that revealed the successful solubilisation of GlaEst12 from inclusion bodies. The expression of recombinant GlaEst12 was optimised with the temperature, induction time, and isopropyl $\beta$-D-1-thiogalactopyranoside concentration at $16^{\circ} \mathrm{C}, 20 \mathrm{~h}$, and $10 \mu \mathrm{M}$, respectively.

The crude refolded GlaEst12 was purified in one-step purification using nickel sepharose affinity chromatography. N-terminal of polyhistidine (His-tag) in pET32b(+) vector was fused and expressed together with esterase, which enables the protein-containing polyhistidine to bind the specific immobilised Nickel (II) ions [23]. The crude refolded GlaEst12 was loaded into a nickel sepharose column, and the bound of protein was eluted using an ascending wise gradient of imidazole concentration. The bound protein was eluted at $300 \mathrm{mM}$ Imidazole concentration and was checked for the presence of target protein by performing a lipase assay and SDS-PAGE. Figure 3 shows a single band on SDS-PAGE with a molecular weight of $63 \mathrm{kDa}$, which is consistent with the size of GlaEst12 (i.e., $45 \mathrm{kDa}$ ) fused with an $18 \mathrm{kDa}$ pET32b(+) vector, indicating the successful purification of GlaEst12 esterase. The esterase was purified for homogeneity with a $40 \%$ yield and a purification fold of 1.72 . The size of protein GlaEst12 was compared with the protein marker. Unlike with other HSL esterases, 
the molecular mass of GlaEst12 is $45 \mathrm{kDa}$, which is slightly higher than the reported range of molecular mass between 30-40 kDa [24-26].

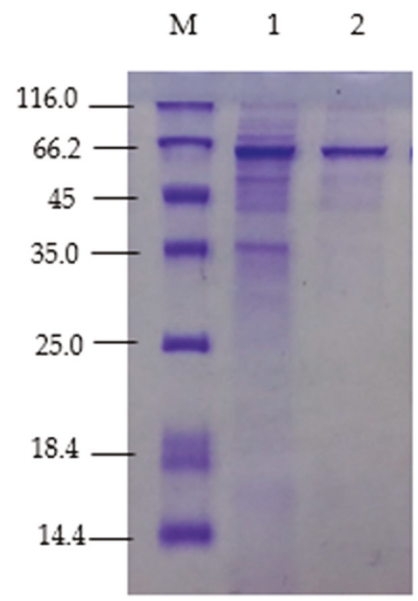

Figure 3. The SDS-PAGE analysis of purified GlaEst12 esterase. Lane M: unstained protein marker (Thermo Scientific, Waltham, MA, USA); Lane 1: refolded GlaEst12; Lane 2: purified GlaEst12-like esterase via Ni-Sepharose affinity chromatography.

\subsection{Characterisation of Purified GlaEst12}

\subsubsection{Effect of Temperature on GlaEst12 Esterase Activity and Stability}

The effect of temperature on GlaEst12 esterase activity and stability was studied by measuring the activity from $10-70{ }^{\circ} \mathrm{C}$ with an interval of $10^{\circ} \mathrm{C}$. Interestingly, the purified GlaEst12 has a broad temperature from $10-70{ }^{\circ} \mathrm{C}$ with an optimum temperature at $60^{\circ} \mathrm{C}$ (Figure 4a) with $980 \mathrm{U} / \mathrm{mL}$, and the activity of GlaEst12 dropped drastically at $70{ }^{\circ} \mathrm{C}$. This indicated that GlaEst12 esterase exhibits thermophilic characteristics rather than psychrophilic, in which most of the reported enzymes from psychrophilic organisms have activity at low temperature with an optimal temperature range between $0-30{ }^{\circ} \mathrm{C}$ [27]. However, this is not the first reported enzyme from a psychrophilic microorganism that has broad temperature because there are already reported microbes isolated from the cold environment that appeared to produce thermotolerant lipases, such as AMS3 lipase from Pseudomonas sp. [28] and lipase ZJB09193 from Candida antarctica [29]. Another explanation of why GlaEst12 is able to withstand at a higher temperature is because of the presence of three cysteines in the amino acid composition. The cysteine consists of a thiolate group in the side chain that will form a disulphide bond that increases the rigidity of the protein, which plays a role in thermostability [27]. Figure $4 \mathrm{~b}$ shows the thermostability of GlaEst12, which was tested by incubating the enzyme at $10-70{ }^{\circ} \mathrm{C}$ for $30 \mathrm{~min}$. The results showed GlaEst12 was most stable at $50^{\circ} \mathrm{C}$ and when incubated at a lower temperature range from $10-40{ }^{\circ} \mathrm{C}$, the reduction of enzyme activity less than $40 \%$. Thermal stability is one of the important criteria for making an enzyme to be used for industrial purposes [30]. Esterases or lipases that have optimal activity at low or high temperatures make them a versatile biocatalyst [31]. 


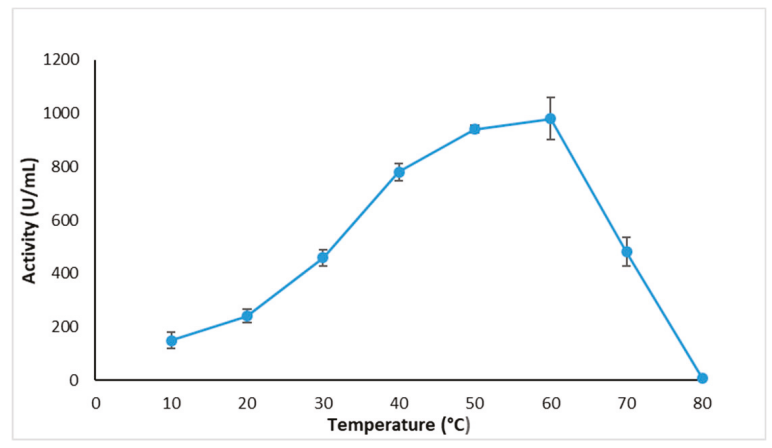

(a)

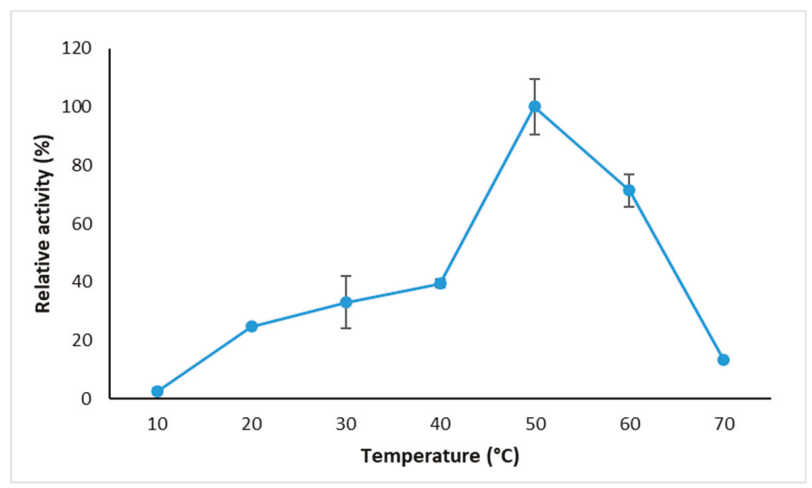

(b)

Figure 4. Effect of temperature on enzyme (a) activity and (b) stability of purified GlaEst12. The optimal temperature was determined by measuring the enzymatic activity at different temperatures ranged from $10-70{ }^{\circ} \mathrm{C}$ by using $\mathrm{C} 10$ as a substrate. The maximum optimal activity was observed at $60{ }^{\circ} \mathrm{C}$. The temperature stability of purified esterase was determined by measuring the residual activities after the enzyme had been incubated for $30 \mathrm{~min}$ at different temperatures $\left(10-80{ }^{\circ} \mathrm{C}\right)$ and the assay was performed at optimum temperature. Error bar represents standard deviation $(n=3)$. The absence of the bar indicates the error smaller than symbols.

\subsubsection{Effects of $\mathrm{pH}$ on GlaEst12 Activity and Stability}

The effect of $\mathrm{pH}$ on purified GlaEst12 esterase was tested on the different buffers with different $\mathrm{pH}$ ranging from $4-11$. This esterase showed maximum activity at $\mathrm{pH} 8$ using the Tris- $\mathrm{HCl}$ buffer. The GlaEst12 tended to be stable at a $\mathrm{pH}$ ranging from 7 to 9 . Figure 5 a shows the increasing trends of enzyme activity from $\mathrm{pH} 6$ of sodium acetate to $\mathrm{pH} 7$ and 8 of sodium phosphate, which peaked at $\mathrm{pH} 8$ of Tris- $\mathrm{HCl}$ and then decreased gradually from $\mathrm{pH} 9$ of Tris- $\mathrm{HCl}$ to $\mathrm{pH} 9-10$ of Glycine-OH. Extreme acidic and alkaline buffers (i.e., $\mathrm{pH}$ less than 6 and $\mathrm{pH}$ more than 10, respectively) exhibited unfavourable conditions for this esterase with enzyme activity less than $100 \mathrm{U} / \mathrm{mL}$. The $\mathrm{pH}$ stability of GlaEst12 was studied by treating the enzyme with various buffers for $30 \mathrm{~min}$. Then, the residual activity after incubation was measured, and the highest activity was denoted as $100 \%$ relative activity, as shown in Figure $5 \mathrm{~b}$. The $\mathrm{pH}$ stability shows a similar pattern to the effects of $\mathrm{pH}$ on the enzyme activity since the GlaEst12 esterase showed the most stable in Tris- $\mathrm{HCl} \mathrm{pH} 8$ and more than $50 \%$ of residual activity stable at $\mathrm{pH} 7-9$. Moreover, the result showed similar findings as reported in the other hormone-sensitive lipases, such as from Psychrobacter sp. TA144 and R. miehei, which have higher 
activity and tend to be stable at $\mathrm{pH} 8$ [11,20]. The buffer with $\mathrm{pH}$ range between $4-6$ showed less than $10 \%$ enzyme activity, suggesting that the extreme acidic condition may affect the secondary structures, which ultimately leads to the reduction of the esterase activity.

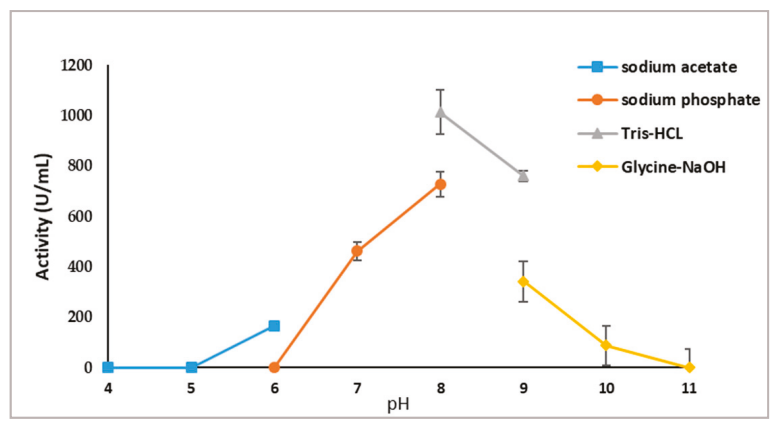

(a)

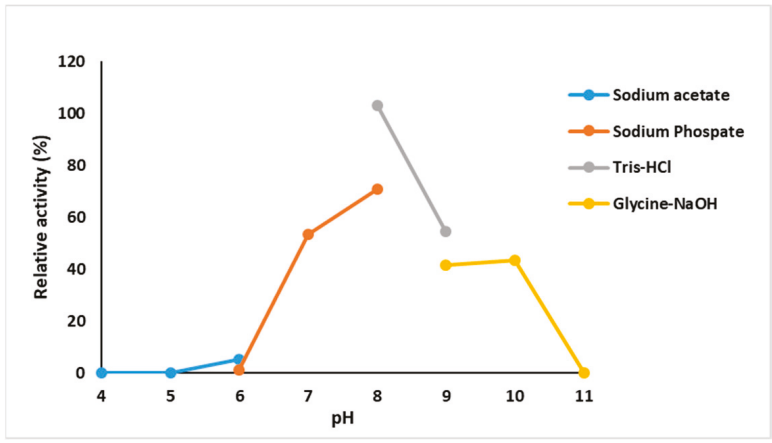

(b)

Figure 5. Effect of purified GlaEst12 esterase on enzyme (a) activity and (b) stability. The optimal $\mathrm{pH}$ was determined by measuring enzyme activity using $\mathrm{pNP}(\mathrm{C} 10)$ as a substrate in different buffer systems ranging from $\mathrm{pH} 4-11$. The $\mathrm{pH}$ stability was determined by incubating an enzyme at different buffers for $30 \mathrm{~min}$ and measuring the residual activity at optimum $\mathrm{pH}$. The buffer systems were used: sodium acetate ( $\mathrm{pH} 4-6$ ) (blue, filled square); sodium phosphate ( $\mathrm{pH} 6-8)$ (orange, filled circle); Tris- $\mathrm{HCl}$ ( $\mathrm{pH}$ 8-9) (grey, filled triangle), and glycine-OH ( $\mathrm{pH}$ 9-11) (yellow, filled diamond). Error bar represents standard deviation $(n=3)$. The absence of the bar indicates the error smaller than symbols.

\subsubsection{Substrate Specificity of GlaEst12 Esterase}

The study on the substrate specificity of GlaEst12 was examined using various $p$-nitrophenyl (pNP) esters with an acyl chain length from C2-C16 using standard assay. The esterase showed high substrate specificity toward middle chain esters, pNP decanoate rather than a shorter or a longer chain of pNP ester. Figure 6 shows that more than $80 \%$ of activity was achieved when GlaEst12 used C 8 as a substrate, while about $50 \%$ activity dropped when this esterase was assayed with a longer chain that is more than 10 carbons. The shorter chain of carbon, such as C2 and C4, had the lowest activity, which was less than $10 \%$, indicating that the GLA has a low specificity toward the shorter carbon chain. The results showed differently from other esterases, for example, HSL esterase that has a protein sequence similarity with GlaEst12, E40 had the highest activity toward pNP butyrate (C4) [32], RmEstA from $R$. miehei prefers pNP hexanoate (C5) [24] and Est22 from deep-sea metagenomic library has the highest activity on pNP butyrate [33]. 


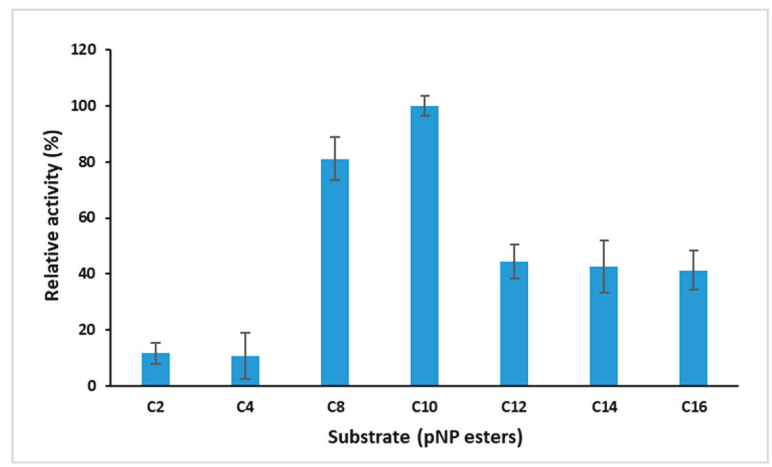

Figure 6. Effect of different pNP esters on purified GlaEst12 esterase. The activity of esterase was measured using different pNP esters at $60{ }^{\circ} \mathrm{C}$ using $50 \mathrm{mM}$ Tris- $\mathrm{HCl} \mathrm{pH}$. The highest activity with p-nitrophenol decanoate (C10) substrate is shown as $100 \%$. Error bar represents standard deviation $(n=3)$.

\subsubsection{Effect of Metal Ions on Esterase Activity}

The importance of metal ions in enzyme catalysis is well established since there are many reported metal-dependent enzymes that enhanced enzyme activity. Each metal ion has different roles since they may play an important role in a redox reaction, stabilisation of negative charges, and activation of substrates by virtue of their Lewis acid properties [34]. Effect of metal ions on GlaEst12-like esterase was conducted by treating the enzyme with various metals ions at the concentration of $1 \mathrm{mM}$ and $5 \mathrm{mM}$. Figure 7 shows that metal ions $\left(\mathrm{Na}^{+}, \mathrm{K}^{+}, \mathrm{Ca}^{2+}\right.$, and $\left.\mathrm{Mn}^{2+}\right)$ enhanced the activity, which was higher than that in the control (enzyme without metal ions). However, $1 \mathrm{mM}$ and $5 \mathrm{mM}$ of $\mathrm{Mg}^{2+}$, $\mathrm{Ni}^{2+}$, and $\mathrm{Cu}^{2+}$ decreased and abolished the GlaEst12 esterase activity. For $\mathrm{Rb}^{+}$, lower concentration showed an increase in the enzyme activity, but the high concentration of $\mathrm{Rb}^{+}$had a negative effect on the enzyme activity. Most of the experiments that involved the HSL-like esterases showed that $\mathrm{Ni}^{2+}$ and $\mathrm{Cu}^{2+}$ tended to decrease the enzyme activity, such as EstAG1 from Staphylococcus saprophyticus and RmEsT from $R$. miehei $[11,35]$.

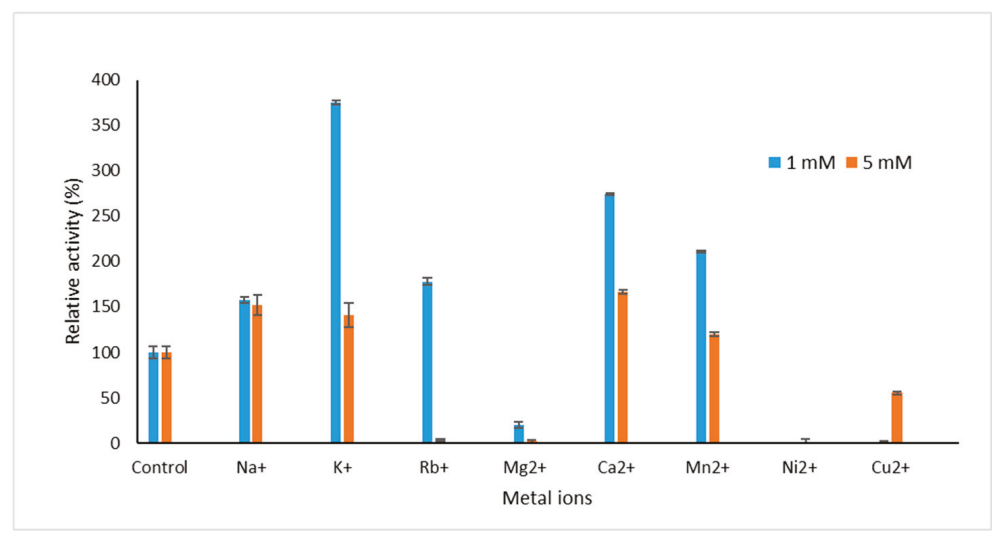

Figure 7. Effect of metal ions on the activity of purified GlaEst12-like esterase. The relative activity of the unincubated enzyme without metal ions (control) was taken $100 \%$. Error bar represents standard deviation $(n=3)$. 


\subsubsection{Effect of Organic Solvents on GlaEst12}

The stability of GlaEst12 esterase on organic solvents was studied by incubating the enzyme with polar and non-polar organic solvents based on $\log$ P-value. Figure 8 reveals the activity of GlaEst12 that is increasing with dimethyl sulfoxide (DMSO) (104\%), 1-propanol (123\%), and Toluene (113\%) compared to the control. However, other solvents such as methanol, acetonitrile, benzene, octanol, xylene, and $n$-hexane caused instability in the protein. Among organic solvents, DMSO tends to give better stability to the GlaEst12 and other HSL esterases, consistent with many previous studies that have reported that this solvent is able to enhance lipolytic activities, such as RmEstB esterase from R. miehei, rEst1 from Rheinheimera sp., and EstAG1 from S. saprophyticus $[11,35,36]$. Based on these results, the enzyme showed less tolerance to the organic solvents since they were unable to resist the denaturation by the organic solvent, and the presence of these solvents may prevent accessibility of substrate to the active site [37].

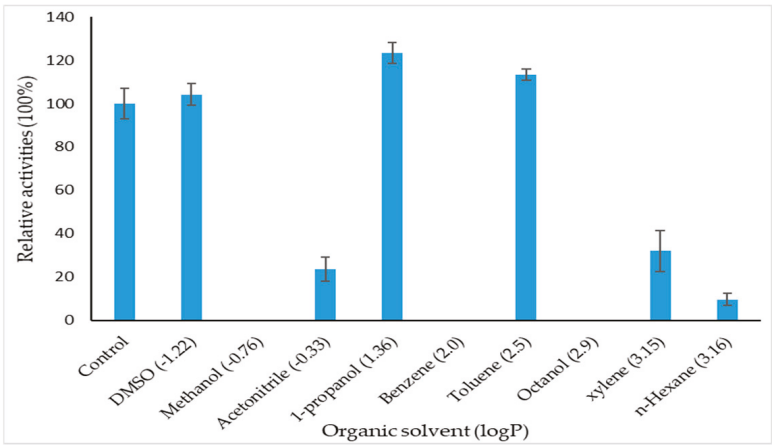

Figure 8. Effect of various organic solvents on the activity of purified GlaEst12-like esterase. The relative activity of the unincubated enzyme without organic solvent (control) was taken $100 \%$. The log $\mathrm{P}$ is the logarithm of the partition coefficient, $\mathrm{P}$, of the solvent between n-octanol and water, and is used as a quantitative measure of the polarity. Error bar represents standard deviation $(n=3)$.

\subsection{Homology Modelling and Validation of GlaEst12}

The homology modelling of GlaEst12 was done using the Robetta server (http://robetta.bakerlab. org/). The software uses two approaches to predict the structure, namely, comparative modelling or de novo structure prediction method. The de novo method was used when the query sequence was not matched with the template sequence and is known as the de novo Rosetta fragment insertion method [38]. Based on the multiple sequence alignments result, a crystal structure of Esterase 40 from the bacterial HSL family was chosen as the template to generate a 3D structure of GlaEst12 because it gave a higher score of sequence identity (about 30\%), and the structure E40 was already solved using $X$-ray diffraction method [32]. Figure 9a shows the predicted model of this esterase that exists as a dimer comprised of two monomers of the subunits. Each monomer is dominated by $33.08 \%$ of $\alpha$-helix followed by $9.52 \%$ and $57.39 \%$ of $\beta$-sheets and others, respectively. A higher number of $\alpha$-helix present in the structure might be helping the survival of this enzyme in the Antarctica environment because an increase in the number of $\alpha$-helix in protein structure tends to make the enzyme more flexible, which is responsible for enzyme activity at low temperatures [39]. The active site of GlaEst12-like esterase was predicted to be at position Ser 232, Glu 341, and His 371 (Figure 9b), which plays an important role in allowing the accessibility of the substrate. Serine residue located at the active site acts as a nucleophile, which is responsible for attacking the carbonyl group of the substrate, and this reaction later forms a tetrahedral intermediate together with the substrates, i.e., histidine and glutamate. In contrast with other esterases and lipases, mammalian HSL and the HSL-like esterase group exhibited conserved motif HGGG sequences. This sequence usually forms a loop in the secondary structure that is located 
in close proximity to the active site and contributes to the formation and stabilisation of the oxyanion hole [40].

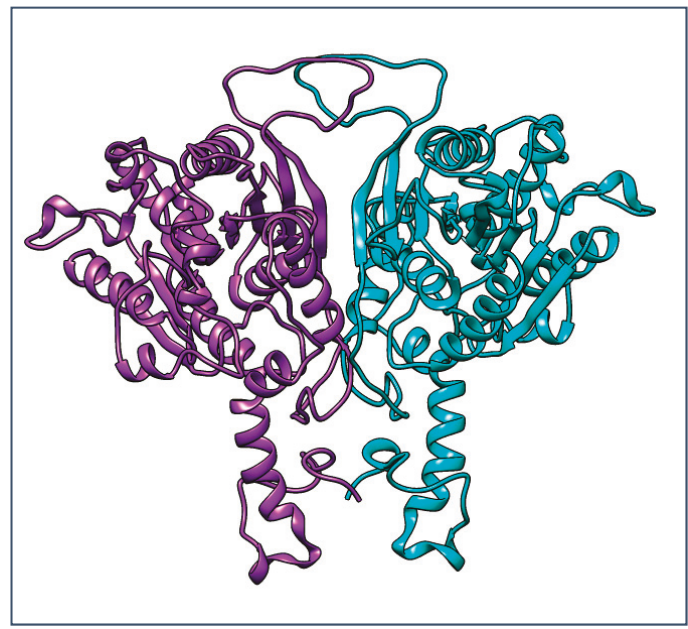

(a)

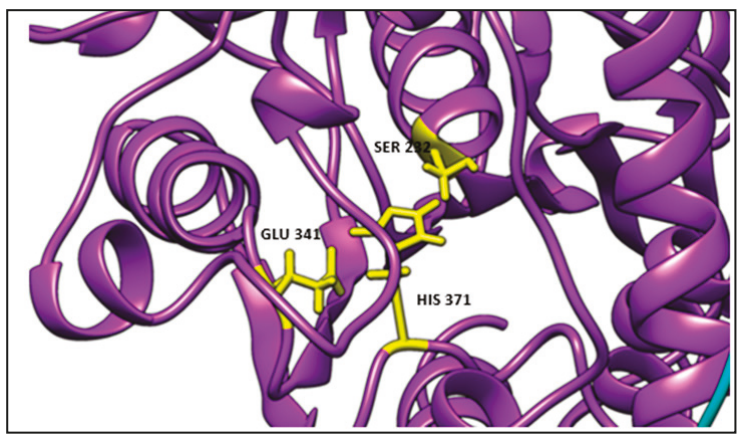

(b)

Figure 9. (a) The predicted GlaEst12 exists as dimer composed of two chain A (purple) and B (cyan) of $\alpha$-helix structure, $\beta$-sheet, and coiled structures. (b) The catalytic triad of GlaEst12 was positioned at $\mathrm{Ser}^{232}, \mathrm{Glu}^{341}$, and $\mathrm{His}^{371}$ and depicted in yellow.

The assessment of protein models with 3D profiles was performed using online websites with the predicted structure of HSL esterase as a subject (Table 1). VERIFY 3D was used to determine the accuracy of the atomic model (3D), where the result was generated by comparing the subject with the structures that had already been solved by crystallography or the nuclear magnetic resonance (NMR) method. From the results, it showed that GlaEst12 has $87.8 \%$ residues of amino acid that scored equal and above 0.2 in Verify 3D. Although the value of score was lower than $90 \%$, this structure is accepted because the residues have low scores at the N-terminal region, and the GLA esterase sequence is mostly conserved only at the central region as revealed by the multiple sequence alignment (Figure 1). This result showed consistency with the previous study, which stated that HSL lipase from the psychrophilic Psychrobacter sp. has sequence similarity with other homologous HSL proteins at the central region to the catalytic region. However, this psychrophilic enzyme has an additional sequence at the N-terminal region, which is expected to be the additional domain unique to the cold-adapted protein [20]. The addition of four $\alpha$-helix domains at the N-terminal in GlaEst12 comparing to the other HSLs might 
support the facts of the additional domain in HSL lipase from Psychrobacter since both of them are from the psychrophilic Antarctic. Besides that, the Errat tool was used to determine the accuracy and exactness of the atom distribution in the protein region and GlaEst12 has a high score that is more than $90 \%$. The predicted structure was validated using a Ramachandran plot and revealed that $84.8 \%$ of it, which is about 328 residues, was located at the favoured region, while the remaining $14.8 \%, 0.3 \%$, and $0.1 \%$ located at allowed, general, and outlier, respectively. The residues located at the disallowed region contributed about $0.1 \%$ of the total residues together with one of the catalytic triad, which is serine at position 232. The presence of the catalytic triad serine at negative region suggested that the enzyme is an active conformation. In contrast, the predicted structure of AMS8 lipase revealed that the catalytic serine is located at the allowed region and the protein is a closed conformation since it has the lid structure that covers the active site [41].

Table 1. The summary score for the predicted structure of GlaEst12 esterase using online web tools.

\begin{tabular}{llc}
\hline \multicolumn{1}{c}{ Validation Tools } & Score (\%) \\
\hline (A) & Verify 3D & 87.8 \\
(B) Errat & 91.3 \\
(C) Ramachandran Plot & \\
& Most favoured region & 84.8 \\
& Additional allowed region & 14.8 \\
& Generously allowed region & 0.3 \\
& Disallowed region & 0.1 \\
\hline
\end{tabular}

\section{Materials and Methods}

\subsection{Sequence Analysis of GlaEst12}

Previously, a psychrophilic yeast named G. antarctica was successfully isolated from sea ice near Casey Research Station, Antarctica. The whole-genome sequencing of this organism was done using 454 pyrosequencing and Illumina technology, with the protein information of G. antarctica being deposited in the Glaciozyma antarctica Genome Database (GanDB) (www.mgi-nibm.my/glaciozyma_ antarctica) [42]. The gene encoding for putative esterase was chosen and known as Glaciozyma antarctica hormone-sensitive lipase (GlaEst12) esterase. The protein sequence of GlaEst12 was analysed using the GenBank database BLASTp (http://www.ncbi.nih.gov) from the NCBI to search the protein similarity with the other proteins. The amino acid composition, molecular weight, and predicted pI value of GlaEst12 were determined using Expasy Tools (https://web.expasy.org/protparam/). The presence of the signal peptide was predicted using the online tool SignalP-5.0 server (http: //www.cbs.dtu.dk/services/SignalP/). The sequences similarity and secondary structure information from aligned sequences were performed using ENDscript 2.0 (http://endscript.ibcp.fr). The phylogenetic tree was constructed using MEGA 7.0, whereby the GlasEst12 protein was aligned with eight additional proteins (accession numbers: WP_012330536.1, ADH59412, QBH67630.1, KX580963.1, 4WY8, 4WY5, 4QO5, and 4Q30). The alignment was generated using Clustal $\mathrm{W}$, and the evolutionary history was inferred by using the Neighbour Joining method with a Jones-Taylor-Thornton (JTT) method.

\subsection{Gene Synthesis, Bacteria Strains, and Plasmids}

The sequence of GlaEst12-like esterase that encoded for 1200 nucleotides was sent for gene synthesis. Codon optimisation was performed based on preferred codons by E. coli to enhance GLA HSL lipase expression in the E. coli host system. This codon-optimised gene was synthesised together with restriction endonuclease EcoR1 and Xho1 placed at the beginning and at the end of the gene sequence (Integrated DNA Technologies, Coralville, IA, USA). This gene was also cloned into a cloning vector (pUCIDT) and supplied in the dried plasmids. Since the pUCIDT/GLA HSL plasmid was in the form of powder, plasmid resuspension was carried out according to the manufacturer's protocol (Integrated DNA Technologies, Coralville, IA, USA). For cloning and expression of the protein, pET32b 
(Merck, Kenilworth, NJ, USA) was used together with E. coli BL21(De3) as vector and expression host, respectively.

\subsection{Cloning of GlaEst12 in E. coli}

The gene that encoded GLA HSL lipase gene was amplified by PCR using recombinant plasmid pUCIDT/GLA HSL as a template. A set of forward and reverse primers with EcoRI and XhoI restriction sites were designed based on an optimised GLA HSL esterase gene sequence. The forward and reverse sequences are 5'CGTGAATTCGATGTTGAGTCCTG-3' and 5' GAGCTCTTAAAACTTCCCGTCTA-3', respectively, in which the underlined nucleotide sequences represent the sequences of EcoRI and XhoI. The PCR product was purified using a Gel Extraction kit (GeneAll, Seoul, Korea) and then digested with restriction enzymes EcoRI and XhoI. The digested PCR product was cloned into a pET32b vector (Merck, Kenilworth, NJ, USA) and transformed into E. coli BL21(De3) in tributyrin-containing ampicillin agar plates. The agar plates were incubated at $37^{\circ} \mathrm{C}$ for $16 \mathrm{~h}$ and followed by incubation at $4{ }^{\circ} \mathrm{C}$ for $24 \mathrm{~h}$. The positively transformed colonies were indicated by the formation of halo zones of colonies in tributyrin agar supplemented with ampicillin.

\subsection{Expression, Solubilisation, and Refolding of GlaEst12 Inclusion Bodies}

The recombinant GlaEst12 was expressed using pET32(b) + vector and transformed into E. coli BL21(De3). The expression was induced using $10 \mu \mathrm{M}$ IPTG at $16^{\circ} \mathrm{C}$ for $20 \mathrm{~h}$. Solubilisation of GlaEst12 was conducted as the enzyme was mostly expressed as inclusion bodies. The E. coli cell was harvested by centrifugation at $10,000 \times g$ for $15 \mathrm{~min}$. Then, the supernatant was discarded, and the pellet was resuspended with $20 \mathrm{~mL}$ of $50 \mathrm{mM}$ Tris- $\mathrm{HCl}(\mathrm{pH} 8)$ and subjected to sonication for 6 min under the output of 2 and duty cycle of 20 (Sonifer ${ }^{\circledR}$ SLP150 Branson, Danbury, CT, USA). The clear lysate was centrifuged at $10,000 \times g$ for $15 \mathrm{~min}$, and the pellet-containing insoluble protein was further resuspended with Tris- $\mathrm{HCl}$ buffer ( $\mathrm{pH}$ ) containing $8 \mathrm{M}$ of urea. The resuspend mixture was then incubated at $4{ }^{\circ} \mathrm{C}$ for $4 \mathrm{~h}$ with constant agitation. After incubation, the mixture was centrifuged with the same condition stated above, and the supernatant was used for further reaction. Renaturation of the supernatant containing the GlaEst12-like esterase was achieved by a $10 \times$ dilution of the denaturant in $50 \mathrm{mM}$ Tris- $\mathrm{HCl}$ buffer $(\mathrm{pH}$ 8). The solubilised protein was diluted in one-step with a peristaltic pump of the flow rate of $0.5 \mathrm{~mL} / \mathrm{min}$ and stirred thoroughly at $4{ }^{\circ} \mathrm{C}$. The refolded protein was then subjected to enzyme assay.

\subsection{Purification of Recombinant of GlaEst12-Like Esterase}

The His-tagged of recombinant GlaEst12 was purified by single-step Ni-sepharose affinity chromatography. The filtered crude protein was loaded onto a Nickel-Sepharose HP column (XK16/20) (GE Healthcare, Boston, MA, USA). The binding buffer $[20 \mathrm{mM}$ Sodium phosphate, $10 \mathrm{mM}$ imidazole, $500 \mathrm{mM} \mathrm{NaCl}$ (pH 7.4)] was used to equilibrate the column at a flow rate of $1 \mathrm{~mL} / \mathrm{min}$. Then, the crude protein was loaded onto the column, and the bound protein was eluted with an ascending step gradient of elution buffer [20 mM Sodium phosphate, $500 \mathrm{mM}$ imidazole, $500 \mathrm{mM} \mathrm{NaCl}$ (pH 7.4)]. The eluted proteins were collected in $2 \mathrm{~mL}$ per fraction. The fractions containing the protein of interest were confirmed through pNP assay and SDS-PAGE. The fractions containing protein of interest were pooled, dialysed with buffer [ $50 \mathrm{mM}$ Tris- $\mathrm{HCl}, 50 \mathrm{mM} \mathrm{NaCl}(\mathrm{pH} 8)]$, and stored at $4{ }^{\circ} \mathrm{C}$ for further characterisation. The molecular weight of GlaEst12 was determined by using SDS-PAGE with $6 \%$ stacking gel and $12 \%$ separating gel, as described by Laemmli., 1970, with some modification [43]. The gel was stained using Coomassie Brilliant Blue R 250 (BioRad, Hercules, CA, USA) and destained with a destaining solution. The molecular mass of the protein was estimated using a broad range of protein standard markers (unstained protein marker 18.4-116 kDa, Thermo Scientific, Waltham, MA, USA). 


\subsection{Enzyme Assay}

A spectrophotometric method was used to determine the GlaEst12 activity using pNP substrate. The pNP released from the substrate was measured according to the method described by Sumby et al., 2009, with some modifications [44]. The mixture reaction consisted of $950 \mu \mathrm{L}$ of $50 \mathrm{mM}$ Tris- $\mathrm{HCl}(\mathrm{pH} 8)$, $25 \mu \mathrm{L}$ of $10 \mathrm{mM}$-nitrophenyl decanoate (C10:0), and $25 \mu \mathrm{L}$ of $0.1 \mathrm{mg} / \mathrm{mL}$ enzyme. The mixture was assayed with shaking at $150 \mathrm{rpm}, 60^{\circ} \mathrm{C}$ for $10 \mathrm{~min}$. Then, the liberation of pNP was measured using Biochrom WPA UV/Visible spectrophotometer (Cambridge, UK) at $410 \mathrm{~nm}$. The absorbance of the sample was deduced with the control that the mixture stated above without the enzyme. One unit of esterase was defined as $1.0 \mu \mathrm{mol}$ of pNP released per min under the conditions stated above.

\subsection{Characterisation of Purified GlaEst12}

\subsubsection{Effect of Temperature on Activity and Stability}

The determination of the effective temperature of purified GlaEst12-like esterase on its activity was conducted by measuring the esterase activity (as mentioned in Section 3.6) assayed at different temperatures of $10-80^{\circ} \mathrm{C}\left(10^{\circ} \mathrm{C}\right.$ interval $)$ for $10 \mathrm{~min}$. For thermostability, $25 \mu \mathrm{L}$ of the enzyme was first incubated with $50 \mathrm{mM}$ Tris- $\mathrm{HCl} \mathrm{pH} 8$ at different temperatures of $10-70{ }^{\circ} \mathrm{C}\left(10^{\circ} \mathrm{C}\right.$ interval $)$ for $30 \mathrm{~min}$ without substrate. Then, the residual of enzyme activity was assayed together with $10 \mathrm{mM}$ $p$-nitrophenyl decanoate $(\mathrm{C} 10)$ as substrate at the optimum temperature of $60{ }^{\circ} \mathrm{C}$ for $10 \mathrm{~min}$.

\subsubsection{Effect of $\mathrm{pH}$ and $\mathrm{pH}$ Stability}

Different buffers were used to study and determine the optimum buffer for GlaEst12-like esterase under $\mathrm{pH}$ range from 4-11. The buffers used were $50 \mathrm{mM}$ sodium acetate $(\mathrm{pH} 4.0-6.0), 50 \mathrm{mM}$ sodium phosphate (pH 6.0-8.0), $50 \mathrm{mM}$ Tris- $\mathrm{HCl}$ (pH 8.0-9.0), and $50 \mathrm{mM}$ glycine- $\mathrm{NaOH}$ (pH 9.0-11.0). The $\mathrm{pH}$ stability was investigated by incubating the enzyme with different buffers as stated above at $60{ }^{\circ} \mathrm{C}$ for $30 \mathrm{~min}$ and followed by enzyme assay (same as in point 3.6).

\subsubsection{Effect of Substrate Specificity}

The substrate specificity was determined by p-nitrophenyl esters with various chain lengths, including $p$-nitrophenyl acetate (C2), p-nitrophenyl butyrate (C4), p-nitrophenyl octanoate (C8), p-nitrophenyl decanoate (C10), p-nitrophenyl laurate (C12), p-nitrophenyl myristate (C14), and $p$-nitrophenyl palmitate (C16). The reaction mixtures containing $25 \mu \mathrm{L}$ of the purified enzyme, $950 \mu \mathrm{L}$ of $50 \mathrm{mM}$ Tris- $\mathrm{HCl} \mathrm{pH} \mathrm{8,} \mathrm{and} 10 \mathrm{mM}$ of different substrates were assayed at $60^{\circ} \mathrm{C}$ for $10 \mathrm{~min}$.

\subsubsection{Effect of Metals Ions}

GlaEst12-like esterase was treated with $1 \mathrm{mM}$ and $5 \mathrm{mM}$ metal ions (i.e., $\mathrm{Li}^{+}, \mathrm{Na}^{+}, \mathrm{K}^{+}, \mathrm{Rb}^{2+}, \mathrm{Mg}^{2+}$, $\left.\mathrm{Ca}^{2+}, \mathrm{Mn}^{2+}, \mathrm{Ni}^{2+}, \mathrm{Cu}^{2+}\right)$. The treated enzyme was then subjected to enzyme assay. For $1 \mathrm{mM}$ of metal ions, $940 \mu \mathrm{L}$ of Tris- $\mathrm{HCl}$ buffer $\mathrm{pH} 8,25 \mu \mathrm{L}$ of the enzyme was treated with $10 \mu \mathrm{L}$ of metal ions for $30 \mathrm{~min}$ at $60{ }^{\circ} \mathrm{C}$. Then, $25 \mu \mathrm{L}$ of $10 \mathrm{mM}$-nitrophenyl decanoate (C10) was added to the mixture and assay, as mentioned in point 3.6. For $5 \mathrm{mM}$, all the composition are same as $1 \mathrm{mM}$ except for the composition of buffer and metal ions, which used $900 \mu \mathrm{L}$ and $50 \mu \mathrm{L}$, respectively. The stability was determined as the relative activity to the control (i.e., without a metal ion).

\subsubsection{Effect of Organic Solvents}

The esterase was incubated for $30 \mathrm{~min}$ at $60{ }^{\circ} \mathrm{C}$ with various organic solvents at a concentration of $25 \%(v / v)$. The solvents were selected based on their log P values (in parentheses): DMSO (-1.22), methanol (-0.76), acetonitrile (-0.33), 1-propanol (1.36) benzene (2.0), toluene (2.5), octanol (2.9), xylene (3.15), and $n$-hexane (3.16). The mixtures pre-incubate for $30 \mathrm{~min}$, which contained $700 \mu \mathrm{L}$ of $50 \mathrm{mM}$ of Tris- $\mathrm{HCl}(\mathrm{pH} 8), 25 \mu \mathrm{L}$ of the enzyme, and $250 \mu \mathrm{L}$ of organic solvents and later were assayed together 
with $10 \mathrm{mM}$ of $p$-nitrophenyl decanoate $(\mathrm{C} 10)$ at $60^{\circ} \mathrm{C}$. The stability was determined as the relative activity to the control (i.e., without organic solvent).

\subsection{Homology Modelling and Structure Validation}

The homology modelling was used to predict 3D structure using templates deposited in the Protein Data Bank (PDB) that have high similarity to GlaEst12. The 3D structure of GlaEst12 was generated by using the Robetta server (http://robetta.bakerlab.org) that provides automated tools for protein structure prediction, while the figures were prepared using the Chimera visual system (www.cgl.ucsf.edu/chimera). The validation of protein structure was done using online software such as Ramachandran Plot (http://www-cryst.bioc.cam.ac.uk/), Errat [45], and VERIFY 3D [46].

\section{Conclusions}

A novel HSL-like esterase family known as GlaEst12 is being introduced from G. antarctica, a psychrophilic yeast. Multiple sequence alignment with another hormone-sensitive lipase proteins revealed GlaEst12 as a new member of the GDSAG motif subfamily of the HSL family. GlaEst12-like esterase was successfully expressed in E. coli and purified with single-step nickel-sepharose affinity chromatography. Biochemical characterisation of this esterase showed interestingly higher activity and stability at a higher temperature, which gives a unique feature to HSL-like esterase that was isolated from psychrophilic yeast. Besides that, this esterase was activated when treated with metal ions $\mathrm{Na}^{+}$, $\mathrm{K}^{+}, \mathrm{Ca}^{2+}, \mathrm{Mn}^{2+}$ ) and stabilised when incubated with 1-propanol and toluene. Homology modelling of this GlaEst12-like esterase showed the predicted structure of this enzyme that is composed of a typical $\alpha / \beta$ hydrolase fold with the catalytic residues found at $\mathrm{Ser}^{232}{ }^{2} \mathrm{Glu}^{341}$, and $\mathrm{His}{ }^{371}$. The characterisation of GlaEst12 that can withstand a broad temperature and remain stable in an alkaline environment make it a potential catalyst in industrial application.

Author Contributions: Conceptualisation, H.M.T. and M.S.M.A.; methodology, H.M.T. and M.S.M.A.; validation, M.S.M.A., R.N.Z.R.A.R. and A.T.C.L.; formal analysis, H.M.T. and M.S.M.A.; investigation, H.M.T.; Resources, M.S.M.A., R.N.Z.R.A.R. and A.T.C.L.; data curation, H.M.T. and M.S.M.A.; writing (review and editing) H.M.T. and M.S.M.A.; visualisation, H.M.T., M.S.M.A. and R.N.Z.R.A.R.; supervision, M.S.M.A., R.N.Z.R.A.R., A.T.C.L.; project administration, M.S.M.A.; funding acquisition, M.S.M.A., R.N.Z.R.A.R. and A.T.C.L. All authors have read and agreed to the published version of the manuscript.

Funding: Putra Grant funded this research, grant number 9601600.

Acknowledgments: This research and H.M.T scholarship were supported by research grant (GP-IPS/2017/9601600) and Graduate Research Fellowship (GRF) fund from Universiti Putra Malaysia.

Conflicts of Interest: The authors declare no conflict of interest.

\section{References}

1. Jensen, M.B.V.; Horsfall, L.E.; Wardrope, C.; Togneri, P.D.; Marles-Wright, J.; Rosser, S.J. Characterisation of a New Family of Carboxyl Esterases with an OsmC Domain. PLoS ONE 2016, 11, e0166128. [CrossRef]

2. Fojan, P. What Distinguishes an Esterase from a Lipase: A Novel Structural Approach. Biochimie 2000, 82, 1033-1041. [CrossRef]

3. De Simone, G.; Mandrich, L.; Menchise, V.; Giordano, V.; Febbraio, F.; Rossi, M.; Pedone, C.; Manco, G. A Substrate-Induced Switch in the Reaction Mechanism of a Thermophilic Esterase: KINETIC EVIDENCES AND STRUCTURAL BASIS. J. Biol. Chem. 2004, 279, 6815-6823. [CrossRef]

4. Lampidonis, A.D.; Rogdakis, E.; Voutsinas, G.E.; Stravopodis, D.J. The Resurgence of Hormone-Sensitive Lipase (HSL) in Mammalian Lipolysis. Gene 2011, 477, 1-11. [CrossRef]

5. Langin, D.; Laurell, H.; Holst, L.S.; Belfrage, P.; Holm, C. Gene Organization and Primary Structure of Human Hormone-Sensitive Lipase: Possible Significance of a Sequence Homology with a Lipase of Moraxella TA144, an Antarctic Bacterium. Proc. Natl. Acad. Sci. USA 1993, 90, 4897-4901. [CrossRef]

6. Kim, T.D. Bacterial Hormone-Sensitive Lipases (BHSLs): Emerging Enzymes for Biotechnological Applications. J. Microbiol. Biotechnol. 2017, 27, 1907-1915. [CrossRef] 
7. Pöhlmann, C.; Wang, Y.; Humenik, M.; Heidenreich, B.; Gareis, M.; Sprinzl, M. Rapid, Specific and Sensitive Electrochemical Detection of Foodborne Bacteria. Biosens. Bioelectron. 2009, 24, 2766-2771. [CrossRef]

8. Febbraio, F.; Merone, L.; Cetrangolo, G.P.; Rossi, M.; Nucci, R.; Manco, G. Thermostable Esterase 2 from Alicyclobacillus acidocaldarius as Biosensor for the Detection of Organophosphate Pesticides. Anal. Chem. 2011, 83, 1530-1536. [CrossRef]

9. Jaeger, K.E.; Eggert, T. Lipases for Biotechnology. Curr. Opin. Biotechnol. 2002, 13, 390-397. [CrossRef]

10. Bassegoda, A.; Fillat, A.; Pastor, F.I.J.; Diaz, P. Special Rhodococcus sp. CR-53 Esterase Est4 Contains a GGG(A)X-Oxyanion Hole Conferring Activity for the Kinetic Resolution of Tertiary Alcohols. Appl. Microbiol. Biotechnol. 2013, 97, 8559-8568. [CrossRef]

11. Yan, Q.; Yang, S.; Duan, X.; Xu, H.; Liu, Y.; Jiang, Z. Characterization of a Novel Hormone-Sensitive Lipase Family Esterase from Rhizomucor miehei with Tertiary Alcohol Hydrolysis Activity. J. Mol. Catal. B Enzym. 2014, 109, 76-84. [CrossRef]

12. Petrovskaya, L.E.; Novototskaya-Vlasova, K.A.; Gapizov, S.S.; Spirina, E.V.; Durdenko, E.V.; Rivkina, E.M. New Member of the Hormone-Sensitive Lipase Family from the Permafrost Microbial Community. Bioengineered 2017, 8, 420-423. [CrossRef]

13. Li, P.Y.; Ji, P.; Li, C.Y.; Zhang, Y.; Wang, G.L.; Zhang, X.Y.; Xie, B.B.; Qin, Q.L.; Chen, X.L.; Zhou, B.C.; et al. Structural Basis for Dimerization and Catalysis of a Novel Esterase from the GTSAG Motif Subfamily of the Bacterial Hormone-Sensitive Lipase Family. J. Biol. Chem. 2014, 289, 19031-19041. [CrossRef]

14. Turchetti, B.; Thomas Hall, S.R.; Connell, L.B.; Branda, E.; Buzzini, P.; Theelen, B.; Müller, W.H.; Boekhout, T. Psychrophilic Yeasts from Antarctica and European Glaciers: Description of Glaciozyma Gen. Nov., Glaciozyma martinii sp. Nov. and Glaciozyma watsonii sp. Nov. Extremophiles 2011, 15, 573-586. [CrossRef]

15. Boo, S.Y.; Wong, C.M.V.L.; Rodrigues, K.F.; Najimudin, N.; Murad, A.M.A.; Mahadi, N.M. Thermal Stress Responses in Antarctic Yeast, Glaciozyma antarctica PI12, Characterized by Real-Time Quantitative PCR. Polar Biol. 2013, 36, 381-389. [CrossRef]

16. Alias, N.; Mazian, A.; Salleh, A.B.; Basri, M.; Rahman, R.N.Z.R. Molecular Cloning and Optimization for High Level Expression of Cold-Adapted Serine Protease from Antarctic Yeast Glaciozyma antarctica PI12. Enzym. Res. 2014, 2014, 1-20. [CrossRef]

17. Hashim, N.H.F.; Sulaiman, S.; Abu Bakar, F.D.; Illias, R.M.; Kawahara, H.; Najimudin, N.; Mahadi, N.M.; Murad, A.M.A. Molecular Cloning, Expression and Characterisation of Afp4, an Antifreeze Protein from Glaciozyma antarctica. Polar Biol. 2014, 37, 1495-1505. [CrossRef]

18. Ramli, A.N.M.; Azhar, M.A.; Shamsir, M.S.; Rabu, A.; Murad, A.M.A.; Mahadi, N.M.; Illias, R.M. Sequence and Structural Investigation of a Novel Psychrophilic $\alpha$-Amylase from Glaciozyma antarctica PI12 for Cold-Adaptation Analysis. J. Mol. Model. 2013, 19, 3369-3383. [CrossRef]

19. Ramli, A.; Mahadi, N.; Rabu, A.; Murad, A.; Bakar, F.; Illias, R. Molecular Cloning, Expression and Biochemical Characterisation of a Cold-Adapted Novel Recombinant Chitinase from Glaciozyma antarctica PI12. Microb. Cell Fact. 2011, 10, 94. [CrossRef]

20. De Santi, C.; Tutino, M.L.; Mandrich, L.; Giuliani, M.; Parrilli, E.; Del Vecchio, P.; de Pascale, D. The Hormone-Sensitive Lipase from Psychrobacter sp. TA144: New Insight in the Structural/Functional Characterization. Biochimie 2010, 92, 949-957. [CrossRef]

21. Li, Z.; Su, L.; Wang, L.; Liu, Z.; Gu, Z.; Chen, J.; Wu, J. Novel Insight into the Secretory Expression of Recombinant Enzymes in Escherichia coli. Process Biochem. 2014, 49, 599-603. [CrossRef]

22. Deb, C. A Novel Lipase Belonging to the Hormone-Sensitive Lipase Family Induced under Starvation to Utilize Stored Triacylglycerol in Mycobacterium tuberculosis. J. Biol. Chem. 2006, 281, 3866-3875. [CrossRef] [PubMed]

23. Bornhorst, J.A.; Falke, J.J. Purification of Proteins Using Polyhistidine Affinity Tags. In Methods in Enzymology; Elsevier: Amsterdam, The Netherlands, 2000; Volume 326, pp. 245-254.

24. Liu, Y.; Xu, H.; Yan, Q.; Yang, S.; Duan, X.; Jiang, Z. Biochemical Characterization of a First Fungal Esterase from Rhizomucor miehei Showing High Efficiency of Ester Synthesis. PLoS ONE 2013, 8, e77856. [CrossRef]

25. Jeon, J.H.; Lee, H.S.; Kim, J.T.; Kim, S.J.; Choi, S.H.; Kang, S.G.; Lee, J.H. Identification of a New Subfamily of Salt-Tolerant Esterases from a Metagenomic Library of Tidal Flat Sediment. Appl. Microbiol. Biotechnol. 2012, 93, 623-631. [CrossRef] 
26. Jin, P.; Pei, X.; Du, P.; Yin, X.; Xiong, X.; Wu, H.; Zhou, X.; Wang, Q. Overexpression and Characterization of a New Organic Solvent-Tolerant Esterase Derived from Soil Metagenomic DNA. Bioresour. Technol. 2012, 116, 234-240. [CrossRef]

27. Salwoom, L.; Rahman, R.A.; Zaliha, R.N.; Salleh, A.B.; Convey, P.; Ali, M.; Shukuri, M. New Recombinant Cold-Adapted and Organic Solvent Tolerant Lipase from Psychrophilic Pseudomonas sp. LSK25, Isolated from Signy Island Antarctica. Int. J. Mol. Sci. 2019, 20, 1264. [CrossRef]

28. Latip, W.; Rahman, R.N.; Leow, A.T.; Shariff, F.M.; Ali, M.S. Expression and Characterization of Thermotolerant Lipase with Broad PH Profiles Isolated from an Antarctic Pseudomonas sp. Strain AMS3. PeerJ 2016, 4, e2420. [CrossRef]

29. Liu, Z.Q.; Zheng, X.B.; Zhang, S.P.; Zheng, Y.G. Cloning, Expression and Characterization of a Lipase Gene from the Candida antarctica ZJB09193 and Its Application in Biosynthesis of Vitamin A Esters. Microbiol. Res. 2012, 167, 452-460. [CrossRef]

30. Joseph, B.; Ramteke, P.W.; Thomas, G. Cold Active Microbial Lipases: Some Hot Issues and Recent Developments. Biotechnol. Adv. 2008, 26, 457-470. [CrossRef]

31. Lopez-Lopez, O.; Cerdan, M.; Siso, M. New Extremophilic Lipases and Esterases from Metagenomics. Curr. Protein Pept. Sci. 2014, 15, 445-455. [CrossRef]

32. Li, P.Y.; Chen, X.L.; Ji, P.; Li, C.Y.; Wang, P.; Zhang, Y.; Xie, B.B.; Qin, Q.L.; Su, H.N.; Zhou, B.C.; et al. Interdomain Hydrophobic Interactions Modulate the Thermostability of Microbial Esterases from the Hormone-Sensitive Lipase Family. J. Biol. Chem. 2015, 290, 11188-11198. [CrossRef] [PubMed]

33. Huang, J.; Huo, Y.Y.; Ji, R.; Kuang, S.; Ji, C.; Xu, X.W.; Li, J. Structural Insights of a Hormone Sensitive Lipase Homologue Est22. Sci. Rep. 2016, 6, 28550. [CrossRef] [PubMed]

34. Andreini, C.; Bertini, I.; Cavallaro, G.; Holliday, G.L.; Thornton, J.M. Metal Ions in Biological Catalysis: From Enzyme Databases to General Principles. J. Biol. Inorg. Chem. 2008, 13, 1205-1218. [CrossRef] [PubMed]

35. Gricajeva, A.; Bikute, I.; Kalèdienè, L. Atypical Organic-Solvent Tolerant Bacterial Hormone Sensitive Lipase-like Homologue EstAG1 from Staphylococcus Saprophyticus AG1: Synthesis and Characterization. Int. J. Biol. Macromol. 2019, 130, 253-265. [CrossRef] [PubMed]

36. Virk, A.P. A New Esterase, Belonging to Hormone-Sensitive Lipase Family, Cloned from Rheinheimera sp. Isolated from Industrial Effluent. J. Microbiol. Biotechnol. 2011, 21, 667-674. [CrossRef] [PubMed]

37. Bansal, V.; Delgado, Y.; Fasoli, E.; Ferrer, A.; Griebenow, K.; Secundo, F.; Barletta, G.L. Effect of Prolonged Exposure to Organic Solvents on the Active Site Environment of Subtilisin Carlsberg. J. Mol. Catal. B Enzym. 2010, 64, 38-44. [CrossRef] [PubMed]

38. Kim, D.E.; Chivian, D.; Baker, D. Protein Structure Prediction and Analysis Using the Robetta Server. Nucleic Acids Res. 2004, 32, W526-W531. [CrossRef]

39. D'Amico, S.; Collins, T.; Marx, J.C.; Feller, G.; Gerday, C. Psychrophilic Microorganisms: Challenges for Life. EMBO Rep. 2006, 7, 385-389. [CrossRef]

40. Rehdorf, J.; Behrens, G.A.; Nguyen, G.S.; Kourist, R.; Bornscheuer, U.T. Pseudomonas Putida Esterase Contains a GGG(A)X-Motif Confering Activity for the Kinetic Resolution of Tertiary Alcohols. Appl. Microbiol. Biotechnol. 2012, 93, 1119-1126. [CrossRef]

41. Ali, M.S.M.; Ganasen, M.; Rahman, R.N.Z.R.A.; Chor, A.L.T.; Salleh, A.B.; Basri, M. Cold-Adapted RTX Lipase from Antarctic Pseudomonas sp. Strain AMS8: Isolation, Molecular Modeling and Heterologous Expression. Protein J. 2013, 32, 317-325. [CrossRef]

42. Firdaus-Raih, M.; Hashim, N.H.F.; Bharudin, I.; Abu Bakar, M.F.; Huang, K.K.; Alias, H.; Lee, B.K.B.; Mat Isa, M.N.; Mat-Sharani, S.; Sulaiman, S.; et al. The Glaciozyma antarctica Genome Reveals an Array of Systems That Provide Sustained Responses towards Temperature Variations in a Persistently Cold Habitat. PLoS ONE 2018, 13, e0189947. [CrossRef] [PubMed]

43. Laemmli, U.K. Cleavage of Structural Proteins during the Assembly of the Head of Bacteriophage T4. Nature 1970, 227, 680-685. [CrossRef] [PubMed]

44. Sumby, K.M.; Matthews, A.H.; Grbin, P.R.; Jiranek, V. Cloning and Characterization of an Intracellular Esterase from the Wine-Associated Lactic Acid Bacterium Oenococcus oeni. Appl. Environ. Microbiol. 2009, 75, 6729-6735. [CrossRef] [PubMed] 
45. Colovos, C.; Yeates, T.O. Verification of Protein Structures: Patterns of Nonbonded Atomic Interactions. Protein Sci. 1993, 2, 1511-1519. [CrossRef] [PubMed]

46. Luthy, R.; Bowie, J.U.; Eisenberg, D. Assesment of Protein Models with 3 Dimensional Profile. Nature 1992, 356, 83-85. [CrossRef]

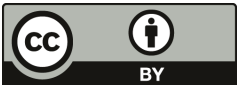

(C) 2020 by the authors. Licensee MDPI, Basel, Switzerland. This article is an open access article distributed under the terms and conditions of the Creative Commons Attribution (CC BY) license (http://creativecommons.org/licenses/by/4.0/). 



\title{
Article \\ Characterization of the Novel Ene Reductase Ppo-Er1 from Paenibacillus Polymyxa
}

\author{
David Aregger, Christin Peters and Rebecca M. Buller * \\ Competence Center for Biocatalysis, Institute of Chemistry and Biotechnology, Department of Life Sciences and \\ Facility Management, Zurich University of Applied Sciences, Einsiedlerstrasse 31, \\ 8820 Waedenswil, Switzerland; David.Aregger@zhaw.ch (D.A.); Christin.peters@zhaw.ch (C.P.) \\ * Correspondence: rebecca.buller@zhaw.ch; Tel.: +41-58-934-5438
}

Received: 31 January 2020; Accepted: 14 February 2020; Published: 19 February 2020

\begin{abstract}
Ene reductases enable the asymmetric hydrogenation of activated alkenes allowing the manufacture of valuable chiral products. The enzymes complement existing metal-and organocatalytic approaches for the stereoselective reduction of activated $\mathrm{C}=\mathrm{C}$ double bonds, and efforts to expand the biocatalytic toolbox with additional ene reductases are of high academic and industrial interest. Here, we present the characterization of a novel ene reductase from Paenibacillus polymyxa, named Ppo-Er1, belonging to the recently identified subgroup III of the old yellow enzyme family. The determination of substrate scope, solvent stability, temperature, and $\mathrm{pH}$ range of Ppo-Er1 is one of the first examples of a detailed biophysical characterization of a subgroup III enzyme. Notably, Ppo-Er1 possesses a wide temperature optimum $\left(\mathrm{T}_{\text {opt }}: 20-45^{\circ} \mathrm{C}\right)$ and retains high conversion rates of at least $70 \%$ even at $10{ }^{\circ} \mathrm{C}$ reaction temperature making it an interesting biocatalyst for the conversion of temperature-labile substrates. When assaying a set of different organic solvents to determine Ppo-Er1's solvent tolerance, the ene reductase exhibited good performance in up to $40 \%$ cyclohexane as well as $20 \mathrm{vol} \%$ DMSO and ethanol. In summary, Ppo-Er1 exhibited activity for thirteen out of the nineteen investigated compounds, for ten of which Michaelis-Menten kinetics could be determined. The enzyme exhibited the highest specificity constant for maleimide with a $k_{\text {cat }} / K_{\mathrm{M}}$ value of $287 \mathrm{mM}^{-1} \mathrm{~s}^{-1}$. In addition, Ppo-Er1 proved to be highly enantioselective for selected substrates with measured enantiomeric excess values of $92 \%$ or higher for 2-methyl-2-cyclohexenone, citral, and carvone.
\end{abstract}

Keywords: biocatalysis; ene reductase; enzyme sourcing; old yellow enzyme; solvent stability

\section{Introduction}

Many bioactive molecules contain at least one chiral center rendering the development of effective asymmetric synthesis methods essential for the chemical industry. Besides the well-established metal- and organocatalytic approaches [1], biocatalytic strategies offer an interesting alternative to install chirality into small molecules. To date, industrial biocatalysis has mastered a range of enzyme families including ketoreductases [2], transaminases [3], and imine reductases [4]. Looking forward, the increasing power of genomic mining and enzyme engineering will allow industrial access to even more enzyme families leading to an expansion of the available biocatalytic toolbox [5].

The families of enzymes collectively known as ene reductases (ERs) catalyze the stereoselective trans- and, more rarely, cis-hydrogenation of activated alkenes [6-9]. Thus, ene reductases offer a valuable access route to asymmetric compounds, which is complementary to the chemical cis-hydrogenation catalyzed by chiral rhodium or ruthenium phosphine catalysts $[10,11]$. Today, ene reductases are classified into five enzyme groups, which differ in structure, reaction mechanism, substrate spectrum, and stereoselectivity (Figure 1) [12]. While enoate reductases, medium- and short-chain dehydrogenases/reductases (MDR and SDR), as well as the recently discovered quinone reductase-like ene reductases [13], are currently being investigated in terms of their industrial 
potential [14], enzymes stemming from the old yellow enzyme (OYE) family are established members of the biocatalytic toolbox and are the best characterized and most extensively employed ene reductases today [6].

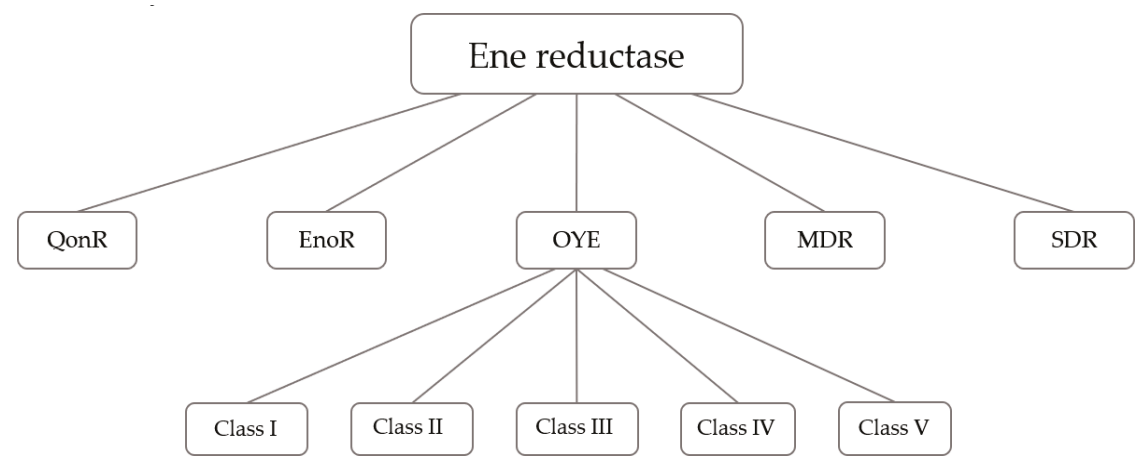

Figure 1. Overview of the classification within the ene reductase family [15]. QnoR (NADPH-dependent quinone reductase like ene-reductases), EnoR (enoate reductase), OYE (old yellow enzyme), MDR (medium-chain dehydrogenase/reductase), and SDR (short-chain dehydrogenase/reductase); Class I (classical OYE); Class II (thermophilic-like OYE) and Class V (fungal OYE).

Isolated in 1932 by Warburg and Christian from bottom-fermented brewer's yeast (Saccharomyces pastorianus), the first such ene reductase was named "yellow enzyme" [16]. After the discovery of several additional members belonging to the same enzyme family the "yellow enzyme" was renamed to "old yellow enzyme" (OYE1) [17]. OYEs preferentially accept $\alpha, \beta$-unsaturated ketones, aldehydes, nitroalkenes, and some carboxylic acids as substrates [7]. In the last decade, the catalytic mechanism of OYEs has been exhaustively investigated and its general principle is well understood: The enzymes follow a bi-bi ping-pong mechanism, which can be divided into a reductive and an oxidative half reaction [18]. In the reductive half-reaction, flavin mononucleotide (FMN) is reduced through hydride transfer from $\mathrm{NAD}(\mathrm{P}) \mathrm{H}$, whereas in the oxidative half reaction a hydride is transferred from the reduced flavin to the $C_{\beta}$ of the activated alkene. The missing proton for the $C_{\alpha}$ is transferred via a tyrosine residue from the opposite site $[18,19]$, ultimately leading to an anti-addition hydrogenation.

The catalytic machinery of OYE enzymes is supported by a typical $(\alpha, \beta) 8$-barrel (TIM-barrel) fold with additional secondary structural elements present (e.g., four $\beta$-strands and five $\alpha$-helices in OYE1 [20]; six $\beta$-strands and two $\alpha$-helices in 12-oxophytodienoate reductase OPR [18]). The folded domain is known to occur in different oligomeric states, such as monomers (PETN reductase) [21], dimers (OYE1) [20], tetrameters (dimers of dimers such as YqjM [22] or TOYE [23]), octamers, and dodecamers [23]. The oligomerization state is described to be often governed by the position and amino acid composition of surface loops [7]. In addition, the constitution of the loops can have an influence on thermostability [23].

Notably, amino acid sequence alignments of OYE homologs show high conservation in specific regions of the proteins, such as residues involved in catalysis, FMN, and substrate binding $[7,15,23]$. To account for these differences in sequence and the resulting structural features, the old yellow enzyme family can be further divided into five subclasses [15]. While enzyme members of the subclass I, also termed "classical" old yellow enzymes, and class II, introduced by Scrutton's group in 2010 and dubbed "thermophilic-like" [23], have been well explored [7,14], the recently described class III-V are less well investigated $[15,24]$.

Synthetic applications of ene reductases are manifold and range from the preparation of profens [25-27] and chiral $\gamma$-amino acids [28-30] to the synthesis of chiral phosphonates [31] and nitroalkanes [32], precursors in the synthesis of pharmaceutically active ingredients. To further 
promote an off-the-shelve synthetic use of ene reductases, which can reduce the time and cost of the implementation of a biocatalytic step into a process significantly, we set out to expand the available biocatalytic toolbox [15]. In this context, not only the discovery and engineering of novel ene reductases is of great utility [33], but also a careful characterization of the new biocatalysts is needed as it may lead to the construction of a more targeted enzyme library associated with reduced screening time and costs.

Herein, we showcase the detailed characterization of Ppo-Er1 from Paenibacillus polymyxa, an OYE subclass III enzyme, and highlight the enzyme's substrate scope, kinetic parameters, solvent tolerance, as well as $\mathrm{pH}$ and temperature profile. The data presented may facilitate future screening and engineering studies and, in selected cases, thus, lead to the faster adoption of an ene reductase in chemical process development.

\section{Results and Discussion}

The enzyme Ppo-Er1 from P. polymyxa was discovered during the screening of 19 bacterial wild-type strains from the Culture Collection of Switzerland, as previously described [15]. Ppo-Er1 $(41.3 \mathrm{kDa})$ is characterized by a substantial sequence similarity with the old yellow enzyme YqiG from Bacillus subtilis (50\%) [34], Bac-OYE2 from Bacillus sp. (50\%) [35], Lla-Er from Lactococcus lactis (39\%) [15], and LacER from Lactobacillus paracasei (47\%) [36], all of which belong to the subclass III of the OYE family. In detail, Ppo-Er1 contains a specific combination of motifs known from the classical and thermophilic-like groups that has been found to be characteristic for class III enzymes [15]: Gln104 and Arg228 predicted to interact with the pyrimidine ring of FMN [22], His 171, and Asn 175 proposed to interact with N1 and N3 of FMN [22,37]; Thr30 suggested to interact with isoalloxazine ring O4 of FMN [38]; and Met29, Leu324, and Arg321, which presumably interact with the dimethyl benzene moiety of FMN. As expected, subclass III old yellow enzyme Ppo-Er1 is thus phylogenetically positioned between classical and thermophilic-like OYEs.

\subsection{Expression and Characterization of Ppo-Er1}

The ready-to-use plasmid consisting of pET-28b(+) vector and the Ppo-Er1 sequence was assembled by Twist Bioscience and a $\mathrm{C}$-terminal $\mathrm{His}_{6}$ tag for protein purification by affinity chromatography was included. The soluble recombinant expression of Ppo-Er1 in Escherichia coli BL21 (DE3) was achieved in terrific broth (TB) medium at $25^{\circ} \mathrm{C}$. Ppo-Er1 was purified by affinity chromatography using Ni-NTA resin (Figure S1) and the cofactor FMN was reconstituted before further analysis. FMN reconstitution $(100 \mu \mathrm{M})$ proved necessary to obtain a fully active enzyme as without this step the enzyme preparation only exhibited $8 \%$ ( $0.05 \mathrm{U} / \mathrm{mg}$ for cyclohexanone) of the expected activity $(0.61 \mathrm{U} / \mathrm{mg}$ for cyclohexanone). This effect was also described for the OYEs LacER [36] and Lla-Er [15]. In the case of LacER, for example, the addition of FMN after purification by DEAE ion exchange chromatography increased the activity by a factor of 92 from 0.0018 to $0.168 \mathrm{U} / \mathrm{mg}$ for the substrate trans-2-hexen-1-al. This observation suggests that-similar to other known OYEs-the binding affinity of Ppo-Er1 to FMN under purification conditions is low, a fact that has to be kept in mind for any following activity analysis. The storage stability of the purified Ppo-Er1 proved to be very good, boding well for the enzyme's incorporation in potential enzyme screens: At $-20{ }^{\circ} \mathrm{C}$ and in the presence of $20 \%$ glycerol, the enzyme did not lose any activity even when stored for an extended period of time (one week), whereas an activity drop of approximately $20 \%$ was observed after incubation for 10 days at $4{ }^{\circ} \mathrm{C}$ (no additives). In contrast to a number of reported OYEs [15,39], we found that NADPH and NADH are equally preferred physiological cofactors of Ppo-ER1 (Figure S14) allowing for maximum flexibility in the choice of recycling system during process development. Both, the coupled-enzyme approach [40] or the use of alternative hydride sources $[41,42]$ will thus be conceivable options to avoid having to add stoichiometric amounts of the coenzymes.

The oligomeric state of Ppo-Er1 was determined via gel filtration by correlation with a commercial gel filtration standard containing proteins of specific size. Based on this comparison, Ppo-Er1 mostly 
occurs as a monomer (Figure S2) as do for example PETN from Enterobacter cloacae [21] and RmER from Ralstonia metallidurans [43], both thermophilic-like ene reductases.

Further relevant parameters for application such as optimum $\mathrm{pH}$, optimum temperature, and long-term temperature stability were determined using the substrate cyclohexenone. The $\mathrm{pH}$ profile of Ppo-Er1 was measured in Davies buffer covering $\mathrm{pH} 5$ to $\mathrm{pH} 10$ [44], in which the enzyme reached about $50 \%$ of the activity observed in $50 \mathrm{mM}$ phosphate buffer (Figure S3). The $\mathrm{pH}$ profile was found to be bell-shaped, exhibiting a narrow optimum at pH 6.5-7.5 (Figure 2). Beyond this range, enzyme activity decreases rapidly, especially when the enzyme was pre-incubated for a longer time period $(24 \mathrm{~h})$ in the measurement buffers (Figure 2). In the case of other characterized class III OYEs such as LacER [36] and YqiG [15,34], a similar $\mathrm{pH}$ profile was determined albeit with a wider $\mathrm{pH}$ working range as indicated by the reported optimum activities in the range of $\mathrm{pH}_{\text {opt }} 8-9$ and $\mathrm{pH}_{\text {opt }} 6-9$, respectively. Notably, OYE enzymes belonging to other subclasses exhibit similar $\mathrm{pH}$ profiles as reported for Ppo-Er1, e.g., the "classical" XenB [45] and NemA [45] with a $\mathrm{pH}_{\text {opt }}$ of 6-7.5, the "thermophilic-like" YqjM [46] and Chr-OYE3 [47] with a $\mathrm{pH}_{\mathrm{opt}}$ of 6-8, and the class IV enzyme Ppo-Er3 [15] with a pH $\mathrm{opt}_{\text {of }}$ 7-8.5.

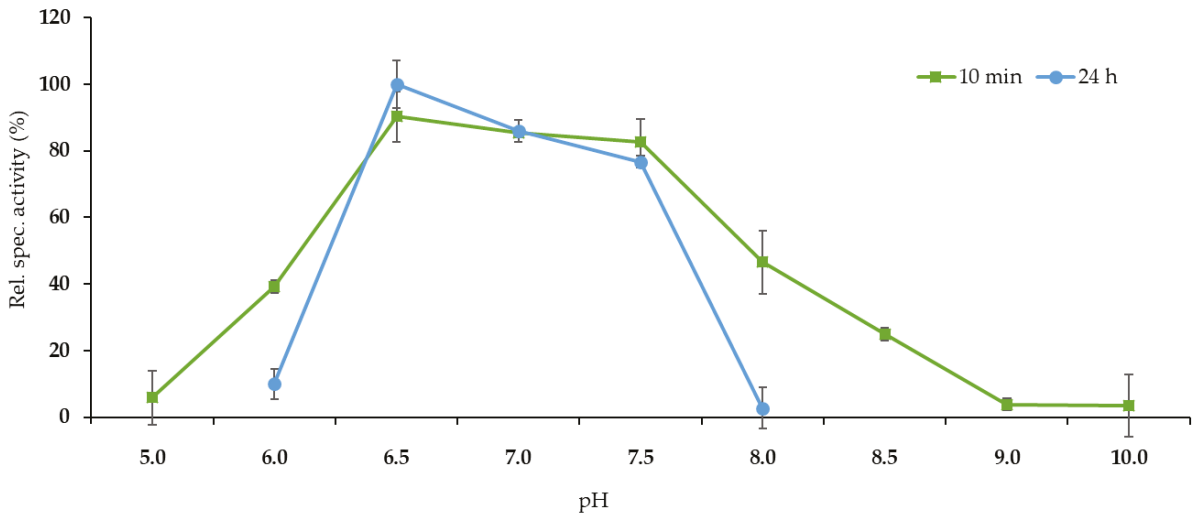

Figure 2. $\mathrm{pH}$ profile of Ppo-Er1 measured between $\mathrm{pH} 5$ and $\mathrm{pH} 10$ in Davies buffer [44]. The enzyme was preincubated at $25{ }^{\circ} \mathrm{C}$ in the respective measurement buffer solution for $10 \mathrm{~min}$ and $24 \mathrm{~h}$, respectively, to determine the stability and activity of Ppo-Er1 in dependence of $\mathrm{pH}$. Relative specific activity corresponds $100 \%$ to an activity of $0.41 \mathrm{U} / \mathrm{mg}$ for cyclohexenone. The error bars show the standard deviation of triplicates.

In terms of thermal robustness, Ppo-Er1 possesses interesting long-term stability. After $24 \mathrm{~h}$ incubation at $20^{\circ} \mathrm{C}$, enzyme activity toward cyclohexenone remained virtually unchanged, whereas residual activity of approximately $70 \%$ was detected after an equally long incubation time at $30{ }^{\circ} \mathrm{C}$. Furthermore, short-term exposure of Ppo-Er1 to $45^{\circ} \mathrm{C}$ led to only a marginal loss in activity $(<10 \%)$ allowing the enzyme to be used for applications that require higher temperatures (Figure 3). These results are in line with data obtained for other class III and IV enzymes such as YqiG and Ppo-Er3, which have reported $\mathrm{T}_{\text {opt }}$ values of $25-40^{\circ} \mathrm{C}$ [15,34]. Strikingly, Ppo-Er1 retained a relative specific activity of $>70 \%$ at temperatures as low as $10{ }^{\circ} \mathrm{C}$ making the enzyme an interesting candidate to be used for the transformation of thermolabile substrates such as aldehydes (Figure 3). Overall, our Ppo-Er1 data confirm that the temperature profile of class III enzymes resembles those of their mesophilic counterparts of class I, for example NemA [45] with a reported $\mathrm{T}_{\text {opt }}$ of $30-50{ }^{\circ} \mathrm{C}$ and OYE2p [48] with a $\mathrm{T}_{\text {opt }}$ of $25-40{ }^{\circ} \mathrm{C}$. Finally, we employed the ThermoFAD technique to determine the melting temperature of Ppo-Er1 and found that the ene reductase unfolds at $\mathrm{T}_{\mathrm{m}}=46.5 \pm 1{ }^{\circ} \mathrm{C}$ (Figure S15). 


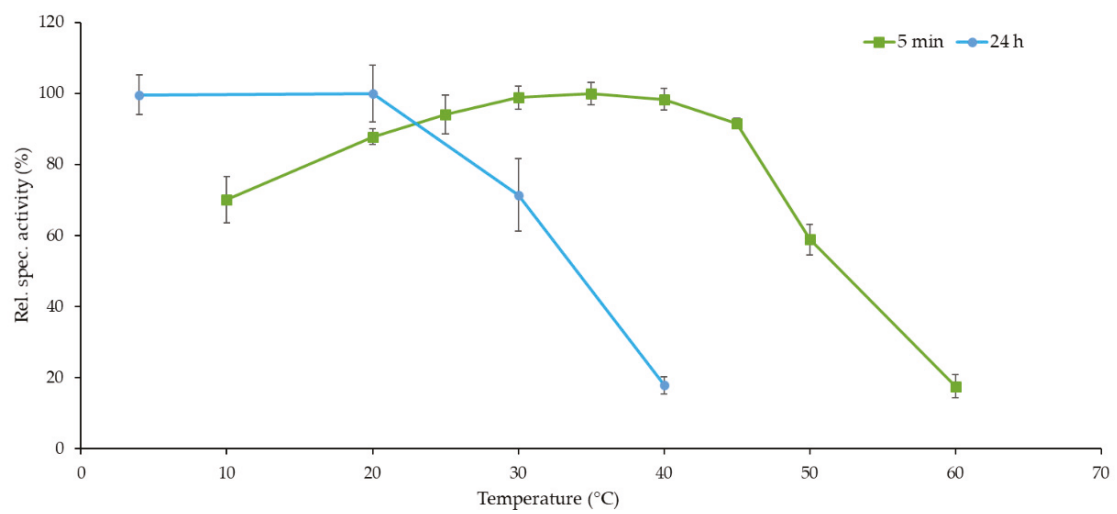

Figure 3. The temperature profile and the temperature stability of Ppo-Er1. For the temperature profile Ppo-Er1 was incubated for $5 \mathrm{~min}$ at different temperatures $\left(10-60^{\circ} \mathrm{C}\right)$ and directly measured for the conversion of substrate cyclohexenone $(1 \mathrm{mM})$. For the temperature stability measurement, Ppo-Er1 was incubated at four different temperatures $\left(4-40{ }^{\circ} \mathrm{C}\right)$ and measured after $24 \mathrm{~h}$ at $25^{\circ} \mathrm{C}$. The error bars show the standard deviation of triplicates. Relative specific activity corresponds $100 \%$ to an activity of $0.52 \mathrm{U} / \mathrm{mg}$ for cyclohexenone.

The use of cosolvents is often a "must" in biocatalytic processes due to the presence of high concentrations of various organic substrates. Consequently, in many instances the solvent stability of enzymes needs to be optimized by enzyme engineering to generate catalysts that are compatible with the process conditions [49]. To verify the stability of Ppo-Er1 in the presence of a set of typical solvents, we thus determined the enzymatic activity over a concentration range of $10-40 \%$ of DMSO, DMF, cyclohexane, ethanol, and ethyl acetate. The enzyme performed best in cyclohexane (assayed substrate: $1 \mathrm{mM}$ hexenal), which did not cause a significant loss in activity even when supplemented to a final volume of up to $40 \%$ in the assay. Alternatively, DMSO could be considered as a viable cosolvent for Ppo-Er1 as the enzyme was virtually unaffected up to a concentration of $20 \% v / v$. Even at a concentration of $30 \% v / v$ DMSO, Ppo-Er1 retained a relative activity of approximately $80 \%$ (assay substrate: $1 \mathrm{mM}$ cyclohexenone). The solvent ethanol was shown to also be a suitable choice for this enzyme, as it was tolerated well up to a concentration of $10 \% v / v$. DMF or ethyl acetate, however, should not be used in combination with Ppo-Er1 as their presence was found to be detrimental for enzymatic activity. Already at a concentration of $10 \% v / v$ activity drops of $30 \%$ and $85 \%$ were observed, respectively (Figure 4 ).

In comparison to most known old yellow enzymes, Ppo-Er1 exhibits similar solvent resistance: The thermophilic-like OYE YqjM [46] has been reported to remain active in an analogous concentration range of DMSO, DMF, and ethyl acetate as Ppo-Er1. However, an ethanol concentration of $10 \% v / v$ led to a strong reduction of the half-life of YqjM, which we did not observe in the case of Ppo-Er1. TOYE [23], another thermophilic-like OYE, was reported to exhibit a 50\% loss of activity at an ethanol concentration of $45 \%$ corresponding to a higher stability toward this solvent compared to Ppo-Er1, whereas the classical PETNR [50] already lost 50\% activity in the presence of an ethanol concentration of $20 \% v / v$. In this context, it should be noted that organic-solvent-tolerant ene reductases have also been reported: FOYE1, originating from an acidophilic iron oxidizer, was shown to perform well in many solvent systems with up to $20 \%$ v/v solvents (ethanol, methanol, acetone, isopropanol, DMSO, THF) clearly outperforming all abovementioned ene reductases in terms of solvent stability [51]. 


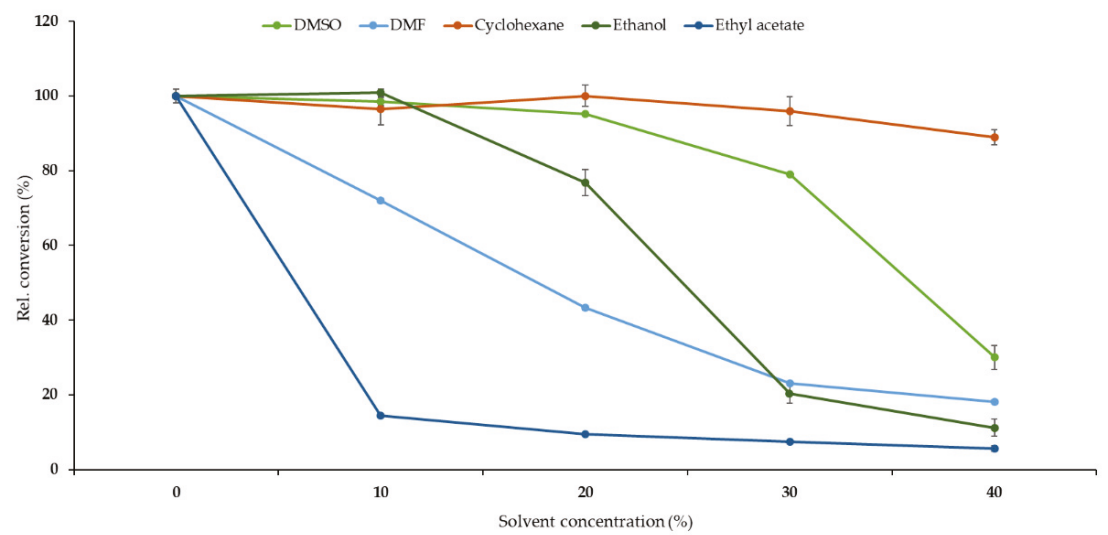

Figure 4. Overview of the solvent stability of Ppo-Er1 in DMSO (dimethyl sulfoxide), DMF (dimethyl formamide), cyclohexane, ethanol, and ethyl acetate in a concentration range of $10 \%-40 \% v / v$. The standard enzyme assay was performed while the concentration of solvents was varied (substrate for cyclohexane: $1 \mathrm{mM}$ hexenal, all other solvents: $1 \mathrm{mM}$ cyclohexenone). Data are shown as values relative to an enzyme assay without cosolvent in which $100 \%$ relative conversion corresponds to the production of $0.84 \mathrm{mM}$ cyclohexanone or $0.49 \mathrm{mM}$ hexanal, respectively. The error bars show the standard deviation of triplicates, except for the $30 \% v / v$ cyclohexane point for which only two measurements were available.

\subsection{Substrate Scope, Determination of Michaelis-Menten Parameters, and Stereoselectivity}

To determine the substrate profile of Ppo-Er1, the enzyme was tested for the conversion of nineteen structurally diverse aliphatic and cyclic alkenes bearing ketone, aldehyde, nitro, carboxylic acid, or ester moieties as electron-withdrawing groups. For thirteen substrates, product formation by Ppo-Er1 could be detected. Cyclohexenone, hexenal, 2-methyl-2-pentenal, 4-phenyl-3-buten-2-one, cinnamic aldehyde, maleimide, and carvone (at $5 \mathrm{mM}$ concentration) were converted especially well, and $>99 \%$ conversion was obtained within $4 \mathrm{~h}$ (Table 1). Substrates not accepted by Ppo-Er1 included $\alpha, \beta$-unsaturated carboxylic acids such as butenic acid, cinnamic acid, and citraconic acid as well as the ketones 3-methyl-2-cyclohexenone and 3-methyl-2-cyclopentenone, which are characterized by an additional methyl group in the $\beta$-position. The $\alpha, \beta$-unsaturated ester ethyl crotonate was also not converted.

Based on the obtained data, it can be concluded that the overall substrate profile of Ppo-Er1 resembles that of other subclass III enzymes such as YqiG [15,34] and Lla-Er [15]. For example, $5 \mathrm{mM}$ of cinnamic aldehyde and cyclohexenone are also well converted by Lla-Er [15] (65\% $\pm 4.2 \%$ and $23 \%$ $\pm 3.1 \%)$ and YqiG [15] $(58 \% \pm 2.4 \%$ and $55 \% \pm 6.1 \%)$ after $1 \mathrm{~h}$ at $30{ }^{\circ} \mathrm{C}$. Notably, however, marked differences in substrate acceptance by class III enzymes occur for some of the investigated substrates highlighting the importance of an in-depth substrate profiling: Whereas carvone and maleimide are very well converted by Ppo-Er1 (both: >99\%), Lla-Er, for example, accepts this compound only poorly (carvone: $2.6 \% \pm 0.1 \%$, maleimide: not converted) [15]. Diethylbenzylidenemalonate conversion by YqiG $[15,34](11 \% \pm 1.3 \%)$, on the other hand, significantly exceeded the detected product formations achieved by Lla-Er (<1\%) [15] and Ppo-Er1 (1.2\%). Moreover, 3-methyl-2-cyclopentenone, which is not converted by Ppo-Er1, Lla-Er [15], and YqiG [15,34], has been shown to be accepted by LacER [36]. Generally, we noted that Ppo-Er1 has a restricted substrate acceptance for cyclic $\beta$-methylated substrates such as 3-methyl-2-cyclohexenone and 3-methyl-2-cyclopentenone, which possibly results from a difficulty in accepting substituents at the $C_{\beta}$ position of cyclic compounds in the active site in analogy to other class II, III, and IV enzymes [15,39]. In addition, carboxylic acids 
and esters seem to be non-optimal alkene activating groups for this enzyme as conversion of the corresponding substrates was low or not detectable.

Table 1. Conversion, steady state kinetics, ${ }^{(a)}$ and enantiomeric excess (ee) of various substrates converted with purified enzymes as determined after $4 \mathrm{~h}$ at $20^{\circ} \mathrm{C}$ (n.d.: not detected; n.s.: not soluble). The given uncertainties show the standard deviation of triplicates.

\begin{tabular}{|c|c|c|c|c|c|c|}
\hline \multicolumn{2}{|l|}{ Substrate } & $\begin{array}{c}\text { Conversion } \\
(\%)\end{array}$ & $\begin{array}{c}\text { ee } \\
(\%)\end{array}$ & $\frac{k_{\text {cat }} / K_{\mathrm{m}}}{\left(\mathrm{mM}^{-1} \mathrm{~s}^{-1}\right)}$ & $\frac{K_{\mathrm{m}}}{(\mathrm{mM})}$ & $\begin{array}{l}k_{\text {cat }} \\
\left(\mathrm{s}^{-1}\right)\end{array}$ \\
\hline trans- $\beta$-Methyl- $\beta$-nitrostyrene & & $81 \pm 1.0$ & & $41.4 \pm 0.23$ & $0.12 \pm 0.03$ & $4.97 \pm 0.36$ \\
\hline Cinnamaldehyde & & $\geq 99 \pm 1.5$ & & $14.6 \pm 0.14$ & $0.36 \pm 0.05$ & $5.27 \pm 0.18$ \\
\hline Hexenal & & $\geq 99 \pm 3.4$ & & $3.3 \pm 0.10$ & $2.22 \pm 0.21$ & $7.42 \pm 0.01$ \\
\hline Cyclohexenone & & $\geq 99 \pm 0.5$ & & $0.4 \pm 0.08$ & $13.42 \pm 1.0$ & $5.25 \pm 0.1$ \\
\hline Citral & & $29 \pm 1.4$ & (S) 94 & $0.2 \pm 0.93$ & $1.12 \pm 1.0$ & $0.17 \pm 0.04$ \\
\hline 2-Methyl-2-cyclohexenone & & $76.2 \pm 0.4$ & (R) 92 & $0.1 \pm 0.23$ & $14.93 \pm 3.3$ & $1.30 \pm 0.08$ \\
\hline Cyclopentenone & & $59 \pm 1.7$ & & $0.03 \pm 0.17$ & $57.24 \pm 9.4$ & $1.75 \pm 0.16$ \\
\hline 4-Phenyl-3-buten-2-one & & $\geq 99 \pm 1.0$ & & & n.s. & \\
\hline 3-Methyl-2-cyclopentenone & & n.d. & & & & \\
\hline Etylcrotonate & & n.d. & & & & \\
\hline Butenoic acid & & n.d. & & & & \\
\hline Cinnamic acid & & n.d. & & & & \\
\hline Citraconic acid & & n.d. & & & & \\
\hline
\end{tabular}

(a) Reactions $(1 \mathrm{~mL}$ ) were performed in potassium phosphate buffer $(50 \mathrm{mM}, \mathrm{pH} 7.0)$ containing NADPH (175 $\mu \mathrm{M})$ and substrate $(20 \mu \mathrm{M}-80 \mathrm{mM})$, depending on substrate, Ppo-Er1 $(0.61 \mu \mathrm{M})$, and DMSO to solubilize the substrates. The reactions were followed continuously by monitoring NADPH oxidation at $340 \mathrm{~nm}$ for $90 \mathrm{sec}$ at $25^{\circ} \mathrm{C}$.

To complement the substrate acceptance profile, Michaelis-Menten parameters of Ppo-Er1 for ten diverse substrates were determined (Table 1, Figures S4-S13). Within the tested substrate range, Ppo-Er1 showed the highest catalytic efficiency for maleimide $\left(k_{\mathrm{cat}} / K_{\mathrm{m}}=287 \mathrm{mM}^{-1} \mathrm{~s}^{-1}\right)$ followed by trans- $\beta$-methyl- $\beta$-nitrostyrene $\left(k_{\mathrm{cat}} / K_{\mathrm{m}}=41 \mathrm{mM}^{-1} \mathrm{~s}^{-1}\right)$. In combination with the conversion data, the 
measured kinetic parameters (Table 1) indicate a general preference for alkenes carrying a phenyl substituent at the $C_{\beta}$ position of the substrates. Overall, Ppo-Er1's specific activity for other typical ene reductase substrates such as carvone $\left(k_{\text {cat }} / K_{\mathrm{m}}=0.5 \mathrm{mM}^{-1} \mathrm{~s}^{-1}\right)$ and cyclohexanone $\left(k_{\text {cat }} / K_{\mathrm{m}}=\right.$ $0.4 \mathrm{mM}^{-1} \mathrm{~s}^{-1}$ ) was found to be in a similar range as those described for other well-known OYEs such as the classical PETNR (carvone: $k_{\text {cat }} / K_{\mathrm{m}}=2 \mathrm{mM}^{-1} \mathrm{~s}^{-1}$; cyclohexanone: $k_{\text {cat }} / K_{\mathrm{m}}=5 \mathrm{mM}^{-1} \mathrm{~s}^{-1}$ ) [50] and the thermophilic-like YqjM (cyclohexanone: $k_{\text {cat }} / K_{\mathrm{m}}=6.4 \mathrm{mM}^{-1} \mathrm{~s}^{-1}$ ) [46] (Table 2). Maleimide, however, is better converted by ene reductases from photosynthetic extremophiles such as CtOYE $\left(k_{\text {cat }} / K_{\mathrm{m}}=1940 \mathrm{mM}^{-1} \mathrm{~s}^{-1}\right)$ or GSOYE $\left(k_{\text {cat }} / K_{\mathrm{m}}=399 \mathrm{mM}^{-1} \mathrm{~s}^{-1}\right)$ [52] the thermophilic-like OYERo2 $\left(k_{\text {cat }} / K_{\mathrm{m}}=10,800 \mathrm{mM}^{-1} \mathrm{~s}^{-1}\right)$ [53] or the class III OYE YqiG $\left(k_{\text {cat }} / K_{\mathrm{m}}=800 \mathrm{mM}^{-1} \mathrm{~s}^{-1}\right)$ (Table 2$)$.

Table 2. Comparison of the catalytic efficiencies $\left(\mathrm{mM}^{-1} \mathrm{~s}^{-1}\right)$ of a range of known old yellow enzymes (OYEs) (YqiG [34], PETNR [50], YqjM [46], TOYE [23], DrER [43], RmER [43], and OYERo2 [53]) from class I-III.

\begin{tabular}{c|c|ccccc|cc}
\hline Substrate & Class I & \multicolumn{5}{c|}{ Class II } & \multicolumn{3}{c}{ Class III } \\
& PETNR & YqjM & TOYE & DrER & RmER & OYERo2 & Ppo-Er1 & YqiG \\
\hline Cyclohexenone & 5 & 6.4 & 0.5 & 2.1 & 0.7 & & 0.4 & 22 \\
2-Methyl-cyclohexenone & 4 & 1.0 & & & & & 0.1 & \\
Cyclopentenone & $<0.5$ & 1.9 & 0.6 & & & & 0.03 \\
Hexenal & & 0.60 & & & & & 3.3 & 0.2 \\
Citral & 9 & 0.02 & 0.05 & & & & 15.3 & 18 \\
2-Methyl-2-pentenal & 61 & & 0.14 & & & & 14.6 & \\
Cinnamaldehyde & 8 & & & & & & 0.5 & 7.5 \\
Carvone & 2 & & 1.5 & & & 10,800 & 287.8 & 800 \\
Maleimide & & & & & & & 41.4 & \\
\hline
\end{tabular}

In addition to determining the steady-state kinetic parameters, we also investigated the stereopreference of Ppo-Er1. Based on our results with four selected substrates, Ppo-Er1 displays a similar stereopreference to other reported OYE class III enzymes (Table 3), preferentially forming the $S$-product when converting 2-methy-2-pentenal and citral and forming the $R$-product when transforming carvone and 2-methyl-2-cyclohexenone. Notably, the detected ee values of Ppo-Er1 are generally superior to values determined for YqiG and Lla-Er [15] with the only exception being the enantiomeric excess reported for the conversion of carvone by Lla-Er ( $>99.9 \%$ ee). It should be noted, however, that Lla-Er displayed a low conversion of $2.6 \%$ of $5 \mathrm{mM}$ substrate after $1 \mathrm{~h}$ at $30{ }^{\circ} \mathrm{C}$ compared to the $>99 \%$ conversion of $5 \mathrm{mM}$ substrate by Ppo-Er1 after $4 \mathrm{~h}$ at $20^{\circ} \mathrm{C}$.

Table 3. The enantiomeric excess of some selected OYEs (YqiG [15], Lla-Er [15], Ppo-Er3 [15], OPR1 [54], OPR3 [54], PETNR [50], YqjM [54], TOYE [23]) from classes I-IV. The values presented for YqjM were measured as a reference for Ppo-Er1 and compared with the literature [54].

\begin{tabular}{|c|c|c|c|c|c|c|c|c|c|}
\hline \multirow[b]{2}{*}{ Substrate } & \multicolumn{3}{|c|}{ Class I } & \multicolumn{2}{|c|}{ Class II } & \multicolumn{3}{|c|}{ Class III } & \multirow{2}{*}{$\begin{array}{l}\text { Class IV } \\
\text { Ppo-Er3 }\end{array}$} \\
\hline & OPR1 & OPR3 & PETNR & YqjM & TOYE & Ppo-Er1 & YqiG & Lla-ER & \\
\hline $\begin{array}{l}\text { 2-Methyl-2-pentenal } \\
\text { Carvone } \\
\text { 2-Methyl-2-cyclohexenone } \\
\text { Citral }\end{array}$ & $\begin{array}{l}\text { (R) } 47 \\
\\
(R) 77 \\
(S)>95\end{array}$ & $\begin{array}{l}\text { (S) } 78 \\
\text { (R) } 62 \\
(S)>95\end{array}$ & (R) 95 & $\begin{array}{l}\text { (R) } 20 \\
\text { (R) } 82 \\
\text { (R) } 81 \\
\text { (S) } 95\end{array}$ & $\begin{array}{l}\text { (S) } 55 \\
(R) 95 \\
(S) 91\end{array}$ & $\begin{array}{l}\text { (S) } 63 \\
\text { (R) } 98 \\
(R) 92 \\
(S) 94\end{array}$ & $\begin{array}{l}\text { (S) } 33 \\
\text { (R) } 89 \\
\text { (R) } 83\end{array}$ & $\begin{array}{c}(S) 5 \\
(R)>>99.9 \\
(R) 11\end{array}$ & $\begin{array}{l}\text { (S) } 67 \\
\text { (R) } 91 \\
\text { (R) } 86\end{array}$ \\
\hline
\end{tabular}

\section{Materials and Methods}

\subsection{Materials}

All chemicals were purchased from Merck (Darmstadt, Germany), VWR (Hannover, Germany), or Carl Roth (Karlsruhe, Germany). The purchased chemicals were of the highest available purity or of analytical grade and were used without further purification unless otherwise specified. NADPH tetrasodium salt was ordered from Oriental Yeast Co. Ltd. (Tokyo, Japan). The plasmid (pET 28b(+) 
incl. Ppo-Er1) was ordered from Twist Bioscience (San Francisco, CA, USA). The HisTrap FF and the HiTrap Desalting columns were ordered from GE Healthcare (Uppsala, Sweden).

\subsection{Plasmid}

Twist Bioscience (San Franscisco, CA, USA) cloned the synthetic gene of the codon optimized Ppo-Er1 (Accession Nr: WP_013369181) with NdeI and XhoI in the commercial pET28b(+) vector.

\subsection{Bacterial Strains and Culture Conditions}

E. coli BL21 (DE3) [fhuA2 [lon] ompT gal ( $\lambda \mathrm{DE} 3$ ) [dcm] $\Delta h s d S$ ] was purchased from New England Biolabs (Beverly, MA, USA). E. coli strains were cultured routinely in Lysogeny broth (LB) or TB media and were supplemented with kanamycin $\left(50 \mu \mathrm{g} \mathrm{mL}^{-1}\right)$. Bacterial cultures were incubated in baffled Erlenmeyer flasks in a New Brunswick Innova 42 orbital shaker at $200 \mathrm{rpm}$ and $37^{\circ} \mathrm{C}$. Bacteria on agar plates were incubated in a HERATherm Thermo Scientific incubator under air. All materials and biotransformation media were sterilized by autoclaving at $121^{\circ} \mathrm{C}$ for $20 \mathrm{~min}$. Aqueous stock solutions were sterilized by filtration through $0.22 \mu \mathrm{m}$ syringe filters. Agar plates were prepared with LB medium supplemented by $1.5 \%(\mathrm{w} / \mathrm{v})$ agar.

\subsection{Expression}

The expression of Ppo-Er1 in E. coli BL21 (DE3) was performed by inoculation of TB media (400 mL) supplemented with kanamycin $\left(50 \mu \mathrm{g} \mathrm{mL}^{-1}\right)$ with an overnight culture $(4 \mathrm{~mL} ; 1: 100)$. The culture was incubated at $37^{\circ} \mathrm{C}$ and $180 \mathrm{rpm}$ until optical density $\mathrm{OD}_{600}=0.5-0.8$ was reached. Afterward expression was induced by the addition of $100 \mu \mathrm{M}$ IPTG, and incubation was continued at $25^{\circ} \mathrm{C}$ for 18 h. Cells were harvested by centrifugation at $4500 \times \mathrm{g}$ for $10 \mathrm{~min}$ at $4{ }^{\circ} \mathrm{C}$ and either used directly or the pellet was stored by freezing at $-20^{\circ} \mathrm{C}$.

\subsection{Enzyme Purification}

The cell disruption was performed by resuspending the pellet from a $400 \mathrm{~mL}$ culture in $20 \mathrm{~mL}$ buffer (100 mM sodium phosphate buffer $\mathrm{pH} 7.5,300 \mathrm{mM} \mathrm{NaCl}$, supplemented by $30 \mathrm{mM}$ imidazole) and a single passage through a French press (2000 psi). The crude extract was separated from the cell debris by centrifugation at $8000 \times g$ for $45 \mathrm{~min}$. Purification was achieved by affinity chromatography exploiting the C-terminal His-Tag using an automated Äkta purifier system. The crude extract was filtered $(0.45 \mu \mathrm{m})$ and applied to a pre-equilibrated $5 \mathrm{~mL}$ HisTrap FF column. The unbound protein was washed with five column volumes of buffer supplemented with $45 \mathrm{mM}$ imidazole. The elution of Ppo-Er1 was accomplished by a three-column volume of buffer supplemented with $300 \mathrm{mM}$ of imidazole. The resulting fractions were collected and analyzed by SDS-PAGE. The fractions with a high content of Ppo-Er1 were pooled and desalted using $50 \mathrm{mM}$ sodium phosphate buffer ( $\mathrm{pH}$ 7.5) to remove the imidazole. This step was performed employing the Äkta purifier system using three coupled $5 \mathrm{~mL}$ HiTrap desalting columns. After the system was equilibrated, the Ppo-Er1-containing sample was applied and fractioned. The protein fractions were analyzed via the integrated online absorption measurement at $280 \mathrm{~nm}$. The protein content of the pooled purified sample was determined by measuring the adsorption with a NanoDrop One (Thermo Fisher Scientific) system and using the molecular weight $(41.3 \mathrm{kDa})$ and extinction coefficient $\left(\epsilon_{\lambda}=280 \mathrm{~nm}=38^{\prime} 390 \mathrm{M}^{-1} \mathrm{~cm}^{-1}\right)$ of Ppo-Er1 for the calculation. The extinction coefficient was obtained by using the online calculation tool Prot pi [55].

\subsection{Activity Assay}

The activity measurements were recorded spectrophotometrically by observing NADPH consumption at $340 \mathrm{~nm}$ for $60-90 \mathrm{~s}$ in a $1 \mathrm{~mL}(1 \mathrm{~cm})$ plastic cuvette in the Lambda 465 (PDA UV/VIS) system from Perkin Elmer. The biocatalytic experiments to obtain the $\mathrm{pH}$ and the temperature profile were conducted in sodium phosphate buffer ( $50 \mathrm{mM}$, pH 7.5) using $175 \mu \mathrm{M}$ NADPH, $1 \mathrm{mM}$ 
cyclohexenone, and $0.61 \mu \mathrm{M}$ purified Ppo-Er1. For the determination of the Michaelis-Menten parameters, the substrate concentration was varied in the range of $20 \mu \mathrm{M}-80 \mathrm{mM}$ depending on the substrate while the enzyme concentration was kept constant at $0.61 \mu \mathrm{M}$. For the $\mathrm{pH}$ profile, Davies buffer [44] was used. All measurements were done in triplicates. Background NADPH consumption was determined in assays in which either the enzyme or the substrate had been eliminated. The substrates were solubilized as $1 \mathrm{M}$ stock in DMSO.

\subsection{Biocatalysis Reaction}

The in vitro biocatalysis reaction were performed by using desalted Ppo-Er1 (with a concentration of $12.1 \mu \mathrm{M}$ ), $5 \mathrm{mM}$ substrate (1 M stock in DMSO) supplemented with $100 \mu \mathrm{M}$ NADPH, $10 \mathrm{mM}$ glucose,

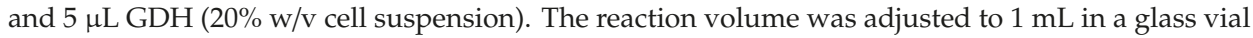
by using sodium phosphate buffer (200 mM, pH 7.0) and incubated for $4 \mathrm{~h}$ at $20^{\circ} \mathrm{C}$ and $1000 \mathrm{rpm}$. To determine the solvent stability of Ppo-Er1, the biocatalysis reaction conditions were adapted to include $2.4 \mu \mathrm{M}$ Ppo-Er1 and 0\%-40\% v/v solvent (ethanol, ethyl acetate, DMSO, DMF, cyclohexane) in a total reaction volume of $1 \mathrm{~mL}$ for $50 \mathrm{~min}$ at $20^{\circ} \mathrm{C}$ and $1000 \mathrm{rpm}$. All biocatalysis reactions were done in triplicate, biocatalysis results were verified by control reactions omitting the enzyme.

\subsection{GC-Analysis}

One milliliter biocatalysis reactions were extracted once with $500 \mu \mathrm{L}$ methyl tert-butyl ether (incl. $1 \mathrm{~g} / \mathrm{L} 1$-octanol as internal standard). The phase separation was achieved by centrifugation of the biphasic sample, and the organic phase was separated and subjected to GC analysis (Table S1).

\subsection{Gel Filtration}

For the determination of the oligomeric state of Ppo-Er1, the Äkta purifier system employing a HiLoad 16/600 Superdex 75 pg column (GE Healthcare (Uppsala, Sweden)) and sodium phosphate buffer $(50 \mathrm{mM}, \mathrm{pH} 7.5)$ was used. In a first step, the system was calibrated by using the gel filtration standard from Bio Rad (1.35-670 kDa Prod. no.: \#1511901). Then flavin-saturated Ppo-Er1 was applied to system under identical conditions.

\subsection{Melting Temperature}

The unfolding temperature was determined by a ThermoFAD assay [56] using Rotor-Gene $\mathrm{Q}$ RT-PCR machine. Protein samples $(0.5-0.3 \mathrm{mg} / \mathrm{mL})$ in $20 \mu \mathrm{L}$ sodium phosphate buffer $\mathrm{pH} 7$ were measured using a temperature gradient from 25 to $90{ }^{\circ} \mathrm{C}$, performing fluorescence measurements every $0.5^{\circ} \mathrm{C}$ increase after a $10 \mathrm{~s}$ delay for signal stabilization. The measurements were performed in triplicates using $470 \mathrm{~nm}$ excitation wavelength and $510 \mathrm{~nm}$ emission wavelength.

\section{Conclusions}

Ppo-Er1 is a well-expressed, easy to purify, old yellow enzyme belonging to the recently introduced subclass III designation. In terms of cofactor preference, the enzyme accepts NADPH and NADH equally well, whereas $\mathrm{pH}$ and optimum temperature resemble those of previously described OYEs. Notably, the enzyme exhibits only slightly reduced performance ( $>70 \%$ conversion of $1 \mathrm{mM}$ cyclohexenone) at lowered temperatures $\left(10^{\circ} \mathrm{C}\right)$ making it a possible candidate for the transformation of labile substrates such as some aldehydes. In addition, the enzyme was shown to have noteworthy stability in the presence of the solvents cyclohexane (up to at least $40 \% \mathrm{v} / \mathrm{v}$ ), DMSO, and ethanol (up to $20 \% \mathrm{v} / \mathrm{v}$ ).

The substrate profile analysis with a set of 19 representative alkenes allowed the establishment of Ppo-Er1's substrate scope highlighting its acceptance of a variety of linear and cyclic compounds with often excellent transformation efficiencies and exquisite stereoselectivity (e.g., $98 \%$ ee for carvone). Complementing this analysis with the determination of steady-state kinetics for ten of the substrates allowed us to conclude that Ppo-Er1 classifies well with other subgroup III old yellow enzymes. 
In summary, our in-depth characterization of Ppo-Er1 allows the enlargement of the available panel of ene reductases with a versatile biocatalyst having interesting synthetic properties. Its introduction in the biocatalytic toolbox may further facilitate academic and industrial efforts when screening for biocatalysts capable of asymmetric double bond reduction. Looking forward, Ppo-Er1's performance could be further optimized via enzyme and process engineering.

Supplementary Materials: The following are available online at http://www.mdpi.com/2073-4344/10/2/254/s1. Figure S1: SDS-PAGE of the different purification steps for the ene reductase Ppo-ER1; Figure S2: Gel filtration of Ppo-ER1; Figure S3: Activity of Ppo-ER1 in the two used buffers; Table S1: Overview of the used GC-methods; Figure S4: Michaelis-Menten kinetic for maleimide; Figure S5: Michaelis-Menten kinetic for trans- $\beta$-methyl- $\beta$-nitrostyrene; Figure S6: Michaelis-Menten kinetic for cyclohexanone; Figure S7: Michaelis-Menten kinetic for cinnamaldehyde; Figure S8: Michaelis-Menten kinetic for 2-methyl-2-pentenal; Figure S9: Michaelis-Menten kinetic for carvone; Figure S10: Michaelis-Menten kinetic for citral; Figure S11: Michaelis-Menten kinetic for 2-methyl-2-cyclohexenone; Figure S12: Michaelis-Menten kinetic for cyclopentenone; Figure S13: Michaelis-Menten kinetic for hexenal; Figure S14: Comparison conversion with NADH and NADPH; Figure S15: Melting curve.

Author Contributions: Conceptualization: C.P. and R.M.B.; experimental work: D.A.; writing: D.A., C.P., and R.M.B. All authors have read and agreed to the published version of the manuscript.

Funding: This research received no external funding.

Conflicts of Interest: The authors declare no conflict of interest.

\section{References}

1. List, B.; Yang, J.W. Chemistry. The organic approach to asymmetric catalysis. Science 2006, 313, $1584-1586$. [CrossRef] [PubMed]

2. Huffman, M.A.; Fryszkowska, A.; Alvizo, O.; Borra-Garske, M.; Campos, K.R.; Canada, K.A.; Devine, P.N.; Duan, D.; Forstater, J.H.; Grosser, S.T.; et al. Design of an in vitro biocatalytic cascade for the manufacture of islatravir. Science 2019, 366, 1255-1259. [CrossRef] [PubMed]

3. Savile, C.K.; Janey, J.M.; Mundorff, E.C.; Moore, J.C.; Tam, S.; Jarvis, W.R.; Colbeck, J.C.; Krebber, A.; Fleitz, F.J.; Brands, J.; et al. Biocatalytic asymmetric synthesis of chiral amines from ketones applied to sitagliptin manufacture. Science 2010, 329, 305-309. [CrossRef] [PubMed]

4. Schober, M.; MacDermaid, C.; Ollis, A.A.; Chang, S.; Khan, D.; Hosford, J.; Latham, J.; Ihnken, L.A.F.; Brown, M.J.B.; Fuerst, D.; et al. Chiral synthesis of lsd1 inhibitor gsk2879552 enabled by directed evolution of an imine reductase. Nat. Catal. 2019, 2, 909-915. [CrossRef]

5. Adams, J.P.; Brown, M.J.B.; Diaz-Rodriguez, A.; Lloyd, R.C.; Roiban, G.D. Biocatalysis: A pharma perspective. Adv. Synth. Catal. 2019, 361, 2421-2432. [CrossRef]

6. Toogood, H.S.; Scrutton, N.S. Discovery, characterisation, engineering and applications of ene reductases for industrial biocatalysis. ACS Catal. 2019, 8, 3532-3549. [CrossRef]

7. Toogood, H.S.; Gardiner, J.M.; Scrutton, N.S. Biocatalytic reductions and chemical versatility of the old yellow enzyme family of flavoprotein oxidoreductases. Chemcatchem 2010, 2, 892-914. [CrossRef]

8. Winkler, C.K.; Faber, K.; Hall, M. Biocatalytic reduction of activated cc-bonds and beyond: Emerging trends. Curr. Opin. Chem. Biol. 2018, 43, 97-105. [CrossRef]

9. Shimoda, K.; Ito, D.I.; Izumi, S.; Hirata, T. Novel reductase participation in the syn-addition of hydrogen to the $\mathrm{c}=\mathrm{c}$ bond of enones in the cultured cells of Nicotiana tabacum. J. Chem. Soc. Perkin Trans. 1996, 1, 355-358. [CrossRef]

10. Knowles, W.S. Asymmetric hydrogenations (nobel lecture). Angew. Chem. Int. Ed. Engl. 2002, 41, 1999-2007.

11. Noyori, R. Asymmetric catalysis: Science and opportunities (nobel lecture). Angew. Chem. Int. Ed. 2002, 41, 2008-2022. [CrossRef]

12. Knaus, T.; Toogood, H.S.; Scrutton, N.S. Ene-reductases and their applications. In Green Biocatalysis; John Wiley \& Sons, Inc.: Hoboken, NJ, USA, 2016; pp. 473-488.

13. Steinkellner, G.; Gruber, C.C.; Pavkov-Keller, T.; Binter, A.; Steiner, K.; Winkler, C.; Lyskowski, A.; Schwamberger, O.; Oberer, M.; Schwab, H.; et al. Identification of promiscuous ene-reductase activity by mining structural databases using active site constellations. Nat. Commun. 2014, 5, 4150. [CrossRef] [PubMed] 
14. Hecht, K.; Buller, R. Ene-reductases in pharmaceutical chemistry. In Pharmaceutical Biocatalysis: Chemoenzymatic Synthesis of Active Pharmaceutical Ingredients; Grunwald, P., Ed.; Jenny Stanford Publishing: Singapore, 2019.

15. Peters, C.; Frasson, D.; Sievers, M.; Buller, R. Novel old yellow enzyme subclasses. Chembiochem 2019, 20, 1569-1577. [CrossRef] [PubMed]

16. Warburg, O.; Christian, W. Ein zweites sauerstoffübertragendes ferment und sein absorptionsspektrum. Naturwissenschaften 1932, 20, 688. [CrossRef]

17. Haas, E. Isolierung eines neuen gelben ferments. Biochem. Z 1938, 298, 369-390.

18. Breithaupt, C.; Strassner, J.; Breitinger, U.; Huber, R.; Macheroux, P.; Schaller, A.; Clausen, T. X-ray structure of 12-oxophytodienoate reductase 1 provides structural insight into substrate binding and specificity within the family of oye. Structure 2001, 9, 419-429. [CrossRef]

19. Kohli, R.M.; Massey, V. The oxidative half-reaction of old yellow enzyme: The role of tyrosine 196. J. Biol. Chem. 1998, 273, 32763-32770. [CrossRef]

20. Fox, K.M.; Karplus, P.A. Old yellow enzyme at 2 å resolution: Overall structure, ligand binding, and comparison with related flavoproteins. Structure 1994, 2, 1089-1105. [CrossRef]

21. Barna, T.M.; Khan, H.; Bruce, N.C.; Barsukov, I.; Scrutton, N.S.; Moody, P.C.E. Crystal structure of pentaerythritol tetranitrate reductase: "Flipped" binding geometries for steroid substrates in different redox states of the enzyme. J. Mol. Biol. 2001, 310, 433-447. [CrossRef]

22. Kitzing, K.; Fitzpatrick, T.B.; Wilken, C.; Sawa, J.; Bourenkov, G.P.; Macheroux, P.; Clausen, T. The 1.3 å crystal structure of the flavoprotein yqjm reveals a novel class of old yellow enzymes. J. Biol. Chem. 2005, 280, 27904-27913. [CrossRef]

23. Adalbjörnsson, B.V.; Toogood, H.S.; Fryszkowska, A.; Pudney, C.R.; Jowitt, T.A.; Leys, D.; Scrutton, N.S. Biocatalysis with thermostable enzymes: Structure and properties of a thermophilic 'ene'-reductase related to old yellow enzyme. ChemBioChem 2010, 11, 197-207. [CrossRef] [PubMed]

24. Nizam, S.; Verma, S.; Borah, N.N.; Gazara, R.K.; Verma, P.K. Comprehensive genome-wide analysis reveals different classes of enigmatic old yellow enzyme in fungi. Sci. Rep. 2014, 4, 4013. [CrossRef] [PubMed]

25. Pietruszka, J.; Schölzel, M. Ene reductase-catalysed synthesis of (r)-profen derivatives. Adv. Synth. Catal. 2012, 354, 751-756. [CrossRef]

26. Li, Z.N.; Wang, Z.X.; Meng, G.; Lu, H.; Huang, Z.D.; Chen, F.E. Identification of an ene reductase from yeast Kluyveromyces marxianus and application in the asymmetric synthesis of (R)-profen esters. Asian. J. Org. Chem. 2018, 7, 763-769. [CrossRef]

27. Waller, J.; Toogood, H.S.; Karuppiah, V.; Rattray, N.J.W.; Mansell, D.J.; Leys, D.; Gardiner, J.M.; Fryszkowska, A.; Ahmed, S.T.; Bandichhor, R.; et al. Structural insights into the ene-reductase synthesis of profens. Org. Biomol. Chem. 2017, 15, 4440-4448. [CrossRef] [PubMed]

28. Fryszkowska, A.; Fisher, K.; Gardiner, J.M.; Stephens, G.M. A short, chemoenzymatic route to chiral $\beta$-aryl- $\gamma$-amino acids using reductases from anaerobic bacteria. Org. Biomol. Chem. 2010, 8, 533-535. [CrossRef] [PubMed]

29. Winkler, C.K.; Clay, D.; Davies, S.; O’Neill, P.; McDaid, P.; Debarge, S.; Steflik, J.; Karmilowicz, M.; Wong, J.W.; Faber, K. Chemoenzymatic asymmetric synthesis of pregabalin precursors via asymmetric bioreduction of $\beta$-cyanoacrylate esters using ene-reductases. J. Org. Chem. 2013, 78, 1525-1533. [CrossRef]

30. Winkler, C.K.; Clay, D.; Turrini, N.G.; Lechner, H.; Kroutil, W.; Davies, S.; Debarge, S.; O'Neill, P.; Steflik, J.; Karmilowicz, M.; et al. Nitrile as activating group in the asymmetric bioreduction of beta-cyanoacrylic acids catalyzed by ene-reductases. Adv. Synth. Catal. 2014, 356, 1878-1882. [CrossRef]

31. Janicki, I.; Kiełbasiński, P.; Turrini, N.G.; Faber, K.; Hall, M. Asymmetric bioreduction of $\beta$-activated vinylphosphonate derivatives using ene-reductases. Adv. Synth. Catal. 2017, 359, 4190-4196. [CrossRef]

32. Bertolotti, M.; Brenna, E.; Crotti, M.; Gatti, F.G.; Monti, D.; Parmeggiani, F.; Santangelo, S. Substrate scope evaluation of the enantioselective reduction of $\beta$-alkyl- $\beta$-arylnitroalkenes by old yellow enzymes $1-3$ for organic synthesis applications. ChemCatChem 2016, 8, 577-583. [CrossRef]

33. Dobrijevic, D.; Benhamou, L.; Aliev, A.E.; Méndez-Sánchez, D.; Dawson, N.; Baud, D.; Tappertzhofen, N.; Moody, T.S.; Orengo, C.A.; Hailes, H.C.; et al. Metagenomic ene-reductases for the bioreduction of sterically challenging enones. RSC Adv. 2019, 9, 36608-36614. [CrossRef]

34. Sheng, X.; Yan, M.; Xu, L.; Wei, M. Identification and characterization of a novel old yellow enzyme from Bacillus subtilis str.168. J. Mol. Catal. B Enzym. 2016, 130, 18-24. [CrossRef] 
35. Zhang, H.; Gao, X.; Ren, J.; Feng, J.; Zhang, T.; Wu, Q.; Zhu, D. Enzymatic hydrogenation of diverse activated alkenes. Identification of two bacillus old yellow enzymes with broad substrate profiles. J. Mol. Catal. B Enzym. 2014, 105, 118-125. [CrossRef]

36. Gao, X.; Ren, J.; Wu, Q.; Zhu, D. Biochemical characterization and substrate profiling of a new nadh-dependent enoate reductase from Lactobacillus casei. Enzyme Microb. Technol. 2012, 51, 26-34. [CrossRef] [PubMed]

37. Brown, B.J.; Deng, Z.; Karplus, P.A.; Massey, V. On the active site of old yellow enzyme: Role of histidine 191 and asparagine 194. J. Biol. Chem. 1998, 273, 32753-32762. [CrossRef]

38. Spiegelhauer, O.; Dickert, F.; Mende, S.; Niks, D.; Hille, R.; Ullmann, M.; Dobbek, H. Kinetic characterization of xenobiotic reductase a from Pseudomonas putida 86. Biochemistry 2009, 48, 11412-11420. [CrossRef]

39. Scholtissek, A.; Tischler, D.; Westphal, A.; van Berkel, W.; Paul, C. Old yellow enzyme-catalysed asymmetric hydrogenation: Linking family roots with improved catalysis. Catalysts 2017, 7, 130. [CrossRef]

40. Hummel, W.; Gröger, H. Strategies for regeneration of nicotinamide coenzymes emphasizing self-sufficient closed-loop recycling systems. J. Biotechnol. 2014, 191, 22-31. [CrossRef]

41. Knaus, T.; Paul, C.E.; Levy, C.W.; de Vries, S.; Mutti, F.G.; Hollmann, F.; Scrutton, N.S. Better than nature: Nicotinamide biomimetics that outperform natural coenzymes. J. Am. Chem. Soc. 2016, 138, 1033-1039. [CrossRef]

42. Lee, S.H.; Choi, D.S.; Pesic, M.; Lee, Y.W.; Paul, C.E.; Hollmann, F.; Park, C.B. Cofactor-free, direct photoactivation of enoate reductases for the asymmetric reduction of $\mathrm{c}=\mathrm{c}$ bonds. Angew. Chem. Int. Ed. 2017, 56, 8681-8685. [CrossRef]

43. Litthauer, S.; Gargiulo, S.; van Heerden, E.; Hollmann, F.; Opperman, D.J. Heterologous expression and characterization of the ene-reductases from Deinococcus radiodurans and Ralstonia metallidurans. J. Mol. Catal. B Enzym. 2014, 99, 89-95. [CrossRef]

44. Davies, M.T. A universal buffer solution for use in ultra-violet spectrophotometry. Analyst 1959, 84, $248-251$. [CrossRef]

45. Peters, C.; Kölzsch, R.; Kadow, M.; Skalden, L.; Rudroff, F.; Mihovilovic, M.D.; Bornscheuer, U.T. Identification, characterization, and application of three enoate reductases from Pseudomonas putida in in vitro enzyme cascade reactions. Chem CatChem 2014, 6, 1021-1027. [CrossRef]

46. Pesic, M.; Fernández-Fueyo, E.; Hollmann, F. Characterization of the old yellow enzyme homolog from Bacillus subtilis (yqjm). ChemistrySelect 2017, 2, 3866-3871. [CrossRef]

47. Xu, M.-Y.; Pei, X.-Q.; Wu, Z.-L. Identification and characterization of a novel "thermophilic-like" old yellow enzyme from the genome of Chryseobacterium sp. Ca49. J. Mol. Catal. B Enzym. 2014, 108, 64-71. [CrossRef]

48. Zheng, L.; Lin, J.; Zhang, B.; Kuang, Y.; Wei, D. Identification of a yeast old yellow enzyme for highly enantioselective reduction of citral isomers to (R)-citronellal. Bioresour. Bioprocess. 2018, 5, 1-12. [CrossRef]

49. Rudroff, F.; Mihovilovic, M.D.; Gröger, H.; Snajdrova, R.; Iding, H.; Bornscheuer, U.T. Opportunities and challenges for combining chemo- and biocatalysis. Nat. Catal. 2018, 1, 12-22. [CrossRef]

50. Fryszkowska, A.; Toogood, H.; Sakuma, M.; Gardiner, J.M.; Stephens, G.M.; Scrutton, N.S. Asymmetric reduction of activated alkenes by pentaerythritol tetranitrate reductase: Specificity and control of stereochemical outcome by reaction optimisation. Adv. Synth. Catal. 2009, 351, 2976-2990. [CrossRef]

51. Tischler, D.; Gadke, E.; Eggerichs, D.; Gomez Baraibar, A.; Mugge, C.; Scholtissek, A.; Paul, C.E. Asymmetric reduction of (r)-carvone through a thermostable and organic-solvent-tolerant ene-reductase. Chembiochem 2019. [CrossRef]

52. Robescu, M.S.; Niero, M.; Hall, M.; Cendron, L.; Bergantino, E. Two new ene-reductases from photosynthetic extremophiles enlarge the panel of old yellow enzymes: Ctoye and gsoye. Appl. Microbiol. Biotechnol. 2020, 104, 2051-2066. [CrossRef]

53. Riedel, A.; Mehnert, M.; Paul, C.E.; Westphal, A.H.; van Berkel, W.J.; Tischler, D. Functional characterization and stability improvement of a 'thermophilic-like' ene-reductase from Rhodococcus opacus 1cp. Front. Microbiol. 2015, 6, 1073. [CrossRef] [PubMed]

54. Hall, M.; Stueckler, C.; Ehammer, H.; Pointner, E.; Oberdorfer, G.; Gruber, K.; Hauer, B.; Stuermer, R.; Kroutil, W.; Macheroux, P.; et al. Asymmetric bioreduction of $\mathrm{c}=\mathrm{c}$ bonds using enoate reductases opr1, opr3 and yqjm: Enzyme-based stereocontrol. Adv. Synth. Catal. 2008, 350, 411-418. [CrossRef] 
55. Josuran, R. Prot pi. Available online: https://www.protpi.ch/ (accessed on 22 January 2020).

56. Forneris, F.; Orru, R.; Bonivento, D.; Chiarelli, L.R.; Mattevi, A. Thermofad, a thermofluor-adapted flavin ad hoc detection system for protein folding and ligand binding. FEBS J. 2009, 276, 2833-2840. [CrossRef] [PubMed]

(c)

(C) 2020 by the authors. Licensee MDPI, Basel, Switzerland. This article is an open access article distributed under the terms and conditions of the Creative Commons Attribution (CC BY) license (http://creativecommons.org/licenses/by/4.0/). 


\title{
Review \\ Cofactor $\mathrm{F}_{420}$-Dependent Enzymes: An Under-Explored Resource for Asymmetric Redox Biocatalysis
}

\author{
Mihir V. Shah ${ }^{1,+}$, James Antoney ${ }^{1,2, \dagger}$, Suk Woo Kang ${ }^{1,2}$, Andrew C. Warden ${ }^{1}$, Carol J. Hartley ${ }^{1}$, \\ Hadi Nazem-Bokaee ${ }^{1}$, Colin J. Jackson ${ }^{1,2}$ and Colin Scott ${ }^{1, *}$ \\ 1 CSIRO Synthetic Biology Future Science Platform, Canberra 2601, Australia; Mihir.Shah@csiro.au (M.V.S.); \\ James.Antoney@anu.edu.au (J.A.); Suk.Kang@anu.edu.au (S.W.K.); andrew.warden@csiro.au (A.C.W.); \\ Carol.Hartley@csiro.au (C.J.H.); Hadi.Nazem-Bokaee@csiro.au (H.N.-B.); colin.jackson@anu.edu.au (C.J.J.) \\ 2 Research School of Chemistry, Australian National University, Canberra 2601, Australia \\ * Correspondence: colin.scott@csiro.au; Tel.: +61-2-6246-4090 \\ + M.V.S. and J.A. contributed equally to this review.
}

Received: 20 September 2019; Accepted: 10 October 2019; Published: 20 October 2019

\begin{abstract}
The asymmetric reduction of enoates, imines and ketones are among the most important reactions in biocatalysis. These reactions are routinely conducted using enzymes that use nicotinamide cofactors as reductants. The deazaflavin cofactor $\mathrm{F}_{420}$ also has electrochemical properties that make it suitable as an alternative to nicotinamide cofactors for use in asymmetric reduction reactions. However, cofactor $\mathrm{F}_{420}$-dependent enzymes remain under-explored as a resource for biocatalysis. This review considers the cofactor $\mathrm{F}_{420}$-dependent enzyme families with the greatest potential for the discovery of new biocatalysts: the flavin/deazaflavin-dependent oxidoreductases (FDORs) and the luciferase-like hydride transferases (LLHTs). The characterized $\mathrm{F}_{420}$-dependent reductions that have the potential for adaptation for biocatalysis are discussed, and the enzymes best suited for use in the reduction of oxidized cofactor $\mathrm{F}_{420}$ to allow cofactor recycling in situ are considered. Further discussed are the recent advances in the production of cofactor $\mathrm{F}_{420}$ and its functional analog $\mathrm{F}_{\mathrm{O}}-5^{\prime}$-phosphate, which remains an impediment to the adoption of this family of enzymes for industrial biocatalytic processes. Finally, the prospects for the use of this cofactor and dependent enzymes as a resource for industrial biocatalysis are discussed.
\end{abstract}

Keywords: cofactor $\mathrm{F}_{420}$; deazaflavin; oxidoreductase; hydride transfer; hydrogenation; asymmetric synthesis; cofactor biosynthesis

\section{Introduction}

Enzymes that catalyze the asymmetric reduction of activated double bonds are among the most important in biocatalysis, allowing access to chiral amines from imines $(\mathrm{C}=\mathrm{N})$, sec-alcohols from ketones $\mathrm{C}=\mathrm{O})$, and enantiopure products derived from enoates $(\mathrm{C}=\mathrm{C})$. To date, the reduction of imines, ketones and enoates has been achieved largely using enzymes that draw their reducing potential from the nicotinamide cofactors NADH and NADPH; e.g., imine reductases, ketoreductases and Old Yellow Enzymes [1-4]. However, there has been recent interest in an alternative reductive cofactor, cofactor $\mathrm{F}_{420}$ (8-hydroxy-5-deazaflavin) $[5,6]$.

Cofactor $\mathrm{F}_{420}$ is a deazaflavin that is structurally similar to flavins (Figure 1), with a notable difference at position 5 of the isoalloxazine ring, which is a nitrogen in flavins and a carbon in deazaflavins. Additionally, while C-7 and C-8 are methylated in riboflavin, they are not in cofactor $\mathrm{F}_{420}$ : C-7 is hydroxylated and C-8 is unsubstituted. These structural differences cause significant differences in the electrochemical properties of cofactor $\mathrm{F}_{420}$ and flavins: a $-360-340 \mathrm{mV}$ the redox mid-point 
potential of cofactor $\mathrm{F}_{420}$ is not only lower than that of the flavins ( $-205 \mathrm{mV}$ to $-220 \mathrm{mV}$ ), but it is also lower than that of the nicotinamides $(-320 \mathrm{mV})$ [7]. Additionally, as a consequence of the substitution of $\mathrm{N}-5$ for a carbon, cofactor $\mathrm{F}_{420}$ cannot form a semiquinone (Figure 1), which means that unlike other flavins, cofactor $\mathrm{F}_{420}$ can only perform two-electron reductions.

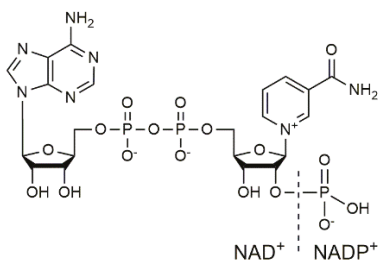

Oxidized

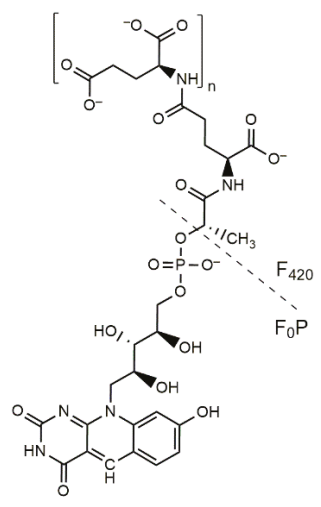

Oxidized

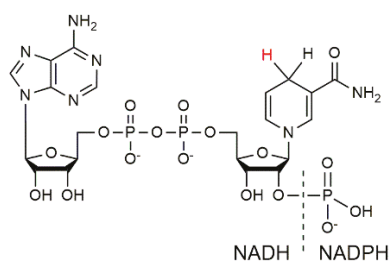

Reduced

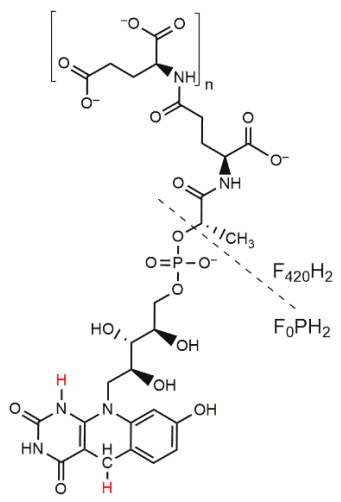

Reduced

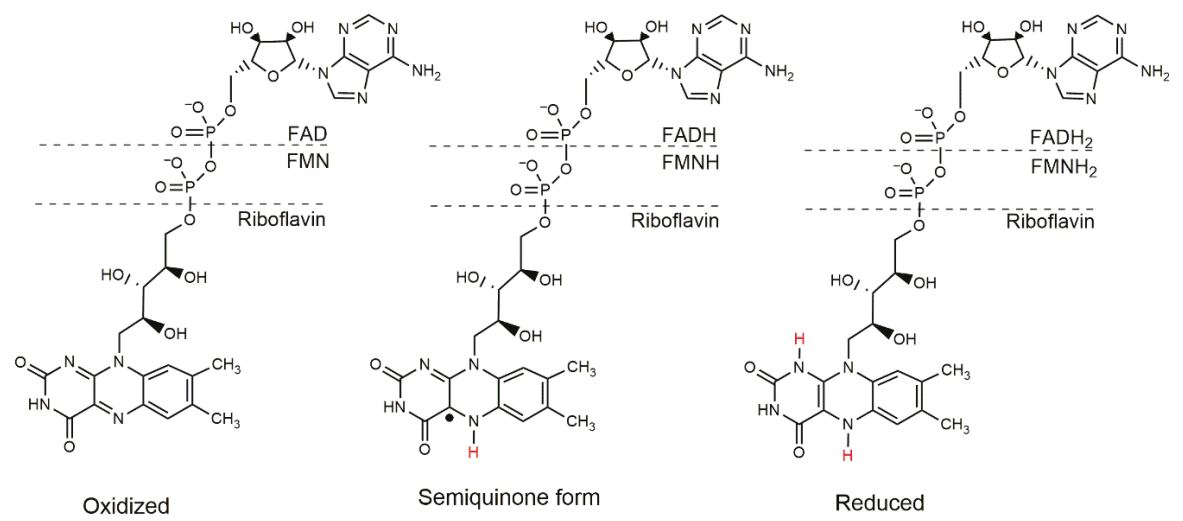

Figure 1. The structures of $\mathrm{NAD}(\mathrm{P})$ (top), cofactor $\mathrm{F}_{420}$ and its synthetic analog $\mathrm{F}_{\mathrm{O}} \mathrm{P}$ (center) and common flavins (riboflavin, FMN and FAD; bottom). The oxidized and reduced forms are shown, as is the flavin semiquinone. Dashed lines indicate the differences in the structures of $\mathrm{F}_{\mathrm{O}} \mathrm{P}$ and cofactor $\mathrm{F}_{420}$, and riboflavin, FMN and FAD.

Cofactor $\mathrm{F}_{420}$ was originally described in methanogenic archaea, where it plays a pivotal role in methanogenesis $[8,9]$. Cofactor $\mathrm{F}_{420}$ has since been described in a range of soil bacteria supporting 
a range of metabolic activities, including catabolism of recalcitrant molecules (such as picric acid) and the production of secondary metabolites, such as antibiotics [7]. A comprehensive review of the biochemistry and physiological roles of cofactor $\mathrm{F}_{420}$ was recently published by Greening and coworkers [7]. This review considers the potential of $\mathrm{F}_{420}$-dependent enzymes in industrial biocatalysis, focusing on the enzyme families relevant to biocatalytic applications and the reactions that they catalysis. Cofactor recycling strategies and cofactor production are also discussed, with a focus on the prospects for achieving low-cost production at scale in the latter case.

\section{Families of $\mathrm{F}_{420}$-Dependent Enzymes Relevant to Biocatalysis}

With respect to their prospective biocatalytic applications, the two most important families of $\mathrm{F}_{420}$-dependent enzymes are the Flavin/Deazaflavin Oxidoreductase (FDOR) and Luciferase-Like Hydride Transferase (LLHT) families, albeit $\mathrm{F}_{420}$-dependent enzyme from other families have also been shown to have catalytic activities of interest (e.g., TomJ, the imine reducing flavin-dependent monooxygenase or OxyR, the tetracycline oxidoreductase) $[10,11]$. The FDOR and LLHT families are large and contain highly diverse flavin/deazaflavin-dependent enzymes. In both families, there are enzymes with preferences for flavins, such as flavin mononucleotide (FMN) and flavin adenine dinucleotide (FAD), as well as those that use cofactor $F_{420}[12,13]$. Moreover, there are $F_{420}$-dependent FDORs that have been shown to be able to promiscuously bind FMN and use it in oxidation reactions [14]. In this section, the FDOR and LLHT families and the classes of reaction that they catalyze are discussed.

\subsection{The FDOR Superfamily}

The FDOR superfamily (PFAM Clan CL0336) can be broadly divided into two groups: the FDOR-As (which includes a sub-group called the FDOR-AAs) and the FDOR-Bs. The FDOR-As are restricted to Actinobacteria and Chloroflexi and to date no FDOR-As have been described that use cofactors other than $\mathrm{F}_{420}$ [7,12]. The FDOR-Bs are found in a broader range of bacterial genera than the FDOR-A enzymes, and in addition to $\mathrm{F}_{420}$-dependent enzymes, this group also includes heme oxygenases, flavin-sequestering proteins, pyridoxine 5' oxidases and a number of proteins of unknown function [12,15-17]. Both groups of FDOR are highly diverse, with many homologs often found within a single bacterial genome (e.g., Mycobacterium smegmatis has 28 FDORs) [18]. In addition, the majority of the enzymes of this family are yet to be characterized with respect to either their biochemical or physiological function, and therefore the FDORs represent a currently under-explored source of enzymes for biocatalysis.

The FDOR enzymes share a characteristic split $\beta$-barrel fold that forms part of the cofactor-binding pocket. The majority of the protein sequences of enzymes currently identified as belonging to this family are small single-domain proteins. The topologies of the two FDOR subgroups are broadly similar (Figure 2), with the split-barrel core composed of 7-8 strands and with 4-5 helices interspersed. All FDOR-Bs studied so far have been demonstrated to be dimeric, with stands $\beta 2, \beta 3, \beta 5$ and $\beta 6$ making up the core of the dimer interface (Figure 2). In structures of full-length FDOR-As solved to date, the N-terminal helix (if present) lies on the opposite face of the beta sheet to that in FDOR-Bs. Thus, the N-terminus occupies part of the dimer interface region and prevents interaction between the sheets of adjacent monomers. In contrast to the FDOR-Bs, the oligomerization state of the FDOR-As is more varied. While a number of FDOR-As have been determined to be monomeric [18], the deazaflavin-dependent nitroreductase (DDN) from $M$. tuberculosis forms soluble aggregates through the amphipathic N-terminal helix [19]. DDN and the FDOR-AA subgroup have been shown to be membrane-associated [20-22], and FDOR-AAs have been associated with fatty acid metabolism [12]. No structures of FDOR-AAs have been solved to date. 
A

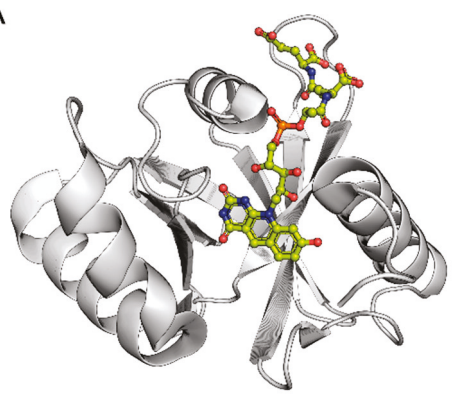

c

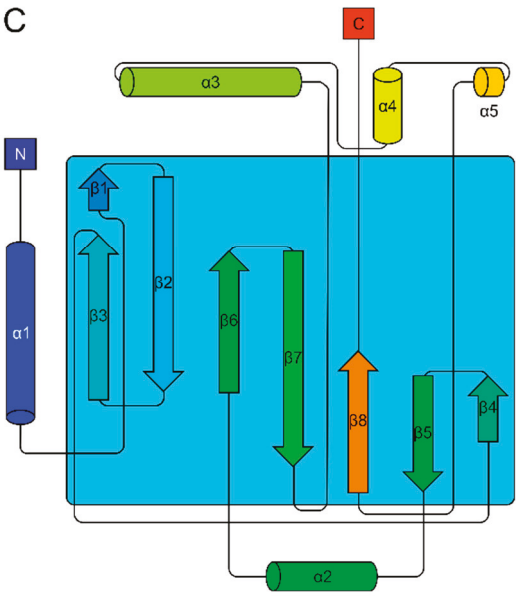

B

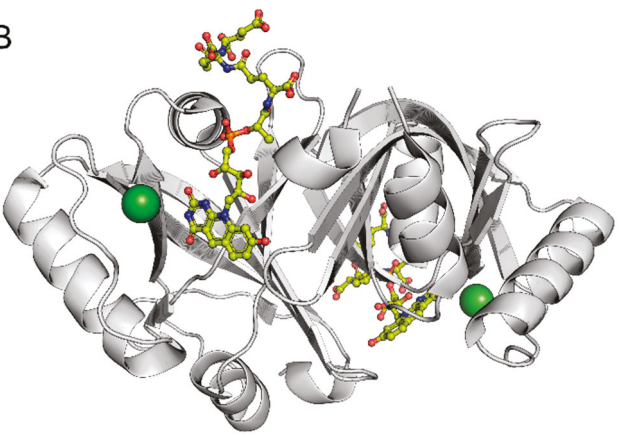

D

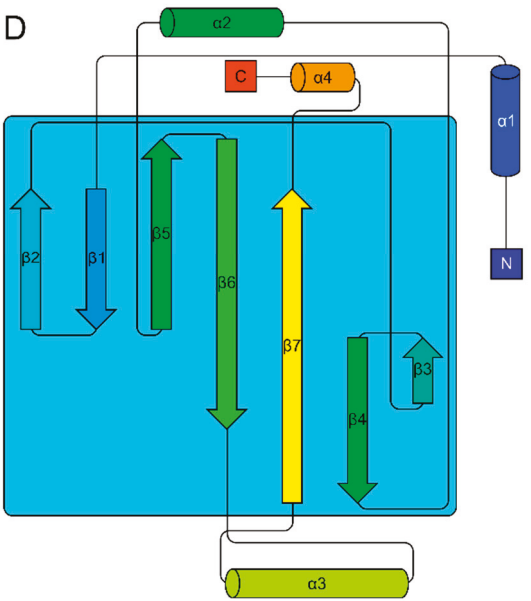

Figure 2. Representative structures of $\mathrm{F}_{420}$-dependent FDOR-A (PDB: $3 R 5 Z$, panels $\mathbf{A}$ and $\mathbf{C}$ ) and FDOR-B (PDB: 5JAB, panels B and D). Both are predominantly composed of a single $\beta$-sheet forming a split barrel. The $\mathrm{N}$-terminal helices are spatially displaced between the two families, falling on opposite faces of the $\beta$-sheet.

\subsection{The LLHT Family:}

The LLHT family form part of the Luciferase-Like Monooxygenase family (PFAM PF00296). They adopt an $(\alpha / \beta)_{8}$ TIM-barrel fold with three insertion regions, IS1-4 (Figure 3). IS1 contains a short loop and forms part of the substrate cleft. IS2 contains two antiparallel $\beta$-strands, and IS3 contains a helical bundle at the C-terminus of the $\beta$-barrel and contains the remainder of the substrate-binding pocket (Figure 3). All structures solved to date from the LLHT family contain a non-prolyl cis peptide in $\beta 3$ [23-26]. Recent phylogenetic reconstructions have shown that the $\mathrm{F}_{420}$-dependent LLHTs form two clades: the $\mathrm{F}_{420}$-dependent reductases and the $\mathrm{F}_{420}$-depented dehydrogenases [27]. The $\mathrm{F}_{420}$-reductases contain methylenetetrahydromethanopterin reductases (MERs), which catalyze the reversable, ring-opening cleavage of a carbon-nitrogen bond during the biosynthesis of folate in some archaea [28-30]. The $\mathrm{F}_{420}$-dependent dehydrogenases can be further divided into three subgroups. The first contains $\mathrm{F}_{420}$-dependent secondary alcohol dehydrogenases (ADFs) and the hydroxymycolic acid reductase from $M$. tuberculosis [31]. The second contains the $\mathrm{F}_{420}$-dependent glucose-6-phosphate dehydrogenases (FGDs) from Mycobacteria and Rhodococcus, while the third appear to be more general sugar-phosphate dehydrogenases [27]. In contrast to the heterodimeric structure of bacterial luciferase, the $\mathrm{F}_{420}$-dependent dehydrogenases form homodimers with the dimer interface burying a relatively large portion of the surface area of the monomers ( $\approx 2000 \AA^{2}$, roughly $15 \%$ 
of the total surface area) [24-26]. A number of enzymes involved in the $\mathrm{F}_{420}$-dependent degradation of nitroaromatic explosives, such as picrate and 2,4-dinitroanisole, appear to belong to the LLHT family as well $[32,33]$.

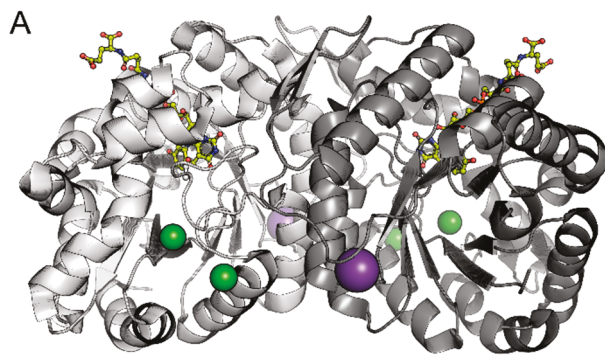

B

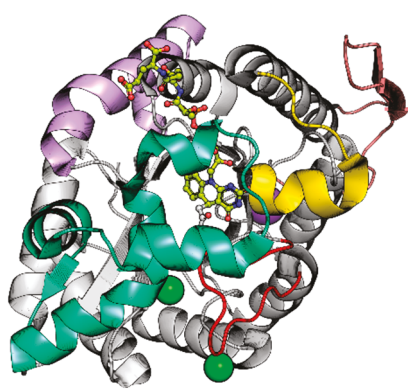

C

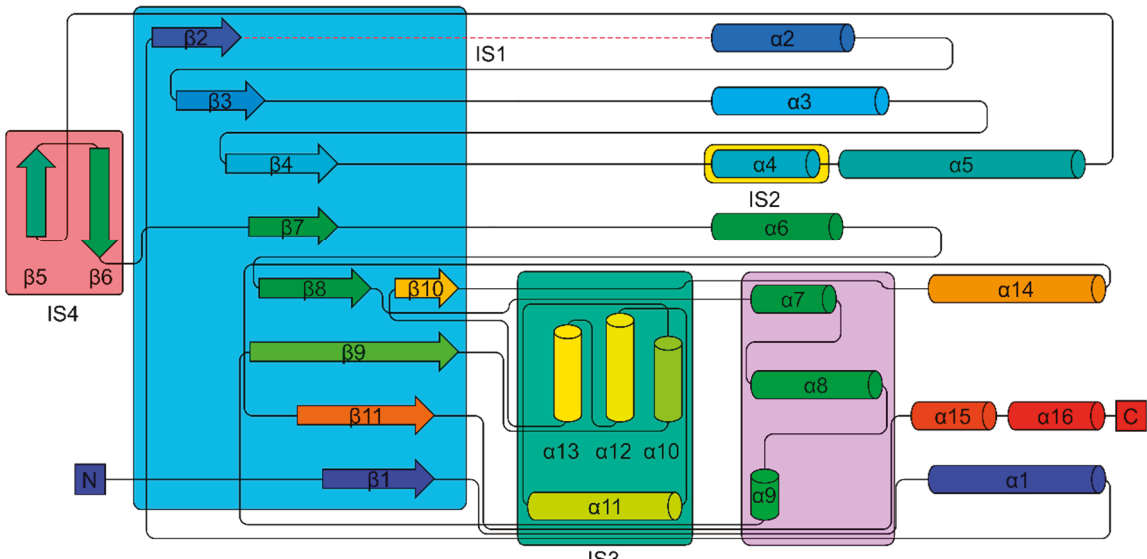

IS3

Figure 3. Structure of representative luciferase-like hydride transferase (LLHT) (PDB: 1RHC). (A) A 3D representation of the biologically relevant dimer (panel A). Monomer of an LLHT with insertion sequences IS1-4 highlighted, along with the helical bundle composed of $\alpha 7-9$ (panel B). Topology diagram showing $(\alpha / \beta)_{8}$ fold with insertion sequences highlighted: IS1, red; IS2, orange; IS3, light green, IS4, pink. The helical bundle of $\alpha 7-9$ is highlighted in purple (panel C).

\subsection{Cofactor $F_{420}$-Dependent Reactions with Relevance to Biocatalysis}

From the perspective of biocatalysis, cofactor $\mathrm{F}_{420}$-dependent enzymes catalyze a number of key reductions including the reduction of enoates, imines, ketones and nitro-groups (Table 1; Figure 4). 

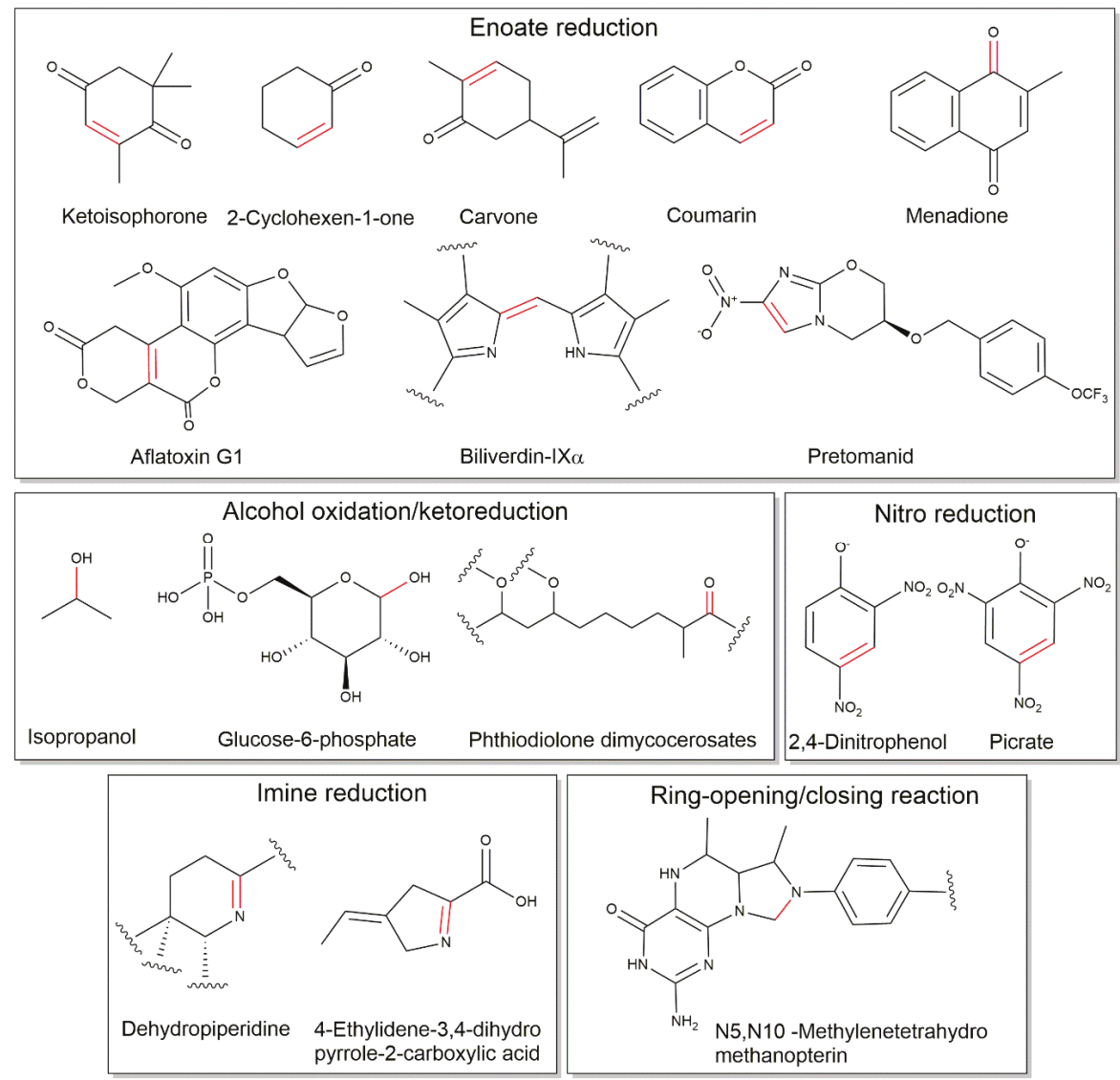

Figure 4. Representative cofactor $\mathrm{F}_{420}$-dependent oxidoreductions with the potential for adaptation to biocatalytic applications. Included are: nitroreduction, enoate reduction, ketoreduction and imine reduction (from top to bottom). For clarity, only the dehydropiperidine ring of the thiopeptide is shown and partial structures for biliverdin-Ix $\alpha$ and phthiodiolone dimycocerosates are shown.

For enoate reductions, a small number of FDORs have been studied. However, the substrate range for most of these enzymes is yet to be fully elucidated. The ability of the mycobacterial FDORs to reduce activated $\mathrm{C}=\mathrm{C}$ double bonds was first identified when $\mathrm{DDN}$ was shown to be responsible for activating the bicyclic nitroimidazole PA-824 in M. tuberculosis. These enzymes were then shown to also reduce enoates in aflatoxins, coumarins, furanocoumarins and quinones $[6,12,14,16,34-38]$. Recent studies have shown that these enzymes are promiscuous and can use cyclohexen-1-one, malachite green and a wide range of other activated ene compounds as substrates [35]. However, there have been a few FDOR studies to date that have examined their kinetic properties and stereospecificity. In one of these studies, FDORs from Mycobacterium hassiacum (FDR-Mha) and Rhodococcus jostii RHA1 (FDR-Rh1 and FDR-Rh2) were shown to reduce a range of structurally diverse enoates with conversions ranging from 12 to $>99 \%$ and e.e. values of up to $>99 \%$ [6]. Interestingly, it has been proposed that both the hydride and proton transfer from $\mathrm{F}_{420} \mathrm{H}_{2}$ in these reactions was directed to the same face of the activated double bond (Figure 5), which results in the opposite enantioselectivity compared to that of the FMN-dependent Old Yellow Enzyme family of enoate reductases [6]. This suggests that the $\mathrm{F}_{420}$-dependent FDORs may provide a stereocomplementary enoate reductase toolbox. However, other studies suggest that protonation of the substrate is mediated by solvent or an enzyme side-chain (as it 
is in Old Yellow Enzyme) [37]. Further structure/function studies are needed to fully understand the mechanistic diversity of this family of enzymes.

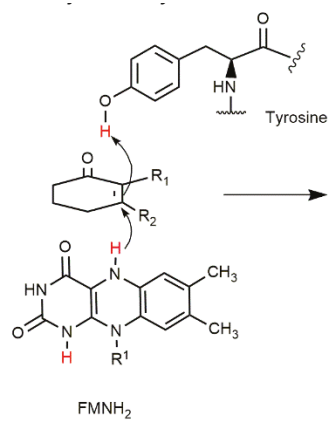<smiles>CC1(C(=O)O)CCCC1=O</smiles>

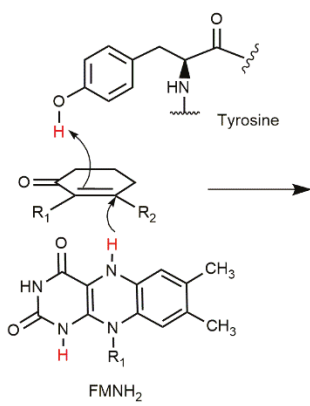<smiles>CC1(O)C(=O)CCC[C@]1(C)O</smiles>

Old Yellow Enzyme reduction mechanism

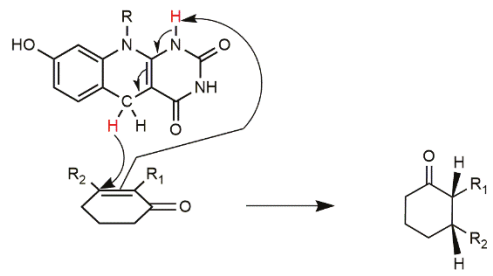

$\mathrm{F}_{420}$ dependent enzyme reduction mechanism

Figure 5. Enoate reduction by a flavin-dependent enzyme (Old Yellow Enzyme) and the proposed mechanism for cofactor $\mathrm{F}_{420}$-dependent reduction. Notably the mechanism of reduction yields trans-hydrogenation products for Old Yellow Enzyme and cis-hydrogenation products for the $\mathrm{F}_{420}$-dependent enzymes.

The LLHT family contains several enzymes with alcohol oxidase or ketoreductase activity (Table 1; Figure 4). The $\mathrm{F}_{420}$-dependent glucose-6-phosphate dehydrogenases of several species have been investigated $[25,26,39]$. Although an extensive survey of their substrate ranges has yet to be conducted, it has been demonstrated that glucose is a substrate for the Rhodococcus jostii RHA1 enzymes [26]. An $\mathrm{F}_{420}$-dependent alcohol dehydrogenase (ADH) from Methanogenium liminatans has been shown to catalyze the oxidation of the short chain aliphatic alcohols 2-propanol, 2-butanol and 2-pentanol (85, 49 and $23.1 \mathrm{~s}^{-1} k_{\text {cat }}, 2.2,1.2$ and $7.2 \mathrm{mM} K_{\mathrm{M}}$ respectively) [40], but it was unable to oxidize primary alcohols, polyols or secondary alcohols with more than five carbons. It is unclear whether these alcohol oxidations are reversible, but in the oxidative direction, these reactions provide enzymes that can be used to recycle reduced cofactor $\mathrm{F}_{420}$ (see Section 4). Alcohol oxidation can also be used to produce ketones as intermediates in biocatalytic cascades that can then be used in subsequent reactions, such those catalyzed by transaminases or amine dehydrogenases in chiral amine synthesis [1,41-43] or by ketoreductases or alcohol dehydrogenases in chiral sec-alcohol synthesis (i.e., deracemization or stereoinversion of sec-alcohols). This approach can be achieved in a one pot cascade if different cofactors are used for the oxidation and reduction (Figure 6) [44].

At least one $\mathrm{F}_{420}$-dependent ketoreductase has been described. The mycobacterial $\mathrm{F}_{420}$-dependent phthiodiolone ketoreductase catalyzes a key reduction in the production of phthiocerol dimycocerosate, a diacylated polyketide found in the mycobacterial cell wall [45]. Although the physiological role of 
this enzyme has been elucidated, biochemical studies of the catalytic properties and substrate range are required to assess this enzymes' potential for use as a biocatalyst.

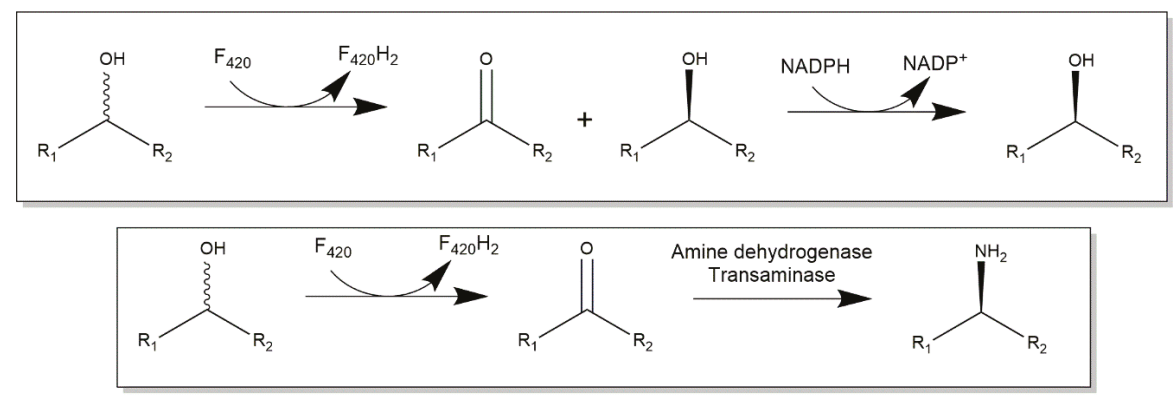

Figure 6. Proposed scheme for one-pot, enzyme cascades for deracemization/steroinversion of sec-alcohols (top) and chiral amine synthesis (bottom) using cofactor $\mathrm{F}_{420}$-dependent alcohol oxidation.

$\mathrm{F}_{420}$-dependent enzymes have also been shown to reduce imines (Table 1; Figure 4). An FDOR fromr Streptomyces tateyamensis (TpnL) is responsible for the reduction of dehydropiperidine in the piperidine-containing series $a$ group of thiopeptide antibiotics produced in this bacterium (Figure 4). TpnL was identified as the $\mathrm{F}_{420}$-dependent dehydropiperidine reductase responsible for the reduction of dehydropiperidine ring in thiostrepton A to produce the piperidine ring in the core macrocycle of thiostrepton A [45]. TpnL activity was affected by substrate inhibition at concentrations higher than $2 \mu \mathrm{M}$ of thiostrepton A, preventing the measurement of the $K_{\mathrm{M}}$, but its $k_{\text {cat }} / K_{\mathrm{M}}$ was measured at $2.80 \times 10^{4} \mathrm{M}^{-1} \mathrm{~S}^{-1}$ [45]. The substrates for phthiodiolone ketoreductase and TpnL are large secondary metabolites and, as yet, it is unclear if it will accept smaller substrates or substrates with larger/smaller heterocycles (e.g., dehydropyrroles).

Another $\mathrm{F}_{420}$-dependent imine reductase (TomJ) has been described from Streptomyces achromogenes that reduces the imine in 4-ethylidene-3,4-dehydropyrrole-2-carboxylic acid during the production of the secondary metabolite tomaymycin, which has been shown to have potentially interesting pharmaceutical properties [11]. Additionally, the reduction of a prochiral dihydropyrrole to a pyrrole is a reaction with a number of biocatalytic applications [5].

Nitroreductases have the potential application in the reduction of a prochiral nitro group to form a chiral amine [46]. The LLHT family $\mathrm{F}_{420}$-dependent nitroreductase Npd from Rhodococcus catalyzes the two-electron reduction of two nitro groups in picric acid during catabolism of the explosive TNT (Table 1; Figure 4) [47]. While this stops short of reducing the nitro group to an amine, this catalytic activity may contribute to a reductive cascade that achieves this conversion.

The final class of reaction for consideration in this review is the unusual, reversable ring-opening/ closing reaction catalyzed by the MERs (Figure 4; Table 1). This reaction is required for folate biosynthesis in some archaea [23,28-30]. However, ring-closing reactions of this type could be used for producing $\mathrm{N}$-containing heterocycles, which are intermediates in the synthesis of numerous pharmaceuticals $[48,49]$. The promiscuity of the MERs has not yet been investigated, and so the potential to re-engineer these enzymes is not fully understood. 
Table 1. Characterized $\mathrm{F}_{420}$-dependent enzymes with activities that could be adapted for biocatalytic applications.

\begin{tabular}{ccc}
\hline Reaction & Family & Reference \\
\hline Enoate reduction & & \\
\hline Aflatoxins & FDOR & {$[14,18,34]$} \\
Coumarins & FDOR & {$[14,34,35]$} \\
Quinones & FDOR & {$[36]$} \\
Biliverdin reduction & FDOR & {$[12,16]$} \\
Nitroimidazoles & FDOR & {$[36]$} \\
Cyclohexenones & FDOR & {$[6,34,38]$} \\
Citral/Neral/Geranial & FDOR & {$[6]$} \\
Carvone & FDOR & {$[6]$} \\
Ketoisophorone & FDOR & {$[6]$} \\
\hline Alcohol oxidation/ketoreduction & & {$[26,50]$} \\
Glucose-6-phosphate & LLHT & {$[51]$} \\
Phthiodiolone dimycocerosate & LLHT & {$[40]$} \\
Isopropanol & LLHT & {$[45]$} \\
\hline Imine reductions & & {$[11]$} \\
\hline C-N bond cleavage/formation in & FDOR & {$[23,28-30]$} \\
\hline 4-ethylidene-3,4-dihydropyrrole-2-carboxylic acid & Flavin-dependent & monooxygenase \\
\hline Nitroreductions & & {$[48,50]$} \\
\hline Picrate & LLHT & \\
\hline 2,4-DNP & LLHT & \\
\hline
\end{tabular}

\section{Cofactor Recycling for Cofactor $\mathrm{F}_{420}$}

Cofactor recycling is essential for the practical application of the $\mathrm{F}_{420}$-dependent enzymatic processes in biocatalysis. There are various strategies for cofactor regeneration for NADH and NADPH, including enzymatic, chemical, electrochemical and photochemical methods [52]. In this section, the potential enzymes for the regeneration of cofactor $\mathrm{F}_{420}$ are discussed. As most of the industrially relevant $\mathrm{F}_{420}$-dependent reactions are asymmetric reductions, $\mathrm{F}_{420}$-dependent oxidases are required for cofactor regeneration. Figure 7 shows the characterized enzymes that catalyze $\mathrm{F}_{420}$-dependent oxidations that could be applied in cofactor $\mathrm{F}_{420}$ reduction.

Emulating methods developed for nicotinamide cofactors, both formate dehydrogenase (FDH) and glucose 6-phosphate dehydrogenase (G6PD) enzymes are attractive enzymatic routes for cofactor reduction both in vitro [53-56] and in vivo [57,58]. Fortunately, $\mathrm{F}_{420}$-dependent G6PDs and FDHs have been identified and characterized. The $\mathrm{F}_{420}$-dependent G6PD from Mycobacteria (FGD) is one potential cofactor $\mathrm{F}_{420}$-recycling enzyme. FGD is the only enzyme in these bacteria known to reduce oxidized cofactor $\mathrm{F}_{420}$. The intracellular concentration of G6P in Mycobacteria is up to 100-fold higher than it is in E. coli, which provides a ready source of reducing power for $\mathrm{F}_{420}$-dependent reduction reactions [59]. FGD from Rhodococcus jostii and Mycobacterium smegmatis have been studied and expressed in E. coli, both the enzymes were stable in in vitro assays [26,39,60]. Both FGDs have been expressed in engineered $E$. coli producing cofactor $\mathrm{F}_{420}$ together with FDORs $[38,59]$ FGDs have been shown to efficiently regenerate reduced cofactor $F_{420}$ both in vivo and in vitro. However, the cost of the glucose-6-phosphate and the need to separate reaction products from the accumulated FGD byproduct (6-phosphoglucono-D-lactone) may prove to be impediments for the adoption of FGD as a recycling system for cofactor $\mathrm{F}_{420}$ in the in vitro biotransformations. 

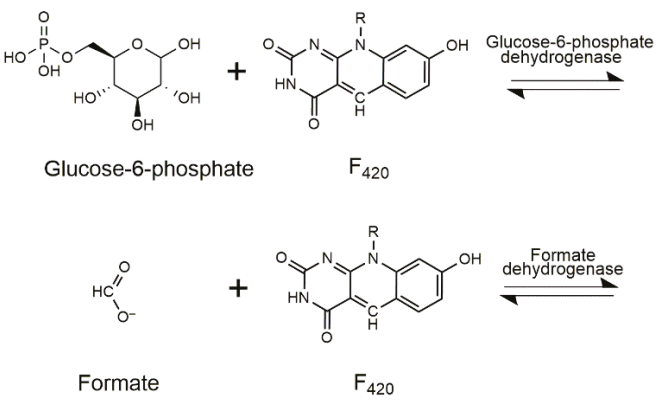<smiles>[Y]N1C=CCC(C(N)=O)=C1</smiles><smiles>[R]n1c2nc(=O)[nH]c(=O)c-2cc2ccc(O)cc21</smiles>
NADPH

$$
\mathrm{H}-\mathrm{H}
$$$$
+\quad
$$

Hydrogen
$F_{420}$

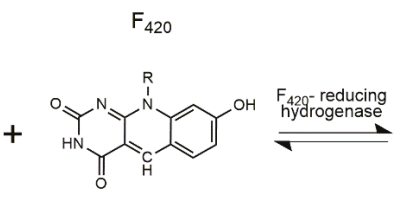

$\mathrm{F}_{420}$<smiles>[R]N1c2cc(O)ccc2Cc2c1[nH]c(=O)[nH]c2=O</smiles>

6-Phosphoglucono-D-lactone $\quad \mathrm{F}_{420} \mathrm{H}_{2}$<smiles>[R]N1c2cc(O)ccc2Cc2c([nH]c(=O)[nH]c2=O)N1[R]</smiles>

Carbon dioxide<smiles>NC(=O)c1ccc[n+](Br)c1</smiles>

$\mathrm{NADP}^{+}$<smiles></smiles><smiles>[R]N1c2cc(O)ccc2Cc2c1[nH]c(=O)[nH]c2=O</smiles>

$\mathrm{F}_{420} \mathrm{H}_{2}$

Figure 7. Cofactor $\mathrm{F}_{420}$-dependent oxidation reactions that could be exploited to produce reduced cofactor $\mathrm{F}_{420}$.

Formate is an excellent reductant for cofactor recycling, with FDH-dependent cofactor reduction yielding carbon dioxide, a volatile byproduct that can be easily removed from the reaction mixture, thereby simplifying the downstream processing of the product of interest. Additionally, formate is a low-cost reagent, leading to favorable process economics. Most methanogens have the capability to use formate as sole electron donor using $\mathrm{F}_{420}$-dependent formate dehydrogenase [61]. The soluble $\mathrm{F}_{420}$-dependent FDH from Methanobacterium formicium has been expressed in E. coli [62], purified and studied in vitro with the reduction of $41.2 \mu \mathrm{mol}$ of $\mathrm{F}_{420} \mathrm{~min}^{-1} \mathrm{mg}^{-1}$ of FDH, with non-covalently bound FAD required for optimal activity [8]. Methanobacterium ruminantium FDH reduces cofactor $\mathrm{F}_{420}$ at a much slower rate than $M$. formicium: $0.11 \mu \mathrm{mol}$ of $\mathrm{F}_{420} \mathrm{~min}^{-1} \mathrm{mg}^{-1}$ of FDH [8]. As yet, the use of $\mathrm{F}_{420}$-dependnt FDHs for in vitro cofactor recycling has been sparsely studied. However, as these enzymes are soluble and can be heterologously expressed, they represent a promising system for use in cofactor $\mathrm{F}_{420}$-dependent biocatalytic processes.

Another potential recycling system for cofactor $\mathrm{F}_{420}$ is the $\mathrm{F}_{420}$ :NADPH oxidoreductase (Fno), which couples the reduction of cofactor $\mathrm{F}_{420}$ with oxidation of NADPH. Methanogenic archaea use this enzyme to transfer reducing equivalents from hydrogenases to produce NADPH via $\mathrm{F}_{420}$, while in bacteria it functions in the opposite direction, that is, to provide the cell with reduced $\mathrm{F}_{420}$ via NADPH [63]. Fno is also required for the production of reduced $F_{420}$ for tetracycline production in Streptomyces [63]. The Fno enzymes from the thermophilic bacteria Thermobifida fusca and the thermophilic archaeon Archeoglobus fulgidus have been expressed in E. coli [64,65]. These enzymes are thermostable, with their highest activity observed at $65^{\circ} \mathrm{C}$. As the redox midpoint potentials of NADP and cofactor $\mathrm{F}_{420}$ are very similar, it is perhaps unsurprising that $\mathrm{pH}$ has a significant influence on the equilibrium of the reaction, with the reduction of $\mathrm{NADP}^{+}$favored at high $\mathrm{pH}(8-10)$ and the reduction of $\mathrm{F}_{420}$ favored at low $\mathrm{pH}(4-6)$ [64,65]. The Fno Streptomyces griseus has also been purified and characterized, and also displayed $\mathrm{pH}$-dependent reaction directionality [66]. Fno may be an excellent enzyme for the in vivo reduction of cofactor $F_{420}$, where NADPH would be provided from 
central metabolism. However, for its use as a cofactor $\mathrm{F}_{420}$ recycling enzyme in vitro, Fno would need to be coupled with an NADPH regenerating enzyme, such as an NADPH-dependent formate dehydrogenase [67]. This added complexity and cost may limit the use of Fno-dependent cofactor $\mathrm{F}_{420}$ recycling in vivo.

Hydrogenotrophic archaea, including methanogens and sulfate-reducing archaea, possess an essential, cofactor $\mathrm{F}_{420}$-dependent hydrogenase (FhrAGB) [68-71]. These nickel/iron enzymes could potentially be used in vivo to allow the direct $\mathrm{H}_{2}$-dependent reduction of cofactor $\mathrm{F}_{420}$. However, as these heterododecameric enzymes have complex cofactor requirements (four [4Fe 4S] clusters, and NiFe center and FAD), are oxygen-sensitive and tend to aggregate [71], it is unclear if they can be made suitable for in vitro use.

\section{Cofactor Production}

The lack of a scalable production system for cofactor $\mathrm{F}_{420}$ has been noted as a major impediment to the adoption of $\mathrm{F}_{420}$-dependent enzymes by industry [5]. Cofactor $\mathrm{F}_{420}$ is available as a research reagent (http://www.gecco-biotech.com/), but its production at scale is not yet economic. In fact, most research laboratories with an interest in cofactor $\mathrm{F}_{420}$-dependent enzymes synthesize and purify the cofactor themselves using slow-growing $\mathrm{F}_{420}$ producing microorganisms, most commonly methanogens and actinobacteria (Table 2). The economic production of cofactor $\mathrm{F}_{420}$ at large scale is not feasible using natural producers as they are ill-suited to industrial fermentation and generally lack the genetic tools required to improve cofactor $\mathrm{F}_{420}$ yield.

Table 2. Published production systems for cofactor $\mathrm{F}_{420}$.

\begin{tabular}{|c|c|c|c|}
\hline Source & $\begin{array}{l}\text { F }_{420} \text { Yield ( } \mu \mathrm{mol} / \mathrm{g} \\
\text { Cell Weight) }\end{array}$ & Growth Conditions & Ref \\
\hline $\begin{array}{l}\text { Methanobacterium } \\
\text { thermoautotrophicum }\end{array}$ & $0.42^{\mathrm{a}, \mathrm{c}}$ & $\begin{array}{c}\text { Grown at } 60{ }^{\circ} \mathrm{C} \text { using complex media in fermenter, } \\
\text { under pressurized hydrogen }\end{array}$ & [9] \\
\hline Methanobacterium formicium & $0.27^{\mathrm{a}, \mathrm{c}}$ & Grown at $37^{\circ} \mathrm{C}$ using complex media in fermenters & [9] \\
\hline Methanospirillum hungatii & $0.41^{\mathrm{a}, \mathrm{c}}$ & Grown at $37^{\circ} \mathrm{C}$ using complex media in fermenters & [9] \\
\hline Methanobacterium strain M.o.H & $0.53^{a, c}$ & Grown at $40^{\circ} \mathrm{C}$ using complex media in fermenters & [9] \\
\hline $\begin{array}{l}\text { Methanobacterium } \\
\text { thermoautotrophicum }\end{array}$ & $1.7^{\mathrm{e}}$ & $\begin{array}{l}\text { Grown using complex media in fermenters, under } \\
\text { pressurized hydrogen gas }\end{array}$ & {$[73]$} \\
\hline Streptomyces flocculus & $0.62^{\mathrm{e}}$ & Grown using complex media in fermenters & {$[73]$} \\
\hline Streptomyces coelicolor & $0.04^{\mathrm{e}}$ & Grown using complex media in fermenters & [73] \\
\hline Streptomyces griseus & $0.008^{a, c}$ & $\begin{array}{l}\text { Growth conditions not mentioned in } \\
\text { the publication }\end{array}$ & [74] \\
\hline Rhodococcus rhodochrous & $0.11^{\mathrm{e}}$ & Grown using complex media in fermenters & [73] \\
\hline Mycobacterium smegmatis & $0.30^{\mathrm{e}}$ & Grown using complex media in fermenters & [73] \\
\hline Mycobacterium smegmatis & $3.0^{\mathrm{d}}$ & $\begin{array}{l}\text { Overexpression of } \mathrm{F}_{420} \text { pathway genes, cultivation } \\
\text { in complex media at } 37^{\circ} \mathrm{C} \text { in shake flasks }\end{array}$ & {$[72]$} \\
\hline Escherichia coli & $0.38^{b}$ & $\begin{array}{l}\text { Overexpressing } \mathrm{F}_{420} \text { pathway genes, grown in } \\
\text { minimal media at } 30^{\circ} \mathrm{C} \text { in shake flasks. }\end{array}$ & [59] \\
\hline
\end{tabular}

${ }^{a}$ Mol weight of $\mathrm{F}_{420}$ with 1 glutamate tail is $773.6 \mathrm{Da}$, which was used to convert values published as $\mu \mathrm{g}$ of

$\mathrm{F}_{420}$, noting that micro-organisms produce mixture of $\mathrm{F}_{420}$ with different number of glutamates (1-9) attached.

$\mathrm{b}$ Concentration estimated through absorbance at $420 \mathrm{~nm}$ and using extinction coefficient of $41.4 \mathrm{mM}^{-1} \mathrm{~cm}^{-1}[73]$.

${ }^{c} \mathrm{~F}_{420}$ concentration per $\mathrm{g}$ of wet cell weight. ${ }^{\mathrm{d}}$ Concentration of $\mathrm{F}_{420}$ not mentioned in the publication, but $\mathrm{F}_{420}$

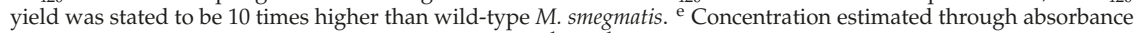
at $400 \mathrm{~nm}$ and using extinction coefficient of $25.7 \mathrm{mM}^{-1} \mathrm{~cm}^{-1}$ [74].

Recently, there have been significant advances towards the scalable production of the cofactor for $\mathrm{F}_{420}$-dependent enzymes. $M$. smegmatis has been engineered to overexpress the biosynthetic genes for cofactor $\mathrm{F}_{420}$ production, leading to a substantial improvement in yields (Table 2) [72]. However, M. smegmatis is not ideally suited as a fermentation organism as it is slow growing, forms clumps 
during cultivation and is not recognized as GRAS (generally regarded as safe). More recently, the biosynthetic pathway for cofactor $\mathrm{F}_{420}$ has been successfully transplanted to E. coli [59], allowing the heterologous production of the cofactor at levels similar to those of the natural $\mathrm{F}_{420}$ producers (Table 2) [59], accumulated to $0.38 \mu \mathrm{mol}$ of $\mathrm{F}_{420}$ per gram of dry cells.

There is scope to further improve the production of $\mathrm{F}_{420}$ in $E$. coli. Cofactor $\mathrm{F}_{420}$ does not appear to be toxic to E. coli [59], which suggests that there is little interaction between $\mathrm{F}_{420}$ and the enzymes E. coli (although this is yet to be confirmed experimentally). The thermodynamics of cofactor $\mathrm{F}_{420}$ production are favorable (Appendix A), suggesting that there are no major thermodynamic impediments to improving yield. Interestingly, the first dedicated step of cofactor $\mathrm{F}_{420}$ production (catalyzed by Cof $(\mathrm{FbiD}$ ) is not energetically favorable and may consequently be sensitive to intracellular metabolite concentrations. In addition to the engineering considerations that this may impose, it may also be responsible for the biochemical diversity of this step in different microorganisms. In different microbes, the CofC/FbiD-dependent step uses 2-phospholactate [75], 3-phosphoglycerate [76] or phosphoenolpyruvate [59] as a substrate, which may reflect the relative abundance of those metabolites in various bacteria and archaea and the thermodynamic constraints on this step.

Another recent advance is the production of a synthetic analog of cofactor $\mathrm{F}_{420}$, called $\mathrm{F}_{\mathrm{O}}-5^{\prime}$-phosphate $\left(\mathrm{F}_{\mathrm{O}} \mathrm{P}\right)$. $\mathrm{F}_{\mathrm{O}} \mathrm{P}$ was derived from $\mathrm{F}_{\mathrm{O}}$, the metabolic precursor of cofactor $\mathrm{F}_{420}$, which is phosphorylated using an engineered riboflavin kinase [38]. $\mathrm{F}_{\mathrm{O}} \mathrm{P}$ has also been shown to function as an active cofactor for cofactor $\mathrm{F}_{420}$-dependent enzymes activities, albeit there is a penalty in the rates of these reactions [38]. Drenth and coworkers prepared $\mathrm{F}_{\mathrm{O}}$ by chemical synthesis, using a method developed by Hossain et al. [77]. However, it is likely that the engineered kinase for the phosphorylation of $F_{O}$ could be introduced into an organism that over-produces $F_{O}$ allowing for the production of $\mathrm{F}_{\mathrm{O}} \mathrm{P}$ by fermentation. This semisynthetic pathway would have the advantage that it needs only two biosynthetic steps, instead of the four steps needed for cofactor $\mathrm{F}_{420}$ production, and demands less metabolic input from the native host metabolism (e.g., no glutamate is required) [38]. The production of $\mathrm{F}_{\mathrm{O}} \mathrm{P}$ also opens the possibility of making deazaflavin analogs of FMN and FAD, which would be electrochemically more like $\mathrm{F}_{420}$ than flavins, but may still bind FMN and FAD- dependent enzymes and potentially allow access to new chemistry with already well-characterized enzymes.

\section{Prospects}

Reduced cofactor $\mathrm{F}_{420}$ is electrochemically well suited for biocatalytic applications, and the small number of $\mathrm{F}_{420}$-dependent enzymes characterized to date show promise as potential biocatalysts (as discussed above). However, before these enzymes can be widely and effectively used as biocatalysts, further research is needed to better characterize them as the biochemistry of cofactor $\mathrm{F}_{420}$-dependent enzymes remains under-explored. The LLHT and FDOR families are a rich source of highly diverse enzymes with considerable potential for biocatalysis, albeit much of the research to date has focused on the physiological roles of these enzymes, rather than their in vitro enzymology. Although some of these enzymes have been shown to have small molecule substrates, those involved with secondary metabolite biosynthesis tend to act on high molecular weight substrates and it is not yet clear whether they will accept lower molecular weight molecules.

To be cost competitive, cofactor $\mathrm{F}_{420}$ needs to have effective recycling systems. The enzymes for cofactor recycling have already been identified, although there have been a few studies investigating their performance in this role. Moreover, alternative cofactor recycling strategies, such electrochemical or photochemical recycling, have not yet been investigated for cofactor $\mathrm{F}_{420}$. The production of cofactor $\mathrm{F}_{420}$ at scale and at low cost remains a roadblock for the use of these enzymes by industry. However, considerable progress has been made on this front in the last few years and it is likely that low cost cofactor $\mathrm{F}_{420}$, or $\mathrm{F}_{420}$ surrogates, will soon be available. Additionally, the availability of $\mathrm{F}_{420}$-producing bacteria with tools for facile genetic manipulation, along with a growing number of empirically determined protein structures, opens up the prospect of improving this class of enzymes using in vitro evolution and rational design. It is notable that there is still some uncertainty concerning 
the mechanistic detail of $\mathrm{F}_{420}$-dependent reactions, which need to be addressed through a detailed structure/function analysis to enable a rational design of these enzymes.

Supplementary Materials: The following are available online at http://www.mdpi.com/2073-4344/9/10/868/s1.

Author Contributions: Writing—original draft preparation, M.V.S., J.A., S.W.K., H.N.-B., C.J.J. and C.S.; writingreview and editing, M.V.S., J.A., S.W.K., H.N.-B., A.C.W., C.J.H., C.J.J. and C.S.

Funding: M.V.S. and H.N.-B. are funded by the CSIRO Synthetic Biology Future Science Platform. J.A. is funded by the Australian Government Research Training Program (AGRTP) and S.W.K. is funded by the Korean Institute of Science and Technology and the AGRTP.

Conflicts of Interest: The authors declare no conflict of interest.

\begin{abstract}
Abbreviations
5AD: 5'-Deoxyadenosine; 5ARPD: 5-amino-6-(D-ribitylamino)uracil; 5ARPD4HB: 5-amino-5-(4-hydroxybenzyl)6-(D-ribitylimino)-5,6-dihydrouracil; $\mathrm{d}_{\mathrm{F} 420}-0$ : Dehydro coenzyme $\mathrm{F}_{420}-0$ (oxidized); EPPG: Enolpyruvyl-diphospho5'-guanosine; $\mathrm{F}_{\mathrm{o}}$ : 7,8-Didemethyl-8-hydroxy-5-deazariboflavin; $\mathrm{F}_{420}-0$ : Coenzyme $\mathrm{F}_{420}-0$ (oxidized); $\mathrm{F}_{420}-1$ : Coenzyme $\mathrm{F}_{420}-1$ (oxidized); $\mathrm{F}_{420}-2$ : Coenzyme $\mathrm{F}_{420}-2$ (oxidized); $\mathrm{F}_{420}-3$ : Coenzyme $\mathrm{F}_{420}-3$ (oxidized); FMN: Flavin mononucleotide (oxidized); $\mathrm{FMNH}_{2}$ : Flavin mononucleotide (reduced); GDP: Guanosine diphosphate; GMP: Guanosine monophosphate; Glu: L-Glutamate; GTP: Guanosine triphosphate; $\mathrm{H}^{+}$: Proton; ImiAce: 2-iminoacetate or Dehydroglycine; Met: L-Methionine; $\mathrm{NH}_{4}$ : Ammonium; PEP: Phosphoenolpyruvate; Pi: Phosphate; PPi: Diphosphate; SAMe: S-Adenosyl-L-methionine; Tyr: L-Tyrosine.
\end{abstract}

\title{
Appendix A Thermodynamics of F420 Biosynthesis
}

The thermodynamic properties of each of the steps in cofactor $\mathrm{F}_{420}$ biosynthesis were estimated to evaluate the feasibility of increasing the production of the cofactor in an engineered microorganism. The pathway assembled by Bashiri et al. [59] in E. coli was used (i.e., PEP was used as substrate for CofC). The standard transformed Gibbs free energy $\left(\Delta_{\mathrm{r}} \mathrm{G}^{\mathrm{t}}\right)$ of each step were calculated under the physiological conditions $\left(25^{\circ} \mathrm{C}, \mathrm{pH} 7\right.$, and ionic concentration of $\left.0.25 \mathrm{M}\right)$ as described elsewhere [78,79]. The overall Gibbs free energy $\left(\Delta G^{t}\right)$ was then calculated by summing up all individual $\Delta_{\mathrm{r}} \mathrm{G}^{\mathrm{t}}$ (Table A1). The Gibbs free energy of metabolite formation $\left(\Delta_{\mathrm{f}} \mathrm{G}\right)$ for each metabolite in the pathway was obtained (Supplementary Information) from comprehensive lists of metabolites whose $\Delta_{\mathrm{f}} \mathrm{G}$ were estimated using a group contribution method $[80,81]$. The $\Delta_{\mathrm{f}} \mathrm{G}$ for each metabolite was then converted into its transformed type $\left(\Delta_{\mathrm{f}} \mathrm{G}^{\mathrm{t}}\right)$ method of Alberty [78]. The data were collected from relevant biochemical databases and the literature for any metabolite with missing $\Delta_{\mathrm{f}} \mathrm{G}$ [82-84]. Owing to possessing different protonation states, the inconsistencies in $\Delta_{\mathrm{f}} \mathrm{G}$ of certain metabolites such as the glutamates in $\mathrm{F}_{420}$-n among databases and the literature are inevitable. Thus, $\Delta_{\mathrm{r}} \mathrm{G}^{\mathrm{t}}$ for reactions containing metabolites with varying $\Delta_{\mathrm{f}} \mathrm{G}$ were calculated considering the differences in their $\Delta_{\mathrm{f}} \mathrm{G}$ leading to the generation of a total of four sets of $\Delta_{\mathrm{r}} \mathrm{G}^{\mathrm{t}}$. Finally, the mean and standard deviations were calculated for these sets to yield the variation in each reaction as well as in the overall pathway (Table A1).

The data shown in Table A1 confirms that the overall cofactor $F_{420}$ biosynthesis pathway is thermodynamically feasible under the given conditions. However, certain steps in this pathway impose a thermodynamic barrier with respect to the physiological conditions examined. For example, CofC seems to be one of the major thermodynamically unfavorable steps in the whole pathway possibly due to the energy-dependent synthesis of EPPG, one of the precursors for making $\mathrm{F}_{420}$. CofG/H combined appears to be the most thermodynamically favorable step in the whole pathway driving the biosynthesis of $\mathrm{F}_{0}$, the other key precursor for $\mathrm{F}_{420}$ biosynthesis. Interestingly, the formation of $\mathrm{F}_{420}-2$ molecule seems to be the most favorable step among other $\mathrm{F}_{420}$ molecules downstream of the pathway. It should be noted that the thermodynamic calculations were only performed up to three steps of $\mathrm{F}_{420}$ molecule production (i.e., $\mathrm{F}_{420}-3$ ) largely because of the high levels of inconsistencies of the data available for $\Delta_{\mathrm{f}} \mathrm{G}$ of higher $\mathrm{F}_{420}$ molecules. 
Table A1. Standard transformed Gibbs free energy of reaction $\left(\Delta_{\mathrm{r}} \mathrm{G}^{\mathrm{t}}\right)$, for the $\mathrm{F}_{420}$ biosynthesis pathway, calculated based on Gibbs free energy of metabolite formation $\left(\Delta_{\mathrm{f}} \mathrm{G}^{\mathrm{t}}\right)$ calculated at $25^{\circ} \mathrm{C}, \mathrm{pH}$ of 7 , and ionic concentration of $0.25 \mathrm{M}$.

\begin{tabular}{|c|c|c|}
\hline Enzyme & Reaction $^{a}$ & $\Delta_{\mathrm{r}} \mathrm{G}^{\mathrm{t}}(\mathrm{kJ})^{\mathrm{b}}$ \\
\hline CofC/FbiD & $\mathrm{PEP}+\mathrm{GTP} \rightarrow \mathrm{EPPG}+\mathrm{PP}_{\mathrm{i}}{ }^{\mathrm{d}}$ & $+71.27( \pm 67)$ \\
\hline CofG/FbiC & $5 \mathrm{ARPD}+\mathrm{Tyr}+\mathrm{SAMe} \rightarrow 5 \mathrm{ARPD} 4 \mathrm{HB}+\mathrm{ImAcet}+\mathrm{Met}+5 \mathrm{AD}$ & $-1192.39( \pm 0)^{c}$ \\
\hline $\mathrm{CofH} / \mathrm{FbiC}$ & $5 \mathrm{ARPD} 4 \mathrm{HB}+\mathrm{SAMe} \rightarrow \mathrm{FO}_{\mathrm{O}}+\mathrm{NH}_{4}^{+}+\mathrm{Met}+5 \mathrm{AD}$ & $+71.90( \pm 36)^{\mathrm{c}}$ \\
\hline CofD/FbiA & $\mathrm{F}_{\mathrm{O}}+\mathrm{EPPG} \rightarrow \mathrm{d}_{\mathrm{F} 420^{-}-0}+\mathrm{GMP}$ & $-31.3( \pm 128)$ \\
\hline CofX/FbiB & $\mathrm{d}_{\mathrm{F} 420^{-}} 0+\mathrm{FMNH}_{2} \rightarrow \mathrm{F}_{420^{-}}-0+\mathrm{FMN}$ & $-74.59( \pm 87)$ \\
\hline CofE/FbiB & $\mathrm{F}_{420^{-}} 0+\mathrm{GTP}+\mathrm{Glu} \rightarrow \mathrm{F}_{420^{-}}-\mathrm{GDP}+\mathrm{P}_{\mathrm{i}}$ & $-7.50( \pm 24)$ \\
\hline CofE/FbiB & $\mathrm{F}_{420}-1+\mathrm{GTP}+\mathrm{Glu} \rightarrow \mathrm{F}_{420}-2+\mathrm{GDP}+\mathrm{P}_{\mathrm{i}}$ & $-39.44( \pm 35)$ \\
\hline CofE/FbiB & $\mathrm{F}_{420}-2+\mathrm{GTP}+\mathrm{Glu} \rightarrow \mathrm{F}_{420}-3+\mathrm{GDP}+\mathrm{P}_{\mathrm{i}}$ & $-21.99( \pm 38)$ \\
\hline Overall & $\begin{array}{c}\text { PEP + 5ARPD + Tyr + (2) SAMe + FMNH }{ }_{2}+(3) \mathrm{Glu}+(4) \mathrm{GTP} \\
\rightarrow \mathrm{F}_{420-3}+\text { (2) Met + (2) } 5 \mathrm{AD}+\mathrm{ImAcet}+\mathrm{NH}_{4}^{+}+\mathrm{FMN}+\text { (3) GDP + } \\
\text { (3) } \mathrm{P}_{\mathrm{i}}+\mathrm{GMP}+\mathrm{PP}_{\mathrm{i}}\end{array}$ & $-1224.05( \pm 82)$ \\
\hline \multicolumn{3}{|c|}{$\begin{array}{l}\text { a For simplicity, protons were omitted in these equations and subsequent calculations as the } \Delta_{\mathrm{f}} \mathrm{G}^{\mathrm{t}} \text { of a proton under } \\
\text { the set conditions is } \sim 0.08 \mathrm{~kJ} \text {. However, all } \Delta_{\mathrm{r}} \mathrm{G}^{\mathrm{t}} \text { calculations are based on a balanced equation. }{ }^{\mathrm{b}} \text { The mean values of } \\
\text { four sets and their standard deviations in parenthesis shown for each reaction. }{ }^{c} \Delta_{\mathrm{f}} \mathrm{G} \text { of } 5 \mathrm{ARPD} 4 \mathrm{HB} \text { has only been } \\
\text { reported in MetaCyc inferred by computational analysis. Including it in the calculations of } \Delta_{\mathrm{r}} \mathrm{G}^{\mathrm{t}} \text { for CofG and CofH } \\
\text { results in }-225.88( \pm 0) \text { and }-894.62( \pm 36) \text {, respectively. }{ }^{\mathrm{d}} \text { Hydrolysis of } \mathrm{PP}_{\mathrm{i}}\left(\mathrm{H}_{3} \mathrm{P}_{2} \mathrm{O}_{7}{ }^{3-}+\mathrm{H}_{2} \mathrm{O} \rightarrow 2 \mathrm{HPO}_{4}{ }^{2-}+\mathrm{H}^{+}\right) \\
\text {yields a } \Delta_{\mathrm{r}} \mathrm{G}^{\mathrm{t}} \text { of } \sim 17 \mathrm{~kJ} / \mathrm{mole} \text {, resulting in less than } 2 \% \text { change in the overall } \Delta_{\mathrm{r}} \mathrm{G}^{\mathrm{t}} \text {. }\end{array}$} \\
\hline
\end{tabular}

\section{References}

1. Patil, M.D.; Grogan, G.; Bommarius, A.; Yun, H. Oxidoreductase-catalyzed synthesis of chiral amines. ACS Catal. 2018, 8, 10985-11015. [CrossRef]

2. Toogood, H.S.; Scrutton, N.S. New developments in 'ene'-reductase catalysed biological hydrogenations. Curr. Opin. Chem. Biol. 2014, 19, 107-115. [CrossRef] [PubMed]

3. Cosgrove, S.C.; Brzezniak, A.; France, S.P.; Ramsden, J.I.; Mangas-Sanchez, J.; Montgomery, S.L.; Heath, R.S.; Turner, N.J. Imine reductases, reductive aminases, and amine oxidases for the synthesis of chiral amines: Discovery, characterization, and synthetic applications. In Enzymes in Synthetic Biology; Scrutton, N., Ed.; Elsevier Academic Press Inc.: San Diego, CA, USA, 2018; Volume 608, pp. 131-149.

4. Bai, D.Y.; He, J.Y.; Ouyang, B.; Huang, J.; Wang, P. Biocatalytic asymmetric synthesis of chiral aryl alcohols. Prog. Chem. 2017, 29, 491-501.

5. Taylor, M.; Scott, C.; Grogan, G. F-420-dependent enzymes-potential for applications in biotechnology. Trends Biotechnol. 2013, 31, 63-64. [CrossRef]

6. Mathew, S.; Trajkovic, M.; Kumar, H.; Nguyen, Q.-T.; Fraaije, M.W. Enantio- and regioselective ene-reductions using $\mathrm{F}_{420} \mathrm{H}_{2}$-dependent enzymes. Chem. Commun. 2018, 54, 11208-11211. [CrossRef]

7. Greening, C.; Ahmed, F.H.; Mohamed, A.E.; Lee, B.M.; Pandey, G.; Warden, A.C.; Scott, C.; Oakeshott, J.G.; Taylor, M.C.; Jackson, C.J. Physiology, biochemistry, and applications of $\mathrm{F}_{420}$ - and Fo-dependent redox reactions. Microbiol. Mol. Biol. Rev. 2016, 80, 451-493. [CrossRef]

8. Tzing, S.F.; Bryant, M.P.; Wolfe, R.S. Factor 420-dependent pyridine nucleotide-linked formate metabolism of Methanobacterium ruminantium. J. Bacteriol. 1975, 121, 192-196.

9. Eirich, L.D.; Vogels, G.D.; Wolfe, R.S. Distribution of coenzyme $\mathrm{F}_{420}$ and properties of its hydrolytic fragments. J. Bacteriol. 1979, 140, 20-27.

10. Wang, P.; Bashiri, G.; Gao, X.; Sawaya, M.R.; Tang, Y. Uncovering the enzymes that catalyze the final steps in oxytetracycline biosynthesis. J. Am. Chem. Soc. 2013, 135, 7138-7141. [CrossRef]

11. Li, W.; Chou, S.C.; Khullar, A.; Gerratana, B. Cloning and characterization of the biosynthetic gene cluster for tomaymycin, an SJG-136 monomeric analog. Appl. Environ. Microbiol. 2009, 75, 2958-2963. [CrossRef]

12. Ahmed, F.H.; Carr, P.D.; Lee, B.M.; Afriat-Jurnou, L.; Mohamed, A.E.; Hong, N.-S.; Flanagan, J.; Taylor, M.C.; Greening, C.; Jackson, C.J. Sequence-structure-function classification of a catalytically diverse oxidoreductase superfamily in mycobacteria. J. Mol. Biol. 2015, 427, 3554-3571. [CrossRef] [PubMed]

13. Selengut, J.D.; Haft, D.H. Unexpected abundance of coenzyme $\mathrm{F}_{420}$-dependent enzymes in Mycobacterium tuberculosis and other actinobacteria. J. Bacteriol. 2010, 192, 5788-5798. [CrossRef] [PubMed] 
14. Lapalikar, G.V.; Taylor, M.C.; Warden, A.C.; Onagi, H.; Hennessy, J.E.; Mulder, R.J.; Scott, C.; Brown, S.E.; Russell, R.J.; Easton, C.J.; et al. Cofactor promiscuity among $\mathrm{F}_{420}$-dependent reductases enables them to catalyse both oxidation and reduction of the same substrate. Catal. Sci. Technol. 2012, 2, 1560-1567. [CrossRef]

15. Harold, L.K.; Antoney, J.; Ahmed, F.H.; Hards, K.; Carr, P.D.; Rapson, T.; Greening, C.; Jackson, C.J.; Cook, G.M. FAD-sequestering proteins protect Mycobacteria against hypoxic and oxidative stress. J. Biol. Chem. 2019, 294, 2903-2912. [CrossRef] [PubMed]

16. Ahmed, F.H.; Mohamed, A.E.; Carr, P.D.; Lee, B.M.; Condic-Jurkic, K.; O’Mara, M.L.; Jackson, C.J. Rv2074 is a novel $\mathrm{F}_{420} \mathrm{H}_{2}$-dependent biliverdin reductase in Mycobacterium tuberculosis. Protein Sci. 2016, 25, 1692-1709. [CrossRef] [PubMed]

17. Mashalidis, E.H.; Mukherjee, T.; Śledź, P.; Matak-Vinković, D.; Boshoff, H.I.; Abell, C.; Barry, C.E. Rv2607 from Mycobacterium tuberculosis is a pyridoxine $5^{\prime}$-phosphate oxidase with unusual substrate specificity. PLoS ONE 2011, 6, e27643. [CrossRef] [PubMed]

18. Taylor, M.C.; Jackson, C.J.; Tattersall, D.B.; French, N.; Peat, T.S.; Newman, J.; Briggs, L.J.; Lapalikar, G.V.; Campbell, P.M.; Scott, C.; et al. Identification and characterization of two families of $\mathrm{F}_{420} \mathrm{H}_{2}$-dependent reductases from Mycobacteria that catalyse aflatoxin degradation. Mol. Microbiol. 2010, 78, 561-575. [CrossRef]

19. Cellitti, S.E.; Shaffer, J.; Jones, D.H.; Mukherjee, T.; Gurumurthy, M.; Bursulaya, B.; Boshoff, H.I.; Choi, I.; Nayyar, A.; Lee, Y.S.; et al. Structure of DDN, the deazaflavin-dependent nitroreductase from Mycobacterium tuberculosis involved in bioreductive activation of PA-824. Structure 2012, 20, 101-112. [CrossRef]

20. De Souza, G.A.; Leversen, N.A.; Målen, H.; Wiker, H.G. Bacterial proteins with cleaved or uncleaved signal peptides of the general secretory pathway. J. Proteom. 2011, 75, 502-510. [CrossRef]

21. He, Z.; De Buck, J. Cell wall proteome analysis of Mycobacterium smegmatis strain mc2 155. BMC Microbiol. 2010, 10, 121. [CrossRef]

22. Sinha, S.; Kosalai, K.; Arora, S.; Namane, A.; Sharma, P.; Gaikwad, A.N.; Brodin, P.; Cole, S.T. Immunogenic membrane-associated proteins of Mycobacterium tuberculosis revealed by proteomics. Microbiology 2005, 151, 2411-2419. [CrossRef] [PubMed]

23. Aufhammer, S.W.; Warkentin, E.; Ermler, U.; Hagemeier, C.H.; Thauer, R.K.; Shima, S. Crystal structure of methylenetetrahydromethanopterin reductase (MER) in complex with coenzyme $\mathrm{F}_{420}$ : Architecture of the $\mathrm{F}_{420} / \mathrm{FMN}$ binding site of enzymes within the nonprolyl cis-peptide containing bacterial luciferase family. Protein Sci. 2005, 14, 1840-1849. [CrossRef] [PubMed]

24. Aufhammer, S.W.; Warkentin, E.; Berk, H.; Shima, S.; Thauer, R.K.; Ermler, U. Coenzyme binding in $\mathrm{F}_{420}$-dependent secondary alcohol dehydrogenase, a member of the bacterial luciferase family. Structure 2004, 12, 361-370. [CrossRef] [PubMed]

25. Bashiri, G.; Squire, C.J.; Moreland, N.J.; Baker, E.N. Crystal structures of $\mathrm{F}_{420}$-dependent glucose-6-phosphate dehydrogenase FGD1 involved in the activation of the anti-tuberculosis drug candidate PA-824 reveal the basis of coenzyme and substrate binding. J. Biol. Chem. 2008, 283, 17531-17541. [CrossRef] [PubMed]

26. Nguyen, Q.T.; Trinco, G.; Binda, C.; Mattevi, A.; Fraaije, M.W. Discovery and characterization of an $\mathrm{F}_{420}$-dependent glucose-6-phosphate dehydrogenase (Rh-FGD1) from rhodococcus jostii rha1. Appl. Microbiol. Biotechnol. 2017, 101, 2831-2842. [CrossRef] [PubMed]

27. Mascotti, M.L.; Kumar, H.; Nguyen, Q.-T.; Ayub, M.J.; Fraaije, M.W. Reconstructing the evolutionary history of $\mathrm{F}_{420}$-dependent dehydrogenases. Sci. Rep. 2018, 8, 17571. [CrossRef] [PubMed]

28. Ceh, K.; Demmer, U.; Warkentin, E.; Moll, J.; Thauer, R.K.; Shima, S.; Ermler, U. Structural basis of the hydride transfer mechanism in $\mathrm{F}_{420}$-dependent methylenetetrahydromethanopterin dehydrogenase. Biochemistry 2009, 48, 10098-10105. [CrossRef]

29. Shima, S.; Warkentin, E.; Grabarse, W.; Sordel, M.; Wicke, M.; Thauer, R.K.; Ermler, U. Structure of coenzyme $\mathrm{F}_{420}$ dependent methylenetetrahydromethanopterin reductase from two methanogenic archaea. J. Mol. Biol. 2000, 300, 935-950. [CrossRef]

30. Vaupel, M.; Thauer, R.K. Coenzyme $\mathrm{F}_{420}$ dependent N-5, N-10-methylenetetrahydromethanopterin reductase (MER) from Methanobacterium thermautotrophicum strain marburg: Cloning, sequencing, transcriptional analysis and functional expression in Escherichia coli of the mer gene. Eur. J. Biochem. 1995, 231, 773-778.

31. Purwantini, E.; Mukhopadhyay, B. Rv0132c of Mycobacterium tuberculosis encodes a coenzyme $\mathrm{F}_{420}$-dependent $^{-\mathrm{d}}$ hydroxymycolic acid dehydrogenase. PLoS ONE 2013, 8, e81985. [CrossRef] 
32. Fida, T.T.; Palamuru, S.; Pandey, G.; Spain, J.C. Aerobic biodegradation of 2,4-dinitroanisole by Nocardioides sp. Strain js1661. Appl. Environ. Microbiol. 2014, 80, 7725-7731. [CrossRef] [PubMed]

33. Ebert, S.; Rieger, P.G.; Knackmuss, H.J. Function of coenzyme $\mathrm{f}_{420}$ in aerobic catabolism of 2,4,6-trinitrophenol and 2,4-dinitrophenol by Nocardioides simplex FJ2-1A. J. Bacteriol. 1999, 181, 2669-2674. [PubMed]

34. Lapalikar, G.V.; Taylor, M.C.; Warden, A.C.; Scott, C.; Russell, R.J.; Oakeshott, J.G. $\mathrm{F}_{420} \mathrm{H}_{2}$-dependent degradation of aflatoxin and other furanocoumarins is widespread throughout the Actinomycetales. PLoS ONE 2012, 7, e30114. [CrossRef] [PubMed]

35. Greening, C.; Jirapanjawat, T.; Afroze, S.; Ney, B.; Scott, C.; Pandey, G.; Lee, B.M.; Russell, R.J.; Jackson, C.J.; Oakeshott, J.G.; et al. Mycobacterial $\mathrm{F}_{420} \mathrm{H}_{2}$-dependent reductases promiscuously reduce diverse compounds through a common mechanism. Front. Microbiol. 2017, 8. [CrossRef]

36. Gurumurthy, M.; Rao, M.; Mukherjee, T.; Rao, S.P.S.; Boshoff, H.I.; Dick, T.; Barry, C.E.; Manjunatha, U.H. A novel $\mathrm{F}_{420}$-dependent anti-oxidant mechanism protects Mycobacterium tuberculosis against oxidative stress and bactericidal agents. Mol. Microbiol. 2013, 87, 744-755. [CrossRef]

37. Mohamed, A.E.; Ahmed, F.H.; Arulmozhiraja, S.; Lin, C.Y.; Taylor, M.C.; Krausz, E.R.; Jackson, C.J.; Coote, M.L. Protonation state of $\mathrm{F}_{420} \mathrm{H}_{2}$ in the prodrug-activating deazaflavin dependent nitroreductase (DDN) from Mycobacterium tuberculosis. Mol. BioSys. 2016, 12, 1110-1113. [CrossRef]

38. Drenth, J.; Trajkovic, M.; Fraaije, M.W. Chemoenzymatic synthesis of an unnatural deazaflavin cofactor that can fuel $\mathrm{F}_{420}$-dependent enzymes. ACS Catal. 2019, 9, 6435-6443. [CrossRef]

39. Purwantini, E.; Daniels, L. Molecular analysis of the gene encoding $\mathrm{F}_{420}$-dependent glucose-6-phosphate dehydrogenase from Mycobacterium smegmatis. J. Bacteriol. 1998, 180, 2212-2219.

40. Bleicher, K.; Winter, J. Purification and properties of $\mathrm{F}_{420}$-and $\mathrm{NADP}^{+}$-dependent alcohol dehydrogenases of Methanogenium liminatans and Methanobacterium palustre, specific for secondary alcohols. Europ. J. Biochem. 1991, 200, 43-51. [CrossRef]

41. Knaus, T.; Cariati, L.; Masman, M.F.; Mutti, F.G. In vitro biocatalytic pathway design: Orthogonal network for the quantitative and stereospecific amination of alcohols. Org. Biomol. Chem. 2017, 15, 8313-8325.

42. Guo, F.; Berglund, P. Transaminase biocatalysis: Optimization and application. Green Chem. 2017, 19, 333-360. [CrossRef]

43. Adams, J.P.; Brown, M.J.B.; Diaz-Rodriguez, A.; Lloyd, R.C.; Roiban, G.D. Biocatalysis: A pharma perspective. Adv. Synth. Catal. 2019, 361, 2421-2432. [CrossRef]

44. Musa, M.M.; Hollmann, F.; Mutti, F.G. Synthesis of enantiomerically pure alcohols and amines via biocatalytic deracemisation methods. Cat. Sci. Technol. 2019, 9, 10-1039. [CrossRef]

45. Ichikawa, H.; Bashiri, G.; Kelly, W.L. Biosynthesis of the thiopeptins and identification of an $\mathrm{F}_{420} \mathrm{H}_{2}$-dependent dehydropiperidine reductase. J. Am. Chem. Soc. 2018, 140, 10749-10756. [CrossRef]

46. Miller, A.F.; Park, J.T.; Ferguson, K.L.; Pitsawong, W.; Bommarius, A.S. Informing efforts to develop nitroreductase for amine production. Molecules 2018, 23, 22. [CrossRef]

47. Heiss, G.; Hofmann, K.W.; Trachtmann, N.; Walters, D.M.; Rouvière, P.; Knackmuss, H.J. Npd gene functions of Rhodococcus (opacus) erythropolis HI PM-1 in the initial steps of 2,4,6-trinitrophenol degradation. Microbiology 2002, 148, 799-806. [CrossRef]

48. Xu, J.; Green, A.P.; Turner, N.J. Chemo-enzymatic synthesis of pyrazines and pyrroles. Angew. Chem.-Int. Ed. 2018, 57, 16760-16763. [CrossRef]

49. Busacca, C.A.; Fandrick, D.R.; Song, J.J.; Senanayake, C.H. The growing impact of catalysis in the pharmaceutical industry. Adv. Synth. Catal. 2011,353, 1825-1864. [CrossRef]

50. Heiss, G.; Trachtmann, N.; Abe, Y.; Takeo, M.; Knackmuss, H.J. Homologous npdgi genes in 2,4-dinitrophenoland 4-nitrophenol-degrading Rhodococcus spp. Appl. Environ. Microbiol. 2003, 69, 2748-2754. [CrossRef]

51. Purwantini, E.; Daniels, L.; Mukhopadhyay, B. $\mathrm{F}_{420} \mathrm{H}_{2}$ is required for phthiocerol dimycocerosate synthesis in Mycobacteria. J. Bacteriol. 2016, 198, 2020-2028. [CrossRef]

52. Wichmann, R.; Vasic-Racki, D. Cofactor regeneration at the lab scale. In Technology Transfer in Biotechnology; Springer: Berlin, Germany, 2005; pp. 225-260.

53. Tishkov, V.I.; Popov, V.O. Catalytic mechanism and application of formate dehydrogenase. Biochemistry 2004, 69, 1252. [CrossRef] [PubMed]

54. Eguchi, T.; Kuge, Y.; Inoue, K.; Yoshikawa, N.; Mochida, K.; Uwajima, T. NADPH regeneration by glucose dehydrogenase from Gluconobacter scleroides for L-leucovorin synthesis. Biosci. Biotechnol. Biochem. 1992, 56, 701-703. [CrossRef] [PubMed] 
55. Demir, A.S.; Talpur, F.N.; Sopaci, B.; Kohring, G.-W.; Celik, A. Selective oxidation and reduction reactions with cofactor regeneration mediated by galactitol-, lactate-, and formate dehydrogenases immobilized on magnetic nanoparticles. J. Biotechnol. 2011, 152, 176-183. [CrossRef] [PubMed]

56. Wong, C.-H.; Whitesides, G.M. Enzyme-catalyzed organic synthesis: NAD(P)H cofactor regeneration by using glucose-6-phosphate and the glucose-5-phosphate dehydrogenase from Leuconostoc mesenteroides. J. Am. Chem. Soc. 1981, 103, 4890-4899. [CrossRef]

57. Lee, W.-H.; Park, J.-B.; Park, K.; Kim, M.-D.; Seo, J.-H. Enhanced production of $\epsilon$-caprolactone by overexpression of NADPH-regenerating glucose 6-phosphate dehydrogenase in recombinant Escherichia coli harboring cyclohexanone monooxygenase gene. Appl. Microbiol. Biotechnol. 2007, 76, 329-338. [CrossRef] [PubMed]

58. Berrios-Rivera, S.J.; Bennett, G.N.; San, K.Y. Metabolic engineering of Escherichia coli: Increase of NADH availability by overexpressing an $\mathrm{NAD}^{+}$-dependent formate dehydrogenase. Metab. Eng. 2002, 4, $217-229$. [CrossRef]

59. Bashiri, G.; Antoney, J.; Jirgis, E.N.M.; Shah, M.V.; Ney, B.; Copp, J.; Stuteley, S.M.; Sreebhavan, S.; Palmer, B.; Middleditch, M.; et al. A revised biosynthetic pathway for the cofactor $\mathrm{F}_{420}$ in prokaryotes. Nat. Commun. 2019, 10, 1558. [CrossRef]

60. Purwantini, E.; Daniels, L. Purification of a novel coenzyme $\mathrm{F}_{420}$-dependent glucose-6-phosphate dehydrogenase from Mycobacterium smegmatis. J. Bacteriol. 1996, 178, 2861-2866. [CrossRef]

61. Costa, K.C.; Wong, P.M.; Wang, T.; Lie, T.J.; Dodsworth, J.A.; Swanson, I.; Burn, J.A.; Hackett, M.; Leigh, J.A. Protein complexing in a methanogen suggests electron bifurcation and electron delivery from formate to heterodisulfide reductase. Proc. Natl. Acad. Sci. USA 2010, 107, 11050-11055. [CrossRef]

62. Shuber, A.P.; Orr, E.C.; Recny, M.A.; Schendel, P.F.; May, H.D.; Schauer, N.L.; Ferry, J.G. Cloning, expression, and nucleotide sequence of the formate dehydrogenase genes from Methanobacterium formicicum. J. Biol. Chem. 1986, 261, 12942-12947.

63. Novotná, J.; Neužil, J.; Hoš?álek, Z. Spectrophotometric identification of 8-hydroxy-5-deazaflavin: Nadph oxidoreductase activity in Streptomycetes producing tetracyclines. FEMS Microbiol. Lett. 1989, 59, 241-245. [CrossRef]

64. Kumar, H.; Nguyen, Q.T.; Binda, C.; Mattevi, A.; Fraaije, M.W. Isolation and characterization of a thermostable $\mathrm{F}_{420}$ :NADPH oxidoreductase from Thermobifida fusca. J. Biol. Chem. 2017, 292, 10123-10130. [CrossRef] [PubMed]

65. Kunow, J.; Schwörer, B.; Stetter, K.O.; Thauer, R.K. A F F ${ }_{420}$-dependent NADP reductase in the extremely thermophilic sulfate-reducing Archaeoglobus fulgidus. Arch. Microbiol. 1993, 160, 199-205.

66. Eker, A.P.M.; Hessels, J.K.C.; Meerwaldt, R. Characterization of an 8-hydroxy-5-deazaflavin: NADPH oxidoreductase from Streptomyces griseus. Biochim. Biophys. Acta 1989, 990, 80-86. [CrossRef]

67. Seelbach, K.; Riebel, B.; Hummel, W.; Kula, M.R.; Tishkov, V.I.; Egorov, A.M.; Wandrey, C.; Kragl, U. A novel, efficient regenerating method of NADPH using a new formate dehydrogenase. Tetrahedron Lett. 1996, 37, 1377-1380. [CrossRef]

68. Alex, L.A.; Reeve, J.N.; Ormejohnson, W.H.; Walsh, C.T. Cloning, sequence determination, and expression of the genes encoding the subunits of the nickel-containing 8-hydroxy-5-deazaflavin reducing hydrogenase from Methanobacterium thermoautotrophicum delta-H. Biochemistry 1990, 29, 7237-7244. [CrossRef]

69. Tersteegen, A.; Hedderich, R. Methanobacterium thermoautotrophicum encodes two multisubunit membrane-bound NiFe hydrogenases - transcription of the operons and sequence analysis of the deduced proteins. Eur. J. Biochem. 1999, 264, 930-943. [CrossRef]

70. Hocking, W.P.; Stokke, R.; Roalkvam, I.; Steen, I.H. Identification of key components in the energy metabolism of the hyperthermophilic sulfate-reducing archaeon archaeoglobus fulgidus by transcriptome analyses. Front. Microbiol. 2014, 5, 20. [CrossRef]

71. Vitt, S.; Ma, K.; Warkentin, E.; Moll, J.; Pierik, A.J.; Shima, S.; Ermler, U. The F-420-reducing NiFe -hydrogenase complex from methanothermobacter marburgensis, the first x-ray structure of a group 3 family member. J. Mol. Biol. 2014, 426, 2813-2826. [CrossRef]

72. Bashiri, G.; Rehan, A.M.; Greenwood, D.R.; Dickson, J.M.; Baker, E.N. Metabolic engineering of cofactor $\mathrm{F}_{420}$ production in Mycobacterium smegmatis. PLoS ONE 2010, 5, e15803. [CrossRef]

73. Isabelle, D.; Simpson, D.R.; Daniels, L. Large-scale production of coenzyme $\mathrm{F}_{420}-5,6$ by using Mycobacterium smegmatis. Appl. Environ. Microbiol. 2002, 68, 5750-5755. [CrossRef] [PubMed] 
74. Eker, A.P.M.; Pol, A.; van der Meyden, P.; Vogels, G.D. Purification and properties of 8-hydroxy-5-deazaflavin derivatives from Streptomyces griseus. FEMS Microbiol. Lett. 1980, 8, 161-165. [CrossRef]

75. Grochowski, L.L.; Xu, H.M.; White, R.H. Identification and characterization of the 2-phospho-L-lactate guanylyltransferase involved in coenzyme F-420 biosynthesis. Biochemistry 2008, 47, 3033-3037. [CrossRef] [PubMed]

76. Braga, D.; Lasta, D.; Hasan, M.; Guo, H.; Leichnitz, D.; Uzum, Z.; Richter, I.; Schalk, F.; Beemelmanns, C.; Hertweck, C.; et al. Metabolic pathway rerouting in Paraburkholderia rhizoxinica evolved long-overlooked derivatives of coenzyme $\mathrm{F}_{420}$. ACS Chem. Biol. 2019, 2088-2094. [CrossRef]

77. Hossain, M.S.; Le, C.Q.; Joseph, E.; Nguyen, T.Q.; Johnson-Winters, K.; Foss, F.W. Convenient synthesis of deazaflavin cofactor $\mathrm{F}_{\mathrm{o}}$ and its activity in $\mathrm{F}_{420}$-dependent NADP reductase. Organ. Biomol. Chem. 2015, 13, 5082-5085. [CrossRef]

78. Alberty, R.A. Calculation of standard transformed formation properties of biochemical reactants and standard apparent reduction potentials of half reactions. Arch. Biochem. Biophys. 1998, 358, 25-39. [CrossRef]

79. Alberty, R.A. Calculation of standard transformed gibbs energies and standard transformed enthalpies of biochemical reactants. Arch. Biochem. Biophys. 1998, 353, 116-130. [CrossRef]

80. Benedict, M.N.; Gonnerman, M.C.; Metcalf, W.W.; Price, N.D. Genome-scale metabolic reconstruction and hypothesis testing in the methanogenic archaeon Methanosarcina acetivorans C2A. J. Bacteriol. 2012, 194, 855-865. [CrossRef]

81. Jankowski, M.D.; Henry, C.S.; Broadbelt, L.J.; Hatzimanikatis, V. Group contribution method for thermodynamic analysis of complex metabolic networks. Biophys. J. 2008, 95, 1487-1499. [CrossRef]

82. Henry, C.S.; DeJongh, M.; Best, A.A.; Frybarger, P.M.; Linsay, B.; Stevens, R.L. High-throughput generation, optimization and analysis of genome-scale metabolic models. Nat. Biotechnol. 2010, 28, 977-982. [CrossRef]

83. Nazem-Bokaee, H.; Gopalakrishnan, S.; Ferry, J.G.; Wood, T.K.; Maranas, C.D. Assessing methanotrophy and carbon fixation for biofuel production by Methanosarcina acetivorans. Microb. Cell Fact. 2016, 15, 10. [CrossRef] [PubMed]

84. Caspi, R.; Billington, R.; Fulcher, C.A.; Keseler, I.M.; Kothari, A.; Krummenacker, M.; Latendresse, M.; Midford, P.E.; Ong, Q.; Ong, W.K.; et al. The metacyc database of metabolic pathways and enzymes. Nucleic Acids Res. 2018, 46, D633-D639. [CrossRef] [PubMed]

(C) 2019 by the authors. Licensee MDPI, Basel, Switzerland. This article is an open access article distributed under the terms and conditions of the Creative Commons Attribution (CC BY) license (http://creativecommons.org/licenses/by/4.0/). 


\title{
Article \\ A Machine Learning Approach for Efficient Selection of Enzyme Concentrations and Its Application for Flux Optimization
}

\author{
Anamya Ajjolli Nagaraja ${ }^{1,2,3,4}$, Philippe Charton ${ }^{2,3,4}$, Xavier F. Cadet ${ }^{5}$, Nicolas Fontaine ${ }^{5}$, \\ Mathieu Delsaut ${ }^{1}$, Birgit Wiltschi ${ }^{6}$, Alena Voit ${ }^{6}$, Bernard Offmann ${ }^{7}$, Cedric Damour ${ }^{1}$, \\ Brigitte Grondin-Perez ${ }^{1}$ and Frederic Cadet ${ }^{2,3,4, *}$ \\ 1 Laboratory of Energy, Electronics and Processes (LE2P-EnergyLab), EA 4079, Faculty of Sciences and \\ Technology, University of La Reunion, 97444 St Denis CEDEX, France; \\ anamya.ajjolli-nagaraja@univ-reunion.fr (A.A.N.); mathieu.delsaut@univ-reunion.fr (M.D.); \\ cedric.damour@univ-reunion.fr (C.D.); Brigitte.Grondin@univ-reunion.fr (B.G.-P.) \\ 2 University of Paris, BIGR—Biologie Intégrée du Globule Rouge, Inserm, UMR_S1134, F-75015 Paris, France; \\ philippe.charton@univ-reunion.fr \\ 3 Laboratory of Excellence GR-Ex, Boulevard du Montparnasse, F-75015 Paris, France \\ 4 DSIMB - Dynamics of Structures and Interactions of Biological Macromolecules, UMR_S1134, BIGR, Inserm, \\ Faculty of Sciences and Technology, University of La Reunion, F-97715 Saint-Denis, France \\ 5 PEACCEL_Protein Engineering Accelerator, 6 Square Albin Cachot, box 42, 75013 Paris, France; \\ xavier.cadet.fff@gmail.com (X.F.C.); nicolas.fontaine@peaccel.com (N.F.) \\ 6 ACIB-Austrian Centre of Industrial Biotechnology, Synthetic Biology Group, Petersgasse 14, 8010 Graz, \\ Austria; birgit.wiltschi@acib.at (B.W.); alenavoit@acib.at (A.V.) \\ 7 Unité Fonctionnalité et Ingénierie des Protéines (UFIP), UFR Sciences et Techniques, Université de Nantes, \\ UMR 6286 CNRS, 2, Chemin de la Houssinière, 0344322 Nantes CEDEX, France; \\ bernard.offmann@univ-nantes.fr \\ * Correspondence: frederic.cadet.run@gmail.com; Tel.: +33-69-591-8108
}

Received: 28 January 2020; Accepted: 28 February 2020; Published: 4 March 2020

\begin{abstract}
The metabolic engineering of pathways has been used extensively to produce molecules of interest on an industrial scale. Methods like gene regulation or substrate channeling helped to improve the desired product yield. Cell-free systems are used to overcome the weaknesses of engineered strains. One of the challenges in a cell-free system is selecting the optimized enzyme concentration for optimal yield. Here, a machine learning approach is used to select the enzyme concentration for the upper part of glycolysis. The artificial neural network approach (ANN) is known to be inefficient in extrapolating predictions outside the box: high predicted values will bump into a sort of "glass ceiling". In order to explore this "glass ceiling" space, we developed a new methodology named glass ceiling ANN (GC-ANN). Principal component analysis (PCA) and data classification methods are used to derive a rule for a high flux, and ANN to predict the flux through the pathway using the input data of 121 balances of four enzymes in the upper part of glycolysis. The outcomes of this study are i. in silico selection of optimum enzyme concentrations for a maximum flux through the pathway and ii. experimental in vitro validation of the "out-of-the-box" fluxes predicted using this new approach. Surprisingly, flux improvements of up to $63 \%$ were obtained. Gratifyingly, these improvements are coupled with a cost decrease of up to $25 \%$ for the assay.
\end{abstract}

Keywords: machine learning; flux optimization; artificial neural network; synthetic biology; glycolysis; metabolic pathways optimization; cell-free systems 


\section{Introduction}

Many chemical molecules like peptides, organic acids, etc., are synthesized by different methods such as chemical reactions [1-5] and fermentation process for their application in everyday life. Due to the depletion of non-renewable resources, synthesis of these molecules through a biological system is essential on an industrial scale [6,7]. For decades, scientists have been successful in producing different chemical molecules through microbial fermentation by optimizing the process [7-10]. The costs of microbial fermentation are low, for instance, in comparison to mammalian cell cultures. Microbial systems are easily scalable, use inexpensive synthetic media and have lower batch-to-batch variability [11]. However, microbial systems such as Escherichia coli or yeasts have no or only limited capacity for post-translational modifications. Microbial biosynthesis may show low productivity and the coproduction of by-products is possible, which make product recovery complex and protracted [12]. With the advancement of science and technology, there is a continuous effort to improve productivity through novel techniques like gene regulation, which helps to channel the pathway in particular directions, substrate channeling where reactants are directed to the active site of enzymes $[13,14]$, quorum sensing [15], enzyme engineering, etc. However, even after numerous studies, synthesizing some molecules on an industrial scale through microbial fermentation is not cost-effective.

Nobel laureate Eduard Buchner laid the foundation for the cell-free system (CFS) of biomolecule production by converting sugar into ethanol in 1897. It has been successfully used in the synthesis of many products like bio-hydrogen [16,17], bio-ethanol [18,19], antibodies [20], vaccines [21], proteins [22], etc. The CFS is classified into two broad categories: i) cell-extract based: in which the host cells are lysed $[23,24]$ and ii) purified-enzyme based: a mixture of purified enzymes and cofactors are in the system [25]. The CFS has high toxic tolerance, rapid development timeline, easy incorporation of unnatural amino acids and easy purification of the product. The disadvantages of CFS include poor scalability, and post-translation modification of proteins is challenging [22]. The selection of enzymes is crucial in metabolic engineering since low performing enzymes result in poor titer and yield. Homology based methodologies like Selenzyme [26] have been developed to select better performing enzymes. One of the main challenges of purified enzyme-based CFS is the selection of optimum enzyme concentrations for maximum product formation. The experimental selection of optimum enzyme concentrations is expensive and tedious.

Researchers became more interested in the mathematical modeling of biological systems due to the availability of data from omics studies [27]. The modeling helps to organize the system information, to simulate and hence optimize the experiment and to understand system characteristics. Out of many different kinds of modeling methods, constraints-based and statics-based models, as well as kinetics-based or dynamic models have been used extensively to study metabolic pathways. The constraints-based methods such as the flux balance analysis [28] depend on physicochemical constraints like mass and energy balance [29]. However, the constraint-based method does not provide information about the concentration of metabolites. Kinetic modeling depends on the kinetic parameters of the enzymes involved in the pathway and provides information about their concentrations [30]. Kinetic modeling of pathways helps to better understand their behavior and replicate the system. Since the kinetic parameters are essential for this kind of modeling, it is not always easy to replicate the system. Finding the kinetic parameters is expensive, tedious [31], and some parameters are difficult to estimate experimentally [32]. For example, phosphofructokinase requires more than ten parameters to model [33]. Hence, the development of a computational method for selecting optimum enzyme concentrations without detailed knowledge of their kinetic parameters, using other existing experimental data, is helpful.

Machine learning methods help to predict the outcome based on the existing experimental data. The artificial neural network (ANN) is one such method inspired by brain architecture [34]. The neural network consists of connections between three layers: input, hidden and output layer. An activation function for the hidden layer is used to define the output. The neural network has been widely used in different fields of science for system identification and control, pattern recognition, medical diagnosis, 
weather prediction, etc. In particular, the ANN has been used for the selection of optimized medium components in the fermentation process for producing different molecules such as lipids from Chlorella vulgaris [35] and Spinosyns from Saccharopolyspora spinose [36]. ANN was employed, for instance, for the prediction of the flux through mammalian gluconeogenesis, using the simulated data from metabolite isotopic labeling [37]. Glycolysis, one of the central carbon metabolism pathways, is not only important for organisms, but also in biotechnology for producing different biomolecules [38]. Many chemicals such as organic acids $[39,40]$ and biofuels $[41,42]$ have been successfully produced with high titer using engineered microorganisms including Saccharomyces cerevisiae or Escherichia coli. Glycolysis is widely studied from various perspectives. The availability of data from Fievet et al. [43] for flux prediction with different enzyme concentrations makes it a good candidate for developing a new approach to select optimum enzyme concentrations.

Previously, ANN was used to predict the flux through the upper part of glycolysis using enzyme concentrations, i.e., phosphogluco isomerase (PGI), phosphofructokinase (PFK), fructose biphosphate aldolase (FBA), and triosephosphate isomerase (TPI) as the input to the model [44]. The predicted flux has a root mean square error (RMSE) of 0.84 and an $R^{2}$ of 0.93 , with 13 hidden units. Since the ANN is a training-based method, the new prediction depends on the training dataset. Since ANN is not efficient in extrapolating predictions $[45,46]$, the new predictions will always lie in the range of the known output predictions; in other words, we could say that they will remain "in-the-box". High predicted output values will bump into a sort of "glass ceiling". Our working hypothesis was that, in reality, actual flux values could be higher than the predicted ones. So, in order to explore this "glass ceiling" space, we developed a new methodology (GC-ANN, for glass ceiling ANN) to predict the flux for the upper part of glycolysis, given enzyme concentrations using an artificial neural network. The outcomes of this study are i. in silico selection of optimum enzyme concentrations for maximum flux through the pathway and ii. experimental in vitro validation of the "out-of-the-box" flux predicted using this new approach. Initially, we expected to obtain slight improvements, i.e., improved flux values close to the highest one that we fed into the model. Surprisingly, improvements up to $63 \%$ were obtained. Moreover, these improvements are coupled with a cost decrease of up to $25 \%$ for the assay.

\section{Methodology}

\subsection{Data for New Methodology}

The data from Fievet et al. [43] were used to develop the new methodology for selecting optimum enzyme concentrations using ANN. The dataset consisted of 121 combinations of four enzymes (PGI, PFK, FBA and TPI) for the upper stage of glycolysis for a flux value of $0.74-12.9 \mu \mathrm{M} / \mathrm{s}$. The total enzyme concentration was kept constant for four enzymes of $101.9 \mathrm{mg} / \mathrm{L}$. The flux was measured as NADH consumption through G3PDH. For more details about the data, please refer to the experimental section of the research article by Fievet et al. [43].

\subsection{ANN-Based Flux Prediction Workflow}

The new GC-ANN methodology is explained in three steps: i.) the preparation stage: the data dimension is reduced to find the possibly correlated variable, the rule for obtaining higher flux ( $>12 \mu \mathrm{M} / \mathrm{s}$ ) is derived from the data, and a neural network model is built to predict the flux using the enzyme concentrations; ii.) execution stage: new enzyme concentrations are generated using the rule obtained and the flux is predicted for the new concentration using ANN; and iii.) validation of the methodology: the new methodology of predicting flux using ANN is validated through simulation and experiment. 


\subsubsection{Preparation stage}

\section{Reduction of Data Dimensionality}

Principal component analysis (PCA) is one of the methods for the reduction of dimensionality of the dataset $[47,48]$. For datasets with a high degree of freedom, PCA is very useful to find possible correlations between the variables. PCA is performed using the R (V 3.4.3; R Development Core Team (2008)) package FactoMineR [49].

\section{Visualization of Data}

Three-dimensional viewing of data could provide insight into the distribution of flux in the space. Therefore, the fluxes in the 3D space of concentrations PGI, PFK, and TPI were visualized using R statistical packages plot3D [50] and plot3Drgl [51].

\section{Classification of Data for Higher Flux $(>12 \mu \mathrm{M} / \mathrm{s})$}

Data classification is the process of categorizing data into various homogeneous groups or types based on common characteristics. Decision tree analysis is a method of data classification helping to search for possible associations within the dataset. The decision tree is a simple tree-like graph method to understand and interpret the observations. The discriminant analysis helps to discriminate between the groups of data. The classification is supported by a discriminant analysis.

The data were classified into 5 groups, i.e., flux value from $0.728-3.17,3.17-5.6,5.6-8.04,8.04-10.5$ and 10.5-12.9. Approximately, 40\% of the data are in the final group, which consists of higher flux concentrations (greater than $10.5 \mu \mathrm{M} / \mathrm{s}$ ). The R packages klaR [52] and rpart [53] were used for discriminant analysis and decision tree respectively. The results from the decision tree and discriminant analysis were used to derive the concentration rule for higher flux values $(>12 \mu \mathrm{M} / \mathrm{s})$ through the pathway.

\section{Neural Network Model}

The artificial neural network for predicting the flux through the upper part of glycolysis is built using the data described earlier in the section "Data for new methodology". The model predicts flux as an NADH consumption through the pathway. The model is built using the R package neuralnet [54], which gives us the freedom to choose two different activation functions: logistic and tanh [44].

\subsubsection{Execution Stage}

\section{Generation of New Enzyme Concentration}

The new enzyme concentrations were generated between the highest $(\mathrm{PGI}=70, \mathrm{PFK}=70$, $\mathrm{FBA}=86.1, \mathrm{TPI}=66.1 \mathrm{mg} / \mathrm{L})$ and lowest $(\mathrm{PGI}=1, \mathrm{PFK}=1, \mathrm{FBA}=2, \mathrm{TPI}=1.66 \mathrm{mg} / \mathrm{L})$ concentrations of the data from Fievet et al. [43], with a step size of $1 \mathrm{mg} / \mathrm{L}$ using $\mathrm{R}$ script. The total enzyme concentration of four enzymes was kept constant at $101.9 \mathrm{mg} / \mathrm{L}$ as in Fievet et al. [43]. The newly generated concentrations were used in the additional analysis.

\section{Flux Prediction Using ANN}

Newly generated enzyme concentrations were fed to the ANN model to predict the flux. The data consisted of flux values ranging from 0.74 to $12.9 \mu \mathrm{M} / \mathrm{s}$. Since ANN is not good for extrapolation, these values limit the prediction to this range. Nevertheless, it is likely that new enzyme concentrations could provide higher flux. However, ANN prediction will remain in the glass ceiling space. Hence, we decided to explore this space with squeezed flux, i.e., the flux that lies in this particular space. Thus, for our study, fluxes $>12 \mu \mathrm{M} / \mathrm{s}$ predicted by ANN and the concentrations that obeyed the rule derived to obtain possible higher flux values from data classification were retained. 


\subsubsection{Validation of Methodology}

The artificial neural network-based methodology for flux prediction was validated in two steps. In the first step of validation, the available kinetic parameters from Fievet et al. [43] helped us to build the model and replicate the experimental conditions. In the second step, the methodology was experimentally validated.

Simulation of Upper Part of Glycolysis

In CellDesigner (ver4.4) [55,56], the kinetic model of the upper part of glycolysis was built using the kinetic parameters from Fievet et al. [43] and the parameters for cofactors chosen from the BRENDA [57] database (Table 1). The model was built to replicate the experimental condition with the Michaelis-Menten equation (Table 1). ATP is regenerated using the creatine kinase system. The hexokinase concentration was kept constant at $0.1 \mu \mathrm{M}$ and flux was measured as NADH consumption, as catalyzed by $1 \mu \mathrm{M}$ of G3PDH. The concentrations of PGI, PFK, FBA and TPI were varied according to the selected balance from Section 2.2.2. (i.e., with concentrations that provide a flux $\geq 12 \mu \mathrm{M} / \mathrm{s}$ as predicted by the ANN model). The concentrations were converted from $\mathrm{mg} / \mathrm{L}$ to $\mu \mathrm{M}$ using the molecular weight as suggested by Fievet et al.

The model was simulated for $120 \mathrm{~s}$ using COPASI [58] to measure NADH consumption. The slope of NADH decay between 60 and $120 \mathrm{~s}$ was estimated as flux through the pathway 182 enzyme balances yielding flux $\geq 15 \mu \mathrm{M} / \mathrm{s}$ from simulation using an in silico model were selected as the potential higher flux balances.

\section{Experimental Validation}

The upper part of glycolysis was reconstructed as described in Fievet et al. [43] (Figure 1). The in vitro system consisted of varied concentrations of PGI, PFK, FBA and TPI. The HK and G3PDH were kept constant and creatine kinases were used to regenerate ATP in the system. The NADH decay was measured as flux through the pathway. The slope of the linear NADH decay was used to calculate the flux in $\mu \mathrm{M} / \mathrm{s}$.

\subsubsection{The Workflow of the Proposed Methodology}

Based on the data listed in Fievet et al. [43], the ANN model was built to predict the flux using enzyme balances, and the rule for enzyme balance for higher flux was obtained by data classification. The fluxes for newly generated enzyme balances were predicted using the ANN model. The balances with a flux value $>12 \mu \mathrm{M} / \mathrm{s}$ (balances from the glass-ceiling) and the balances obeying the derived rule for higher flux were selected as potential higher flux balances. These selected balances were validated using the kinetic model and by experiments. The methodology that followed for exploring the glass-ceiling of ANN (GC-ANN) is represented diagrammatically in Figure 2. 


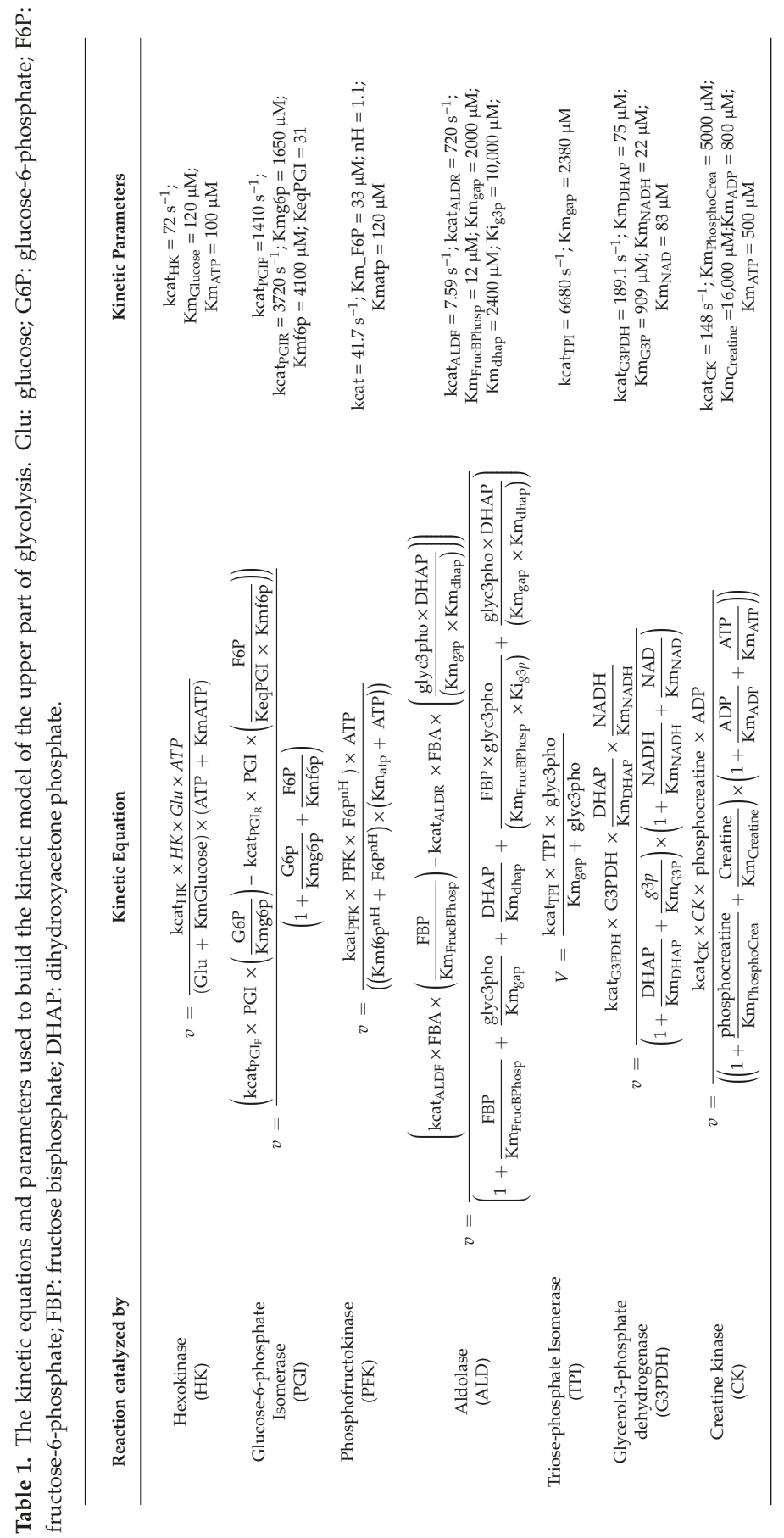




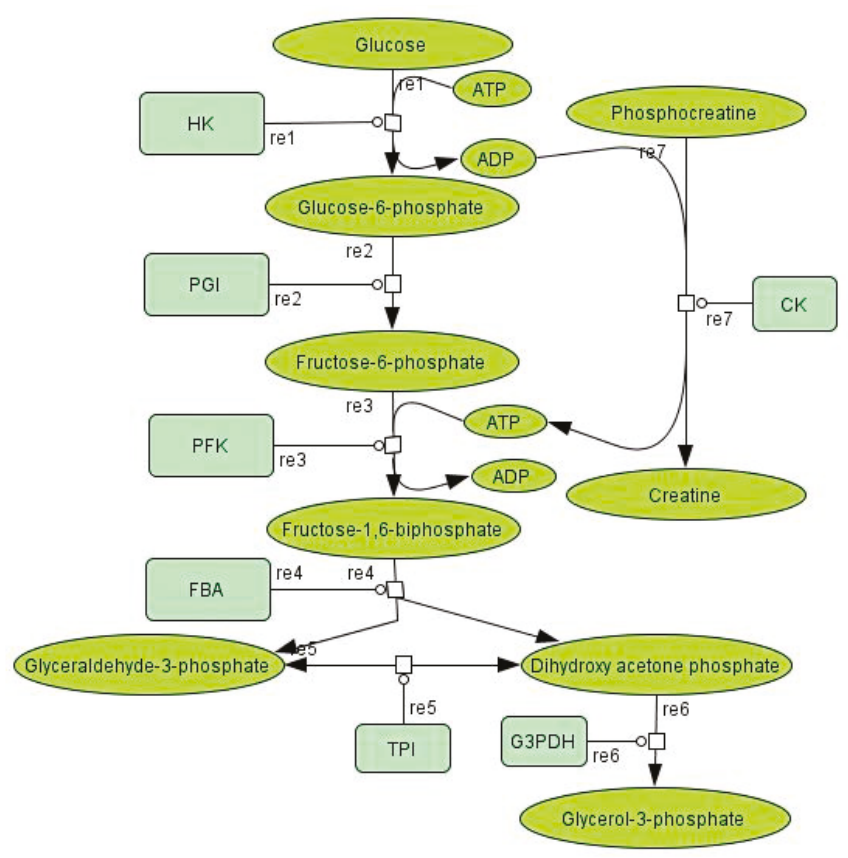

Figure 1. CellDesigner diagram for the upper part of glycolysis, which replicates the experimental conditions described by Fievet et al. [41]. HK: hexokinase, PGI: glucose 6- phosphate isomerase, PFK: phosphofructokinase, FBA: aldolase, TPI: triose-phosphate Isomerase, G3PDH: glycerol-3-phosphate dehydrogenase, CK: creatine kinase, re: reaction.
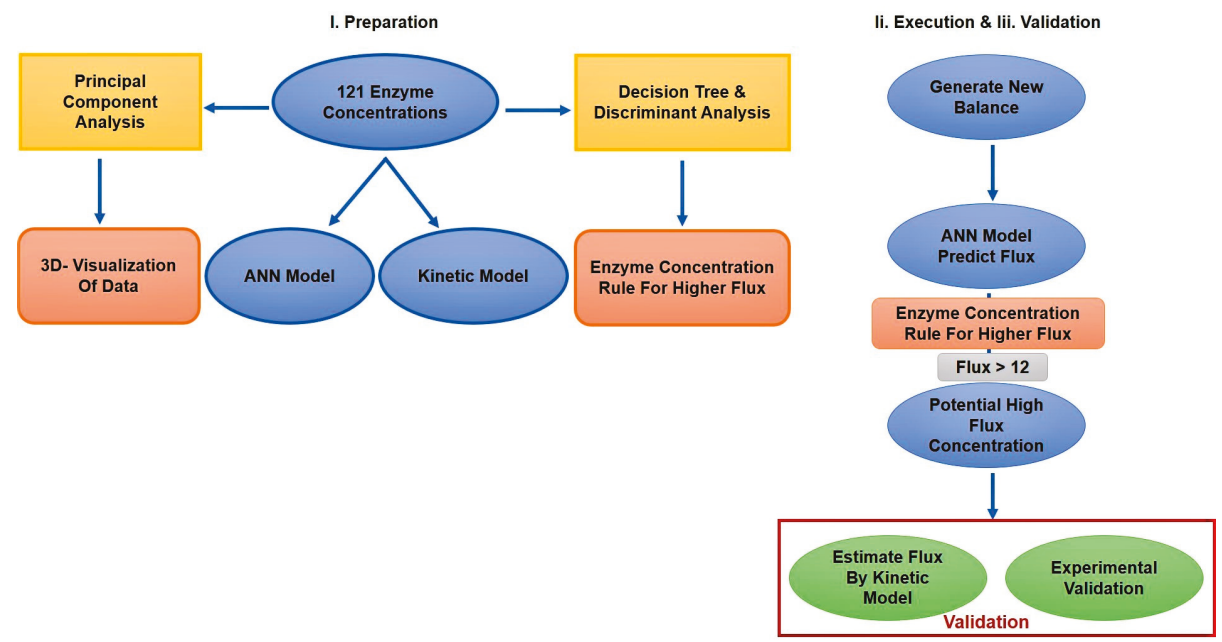

Figure 2. The methodology followed to obtain the new flux values from the generated enzyme concentration. 


\section{Application and Results}

\subsection{Preparation}

\subsubsection{Data Dimension Reduction}

In our study, PCA did not provide much information regarding the data. The total four-enzyme concentration was constant in the system, which reduced the degree of freedom to limit the enzyme concentrations to three. If the total enzyme concentration is not constant or the dataset presents a high degree of freedom, PCA will be more useful for obtaining uncorrelated variables: this is why we mentioned PCA as a useful tool in the framework of this methodology.

\subsubsection{Visualization of Data}

After the PCA, data was visualized in 3D (Figure 3). We could observe on the plot that the higher flux (red dots) was quite distinct. This is a good indication that a quantitative method could be applied and should provide good results. Indeed, this is verified in the section "Flux prediction using ANN" (Figure 3). In this methodology, we were exploring the space around those higher flux concentrations to obtain new concentrations of PGI, PFK and TPI.

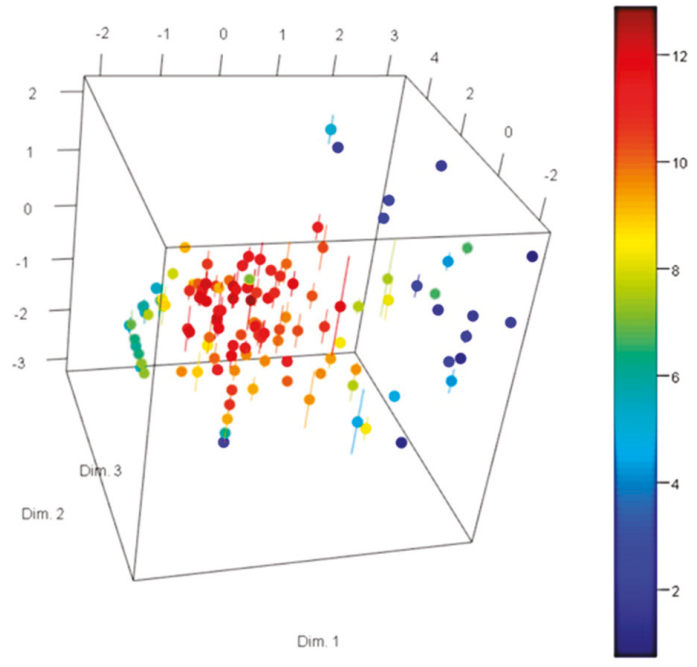

Figure 3. Three-dimensional visualization of Fievet et al. [43] enzyme balances after PCA (Dim1: 43.55\%, Dim2: $23.78 \%$ and Dim 3: $17.56 \%$ ). The change from blue to red indicates the gradient from low to high fluxes, respectively. Standard deviation of experimental flux is represented on the third-dimension.

\subsubsection{Enzyme Concentration Rule}

Decision tree analysis was performed using the $\mathrm{R}$ package rpart by dividing the data into five groups; this provides the best compromise on the gain in inter-class inertia. The five groups were determined using kmeans clustering.

Figure 4 represents the classification of data where the percentage of data belongs to the branch of tree and fraction represents the distribution into different groups. For example, $89 \%$ of the data had FBA concentration $>11$ and is distributed in five groups as a fraction of $0.01,0.09,0.17,0.29$ and 0.44 (Figure 4, node 3 ). 


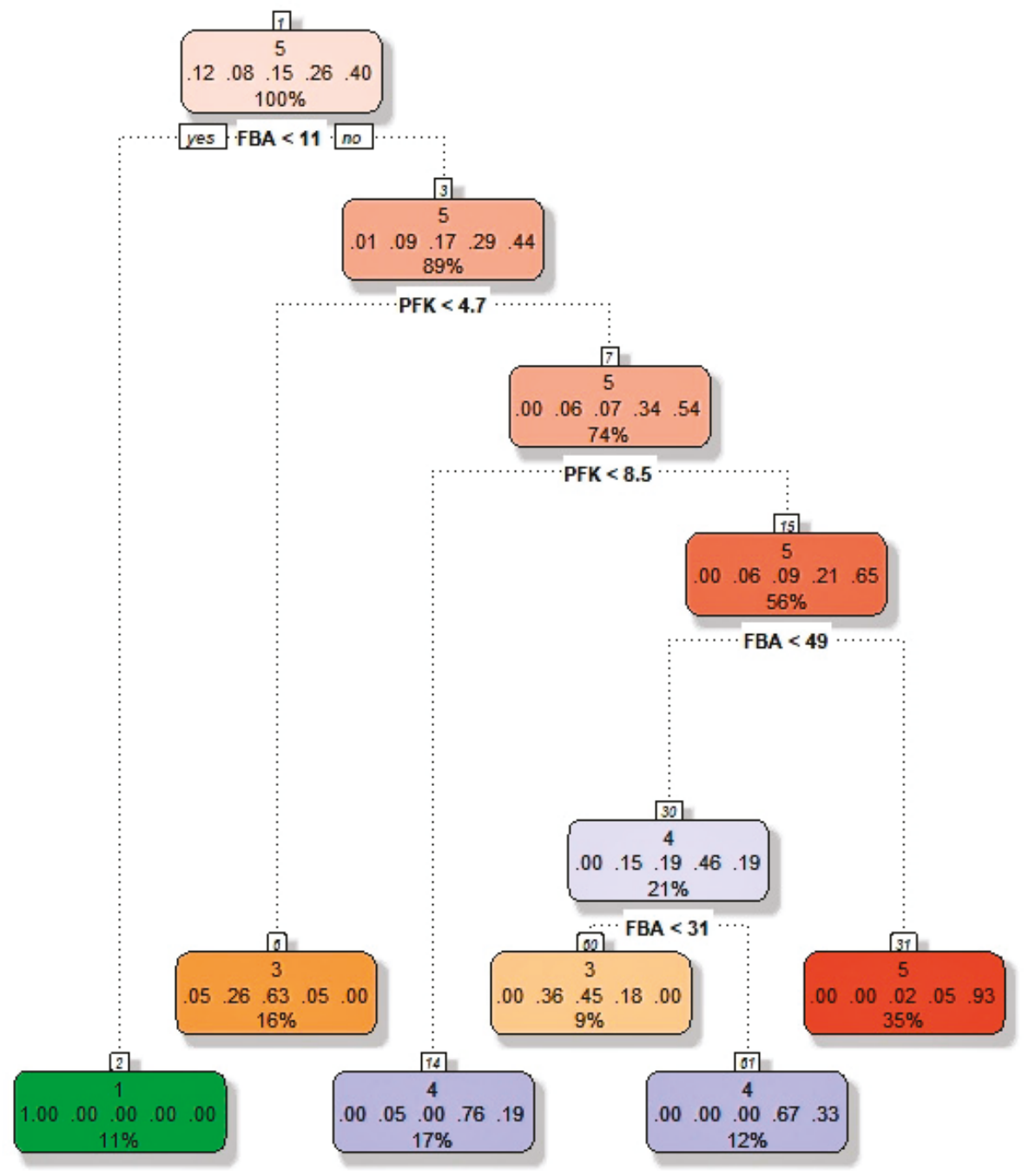

Figure 4. Decision tree analysis for Fievet et al. [43] data to obtain the rule for higher flux ( $\geq 12 \mu \mathrm{M} / \mathrm{s})$. The data is classified into 5 groups (i.e., flux value from (0.728-3.17), (3.17-5.6), (5.6-8.04), (8.04-10.5) and (10.5-12.9).

Among the different methods of discriminant analysis studied, rpart performed the best with an approximate error rate of 0.1. The different methods studied were LDA (linear discriminant analysis), QDA (quadratic discriminant analysis), SKNN (simple k nearest neighbors), RDA (regularized discriminant analysis) and naïve Bayes (under R package). For the SKNN method, the error rate was low but it led to an over-classification (data not shown). Figure 5 represents the discriminant analysis for the classification of data from Fievet et al. [43] using the rpart [53] method from R. 

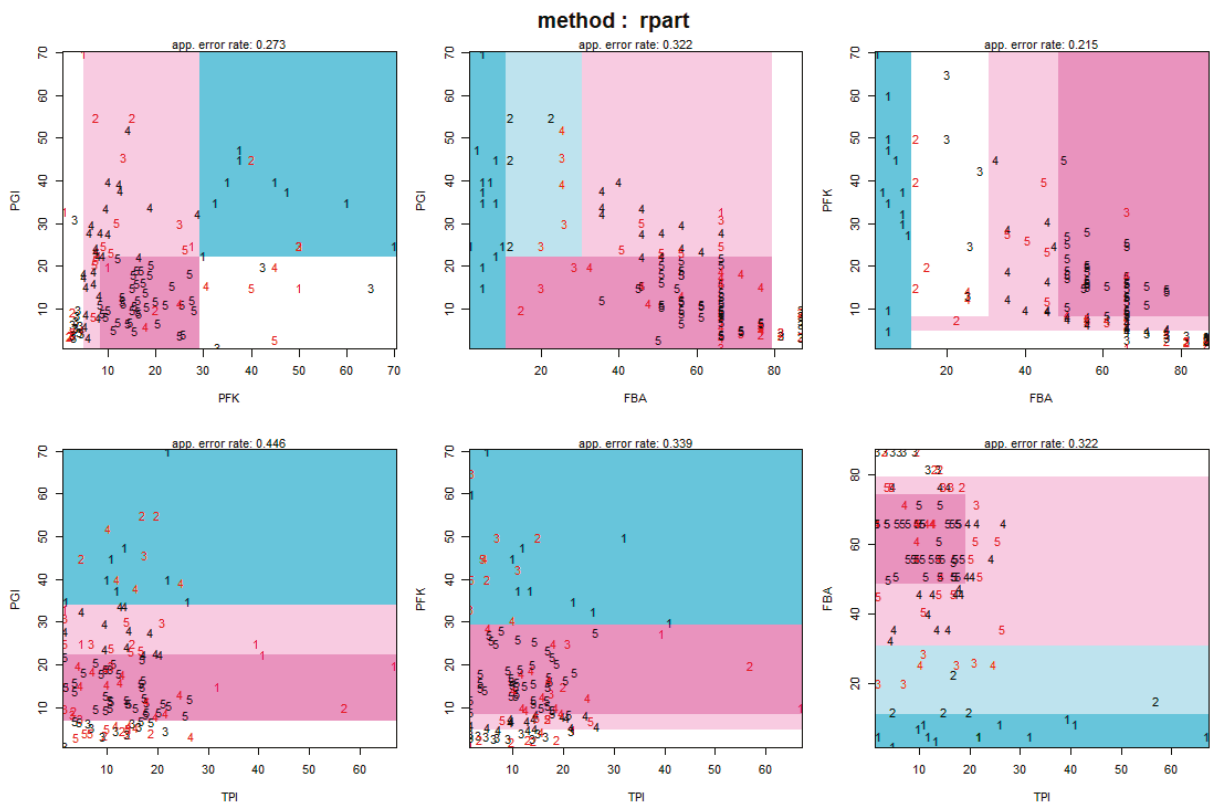

Figure 5. Discriminant analysis for the classification of data from Fievet et al. [43] using the rpart50 method from R. Color code according to the feature space of data, where group 1 (flux: $0.728-3.17 \mu \mathrm{M} / \mathrm{s}$ ) is shown in light blue, group 2 (flux: $3.17-5.6 \mu \mathrm{M} / \mathrm{s}$ ) in dark blue, group 3 (flux: $5.6-8.04 \mu \mathrm{M} / \mathrm{s}$ ) in white, group 4 (flux: $8.04-10.5 \mu \mathrm{M} / \mathrm{s}$ ) in light pink and group 5 (flux: $10.5-12.9 \mu \mathrm{M} / \mathrm{s}$ ) in dark pink. Numbers in black represent the data classified to the same group, and in red represent data misclassified into the other groups.

After using the decision tree (Figure 4) and discriminant analysis (Figure 5), the following rule was derived to obtain a flux $\geq 12 \mu \mathrm{M} / \mathrm{s}$ :

PGI $<11 ; 10<$ PFK < 16; TPI $<18 ; 59>$ FBA $(\mathrm{mg} / \mathrm{L})$, which corresponds to PGI $<15.07 \mathrm{U} / \mathrm{mL}$; $0.7 \mathrm{U} / \mathrm{mL}<\mathrm{PFK}<1.12 \mathrm{U} / \mathrm{mL} ; \mathrm{TPI}<264.42 \mathrm{U} / \mathrm{mL} ; 2.48 \mathrm{U} / \mathrm{mL}>$ FBA.

The conversion from $\mathrm{mg} / \mathrm{L}$ to $\mathrm{U} / \mathrm{mL}$ is given in Methods S1 in Supplementary Materials. The derived rule is applied for the selection of the best concentrations of the enzymes PFK, PGI, TPI, and FBA to obtain a high flux through the pathway.

\subsubsection{Neural Network Model}

ANN is a training-based method, the structure of the neural network needs to be chosen carefully since it depends on the number of inputs, sampling in the training dataset and the outputs. The structure was determined based on our previous study [44]. The neuralnet package from $R$ statistical tool with the logistic activation function was used. It has 13 hidden units in a single layer. The ANN model used has an RMSE value of 0.84 and an $\mathrm{R}^{2}$ value of 0.93 , using leave-one-out cross-validation [44].

\subsection{Execution}

\subsubsection{Generation of New Enzyme Concentrations}

The new concentrations of PFK, PGI, TPI and FBA were generated as explained in the methodology section. These new balances were used for further analysis to predict the flux. 


\subsubsection{Flux Prediction Using ANN}

The new balances were fed into the previously built neural network to predict the flux. The ANN predicted flux from the newly generated data was visualized in 3-dimensions (Figure 6).

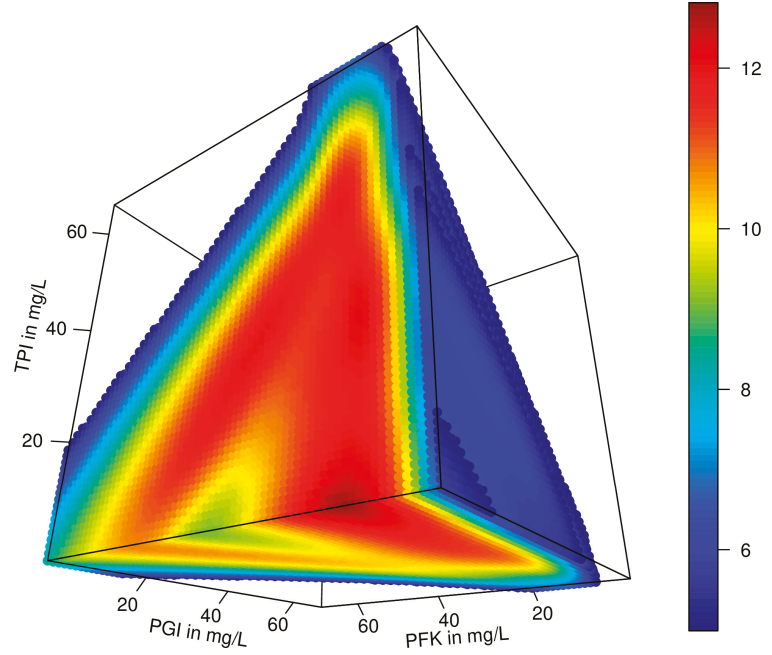

Figure 6. Three-dimensional visualization of flux predicted by an artificial neural network (ANN) for newly generated enzyme concentrations. The color gradient is from the lowest (blue) to the highest (red) predicted flux.

As expected, the new prediction remained in the box (see the maximum value of the color gradient bar in Figure 6) since ANN is a training-based method that depends on the training dataset. The high predicted values bump into the "glass ceiling". Our hypothesis was that even though they remain in the roof of the "glass ceiling", the experimental values could be higher than the predicted ones. By exploring this space, we could obtain new balances with higher flux values.

In order to explore the "glass ceiling" space, we developed this new methodology (named GC-ANN) using the artificial neural network to predict the flux through the upper part of glycolysis for given enzyme concentrations. In this study, we showed (see below in the section validation) that by careful selection of enzyme concentrations from the "glass-ceiling" space, it is possible to obtain higher flux values "out-of-the-box".

For all the enzyme concentrations generated between minimum and maximum of experimental data, only flux values above $12 \mu \mathrm{M} / \mathrm{s}$ predicted by neural network, and only enzyme balances (total of 335 balances, a balance being defined as a mixture of the four enzymes PGI, PFK, FBA and TPI) obeying the enzyme concentration rule were selected as potential high-flux balances.

\subsection{Validation}

The methodology for exploring the glass-ceiling using ANN (GC-ANN) was validated in two steps: first using the kinetic model and second, in vitro.

\subsubsection{Simulation of Upper Part of Glycolysis}

The kinetic model is built using CellDesigner [55,56] (Figure 1) and validated with COPASI [58] using the 121 concentrations from Fievet et al. [43]. The model has an RMSE value of 1.58 and $R^{2}$ of 0.84 in a cross-validation procedure, compared to the experimentally determined flux (Figure 7). Figure 7 proves that the kinetic model was good and could be used for the validation of the new 
approach. The highest flux predicted by the kinetic model of the reconstituted upper part of glycolysis was $14.93 \mu \mathrm{M} / \mathrm{s}$, where the highest experimentally observed flux was $12.9 \mu \mathrm{M} / \mathrm{s}$. The flux predicted by ANN for new enzyme balances from the section "Flux prediction using ANN" was compared with the simulated flux for each enzyme (Figure 8). Figure 8 shows that the balances that were predicted with higher flux through GC-ANN were also estimated to have higher flux using the kinetic model. This validates the good quality of the kinetic model.

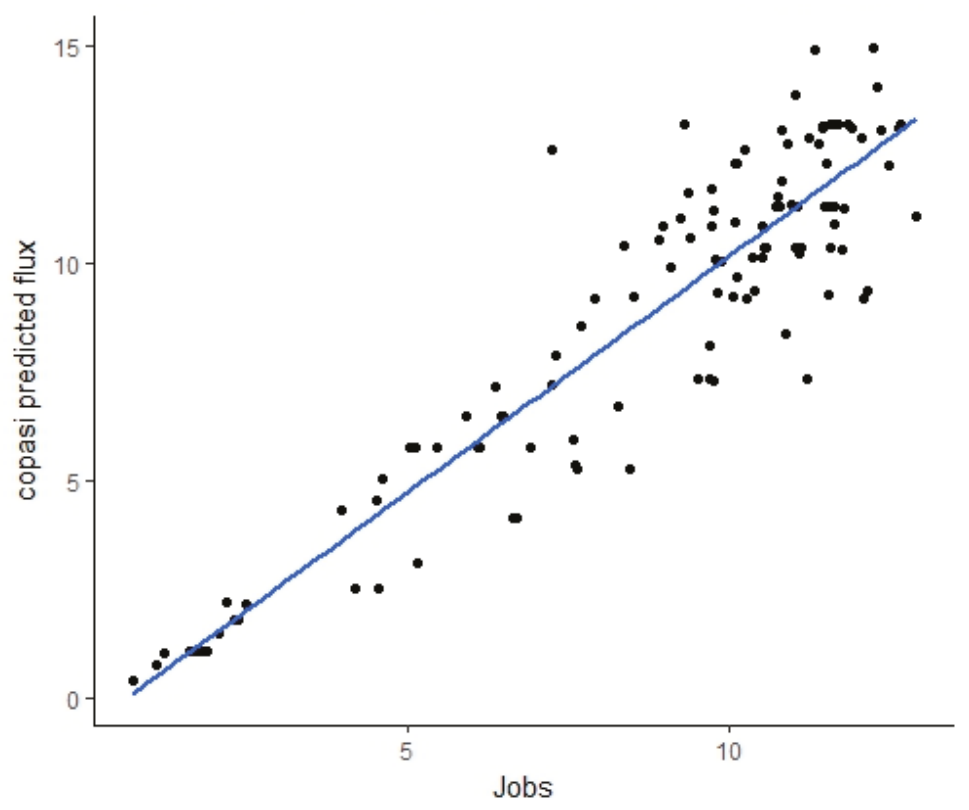

Figure 7. Relationship between experimental flux (Jievet $)$ estimated by Fievet et al. [43] and COPASI [58] estimated by the kinetic model.

\subsubsection{Experimental Validation of the Methodology}

To validate this new approach to exploring the glass-ceiling (GC-ANN), the new enzyme balances generated were assayed in vitro. For the control experiment, 10 enzyme balances from previously used Fievet et al. [43] enzyme concentrations (Figure 9) were selected (Figure 10; Table S1). These selected balances have a correlation $\mathrm{R}^{2}$ of 0.99 and an RMSE of 0.17 between the predicted flux from our kinetic model and the experimental flux assessed by Fievet et al. [43]. Figure 9 shows that balances selected for the control study are an appropriate choice. Two of these selected Fievet's balances were tested experimentally. The resulting fluxes for these two balances were $0.59( \pm 0.10) \mu \mathrm{M} / \mathrm{s}$ and 8.03 $( \pm 0.56) \mu \mathrm{M} / \mathrm{s}$ (see Table S2 in the Supporting Information) while Fievet et al. had determined 1.22 $( \pm 0.08) \mu \mathrm{M} / \mathrm{s}$ and $11.05( \pm 0.29) \mu \mathrm{M} / \mathrm{s}$, respectively. 

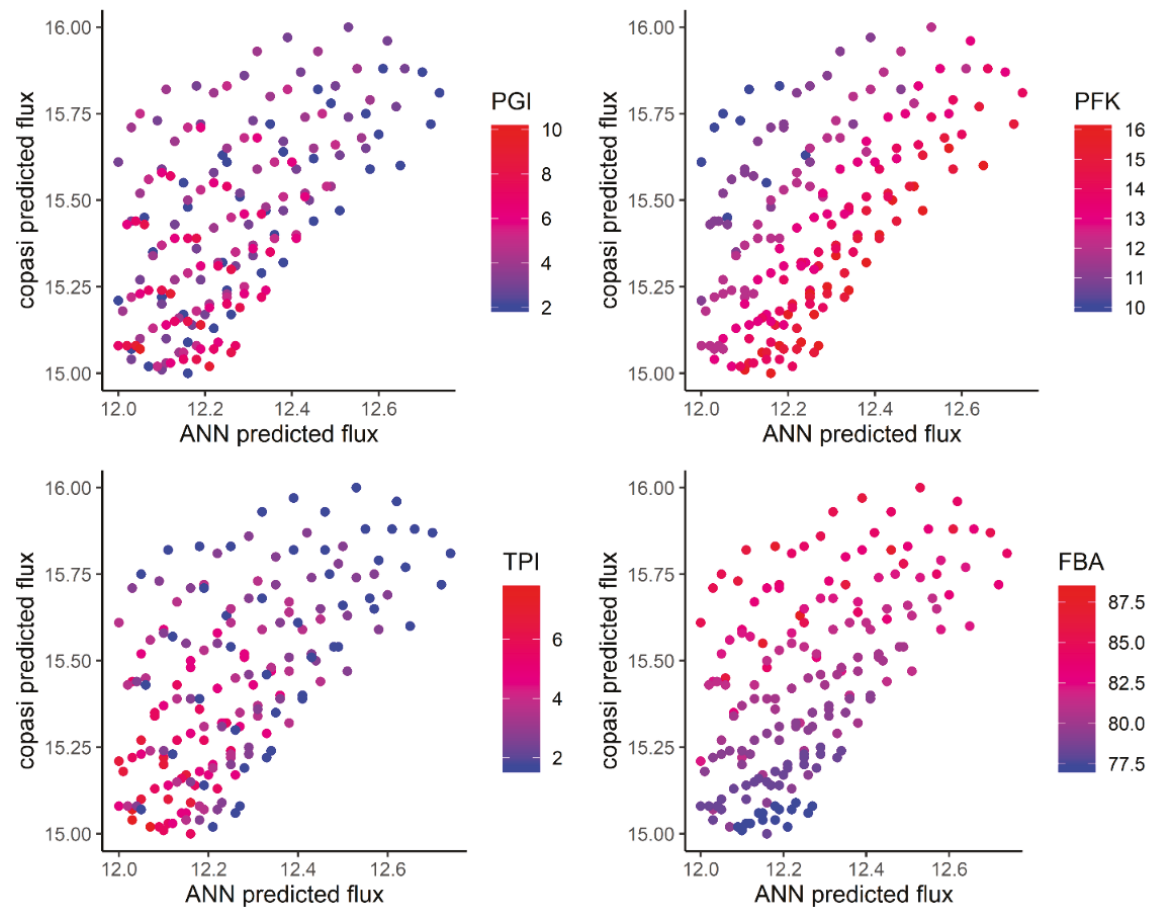

Figure 8. The relationship between flux values predicted by ANN vs COPASI for newly generated enzyme balances. The enzymes considered are: upper, left (PGI), right (PFK), lower left (TPI), right (FBA). The color gradient from blue to red represents the particular enzyme concentration from low to high, respectively.

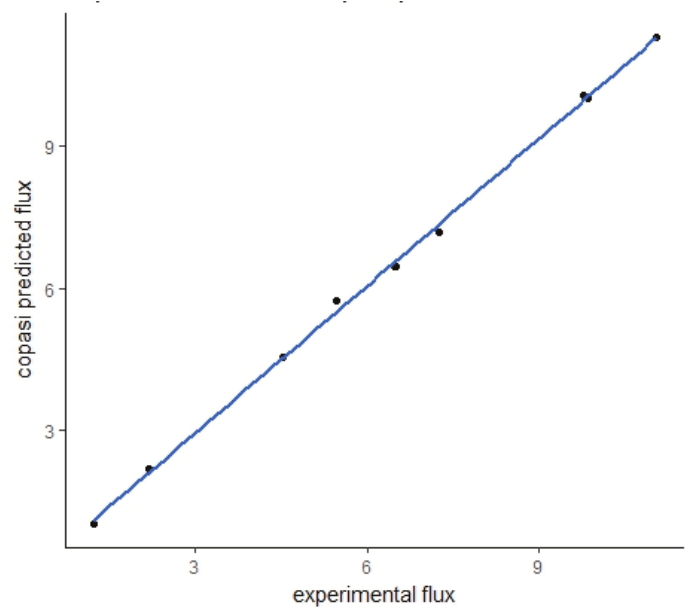

Figure 9. Correlation between Fievet et al. [43] experimental flux and Copasi predicted flux. The balances corresponding to these flux values are selected as experimental control. 


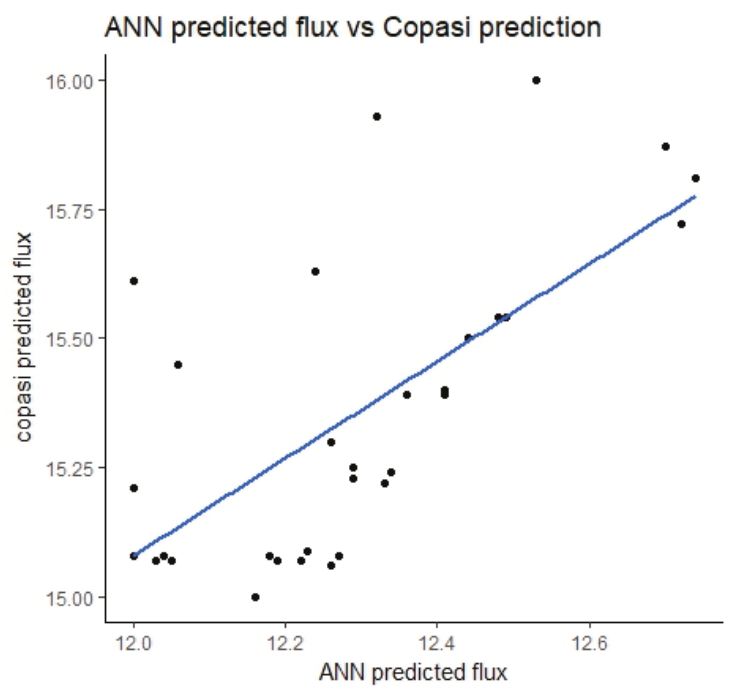

Figure 10. Comparison between glass ceiling ANN (GC-ANN) predicted flux and simulated flux. The enzyme balance corresponding to these flux values are selected for experimental validation of the methodology.

From the GC-ANN approach, 31 new balances were selected (Figure 10; Table S1) for experimental validation. The flux values associated with the selected balances had a coefficient of determination $\mathrm{R}^{2}$ of 0.44 , between GC-ANN predictions and simulated flux. This low $\mathrm{R}^{2}$ between ANN and Copasi prediction is due to the glass-ceiling effect: the underestimation of the flux due to the inability to obtain "out-of-the-box" values for the ANN was expected.

Enzyme Assays for Measurement of Kinetic Parameters

HK activity was assessed using glucose-6-phosphate dehydrogenase (G6PDH) in a coupled reaction. The substrate glucose was converted to 6-phosphogluconate, the formation of NADPH was followed spectrophotometrically at $340 \mathrm{~nm}$ (Figure 11A).

We assessed the activities of PGI, PFK and FBA using a coupled NADH assay applied to the upper part of glycolysis (Figure 11B). To determine the activity of PGI, we started the assay with glucose-6-P (Figure 11B, reaction 1); for the measurement of the activities of PFK and FBA, fructose 6-P and fructose 1,6-bisP were used as the substrates (Figure 11B, reactions 2 and 3). All reactions were monitored by reading the absorbance of NADH at $340 \mathrm{~nm}$ and the initial rates were used to calculate the Michaelis constant $K_{m}$ and the maximal velocity $V_{\max }$. The kinetic parameters $K_{m}$ for HK, PGI, PFK and FBA corresponded well to the values listed by the manufacturer (Sigma) or by the Enzyme Database Brenda (Table 2). Nevertheless, some enzymes, particularly HK and FBA, showed lower specific activity compared to the Sigma reference. The loss of activity could have occurred during delivery and/or storage of the enzymes or could be attributed to a different enzyme assay. 

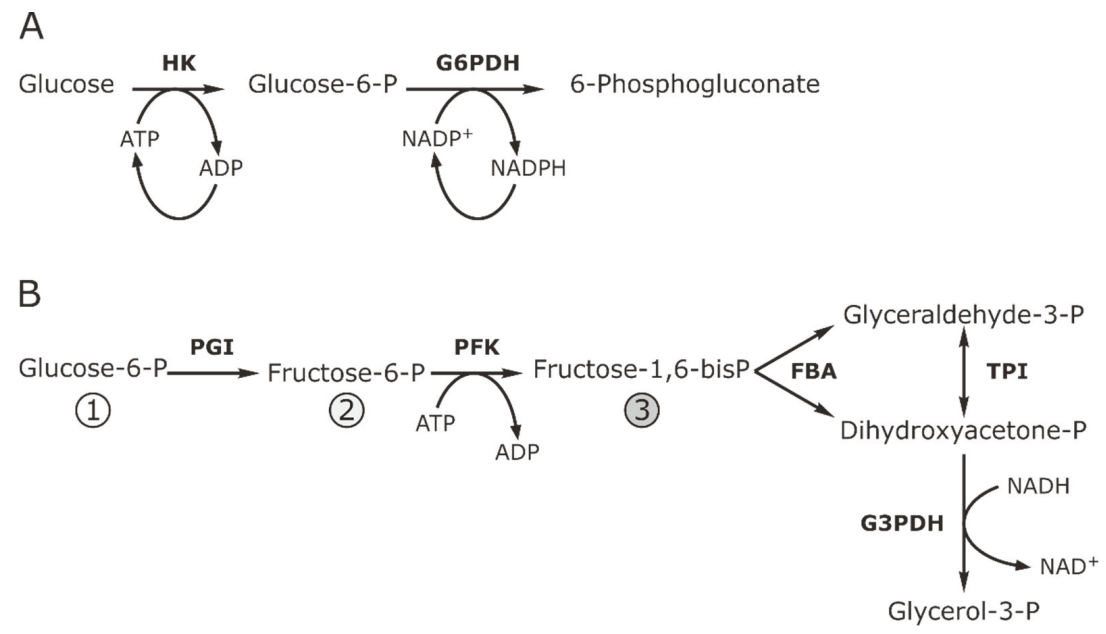

Figure 11. (A) Coupled HK/G6PDH assay to assess the HK activity. (B) Coupled NADH assay to assess the activities of PGI, PFK, and FBA. The individual reactions were started with substrates indicated by the numbers in circles.

Table 2. Summary of the kinetic parameters of HK, PGI, PFK, and FBA. The experimentally assessed values were deduced from Lineweaver-Burk and Eadie-Hofstee plots. Reference values for $\mathrm{K}_{\mathrm{m}}$ and $\mathrm{V}_{\max }$ from Brenda and Sigma's product data sheets are indicated, respectively. Lot No., lot number; $\mathrm{sp}$. act., specific activity.

\begin{tabular}{|c|c|c|c|c|c|c|c|c|c|c|}
\hline \multirow[b]{2}{*}{ Enzyme } & \multirow[b]{2}{*}{ Lot No. } & \multicolumn{2}{|c|}{ Reference This } & \multirow{2}{*}{$\begin{array}{c}\begin{array}{c}\text { Reference } \\
\text { Brenda }\end{array} \\
\mathrm{K}_{\mathrm{m}}(\mathrm{mM}) \\
\end{array}$} & \multicolumn{3}{|c|}{ Lineweaver-Burk * } & \multicolumn{3}{|c|}{ Eadie-Hofstee * } \\
\hline & & $\begin{array}{l}\text { sp. act. } \\
\text { (U/mg) }\end{array}$ & $\begin{array}{l}\text { sp. act. } \\
\text { (U/mg) }\end{array}$ & & $\begin{array}{c}\mathrm{K}_{\mathrm{m}} \\
(\mathrm{mM})\end{array}$ & $\begin{array}{l}\mathrm{V}_{\max } \\
(\mathrm{U} / \mathrm{mL})\end{array}$ & $\begin{array}{l}\mathrm{k}_{\mathrm{cat}} \\
\mathrm{s}^{-1}\end{array}$ & $\begin{array}{c}\mathrm{K}_{\mathrm{m}} \\
(\mathrm{mM})\end{array}$ & $\begin{array}{c}V_{\max } \\
(\mathrm{U} / \mathrm{mL})\end{array}$ & $\begin{array}{l}\mathrm{k}_{\mathrm{cat}} \\
\mathrm{s}^{-1}\end{array}$ \\
\hline HK & SLBT5451 & 472 & 163 & $0.12-0.5[59]$ & 0.28 & 225.5 & 299 & 0.30 & 248.7 & 330 \\
\hline PGI & SLBW8689 & 9618 & 556 & $0.084-1.5[60]$ & 1.1 & 7409 & 1107 & 0.9 & 7685 & 1147 \\
\hline PFK & SLBW6641 & 172 & 73 & $0.023-0.15[61]$ & 0.13 & 196 & 166 & 0.11 & 206 & 175 \\
\hline \multirow{2}{*}{ FBA } & SLBR7752V & V 11.5 & 6.4 & $0.00084-2[62]$ & 0.14 & 19.6 & 17 & 0.12 & 18.7 & 16 \\
\hline & SLBV7445 & 12.4 & 10 & $0.00084-2[62]$ & n.d. & n.d. & n.d. & n.d. & n.d. & n.d. \\
\hline
\end{tabular}

\section{Flux Determinations}

The reaction mixtures for the measurements of the flux through the upper part of glycolysis were based on Fievet et al. [43] (Table 3). In contrast to Fievet et al., we based our mixtures on relative enzyme activities rather than enzyme concentrations. Calculations are explained in Method S1, in the Supplementary Materials. 
Table 3. Comparison of ANN predicted flux ( $\mathrm{J}_{\mathrm{ANN}}$ in $\left.\mu \mathrm{M} / \mathrm{s}\right)$, simulated flux ( $\mathrm{J}_{\text {Copasi }}$ in $\mu \mathrm{M} / \mathrm{s}$ ) and experimentally assessed flux ( $\mathrm{J}_{\operatorname{Exp}}$ in $\mu \mathrm{M} / \mathrm{s}$ ). The four enzymes PGI, PFK, FBA and TPI were used at the indicated concentrations for the experimental assessment of the flux with mean deviation (M.D) of triplicates.

\begin{tabular}{ccccccccc}
\hline \multirow{2}{*}{ Index } & \multicolumn{7}{c}{ U/mL } & \multicolumn{5}{c}{$\mu \mathrm{M} / \mathbf{s}$} \\
\cline { 2 - 8 } & PGI & PFK & FBA & TPI & J ANN & JCopasi & JExp & M.D \\
\hline 11 & 2.74 & 0.7 & 3.71 & 24.39 & 12.24 & 15.63 & 15.7 & 2.5 \\
12 & 2.74 & 0.7 & 3.62 & 53.77 & 12.06 & 15.45 & 16.3 & 2.7 \\
13 & 2.74 & 0.77 & 3.45 & 97.84 & 12 & 15.21 & 12.1 & 4.2 \\
14 & 2.74 & 0.84 & 3.37 & 112.53 & 12.03 & 15.07 & 16.6 & 0.1 \\
15 & 2.74 & 0.91 & 3.58 & 24.39 & 12.7 & 15.87 & 13.9 & 3.9 \\
16 & 2.74 & 0.98 & 3.54 & 24.39 & 12.74 & 15.81 & 18.3 & 1.2 \\
17 & 2.74 & 1.05 & 3.50 & 24.39 & 12.72 & 15.72 & 17.1 & 0.2 \\
18 & 2.74 & 1.12 & 3.29 & 83.15 & 12.16 & 15 & 20.1 & 0.3 \\
19 & 4.11 & 0.7 & 3.58 & 53.77 & 12 & 15.61 & 14.4 & 0.1 \\
20 & 4.11 & 0.84 & 3.58 & 24.39 & 12.53 & 16 & 15.8 & 0.2 \\
21 & 4.11 & 1.12 & 3.37 & 39.08 & 12.44 & 15.5 & 20.6 & 0.2 \\
22 & 5.48 & 0.77 & 3.58 & 24.39 & 12.32 & 15.93 & 15.4 & 0.2 \\
23 & 5.48 & 1.12 & 3.37 & 24.39 & 12.49 & 15.54 & 16.1 & 2.3 \\
24 & 5.48 & 1.12 & 3.33 & 39.08 & 12.36 & 15.39 & 19.3 & 0.6 \\
25 & 6.85 & 1.05 & 3.37 & 24.39 & 12.48 & 15.54 & 18.5 & 0.6 \\
26 & 6.85 & 1.12 & 3.33 & 24.39 & 12.41 & 15.4 & 17.8 & 0.1 \\
27 & 6.85 & 1.12 & 3.29 & 39.08 & 12.29 & 15.25 & 16.3 & 0.3 \\
28 & 6.85 & 1.12 & 3.24 & 53.77 & 12.18 & 15.08 & 19.7 & 2.5 \\
29 & 8.22 & 1.05 & 3.33 & 24.39 & 12.41 & 15.39 & 17.8 & 1 \\
30 & 8.22 & 1.05 & 3.29 & 39.08 & 12.29 & 15.23 & 19 & 0.6 \\
31 & 8.22 & 1.05 & 3.24 & 53.77 & 12.19 & 15.07 & 21 & 0.6 \\
32 & 8.22 & 1.12 & 3.29 & 24.39 & 12.34 & 15.24 & 15.6 & 3.1 \\
33 & 8.22 & 1.12 & 3.24 & 39.08 & 12.23 & 15.09 & 17.8 & 2.2 \\
34 & 9.59 & 0.84 & 3.29 & 68.46 & 12 & 15.08 & 17.1 & 0.7 \\
35 & 9.59 & 1.05 & 3.29 & 24.39 & 12.33 & 15.22 & 17.7 & 1 \\
36 & 9.59 & 1.05 & 3.24 & 39.08 & 12.22 & 15.07 & 18.8 & 1.8 \\
37 & 9.59 & 1.12 & 3.24 & 24.39 & 12.27 & 15.08 & 20.4 & 0.6 \\
38 & 10.96 & 0.91 & 3.33 & 24.39 & 12.26 & 15.3 & 15.9 & 0.9 \\
39 & 10.96 & 1.05 & 3.24 & 24.39 & 12.26 & 15.06 & 17.9 & 0.8 \\
40 & 12.33 & 0.84 & 3.29 & 39.08 & 12.04 & 15.08 & 15.8 & 0.9 \\
41 & 13.7 & 0.84 & 3.29 & 24.39 & 12.05 & 15.07 & 13.6 & 2.4 \\
\hline
\end{tabular}

Out of 41 selected balances, 31 newly predicted enzyme concentrations were tested experimentally to estimate flux. All 31 new enzyme balances experimentally tested were estimated with flux values greater than $12 \mu \mathrm{M} / \mathrm{s}$ (Table 3). Table 3 shows that 28 out of 31, i.e., $90.3 \%$, had a value above $15.0 \mu \mathrm{M} / \mathrm{s}$, as expected according to the kinetic model. Moreover, 31 out of 31 , i.e., $100 \%$, had a value above $12.0 \mu \mathrm{M} / \mathrm{s}$, as expected according to our methodology.

\subsection{Application: Selection of Cost-Efficient Enzyme Balances}

For industrial-scale production, the selection of best enzyme concentrations in terms of cost is essential. Therefore, we estimated the cost per $\mu \mathrm{M}$ of NADH consumed per second for all the enzyme balances generated (Figure 12) and for those selected balances from ANN prediction that obey the enzyme concentration rule (flux greater than $12 \mu \mathrm{M} / \mathrm{s}$ ), i.e., 335 balances from the section "Flux prediction using ANN" (Figure 13). The calculations were described in Method S2 in the Supplementary Materials. The cost calculation for each reaction observed in the selection of enzymes could help to reduce cost. Figures 12 and 13 show the variation in cost according to each balance and its flux and allow the selection of balances with higher flux at low cost. 


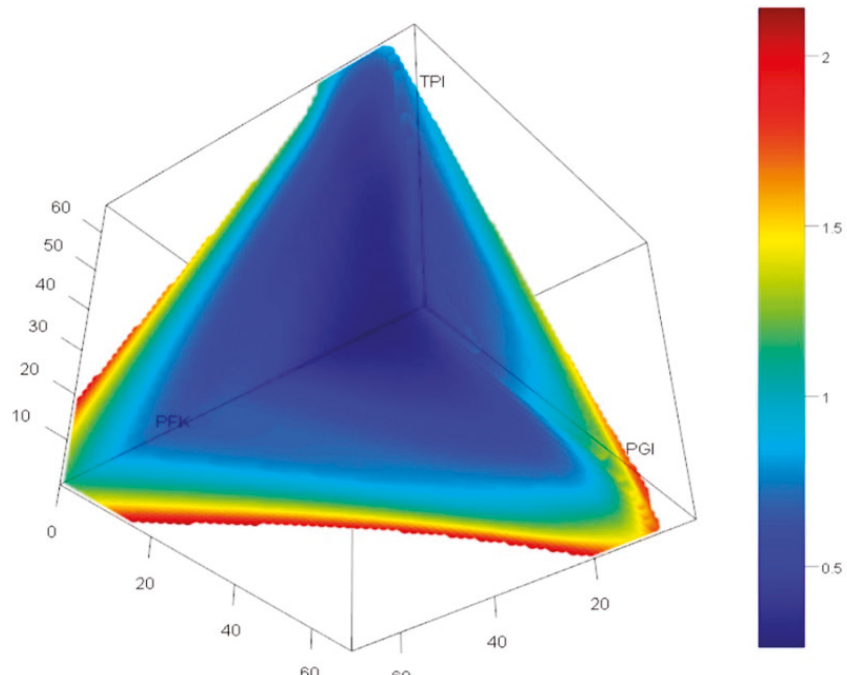

Figure 12. 3D-representation of cost estimated for all the enzyme concentrations generated. The color gradient is according to the cost required for each balance: blue is the lowest and red is the highest cost for a selected balance of the four enzymes PGI, PFK, FBA and TPI.
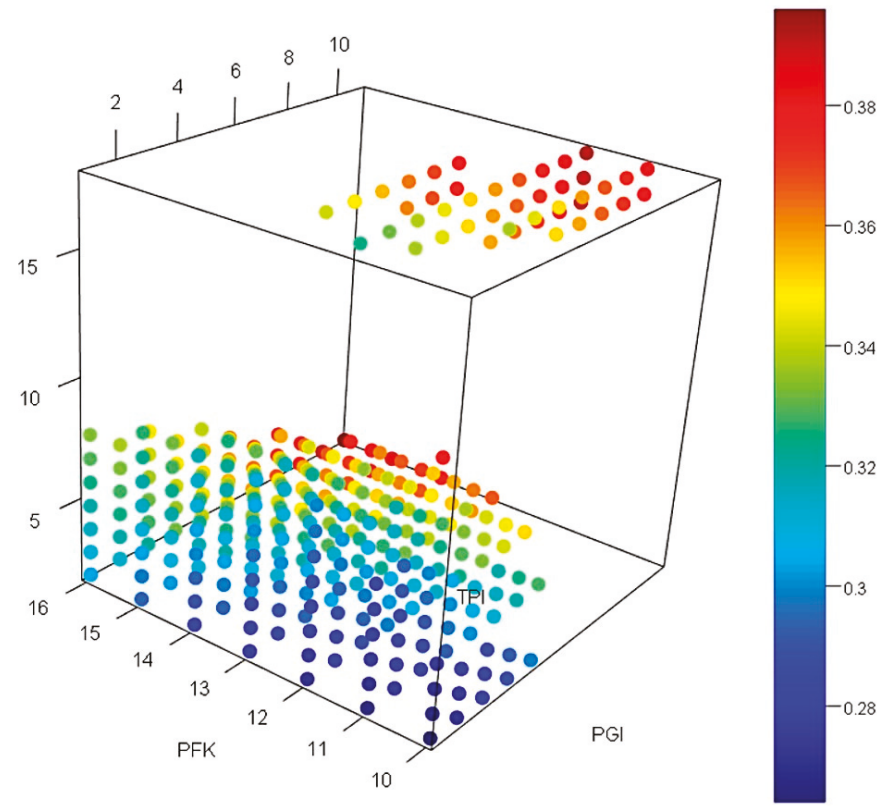

Figure 13. 3D-representation of the cost estimated for the enzyme concentration that obeys the rule obtained for higher flux values. The color gradient is according to the cost required for each balance, blue is the lowest and red is the highest cost for a selected balance of the four enzymes PGI, PFK, FBA and TPI. 
As an example: the enzyme balance (in $\mathrm{mg} / \mathrm{L}$ ) with $\mathrm{PGI}=2, \mathrm{PFK}=12, \mathrm{FBA}=81.24$ and $\mathrm{TPI}=4.66$ (index 13 in Table S6 of the Supporting Information) could give a flux of $12.1 \mu \mathrm{M} / \mathrm{s}$ with a cost of 3.79 EUR.

\section{Discussion}

Traditionally, chemical molecules are synthesized by the chemical reaction of petroleum-based products. Due to the depletion of petroleum products, in-vivo biosynthesis has gained a lot of attention. Limitations of the cellular production system, such as low productivity, by-product formation, and low host cell tolerance to toxins moved the focus towards development of cell-free systems. Compared to cell systems, cell-free systems have high productivity and high toxin tolerance [22]. The selection of optimal enzyme concentrations for maximal productivity is a crucial step for industrial scale, cell-free production of biomolecules. The modeling of metabolic pathways helps to study and predict the behavior of the biological system. Constraint-based methods facilitate the understanding of the system but do not provide information about the concentration of the individual metabolites. In contrast, kinetic models provide information about individual metabolite concentrations but require kinetic parameters of enzymes, which are tedious and expensive to determine [32]. Design of experiment (DOE) is a systematic approach to optimize the conditions for biomolecule production in the field of biotechnology [63]. In DOE, multiple variables are studied to find the correlation between the variables and the final outcome. The main objective of DOE is to reduce the number of experiments, time and cost; our study has the same objective. The benefit of GC-ANN is that the objective optimum can be "out-of-the-box" but will nevertheless be found without additional experiments.

\subsection{GC-ANN Approach Could be Used to Predict "Out-of-the-Box" Values}

In this study, a new methodology, GC-ANN, to select the optimum enzyme balances for industrial biotechnology is devised. This approach aims to see beyond the "glass ceiling", using an artificial neural network and different statistical methods like PCA and data classification. The method was designed and validated for the upper part of glycolysis but could be applied to any other natural or reconstituted biosynthesis pathway.

The workflow of the methodology used in the upper part of glycolysis is summarized in Figure 2. In the first step, for selecting the optimum concentrations of the four relevant enzymes PGI, PFK, FBA and TPI, a rule was devised for high flux values (supported by Figures 3-5). We generated all possible balances using a step of $1 \mathrm{mg} / \mathrm{L}$ in terms of variation for each enzyme concentration. The balances newly generated in the present study have higher and lower limits than those in Fievet et al. [43]. These new enzyme balances were used to predict the flux through the upper glycolysis using ANN, and the predicted fluxes were depicted in 3D representation (Figure 6); we observed a zone (Figure 6, brown zone) with predicted flux $>12 \mu \mathrm{M} / \mathrm{s}$. To explore this space in order to obtain even higher fluxes, the high-flux-rule was applied, i.e., $10<$ PFK $<16$; PGI $<11$; TPI $<18$; $59<$ FBA (in mg/L), and 335 enzyme balances were scrutinized. The main idea behind our approach is based on the fact that: $i$. ANN is known to be a good tool for predicting class and/or quantitative values inside the box (i.e., prediction close to training data), $i i$. the brown region in Figure 6 contains values that are all very close to $12 \mu \mathrm{M} / \mathrm{s}$ (from 12 to $12.9 \mu \mathrm{M} / \mathrm{s}$ ) because $\mathrm{ANN}$ is not useful for extrapolation and new predictions remain inside the box; and iii. we postulate that among these flux values, in fact, some could be higher than predicted.

In the second step, to validate our hypothesis we conducted in silico and in vitro experiments.

\subsubsection{In-Silico Validation}

Due to the availability of kinetic parameters, to avoid unnecessary expenses linked to in vitro assays:

First, we built a kinetic model. Figure 7 shows good agreement $\left(R^{2}=0.84\right)$ between the fluxes predicted by the kinetic model and all the flux values experimentally assessed by Fievet et al. [41]. Then, we selected 10 balances associated with experimental values between 0.74 and $12.9 \mu \mathrm{M} / \mathrm{s}$ of 
Fievet's data for the benchmark study. Figure 9 shows excellent correlation with $\mathrm{R}^{2}$ of 0.99 and an RMSE of 0.17 between the predicted flux from our kinetic model and the experimental flux assessed by Fievet et al. Taken together, these first results were a good validation of our kinetic model.

Second, we intended to validate our in vitro assay by reproducing the results obtained by Fievet et al. [43]. We decided to carry out in vitro experiments for the balances that had a good correlation between simulated and experimental flux. The experimentally determined fluxes using the balances selected from the Fievet data were lower than those previously determined by these authors (Table S3). Nevertheless, the fold-increase was comparable (approximately 9-fold, this study vs. 13-fold, Fievet et al. [43]). The deviation of the absolute flux values could be attributed to experimental settings, i.e., NADH depletion assay in cuvettes at $390 \mathrm{~nm}$ (Fievet et al. [43]) vs. in 96 well plates at $365 \mathrm{~nm}$, in this study; or to differences in the assays performed to measure kinetic parameters of the individual enzymes.

Finally, as our kinetic model has been validated, we used it to conduct the first verification, in silico, of our hypothesis. For 31 new balances selected according to the methodology described above (Section 3.3.2), Figure 10 shows how flux values predicted by the kinetic model fit with the simulated values. All the balances selected from the brown zone (Figure 6) were indeed superior to $12.0 \mu \mathrm{M} / \mathrm{s}$. Moreover, the flux should be above $15.0 \mu \mathrm{M} / \mathrm{s}$. So, this is a first, in silico, validation of our hypothesis, i.e., the ANN-based approach could be used to predict "out-of-the-box" values.

At this point, we had to keep in mind that this preliminary verification was conducted because the kinetic model was possible to establish, but this step is not mandatory in the proposed methodology. Indeed, the 31 balances were chosen first, based only on the outcome of GC-ANN methodology that combines ANN and different statistical methods like PCA and data classification.

\subsubsection{In Vitro Validation}

The 31 new enzyme balances were assessed experimentally. Table 3 proves our hypothesis: with careful selection of enzyme concentrations from the glass ceiling, it is possible to obtain higher flux values. For the 27 best enzyme balances, the improvement of flux ranged from $20 \%$ (observed flux: 15.4, original flux: 12.9 ) to $63 \%$ (observed flux: 21.0 , original flux: 12.9 ). This clearly demonstrates that exploring the predicted values, which hit the "glass ceiling" using the GC-ANN approach is a good way to select the optimum enzyme concentration.

Since artificial neural networks do not require much information regarding experimental conditions, and particularly, in our case, kinetic parameters hard to obtain, they are easy to apply in different fields of science. Our GC-ANN approach could be applied to any pathway provided the experimental data are available. Currently, we are looking for other experimental datasets to which this methodology can be applied.

\subsection{The Proposed Methodology Is Cost-Efficient}

From an industrial perspective, production costs per quantity of product are very important. Choosing an enzyme balance that results in maximum flux at a very low cost per given quantity of product is essential. The ANN-based methodology makes it easy to estimate the total cost. The approximate price for each reaction was calculated using the details provided by the manufacturer, such as specific activity and units of enzyme in the sample. We could calculate the approximate cost required for $1 \mu \mathrm{M}$ of product formation per second through the pathway. This would help us to decide which is the most suitable enzyme balance for maximum flux in terms of cost minimization, which is important for industrial-scale production. For example, to obtain a flux of $12.1 \mu \mathrm{M} / \mathrm{s}$, the approximate cost should be 6.28 EUR, whereas we could achieve the same flux value with a cheaper rate of 3.79 EUR $(40 \%)$. Figure 12 clearly shows how costs vary. Details are provided in Table S6 and Figure S1. Among the enzyme combinations selected for the validation of our methodology, $\mathrm{PGI}=3, \mathrm{PFK}=16$, FBA $=80.24$ and TPI $=2.66(\mathrm{mg} / \mathrm{L})$ had an estimated flux value of $20.6 \mu \mathrm{M} / \mathrm{s}$ with the lowest cost of 0.197 EUR per $\mu \mathrm{M}$ of NADH consumed per second using GC-ANN methodology for the selection of 
enzyme balances (Figure S2). In contrast, the lowest price in Fievet et al. [43] with the selected balance PGI $=7, \mathrm{PFK}=12, \mathrm{FBA}=66.23$ and TPI $=16.66(\mathrm{mg} / \mathrm{L})$ was $0.349 \mathrm{EUR}$ per $\mu \mathrm{M} / \mathrm{s}$ with an experimentally estimated flux value of $12.35 \mu \mathrm{M} / \mathrm{s}$ (Figure S2). This method, therefore, makes it possible to identify the production costs of $1 \mu \mathrm{M}$ of product from 0.197 to $6.28 €$ in order to choose the best compromise between the cost and speed of the reaction.

Lastly and interestingly, the validated kinetic model makes it possible to generate a huge amount of data so as to feed our ANN-based model with more flux values from the newly predicted enzyme balances. This should be explored in future studies.

\section{Materials and Methods}

All enzymes as well as phosphocreatine, glucose-6-phosphate, fructose-6-phosphate and fructose-1,6-bisphosphate were purchased from Sigma-Aldrich (St. Louis, MO, USA). D-Glucose, ATP, NADH, and NADP were obtained from Carl Roth GmbH (Karlsruhe, Germany). Hexokinase (HK), phosphoglucoisomerase (PGI), triose-phosphate isomerase (TPI), and glucose-6-phosphate dehydrogenase (G6PDH) originated from baker's yeast; fructose biphosphate aldolase (FBA), glycerol-3-phosphate dehydrogenase (G3PDH), and creatine kinase (CK) were obtained from rabbit muscle and phosphofructokinase (PFK) originated from Bacillus stearothermophilus. The enzymes were obtained as lyophilized powder except for PGI and TPI, which were ammonium sulphate suspensions. Detailed information on the enzymes used is provided in Table S1 of Supplementary Materials.

\subsection{Determination of Protein Concentration}

Protein concentrations were determined using the Bradford protein assay [64] from Bio-Rad Laboratories (Hercules, CA). Of the protein solutions $10 \mu \mathrm{L}$ was mixed with $200 \mu \mathrm{L}$ of Bio-Rad Protein Assay Dye Reagent, incubated for 5 minutes at room temperature, and the absorbance was measured spectrophotometrically at $595 \mathrm{~nm}$. A dilution series of $0.06-0.5 \mathrm{mg} / \mathrm{mL}$ BSA (Carl Roth GmbH) was used for calibration.

\subsection{Enzyme Assays for the Determination of Kinetic Parameters}

Enzyme assays were performed in 96-well UV-STAR®microplates (Greiner Bio-One GmbH, Kremsmünster, Austria) in a total volume of $100 \mu \mathrm{L}$ at $25^{\circ} \mathrm{C}$. The reaction buffer contained $50 \mathrm{mM}$ PIPES (pH 7.5), $100 \mathrm{mM} \mathrm{KCl}$, and $5 \mathrm{mM}$ magnesium acetate. The cofactors for the reactions were $1 \mathrm{mM}$ ATP and $1 \mathrm{mM}$ NADH or NADP.

HK activity was measured with $0.05 \mathrm{U} \mathrm{HK}, 2.5 \mathrm{U}$ G6PDH, and glucose concentrations from 10 to $0.01 \mathrm{mM}$. PGI activity was measured with 0.02-0.01 U PGI, 1-0.5 U PFK, 0.5 U FBA, 2 U G3PDH, 5 U TPI, and glucose 6-phosphate concentrations ranging from 30 to $0.03 \mathrm{mM}$. PFK activity was measured with $0.02 \mathrm{U}$ PFK, $0.5 \mathrm{U}$ FBA, $2 \mathrm{U}$ G3PDH, 5 U TPI, and fructose 6-phosphate concentrations from 10 to $0.01 \mathrm{mM}$. FBA activity was measured with $0.01-0.05 \mathrm{U}$ FBA, $2 \mathrm{U}$ G3PDH, $5 \mathrm{U}$ TPI, and fructose 1,6-phosphate concentrations from 10 to $0.01 \mathrm{mM}$. All reactions were monitored by recording the absorption at a wavelength of $340 \mathrm{~nm}$ (molar extinction coefficient $\varepsilon_{340 \mathrm{~nm}, 25^{\circ} \mathrm{C}} 6.22 \mathrm{~L} \mathrm{mmol}^{-1} \mathrm{~cm}^{-1}$ ). For calculation of the kinetic parameters $\mathrm{V}_{\max }, \mathrm{K}_{\mathrm{m}}$, and $\mathrm{k}_{\text {cat }}$ we used Lineweaver-Burk as well as Eadie-Hofstee representations.

\subsection{Flux Measurements}

The total reaction volume of $100 \mu \mathrm{L}$ contained fixed concentrations of $3 \mathrm{mM} \mathrm{NADH}, 20 \mathrm{mM}$ phosphocreatine, $1 \mu \mathrm{MCK}, 0.1 \mu \mathrm{M}$ HK, and $1 \mu \mathrm{M}$ G3PDH. The concentrations of PGI, PFK, FBA, and TPI were varied as indicated (Section 3.3.2). The reactions were started with $1 \mathrm{mM}$ ATP and $100 \mathrm{mM}$ glucose. Blank reactions contained all ingredients except ATP and glucose. Each condition was measured in triplicates. The NADH decay was monitored every $3 \mathrm{~s}$ at $365 \mathrm{~nm}$ using a SynergyMxSMATBLD(+) Gen5 SW plater reader (SZABO-SCANDIC, Vienna, Austria). The slope of NADH decay was measured as the flux through the pathway (molar extinction coefficient $\varepsilon_{365 \mathrm{~nm}, 25^{\circ} \mathrm{C}} 3.4 \mathrm{~L} \mathrm{mmol}^{-1} \mathrm{~cm}^{-1}$ ). 


\section{Conclusions}

The selection of enzymes is an important step in the production of biomolecules. Methods based on homology are widely used to select the best performing enzymes. In addition, the selection of optimum enzyme balances is also crucial. Most methods use kinetic information for concentration selection via modeling. However, the determination of kinetic parameters is not always easy; therefore, developing new methodologies for selecting the optimum enzyme balances is of great interest.

In this study, we developed a new approach, GC-ANN, which uses an artificial neural network along with different statistical methods (PCA and data classification) to select enzyme balances that improve the flux as well as the costs. The selected balances might not be the balances with the highest flux, but they would be among the best. This approach allows cost-efficient selection of enzyme balances using a small existing dataset, and it opens the door for rapid optimization of cell-free systems in an industrial environment.

Supplementary Materials: The following are available online at http://www.mdpi.com/2073-4344/10/3/291/s1, Figure S1: The cost predicted (in EUR) for the four-enzyme concentration (PGI, PFK, FBA, and TPI) selected for experimental validation. The blue is lowest, to highest in red; Figure S2: The cost predicted (in EUR) for the four-enzyme concentration (PGI, PFK, FBA, and TPI) selected by Fievet et al. (2006). The blue is lowest, to highest in red; Table S1: Enzymes used in this study for the upper part of glycolysis. All enzymes were from Sigma; Table S2: The measured enzyme activities for the enzymes involved in the upper part of glycolysis (see also Table 2 in the main text); Table S3: The enzyme concentrations (mg/L) predicted from ANN and in-silico modeling to have higher flux values. For the experimental validation, we used relative concentrations of enzymes obtained as explained in Method S1; Table S4: Specification of enzymes used for the calculation of cost for the preparatory stage of glycolysis from sigma. Specific activities are calculated by Fievet et al; Table S5: Comparison of flux predicted between Fievet et al. selected concentration (JFievet) and new estimation during current work (Jobs); Table S6: The calculated price for the $\mu \mathrm{M}$ of NADH consumed per second by the enzyme concentration selected for the experiment; Methods S1: concentration based on relative activity; Method S2: Cost Calculation.

Author Contributions: F.C., C.D. and P.C. designed the method. A.A.N., P.C., X.F.C., N.F., M.D., B.W., A.V., B.O., C.D., B.G.-P. and F.C. participated in the design of the study and performed the analysis. A.A.N. and M.D. wrote algorithms. A.A.N., P.C., X.F.C., C.D. and F.C. wrote and corrected the manuscript. All authors read and approved the final version of the manuscript.

Funding: AAN is supported by a PhD grant from the Region Reunion and European Union (FEDER) under European operational program INTERRG V-2014-2020, file number 20161449, tiers 234273. We gratefully acknowledge support from: $i$. the Federal Ministry for Digital and Economic Affairs (bmwd), the Federal Ministry for Transport, Innovation and Technology (bmvit), the Styrian Business Promotion Agency SFG, the Standortagentur Tirol, Government of Lower Austria and ZIT-Technology Agency of the City of Vienna through the COMET-Funding Program managed by the Austrian Research Promotion Agency FFG.; ii. Peaccel via a research program co-funded by the European Union (UE) and Region Reunion (FEDER). The funding agencies had no influence on the research process.

Conflicts of Interest: Authors declare no conflict of interest.

Availability of Data and Materials: R-scripts used for the analysis are found at https://github.com/DSIMB/GCANN-Enzyme-Concentration-Selection.

\section{References}

1. Borgia, J.A.; Fields, G.B. Chemical synthesis of proteins. Trends Biotechnol. 2000, 18, 243-251. [CrossRef]

2. Hojo, H. Recent progress in the chemical synthesis of proteins. Curr. Opin. Struct. Biol. 2014, 26, 16-23. [CrossRef]

3. Liu, F.; Zaykov, A.N.; Levy, J.J.; Dimarchi, R.D.; Mayer, J.P. Chemical synthesis of peptides within the insulin superfamily. J. Pept. Sci. 2016, 22, 260-270. [CrossRef] [PubMed]

4. Graf, M.; Mardirossian, M.; Nguyen, F.; Seefeldt, A.C.; Guichard, G.; Scocchi, M.; Innis, C.A.; Wilson, D.N. Proline-rich antimicrobial peptides targeting protein synthesis. Nat. Prod. Rep. 2017, 34, 702-711. [CrossRef] [PubMed]

5. Arora, K.; Program, B.; Arbor, A. Total Synthesis of Glycosylated Proteins Alberto; Springer: Berlin/Heidelberg, Germany, 2015; Volume 200, pp. 165-187.

6. Zhang, Y.H.P. Renewable carbohydrates are a potential high-density hydrogen carrier. Int. J. Hydrogen Energy 2010, 35, 10334-10342. [CrossRef] 
7. Yim, H.; Haselbeck, R.; Niu, W.; Pujol-Baxley, C.; Burgard, A.; Boldt, J.; Khandurina, J.; Trawick, J.D.; Osterhout, R.E.; Stephen, R.; et al. Metabolic engineering of Escherichia coli for direct production of 1,4-butanediol. Nat. Chem. Biol. 2011, 7, 445-452. [CrossRef]

8. Martínez, J.A.; Bolívar, F.; Escalante, A. Shikimic Acid Production in Escherichia coli: From Classical Metabolic Engineering Strategies to Omics Applied to Improve Its Production. Front. Bioeng. Biotechnol. 2015, 3, 1-16. [CrossRef]

9. Lee, J.W.; Na, D.; Park, J.M.; Lee, J.; Choi, S.; Lee, S.Y. Systems metabolic engineering of microorganisms for natural and non-natural chemicals. Nat. Chem. Biol. 2012, 8, 536-546. [CrossRef] [PubMed]

10. Chen, X.; Wang, Y.; Dong, X.; Hu, G.; Liu, L. Engineering rTCA pathway and C4-dicarboxylate transporter for l-malic acid production. Appl. Microbiol. Biotechnol. 2017, 101, 4041-4052. [CrossRef]

11. Stanton, D. Microbial or Mammalian? Biosilta Backs the Former Licensing E. Coli platform. Biopharma Reporter. Available online: https://www.biopharma-reporter.com/Article/2016/04/08/Microbialor-mammalian-BioSilta-licenses-E.-Coli-tech (accessed on 20 February 2020).

12. Theisen, M.; Liao, J.C. Industrial Biotechnology: Escherichia coli as a Host. Ind. Biotechnol. 2016, 1, $149-181$.

13. Zhang, Y.H.P. Substrate channeling and enzyme complexes for biotechnological applications. Biotechnol. Adv. 2011, 29, 715-725. [CrossRef]

14. Wheeldon, I.; Minteer, S.D.; Banta, S.; Barton, S.C.; Atanassov, P.; Sigman, M. Substrate channelling as an approach to cascade reactions. Nat. Chem. 2016, 8, 299-309. [CrossRef]

15. Tan, S.Z.; Prather, K.L. Dynamic pathway regulation: Recent advances and methods of construction. Curr. Opin. Chem. Biol. 2017, 41, 28-35. [CrossRef]

16. Fontaine, N.; Grondin-Perez, B.; Cadet, F.; Offmann, B. Modeling of a Cell-Free Synthetic System for Biohydrogen Production. J. Comput. Sci. Syst. Biol. 2015, 8, 132-139.

17. Ye, X.; Wang, Y.; Hopkins, R.C.; Adams, M.W.W.; Evans, B.R.; Mielenz, J.R.; Zhang, Y.H.P. Spontaneous high-yield production of hydrogen from cellulosic materials and water catalyzed by enzyme cocktails. ChemSusChem 2009, 2, 149-152. [CrossRef]

18. Khattak, W.A.; Ul-Islam, M.; Ullah, M.W.; Yu, B.; Khan, S.; Park, J.K. Yeast cell-free enzyme system for bio-ethanol production at elevated temperatures. Process. Biochem. 2014, 49, 357-364. [CrossRef]

19. Zhang, Y.H.P. Production of biofuels and biochemicals by in vitro synthetic biosystems: Opportunities and challenges. Biotechnol. Adv. 2015, 33, 1467-1483. [CrossRef]

20. Huang, L.; Sheng, J.; Xu, Z.; Zhu, X.; Cai, J. Reconstitution of the peptidoglycan cytoplasmic precursor biosynthetic pathway in cell-free system and rapid screening of antisense oligonucleotides for Mur enzymes. Appl. Microbiol. Biotechnol. 2014, 98, 1785-1794.

21. Yang, J.; Voloshin, A.; Swartz, J.R.; Velkeen, H.; Levy, R.; Michel-Reydellet, N. Rapid expression of vaccine proteins for B-cell lymphoma in a cell-free system. Biotechnol. Bioeng. 2005, 89, 503-511. [CrossRef]

22. Lu, Y. Cell-free synthetic biology: Engineering in an open world. Synth. Syst. Biotechnol. 2017, 2, $23-27$. [CrossRef]

23. Schoborg, J.A.; Hodgman, C.E.; Anderson, M.J.; Jewett, M.C. Substrate replenishment and byproduct removal improve yeast cell-free protein synthesis. Biotechnol. J. 2014, 9, 630-640. [CrossRef]

24. Shrestha, P.; Holland, T.M.; Bundy, B.C. Streamlined extract preparation for Escherichia coli-based cell-free protein synthesis by sonication or bead vortex mixing. Biotechniques 2012, 53, 163-174. [CrossRef]

25. Zhang, Y.-H.P. Production of biocommodities and bioelectricity by cell-free synthetic enzymatic pathway biotransformations: Challenges and opportunities. Biotechnol. Bioeng. 2009, 105, 663-677. [CrossRef]

26. Carbonell, P.; Wong, J.; Swainston, N.; Takano, E.; Turner, N.J.; Scrutton, N.S.; Kell, D.B.; Breitling, R.; Faulon, J.-L. Selenzyme: Enzyme selection tool for pathway design. Bioinformatics 2018, 34, 2153-2154. [CrossRef]

27. Stelling, J. Mathematical models in microbial systems biology. Curr. Opin. Microbiol. 2004, 7, 513-518. [CrossRef]

28. Orth, J.D.; Thiele, I.; Palsson, B.O. What is flux balance analysis? Nat. Biotechnol. 2010, 28, 245-248. [CrossRef]

29. Covert, M.W.; Famili, I.; Palsson, B.O. Identifying Constraints that Govern Cell Behavior: A Key to Converting Conceptual to Computational Models in Biology? Biotechnol. Bioeng. 2003, 84, 763-772. [CrossRef]

30. Smallbone, K.; Simeonidis, E.; Broomhead, D.S.; Kell, D.B. Something from nothing-Bridging the gap between constraint-based and kinetic modelling. FEBS J. 2007, 274, 5576-5585. [CrossRef] 
31. Schmeier, S.; Hakenberg, J.; Klipp, E.; Leser, U.; Kowald, A. Finding Kinetic Parameters Using Text Mining. Omi. A J. Integr. Biol. 2004, 8, 131-152.

32. Bisswanger, H. Enzyme assays. Perspect. Sci. 2014, 1, 41-55. [CrossRef]

33. Teusink, B.; Passarge, J.; Reijenga, C.A.; Esgalhado, E.; van der Weijden, C.C.; Schepper, M.; Walsh, M.C.; Bakker, B.M.; van Dam, K.; Westerhoff, H.V.; et al. Can yeast glycolysis be understood in terms of in vitro kinetics of the constituent enzymes? Testing biochemistry. Eur. J. Biochem. 2000, 267, 5313-5329. [CrossRef] [PubMed]

34. Basheer, I.A.; Hajmeer, M. Artificial neural networks: Fundamentals, computing, design, and application. J. Microbiol. Methods. 2000, 43, 3-31. [CrossRef]

35. Morowvat, M.H.; Ghasemi, Y. Medium optimization by artificial neural networks for maximizing the triglycerides-rich lipids from biomass of Chlorella vulgaris. Int. J. Pharm. Clin. Res. 2016, 8, 1414-1417.

36. Lan, Z.; Zhao, C.; Guo, W.; Guan, X.; Zhang, X. Optimization of culture medium for maximal production of spinosad using an artificial neural network-genetic algorithm modeling. J. Mol. Microbiol. Biotechnol. 2015, 25, 253-261. [CrossRef]

37. Antoniewicz, M.R.; Stephanopoulos, G.; Kelleher, J.K. Evaluation of regression models in metabolic physiology: Predicting fluxes from isotopic data without knowledge of the pathway. Metabolomics 2006, 2, 41-52. [CrossRef]

38. Liu, J.; Li, J.; Shin, H.D.; Liu, L.; Du, G.; Chen, J. Protein and metabolic engineering for the production of organic acids. Bioresour. Technol. 2017, 239, 412-421. [CrossRef]

39. Song, C.W.; Kim, D.I.; Choi, S.; Jang, J.W.; Lee, S.Y. Metabolic engineering of Escherichia coli for the production of fumaric acid. Biotechnol. Bioeng. 2013, 110, 2025-2034. [CrossRef]

40. Yang, J.; Wang, Z.; Zhu, N.; Wang, B.; Chen, T.; Zhao, X. Metabolic engineering of Escherichia coli and in silico comparing of carboxylation pathways for high succinate productivity under aerobic conditions. Microbiol. Res. 2014, 169, 432-440. [CrossRef]

41. Clomburg, J.M.; Gonzalez, R. Biofuel production in Escherichia coli: The role of metabolic engineering and synthetic biology. Appl. Microbiol. Biotechnol. 2010, 86, 419-434. [CrossRef]

42. Yang, X.; Xu, M.; Yang, S.T. Metabolic and process engineering of Clostridium cellulovorans for biofuel production from cellulose. Metab. Eng. 2015, 32, 39-48. [CrossRef]

43. Fiévet, J.B.; Dillmann, C.; Curien, G.; de Vienne, D. Simplified modelling of metabolic pathways for flux prediction and optimization: Lessons from an in vitro reconstruction of the upper part of glycolysis. Biochem. J. 2006, 396, 317-326. [CrossRef]

44. Ajjolli Nagaraja, A.; Fontaine, N.; Delsaut, M.; Charton, P.; Damour, C.; Offmann, B.; Grondin-Perez, B.; Cadet, F. Flux prediction using artificial neural network (ANN) for the upper part of glycolysis. PLoS ONE 2019, 14, 1-15. [CrossRef]

45. Minns, A.W.; Hall, M.J. Artificial neural networks as rainfall- runoff models. Hydrol. Sci. J. 1996, 41, $399-417$. [CrossRef]

46. Balabin, R.M.; Smirnov, S.V. Interpolation and extrapolation problems of multivariate regression in analytical chemistry: Benchmarking the robustness on near-infrared (NIR) spectroscopy data. Analyst 2012, 137, 1604-1610. [CrossRef]

47. Wold, S.; Esbensen, K.; Geladi, P. Principal Component Analysis. Chemom. Intell. Lab. Syst. 1987, 2, 37-52. [CrossRef]

48. Ringnér, M. What is principal component analysis? Nat. Biotechnol. 2008, 26, 303-304. [CrossRef]

49. Le, S.; Josse, J.; Husson, F. FactoMineR: An R Package for Multivariate Analysis. J. Stat. Softw. 2008, 25, 1-18. [CrossRef]

50. Soetaert, K. plot3D: Plotting Multi-Dimensional Data, 2017. Available online: https://CRAN.R-project.org/ package $=$ plot3D (accessed on 2 March 2020).

51. Soetaert, K. plot3Drgl: Plotting Multi-Dimensional Data-Using "rgl". 2016. Available online: https: //CRAN.R-project.org/package=plot3Drgl (accessed on 2 March 2020).

52. Weihs, C.; Ligges, U.; Luebke, K.; Raabe, N. klaR Analyzing German Business Cycles. In Data Analysis and Decision Support; Baier, D., Decker, R., Schmidt-Thieme, L., Eds.; Springer-Verlag: Berlin, Germany, 2005; pp. 335-343.

53. Therneau, T.; Atkinson, B.; Ripley, B. rpart: Recursive Partitioning and Regression Trees. R Package 2018, 4, 1-9. 
54. Günther, F.; Fritsch, S. Neuralnet: Training of Neural Networks. R. J. 2010, 2, 30-38. [CrossRef]

55. Funahashi, A.; Morohashi, M.; Kitano, H.; Tanimura, N. CellDesigner: A process diagram editor for gene-regulatory and biochemical networks. Biosilico 2003, 1, 159-162. [CrossRef]

56. Funahashi, A.; Matsuoka, Y.; Jouraku, A.; Morohashi, M.; Kikuchi, N.; Kitano, H. CellDesigner 3.5: A Versatile Modeling Tool for Biochemical Networks. Proc IEEE. 2008, 96, 1254-1265. [CrossRef]

57. Schomburg, I.; Chang, A.; Schomburg, D. BRENDA, enzyme data and metabolic information. Nucleic. Acids Res. 2002, 30, 47-49. [CrossRef]

58. Lee, C.; Pahle, J.; Singhal, M.; Gauges, R.; Sahle, S.; Mendes, P.; Kummer, U.; Hoops, S. COPASI-a COmplex PAthway SImulator. Bioinformatics 2006, 22, 3067-3074.

59. BRENDA-Information on EC 2.7.1.1-hexokinase. Available online: https://www.brenda-enzymes.org/ enzyme.php?ecno=2.7.1.1 (accessed on 22 May 2019).

60. BRENDA-Information on EC 5.3.1.9-glucose-6-phosphate isomerase. Available online: https://www.brendaenzymes.org/enzyme.php?ecno=5.3.1.9 (accessed on 22 May 2019).

61. BRENDA-Information on EC 2.7.1.11-6-phosphofructokinase. Available online: https://www.brendaenzymes.org/enzyme.php?ecno=2.7.1.11 (accessed on 22 May 2019).

62. BRENDA-Information on EC 4.1.2.13-fructose-bisphosphate aldolase. Available online: https://www.brendaenzymes.org/enzyme.php?ecno=4.1.2.13 (accessed on 22 May 2019).

63. Kumar, V.; Bhalla, A.; Rathore, A.S. Design of experiments applications in bioprocessing: Concepts and approach. Biotechnol. Prog. 2014, 30, 86-99. [CrossRef]

64. Bradford, M.M. A rapid and sensitive method for the quantitation of microgram quantities of protein utilizing the principle of protein-dye binding. Anal. Biochem. 1976, 72, 248-254. [CrossRef]

(C) 2020 by the authors. Licensee MDPI, Basel, Switzerland. This article is an open access article distributed under the terms and conditions of the Creative Commons Attribution (CC BY) license (http://creativecommons.org/licenses/by/4.0/). 
Article

\title{
Immobilization of $\beta$-Galactosidases on the Lactobacillus Cell Surface Using the Peptidoglycan-Binding Motif LysM
}

\author{
Mai-Lan Pham ${ }^{1}$, Anh-Minh Tran ${ }^{1,2}$, Suwapat Kittibunchakul ${ }^{1}$, Tien-Thanh Nguyen ${ }^{3}$, \\ Geir Mathiesen ${ }^{4}$ and Thu-Ha Nguyen ${ }^{1, *}$ \\ 1 Food Biotechnology Laboratory, Department of Food Science and Technology, BOKU-University of Natural \\ Resources and Life Sciences, A-1190 Vienna, Austria; mailanpham.22@gmail.com (M.-L.P.); \\ tranminh1703@gmail.com (A.-M.T.); suwapatkt@gmail.com (S.K.) \\ 2 Department of Biology, Faculty of Fundamental Sciences, Ho Chi Minh City University of Medicine and \\ Pharmacy, 217 Hong Bang, Ho Chi Minh City, Vietnam \\ 3 School of Biotechnology and Food Technology, Hanoi University of Science and Technology, 1 Dai Co Viet, \\ Hanoi, Vietnam; nguyenthanh.ibft@gmail.com \\ 4 Faculty of Chemistry, Biotechnology and Food Science, Norwegian University of Life Sciences (NMBU), \\ N-1432 Ås, Norway; geir.mathiesen@nmbu.no \\ * Correspondence: thu-ha.nguyen@boku.ac.at; Tel.: +43-1-47654-75215; Fax: +43-1-47654-75039
}

Received: 25 April 2019; Accepted: 7 May 2019; Published: 12 May 2019

\begin{abstract}
Lysin motif (LysM) domains are found in many bacterial peptidoglycan hydrolases. They can bind non-covalently to peptidoglycan and have been employed to display heterologous proteins on the bacterial cell surface. In this study, we aimed to use a single LysM domain derived from a putative extracellular transglycosylase Lp_3014 of Lactobacillus plantarum WCFS1 to display two different lactobacillal $\beta$-galactosidases, the heterodimeric LacLM-type from Lactobacillus reuteri and the homodimeric LacZ-type from Lactobacillus delbrueckii subsp. bulgaricus, on the cell surface of different Lactobacillus spp. The $\beta$-galactosidases were fused with the LysM domain and the fusion proteins, LysM-LacLMLreu and LysM-LacZLbul, were successfully expressed in Escherichia coli and subsequently displayed on the cell surface of L. plantarum WCFS1. $\beta$-Galactosidase activities obtained for L. plantarum displaying cells were 179 and $1153 \mathrm{U}$ per g dry cell weight, or the amounts of active surface-anchored $\beta$-galactosidase were 0.99 and $4.61 \mathrm{mg}$ per g dry cell weight for LysM-LacLMLreu and LysM-LacZLbul, respectively. LysM-LacZLbul was also displayed on the cell surface of other Lactobacillus spp. including L. delbrueckii subsp. bulgaricus, L. casei and L. helveticus, however L. plantarum is shown to be the best among Lactobacillus spp. tested for surface display of fusion LysM-LacZLbul, both with respect to the immobilization yield as well as the amount of active surface-anchored enzyme. The immobilized fusion LysM- $\beta$-galactosidases are catalytically efficient and can be reused for several repeated rounds of lactose conversion. This approach, with the $\beta$-galactosidases being displayed on the cell surface of non-genetically modified food-grade organisms, shows potential for applications of these immobilized enzymes in the synthesis of prebiotic galacto-oligosaccharides.
\end{abstract}

Keywords: Lactobacillus; $\beta$-galactosidase; immobilization; cell surface display; LysM domains

\section{Introduction}

$\beta$-Galactosidases catalyze the hydrolysis and transgalactosylation of $\beta$-D-galactopyranosides (such as lactose) [1-3] and are found widespread in nature. They catalyze the cleavage of lactose (or related compounds) in their hydrolysis mode and are thus used in the dairy industry to remove lactose from various products. An attractive biocatalytic application is found in the transgalactosylation 
potential of these enzymes, which is based on their catalytic mechanism [1,4]. $\beta$-Galactosidases can be obtained from different sources including microorganisms, plants and animals, however microbial sources of $\beta$-galactosidase are of great biotechnological interest because of easier handling, higher multiplication rates, and production yield. Recently, a number of studies have focused on the use of the genus Lactobacillus for the production and characterization of $\beta$-galactosidases, including the enzymes from L. reuteri, L. acidophilus, L. helveticus, L. plantarum, L. sakei, L. pentosus, L. bulgaricus, L. fermentum, L. crispatus [5-15]. $\beta$-Galactosidases from Lactobacillus species are different at molecular organization $[6,8,10,12,16]$. The predominant glycoside hydrolase family 2 (GH2) $\beta$-galactosidases found in lactobacilli are of the LacLM type, which are heterodimeric proteins encoded by the two overlapping genes, lacL and lacM, including lacLM from L. reuteri [16], L. acidophilus [6], L. helveticus [7], L. pentosus [11], L. plantarum [8], and L. sakei [10]. Di- or oligomeric GH2 $\beta$-galactosidases of the LacZ type, encoded by the single lacZ gene, are sometimes, but not often found in lactobacilli such as in L. bulgaricus [12]. Lactobacilli have been studied intensively with respect to their enzymes for various different reasons, one of which is their 'generally recognized as safe' (GRAS) status and their safe use in food applications. It is anticipated that galacto-oligosaccharides (GOS) produced by these $\beta$-galactosidases will have better selectivity for growth and metabolic activity of this bacterial genus in the gut.

An economical, sustainable and intelligent use of biocatalysts can be achieved through immobilization, where the enzyme is bound onto a suitable food-grade carrier. Efforts have been made to immobilize $\beta$-galactosidases from L. reuteri, a LacLM-type, and Lactobacillus bulgaricus, a LacZ-type, on chitin using the chitin binding domain (ChBD) of Bacillus circulans WL-12 chitinase A1 [17]. Cell surface display has been shown as a new strategy for enzyme immobilization, which involves the use of food-grade organism L. plantarum both as a cell factory for the production of enzymes useful for food applications and as the carrier for the immobilization of the over-expressed enzyme by anchoring the enzyme on the cell surface $[18,19]$. This enables the direct use of the microbial cells straight after the fermentation step as an immobilized biocatalysts, offering the known advantages of immobilization (reuse of enzyme, stabilization, etc.) together with a significant simplification of the production process since costly downstream processing of the cells producing the enzyme (cell disruption, protein purification, etc.) as well as the use of carrier material will not be necessary. We recently reported cell surface display of mannanolytic and chitinolytic enzymes in L. plantarum using two anchors from L. plantarum, a lipoprotein-anchor derived from the Lp_1261 protein and a cell wall anchor (cwa2) derived from the Lp_2578 protein [19]. However, this approach works less efficient with dimeric and oligomeric enzymes, such as $\beta$-galactosidases from lactobacilli, due to low secretion efficiency of target proteins. Therefore, it is of our interest to find another strategy to display lactobacillal $\beta$-galactosidases on Lactobacillus cell surface for use as immobilized biocatalysts for applications in lactose conversion and GOS formation processes.

There are two principally different ways of anchoring a secreted protein to the bacterial cell wall: covalently, via the sortase pathway, or non-covalently, via a protein domain that interacts strongly with cell wall components. In sortase-mediated anchoring, the secreted protein carries a C-terminal anchor containing the so-called LP $\times$ TG motif followed by a hydrophobic domain and a positively charged tail [20]. The hydrophobic domain and the charged tail keep the protein from being released to the medium, thereby allowing recognition of the LP $\times$ TG motif by a membrane-associated transpeptidase called sortase [20-22]. The sortase cleaves the peptide bond between threonine and glycine in the LP $\times$ TG motif and links the now C-terminal threonine of the surface protein to a pentaglycine in the cell wall [21-25]. One of the non-covalent cell display systems exploits so-called LysM domains, the peptidoglycan binding motifs, that are known to promote cell wall association of several natural proteins $[23,26]$. These domains have been used to display proteins in lactic acid bacteria (LAB) by fusing the LysM domain N- or C-terminally to the target protein [27-30]. In L. plantarum WCFS1 ten proteins are predicted to be displayed at the cell wall through LysM domains [31]. 
In this present study, we exploit a single LysM domain derived from the Lp_3014 protein in L. plantarum WCFS1 for external attachment of two lactobacillal $\beta$-galactosidases, a LacLM-type from $L$. reuteri and a LacZ-type from L. bulgaricus, on the cell surface of four Lactobacillus species. The immobilization of active $\beta$-galactosidases through cell-surface display can be utilized as safe and stable non-GMO food-grade biocatalysts that can be used in the production of prebiotic GOS.

\section{Results}

\subsection{Expression of Recombinant Lactobacillal $\beta$-Galactosidases in E. coli}

The overlapping lacLM genes from L. reuteri L103 and the lacZ gene from L. bulgaricus DSM20081, both encoding $\beta$-galactosidases, were fused $\mathrm{N}$-terminally to the LysM motif for expression and later attachment of the hybrid proteins to the peptidoglycan layer of Lactobacillus spp. An 88 residue fragment of the LysM motif from the 204-residue-Lp_3014 protein of an extracellular transglycosylase of L. plantarum WCFS1 [31,32] was fused to two $\beta$-galactosidases for production in E. coli. The two hybrid sequences were then cloned into the expression vector pBAD containing an N-terminal $7 \times$ Histidine tag for immunodetection, yielding pBAD3014LacLMLreu and pBAD3014LacZLbul (Figure 1).
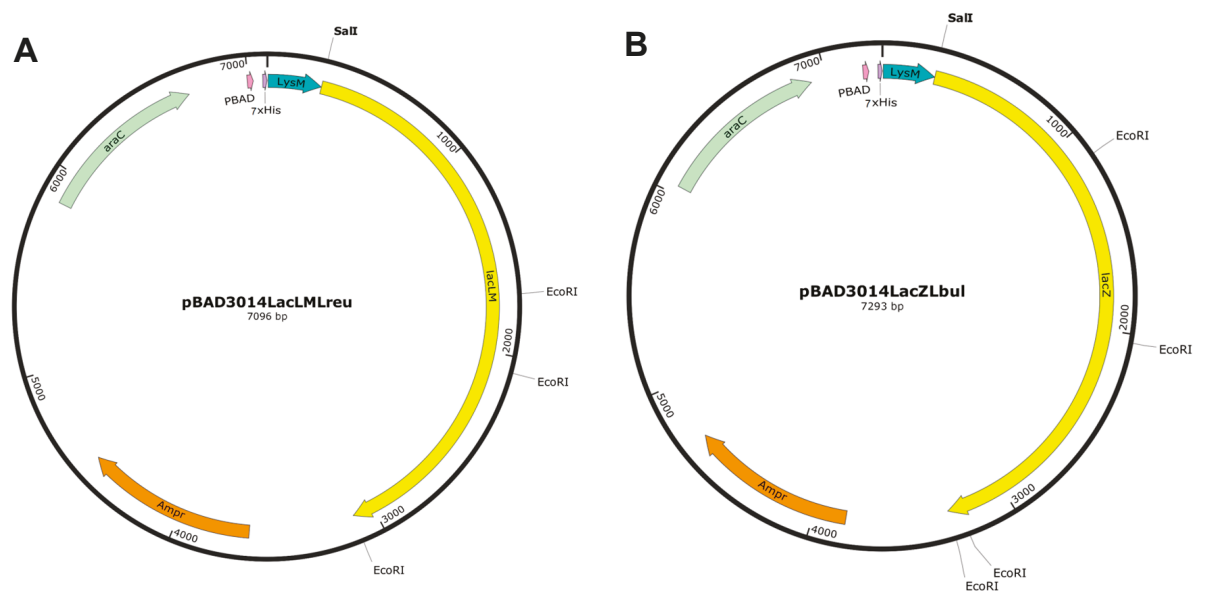

Figure 1. The expression vectors for LysM-LacLMLreu (A) and LysM-LacZLbul (B) in E. coli. The vectors are the derivatives of the $\mathrm{pBAD}$ vector (Invitrogen, Carlsbad, CA, USA) containing a $7 \times$ His tag sequence fused to a single LysM domain from Lp_3014, L. plantarum WCFS1. LacLMLreu encoded by two overlapping genes lacLM and LacZLbul encoded by the lacZ gene are the $\beta$-galactosidases from L. reuteri and L. delbrueckii subsp. bulgaricus DSM 20081, respectively. See text for more details.

The E. coli strains were cultivated in Luria-Bertani (LB) medium, induced for gene expression (as described in Materials and Methods), and the SDS-PAGE and Western blot analyses of cell-free extracts (Figure 2) showed the production of the two recombinant $\beta$-galactosidases, LysM-LacLMLreu and LysM-LacZLbul. As judged by SDS-PAGE (Figure 2A), LysM-LacLMLreu shows two bands with apparent molecular masses corresponding to a large subunit (LacL) and a small subunit (LacM) at $\sim 90 \mathrm{kDa}$ and $\sim 35 \mathrm{kDa}$. These values are in agreement with reported molecular masses of 73 and $35 \mathrm{kDa}$ for these two subunits of $\beta$-galactosidase from $L$. reutei $[5,16]$. The increase in molecular mass of a larger subunit in LysM-LacLMLreu is due to the added His-LysM fragment ( 18 kDa). On the other hand, $\beta$-galactosidase from $L$. bulgaricus was reported to be a homodimer, consisting of two identical subunits of $\sim 115 \mathrm{kDa}$ [12]. A unique band of $\sim 130 \mathrm{kDa}$ corresponding to the molecular mass of a single subunit of LacZ fused with the $18 \mathrm{kDa}$-fragment of the histidine-tag and the LysM domain was shown on SDS-PAGE analysis of a cell-free extract of LysM-LacZLbul as expected (Figure 2A). Western blot 
analysis of the crude, cell-free extracts was performed using anti-His antibody for detection. Figure 2B shows that the recombinant bacteria produced the expected proteins, LysMLacL (lane 2) and LysMLacZ (lane 4). LacM was not detected as it does not contain the histidine-tag.
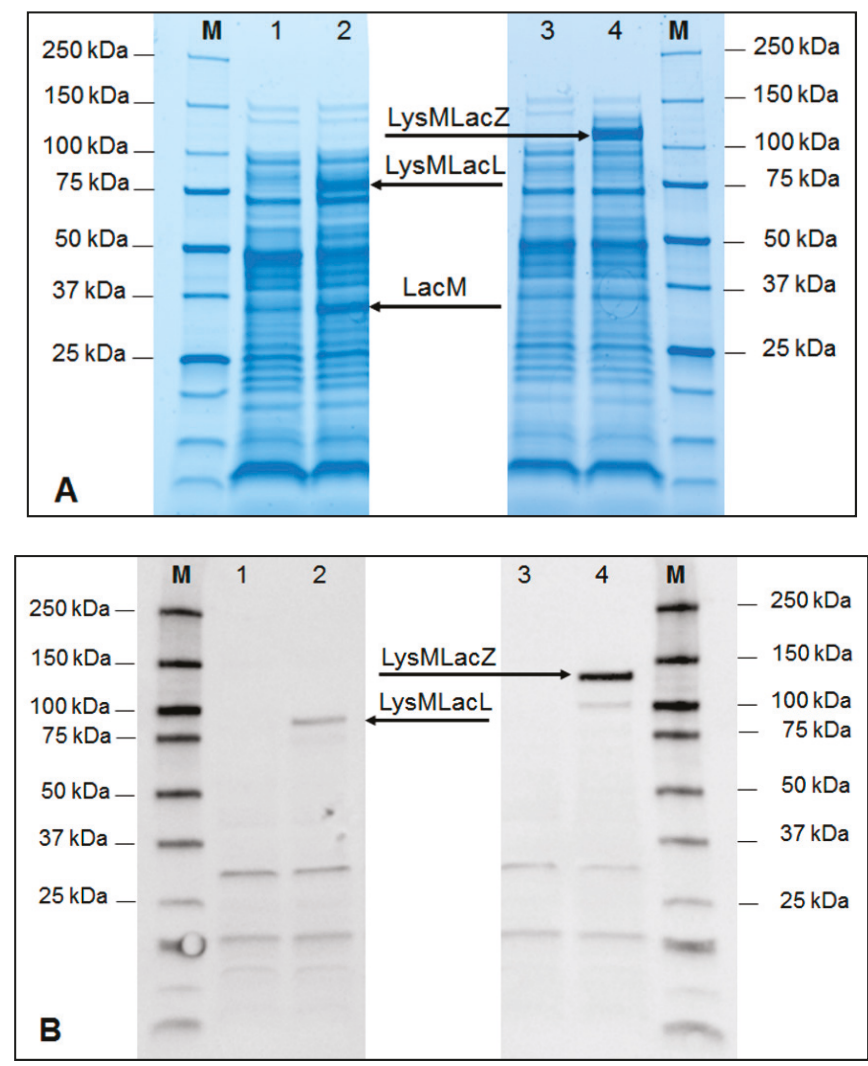

Figure 2. SDS-PAGE analysis (A) and Western blot analysis (B) of a cell-free extract of crude $\beta$-galactosidase fusion proteins, LysM-LacLMLreu (non-induced: lane 1, induced: lane 2) and LysM-LacZLbul (non-induced: lane 3, induced: lane 4), overexpressed in E. coli HST08. LacLMLreu encoded by two overlapping genes lacLM and LacZLbul encoded by lacZ gene are the $\beta$-galactosidases from L. reuteri and L. delbrueckii subsp. bulgaricus DSM 20081, respectively. The cultivation and induction conditions are as described in Materials and Methods and samples were taken at different time points after induction during cultivations. The arrows indicate the subunits of the recombinant $\beta$-galactosidases. M denotes the Precision protein ladder (Biorad, CA, USA).

To check if the heterologously produced enzymes were functionally active, $\beta$-galactosidase activities of cell-free lysates of $E$. coli cells carrying different expression vectors were measured. The highest yields obtained for the two recombinant enzymes were $11.1 \pm 1.6 \mathrm{k} \cdot \mathrm{U}_{o \mathrm{NPG}}$ per L of medium with a specific activity of $6.04 \pm 0.03 \mathrm{U} \cdot \mathrm{mg}^{-1}$ for LysM-LacLMLreu and $46.9 \pm 2.7 \mathrm{kU}_{o \mathrm{NPG}}$ per L of medium with a specific activity of $41.1 \pm 0.9 \mathrm{U} \cdot \mathrm{mg}^{-1}$ for LysM-LacZLbul, respectively (Table 1). The $\beta$-galactosidase activities in non-induced $E$. coli cells were negligible for both LysM-LacLMLreu and LysM-LacZLbul showing that the activity is from the overproduced $\beta$-galactosidases (Table 1). 
Table 1. $\beta$-Galactosidase activities in cell-free lysates of E. coli cells carrying different expression vectors.

\begin{tabular}{lcccc}
\hline \multirow{2}{*}{ Expression Vector } & \multicolumn{2}{c}{ Volumetric Activity (k.U/L Culture Medium) } & \multicolumn{2}{c}{ Specific Activity (U/mg Protein) } \\
\cline { 2 - 5 } & Non-Induced & Induced & Non-Induced & Induced \\
\hline pBAD3014LacLMLreu & n.d. & $11.1 \pm 1.5$ & n.d. & $6.04 \pm 0.03$ \\
pBAD3014LacZLbul & n.d. & $46.9 \pm 2.7$ & n.d. & $41.1 \pm 0.9$ \\
\hline
\end{tabular}

n.d.: not detected.

\subsection{Display of Lactobacillal $\beta$-Galactosidases on Lactobacillus Cell Surface}

To investigate the attachment of the two hybrid proteins, LysM-LacLMLreu and LysM-LacZLbul, to the cell wall of $L$. plantarum, cell-free crude extracts from $E$. coli harboring $\beta$-galactosidases corresponding to $50 \mathrm{U}_{o \mathrm{NPG}}(\sim 5-6 \mathrm{mg}$ protein) were incubated with $L$. plantarum cells collected from one $\mathrm{mL}$ cultures at $\mathrm{OD}_{600} \sim 4.0$. The enzymes and L. plantarum were incubated at $37^{\circ} \mathrm{C}$ with gentle agitation, and after $24 \mathrm{~h}$ of incubation, the residual activities in the supernatant as well as on the cell surface were determined for both enzymes (Table 2A). The immobilization yield (IY) is a measure of how much of the applied protein bound to the surface of Lactobacillus cells. Immobilizations yields for LysM-LacLMLreu and LysM-LacZLbul were 6.5\% and 31.9\%, respectively. SDS-PAGE analysis of the samples after the immobilization procedure showed strong bands of LysM-LacL and LacM or LysM-LacZ in the residual supernatants (Figure 3A, lane 2; Figure 3B, lane 2), indicating relatively high amounts of non-anchored proteins in the supernatants. Two successive washing steps with $50 \mathrm{mM}$ sodium phosphate buffer ( $\mathrm{NaPB}, \mathrm{pH}$ 6.5) did not release the enzymes showing that the immobilization is both effective and stable (Figure 3A, lanes 4, 5; Figure 3B, lanes 3, 4). The low immobilization yield for LysM-LacLMLreu was confirmed by the SDS-PAGE analysis (Figure 3A, lane 3). Western blot analysis of the crude, cell-free extracts of L. plantarum LacZLbul-displaying cells was performed using an anti-His antibody for detection showing the presence of LacZLbul (Figure 3C; lane 3). Flow cytometry confirmed the surface localization of both enzymes LysM-LacLMLreu and LysM-LacZLbul as clear shifts in the fluorescence signals for L. plantarum LacLMLreu- and LacZLbul-displaying cells in comparison to the control strain were observed (Figure 4A,B). The surface-displayed enzymes were shown to be functionally active. $\beta$-Galactosidase activities obtained for $L$. plantarum displaying cells were 179 and $1153 \mathrm{U}$ per g dry cell weight, corresponding to approximately 0.99 and $4.61 \mathrm{mg}$ of active, surface-anchored $\beta$-galactosidase per $\mathrm{g}$ dry cell mass for LysM-LacLMLreu and LysM-LacZLbul (Table 2A), respectivel.

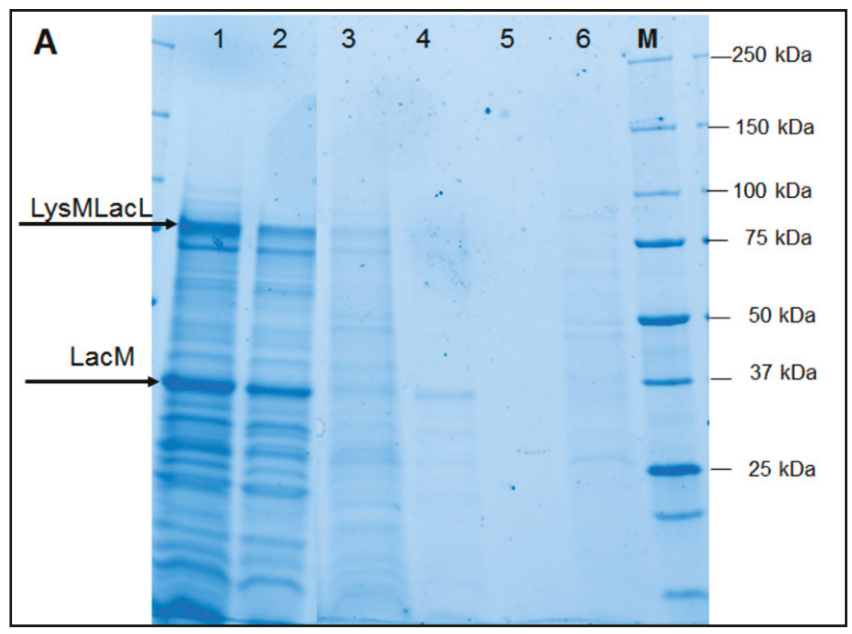

Figure 3. Cont 

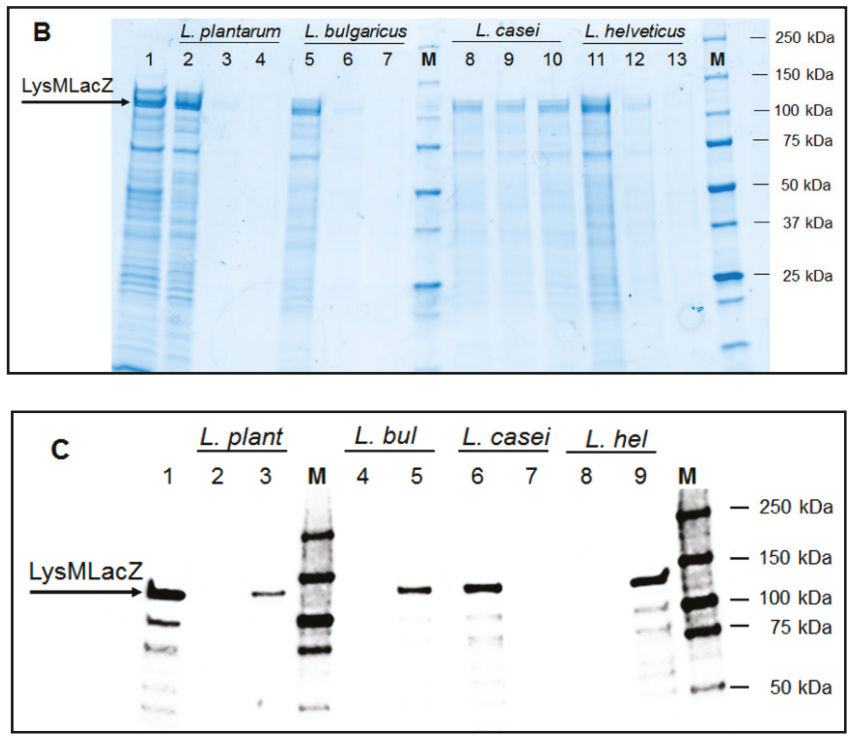

Figure 3. SDS-PAGE analysis (A,B) and Western blot analysis (C) of immobilization of recombinant enzymes. LacLMLreu encoded by two overlapping genes lacLM and LacZLbul encoded by lacZ gene are the $\beta$-galactosidases from $L$. reuteri and L. delbrueckii subsp. bulgaricus DSM 20081, respectively. The arrows indicate the subunits of the recombinant $\beta$-galactosidases. $M$ denotes the Precision protein ladder (Biorad, CA, USA). (A) Cell-free crude extracts of E. coli HST08 harboring pBAD3014LacLMLreu (containing LysM-LacLMLreu) at $18 \mathrm{~h}$ of induction (lane1); flow through during immobilization (lane 2); surface anchored-LysM-LacLMLreu in L. plantarum WCFS1 (lane 3) and washing fractions (lanes 4, 5); non-displaying L. plantarum WCFS1 cells, negative control (lane 6). (B) Cell-free crude extracts of E. coli HST08 harboring pBAD3014LacZLbul (containing LysM-LacZLbul) at $18 \mathrm{~h}$ of induction (lane1); flow through during immobilization on the cell surface of L. plantarum WCFS1 (lane 2) and washing fractions (lanes 3, 4); flow through during immobilization on the cell surface of L. delbrueckii subsp. bulgaricus DSM 20081 (lane 5) and washing fractions (lanes 6, 7); flow through during immobilization on cell surface of L. casei (lane 8) and washing fractions (lanes 9, 10); flow through during immobilization on cell surface of L. helveticus DSM 20075 (lane 11) and washing fractions (lanes 12, 13). (C) Cell-free crude extracts of E. coli HST08 harboring pBAD3014LacZLbul (containing LysM-LacZLbul) at 18 h of induction (lane 1); non-displaying L. plantarum WCFS1 cells (lane 2) and surface anchored-LysM-LacZLbul in L. plantarum WCFS1 (lane 3); non-displaying L. delbrueckii subsp. bulgaricus DSM 20081 cells (lane 4) and surface anchored-LysM-LacZLbul in L. delbrueckii subsp. bulgaricus DSM 20081 (lane 5); surface anchored-LysM-LacZLbul in L. casei (lane 6) and non-displaying L. casei cells (lane 7); non-displaying L. helveticus DSM 20075 cells (lane 8) and surface anchored-LysM-LacZLbul in L. helveticus DSM 20075 (lane 9). 


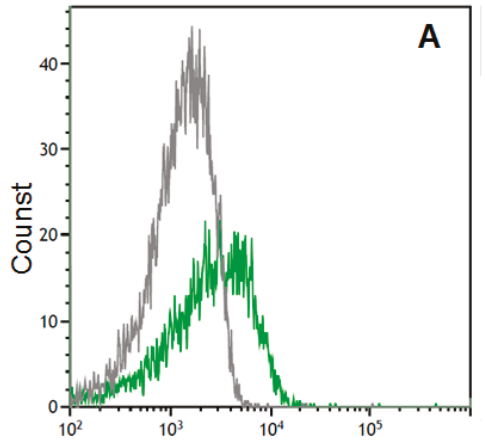

Fluorescence intensity

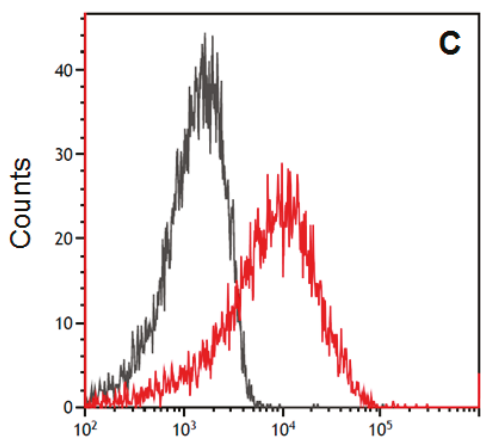

Fluorescence intensity

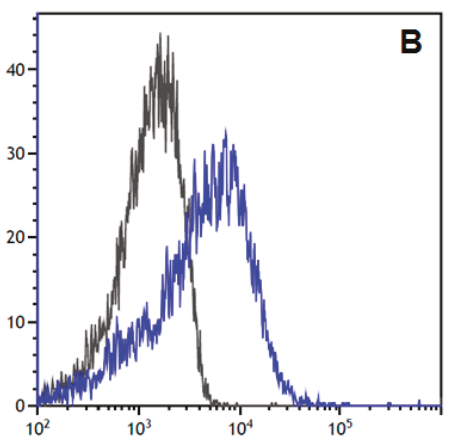

Fluorescence intensity

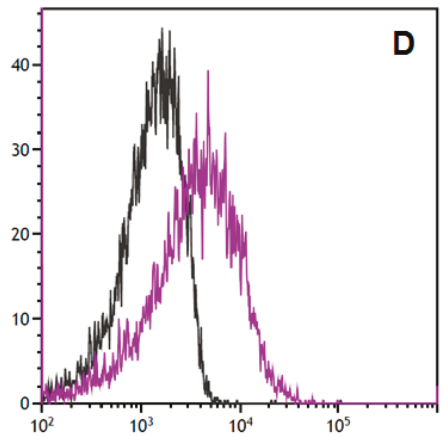

Fluorescence intensity

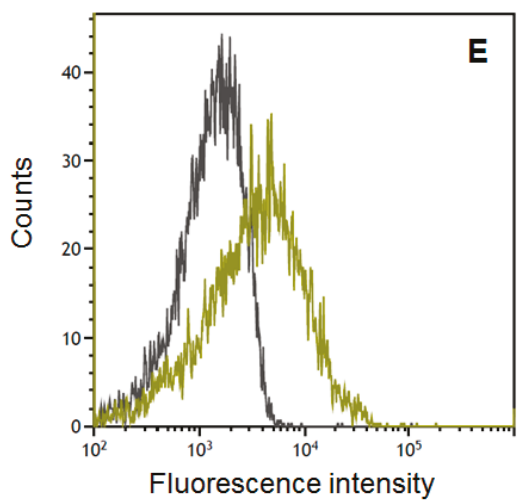

Figure 4. Analysis of surface localization of LysM-LacLMLreu and LysM-LacZLbul in Lactobacillus cells by using flow cytometry: surface anchored-LysM-LacLMLreu in L. plantarum WCFS1 (A, green line); surface anchored-LysM-LacZLbul in L. plantarum WCFS1 (B, blue line), in L. delbrueckii subsp. bulgaricus DSM 20081 (C, red line), in L. casei (D, purple line) and in L. helveticus DSM 20075 (E, olive line). Non-displaying Lactobacillus cells were used as negative controls (A-E, black line). 
Table 2. Immobilization of (A) recombinant lactobacillal $\beta$-galactosidases on L. plantarum WCFS1 cell surface and (B) recombinant $\beta$-galactosidase from L. bulgaricus DSM 20081 (LysM-LacZLbul) on the cell surface of different Lactobacillus spp.

\begin{tabular}{|c|c|c|c|c|c|c|}
\hline & $\begin{array}{c}\text { Residual } \\
\text { Activities in } \\
\text { Supernatant }\end{array}$ & $\begin{array}{c}\begin{array}{c}\text { Immobilization } \\
\text { Yield }^{a}(\mathrm{IY})\end{array} \\
(\%)\end{array}$ & \multicolumn{2}{|c|}{$\begin{array}{l}\text { Activity on Cell } \\
\text { Surface } b\end{array}$} & $\begin{array}{c}\begin{array}{c}\text { Activity } \\
\text { Retention } \\
\text { (AR) }\end{array} \\
(\%)\end{array}$ & $\begin{array}{c}\text { Amount of Active } \\
\text { Surface Anchored } \\
\beta \text {-gal }{ }^{d} \\
\mathrm{mg} / \mathrm{g} \mathrm{DCW}\end{array}$ \\
\hline \multicolumn{7}{|c|}{ (A) Enzyme (on L. plantarum WCFS1 cell surface) } \\
\hline LysM-LacLMLreu & $93.5 \pm 1.2$ & 6.53 & $3.06 \pm 0.08$ & $179 \pm 5$ & 46.9 & $0.99 \pm 0.02$ \\
\hline LysM-LacZLbul & $68.1 \pm 0.1$ & 31.9 & $20.3 \pm 0.2$ & $1153 \pm 12$ & 63.5 & $4.61 \pm 0.05$ \\
\hline L. plantarum WCFS1 & $68.1 \pm 0.1$ & 31.9 & $20.3 \pm 0.2$ & $1153 \pm 12$ & 63.5 & $4.61 \pm 0.05$ \\
\hline L. bulgaricus DSM 20081 & $71.3 \pm 0.9$ & 28.7 & $14.0 \pm 0.9$ & $795 \pm 53$ & 48.5 & $3.18 \pm 0.11$ \\
\hline L. casei & $76.1 \pm 0.9$ & 23.9 & $15.1 \pm 0.8$ & $861 \pm 48$ & 63.2 & $3.44 \pm 0.09$ \\
\hline L. helveticus DSM20075 & $75.3 \pm 0.9$ & 24.7 & $14.3 \pm 0.5$ & $812 \pm 27$ & 57.7 & $3.25 \pm 0.11$ \\
\hline
\end{tabular}

${ }^{a}$ IY (\%) was calculated by subtraction of the residual enzyme activity (\%) in the supernatant after immobilization from the total activity applied $(100 \%) .{ }^{b}$ Activity on the cell surface $(\%)$ is the percentage of enzyme activity measured on the cell surface to the total applied activity. Activity on the cell surface (U/g DCW) is calculated as the amount of enzyme (Units) per g dry cell weight. ${ }^{c}$ Activity retention, AR (\%), is the ratio of activity on the cell surface (\%) to IY (\%). ${ }^{d}$ It was calculated based on specific activities of purified LacLMLreu of $180 \mathrm{U} / \mathrm{mg}$ protein [16] and of purified LacZLbul (His Tagged) of $250 \mathrm{U} / \mathrm{mg}$ protein [12]. Values given are the average value from at least two independent experiments, and the standard deviation was always less than $5 \%$.

Due to higher immobilization yields and increased amounts of active surface-anchored protein in L. plantarum, LysM-LacZLbul was chosen for further analysis of its display on the cell surface of other food-relevant Lactobacillus spp. including L. bulgaricus, L. casei and L. helveticus. The parameters of residual activities in the supernatant after the anchoring experiment, activity on the cell surface, immobilization yields, activity retention and amounts of active surface-anchored LysM-LacZLbul were determined and are presented in Table 2B. It was shown that surface-anchored LysM-LacZLbul was released from the cell surface of L. casei during the subsequent washing steps (Figure 3B, lanes 9, 10). Western blot analysis of the crude, cell-free extracts of Lactobacillus LysM-LacZLbul-displaying cells indicated the binding of LysM-LacZLbul to all four Lactobacillus spp. tested (Figure 3C; lanes 3, 5, 6, 9) as was also confirmed by flow cytometry (Figure 4B-E). L. plantarum bound most efficiently among the tested Lactobacillus species shown by the highest immobilization yield and the highest amount of active, surface-anchored LysM-LacZLbul (Table 2B).

\subsection{Enzymatic Stability of $\beta$-Galactosidase-Displaying Cells}

Both temperature stability and reusability of $\beta$-galactosidase displaying cells were determined. For temperature stability, L. plantarum galactosidase-displaying cells were incubated in $50 \mathrm{mM}$ sodium phosphate buffer (NaPB), pH 6.5 at different temperatures, and at certain time intervals, the residual $\beta$-galactosidase activities on L. plantarum cell surface were measured. Both LysM-LacLMLreu and LysM-LacZLbul-displaying cells are very stable at $-20{ }^{\circ} \mathrm{C}$ with a half-life time of activity $\left(\tau_{\frac{1}{2}}\right)$ of approximately 6 months (Table 3). The half-life time of activity of LysM-LacLMLreu-displaying cells at $30{ }^{\circ} \mathrm{C}$ is $55 \mathrm{~h}$, whereas half-life times of activity of LysM-LacZLbul-displaying cells at $30{ }^{\circ} \mathrm{C}$ and $50{ }^{\circ} \mathrm{C}$ are $120 \mathrm{~h}$ and $30 \mathrm{~h}$, respectively (Table 3 ). 
Table 3. Stability of L. plantarum $\beta$-galactosidase-displaying cells at various temperatures ${ }^{a}$.

\begin{tabular}{cccc}
\hline \multicolumn{2}{c}{ LysM-LacLMLreu } & \multicolumn{2}{c}{ LysM-LacLZLbul } \\
\hline Temperature & $\tau_{\frac{1}{2}}$ & Temperature & $\tau_{\frac{1}{2}}$ \\
\hline$-20^{\circ} \mathrm{C}$ & 6 months & $-20{ }^{\circ} \mathrm{C}$ & 6 months \\
$4{ }^{\circ} \mathrm{C}$ & 3 months & $4{ }^{\circ} \mathrm{C}$ & $\mathrm{Nd}^{b}$ \\
$30^{\circ} \mathrm{C}$ & $55 \mathrm{~h}$ & $30^{\circ} \mathrm{C}$ & $120 \mathrm{~h}$ \\
$50^{\circ} \mathrm{C}$ & $\mathrm{nd}^{b}$ & $50^{\circ} \mathrm{C}$ & $30 \mathrm{~h}$
\end{tabular}

${ }^{a}$ L. plantarum galactosidase-displaying cells were incubated in $50 \mathrm{mM}$ sodium phosphate buffer (NaPB), $\mathrm{pH} 6.5$ at different temperatures. Experiments were performed at least in duplicates. ${ }^{b}$ not determined.

To test the reusability of LysM-LacLMLreu- and LysM-LacZLbul-displaying cells, the enzyme activity was measured during several repeated rounds of lactose conversion with two washing steps between each cycle. The enzymatic activities of L. plantarum LysM-LacZLbul-displaying cells decreased by $\sim 23 \%$ and $27 \%$ at $30^{\circ} \mathrm{C}$ and $50{ }^{\circ} \mathrm{C}$ (Figure 5), respectively, after three conversion/washing cycles, indicating that these displaying cells can be reused for several rounds of biocatalysis at tested temperatures. LysM-LacLMLreu-displaying cells are less stable than LysM-LacZLbul-displaying cells as only $56 \%$ of the initial $\beta$-galactosidase activity are retained at $30^{\circ} \mathrm{C}$ after the third cycle (Figure 5). LysM-LacZLbul-displaying cells retained $35 \%$ of $\beta$-galactosidase activity after the fourth cycle at $50{ }^{\circ} \mathrm{C}$, $57 \%$ and $51 \%$ after the fourth and fifth cycle, respectively, at $30{ }^{\circ} \mathrm{C}$ (Figure 5). These observations indicate that immobilized fusion LysM- $\beta$-galactosidases can be reused for at least four to five repeated rounds of lactose conversion.

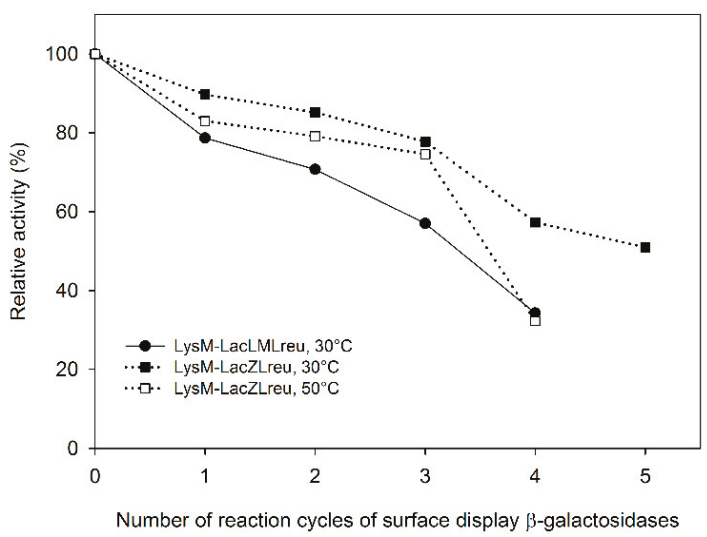

Figure 5. Enzymatic activity of surface display $\beta$-galactosidases, LysM-LacLMLreu- and LysM-LacZLbul, during several repeated rounds of lactose conversion using L. plantarum WCFS1 displaying cells. Experiments were performed in duplicates, and the standard deviation was always less than $5 \%$.

\subsection{Formation of Galacto-Oligosaccharides (GOS)}

Figure 6 shows the formation of GOS using L. plantarum cells displaying $\beta$-galactosidase LacZ from L. bulgaricus (LysM-LacZLbul) with $1.0 \mathrm{U}_{\mathrm{Lac}} \beta$-galactosidase activity per $\mathrm{mL}$ of the reaction mixture and $205 \mathrm{~g} / \mathrm{L}$ initial lactose in $50 \mathrm{mM}$ sodium phosphate buffer $\left(\mathrm{pH}\right.$ 6.5) at $30^{\circ} \mathrm{C}$. The maximal GOS yield was around $32 \%$ of total sugars obtained at $72 \%$ lactose conversion after $7 \mathrm{~h}$ of conversion. This observation shows that surface-displayed LacZ is able to convert lactose to form galacto-oligosaccharides. We

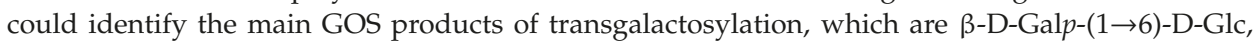

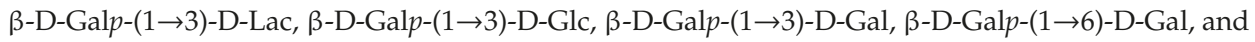


$\beta$-D-Galp-(1 $\rightarrow 6)$-D-Lac. This is similar to the product profile when performing the conversion reaction with the free enzyme as previously reported [12].

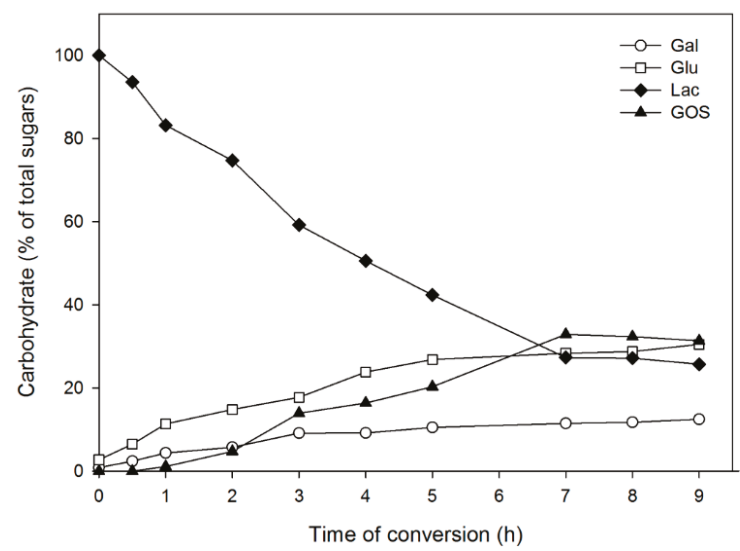

Figure 6. Course of reaction for lactose conversion by surface display $\beta$-galactosidase from L. bulgaricus (LysM-LacZLbul) in L. plantarum WCFS1 as determined by HPLC. The batch conversion was carried out at $30^{\circ} \mathrm{C}$ using $205 \mathrm{~g} / \mathrm{L}$ initial lactose concentration in $50 \mathrm{mM} \mathrm{NaPB}$ (pH 6.5) and constant agitation (500 rpm). L. plantarum LysM-LacZLbul displaying cells were added to equivalent concentrations of $1.0 \mathrm{U}_{\mathrm{Lac}} / \mathrm{mL}$ of the reaction mixture. Experiments were performed in duplicates, and the standard deviation was always less than $5 \%$.

\section{Discussion}

Surface display of proteins on cells of lactic acid bacteria (LAB) generally requires genetic modifications, which might have limitations in food and medical applications due to the sensitive issue of the use of genetically modified organisms (GMO). Anchoring heterologous proteins on the cell surface of non-genetically modified LAB (non-GMO) via mediated cell wall binding domains including surface layer domain (SLPs) [33,34], LysM domain [26,30,35-37], W × L domains [38] attracts increasing interest.

Lysin motif (LysM) domains are found in many bacterial peptidoglycan hydrolases $[26,38,39]$. Peptidoglycan contains sugar (glycan) chains, which consist of $N$-acetylglucosamine (NAG) and $\mathrm{N}$-acetylmuramic acid (NAM) units joined by glycosidic linkages. Proteins harboring LysM motifs have been shown to bind non-covalently to the peptidoglycan layer and have been employed to display heterologous proteins on the bacterial cell-surface $[26,40,41]$. These domains can contain single or multiple LysM motifs [41], and they have been used to display proteins in LAB by fusion either to the N- or C-terminus of a target protein [27-30]. Interestingly, the LysM motif derived from the L. plantarum Lp_3014 transglycosylase has been used successfully for surface display of invasin [36] and a chemokine fused to an HIV antigen [37] previously.

In this work, we used the single LysM domain derived from Lp_3014 to anchor two different lactobacillal $\beta$-galactosidases, a heterodimeric type from $L$. reuteri and a homodimeric type from L. bulgaricus, on the cell surface of four species of lactobacilli. Functional active fusion proteins, LysM-LacLMLreu and LysM-LacZLbul, were successfully expressed in E. coli. However, the expression yield of LysM-LacLMLreu was ten-fold lower than that of the $\beta$-galactosidase from $L$. reuteri (LacLMLreu) without LysM expressed previously in E. coli, which was reported to be $110 \mathrm{kU}$ of $\beta$-galactosidase activity per liter of cultivation medium [16]. This may indicate that the fusion of the LysM domain has a negative effect on the expression level. Interestingly, the expression yields of LysM-LacZLbul were 4-fold and 7-fold higher in terms of volumetric and specific activities, respectively, than that of LysM-LacLMLreu using the same host, expression system and induction conditions. 
$\beta$-Galactosidase from L. bulgaricus (LysM-LacZLbul) is a homodimer whereas $\beta$-galactosidase from L. reuteri (LysM-LacLMLreu) is a heterodimer, and hence the fusion of the LysM domain only to the LacL subunits might lead to the discrepancy between the yields of these two fusion proteins due to different folding mechanisms.

Not surprisingly, the affinity for peptidoglycan of homodimeric LysM-LacZLbul is significantly higher than LysM-LacLMLreu as shown by the immobilization yield (Table 2A). As aforementioned LacLMLreu from L. reuteri is a heterodimer and the LysM domain is fused N-terminally to only LacL, while LacZLbul from L. bulgaricus is a homodimer, hence each of the identical subunits will carry its own LysM domain leading to stronger attachment of LacZ on the L. plantarum cell wall. This could be a likely explanation for the higher immobilization yields observed for LysM-LacZLbul. Even though the immobilization yields obtained in this study were significantly lower than the immobilization yields for these same enzymes when a chitin binding domain (ChBD) together with chitin was used [17], the activity retention (AR) on the L. plantarum cell surface (46.9\% and $63.5 \%$ for LysM-LacLMLreu and LysM-LacZLbul, respectively) were significantly higher. The AR values for ChBD-LacLM, LacLM-ChBD and LacZ-ChBD using chitin beads were 19\%, 26\% and 13\%, respectively [17]. Notably, the amount of active surface anchored LysM-LacLMLreu $(0.99 \pm 0.02 \mathrm{mg}$ per g dry cell weight) on the cell surface of L. plantarum WCFS1 is significantly lower than LysM-LacZLbul ( $4.61 \pm 0.05 \mathrm{mg}$ per g dry cell weight). This is mainly due to the low immobilization yield of LysM-LacLMLreu. L. plantarum collected from one $\mathrm{mL}$ cultures at $\mathrm{OD}_{600} \sim 4.0$ was used in immobilization reactions, hence the amount of L. plantarum cells was estimated to be $\sim 3.0 \times 10^{9} \mathrm{cfu} / \mathrm{mL}$. Therefore, we calculated that $8.22 \mu \mathrm{g}$ LysM-LacLMLreu and $38.3 \mu \mathrm{g}$ LysM-LacZLbul anchored on $3.0 \times 10^{9}$ L. plantarum cells or $0.002 \mathrm{pg}$ LysM-LacLMLreu and $0.012 \mathrm{pg}$ LysM-LacZLbul per L. plantarum cell. Xu et al. (2011) reported the use of the putative muropeptidase MurO (Lp_2162) from L. plantarum containing two putative LysM repeat regions for displaying a green fluorescent protein (GFP) and a $\beta$-galactosidase from Bifidobacterium bifidum on the surface of L. plantarum cells [42]. They reported that $0.008 \mathrm{pg}$ of GFP was displayed per cell on non-treated L. plantarum cells, while the amount of active surface anchored $\beta$-galactosidase from B. bifidum on the surface of L. plantarum cells was not reported in that study.

Further, we tested the capability of binding the fusion protein LysM-LacZLbul to the cell wall of three other Lactobacillus species. L. plantarum showed the best capacity among the tested Lactobacillus for surface anchoring of LysM-LacZLbul (Table 2B), whereas L. bulgaricus, L. casei and L. helveticus are comparable in term of the amount of active surface-anchored enzyme.

The highest GOS yield of $32 \%$ obtained with the surface-immobilized enzyme is lower than the yield obtained with the free enzyme LacZ from L. bulgaricus (Figure 6), which was previously reported to be approximately $50 \%$ [12]. This could be due to the binding of LysM-LacZLbul to the peptidoglycan and the attachment of the enzyme on Lactobacillus cell surface, which might hinder the access of the substrate lactose to the active site of the enzyme. Interestingly, the GOS yield obtained from lactose conversion using $L$. plantarum cells displaying $\beta$-galactosidase (LysM-LacZLbul) from L. bulgaricus is significantly higher than the yield obtained with immobilized $\beta$-galactosidase (LacZ-ChBD) on chitin, which was previously reported around $23 \%-24 \%$ [12]. It indicates that $\beta$-galactosidase from L. bulgaricus anchored on L. plantarum cell surface is more catalytically efficient than its immobilized form on chitin.

\section{Materials and Methods}

\subsection{Bacterial Strains and Culture Conditions}

The bacterial strains and plasmids used in this study are listed in Table 4. Lactobacillus plantarum WCFS1, isolated from human saliva as described by Kleerebezem et al. [32], was originally obtained from NIZO Food Research (Ede, The Netherlands) and maintained in the culture collection of the Norwegian University of Life Sciences, Ås, Norway. L. helveticus DSM 20075 (ATCC 15009) and L. delbrueckii subsp. bulgaricus DSM 20081 (ATCC 11842) were obtained from the German Collection 
of Microorganisms and Cell Cultures (DSMZ; Braunschweig, Germany). L. casei was obtained from the culture collection of the Food Biotechnology Laboratory, BOKU-University of Natural Resources and Life Sciences Vienna. Lactobacillus strains were cultivated on MRS medium (Lactobacillus broth according to De Man, Rogosa and Shape [43]) (Carl Roth, Karlsruhe, Germany) at $37{ }^{\circ} \mathrm{C}$ without agitation. E. coli NEB5 $\alpha$ (New England Biolabs, Frankfurt am Main, Germany) was used as cloning hosts in the transformation of DNA fragments; whereas E. coli HST08 (Clontech, Mountain View, CA, USA) was used as the expression host strain. E. coli strains were cultivated in Luria-Bertani (LB) medium $\left(10 \mathrm{~g} / \mathrm{L}\right.$ tryptone, $10 \mathrm{~g} / \mathrm{L} \mathrm{NaCl}$, and $5 \mathrm{~g} / \mathrm{L}$ yeast extract) at $37^{\circ} \mathrm{C}$ with shaking at $140 \mathrm{rpm}$. Agar media were prepared by adding $1.5 \%$ agar to the respective media. When needed, ampicillin was supplemented to media to a final concentration of $100 \mu \mathrm{g} / \mathrm{mL}$ for E. coli cultivations.

Table 4. Strains and plasmids used in the study.

\begin{tabular}{|c|c|c|}
\hline Strains or Plasmids & Relevant Characteristics & Reference Source \\
\hline \multicolumn{3}{|l|}{ Strains } \\
\hline L. plantarum WCFS1 & & {$[32]$} \\
\hline $\begin{array}{l}\text { L. delbrueckii subsp. } \\
\text { bulgaricus DSM } 20081\end{array}$ & & DSMZ \\
\hline L. casei & & BOKU \\
\hline L. helveticus DSM 20075 & & DSMZ \\
\hline E. coli HST08 & Host strain & Clontech \\
\hline \multicolumn{3}{|l|}{ Plasmids } \\
\hline pBAD_3014_AgESAT_DC & $\begin{array}{l}\text { Amp }^{r} \text {; pBAD derivate with the LysM domain sequence from Lp3014 } \\
\text { fused to the hybrid antigen AgESAT_DC }\end{array}$ & [44] \\
\hline pBAD3014LacLMLreu & $\begin{array}{l}\text { Amp }^{\mathrm{r}} ; \text { pBAD_3014_AgESAT_DC derivative with a fragment of } \\
\text { lacLM genes instead of the gene fragment encoding AgESAT_DC }\end{array}$ & This study \\
\hline pBAD3014LacZLbul & $\begin{array}{l}\text { Amp }^{\mathrm{r}} \text {; pBAD_3014_AgESAT_DC derivate with lacZ fragment } \\
\text { instead of the gene fragment encoding AgESAT_DC }\end{array}$ & This study \\
\hline pHA1032 & $\begin{array}{l}\text { Amp }{ }^{\mathrm{r}} ; \mathrm{pET} 21 \mathrm{~d} \text { derivative for expression of lacLM from L. reuteri } \\
\text { in E. coli }\end{array}$ & [16] \\
\hline pTH103 & $\begin{array}{l}\text { Erm }^{\mathrm{r}} \text {; spp-based expression vector pSIP409 for expression of lacZ } \\
\text { from L. bulgaricus DSM } 20081 \text { in L. plantarum WCFS1 }\end{array}$ & {$[12]$} \\
\hline
\end{tabular}

\subsection{Chemicals, Enzymes and Plasmids}

All chemicals and enzymes were purchased from Sigma (St. Louis, MO, USA) unless stated otherwise and were of the highest quality available. All restriction enzymes, Phusion high-fidelity DNA polymerase, T4 DNA ligase, and corresponding buffers were from New England Biolabs (Frankfurt am Main, Germany). Staining dyes, DNA and protein standard ladders were from Bio-Rad (Hercules, CA, USA). All plasmids used in this study are listed in Table 4.

\subsection{DNA Manipulation}

Plasmids were isolated from E. coli strains using Monarch Plasmid Miniprep Kit (New England Biolabs, Frankfurt am Main, Germany) according to the manufacturer's instructions. PCR amplifications of DNA were done using Q5 High-Fidelity 2X Master Mix (New England Biolabs). The primers used in this study, which were supplied by VBC-Biotech Service (Vienna, Austria), are listed in Table 5. PCR products and DNA fragments obtained by digestion with restriction enzymes were purified using Monarch DNA Gel Extraction Kit (New England Biolabs); and the DNA amounts were estimated using Nanodrop 2000 (Thermo Fisher Scientific, Waltham, MA, USA). The sequences of PCR-generated fragments were verified by DNA sequencing performed by a commercial provider (Microsynth, Vienna, Austria). The ligation of DNA fragments was performed using NEBuilder HiFi Assembly Cloning Kit (New England Biolabs). All plasmids were transformed into E. coli NEB5 $\alpha$ chemical competent cells following the manufacturer's protocol for obtaining the plasmids in sufficient amounts. The constructed plasmids (Table 4) were chemically transformed into expression host strain E. coli HST08. 
Table 5. Primers used in the study.

\begin{tabular}{|c|c|c|}
\hline Primer & Sequence $^{*} 5^{\prime} \rightarrow 3^{\prime}$ & Restriction Site Underlined \\
\hline Fwd1LreuSalI & GAGTTCAACTGTCGACCAAGCAAATATAAA & SalI \\
\hline Rev1LreuEcoRI & AGCCAAGCTTCGAATTCTTATTTTGCATTC & EcoRI \\
\hline Fwd2LbulSalI & GTTCAACTGTCGACAGCAATAAGTTAGTAAAAGAAAAAAGAG & SalI \\
\hline Rev2LbulEcoRI & CAGCCAAGCTTCGAATTCTTATTTTAGTAAAAGGGGCTGAATC & EcoRI \\
\hline
\end{tabular}

\subsection{Plasmid Construction}

Two recombinant fusion proteins were constructed. The first fusion protein was based on LacLM from L. reuteri and the LysM domain attached upstream of LacLM (termed LysM-LacLMLreu). The second fusion protein was based on LacZ from L. delbrueckii subsp. bulgaricus DSM 20081 and the LysM domain attached upstream of LacZ (termed LysM-LacZLbul). Plasmid pBAD_3014AgESAT_DC (Table 4) [44] (was used for the construction of the expression plasmids. This plasmid is a derivate of pBAD vector (Invitrogen, Carlsbad, CA, USA) containing a $7 \times$ His tag sequence and a single LysM domain from Lp_3014, which is a putative extracellular transglycosylase with LysM peptidoglycan binding domain from L. plantarum WCFS1 (NCBI reference sequence no. NC_004567.2) [31,32], fused to the hybrid tuberculosis antigen AgESAT-DC [44]. The fragment of lacLM genes from L. reuteri was amplified from the plasmid pHA1032 (Table 4) [16] with the primer pair Fwd1LreuSalI and Rev1LreuEcoRI (Table 5), whereas the lacZ gene from L. bulgaricus was amplified from the plasmid pTH103 (Table 4) [12] with the primer pair Fwd2LbulSall and Rev2LbulEcoRI (Table 5). The PCR-generated products were then cloned into SalI and EcoRI cloning sites of the pBAD_3014AgESAT_DC vector using and NEBuilder HiFi DNA Assembly Cloning Kit (New England Biolabs) following the manufacturer's instructions, resulting in two expression plasmids pBAD3014LacLMLreu and pBAD3014LacZLbul (Figure 1).

\subsection{Gene Expression in E. coli}

The constructed plasmids pBAD3014LacLMLreu and pBAD3014LacZLbul were chemically transformed into expression host $E$. coli HST08. For gene expression, overnight cultures of E. coli HST08 were diluted in $300 \mathrm{~mL}$ of fresh LB broth containing $100 \mu \mathrm{g} / \mathrm{mL}$ ampicillin to an $\mathrm{OD}_{600}$ of $\sim 0.1$ and incubated at $37^{\circ} \mathrm{C}$ with shaking at $140 \mathrm{rpm}$ to an $\mathrm{OD}_{600} \sim 0.6$. Gene expression was then induced by L-arabinose to a final concentration of $0.7 \mathrm{mg} / \mathrm{mL}$ and the cultures were incubated further at $25^{\circ} \mathrm{C}$ for $18 \mathrm{~h}$ with shaking at $140 \mathrm{rpm}$. Cells were harvested at an $\mathrm{OD}_{600}$ of $\sim 3.0$ by centrifugation at $4000 \times g$ for $30 \mathrm{~min}$ at $4{ }^{\circ} \mathrm{C}$, washed twice, and resuspended in $50 \mathrm{mM}$ sodium phosphate buffer (NaPB), pH 6.5 . Cells were disrupted by using a French press (AMINCO, Maryland, USA). Debris was removed by centrifugation $\left(10,000 \times \mathrm{g}\right.$ for $15 \mathrm{~min}$ at $\left.4{ }^{\circ} \mathrm{C}\right)$ to obtain the crude extract.

\subsection{Immobilization of $\beta$-Galactosidases on Lactobacillus Cell Surface}

One $\mathrm{mL}$ of Lactobacillus cultures were collected at $\mathrm{OD}_{600} \sim 4.0$ by centrifugation $(4000 \times \mathrm{g}$ for $5 \mathrm{~min}$ at $4{ }^{\circ} \mathrm{C}$ ) and the cells were washed with $50 \mathrm{mM}$ sodium phosphate buffer $(\mathrm{NaPB}), \mathrm{pH}$ 6.5. The cell pellets were then mixed with one $\mathrm{mL}$ of diluted cell-free crude extracts of $50 \mathrm{U}_{o \mathrm{NPG}} / \mathrm{mL}(\sim 5-6 \mathrm{mg}$ protein $/ \mathrm{mL}$ ) of fused LysM- $\beta$-galactosidases (LysM-LacLMLreu or LysM-LacZLbul) and incubated at $37^{\circ} \mathrm{C}$ for $24 \mathrm{~h}$ with gentle agitation. Lactobacillus $\beta$-galactosidase displaying cells were separated from the supernatants by centrifugation $\left(4000 \times g\right.$ for 5 min at $\left.4{ }^{\circ} \mathrm{C}\right)$. Cells were then washed with $\mathrm{NaPB}$ ( $\mathrm{pH}$ 6.5) two times; the supernatants and wash solutions were collected for SDS-PAGE analysis and activity and protein measurements. Lactobacillus $\beta$-galactosidase displaying cells were resuspended in $\mathrm{NaPB}(\mathrm{pH}$ 6.5) for further studies. 


\subsection{Protein Determination}

Protein concentrations were determined using the method of Bradford [45] with bovine serum albumin (BSA) as standard.

\section{8. $\beta$-Galactosidase Assays}

$\beta$-Galactosidase activity was determined using $o$-nitrophenyl- $\beta$-D-galactopyranoside $(o \mathrm{NPG})$ or lactose as the substrates as previously described [5] with modifications. When chromogenic substrate $o$ NPG was used, the reaction was started by adding $20 \mu \mathrm{L}$ of Lactobacillus $\beta$-galactosidase displaying cell suspension to $480 \mu \mathrm{L}$ of $22 \mathrm{mM} o \mathrm{NPG}$ in $50 \mathrm{mM} \mathrm{NaBP}$ ( $\mathrm{pH}$ 6.5) and stopped by adding $750 \mu \mathrm{L}$ of $0.4 \mathrm{M} \mathrm{Na}_{2} \mathrm{CO}_{3}$ after $10 \mathrm{~min}$ of incubation at $30^{\circ} \mathrm{C}$. The release of $o$-nitrophenol $(\mathrm{oNP})$ was measured by determining the absorbance at $420 \mathrm{~nm}$. One unit of $o$ NPG activity was defined as the amount of $\beta$-galactosidase releasing $1 \mu \mathrm{mol}$ of $o \mathrm{NP}$ per minute under the defined conditions.

When lactose was used as the substrate, $20 \mu \mathrm{L}$ of Lactobacillus $\beta$-galactosidase displaying cell suspension was added to $480 \mu \mathrm{L}$ of a $600 \mathrm{mM}$ lactose solution in $50 \mathrm{mM}$ sodium phosphate buffer, $\mathrm{pH}$ 6.5. After $10 \mathrm{~min}$ of incubation at $30^{\circ} \mathrm{C}$, the reaction was stopped by heating the reaction mixture at $99{ }^{\circ} \mathrm{C}$ for $5 \mathrm{~min}$. The reaction mixture was cooled to room temperature, and the release of D-glucose was determined using the test kit from Megazyme. One unit of lactase activity was defined as the amount of enzyme releasing $1 \mu \mathrm{mol}$ of D-glucose per minute under the given conditions.

\subsection{Gel Electrophoresis Analysis}

For visual observation of the expression level of the two recombinant $\beta$-galactosidases (LysM-LacLMLreu and LysM-LacZLbul) in E. coli and the effectiveness of the immobilization, cell-free extracts, supernatants, and wash solutions were analyzed by Sodium Dodecyl Sulfate Polyacrylamide Gel Electrophoresis (SDS-PAGE). Protein bands were visualized by staining with Bio-safe Coomassie (Bio-Rad). The determination of protein mass was carried out using Unstained Precision plus Protein Standard (Bio-Rad).

\subsection{Western Blotting}

Proteins in the cell-free extracts were separated by SDS-PAGE. Protein bands were then transferred to a nitrocellulose membrane using the Trans-Blot Turbo ${ }^{\mathrm{TM}}$ Transfer System (Biorad) following the manufacturer's instructions. Monoclonal mouse anti-His antibody (Penta His Antibody, BSA-free) was obtained from Qiagen (Hilden, Germany), diluted 1:5000 and used as recommended by the manufacturer. The protein bands were visualized by using polyclonal rabbit anti-mouse antibody conjugated with horseradish peroxidase (HRP) (Dako, Denmark) and the Clarity ${ }^{\mathrm{TM}}$ Western ECL Blotting Substrate from Bio-Rad (Hercules, CA, USA).

\subsection{Flow Cytometry}

Lactobacillus $\beta$-galactosidase displaying cells were resuspended in $50 \mu \mathrm{L}$ of phosphate buffered saline (PBS) (137 mM NaCl, $2.7 \mathrm{mM} \mathrm{KCl}, 2 \mathrm{mM} \mathrm{KH}_{2} \mathrm{PO}_{4}$, and $\left.10 \mathrm{mM} \mathrm{Na}_{2} \mathrm{HPO}_{4}, \mathrm{pH} 7.4\right)$ containing $2 \%$ of BSA (PBS-B) and 0.1 $\mu \mathrm{L}$ of Penta His Antibody, BSA-free (Qiagen; diluted 1:500 in PBS-B). After incubation at RT for $40 \mathrm{~min}$, the cells were centrifuged at $4000 \times g$ for $5 \mathrm{~min}$ at $4{ }^{\circ} \mathrm{C}$ and washed three times with $500 \mu \mathrm{L}$ PBS-B. The cells were subsequently incubated with $50 \mu \mathrm{L}$ PBS-B and $0.1 \mu \mathrm{L}$ anti-mouse IgG H\&L/Alexa Flour 488 conjugate (Cell Signaling Technology, Frankfurt am Main, Germany, diluted 1:750 in PBS-B) for $40 \mathrm{~min}$ in the dark at room temperature. After washing five times with $500 \mu \mathrm{L}$ PBS-B, the stained cells were analyzed by flow cytometry using a CytoFLEX Flow Cytometer (Beckman Coulter, Brea, CA, USA) following the manufacturer's instructions. 


\subsection{Temperature Stability and Reusability of Immobilized Enzymes}

The temperature stability of immobilized enzymes was studied by incubating L. plantarum LysM-LacLMLreu- and LysM-LacZLbul-displaying cells in $50 \mathrm{mM} \mathrm{NaPB}$ (pH 6.5) at various temperatures $\left(-20,4,30,50{ }^{\circ} \mathrm{C}\right)$. At certain time intervals, samples were withdrawn, the residual activity was measured using $o \mathrm{NPG}$ as the substrate under standard assay conditions and the $\tau_{1 / 2}$ value was determined.

To test the reusability of immobilized enzymes, several repeated rounds of lactose conversion at $30{ }^{\circ} \mathrm{C}$ using LysM-LacLMLreu- and LysM-LacZLbul-displaying cells and at $50{ }^{\circ} \mathrm{C}$ using LysM-LacZLbul-displaying cells were carried out with $600 \mathrm{mM}$ initial lactose in 50mM NaBP (pH 6.5) and constant agitation $(500 \mathrm{rpm})$. The enzyme activity during these repeated cycles with intermediate two washing steps was measured using oNPG as the substrate under standard assay conditions.

\subsection{Lactose Conversion and Formation of Galacto-Oligosaccharides (GOS)}

The conversion of lactose was carried out in discontinuous mode using L. plantarum cells displaying $\beta$-galactosidase LacZ from L. bulgaricus (LysM-LacZLbul). The conversion was performed at $30^{\circ} \mathrm{C}$ using $205 \mathrm{~g} / \mathrm{L}$ initial lactose concentration in $50 \mathrm{mM} \mathrm{NaPB}$ (pH 6.5) and constant agitation (500 rpm). L. plantarum LysM-LacZLbul displaying cells were added to equivalent concentrations of $1.0 \mathrm{U}_{\mathrm{Lac}} / \mathrm{mL}$ of reaction mixture. Samples were withdrawn at intervals, heated at $99{ }^{\circ} \mathrm{C}$ for 5 min and further analyzed for lactose, galactose, glucose and GOS present in the samples.

\subsection{Analysis of Carbohydrate Composition}

The carbohydrate composition in the reaction mixture was analyzed by high-performance liquid chromatography (HPLC) equipped with a Dionex ICS-5000+ system (Thermo Fisher Scientific) consisting of an ICS-5000+ dual pump (DP) and an electrochemical detector (ED). Separations were performed at room temperature on CarboPac PA- 1 column $(4 \times 250 \mathrm{~mm})$ connected to a CarboPac PA-1 guard column $(4 \times 50 \mathrm{~mm})$ (Thermo Fisher Scientific) with flow rate $1 \mathrm{~mL} / \mathrm{min}$. All eluents A $(150 \mathrm{mM}$ $\mathrm{NaOH}), \mathrm{B}(150 \mathrm{mM} \mathrm{NaOH}$ and $500 \mathrm{mM}$ sodium acetate) and C (deionized water) were degassed by flushing with helium for $30 \mathrm{~min}$. Separation of D-glucose, D-galactose, lactose and allolactose was carried out with a run with the following gradient: $90 \% \mathrm{C}$ with $10 \%$ A for $45 \mathrm{~min}$ at $1.0 \mathrm{~mL} / \mathrm{min}$, followed by $5 \mathrm{~min}$ with $100 \% \mathrm{~B}$. The concentration of saccharides was calculated by interpolation from external standards. Total GOS concentration was calculated by subtraction of the quantified saccharides (lactose, glucose, galactose) from the initial lactose concentration. The GOS yield (\%) was defined as the percentage of GOS produced in the samples compared to initial lactose.

\subsection{Statistical Analysis}

All experiments and measurements were conducted at least in duplicate, and the standard deviation (SD) was always less than $5 \%$. The data are expressed as the mean \pm SD when appropriate.

\section{Conclusions}

This work describes the immobilization of two lactobacillal $\beta$-galactosidases, a $\beta$-galactosidase from $L$. reuteri of the heterodimeric LacLM-type and one from L. bulgaricus of the homodimeric LacZ-type, on the Lactobacillus cell surface using a peptidoglycan-binding motif as an anchor, in this case, the single LysM domain Lp_3014 from L. plantarum WCFS1. The immobilized fusion LysM- $\beta$-galactosidases are catalytically efficient and can be reused for several repeated rounds of lactose conversion. Surface anchoring of $\beta$-galactosidases in Lactobacillus results in safe, non-GMO and stable biocatalysts that can be used in the applications for lactose conversion and production of prebiotic galacto-oligosaccharides.

Author Contributions: Conceptualization, G.M. and T.-H.N.; Data Curation, M.-L.P., G.M. and T.-H.N.; Investigation, M.-L.P., A.-M.T., S.K. and T.-T.N.; Methodology, M.-L.P. and T.-H.N.; Supervision, T.-H.N.; Writing-Original Draft Preparation, M.-L.P.; Writing-Review \& Editing, T.-H.N. 
Funding: M.-L.P. thanks the European Commission for the Erasmus Mundus scholarship under the ALFABET project. S.K. and A.-M.T. are thankful for the Ernst Mach-ASEA Uninet scholarships granted by the OeAD-Austrian Agency for International Cooperation in Education and Research and financed by the Austrian Federal Ministry of Science, Research and Economy. T.-H.N. acknowledges the support from the Austrian Science Fund (FWF Project V457-B22).

Conflicts of Interest: The authors declare no conflict of interest.

\section{References}

1. Nakayama, T.; Amachi, T. $\beta$-Galactosidase, enzymology. In Encyclopedia of Bioprocess Technology, Fermentation, Biocatalysis, and Bioseparation; Flickinger, M.C., Drew, S.W., Eds.; John Willey and Sons: New York, NY, USA, 1999; Volume 3, pp. 1291-1305.

2. Pivarnik, L.F.; Senegal, A.G.; Rand, A.G. Hydrolytic and transgalactosylic activities of commercial $\beta$-galactosidase (lactase) in food processing. Adv. Food Nutr. Res. 1995, 38, 1-102.

3. Prenosil, J.E.; Stuker, E.; Bourne, J.R. Formation of oligosaccharises during enzymatic lactose hydrolysis: Part I: State of art. Biotechnol. Bioeng. 1987, 30, 1019-1025. [CrossRef] [PubMed]

4. Petzelbauer, I.; Zeleny, R.; Reiter, A.; Kulbe, K.D.; Nidetzky, B. Development of an ultra-high-temperature process for the enzymatic hydrolysis of lactose: II. Oligosaccharide formation by two thermostable ß-glycosidases. Biotechnol. Bioeng. 2000, 69, 140-149. [CrossRef]

5. Nguyen, T.H.; Splechtna, B.; Steinböck, M.; Kneifel, W.; Lettner, H.P.; Kulbe, K.D.; Haltrich, D. Purification and characterization of two novel $\beta$-galactosidases from Lactobacillus reuteri. J. Agric. Food Chem. 2006, 54, 4989-4998. [CrossRef]

6. Nguyen, T.H.; Splechtna, B.; Krasteva, S.; Kneifel, W.; Kulbe, K.D.; Divne, C.; Haltrich, D. Characterization and molecular cloning of a heterodimeric $\beta$-galactosidase from the probiotic strain Lactobacillus acidophilus R22. FEMS Microbiol. Lett. 2007, 269, 136-144. [CrossRef] [PubMed]

7. Kittibunchakul, S.; Pham, M.-L.; Tran, A.-M.; Nguyen, T.-H. $\beta$-Galactosidase from Lactobacillus helveticus DSM 20075: Biochemical characterization and recombinant expression for applications in dairy industry. Int. J. Mol. Sci. 2019, 20, 947. [CrossRef] [PubMed]

8. Iqbal, S.; Nguyen, T.H.; Nguyen, T.T.; Maischberger, T.; Haltrich, D. $\beta$-galactosidase from Lactobacillus plantarum WCFS1: Biochemical characterization and formation of prebiotic galacto-oligosaccharides. Carbohydr. Res. 2010, 345, 1408-1416. [CrossRef]

9. Gobinath, D.; Prapulla, S.G. Permeabilized probiotic Lactobacillus plantarum as a source of $\beta$-galactosidase for the synthesis of prebiotic galactooligosaccharides. Biotechnol. Lett. 2013, 36, 153-157. [CrossRef]

10. Iqbal, S.; Nguyen, T.H.; Nguyen, H.A.; Nguyen, T.T.; Maischberger, T.; Kittl, R.; Haltrich, D. Characterization of a heterodimeric GH2 $\beta$-galactosidase from Lactobacillus sakei Lb790 and formation of prebiotic galacto-oligosaccharides. J. Agric. Food Chem. 2011, 59, 3803-3811. [CrossRef] [PubMed]

11. Maischberger, T.; Leitner, E.; Nitisinprasert, S.; Juajun, O.; Yamabhai, M.; Nguyen, T.H.; Haltrich, D. $\beta$-galactosidase from Lactobacillus pentosus: Purification, characterization and formation of galacto-oligosaccharides. Biotechnol. J. 2010, 5, 838-847. [CrossRef]

12. Nguyen, T.T.; Nguyen, H.A.; Arreola, S.L.; Mlynek, G.; Djinović-Carugo, K.; Mathiesen, G.; Nguyen, T.H.; Haltrich, D. Homodimeric $\beta$-galactosidase from Lactobacillus delbrueckii subsp. bulgaricus DSM 20081: Expression in Lactobacillus plantarum and biochemical characterization. J. Agric. Food Chem. 2012, 60, 1713-1721. [CrossRef]

13. Black, B.A.; Lee, V.S.Y.; Zhao, Y.Y.; Hu, Y.; Curtis, J.M.; Ganzle, M.G. Structural identification of novel oligosaccharides produced by Lactobacillus bulgaricus and Lactobacillus plantarum. J. Agric. Food Chem. 2012, 60, 4886-4894. [CrossRef]

14. Liu, G.X.; Kong, J.; Lu, W.W.; Kong, W.T.; Tian, H.; Tian, X.Y.; Huo, G.C. Beta-galactosidase with transgalactosylation activity from Lactobacillus fermentum K4. J. Dairy Sci. 2011, 94, 5811-5820. [CrossRef]

15. Nie, C.; Liu, B.; Zhang, Y.; Zhao, G.; Fan, X.; Ning, X.; Zhang, W. Production and secretion of Lactobacillus crispatus $\beta$-galactosidase in Pichia pastoris. Protein Expr. Purif. 2013, 92, 88-93. [CrossRef] [PubMed]

16. Nguyen, T.H.; Splechtna, B.; Yamabhai, M.; Haltrich, D.; Peterbauer, C. Cloning and expression of the $\beta$-galactosidase genes from Lactobacillus reuteri in Escherichia coli. J. Biotechnol. 2007, 129, 581-591. [CrossRef] 
17. Pham, M.L.; Leister, T.; Nguyen, H.A.; Do, B.C.; Pham, A.T.; Haltrich, D.; Yamabhai, M.; Nguyen, T.H.; Nguyen, T.T. Immobilization of $\beta$-galactosidases from Lactobacillus on chitin using a chitin-binding domain. J. Agric. Food Chem. 2017, 65, 2965-2976. [CrossRef]

18. Michon, C.; Langella, P.; Eijsink, V.G.; Mathiesen, G.; Chatel, J.M. Display of recombinant proteins at the surface of lactic acid bacteria: Strategies and applications. Microb. Cell Fact. 2016, 15, 70. [CrossRef]

19. Nguyen, H.M.; Mathiesen, G.; Stelzer, E.M.; Pham, M.L.; Kuczkowska, K.; Mackenzie, A.; Agger, J.W.; Eijsink, V.G.; Yamabhai, M.; Peterbauer, C.K.; et al. Display of a $\beta$-mannanase and a chitosanase on the cell surface of Lactobacillus plantarum towards the development of whole-cell biocatalysts. Microb. Cell Fact. 2016, 15, 169. [CrossRef] [PubMed]

20. Schneewind, O.; Missiakas, D.M. Protein secretion and surface display in Gram-positive bacteria. Philos. Trans. R. Soc. B Biol. Sci. 2012, 367, 1123-1139. [CrossRef] [PubMed]

21. Leenhouts, K.; Buist, G.; Kok, J. Anchoring of proteins to lactic acid bacteria. Antonie van Leeuwenhoek 1999, 76, 367-376. [PubMed]

22. Proft, T. Sortase-mediated protein ligation: An emerging biotechnology tool for protein modification and immobilisation. Biotechnol. Lett. 2009, 32, 1-10.

23. Diep, D.B.; Mathiesen, G.; Eijsink, V.G.H.; Nes, I.F. Use of lactobacilli and their pheromone-based regulatory mechanism in gene expression and drug delivery. Curr. Pharm. Biotechnol. 2009, 10, 62-73. [CrossRef]

24. Boekhorst, J.; De Been, M.W.H.J.; Kleerebezem, M.; Siezen, R.J. Genome-wide detection and analysis of cell wall-bound proteins with LPxTG-like sorting motifs. J. Bacteriol. 2005, 187, 4928-4934. [CrossRef] [PubMed]

25. Marraffini, L.A.; Dedent, A.C.; Schneewind, O. Sortases and the art of anchoring proteins to the envelopes of gram-positive bacteria. Microbiol. Mol. Biol. Rev. 2006, 70, 192-221. [CrossRef] [PubMed]

26. Visweswaran, G.R.; Leenhouts, K.; van Roosmalen, M.; Kok, J.; Buist, G. Exploiting the peptidoglycan-binding motif, LysM, for medical and industrial applications. Appl. Microbiol. Biotechnol. 2014, 98, 4331-4345. [CrossRef]

27. Turner, M.S.; Hafner, L.M.; Walsh, T.; Giffard, P.M. Identification and characterization of the novel LysM domain-containing surface protein Sep from Lactobacillus fermentum BR11 and its use as a peptide fusion partner in Lactobacillus and Lactococcus. Appl. Environ. Microbiol. 2004, 70, 3673-3680. [CrossRef] [PubMed]

28. Raha, A.R.; Varma, N.R.S.; Yusoff, K.; Ross, E.; Foo, H.L. Cell surface display system for Lactococcus lactis: A novel development for oral vaccine. Appl. Microbiol. Biotechnol. 2005, 68, 75-81. [CrossRef]

29. Steen, A.; Buist, G.; Leenhouts, K.J.; El Khattabi, M.; Grijpstra, F.; Zomer, A.L.; Venema, G.; Kuipers, O.P.; Kok, J. Cell wall attachment of a widely distributed peptidoglycan binding domain is hindered by cell wall constituents. J. Biol. Chem. 2003, 278, 23874-23881. [CrossRef]

30. Okano, K.; Zhang, Q.; Kimura, S.; Narita, J.; Tanaka, T.; Fukuda, H.; Kondo, A. System using tandem repeats of the cA peptidoglycan-binding domain from Lactococcus lactis for display of both $\mathrm{N}$-and C-terminal fusions on cell surfaces of lactic acid bacteria. Appl. Environ. Microbiol. 2008, 74, 1117-1123. [CrossRef] [PubMed]

31. Boekhorst, J.; Wels, M.; Kleeberezem, M.; Siezen, R.J. The predicted secretome of Lactobacillus plantarum WCFS1 sheds light on interactions with its environment. Microbiology 2006, 152, 3175-3183. [CrossRef] [PubMed]

32. Kleerebezem, M.; Boekhorst, J.; van Kranenburg, R.; Molenaar, D.; Kuipers, O.P.; Leer, R.; Tarchini, R.; Peters, S.A.; Sandbrink, H.M.; Fiers, M.W.; et al. Complete genome sequence of Lactobacillus plantarum WCFS1. Proc. Natl. Acad. Sci. USA 2003, 100, 1990-1995. [CrossRef] [PubMed]

33. Mesnage, S.; Tosi-Couture, E.; Fouet, A. Production and cell surface anchoring of functional fusions between the SLH motifs of the Bacillus anthrasis S-layer proteins and the Bacillus subtilis levansucrase. Mol. Microbiol. 1999, 31, 927-936. [CrossRef]

34. Mesnage, S.; Weber-Levy, M.; Haustant, M.; Mock, M.; Fouet, A. Cell surface-exposed tetanus toxin fragment $\mathrm{C}$ produced by recombinant Bacillus anthracis protects against tetanus toxin. Infect. Immun. 1999, 67, 4847-4850.

35. Bosma, T.; Kanninga, R.; Neef, J.; Audouy, S.A.; van Roosmalen, M.L.; Steen, A.; Buist, G.; Kok, J.; Kuipers, O.P.; Robillard, G.; et al. Novel surface display system for proteins on non-genetically modified gram-positive bacteria. Appl. Environ. Microbiol. 2006, 72, 880-889. [CrossRef] [PubMed]

36. Fredriksen, L.; Kleiveland, C.R.; Olsen Hult, L.T.; Lea, T.; Nygaard, C.S.; Eijsink, V.G.H.; Mathiesen, G. Surface display of N-terminally anchored invasin by Lactobacillus plantarum activates NF-kB in monocytes. Appl. Environ. Microbiol. 2012, 78, 5864-5871. [CrossRef] [PubMed] 
37. Kuczkowska, K.; Mathiesen, G.; Eijsink, V.G.H.; Øynebråten, I. Lactobacillus plantarum displaying CCL3 chemokine in fusion with HIV-1 Gag derived antigen causes increased recruitment of T cells. Microb. Cell Fact. 2015, 14, 1. [CrossRef] [PubMed]

38. Desvaux, M.; Dumas, E.; Chafsey, I.; Hebraud, M. Protein cell surface display in Gram-positive bacteria: From single protein to macromolecular protein structure. FEMS Microbiol. Lett. 2006, 256, 1-15. [CrossRef]

39. Joris, B.; Englebert, S.; Chu, C.-P.; Kariyama, R.; Daneo-Moore, L.; Shockman, G.D.; Ghuysen, J.-M. Modular design of the Enterococcus hirae muramidase-2 and Streptococcus faecalis autolysin. FEMS Microbiol. Lett. 1992, 91, 257-264. [CrossRef]

40. Buist, G.; Steen, A.; Kok, J.; Kuipers, O.P. LysM, a widely distributed protein motif for binding to (peptido) glycans. Mol. Microbiol. 2008, 68, 838-847. [CrossRef] [PubMed]

41. Mesnage, S.; Dellarole, M.; Baxter, N.J.; Rouget, J.B.; Dimitrov, J.D.; Wang, N.; Fujimoto, Y.; Hounslow, A.M.; Lacroix-Desmazes, S.; Fukase, K.; et al. Molecular basis for bacterial peptidoglycan recognition by LysM domains. Nat. Commun. 2014, 5, 4269. [CrossRef] [PubMed]

42. Xu, W.; Huang, M.; Zhang, Y.; Yi, X.; Dong, W.; Gao, X.; Jia, C. Novel surface display system for heterogonous proteins on Lactobacillus plantarum. Lett. Appl. Microbiol. 2011, 53, 641-648. [CrossRef] [PubMed]

43. De Man, J.C.; Rogosa, M.; Sharpe, M.E. A medium for the cultivation of lactobacilli. J. Appl. Bacteriol. 1960, 23, 130-135. [CrossRef]

44. Målbakken, N. Development of a Non-GMO Tuberculosis Vaccine, Using Lactobacillus as a Delivery Vehicle. Master's Thesis, Norwegian University of Life Sciences, Ås, Norway, 2014.

45. Bradford, M.M. A rapid and sensitive method for the quantitation of microgram quantities of protein utilizing the principle of protein-dye binding. Anal. Biochem. 1976, 72, 248-254. [CrossRef]

(C) 2019 by the authors. Licensee MDPI, Basel, Switzerland. This article is an open access article distributed under the terms and conditions of the Creative Commons Attribution (CC BY) license (http://creativecommons.org/licenses/by/4.0/). 
Article

\title{
Bacillus subtilis Lipase A-Lipase or Esterase?
}

\author{
Paula Bracco ${ }^{1}$, Nelleke van Midden ${ }^{1}$, Epifanía Arango ${ }^{1}$, Guzman Torrelo ${ }^{1}$, Valerio Ferrario ${ }^{2}$, \\ Lucia Gardossi ${ }^{2}$ and Ulf Hanefeld ${ }^{1, *}$ \\ 1 Biokatalyse, Afdeling Biotechnologie, Technische Universiteit Delft, Van der Maasweg 9, 2629 HZ Delft, The \\ Netherlands; paulabracco@gmail.com (P.B.); nellekevanmidden@gmail.com (N.v.M.); \\ epifaniarango@gmail.com (E.A.); guzman.torrelo@hotmail.com (G.T.) \\ 2 Dipartimento di Scienze Chimiche e Farmaceutiche, Università degli Studi di Trieste, Via Licio Giorgieri 1, \\ 34127 Trieste, Italy; valerio.ferrario@gmail.com (V.F.); gardossi@units.it (L.G.) \\ * Correspondence: u.hanefeld@tudelft.nl; Tel.: +31-15-278-9304
}

Received: 20 February 2020; Accepted: 5 March 2020; Published: 7 March 2020

\begin{abstract}
The question of how to distinguish between lipases and esterases is about as old as the definition of the subclassification is. Many different criteria have been proposed to this end, all indicative but not decisive. Here, the activity of lipases in dry organic solvents as a criterion is probed on a minimal $\alpha / \beta$ hydrolase fold enzyme, the Bacillus subtilis lipase A (BSLA), and compared to Candida antarctica lipase B (CALB), a proven lipase. Both hydrolases show activity in dry solvents and this proves BSLA to be a lipase. Overall, this demonstrates the value of this additional parameter to distinguish between lipases and esterases. Lipases tend to be active in dry organic solvents, while esterases are not active under these circumstances.
\end{abstract}

Keywords: hydrolase; lipase; esterase; Bacillus subtilis lipase A; transesterification; organic solvent; water activity

\section{Introduction}

Lipases and esterases both catalyze the hydrolysis of esters. This has led to the longstanding question: how can we distinguish between a lipase and an esterase? As the simple hydrolysis of an ester does not suffice, a range of different criteria has been suggested [1-5]. (1) The oldest distinction is the kinetic and structural criterion of interfacial activation, which was already described in 1936 [6]. However, several lipases do not fulfill this; in particular, the much-used Candida antarctica lipase B (CALB) does not [7]. (2) Directly linked to the interfacial activation is the lid that covers the active site of many lipases and, via a conformational change, makes the active site more accessible once an interface is present. Again, this is not the case for all lipases [1-3,7,8]. (3) Primary sequence data were shown not to be distinctive enough [2]. (4) Substrates and inhibitors, such as Orlistat, can be utilized to distinguish between esterases and lipases but, again, they are not precise. However, the different substrate ranges are indicative. Esterases tend to be capable of the hydrolysis of water-soluble esters and, in general, short and/or branched side chain esters, while lipases hydrolyze triglycerides, apolar esters, substituted with linear side chains, as well as waxes. This is seen as a reliable but not decisive criterion [2,9]. (5) The activity of the enzyme in the presence of (water-miscible) organic solvents has been proposed as a property of lipases, but other enzymes fulfill this criterion, too [2,10-14]. (6) A parameter already investigated some time ago is the activity of lipases in the absence of water, i.e., in modestly polar, water-non-miscible solvents at very low water activities $\left(\mathrm{a}_{\mathrm{W}}\right)$. Out of all enzymes tested, only lipases and the closely related cutinases are active at low $\mathrm{a}_{\mathrm{w}}[1-5,10,15-19]$. While not all lipases display this property, it is highly distinctive [20,21].

To probe whether $\mathrm{a}_{\mathrm{w}}$ is indeed a suitable parameter to distinguish between lipases and esterases and between lipases and other hydrolases in general, we studied the behavior of Bacillus subtilis 
lipase A (BSLA) [9]. BSLA is a small (181 amino acids, $19 \mathrm{kDa}$ ) serine hydrolase (Figure 1). It is neither interfacially activated nor does it have a lid (criteria one and two) $[9,22-24]$ and sequence data are not conclusive, but it is a minimal $\alpha / \beta$ hydrolase fold enzyme $[9,23,25]$. The substrate range clearly qualifies BSLA as a lipase, as does the stability in the presence of solvents [9,26-29]. This stability has even been significantly improved in recent mutational studies and BSLA mutants can be very stable in the presence of water-miscible solvents, such as dimethyl sulfoxide (DMSO), dioxane and trifluoroethanol [30,31]. Studies on BSLA in dry organic solvents are, however, missing. As an experimental parameter, we demonstrate the activity of BSLA in dry toluene. Toluene is not water-miscible and has a $\log \mathrm{P}$ of 2.5 [32]. It is commonly used in organic synthesis and is highly suitable for lipases and also other enzymes with an $\alpha / \beta$ hydrolase fold. To date, only lipases were shown to be active in toluene with a very low $\mathrm{a}_{\mathrm{w}}[1,3]$.

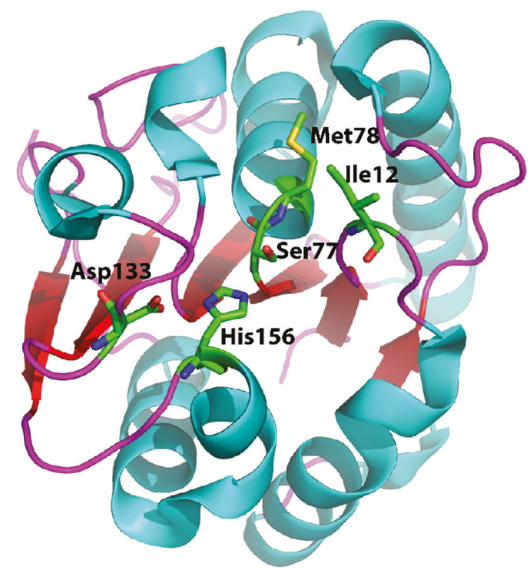

Figure 1. Bacillus subtilis lipase A (BSLA) is the smallest serine hydrolase with an $\alpha / \beta$ hydrolase fold. With only 181 amino acids, it has a molecular weight of $19 \mathrm{kDa}$. The depicted BSLA structure is pdb 1R50 and the catalytic triad His156, Ser77 and Asp133 and the oxyanion hole Ile12 and Met78 are highlighted. The figure was created with PyMOL.

Additionally, we extend the structural assignment of the hydrolase character with the GRID-based (Fortran program [33]) Global Positioning System in Biological Space (Bio GPS) investigation [33]. BioGPS utilizes surface shape and polarity as criteria. It is neither based on direct sequence comparison, nor on structure superimposition [33,34]. Earlier studies with this method had placed CALB in both the esterase and lipase group. CALB works extremely well in dry solvents and is, therefore, often applied in reactions that require these conditions, such as dynamic kinetic resolutions $[1,3,7,35]$. On the other hand, it misses interfacial activation and major conformational changes do not take place when CALB comes into contact with an apolar second phase (see above). As such, BioGPS recognized the ambivalence in the assignment of CALB as a lipase well.

Here, we describe the investigation of BSLA by BioGPS and a comparison to other lipases, in particular CALB. We also probe the lipase character of both BSLA and CALB at different $\mathrm{a}_{\mathrm{w}}$. In this manner, new experimental and computational criteria for the esterases and lipases are introduced and investigated.

\section{Results}

\subsection{BioGPS}

BioGPS descriptors can be utilized to explore enzyme active site properties and to group them according to their similarities and differences. As such, they can help to explore promiscuous activities. 
In an earlier study, the character of CALB was investigated in a set of 42 serine hydrolases. The set contained 11 amidases, nine proteases, 11 esterases and 11 lipases, one of them being CALB [33]. Here, we expand this set with BSLA, utilizing the pdb 1 R50 with a resolution of $1.4 \AA$ for the structural information (Table S1). Three probes were used to map specific electrostatic and geometrical active site properties. The O-probe evaluates the $\mathrm{H}$-bond donor properties of the enzymes; the $\mathrm{N} 1$ probe, on the contrary, evaluates the H-bond acceptor properties and the DRY probe evaluates the hydrophobic interactions [33]. The DRY probe is clearly of special importance for enzymes that accept hydrophobic substrates, as is the case for lipases.

Considering each property separately, the O-probe located BSLA (pdb 1R50) not among the lipases, but in the amidases cluster, together with a number of esterases (Figure S1a). Equally, the N1-probe (Figure S1b) placed BSLA among the amidases. The DRY probe (Figure S1c), again, placed BSLA amongst the amidases and esterases. This is, in all cases, in contrast to CALB (pdb 1TCA) but it should also be noted that Candida rugosa lipase (CRL), a classic lipase with a prominent movement of the lid (criteria one and two) is also always outside the lipase cluster in the different analyses. The previous study ascribed this behavior to the lower hydrophobic nature of the active site of CRL (pdb 1CRL) when compared to the other lipases $[8,33]$.

In the global score, which considers all the mapped properties of the BioGPS together, BSLA can be found firmly among the amidases and esterases (Figure 2), while CALB is in the lipase cluster in the area overlapping with the esterase cluster. CRL, again, is outside the lipase cluster and indeed seems to take a separate position.

\section{Global score}

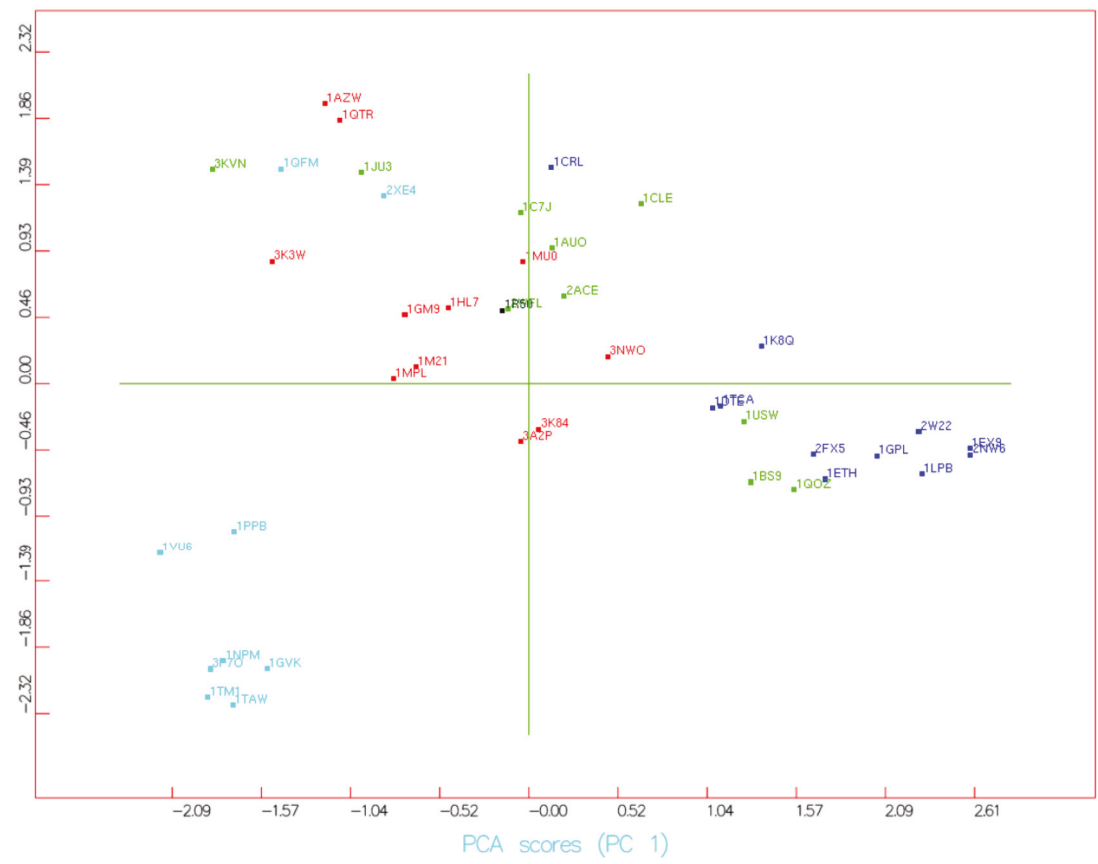

Figure 2. BioGPS of 43 serine hydrolases, for BSLA the data of pdb 1R50 were utilized (global score). Each analyzed enzyme structure is placed within a multidimensional space. Relative distances between each enzyme and all the other enzymes are determined by a statistical principal component analysis. The pdb codes of the processed enzyme structures are indicated in different colors according to their class: lipases in blue, amidases in red, proteases in cyan and esterases in green; the BSLA structure is in black. 
BSLA is, according to its substrate range, very clearly a lipase and not an esterase. Amidase activity has to date not been reported for BSLA. While initially surprising, these results also indicate that the study should be extended with an activity assay for amidases.

\subsection{Amidase Activity}

To probe for amidase activity in BSLA, an amidase activity assay is utilized (Scheme 1). This assay employs benzyl chloroacetamide as standard amide. The released amine reacts with 4-nitro-7-chloro-benzo-2-oxa-1,3-diazole, yielding an adduct that can directly be quantified spectrophotometrically at $475 \mathrm{~nm}$ [36].

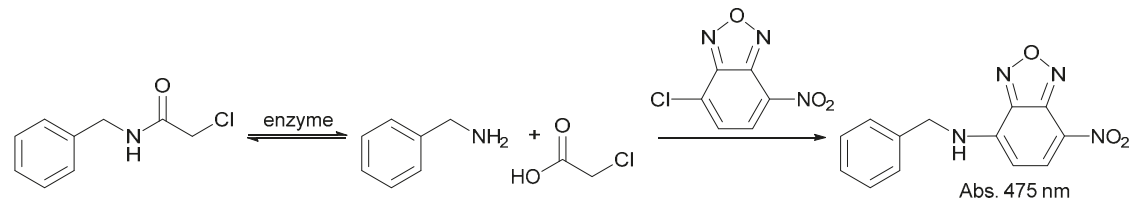

Scheme 1. Amidase activity assay [36]. The assay can be quantified spectrophotometrically. BSLA showed no activity in this assay, ruling out amidase activity.

BSLA showed no activity in this assay. A control experiment with another serine hydrolase, the acyltransferase from Mycobacterium smegmatis (MsAct), was performed. This enzyme is an acyltransferase $[37,38]$ and displays promiscuous amidase activity $[39,40]$. MsAct exhibited activity in this $24 \mathrm{~h}$ assay (>20\% conversion of the $5 \mathrm{mM}$ substrate), showing that even minor, promiscuous activities are detectable. This rules out amidase activity for BSLA and supports the earlier assignment of the enzyme as a lipase.

\subsection{BSLA Activity in Dry Organic Solvents}

To probe the activity of BSLA at low $\mathrm{a}_{\mathrm{w}}$, toluene was used as the solvent and the transesterification of 1-octanol with vinyl acetate was performed as a test reaction (Scheme 2). The use of 1-octanol as a long chain aliphatic compound is a good substrate for lipases [1-5,9] and vinyl acetate is a readily available and widely utilized acyl donor in lipase catalyzed acylation reactions $[1,3,41,42]$. All reactions were performed with lyophilized BSLA. In parallel, CALB was also tested to ensure direct comparability with one of the most-used lipases. CALB was utilized both as lyophilized enzyme and immobilized as Novozym 435. The latter preparation is most commonly employed, both in the laboratory and on industrial scale [43].

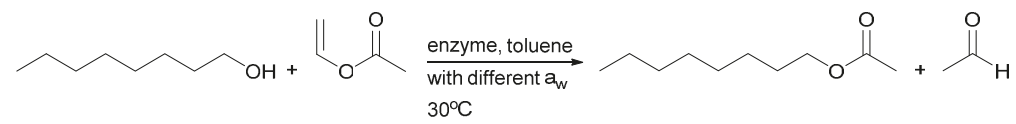

Scheme 2. Test reaction for the activity of BSLA at low $\mathrm{a}_{\mathrm{w}}$. The reaction was performed in toluene at 30 ${ }^{\circ} \mathrm{C}$, with a ratio of 1 -octanol to vinyl acetate of $1: 5$ and $\mathrm{a}_{\mathrm{w}}<0.1,0.23$ and 0.75 .

BSLA and CALB were produced by expressing the codon-optimized genes in E. coli BL21 (DE3) within pET22b. Subsequent purification gave both enzymes a good purity (Figure 3). With this expression system, both enzymes are not glycosylated. The CALB Novozym 435 produced and immobilized by Novozymes, however, is expressed in Aspergillus oryzae and it is, therefore, glycosylated [44]. 


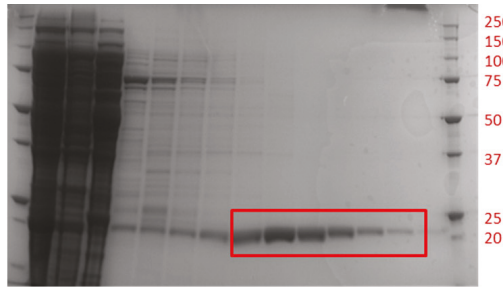

BSLA (19 kDa)

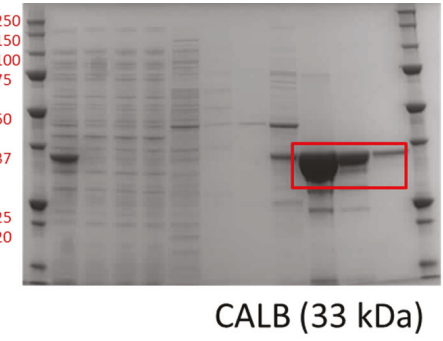

CALB (33 kDa)

Figure 3. Sodium dodecyl sulfate-polyacrylamide gel electrophoresis (SDS-PAGE) gels of purified BSLA (19 kDa) and Candida antarctica lipase B (CALB) (33 kDa).

Three different $\mathrm{a}_{\mathrm{w}}$ were tested $<0.1$ to establish whether BSLA shows the activity in dry solvent only observed for lipases, with $\mathrm{a}_{\mathrm{w}}=0.23$ as a low value at which most enzymes lose all their activity and $\mathrm{a}_{\mathrm{w}}=0.75$, an activity at which most enzymes are active $[10,21,45,46]$. To rigorously ascertain these values of the solvent and reagents, including the internal standard, decane and the enzyme preparations were equilibrated via the vapor phase with dried molecular sieves (activated at elevated temperatures, $5 \AA$ ) for $\mathrm{a}_{\mathrm{w}}<0.1$ [47]. For the other $\mathrm{a}_{\mathrm{w}}$, the enzyme preparations and the other components were equilibrated via the gas phase with an oversaturated solution of potassium acetate $\left(\mathrm{a}_{\mathrm{w}}=0.23\right)$ and sodium chloride $\left(a_{w}=0.75\right)$ [48-52]. For all components, the water content was determined by Karl Fischer titration and equilibrations were considered complete when no changes were observed any more (24-48 h, Table 1). As vinyl acetate was found to negatively affect the Karl Fischer titration, it was freshly distilled and dried with activated molecular sieves for $16 \mathrm{~h}$ before use. The activity of the different enzyme preparations was also followed with the tributyrin and $p$-nitrophenol acetate activity assays [2,5,53-56] during equilibration, to establish optimal equilibration times. For BSLA, a small loss of activity over time was observed, while both CALB preparations were stable.

Table 1. Equilibration to different $a_{w}$ via vapor phase over a saturated solution of salt $[47,51]$ and via the salt pair method [50]. All reaction components, except the acyl donor, were mixed and equilibrated overnight at $30^{\circ} \mathrm{C}$. Finally, dried and freshly distilled vinyl acetate was added in order to start the reaction. The water content was determined by Karl Fischer Titration after $48 \mathrm{~h}$.

\begin{tabular}{cccc}
\hline $\mathbf{a}_{\mathbf{w}}$ & Agent (Vapor Phase or Salt Pair) & Moles of $\mathbf{H}_{\mathbf{2}} \mathbf{O} / \mathbf{m o l}$ of Salt & Water Content (ppm) \\
\hline$<0.1$ & Mol. sieves & 0 & $\sim 20$ \\
0.25 & $\mathrm{NaAc}$ anhydr. (salt pair) & 1.5 & $\sim 180$ \\
0.57 & $\mathrm{Na}_{2} \mathrm{HPO}_{4}$ anhydr. (salt pair) & 5.0 & $\sim 360$ \\
0.23 & $\mathrm{KAc}_{\text {(vapor phase) }}$ & $\mathrm{NA}^{\text {a) }}$ & $\sim 120$ \\
0.75 & $\mathrm{NaCl}$ (vapor phase) & $\mathrm{NA}^{\text {a) }}$ & $\sim 400$ \\
\hline
\end{tabular}

a) Not applicable (NA).

Once reagents and enzymes were equilibrated, the reactions were performed with $100 \mathrm{mM}$ 1-octanol and $500 \mathrm{mM}$ vinyl acetate in previously equilibrated toluene at $30^{\circ} \mathrm{C}$ and $1000 \mathrm{rpm}$ (Figure 4). Equal activity of the enzymes (Units) was utilized as determined with the tributyrin activity assay. CALB and, in particular, the well-established commercial preparation of CALB, Novozym 435, performed very well. In both cases, full conversion to 1-octyl acetate was observed. In comparison, BSLA displayed lower conversions (Figure 4). However, the key indicator for a lipase is its activity at low $a_{w}$. Here, BSLA and Novozym 435 performed best. For the synthesis of 1-octyl acetate, the trend is a reduction in specific rate at higher $\mathrm{a}_{\mathrm{W}}$ (Figure 5). BSLA is very active in dry solvent, as is Novozym 435. Both display lower activities at higher $\mathrm{a}_{\mathrm{w}}$. CALB does not follow this trend. 


\section{BSLA}

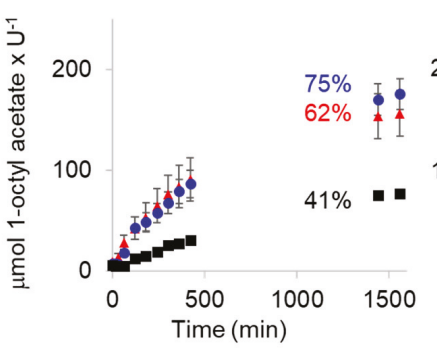

Novozym 435

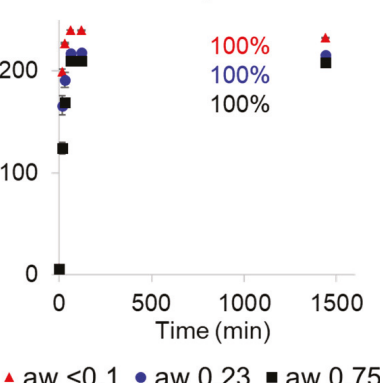

$\Delta$ aw $<0.1 \bullet$ aw 0.23 aw 0.75
CALB

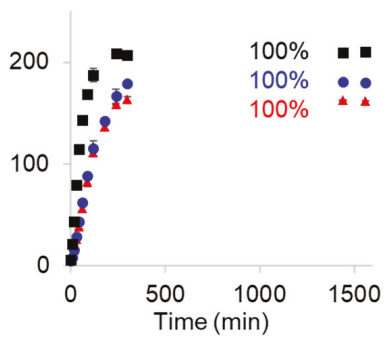

Figure 4. Activity of BSLA, CALB and Novozym 435 in toluene with different $\mathrm{a}_{\mathrm{w}}$. $\mathrm{U}=\mu$ mol butyric acid $\times \mathrm{min}^{-1}$ in tributyrin activity assay, $0.5-1.2 \mathrm{U}$ of catalyst, 1-octanol (100 $\left.\mathrm{mM}\right)$, vinyl acetate (5 eq.), ISTD: Decane (500 mM), $1 \mathrm{~mL}$ reaction volume, $24 \mathrm{~h}, 30^{\circ} \mathrm{C}$ and $1000 \mathrm{rpm}$. Blanks were performed in the absence of enzyme and showed no conversion. Final conversions are given as inset; the color corresponds to the $\mathrm{a}_{\mathrm{w}}$.

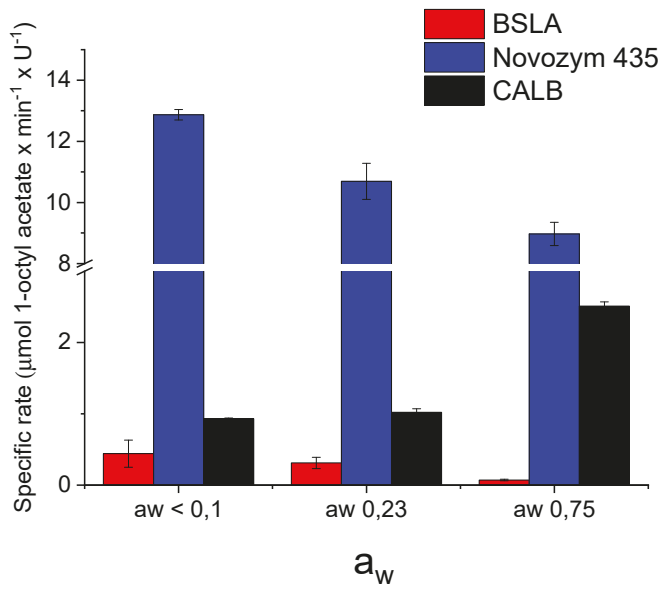

Figure 5. Activity of BSLA, CALB and Novozym 435 in toluene with different $\mathrm{a}_{\mathrm{w}}$. Reaction conditions: 0.5-1.2 U of catalyst, $100 \mathrm{mM}$ 1-octanol, $500 \mathrm{mM}$ vinyl acetate, $500 \mathrm{mM}$ decane (ISTD), in dry toluene (1 mL reaction) at $30^{\circ} \mathrm{C}$ and $1000 \mathrm{rpm}$. U: $\mu \mathrm{mol}$ butyric acid $\times \mathrm{min}^{-1}$. Blanks were performed in the absence of enzyme and showed no conversion.

In an earlier study, it had been demonstrated, for different CALB preparations, that this change in activity in the synthesis reaction to 1-octyl acetate can be due to the hydrolysis of the acyl donor vinyl acetate [47]. Therefore, the synthesis reaction at $\mathrm{a}_{\mathrm{w}}<0.1$ was repeated for BSLA with a 1-octanol to vinyl acetate ratio of 1:1 (Figure 6). Almost the same rate and conversion was observed as with the 1:5 ratio, indicating that, at this low $\mathrm{a}_{\mathrm{w}}$, essentially no hydrolysis occurred, as was the case for Novozym 435, as reported earlier. Overall, these differences in performance at altered $\mathrm{a}_{\mathrm{w}}$ can be ascribed to several influences $[47,57,58]$. Novozyme 435 is an immobilized enzyme and its high activity can be linked to the dispersion of the enzyme on a large surface, promoting its mass transfer and preventing particle aggregation. In contrast, the lyophilized enzymes have a reduced accessibility of the individual enzymes in the preparation. Furthermore, it is well established that immobilized enzymes are better protected against the acetaldehyde that is a side product of the acylation reaction [59]. A 
difference in susceptibility to acetaldehyde induced deactivation might also cause the alterations in rate between the two pure enzymes. However, similarly, ionization and water clustering can influence the activity $[60,61]$, leading to these alterations. To demonstrate that the observed effect is general, the experiments were repeated, but this time with BSLA that was dried by co-lyophilization with a salt to establish the desired $a_{w}[62,63]$. The enzyme is now in a different environment and two different $a_{w}$ were established, $<0.1$ and 0.57. At $<0.1$, very similar results were obtained. Equally, at higher $\mathrm{a}_{\mathrm{w}}$, the ester formation slowed down as before, but could be restarted by adding additional vinyl acetate (Figure 7).

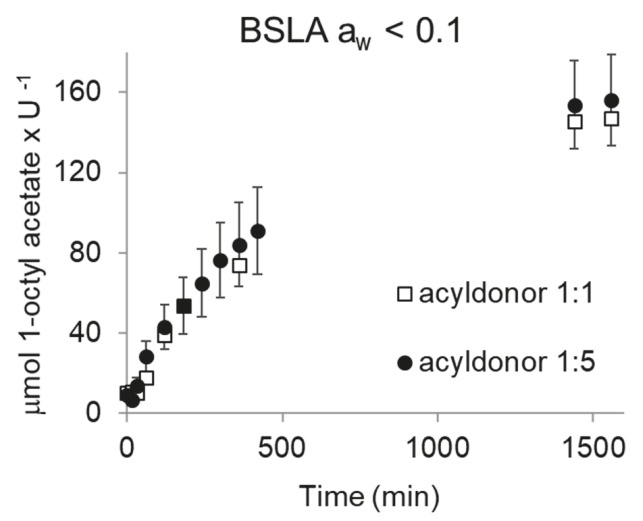

Figure 6. Activity of BSLA, toluene at $\mathrm{a}_{\mathrm{w}}<0.1$. Reaction conditions: $0.5-1.2 \mathrm{U}$ of catalyst, $100 \mathrm{mM}$ 1-octanol, $100 \mathrm{mM}$ or $500 \mathrm{mM}$ vinyl acetate, $500 \mathrm{mM}$ decane (ISTD), in dry toluene (1 $\mathrm{mL}$ reaction) at $30^{\circ} \mathrm{C}$ and $1000 \mathrm{rpm}$. U: $\mu \mathrm{mol}$ butyric acid $\times \mathrm{min}^{-1}$. Blanks were performed in the absence of enzyme and showed no conversion.

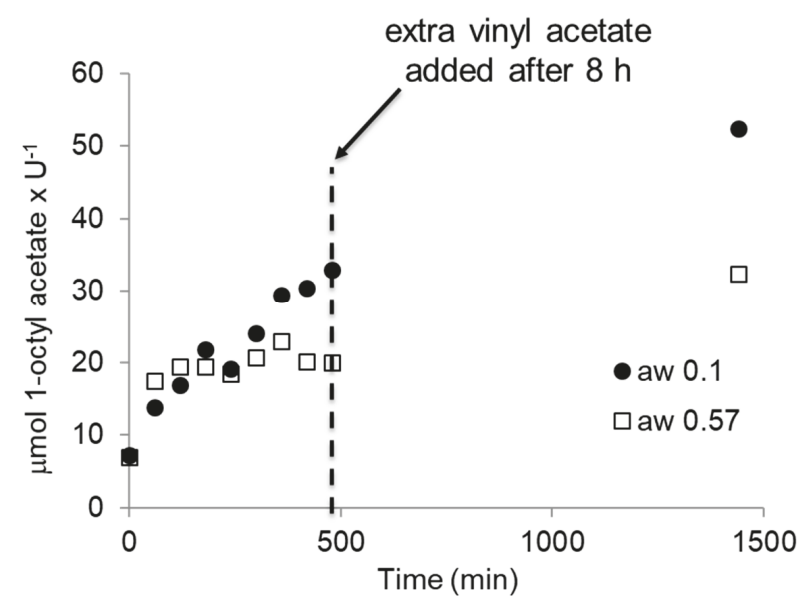

Figure 7. Activity of BSLA co-lyophilized with the appropriate salt, toluene at $\mathrm{a}_{\mathrm{w}}<0.1$ or 0.57 . Reaction conditions: $0.5-1.2 \mathrm{U}$ of catalyst, $100 \mathrm{mM}$ 1-octanol, $100 \mathrm{mM}$ vinyl acetate, $500 \mathrm{mM}$ decane (ISTD), in dry toluene ( $1 \mathrm{~mL}$ reaction) at $30{ }^{\circ} \mathrm{C}$ and $1000 \mathrm{rpm}$. U: $\mu \mathrm{mol}$ butyric acid $\times \mathrm{min}^{-1}$. Blanks were performed in the absence of enzyme, i.e., in the presence of salt, and showed no conversion. After $8 \mathrm{~h}$ (480 $\mathrm{min}$ ) an additional equivalent of vinyl acetate was added. 
To confirm this activity of BSLA (equilibrated via the gas phase) in dry toluene as a general property, the reaction was repeated in dry methyl-t-butyl ether (MTBE) at the same low $\mathrm{a}_{\mathrm{W}}<0.1$. Enzymes display the same activity in organic solvents when these have the same $\mathrm{a}_{\mathrm{w}}$ [64]. Indeed, the BSLA-catalyzed esterification displayed a very similar reaction progress in MTBE and toluene (Figure 8). This confirms the activity of BSLA at low $\mathrm{a}_{\mathrm{w}}$, in line with the earlier observed catalytic activity of CALB at low $\mathrm{a}_{\mathrm{w}}$ [47] and of Rhizomucor miehei lipase at very low $\mathrm{a}_{\mathrm{w}}$ [65].

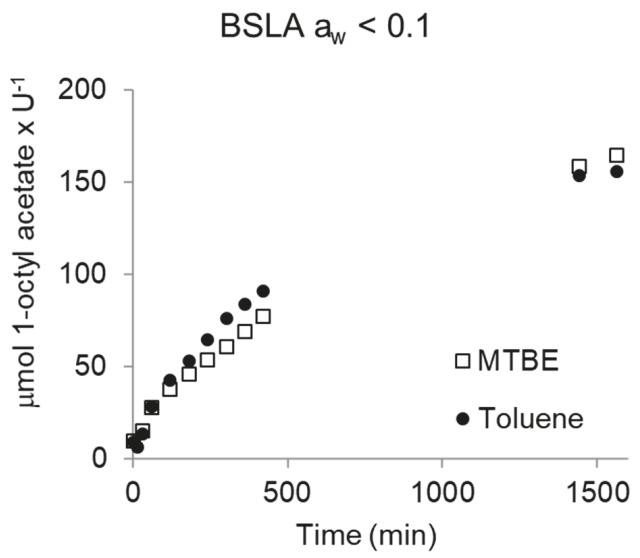

Figure 8. Activity of BSLA, in MTBE and toluene $\mathrm{a}_{\mathrm{w}}<0.1$. Reaction conditions: 0.5-1.2 $\mathrm{U}$ of catalyst, $100 \mathrm{mM}$ 1-octanol, $500 \mathrm{mM}$ vinyl acetate, $500 \mathrm{mM}$ decane (ISTD), in dry solvent $\left(1 \mathrm{~mL}\right.$ reaction) at $30^{\circ} \mathrm{C}$ and $1000 \mathrm{rpm}$. U: $\mu \mathrm{mol}$ butyric acid $\times \mathrm{min}^{-1}$. Blanks were performed in the absence of enzyme and showed no conversion.

\section{Discussion}

Interestingly, the BioGPS analysis seems to identify features of the BSLA active site which are shared by other amidase enzymes. In particular, BSLA seems to share similar H-bond capabilities with amidases, as evidenced by the single-probe clustering. The possible promiscuous amidase activity of BSLA was probed with an amidase activity assay (Scheme 1) [36]. This revealed a complete absence of amidase activity. While indicative, this is not conclusive, as this might also be due to substrate specificity. Amidases are characterized by a developed network of H-bond acceptors and donors as described in previous work [33]. The aromatic moiety of the substrate molecule might thus prevent a good interaction with such H-bond/hydrophilic network. More generally, for amidases, the necessity of a hydrogen bond network that stabilizes the $\mathrm{NH}$ hydrogen to suppress its deprotonation was reported earlier [66]. Given the very open active site of BSLA, the minimal serine hydrolase with an $\alpha / \beta$ hydrolase fold, it is not entirely surprising that this type of hydrogen bond network has never been described for this enzyme.

The test of $\mathrm{a}_{\mathrm{W}}$ as parameter for the assignment of a serine hydrolase as lipase gave conclusive results. BSLA and CALB displayed good activity at low $\mathrm{a}_{\mathrm{w}}$. In line with earlier results, the synthetic catalytic activity of CALB varies depending on the preparation. Earlier studies had shown that the observed synthetic catalytic activity competes with the hydrolytic activity-that is to say, the parallel hydrolysis of vinyl acetate [47]. This can lead to an apparent decrease in synthetic activity, as is observed for Novozym 435 and BSLA at higher $\mathrm{a}_{\mathrm{w}}$ (Figure 5). This trend has already been reported for Novozym 435 [47]. Just like Novozym 435 [47], BSLA displays essentially no hydrolysis of vinyl acetate at low $\mathrm{a}_{\mathrm{w}}<0.1$. This is confirmed in experiments with a ratio of 1:1 of alcohol to vinyl acetate; a similar rate of synthesis was observed (Figures 6 and 7). The fact that free CALB displays higher synthetic rates at higher $a_{w}$ is also in line with the literature [47]. It had earlier been demonstrated for 
CALB that the ratio of synthesis to hydrolysis depends on the preparation of the enzyme used and that it increases with $\mathrm{a}_{\mathrm{w}}$ for purified, free CALB [47]. The activity of BSLA at low $\mathrm{a}_{\mathrm{w}}$ was proven also with a different solvent, MTBE (Figure 8).

BioGPS is a complimentary computational tool to investigate the character of an enzyme and delivers a useful input to help us explore the scope of an enzyme more thoroughly. The parameter $\mathrm{a}_{\mathrm{w}}$ is an indicative tool to determine whether an enzyme is a lipase or and esterase. Just like the substrate scope, it is not absolute, but is highly indicative. Essentially, a serine hydrolase that is active at low $\mathrm{a}_{\mathrm{w}}$ is a lipase and not an esterase, while the reverse statement is not valid. Or, as it was recently summarized: "This long-standing and biased question could be compared to the search for differences between humans and mammals, which implicitly means that one does not consider humans as mammals! Obviously, lipases are a special kind of esterases like humans are a special kind of mammals." [2].

\section{Materials and Methods}

\subsection{Materials}

Chemicals and Enzymes

1-propanol, 1-octanol, toluene extra dry, decane, $p$-nitrophenylbutyrate, $p$-nitrophenol, 3-[(3-cholamidopropyl)dimethylammonio]-1-propanesulfonate (CHAPS), tributyrin and 2-methyl-2-propanol, butyric acid and caprylic acid were purchased from Sigma-Aldrich (Schnelldorf, Germany) and Acros (Geel, Belgium), and used without previous purification. Vinyl acetate was purchased from Sigma-Aldrich and distilled before use. Novozym 435 (immobilized lipase B from Candida antarctica) was made available by Novozymes (Bagsværd, Denmark). Bovine serum albumin protein and lysozyme from chicken egg whites were purchased from Sigma Aldrich. Bradford reagent was purchased from Biorad (Hercules, C.A., USA). Medium and buffer components were purchased from BD, Merck (Darmstadt, Germany) or J.T. Baker (Geel, Belgium).

Strains and Plasmids

Strains Escherichia coli (E. coli) HB2151 and E. coli HB2151 pCANTAB 5E bsla were kindly provided by Prof. Bauke Dijkstra and Prof. Wim Quax, University of Groningen, the Netherlands. Strains Escherichia coli (E. coli) BL21 (DE3), E. coli TOP10 and plasmid pET22b(+) were utilized for all further work.

\subsection{Methods}

Cloning pET22bbsla and pET22bcalb

The gene of BSLA (as confirmed by sequencing ID: CP011115.1, range from 292296 to 292841, protein AKCA5803.1) was amplified by PCR from vector PCANTAB 5E BSLA using primers BSLA F: 5'-CCTTTCTATGCGGCCCAGC-3' and BSLA + Xhol R: 5'-CCGCTCGAGCGCCTTCGTATTCTGG-3' Thereby, restriction site Xhol was introduced for subsequent cloning of BSLA (NcoI, Xhol) into vector $\mathrm{pET} 22 \mathrm{~b}+$ (in frame with pelB and His-tag signals). The resulting vector was named pET22bBSLA. The wild type CALB was synthesized by BaseClear (Leiden, The Netherlands). The codon-optimized genes were cloned into pET22b(+) using the NcoI and NotI restriction sites as previously described [67], in order to be in frame with the pelB sequence and a C-terminal His-tag of the plasmid.

Expression and Purification of BSLA

This protocol was adapted from [24]. A freshly grown colony of E. coli HB 2151 pCANTAB 5E BSLA was used to inoculate a $1 \mathrm{~L}$ shake flask containing $100 \mathrm{~mL}$ of 2 xTY medium $(1.6 \%$ w/v bactotryptone, $1 \% w / v$ bacto yeast extract and $0.5 \% w / v$ sodium chloride), ampicillin (100 $\mu \mathrm{g} / \mathrm{mL}$ final concentration) and isopropyl- $\beta$-d-galactopyranoside (IPTG, $1 \mathrm{mM}$ final concentration). After $16 \mathrm{~h}$ at $28^{\circ} \mathrm{C}$ and $150 \mathrm{rpm}$ (Innova Incubator, Hamburg, Germany) the cells were harvested and washed with 
$10 \mathrm{mM}$ Tris Buffer $\mathrm{pH} 7.4$ and stored at $-20^{\circ} \mathrm{C}$. The periplasm isolation protocol was adapted from [67] and consisted of the resuspension of the overexpressed cells in $1 \mathrm{~mL}$ of $10 \mathrm{mM}$ Tris buffer $\mathrm{pH} 8.0$ containing sucrose $(25 \% w / v)$, EDTA $(2 \mathrm{mM})$ and lysozyme $(0.5 \mathrm{mg} / \mathrm{mL})$. After incubation on ice for 20 $\min , 250 \mu \mathrm{L}$ of $10 \mathrm{mM}$ Tris buffer $\mathrm{pH} 8.0$ containing sucrose $(20 \% w / v)$ and $\mathrm{MgCl}_{2}(125 \mathrm{mM})$ was added. The suspension was centrifuged and the supernatant containing the periplasmic fraction was desalted using a PD10 column (GE, Healthcare, New York, N.Y., USA) to $100 \mathrm{mM}$ potassium phosphate buffer $\mathrm{pH}$ 7.4. Afterwards, the solution was shock-frozen with liquid nitrogen and stored at $-20^{\circ} \mathrm{C}$ for future biocatalysis applications. BSLA was purified mainly from the media. First, proteins were precipitated by adding $50 \% v / v$ saturated ammonium sulphate $\left(2.8 \mathrm{M}\right.$ final concentration) for $5 \mathrm{~h}$ at $4{ }^{\circ} \mathrm{C}$. After centrifugation, the solid fraction was dissolved in $100 \mathrm{~mL}$ of $100 \mathrm{mM}$ potassium phosphate buffer $\mathrm{pH}$ 7.4, filtered through a $0.45 \mu \mathrm{m}$ filter and loaded into a $5 \mathrm{~mL}$ His-Trap previously equilibrated column (GE Healthcare) using a NGC chromatography system (BIORAD, Hercules, C.A., USA). The loaded proteins were washed with equilibration buffer potassium phosphate $(100 \mathrm{mM}, \mathrm{pH} 7.4)$ containing 500 $\mathrm{mM} \mathrm{NaCl}$ and $20 \mathrm{mM}$ imidazole. The His-tagged BSLA was eluted with a linear gradient from $0-100 \%$ potassium phosphate $(100 \mathrm{mM}, \mathrm{pH} 7.4)$ containing $500 \mathrm{mM} \mathrm{NaCl}$ and $500 \mathrm{mM}$ imidazole. The progress of the purification was monitored at $280 \mathrm{~nm}$. Fractions containing the target protein (as confirmed by SDS-PAGE and activity assay, 50-60\% of the gradient) were combined, concentrated and desalted with a PD-10 column (GE Healthcare) to potassium phosphate buffer (100 mM, pH 7.4). The purified enzyme (68-148 $\mu \mathrm{g} / \mathrm{L}$ medium) was aliquoted ( $2.5 \mathrm{U} / \mathrm{vial}$, units determined by tributyrin assay) and freeze dried for $16 \mathrm{~h},-80^{\circ} \mathrm{C}$ and stored at $-20^{\circ} \mathrm{C}$ under nitrogen atmosphere.

Protein Sequence of BSLA-His (AKCA5803.1):

MAAEHNPVVMVHGIGGASFNFAGIKSYLVSQGWSRDKLYAVDFWDKTGTNYNNGPVLSR FVQKVLDETGAKKVDIVAHSMGGANTLYYIKNLDGGNKVANVVTLGGANRLTTGKALPGTDP NQKILYTSIYSSADMIVMNYLSRLDGARNVQIHGVGHIGLLYSSQVNSLIKEGLNGGGQNTKALEH $\mathrm{HHHHH}$

Expression and Purification of CALB

An LB-Amp plate $(100 \mu \mathrm{g} / \mathrm{mL})$ was used to freshly grow E. coli BL21 (DE3) pET22bCALB from a $-80^{\circ} \mathrm{C}$ DMSO stock. After incubation at $37^{\circ} \mathrm{C}$ for $16 \mathrm{~h}$, a single colony was used to inoculate a $5 \mathrm{~mL}$ LB-Amp $(100 \mu \mathrm{g} / \mathrm{mL})$ preculture and grown for $8 \mathrm{~h}$ at the same temperature. Large-scale expressions were carried out in $0.5 \mathrm{~L}$ of ZYM-5052 media (placed in $2 \mathrm{~L}$ shake flask), $2 \% v / v$ of the preculture was used for inoculation. After $17 \mathrm{~h}$ expression at $22{ }^{\circ} \mathrm{C}$ and $170 \mathrm{rpm}$, an optical density $(600 \mathrm{~nm})$ of approximately 3 was obtained in all cases. Afterwards, cells were spun down, washed with $10 \mathrm{mM}$ potassium phosphate buffer $\mathrm{pH} 7.4$ and stored at $-20^{\circ} \mathrm{C}$. ZYM-5052 medium [68]: The main cultures were grown in ZYM-5052 medium containing $50 \mathrm{~mL} 50 \times \mathrm{MM}\left(\mathrm{Na}_{2} \mathrm{HPO}_{4} \cdot 12 \mathrm{H}_{2} \mathrm{O} 448 \mathrm{~g} / \mathrm{L}, \mathrm{KH}_{2} \mathrm{PO}_{4} 170\right.$ $\left.\mathrm{g} / \mathrm{L}, \mathrm{NH}_{4} \mathrm{Cl} 134 \mathrm{~g} / \mathrm{L}, \mathrm{Na}_{2} \mathrm{SO}_{4} 35.5 \mathrm{~g} / \mathrm{L}\right), 20 \mathrm{~mL} 50 x 5052$ (100 g/L $\alpha$-D-lactose, $250 \mathrm{~g} / \mathrm{L}$ glycerol and $25 \mathrm{~g} / \mathrm{L}$ glucose dissolved in $\left.\mathrm{ddH}_{2} \mathrm{O}\right)$ and $2 \mathrm{~mL}$ of $\mathrm{MgSO}_{4}$ solution $\left(1 \mathrm{M}\right.$ in $\left.\mathrm{ddH}_{2} \mathrm{O}\right)$ and filled to $1 \mathrm{~L}$ with $\mathrm{ZY}$ medium (casamino acids $10 \mathrm{~g} / \mathrm{L}$ - tryptone in this case-yeast extract $5 \mathrm{~g} / \mathrm{L}$ ). Additionally, $0.2 \mathrm{~mL}$ of trace element solution was added to the media. The purification of His-tagged CALB was performed from the periplasmic fraction, as described for BSLA in the previous sections.

Protein Sequence of CALB-His (Sequence ID: 4K6G_A):

MALPSGSDPAFSQPKSVLDAGLTCQGASPSSVSKPILLVPGTGTTGPQSFDSNWIPLSTQLGYTPC WISPPPFMLNDTQVNTEYMVNAITALYAGSGNNKLPVLTWSQGGLVAQWGLTFFPSIRSKVDRLMA FAPDYKGTVLAGPLDALAVSAPSVWQQTTGSALTTALRNAGGLTQIVPTTNLYSATDEIVQPQVSNS PLDSSYLFNGKNVQAQAVCGPLFVIDHAGSLTSQFSYVVGRSALRSTTGQARSADYGITDCNPLPAN DLTPEQKVAAAALLAPAAAAIVAGPKQNCEPDLMPYARPFAVGKRTCSGIVTPAAALEHHHHHH

Bradford Assay 
Total protein concentration was determined using Bradford reagent in a microtiter plate (MTP) reader format (96 well plates) [69]. Properly diluted samples were mixed with Bradford reagent (5x), incubated at room temperature (RT) for $5 \mathrm{~min}$ and the absorbance measured at $595 \mathrm{~nm}$ (in triplicate). The calibration curve was carried out using bovine serum albumin protein, as is standard.

Lipase Activity: Tributyrin Assay

A tributyrin assay for determining lipase activity was performed according to the literature [54]. The assay is based on $\mathrm{pH}$ change by acid formation when tributyrin is hydrolyzed by the enzyme. p-Nitrophenol was used as $\mathrm{pH}$ indicator (colorless at $\mathrm{pH} 5.5$ and yellow at $\mathrm{pH} 7.5$ ) and the acid concentration was determined by a calibration curve with known amounts of butyric acid (from $0 \mathrm{mM}$ to $40 \mathrm{mM}$ ). A negative control was performed by adding buffer instead of an enzyme sample. The substrate consumption $\left(0.8 \mathrm{mM}\right.$ initial concentration) was monitored at $410 \mathrm{~nm}, 30^{\circ} \mathrm{C}$ for 15 min, every 38 s by a microtiter plate reader (in 96-well plates, Synergy 2, BioTek, Winooski, V.T., USA). Plates were shaken for $5 \mathrm{~s}$ before every read. The different buffers needed for this assay contained $2.5 \mathrm{mM}$ 3-(N-morpholino)propanesulfonic acid (MOPS) ( $\mathrm{pH} 7.2), \mathrm{CHAPS}$ (to dissolve acids) and $\beta$-cyclodextrin (to dissolve acids into the solution, to increase the linearity). The activity was determined in $U$, which is equivalent to $\mu \mathrm{mol}$ acid formed per minute. The assays were done in triplicate. For performing this assay with immobilized enzymes, a larger scale $(3 \mathrm{~mL})$ in glass vials with a magnetic stirrer was applied. These were placed on a stirring platform and, for Novozym 435 , samples $(120 \mu \mathrm{L})$ were taken over time and placed in a 96-well plate. If desired, the assay can also be performed with Trioctanoin.

Esterase/Lipase Activity: $p$-Nitrophenol Assay

This protocol was adapted from [53] to an MTP reader equipped for 96 well plates. The enzymatic hydrolysis of $p$-nitrophenyl butyrate with the concomitant formation of $p$-nitrophenol was monitored at $405 \mathrm{~nm}, 37^{\circ} \mathrm{C}$ and recorded for $30 \mathrm{~min}$. For this, a calibration curve of $p$-nitrophenol in potassium phosphate buffer $(100 \mathrm{mM}, \mathrm{pH} 7.4)$ was prepared (levels from 0-500 $\mu \mathrm{M}, 200 \mu \mathrm{L}$ total volume, in triplicate) and control reactions without enzyme extracts were performed. Lyophilized cell-free extract or pure enzymes were re-dissolved in potassium phosphate buffer $(100 \mathrm{mM}, \mathrm{pH} 7.4)$ (approximately 20-30 mg/mL) and proper dilutions were added into a preheated potassium phosphate buffer (100 $\mathrm{mM}$, pH 7.4) solution containing $3 \mathrm{mM}$-nitrophenyl butyrate. The esterase activity measured was corrected by subtracting the activity observed in the controls (no enzyme). By definition, one unit of enzyme (U) is equivalent to $1 \mu \mathrm{mol}$ of $p$-nitrophenol formed per minute.

Karl Fischer Titration

A Metrohm KF Coulometer Karl Fischer titration setup was used, according to the manufacturer's instructions, to determine the water content in ppm. Samples $(100 \mu \mathrm{L})$ were taken from the solvent and injected into the system in duplicate. In general, master mixes of toluene after equilibration with $\mathrm{a}_{\mathrm{W}}<0.1, \mathrm{a}_{\mathrm{W}} 0.23$ and $\mathrm{a}_{\mathrm{W}} 0.75$ contained 20,120 and 360 ppm respectively. A deviation of 5-10 ppm per sample was observed.

Equilibration of Solvents/Enzymes to the Desired $\mathrm{a}_{\mathrm{W}}$

All materials, reagents, enzymes and solvents used for the biocatalytic reactions were carefully dried and kept under nitrogen atmosphere with molecular sieves ( $5 \AA$ ) at all times. In all cases, the water content was monitored by Karl Fischer titration and as standard parameter compounds with a water content below 100 ppm were considered dry and suitable for the reaction.

Vapor Phase Method

Oversaturated salt solutions and activated molecular sieves were used to equilibrate the solvents and enzymes needed in the transesterification reaction with a desired water activity [47-50]. In the case of working with dry systems, a master mix was prepared including solvent, substrates (without vinyl acetate) and internal standard, all components previously dried with activated molecular sieves 
achieving $\mathrm{a}_{\mathrm{w}}<0.1$. Lyophilized BSLA, Novozym 435 and CALB were dried over silica in desiccators under a vacuum at room temperature $\left(20-25^{\circ} \mathrm{C}\right)$ for 24,48 and $24 \mathrm{~h}$, respectively. In order to achieve higher water activities, the master mix and the enzymes were equilibrated over saturated salt solutions of potassium acetate $(\mathrm{KAc})$ and sodium chloride $(\mathrm{NaCl})$ at $30^{\circ} \mathrm{C}$ for $48 \mathrm{~h}$, resulting in $\mathrm{a}_{\mathrm{w}} 0.23$ and $\mathrm{a}_{\mathrm{w}}$ 0.75 at $30^{\circ} \mathrm{C}$, respectively [51]. As exceptions, BSLA and free CALB were equilibrated for a shorter period of only $24 \mathrm{~h}$.

\section{Salt Pairs Method}

The protocol was adapted from [62]. The enzymes were lyophilized with anhydrous salts $\left(\mathrm{Na}_{2} \mathrm{HPO}_{4}\right.$ or NaAc) in a ratio 1:99 (3 mg pure BSLA or CALB enzyme and $297 \mathrm{mg}$ of the respective salt). For the background reaction (no-enzyme), only lyophilized salts were added. An amount of $10 \mathrm{mg}$ of the co-lyophilized enzyme was added under a nitrogen atmosphere to the previously dried reaction components (except vinyl acetate) and a specific amount of water was introduced under the nitrogen atmosphere. The moles of water added to the reaction mixture were calculated in order to generate the couple of hepta- and dihydrated phosphates in the case of $\mathrm{Na}_{2} \mathrm{HPO}_{4}(5$ moles of water per mol of salt, $\left.\mathrm{a}_{\mathrm{w}} \sim 0.57\right)$ and the couple of tri- and anhydrous acetate in the case of NaAc (1.5 moles of water per mol of salt, $\mathrm{a}_{\mathrm{w}} \sim 0.25$ ) [50]. After overnight equilibration, the last substrate was added (freshly distilled and dry vinyl acetate) to begin the reaction. In the case of the dry system, no water was added $\left(\mathrm{a}_{\mathrm{W}}<0.1\right)$.

Transesterification Catalyzed by Lipases in Organic Solvents under Fixed Water Activities

The protocol was adapted from [47]. The reaction conditions included substrates 1-propanol, 1-octanol, 2-octanol or benzylacohol (100 mM), vinyl acetate freshly distilled (1 or 5 equiv. in respect to the initial substrate concentration) and decane (ISTD, $500 \mathrm{mM}$ final concentration). A range of $0.5-1$ U of purified enzymes, $1 \mathrm{mg}$ of immobilized Novozym 435 were tested as catalysts. Toluene or methyl-t-butyl ether were used as media ( $1 \mathrm{~mL}$ total volume in GC airtight vials). Reactions were carried out for $25 \mathrm{~h}, 30^{\circ} \mathrm{C}$ and $1000 \mathrm{rpm}$ (thermoblock Eppendorf, Hamburg, Germany). Negative controls were run for both substrates in absence of enzyme. All reactions were performed in duplicate and monitored over time by gas chromatography.

Analytics: GC and GC-MS

Gas chromatograph (GC) and gas chromatograph-mass spectrometry (GC-MS) methods were adapted from [47]. Samples were injected in a gas chromatograph (GC-2014, Shimadzu, Kyoto, Japan) equipped with a CP Sil 5 column $(50 \mathrm{~m} \times 0.53 \mathrm{~mm} \times 1.0 \mathrm{um})$. Injector and detector temperatures were set to 340 and $360{ }^{\circ} \mathrm{C}$, respectively. The initial column temperature was set to $35^{\circ} \mathrm{C}$ for 5 min, followed by an increase of $15{ }^{\circ} \mathrm{C} /$ min up to $60^{\circ} \mathrm{C}$ for $0.5 \mathrm{~min}$ and $15{ }^{\circ} \mathrm{C} / \mathrm{min}$ up to $160{ }^{\circ} \mathrm{C}$ and hold for $2 \mathrm{~min}$. Finally, a burnout was introduced, $30^{\circ} \mathrm{C} / \mathrm{min}$ up to $325^{\circ} \mathrm{C}$. The retention times for 1-propanol, vinyl acetate, toluene, decane, 1-octanol and 1-octylacetate were 1.69, 1.87, 6.64, 10.52, 11.19 and $12.79 \mathrm{~min}$, respectively. To confirm the product's structure, samples were also injected in a gas chromatograph-mass spectrometer (GC-MS QP2010s, Kyoto, Japan) equipped with a CP Sil 5 (25 $\mathrm{m} \times 0.25 \mathrm{~mm} \times 0.4 \mu \mathrm{m})$. The injector, interface and ion source temperatures were set to 315,250 and $200{ }^{\circ} \mathrm{C}$, respectively. The retention times for vinyl acetate, 1 -octanol and 1-octylacetate were 1.78, 11.57 and $12.93 \mathrm{~min}$, respectively.

Amidase Activity Assay: Hydrolysis of Benzyl Chloroacetamide

This protocol was adapted from the literature [36]. The biocatalysis conditions included a total volume $500 \mu \mathrm{L}$ in a $2 \mathrm{~mL}$ Eppendorf tube containing $5 \mathrm{mM}$ benzyl chloroacetamide (stock solution of $500 \mathrm{mM}$ in THF), $100 \mu \mathrm{g} / \mathrm{mL}$ enzyme (as quantified by Bradford assay), in $25 \mathrm{mM}$ potassium phosphate buffer $\mathrm{pH} 7.0$ with $10 \% v / v$ THF. The conversion was carried out for $24 \mathrm{~h}$ at $37^{\circ} \mathrm{C}$ and $500 \mathrm{rpm}$. Afterwards, the derivatization of $200 \mu \mathrm{L}$ of reaction mixture was carried out with $50 \mu \mathrm{L}$ of $\mathrm{NBDCl}(20$ $\mathrm{mM}$ in DMSO) for $1 \mathrm{~h}$, at $37^{\circ} \mathrm{C}$ and $500 \mathrm{rpm}$. UV detection at $475 \mathrm{~nm}$ was performed. 


\section{BSLA Structure}

The structure of BSLA was taken from the Protein Data Bank (PDB). The structure downloaded (1R50) was treated by removing all molecules but the protein chain with the software PyMOL. The thus-generated structure was used for visual inspection with PyMOL as well as input for the BioGPS analysis.

\subsection{BioGPS Computational Analysis}

The BioGPS analysis and projection was taken from the previous published work. The BSLA BioGPS analysis was performed using the BioGPS software provided by Molecular Discovery Ltd. (Borehamwood, Hertfordshire, UK) by projecting the enzyme according to its active site properties in the previously performed analysis. The identification of the BSLA active site and the calculation of its properties has been performed as previously described. Specifically, FLAPsite was used for automatic active site identification. The active site was mapped using a GRID approach and the resulting computed properties were considered as electrondensity-like fields centered on each atom, which correspond to the so-called pseudo-molecular interaction fields (pseudo-MIFs). Four different properties were mapped: the active site shape (H probe), $\mathrm{H}$-bond donor properties (O probe), H-bond acceptor capabilities (N1 probe), and hydrophobicity (DRY probe). The magnitude of the interaction of the N1 and O probes also includes, implicitly, information about the charge contribution, as these probes already have a partially positive and negative charge, respectively. The pseudo-MIF points were filtered, by means of a weighted energy-based and space-coverage function, and then used for the generation of quadruplets obtained from all possible combinations of the four pseudo-MIF points. Thus, the BSLA active site was described by a series of quadruplets. Finally, BSLA was projected according to its series of quadruples and scored by the previously performed BioGPS analysis.

\section{Conclusions}

The longstanding question "what differentiates lipases from esterases?" has led to a list of six parameters that are indicative, but not decisive. Here, we have probed BioGPS and $\mathrm{a}_{\mathrm{w}}$ as parameters to distinguish between lipases and esterases, utilizing the minimal serine hydrolase with an $\alpha / \beta$ fold, BSLA, as a test enzyme. While BioGPS has been used successfully to address similar questions earlier, it was not indicative in this case. The clear assignment of BSLA as either esterase or lipase was a challenging task. The high catalytic activity of BSLA at low $\mathrm{a}_{\mathrm{w}}$ clearly demonstrated this serine hydrolase to be a lipase. In future studies, activity at low $\mathrm{a}_{\mathrm{w}}$ should, therefore, be utilized to support the differentiation of lipases and esterases.

Supplementary Materials: The following file is available online at http://www.mdpi.com/2073-4344/10/3/308/s1, Figure S1: Bio GPS of 43 serine hydrolases, for BSLA the data of pdb 1R50 were utilized: (a) H-bond donor; (b) H-bond acceptor; (c) Hydrophobicity; Table S1: Enzymes utilized for the Bio GPS study with the relevant PDB codes.

Author Contributions: Conceptualization, U.H., L.G., P.B. and G.T.; methodology, P.B., V.F. and G.T.; validation, N.v.M., E.A., P.B. and V.F.; formal analysis, P.B., U.H. and L.G.; investigation, N.v.M., E.A., P.B. and V.F.; resources, U.H. and L.G.; data curation, N.v.M., E.A., P.B. and V.F.; writing-original draft preparation, U.H., P.B. and V.F.; writing-review and editing, U.H. and L.G.; visualization, U.H. and L.G.; supervision, P.B., U.H. and L.G.; project administration, U.H. and L.G.; funding acquisition, U.H. and L.G. All authors have read and agreed to the published version of the manuscript.

Funding: This research was funded by BE-BASIC, grant number FES-0905 to P.B. and G.T. L.G. received funding from the University of Trieste, FRA 2018.

Acknowledgments: Excellent technical support by the technicians of the BOC group and by Linda Otten is gratefully acknowledged. Bauke Dijkstra and Wim Quax, University of Groningen, the Netherlands kindly provided the Escherichia coli (E. coli) HB2151 and E. coli HB2151 pCANTAB 5E bsla. L.G. is grateful to Molecular Discovery Ltd. for providing software access.

Conflicts of Interest: The authors declare no conflict of interest. 


\section{References}

1. Bornscheuer, U.T.; Kazlauskas, R. Hydrolases in Organic Synthesis; Wiley: Hoboken, NJ, USA, 2005; pp. 61-184.

2. Ben Ali, Y.; Verger, R.; Abousalham, A. Lipases or Esterases: Does It Really Matter? Toward a New Bio-Physico-Chemical Classification. In Lipases and Phospholipases: Methods and Protocols; Book Series: Methods in Molecular Biology; Sandoval, G., Ed.; Springer Science+Business Media: New York, NY, USA, 2012; Volume 861, pp. 31-51.

3. Paravidino, M.; Bohm, P.; Gröger, H.; Hanefeld, U. Hydrolysis and Formation of Carboxylic Acid Esters. In Enzyme Catalysis in Organic Synthesis; Wiley: Hoboken, NJ, USA, 2012; pp. 249-362.

4. Arpigny, J.L.; Jaeger, K.E. Bacterial lipolytic enzymes: Classification and properties. Biochem. J. 1999, 343, 177-183. [CrossRef]

5. Jaeger, K.-E.; Kovacic, F. Determination of Lipolytic Enzyme Activities. In Pseudomonas Methods and Protocols; Book Series: Methods in Molecular Biology; Filloux, A., Ramos, J.L., Eds.; Springer Science+Business Media: New York, NY, USA, 2014; Volume 1149, pp. 111-134.

6. Holwerda, K.; Verkade, P.E.; De Willigen, A.H.A. Vergleichende Untersuchungen über die Verseifungsgeschwindigkeit einiger Einsäuriger Triglyceride unter Einfluss von Pankreasextrakt. I. Der Einfluss des Verteilungszustandes der Triglyceride auf die Verseifungsgeschwindigkeit. Rec. Trav. Chim. Pays Bas 1936, 55, 43-57. [CrossRef]

7. Kirk, O.; Christensen, M.W. Lipases from Candida antarctica: Unique Biocatalysts from a Unique Origin. Org. Proc. Res. Develop. 2002, 6, 446-451. [CrossRef]

8. Grochulski, P.; Li, Y.; Schrag, J.D.; Cygler, M. Two conformational states of Candida rugosa lipase. Protein Sci. 1994, 3, 82-91. [CrossRef]

9. $\quad$ Eggert, T.; van Pouderoyen, G.; Pencreac'h, G.; Douchet, I.; Verger, R.; Dijkstra, B.W.; Jaeger, K.-E. Biochemical properties and three-dimensional structures of two extracellular lipolytic enzymes from Bacillus subtilis. Colloids Surf. B Biointerfaces 2002, 26, 37-46. [CrossRef]

10. Adlercreutz, P. Comparison of lipases and glycoside hydrolases as catalysts in synthesis reactions. Appl. Microbiol. Biotechnol. 2017, 101, 513-519. [CrossRef]

11. Lopes, D.B.; Fraga, L.P.; Fleuri, L.F.; Macedo, G.A. Lipase and esterase-To what extent can this classification be applied accurately? Ciênc. Tecnol. Aliment. Camp. 2011, 31, 608-613. [CrossRef]

12. Berlemont, R.; Spee, O.; Delsaute, M.; Lara, Y.; Schuldes, J.; Simon, C.; Power, P.; Daniel, R.; Galleni, M. Novel organic solvent-tolerant esterase isolated by metagenomics: Insights into the lipase/esterase classification. Rev. Argent. Microbiol. 2013, 45, 3-12.

13. Adlercreutz, P. Fundamentals of Biocatalysis in Neat Organic Solvents. In Organic Synthesis with Enzymes in Non-Aqueous Media; Carrea, G., Riva, S., Eds.; WILEY-VCH Verlag GmbH \& Co. KGaA: Weinheim, Germany, 2008; pp. 3-24.

14. Serdakowski, A.L.; Dordick, J.S. Activating Enzymes for Use in Organic Solvents. In Organic Synthesis with Enzymes in Non-Aqueous Media; Carrea, G., Riva, S., Eds.; WILEY-VCH Verlag GmbH \& Co. KGaA: Weinheim, Germany, 2008; pp. 47-74.

15. Svensson, I.; Wehtje, E.; Adlercreutz, P.; Mattiasson, B. Effects of water activity on reaction rates and equilibrium positions in enzymatic esterifications. Biotechnol. Bioeng. 1994, 44, 549-556. [CrossRef]

16. Wehtje, E.; Svensson, I.; Adlercreutz, P.; Mattiasson, B. Continuous control of water activity during biocatalysis in organic media. Biotechnol. Tech. 1993, 7, 873-878. [CrossRef]

17. Ferrario, V.; Pellis, A.; Cespugli, M.; Guebitz, G.; Gardossi, L. Nature Inspired Solutions for Polymers: Will Cutinase Enzymes Make Polyesters and Polyamides Greener? Catalysts 2016, 6, 205. [CrossRef]

18. Pellis, A.; Ferrario, V.; Zartl, B.; Brandauer, M.; Gamerith, C.; Acero, E.H.; Ebert, C.; Gardossi, L.; Guebitz, G.M. Enlarging the tools for efficient enzymatic polycondensation: Structural and catalytic features of cutinase 1 from Thermobifida cellulosilytica. Catal. Sci. Technol. 2016, 6, 3430-3442. [CrossRef]

19. Pellis, A.; Ferrario, V.; Cespugli, M.; Corici, L.; Guarneri, A.; Zartl, B.; Acero, E.H.; Ebert, C.; Guebitz, G.; Gardossi, L. Fully renewable polyesters via polycondensation catalyzed by Thermobifida cellulosilytica cutinase 1: An integrated approach. Green Chem. 2017, 19, 490-502. [CrossRef]

20. Valivety, R.H.; Halling, P.J.; Peilow, A.D.; Macrae, A.R. Relationship between water activity and catalytic activity of lipases in organic media. Effects of supports, loading and enzyme preparation. Eur. J. Biochem. 1994, 222, 461-466. [CrossRef] 
21. Valivety, R.H.; Halling, P.J.; Peilow, A.D.; Macrae, A.R. Lipases from different sources vary widely in dependence of catalytic activity on water activity. Biochim. Biophys. Acta Protein Struct. Mol. Enzym. 1992, 1122, 143-146. [CrossRef]

22. Gupta, R.; Gupta, N.; Rathi, P. Bacterial lipases: An overview of production, purification and biochemical properties. Appl. Microbiol. Biotechnol. 2004, 64, 763-781. [CrossRef]

23. Eggert, T.; van Pouderoyen, G.; Dijkstra, B.W.; Jaeger, K.-E. Lipolytic enzymes LipA and LipB from Bacillus subtilis differ in regulation of gene expression, biochemical properties, and three-dimensional structure. FEBS Lett. 2001, 502, 89-92. [CrossRef]

24. Boersma, Y.L.; Pijning, T.; Bosma, M.S.; van der Sloot, A.; Godinho, L.F.; Dröge, M.J.; Winter, R.T.; van Pouderoyen, G.; Dijkstra, B.W.; Quax, W.J. Loop Grafting of Bacillus subtilis Lipase A: Inversion of Enantioselectivity. Chem. Biol. 2008, 15, 782-789. [CrossRef]

25. van Pouderoyen, G.; Eggert, T.; Jaeger, K.-E.; Dijkstra, B.W. The crystal structure of Bacillus subtilis lipase: A minimal $\alpha / \beta$ hydrolase fold enzyme. J. Mol. Biol. 2001, 309, 215-226. [CrossRef]

26. Augustyniak, W.; Brzezinska, A.A.; Pijning, T.; Wienk, H.; Boelens, R.; Dijkstra, B.W.; Reetz, M.T. Biophysical characterization of mutants of Bacillus subtilis lipase evolved for thermostability: Factors contributing to increased activity retention. Protein Sci. 2012, 21, 487-497. [CrossRef]

27. Kamal, Z.; Ahmad, S.; Molugu, T.R.; Vijayalakshmi, A.; Deshmukh, M.V.; Sankaranarayanan, R.; Rao, N.M. In Vitro Evolved Non-Aggregating and Thermostable Lipase: Structural and Thermodynamic Investigation. J. Mol. Biol. 2011, 413, 726-741. [CrossRef]

28. Ahmad, S.; Kamal, Z.; Sankaranarayanan, R.; Rao, N.M. Thermostable Bacillus subtilis Lipases: In Vitro Evolution and Structural Insight. J. Mol. Biol. 2008, 381, 324-340. [CrossRef]

29. Rajakumara, E.; Acharya, P.; Ahmad, S.; Sankaranaryanan, R.; Rao, N.M. Structural basis for the remarkable stability of Bacillus subtilis lipase (Lip A) at low pH. Biochim. Biophys. Acta Proteins Proteom. 2008, 1784, 302-311. [CrossRef]

30. Frauenkron-Machedjou, V.J.; Fulton, A.; Zhao, J.; Weber, L.; Jaeger, K.E.; Schwaneberg, U.; Zhu, L. Exploring the full natural diversity of single amino acid exchange reveals that 40-60\% of BSLA positions improve organic solvents resistance. Bioresour. Bioprocess. 2018, 5, 2. [CrossRef]

31. Markel, U.; Zhu, L.; Frauenkron-Machedjou, V.J.; Zhao, J.; Bocola, M.; Davari, M.D.; Jaeger, K.-E.; Schwaneberg, U. Are Directed Evolution Approaches Efficient in Exploring Nature's Potential to Stabilize a Lipase in Organic Cosolvents? Catalysts 2017, 7, 142. [CrossRef]

32. Laane, C.; Boeren, S.; Vos, K.; Veeger, C. Rules for optimization of biocatalysis in organic solvents. Biotechnol. Bioeng. 1987, 30, 81-87. [CrossRef]

33. Ferrario, V.; Siragusa, L.; Ebert, C.; Baroni, M.; Foscato, M.; Cruciani, G.; Gardossi, L. BioGPS Descriptors for Rational Engineering of Enzyme Promiscuity and Structure Based Bioinformatic Analysis. PLoS ONE 2014, 9, 109354. [CrossRef]

34. Cross, S.; Baroni, M.; Goracci, L.; Cruciani, G. GRID-Based Three-Dimensional Pharmacophores I: FLAPpharm, a Novel Approach for Pharmacophore Elucidation. J. Chem. Inf. Model. 2012, 52, 2587-2598. [CrossRef]

35. Veum, L.; Kanerva, L.T.; Halling, P.J.; Maschmeyer, T.; Hanefeld, U. Optimisation of the Enantioselective Synthesis of Cyanohydrin Esters. Adv. Synth. Catal. 2005, 347, 1015-1021. [CrossRef]

36. Henke, E.; Bornscheuer, U.T. Fluorophoric Assay for the High-Throughput Determination of Amidase Activity. Anal. Chem. 2003, 75, 255-260. [CrossRef]

37. Mathews, I.; Soltis, M.; Saldajeno, M.; Ganshaw, G.; Sala, R.; Weyler, W.; Cervin, M.A.; Whited, G.; Bott, R. Structure of a Novel Enzyme That Catalyzes Acyl Transfer to Alcohols in Aqueous Conditions. Biochemistry 2007, 46, 8969-8979. [CrossRef] [PubMed]

38. Mestrom, L.; Claessen, J.G.R.; Hanefeld, U. Enzyme-Catalyzed Synthesis of Esters in Water. ChemCatChem 2019, 11, 2004-2010. [CrossRef]

39. Land, H.; Hendil-Forssell, P.; Martinelle, M.; Berglund, P. One-pot biocatalytic amine transaminase/acyl transferase cascade for aqueous formation of amides from aldehydes or ketones. Catal. Sci. Technol. 2016, 6, 2897-2900. [CrossRef]

40. Contente, M.L.; Farris, S.; Tamborini, L.; Molinari, F.; Paradisi, F. Flow-based enzymatic synthesis of melatonin and other high value tryptamine derivatives: A five-minute intensified process. Green Chem. 2019, 21, 3263-3266. [CrossRef] 
41. Hanefeld, U. Reagents for (ir)reversible enzymatic acylations. Org. Biomol. Chem. 2003, 1, 2405-2415. [CrossRef]

42. Paravidino, M.; Hanefeld, U. Enzymatic acylation: Assessing the greenness of different acyl donors. Green Chem. 2011, 13, 2651-2657. [CrossRef]

43. Ortiz, C.; Ferreira, M.L.; Barbosa, O.; dos Santos, J.C.S.; Rodrigues, R.C.; Berenguer-Murcia, Á.; Briand, E.L.; Fernandez-Lafuente, R. Novozym 435: The "perfect" lipase immobilized biocatalyst? Catal. Sci. Technol. 2019, 9, 2380-2420. [CrossRef]

44. Basso, A.; Braiuca, P.; Cantone, S.; Ebert, C.; Linda, P.; Spizzo, P.; Caimi, P.; Hanefeld, U.; Degrassi, G.; Gardossi, L. In Silico Analysis of Enzyme Surface and Glycosylation Effect as a Tool for Efficient Covalent Immobilisation of CalB and PGA on Sepabeads ${ }^{\circledR}$. Adv. Synth. Catal. 2007, 349, 877-886. [CrossRef]

45. Ma, L.; Persson, M.; Adlercreutz, P. Water activity dependence of lipase catalysis in organic media explains successful transesterification reactions. Enzym. Microb. Technol. 2002, 31, 1024-1029. [CrossRef]

46. Paravidino, M.; Sorgedrager, M.J.; Orru, R.V.A.; Hanefeld, U. Activity and Enantioselectivity of the Hydroxynitrile Lyase MeHNL in Dry Organic Solvents. Chem. Eur. J. 2010, 16, 7596-7604. [CrossRef]

47. Secundo, F.; Carrea, G.; Soregaroli, C.; Varinelli, D.; Morrone, R. Activity of different Candida antarctica lipase B formulations in organic solvents. Biotechnol. Bioeng. 2001, 73, 157-163. [CrossRef]

48. Valivety, R.H.; Halling, P.J.; Macrae, A.R. Reaction rate with suspended lipase catalyst shows similar dependence on water activity in different organic solvents. Biochim. Biophys. Acta Protein Struct. Mol. Enzym. 1992, 1118, 218-222. [CrossRef]

49. Fontes, N.; Partridge, J.; Halling, P.J.; Barreiros, S. Zeolite molecular sieves have dramatic acid-base effects on enzymes in nonaqueous media. Biotechnol. Bioeng. 2002, 77, 296-305. [CrossRef] [PubMed]

50. Halling, P.J. Salt hydrates for water activity control with biocatalysts in organic media. Biotechnol. Tech. 1992, 6, 271-276. [CrossRef]

51. Greenspan, L. Humidity fixed points of binary saturated aqueous solutions. J. Res. Natl. Bur. Stand. Sect. A Phys. Chem. 1977, 81, 89-96. [CrossRef]

52. Johnson, J.R.; Affsprung, H.E.; Christian, S.D. The molecular complexity of water in organic solvents. Part II. J. Chem. Soc. A 1966, 77-78. [CrossRef]

53. Gupta, R.; Rathi, P.; Gupta, N.; Bradoo, S. Lipase assays for conventional and molecular screening: An overview. Biotechnol. Appl. Biochem. 2003, 37, 63-71. [CrossRef]

54. Mateos-Díaz, E.; Rodríguez, J.A.; de los Ángeles Camacho-Ruiz, M.; Mateos-Díaz, J.C. High-Throughput Screening Method for Lipases/Esterases. In Lipases and Phospholipases: Methods and Protocols; Book Series: Methods in Molecular Biology; Sandoval, G., Ed.; Springer Science + Business Media: New York, NY, USA, 2012; Volume 861, pp. 89-100.

55. Híreš, M.; Rapavá, N.; Šimkovič, M.; Varečka, L'.; Berkeš, D.; Kryštofová, S. Development and Optimization of a High-Throughput Screening Assay for Rapid Evaluation of Lipstatin Production by Streptomyces Strains. Curr. Microbiol. 2018, 75, 580-587. [CrossRef]

56. Nalder, T.D.; Ashton, T.D.; Pfeffer, F.M.; Marshall, S.N.; Barrow, C.J. 4-Hydroxy-N-propyl-1,8-naphthalimide esters: New fluorescence-based assay for analysing lipase and esterase activity. Biochimie 2016, 128-129, 127-132. [CrossRef]

57. Corici, L.; Ferrario, V.; Pellis, A.; Ebert, C.; Lotteria, S.; Cantone, S.; Voinovich, D.; Gardossi, L. Large scale applications of immobilized enzymes call for sustainable and inexpensive solutions: Rice husk as renewable alternative to fossil-based organic resins. RSC Adv. 2016, 6, 63256-63270. [CrossRef]

58. Secundo, F.; Carrea, G. Lipase activity and conformation in neat organic solvents. J. Mol. Catal. B Enzym. 2002, 19-20, 93-102. [CrossRef]

59. Hanefeld, U.; Gardossi, L.; Magner, E. Understanding enzyme immobilisation. Chem. Soc. Rev. 2009, 38, 453-468. [CrossRef] [PubMed]

60. Stauch, B.; Fisher, S.J.; Cianci, M. Open and closed states of Candida antarctica lipase B: Protonation and the mechanism of interfacial activation. J. Lipid Res. 2015, 56, 2348-2358. [CrossRef] [PubMed]

61. Banik, S.D.; Nordblad, M.; Woodley, J.M.; Peters, G.H. Effect of Water Clustering on the Activity of Candida antarctica Lipase B in Organic Medium. Catalysts 2017, 7, 227. [CrossRef]

62. Ebert, C.; Gardossi, L.; Linda, P. Control of enzyme hydration in penicillin amidase catalysed synthesis of amide bond. Tetrahedron Lett. 1996, 37, 9377-9380. [CrossRef] 
63. Ru, M.T.; Dordick, J.S.; Reimer, J.A.; Clark, D.S. Optimizing the salt-induced activation of enzymes in organic solvents: Effects of lyophilization time and water content. Biotechnol. Bioeng. 1999, 63, 233-241. [CrossRef]

64. Partridge, J.; Dennison, P.R.; Moore, B.D.; Halling, P.J. Activity and mobility of subtilisin in low water organic media: Hydration is more important than solvent dielectric. Biochim. Biophys. Acta Protein Struct. Mol. Enzym. 1998, 1386, 79-89. [CrossRef]

65. Valivety, R.H.; Halling, P.J.; Macrae, A.R. Rhizomucor miehei lipase remains highly active at water activity below 0.0001. FEBS Lett. 1992, 301, 258-260. [CrossRef]

66. Syrén, P.-O.; Hult, K. Amidases Have a Hydrogen Bond that Facilitates Nitrogen Inversion, but Esterases Have Not. ChemCatChem 2011, 3, 853-860. [CrossRef]

67. Larsen, M.W.; Zielinska, D.F.; Martinelle, M.; Hidalgo, A.; Jensen, L.J.; Bornscheuer, U.T.; Hult, K. Suppression of Water as a Nucleophile in Candida antarctica Lipase B Catalysis. ChemBioChem 2010, 11, 796-801. [CrossRef]

68. Studier, F.W. Protein production by auto-induction in high-density shaking cultures. Protein Expr. Purif. 2005, 41, 207-234. [CrossRef] [PubMed]

69. Bradford, M.M. A rapid and sensitive method for the quantitation of microgram quantities of protein utilizing the principle of protein-dye binding. Anal. Biochem. 1976, 72, 248-254. [CrossRef] 

Article

\title{
Hydrolysis of Glycosyl Thioimidates by Glycoside Hydrolase Requires Remote Activation for Efficient Activity
}

\author{
Laure Guillotin $^{1}$, Zeinab Assaf ${ }^{1}$, Salvatore G. Pistorio ${ }^{2}$, Pierre Lafite ${ }^{1}$, Alexei V. Demchenko ${ }^{2}$ \\ and Richard Daniellou ${ }^{1, *}$ \\ 1 Institut de Chimie Organique et Analytique, ICOA, Université d'Orléans, CNRS, UMR 7311, BP6759 Rue de \\ Chartres, F-45067 Orléans CEDEX 2, France; guillotin.laure@gmail.com (L.G.); \\ assaf_zeinab@hotmail.fr (Z.A.); pierre.lafite@univ-orleans.fr (P.L.) \\ 2 Department of Chemistry and Biochemistry, University of Missouri-St. Louis, One University Boulevard, \\ St. Louis, MO 63121, USA; salvopistorio@hotmail.com (S.G.P.); demchenkoa@umsl.edu (A.V.D.) \\ * Correspondence: richard.daniellou@univ-orleans.fr; Tel.: +33-2-38-49-49-78
}

Received: 18 September 2019; Accepted: 30 September 2019; Published: 1 October 2019

\begin{abstract}
Chemoenzymatic synthesis of glycosides relies on efficient glycosyl donor substrates able to react rapidly and efficiently, yet with increased stability towards chemical or enzymatic hydrolysis. In this context, glycosyl thioimidates have previously been used as efficient donors, in the case of hydrolysis or thioglycoligation. In both cases, the release of the thioimidoyl aglycone was remotely activated through a protonation driven by a carboxylic residue in the active site of the corresponding enzymes. A recombinant glucosidase (DtGly) from Dictyoglomus themophilum, previously used in biocatalysis, was also able to use such glycosyl thioimidates as substrates. Yet, enzymatic kinetic values analysis, coupled to mutagenesis and in silico modelling of $D t G l y /$ substrate complexes demonstrated that the release of the thioimidoyl moiety during catalysis is only driven by its leaving group ability, without the activation of a remote protonation. In the search of efficient glycosyl donors, glycosyl thioimidates are attractive and efficient. Their utility, however, is limited to enzymes able to promote leaving group release by remote activation.
\end{abstract}

Keywords: glycoside hydrolase; thioglycosides; biocatalysis

\section{Introduction}

Enzymes proved to be efficient synthetic tools for the eco-compatible synthesis of many classes of compounds. Non-organic solvents, mild experimental conditions and high regio- or stereo- specificity inherent to biocatalyzed reactions have increased the added value of enzymes in transformation processes, from the laboratory bench to the industrial scale [1]. Moreover, genetic modifications of recombinant enzymes are now powerful tools to easily alter versatility and properties of the engineered proteins. Rational mutagenesis, directed evolution, or even de novo design have dramatically broadened the applicability of enzymes in biocatalysis [2].

In the glycochemistry field, a vast array of carbohydrate-metabolizing enzymes (CAZYmes), including glycoside hydrolases (GH) or glycosyltransferases (GT), has been engineered and used for the chemo-enzymatic synthesis of glycosides [3]. The corresponding methodologies have proved useful in numerous applications ranging from glycosylated natural products to pharmaceuticals $[4,5]$. However, only few examples in the literature have been describing the use of CAZYmes for the preparation of synthetic thioglycosides that exhibit a sulphur atom linking the glycone and aglycone counterparts instead of more conventional oxygen or nitrogen atoms [6]. Interestingly, when compared to the corresponding $\mathrm{O}$-glycosides, $\mathrm{S}$-glycosides are highly stable towards enzymatic and acidic hydrolyses. 
As a result, thioglycosides have been used as substrate analogues or inhibitors of $O-G H$ involved in many diseases including cancer, lysosomal storage disorder, viral and bacterial infections [7,8].

Activated glycosyl donors have been used for a long time, especially in chemoenzymatic synthesis of oligosaccharides [9-11]. In retaining GH, where the stereochemistry of the anomeric carbon is conserved, these activated donors are of high interest because they enable the formation of the glycosyl-enzyme intermediate through the release of the leaving group (Figure 1). This first step is common to all enzymatic activities (hydrolase [12], transglycosidase [13], halogenase [12] and thioligase [14]) because the final outcome of the reaction only depends on the nature of the nucleophile that will attack the glycosyl-enzyme intermediate in the second step. Depending on the reaction and the substrate employed, this step can be rate-determining.

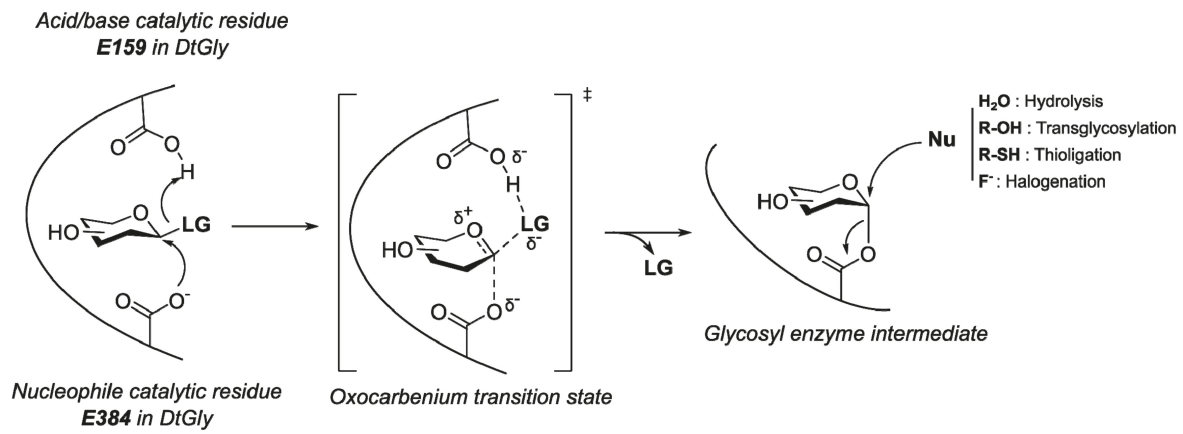

Figure 1. Schematic mechanism of the first step involving the glycosyl-enzyme intermediate formation in retaining GH. The leaving group (LG) release can also be catalysed through another catalytic residue according to its nature. Depending on the nucleophile $(\mathrm{Nu})$ attacking the intermediate, three reactions can take place-hydrolysis, transglycosylation or thioligation.

In addition to the well characterized $O$-glycosides bearing a potent leaving group, some activated S-glycosides have been reported as efficient substrates for thioligases [15] or glycoside hydrolases [16]. This latter hydrolytic activity is peculiar as very few examples of $S$-glycosides hydrolysis by glycoside hydrolases have been reported in literature [16-26]. Among those examples, putting aside GlcNAcase, GH4 and myrosinase that do not operate through the canonical GH mechanism, only almond $\beta$-glucosidase GH1, Aspergillus niger GH3 [16,22,27], Micromonospora viridifaciens sialidase [21], Caldocellum saccharolyticum glucosidase [24] and Oryza sativa Os4BGlu12 [23] have been isolated and identified as thioglycoside hydrolases (Table 1).

Table 1. Comparison of $S$ - and O-glycoside hydrolysis by GH.

\begin{tabular}{|c|c|c|c|c|}
\hline Enzyme & Organism & Substrates Tested & Relative Activity $S$-vs. $O-(\%)$ & Ref \\
\hline \multirow[t]{6}{*}{$\beta$-D-Glucosidase } & Sweet almond & pNPSGlc & $0.13^{\mathrm{a}}$ & {$[22]$} \\
\hline & & pNPSGal & $0.07^{\mathrm{a}}$ & \\
\hline & & pNPSFuc & $0.06^{\mathrm{a}}$ & \\
\hline & & GlcSBiz & $80^{\mathrm{a}}$ & [16] \\
\hline & & $\operatorname{Glc} S(N-M e) B i z$ & $10^{\mathrm{a}}$ & \\
\hline & & GlcSBox & $5^{\mathrm{a}}$ & \\
\hline \multirow[t]{2}{*}{$\beta$-D-Glucosidase } & A. niger & GlcSBiz & $5^{a}$ & [16] \\
\hline & & GlcS(N-Me)Biz & $1^{\mathrm{a}}$ & \\
\hline Sialidase & M. viridifaciens & Substituted pNPSNeuAc & $0.01-60$ & {$[21]$} \\
\hline \multirow[t]{2}{*}{ Os4BGlu12 } & O. sativa & pNPSGlc & $0.5^{\mathrm{a}}$ & [23] \\
\hline & & OctylSGlc & $0.1^{b}$ & \\
\hline
\end{tabular}

${ }^{a}$ ratio of $k_{\text {cat }} / K_{\mathrm{M}}$ for thioglycoside substrate vs. corresponding para-nitrophenyl glycoside. ${ }^{\mathrm{b}}$ ratio of $k_{\mathrm{cat}} / K_{\mathrm{M}}$ for octyl S-glucoside vs. octyl O-glucoside. 
In most cases, $S$-substrate hydrolysis is much less efficient than the rate observed for the corresponding $\mathrm{O}$-substrate. Indeed, thioglycosides are less efficient substrates because no general acid/base catalysis is available [28]. Yet, a new class of reactive thioglucosides (Figure 2, Table 1) bearing a thioimidoyl moiety was reported, which were efficiently hydrolysed by almond GH1, as well as $A$. niger GH3 [16]. In both cases, the authors demonstrated that benzoxazolyl 1-thio- $\beta$-D-glucopyranoside (GlcSBox) and benzimidazolyl 1-thio- $\beta$-D-glucopyranoside (GlcSBiz) hydrolyses were catalysed by remote activation of the C-S bond through protonation of the ring nitrogen in the aglycone. Such remote activation was also described in the case of Araf51 [15], which was able to use similar arabinofuranosyl thioimidates as glycosyl donors in thioglycoligation reaction [29-35]. In the context of chemoenzymatic synthesis of glycosides, these substrates are attractive because of their high stability towards chemical hydrolysis in aqueous solutions, as well as efficient leaving group ability [15].

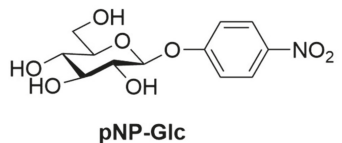

pNP-GIc

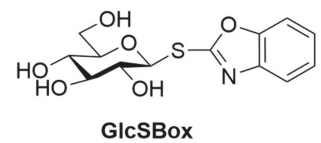

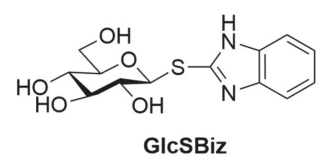

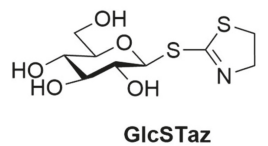

Figure 2. Substrates used in this study.

In this work, we demonstrated that DtGly, a GH previously used in chemoenzymatic synthesis of O-glycosides, was able to hydrolyse these glycosyl thioimidates. Combined in vitro enzymatic analysis with in silico modelling of the enzyme-substrate interaction have helped us to decipher the molecular mechanism of this rare hydrolysis.

\section{Results}

\subsection{DtGly Can Hydrolyze Thioglycosides}

DtGly (uniprot B5YCI2_DICT6) is encoded by dicth_0359 gene in the thermophile Dictyoglomus thermophilum genome. We have recently reported the cloning, expression and purification of this protein [36]. As many other D. thermophilum proteins [37-41], DtGly was found to be thermostable and also exhibited a wide substrate specificity, as it is able to hydrolyse $p$ NP $\beta$-D-glucoside, $p$ NP $\beta$-D-galactoside and $p$ NP $\beta$-D-fucoside. Moreover, our previous study demonstrated that $D t$ Gly could be used in chemoenzymatic synthesis of glycosides, thereby serving as an attractive biocatalyst that needed to be assayed for other substrates [36].

In this context, we have focused on thioglycoside hydrolysis, as few examples of $S$-GH are available in literature. Three S-containing substrates were tested, namely GlcSBiz, GlcSBox and GlcSTaz that bear benzimidazolyl, benzoxazolyl and thiazolinyl aglycones, respectively (Figure 2).

Unlike $p$ NP-Glc, wherein the hydrolysis can be easily monitored by quantification of the released $p \mathrm{NP}$ group, hydrolysis rates of the $S$-containing substrates were determined by quantification of the released glucose. This was achieved by monitoring o-dianisidine oxidation enzymatically coupled to glucose production [42]. This methodology applied to $p$ NP-Glc hydrolysis gave similar kinetic values to those previously reported using $p \mathrm{NP}$ quantification (data not shown).

All three $S$-containing substrates were hydrolysed by DtGly (Table 2), with $K_{\mathrm{M}}$ values higher but in the same order of magnitude, as those observed for $p$ NP-Glc (2- to 5 -fold increase). However, the catalytic rate $k_{\text {cat }}$ was decreased by one order of magnitude, indicating that the reaction is dramatically slowed in the case of $S$-containing substrates. Therefore, the catalytic efficiencies of 
GlcSBiz, GlcSBox and GlcSTaz were found to be 20 to 40 times lower than the value determined for $p$ NP-Glc.

Table 2. Kinetic parameters of WT and acid/base E159Q mutant of DtGly. pNP-Glc hydrolysis activity was measured by $p$ NP release quantification. Other substrate hydrolysis activities were determined by quantification of the released glucose. All experiments were done in three independent replicates and are expressed as Mean $\pm \mathrm{SD}$.

\begin{tabular}{ccccc}
\hline Enzyme & Substrate & $\boldsymbol{K}_{\mathbf{M}}(\boldsymbol{\mu M})$ & $\boldsymbol{k}_{\text {cat }}\left(\mathbf{s}^{\mathbf{- 1}}\right)$ & $\boldsymbol{k}_{\text {cat }} / \boldsymbol{K}_{\mathbf{M}}\left(\mathbf{s}^{\mathbf{- 1}} \cdot \mathbf{m} \mathbf{M}^{\mathbf{- 1}}\right)$ \\
\hline WT & $p$ NP-Glc & \\
WT & GlcSBiz & $460 \pm 40$ & $31 \pm 0.7$ & 67 \\
WT & GlcSBox & $2246 \pm 289$ & $0.38 \pm 0.03$ & 0.15 \\
WT & GlcSTaz & $880 \pm 52$ & $0.31 \pm 0.01$ & 0.17 \\
E159Q & $p$ NP-Glc & $200 \pm 20$ & $0.20 \pm 0.01$ & 0.35 \\
E159Q & GlcSBox & $445 \pm 40$ & $0.06 \pm 0.01$ & 1.0 \\
\hline
\end{tabular}

${ }^{\text {a }}$ Previously reported data [36].

GlcSBiz, GlcSBox and GlcSTaz have previously been used as substrates for sweet almond and $A$. niger $\beta$-glucosidases [16], yet with a much different behaviour. GlcSBiz was hydrolysed by this enzyme as efficiently as $p \mathrm{NP}-\mathrm{Glc}$. Kinetics analysis proved that GlcSBiz was efficiently hydrolysed by those glucosidases thanks to the remote protonation of the imidazole ring nitrogen. A much lower activity was observed for GlcSBox and no activity could be observed for GlcSTaz.

To better understand the chemistry underlying the thioglucoside hydrolysis by DtGly, we first investigated whether these substrates were efficiently binding in the active site, because low GH activities can arise from a second binding mode of substrates, as already reported [43]. Inhibition of $p$ NP-Glc hydrolysis by GlcSBiz demonstrated that the latter is a competitor in the active site to $p$ NP-Glc (Figure 3). Moreover, it efficiently binds into the active site, as an inhibitory constant $K_{\mathrm{i}}$ of $177 \pm 11 \mu \mathrm{M}$ was calculated from the inhibition curves.

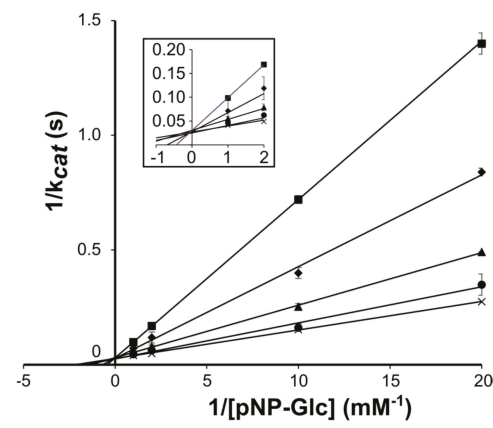

Figure 3. Lineweaver plot of wild-type DtGly inhibition with increasing concentrations of GlcSBiz. Data are expressed as mean \pm SD from three independent experiments. Inhibitor concentrations are respectively depicted as crosses $(0 \mu \mathrm{M})$, circles $(100 \mu \mathrm{M})$, triangles $(250 \mu \mathrm{M})$, diamonds $(500 \mu \mathrm{M})$ and squares $(1000 \mu \mathrm{M})$. Inset: $2 X$ zoom on axes origin highlighting the intersection of fitted lines on $y$-axis.

\subsection{Identification of Residues Surrounding the Thioglycoside Substrates in DtGly Active Site}

Structural analysis of DtGly was carried out to identify potential residues that might be involved in S-containing substrate hydrolysis mechanism. Despite our efforts to crystallize DtGly, no diffracting crystal could be obtained, thus we decided to build a homology model of the enzyme. To do so, a 3D structure of $\beta$-glycosidase from Pyrococcus horikoshii was chosen because of its high sequence identity (resp. homology) with DtGly of $45 \%$ (resp. 63\%) [44]. 
An initial model of residues 2-416 was built using a ModWeb server (ModPipe Protein Quality Score of 1.6, considered as reliable); missing residues were then added and the overall model was equilibrated by several cycles of energy minimization and molecular dynamics (Figure 4A).
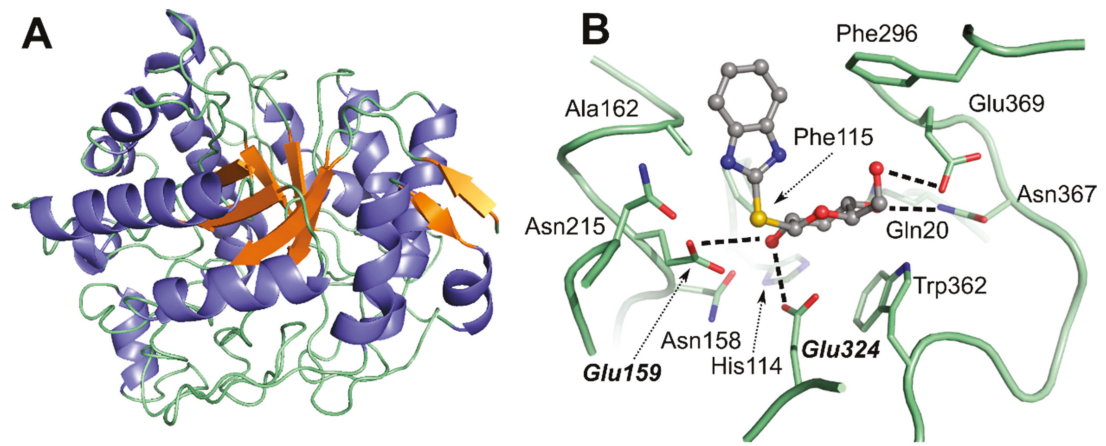

Figure 4. (A) Overall representation of DtGly model. Helices and sheets are respectively coloured in blue and orange. (B) Model of docked GlcSBiz in DtGly active site. Residues surrounding the ligand binding pocket are depicted as sticks. For clarity purposes, hydrogens are not represented. Catalytic residues Glu159 (acid/base) and Glu324 (nucleophile) are highlighted in bold. H-bonds are indicated as dashed lines.

In order to evaluate potential roles of active site residues in sulphur-containing substrate hydrolysis, modelling of substrate-bound $D t$ Gly were done by molecular docking. Using the conformation of glucosides in other closely related GH1 x-ray structures ( $\beta$-glucosidase from Thermotoga maritima PDB $1 \mathrm{OIM}$ and 1OIF [45]), GlcSBiz, GlcSBox and GlcSTaz were independently docked into the DtGly active site. Figure 4B depicts the residues surrounding GlcSBiz, as well as the network of $\mathrm{H}$-bonds between the sugar moiety and several polar residues (Gln20, Glu159, Glu324, Asn367, Glu369). An additional $\mathrm{H}-\pi$ interaction between glucose and Trp362 is also visible, as already seen for other GH [40]. The same interactions were found for other substrates or conformations (see the Supplementary Materials).

In the context of identification of potential residues involved in the $S$-glycoside activation during hydrolysis this model confirms that no acidic residue except Glu159 was close enough to remotely protonate aglycone moieties of substrates, as expected considering in vitro assays.

\subsection{DtGly Hydrolysis of S-Glycosides Does Not Involve General Acid/Base Catalysis}

In our model, the catalytic glutamate Glu159, which acts as the acid/base residue in retaining GH mechanism [46], is the only one close enough to activate thioglycoside hydrolysis. Although direct protonation on sulphur cannot occur in the case of thiogycosides [28], examples of distant protonation of the aglycone by a catalytic residue have been reported [15]. We have thus generated two mutants, namely Glu159Ala and Glu159Gln to assess the potential role of this residue in the thioglycoside hydrolysis. Unlike Glu159Gln that could be purified to homogeneity, Glu159Ala mutant was not soluble after cell lysis and thus could not be purified. This mutant was left aside for further experiments.

Glu159Gln mutation led to a dramatic decrease of catalytic efficiency for $p$ NPGlc, as shown in Table 2. $K_{\mathrm{M}}$ values for this substrate are lower but in the same order of magnitude ( $200 \mu \mathrm{M}$ vs. $460 \mu \mathrm{M})$, which can be explained by conservation of the active site structure in the mutant and decreased $k_{\text {cat }}$ value by a factor of 150 because $K_{\mathrm{M}}$ is related to $k_{\text {cat }}$. This loss of hydrolytic activity upon $\mathrm{acid} / \mathrm{base}$ mutation is usual, as reported in many other studies, especially those concerning thioligase generation $[14,40]$.

When using GlcSBox as a substrate, DtGly Glu159Gln exhibits a reduced $k_{\text {cat }}$ value $\left(0.38\right.$ to $\left.0.06 \mathrm{~s}^{-1}\right)$, as expected because nucleophile water attack is not activated by deprotonation. However, second order rate constant remains unchanged, indicating that the first step of the reaction is not compromised 
by the removal of the glutamate residue. Thus, the release of the thiol leaving group is not activated by Glu159 and is only dictated by its leaving capability (i.e., pKa).

\section{Discussion}

We have previously used $D$. thermophilum $D t$ Gly as a versatile tool for synthesis of glycosides and looked for alternate substrates for this enzyme. Thioimidate glycosyl donors have been used for a long time in organic synthesis to generate a wide range of glycosides and glycans [34,47-49]. In this context, we tested previously reported glycosyl thioimidates as substrates for almond GH1 and A. niger GH3 [16]. Examples of cloning and characterization of thioglycoside hydrolases are scarcely available in literature and even fewer studies on mechanism underlying the thioglycoside hydrolysis by GH have been published.

$D t$ Gly is able to hydrolyse $S$-glycosides, with lower activities than those observed for O-glycosides. This hydrolytic activity is rate-limited by release of the thiol-containing leaving group and not water nucleophilic attack, unlike generally accepted mechanism for the O-glycoside hydrolysis $[19,28]$. The modelling of substrate- $D t$ Gly complexes as well as mutagenesis of the acid/base residue also demonstrated that no residue was able to remotely protonate the benzimidazole group nor the sulphur atom. If $D t G l y$ is able to hydrolyse $S$-containing substrates without general acid catalysis, the hydrolysis rate is limited by the leaving group capability, as no remote activation is possible. The pKa of leaving groups 2-mercaptobenzimidazole (for GlcSBiz) and 2-mercaptobenzoxazole (for GlcSBox) have been experimentally determined at 5.8 [50] and 6.58 [51]. To our knowledge, no value is available for 2-mercaptothiazoline (for GlcSTaz).

In the case of almond and $A$. niger glycosidases, a remote protonation occurring on a nitrogen atom of the benzimidazole moiety of GlcSBiz was shown to accelerate the leaving group release, thus increasing the catalytic rate to a value close to those observed for $\mathrm{O}$-glycosides. Another $\mathrm{GH}$ exhibiting thioglycosidase activity on 2'-thio-benzimidazolyl arabinosides activated by remote deprotonation, namely Araf51 [15], was also reported. The modelling of Araf51/substrate complex demonstrated that the nucleophile catalytic residue was responsible for the remote protonation on imidazole nitrogen, mostly because a furanosyl ring is much more flexible than a pyranosyl ring and allows the nucleophile residue to interact with the aglycone.

\section{Materials and Methods}

\subsection{Materials}

para-Nitrophenyl $\beta$-D-glucopyranoside ( $p$ NP-Glc) was purchased from Carbosynth (Oxford, UK). 2-benzoxazolyl 1-thio- $\beta$-D-glucopyranoside (GlcSBox) [52], 2-benzimidazolyl 1-thio- $\beta$-Dglucopyranoside (GlcSBiz) [16] and 2-thiazolinyl 1-thio- $\beta$-D-glucopyranoside (GlcSTaz) [49] were prepared as previously described. Otherwise specified, all other chemicals were purchased from Thermo Fisher Scientific (Waltham, MA, USA) and were of purest quality available. Mutagenic primers were purchased from Eurofins Genomics (Ebersberg, Germany) and WT DtGly coding expression plasmid (pET28a-dtgly) was prepared as previously described [36].

\subsection{Production of WT and E159Q DtGly}

pET28a-dtgly was used as a template for mutagenic PCR in the Quikchange Site-directed mutagenesis kit (Agilent, Les Ulis, France). Primers containing desired mutation on acid/base residue position (E159) were constituted of a pair of complement oligonucleotides designed using Agilent tools website (www.genomics.agilent.com, mutated codons are highlighted in bold): DtGly E159A: 5'-gaattactggatgactataaatgcgcccaatgcttatgccttt-3' and DtGly E159Q: $5^{\prime}$-atcttgtgaattactggatgactataaatcagcccaatgcttatg-3'. Mutagenesis procedure was performed according to the kit procedure. Sequences of pET28a- $d t g l y \mathrm{E} 159 \mathrm{~A}$ and $\mathrm{pET} 28 \mathrm{a}-d t g l y \mathrm{E} 159 \mathrm{Q}$ were verified by Sanger sequencing at Eurofins Genomics (Ebersberg, Germany). 
Production and purification of $D t G l y$ variants was done as previously reported [36]. Briefly, Escherishia coli Rosetta(DE3) transformed with expression plasmids were grown in LB medium supplemented with chloramphenicol $(34 \mu \mathrm{g} / \mathrm{mL})$ and kanamycin $(30 \mu \mathrm{g} / \mathrm{mL})$ at $37^{\circ} \mathrm{C}$ until $\mathrm{OD}_{600}$ reached 0.6. Induction was then done by addition of $1 \mathrm{mM} \mathrm{IPTG}$ and incubated overnight a $25^{\circ} \mathrm{C}$. Cells were harvested, lyzed by freeze-thaw cycles and sonication and supernatant was clarified by heat treatment for $15 \mathrm{~min}$ at $70^{\circ} \mathrm{C}$ before centrifugation. Finally, supernatant was loaded on a Nickel column (HisPure, Thermo Scientific) and purified by elution with lysis buffer containing $500 \mathrm{mM}$ imidazole.

\section{3. pNP Release Quantification Assay}

$D t$ Gly variants (WT or mutants) activity towards $p$ NP-Glc hydrolysis was determined at $37^{\circ} \mathrm{C}$ in a $200 \mu \mathrm{L}$ incubation containing $5 \mathrm{ng}$ of the enzyme, $0.01-10 \mathrm{mM} p$ NP-Glc, Citrate-Phosphate buffer (20 mM, pH 6) and 0.1-1 mM GlcBox for inhibition studies. After $20 \mathrm{~min}$ of incubation, $100 \mu \mathrm{L}$ of $\mathrm{Na}_{2} \mathrm{CO}_{3} 1 \mathrm{M}$ was added and released $p \mathrm{NP}$ was quantified at $405 \mathrm{~nm}\left(\varepsilon_{405}=19,500 \mathrm{~cm}^{-1} \cdot \mathrm{M}^{-1}\right)$. Prism 4 (GraphPad) was used to fit data according to Michaelis-Menten model, or competitive inhibition model and retrieve kinetic parameters.

\subsection{Glucose Release Assay}

To determine GlcSBox, GlcSTaz and GlcSBiz hydrolysis rate by DtGly variants, produced glucose was quantified using a continuous coupled enzyme assay [42]. Incubations were similar as those for $p$ NP-Glc hydrolysis with the addition of glucose oxidase from Aspergillus niger (Sigma-Aldrich, Saint Louis, MO, USA, $0.4 \mathrm{u}$ ), horseradish peroxidase (Sigma-Aldrich, $0.4 \mathrm{u}$ ) and $o$-dianisidine (Sigma-Aldrich, $100 \mu \mathrm{M}$ ). Dianisidine oxidation coupled to glucose production was monitored at $442 \mathrm{~nm}$ during $30 \mathrm{~min}$. Prism 4 (GraphPad) was used to fit data according to Michaelis-Menten model and retrieve kinetic parameters.

\subsection{Computational Studies}

The structure of $\beta$-glycosidase from Pyrococcus horikoshii [44] (PDB 1VFF, 45\%/63\% sequence identity/homology) was used as a template for homology model building using a ModWeb server from the A. Sali Laboratory (https://modbase.compbio.ucsf.edu/modweb/). The resulting model was prepared with AmberTools [53] and equilibrated using NAMD software [54] and Amber fb15 force field [55] (3 cycles of 10,000 minimization steps and 0.5 ns dynamics at $100 \mathrm{~K}$ ).

Docking of GlcSBox, GlcSTaz and GlcSBiz substrates into DtGly active site model was done by firstly applying AM1-BCC charges on ligands [56]. Then each substrate was placed $10 \AA$ away, facing the active site (according to PDB 1VFF). DtGly-substrate complexes were formed using steered molecular dynamics [57] at $100 \mathrm{~K}$ using the structural alignment of glucose moiety in its binding pocket as the final orientation according to closest structures bearing a ligand in their active site ( $\beta$-glucosidase from Thermotoga maritima PDB 1OIM, 1OIF and 1OIF) [45]. DtGly backbone was kept constrained during the whole procedure. Finally, protein-ligand complexes models were equilibrated by releasing substrate constraints and applying several cycles of energy minimization (10,000 steps, steepest descent) followed by molecular dynamics (100 K, 1 ns). Final complex models were obtained by a final energy minimization. For each substrate, several initial conformations were tested, mostly by rotation of the glycosidic bond. All structural figures were drawn using the PyMOL Molecular Graphics system 1.8 (www.pymol.org).

\section{Conclusions}

This study demonstrates that glycosyl thioimidates are not universal glycosyl donors for chemoenzymatic syntheses. While the above examples of efficient enzymatic activities using such substrates were reported in literature, they rely on an activation by protonation of the aglycone moiety, either with a distant carboxylic acid residue (almond GH1) or the catalytic nucleophile (Araf51, Figure 5). DtGly seems to be the paradigm of the general case of an enzyme that can use those substrates 
without acid catalysis, yet with a much lower activity. This study paves the way for broadening DtGly applications in biocatalysis. Identification of efficient substrates and mutation into a thioligase are currently under further investigation.

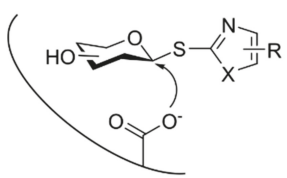

No Activation - low activity (DtGly)

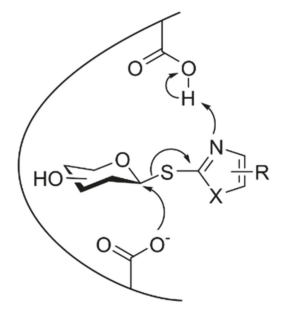

Activation by distant caboxylic residue high activity

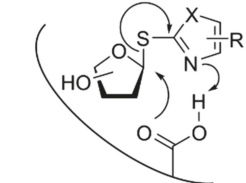

Activation by nucleophile catalytic residue high activity
(Araf51)

Figure 5. Glycosyl thioimidates require remote activation to promote the leaving group release.

Supplementary Materials: The following are available online at http://www.mdpi.com/2073-4344/9/10/826/s1, Figure S1: Model of docked GlcSBox and GlcSTaz in DtGly active site.

Author Contributions: Conceptualization, R.D. and A.V.D.; Enzymatic studies, L.G., P.L. and Z.A.; data curation and modelling, P.L.; chemical synthesis of substrates, S.G.P. writing-original draft preparation, P.L.; writing - review and editing, P.L., R.D. and A.V.D.; project administration, R.D.; funding acquisition, R.D. and A.V.D.

Funding: L.G., P.L. and R.D. thank the Région Centre Val de Loire for funding (APR IR GLYCOPEPS). A.V.D. thanks the NIGMS for generous support of this work (GM GM111835).

Conflicts of Interest: The authors declare no conflict of interest. The funders had no role in the design of the study; in the collection, analyses, or interpretation of data; in the writing of the manuscript, or in the decision to publish the results.

\section{References}

1. Sheldon, R.A.; Woodley, J.M. Role of Biocatalysis in Sustainable Chemistry. Chem. Rev. 2018, 118, 801-838. [CrossRef] [PubMed]

2. Quin, M.B.; Schmidt-Dannert, C. Engineering of Biocatalysts: From Evolution to Creation. ACS Catal. 2011, 1, 1017-1021. [CrossRef] [PubMed]

3. Hancock, S.M.; Vaughan, M.D.; Withers, S.G. Engineering of glycosidases and glycosyltransferases. Curr. Opin. Chem. Biol. 2006, 10, 509-519. [CrossRef] [PubMed]

4. Li, T.-L.; Liu, Y.-C.; Lyu, S.-Y. Combining biocatalysis and chemoselective chemistries for glycopeptide antibiotics modification. Curr. Opin. Chem. Biol. 2012, 16, 170-178. [CrossRef] [PubMed]

5. Ati, J.; Lafite, P.; Daniellou, R. Enzymatic synthesis of glycosides: From natural O- and N-glycosides to rare C- and S-glycosides. Beilstein J. Org. Chem. 2017, 13, 1857-1865. [CrossRef]

6. Guillotin, L.; Lafite, P.; Daniellou, R. Chapter 10 Enzymatic thioglycosylation: Current knowledge and challenges. In Carbohydrate Chemistry; The Royal Society of Chemistry: London, UK, 2014; Volume 40, pp. 178-194. ISBN 978-1-84973-965-8.

7. Driguez, H. Thiooligosaccharides as Tools for Structural Biology. Chembiochem 2001, 2, 311-318. [CrossRef]

8. Wardrop, D.J.; Waidyarachchi, S.L. Synthesis and biological activity of naturally occurring $\alpha$-glucosidase inhibitors. Nat. Prod. Rep. 2010, 27, 1431-1468. [CrossRef]

9. O'Neill, E.C.; Field, R.A. Enzymatic synthesis using glycoside phosphorylases. Carbohydr. Res. 2015, 403, 23-37. [CrossRef]

10. Lairson, L.L.; Henrissat, B.; Davies, G.J.; Withers, S.G. Glycosyltransferases: Structures, Functions and Mechanisms. Annu. Rev. Biochem. 2008, 77, 521-555. [CrossRef]

11. De Bruyn, F.; Maertens, J.; Beauprez, J.; Soetaert, W.; De Mey, M. Biotechnological advances in UDP-sugar based glycosylation of small molecules. Biotechnol. Adv. 2015, 33, 288-302. [CrossRef]

12. Rye, C.S.; Withers, S.G. Glycosidase mechanisms. Curr. Opin. Chem. Biol. 2000, 4, 573-580. [CrossRef] 
13. Wang, L.-X.; Huang, W. Enzymatic transglycosylation for glycoconjugate synthesis. Curr. Opin. Chem. Biol. 2009, 13, 592-600. [CrossRef] [PubMed]

14. Jahn, M.; Marles, J.; Warren, R.A.J.; Withers, S.G. Thioglycoligases: Mutant Glycosidases for Thioglycoside Synthesis. Angew. Chem. Int. Ed. 2003, 42, 352-354. [CrossRef] [PubMed]

15. Almendros, M.; Danalev, D.; François-Heude, M.; Loyer, P.; Legentil, L.; Nugier-Chauvin, C.; Daniellou, R.; Ferrières, V. Exploring the synthetic potency of the first furanothioglycoligase through original remote activation. Org. Biomol. Chem. 2011, 9, 8371-8378. [CrossRef]

16. Avegno, E.A.-B.; Hasty, S.J.; Parameswar, A.R.; Howarth, G.S.; Demchenko, A.V.; Byers, L.D. Reactive thioglucoside substrates for $\beta$-glucosidase. Arch. Biochem. Biophys. 2013, 537, 1-4. [CrossRef] [PubMed]

17. Goodman, I.; Fouts, J.R.; Bresnick, E.; Menegas, R.; Hitchings, G.H. A Mammalian Thioglycosidase. Science 1959, 130, 450-451. [CrossRef]

18. Meulenbeld, G.H.; Hartmans, S. Thioglucosidase activity from Sphingobacterium sp. strain OTG1. Appl. Microbiol. Biotechnol. 2001, 56, 700-706. [CrossRef] [PubMed]

19. Macauley, M.S.; Stubbs, K.A.; Vocadlo, D.J. O-GlcNAcase catalyzes cleavage of thioglycosides without general acid catalysis. J. Am. Chem. Soc. 2005, 127, 17202-17203. [CrossRef] [PubMed]

20. Cetinbaş, N.; Macauley, M.S.; Stubbs, K.A.; Drapala, R.; Vocadlo, D.J. Identification of Asp174 and Asp175 as the key catalytic residues of human O-GlcNAcase by functional analysis of site-directed mutants. Biochemistry 2006, 45, 3835-3844. [CrossRef]

21. Narine, A.A.; Watson, J.N.; Bennet, A.J. Mechanistic requirements for the efficient enzyme-catalyzed hydrolysis of thiosialosides. Biochemistry 2006, 45, 9319-9326. [CrossRef]

22. Shen, H.; Byers, L.D. Thioglycoside hydrolysis catalyzed by beta-glucosidase. Biochem. Biophys. Res. Commun. 2007, 362, 717-720. [CrossRef] [PubMed]

23. Sansenya, S.; Opassiri, R.; Kuaprasert, B.; Chen, C.J.; Cairns, J.R.K. The crystal structure of rice (Oryza sativa L.) Os4BGlu12, an oligosaccharide and tuberonic acid glucoside-hydrolyzing beta-glucosidase with significant thioglucohydrolase activity. Arch. Biochem. Biophys. 2011, 510, 62-72. [CrossRef] [PubMed]

24. Wathelet, J.-P.; Iori, R.; Leoni, O.; Rollin, P.; Mabon, N.; Marlier, M.; Palmieri, S. A recombinant $\beta$-O-glucosidase from Caldocellum saccharolyticum to hydrolyse desulfo-glucosinolates. Biotechnol. Lett. 2001, 23, 443-446. [CrossRef]

25. Reese, E.T.; Clapp, R.C.; Mandels, M. A thioglucosidase in fungi. Arch. Biochem. Biophys. 1958, 75, $228-242$. [CrossRef]

26. Yip, V.L.Y.; Withers, S.G. Family 4 glycosidases carry out efficient hydrolysis of thioglycosides by an alpha,beta-elimination mechanism. Angew. Chem. Int. Ed. 2006, 45, 6179-6182. [CrossRef] [PubMed]

27. Niemec-Cyganek, A.; Szeja, W. Heteroaryl thioglycosides, a new class of substrated for glycosidases. Pol. J. Chem. 2003, 77, 969-973.

28. Jensen, J.L.; Jencks, W.P. Hydrolysis of benzaldehyde O,S-acetals. J. Am. Chem. Soc. 1979, 101, 1476-1488. [CrossRef]

29. Hanessian, S.; Bacquet, C.; Lehong, N. Chemistry of the glycosidic linkage. Exceptionally fast and efficient formation of glycosides by remote activation. Carbohydr. Res. 1980, 80, C17-C22. [CrossRef]

30. Ferrières, V.; Blanchard, S.; Fischer, D.; Plusquellec, D. A novel synthesis of D-galactofuranosyl, D-glucofuranosyl and D-mannofuranosyl 1-phosphates based on remote activation of new and free hexofuranosyl donors. Bioorg. Med. Chem. Lett. 2002, 12, 3515-3518. [CrossRef]

31. Demchenko, A.V.; Malysheva, N.N.; De Meo, C. S-Benzoxazolyl (SBox) Glycosides as Novel, Versatile Glycosyl Donors for Stereoselective 1,2-Cis Glycosylation. Org. Lett. 2003, 5, 455-458. [CrossRef]

32. Demchenko, A.V.; Pornsuriyasak, P.; De Meo, C.; Malysheva, N.N. Potent, Versatile and Stable: Thiazolyl Thioglycosides as Glycosyl Donors. Angew. Chem. Int. Ed. 2004, 43, 3069-3072. [CrossRef] [PubMed]

33. Euzen, R.; Guégan, J.-P.; Ferrières, V.; Plusquellec, D. First O-Glycosylation from Unprotected 1-Thioimidoyl Hexofuranosides Assisted by Divalent Cations. J. Org. Chem. 2007, 72, 5743-5747. [CrossRef] [PubMed]

34. Kamat, M.N.; De Meo, C.; Demchenko, A.V. S-Benzoxazolyl as a Stable Protecting Moiety and a Potent Anomeric Leaving Group in Oligosaccharide Synthesis. J. Org. Chem. 2007, 72, 6947-6955. [CrossRef] [PubMed]

35. Hasty, S.J.; Demchenko, A.V. Glycosyl Thioimidates as Versatile Building Blocks for Organic Synthesis. Chem. Heterocycl. Compd. 2012, 48, 220-240. [CrossRef] [PubMed] 
36. Guillotin, L.; Cancellieri, P.; Lafite, P.; Landemarre, L.; Daniellou, R. Chemo-enzymatic synthesis of 3-O-( $\beta$-d-glycopyranosyl)-sn-glycerols and their evaluation as preservative in cosmetics. Pure Appl. Chem. 2017, 89, 11302. [CrossRef]

37. Fukusumi, S.; Kamizono, A.; Horinouchi, S.; Beppu, T. Cloning and nucleotide sequence of a heat-stable amylase gene from an anaerobic thermophile, Dictyoglomus thermophilum. Eur. J. Biochem. 1988, 174, 15-21. [CrossRef] [PubMed]

38. Shi, R.; Li, Z.; Ye, Q.; Xu, J.; Liu, Y. Heterologous expression and characterization of a novel thermo-halotolerant endoglucanase Cel5H from Dictyoglomus thermophilum. Bioresour. Technol. 2013, 142, 338-344. [CrossRef] [PubMed]

39. Nakajima, M.; Imamura, H.; Shoun, H.; Horinouchi, S.; Wakagi, T. Transglycosylation Activity of Dictyoglomus thermophilum Amylase A. Biosci. Biotechnol. Biochem. 2004, 68, 2369-2373. [CrossRef]

40. Guillotin, L.; Richet, N.; Lafite, P.; Daniellou, R. Is the acid/base catalytic residue mutation in $\beta$-d-mannosidase Dt Man from Dictyoglomus thermophilum sufficient enough to provide thioglycoligase activity? Biochimie 2017, 137, 190-196. [CrossRef] [PubMed]

41. Guillotin, L.; Kim, H.; Traore, Y.; Moreau, P.; Lafite, P.; Coquoin, V.; Nuccio, S.; De Vaumas, R.; Daniellou, R. Biochemical Characterization of the $\alpha$-L-Rhamnosidase Dt Rha from Dictyoglomus thermophilum: Application to the Selective Derhamnosylation of Natural Flavonoids. ACS Omega 2019, 4, 1916-1922. [CrossRef]

42. Huggett, A.S.G.; Nixon, D.A. Use of glucose oxidase, peroxidase and o-dianisidine in determination of blood and urinary glucose. Lancet 1957, 270, 368-370. [CrossRef]

43. Guillotin, L.; Lafite, P.; Daniellou, R. Unraveling the Substrate Recognition Mechanism and Specificity of the Unusual Glycosyl Hydrolase Family 29 BT2192 from Bacteroides thetaiotaomicron. Biochemistry 2014, 53, 1447-1455. [CrossRef] [PubMed]

44. Akiba, T.; Nishio, M.; Matsui, I.; Harata, K. X-ray structure of a membrane-bound $\beta$-glycosidase from the hyperthermophilic archaeon Pyrococcus horikoshii. Proteins Struct. Funct. Bioinform. 2004, 57, 422-431. [CrossRef] [PubMed]

45. Zechel, D.L.; Boraston, A.B.; Gloster, T.; Boraston, C.M.; Macdonald, J.M.; Tilbrook, D.M.G.; Stick, R.V.; Davies, G.J. Iminosugar Glycosidase Inhibitors: Structural and Thermodynamic Dissection of the Binding of Isofagomine and 1-Deoxynojirimycin to $\beta$-Glucosidases. J. Am. Chem. Soc. 2003, 125, 14313-14323. [CrossRef] [PubMed]

46. Zechel, D.L.; Withers, S.G. Dissection of nucleophilic and acid-base catalysis in glycosidases. Curr. Opin. Chem. Biol. 2001, 5, 643-649. [CrossRef]

47. Zhu, X.; Schmidt, R.R. New Principles for Glycoside-Bond Formation. Angew. Chem. Int. Ed. 2009, 48, 1900-1934. [CrossRef] [PubMed]

48. Codée, J.D.C.; Litjens, R.E.J.N.; Van den Bos, L.J.; Overkleeft, H.S.; Van der Marel, G.A. Thioglycosides in sequential glycosylation strategies. Chem. Soc. Rev. 2005, 34, 769-782. [CrossRef] [PubMed]

49. Pornsuriyasak, P.; Demchenko, A.V. S-Thiazolinyl (STaz) Glycosides as Versatile Building Blocks for Convergent Selective, Chemoselective and Orthogonal Oligosaccharide Synthesis. Chem.-Eur J. 2006, 12, 6630-6646. [CrossRef] [PubMed]

50. Jerez, G.; Kaufman, G.; Prystai, M.; Schenkeveld, S.; Donkor, K.K. Determination of thermodynamic p Ka values of benzimidazole and benzimidazole derivatives by capillary electrophoresis. J. Sep. Sci. 2009, 32, 1087-1095. [CrossRef]

51. Akhond, M.; Ghaedi, M.; Tashkhourian, J. Development of a New Copper(II) Ion-selective Poly(vinyl chloride) Membrane Electrode Based on 2-Mercaptobenzoxazole. Bull. Korean Chem. Soc. 2005, 26, 882-886.

52. Kamat, M.N.; Rath, N.P.; Demchenko, A. V Versatile Synthesis and Mechanism of Activation of S-Benzoxazolyl Glycosides. J. Org. Chem. 2007, 72, 6938-6946. [CrossRef] [PubMed]

53. Case, D.A.; Darden, T.A.; III, T.E.C.; Simmerling, C.L.; Wang, J.; Duke, R.E.; Luo, R.; Walker, R.C.; Zhang, W.; Merz, K.M.; et al. AMBER 12 2012; University of California: San Francisco, CA, USA, 2012.

54. Phillips, J.C.; Braun, R.; Wang, W.; Gumbart, J.; Tajkhorshid, E.; Villa, E.; Chipot, C.; Skeel, R.D.; Kale, L.; Schulten, K. Scalable molecular dynamics with NAMD. J. Comput. Chem. 2005, 26, 1781-1802. [CrossRef] [PubMed]

55. Wang, L.-P.; McKiernan, K.A.; Gomes, J.; Beauchamp, K.A.; Head-Gordon, T.; Rice, J.E.; Swope, W.C.; Martínez, T.J.; Pande, V.S. Building a More Predictive Protein Force Field: A Systematic and Reproducible Route to AMBER-FB15. J. Phys. Chem. B 2017, 121, 4023-4039. [CrossRef] [PubMed] 
56. Jakalian, A.; Jack, D.B.; Bayly, C.I. Fast, efficient generation of high-quality atomic charges. AM1-BCC model: II. Parameterization and validation. J. Comput. Chem. 2002, 23, 1623-1641. [CrossRef] [PubMed]

57. Lafite, P.; André, F.; Zeldin, D.C.; Dansette, P.M.; Mansuy, D. Unusual Regioselectivity and Active Site Topology of Human Cytochrome P450 2J2. Biochemistry 2007, 46, 10237-10247. [CrossRef] [PubMed]

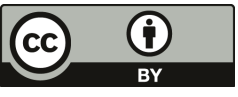

(C) 2019 by the authors. Licensee MDPI, Basel, Switzerland. This article is an open access article distributed under the terms and conditions of the Creative Commons Attribution (CC BY) license (http://creativecommons.org/licenses/by/4.0/). 

Article

\title{
Deciphering the Role of V88L Substitution in NDM-24 Metallo- $\beta$-Lactamase
}

\author{
Zhihai Liu ${ }^{1,2}$, Alessandra Piccirilli ${ }^{3}$, Dejun Liu ${ }^{2}$, Wan $\mathrm{Li}^{2}$, Yang Wang ${ }^{2}$ and Jianzhong Shen ${ }^{2, *}$ \\ 1 Agricultural Bio-pharmaceutical Laboratory, College of Chemistry and Pharmaceutical Sciences, Qingdao \\ Agricultural University, Qingdao 266109, China \\ 2 Beijing Advanced Innovation Center for Food Nutrition and Human Health, College of Veterinary Medicine, \\ China Agricultural University, Beijing 100193, China \\ 3 Dipartimento di Scienze Cliniche Applicate e Biotecnologiche, Università degli Studi dell'Aquila, \\ 67100 L'Aquila, Italy \\ * Correspondence: sjz@cau.edu.cn; Tel.: +86-10-62732803; Fax: +86-10-62731032
}

Received: 25 July 2019; Accepted: 28 August 2019; Published: 2 September 2019

\begin{abstract}
The New Delhi metallo- $\beta$-lactamase-1 (NDM-1) is a typical carbapenemase and plays a crucial role in antibiotic-resistance bacterial infection. Phylogenetic analysis, performed on known NDM-variants, classified NDM enzymes in seven clusters. Three of them include a major number of NDM-variants. In this study, we evaluated the role of the V88L substitution in NDM-24 by kinetical and structural analysis. Functional results showed that V88L did not significantly increase the resistance level in the NDM-24 transformant toward penicillins, cephalosporins, meropenem, and imipenem. Concerning ertapenem, E. coli DH5 $\alpha / \mathrm{NDM}-24$ showed a MIC value 4-fold higher than that of E. coli DH5 $\alpha / \mathrm{NDM}-1$. The determination of the $k_{\mathrm{cat}}, K_{\mathrm{m}}$, and $k_{\mathrm{cat}} / K_{\mathrm{m}}$ values for NDM-24, compared with NDM-1 and NDM-5, demonstrated an increase of the substrate hydrolysis compared to all the $\beta$-lactams tested, except penicillins. The thermostability testing revealed that V88L generated a destabilized effect on NDM-24. The V88L substitution occurred in the $\beta$-strand and low $\beta$-sheet content in the secondary structure, as evidenced by the $\mathrm{CD}$ analysis data. In conclusion, the V88L substitution increases the enzyme activity and decreases the protein stability. This study characterizes the role of the V88L substitution in NDM-24 and provides insight about the NDM variants evolution.
\end{abstract}

Keywords: New Delhi metallo- $\beta$-lactamase; NDM-24; kinetic profile; secondary structure

\section{Introduction}

Metallo- $\beta$-lactamases (MBLs) are a group of enzymes that confer high resistance to most $\beta$-lactams. The active site of these enzymes contains one or two zinc ions, that are crucial for catalytic mechanism [1]. Based on their amino acid sequences, MBLs have been divided into subclasses B1, B2, and B3 [2]. Among subclass B1, the New Delhi metallo- $\beta$-lactamase (NDM-1) is one of the most widespread carbapenemase. NDM-1 was first identified in 2008 in a clinical strain of Klebsiella pneumoniae [3]. NDM-1 producing bacteria can hydrolyse all $\beta$-lactams (except monobactams), including carbapenems, the "last resort" antibiotics used in clinical therapy. NDM-1 genes are located on plasmids that mediate their dissemination across different bacterial strains [4,5]. However, the clinical success of NDM is also due to the fact that it is a lipoprotein anchored to the outer membrane, resulting in an unusual stability of NDM-1 and enabling secretion, in Gram-negative bacteria [6-8].

To date, more than 26 variants differing by a limited number of substitutions have been identified [9]. Previous studies revealed that these substitutions have contributed to NDM-1 to increase the hydrolytic activity toward several $\beta$-lactams resulting in an increment of resistance in the host bacteria [10]. Crystal structures showed that NDM-1 presents the typical $\alpha \beta / \beta \alpha$ fold of MBLs [11,12]. In this enzyme, the zinc ions are coordinated by six conserved residues: H120, H122, and H189 for Zn1 
(BBL numbering) and D124, C208, and H250 for Zn2 (BBL numbering). The active site is surrounded by Loop 3 (residues 67-73) and Loop 10 (residues 210-230), involved in the substrate accommodation [12]. The most frequent substitution in NDM-1 is M154L, found in 11 NDM variants (NDM-4, $-5,-7,-8,-12$, $-13,-15,-17,-19,-20$ and -21) [9,13-16]. Indeed, V88L has been reported in five NDM variants (NDM-5, $-17,-20,-21$ and -24). Other frequent substitutions are A233V (NDM-6, -15, -19 and -27), D130G (NDM-8 and -14), D130N (NDM-7 and -19), and D95N (NDM-3 and -27) [10]. The single substitutions of M154L and D130G seem to increase the carbapenemase activity in NDM-4 and NDM-14, respectively $[17,18]$. Moreover, the combination D130G/M154L (NDM-8), reduces the hydrolysis toward carbapenems [19]. The main goal of the study was to evaluate the role of the V88L substitution in the NDM-24 enzyme. The NDM-24 was generated in the laboratory by a site-directed mutagenesis of NDM-1 and the enzyme properties, protein structure, and thermal stability were studied compared with NDM-1 and NDM-5.

\section{Results and Discussion}

\subsection{Phylogenetic Analysis}

A phylogenetic analysis of NDM-1 variants was performed in order to classify these enzymes based on their amino acid similarities. Overall, the NDM variants were classified into three major clusters (NDM-1, NDM-4, and NDM-24), two minor clusters (NDM-3 and NDM-6), and two divergent proteins (NDM-14 and NDM-10). As shown in Figure 1, the NDM variants are well categorized. The NDM-1 cluster includes eight variants that showed only one amino acid replacement, except for NDM-18 where an insertion of five amino acids have been found (position 48-52). In the NDM-4 group, all variants possess the replacement at position 154. In particular, except for NDM-11 containing the M154V substitution, all variants shared M154L. In the NDM-24 group, Valine at position 88 has been replaced by a Leucine (V88L). Concerning the two minor groups, similar characteristics were observed with the D95N and A233V substitution for the NDM-3 and NDM-6 clusters, respectively.

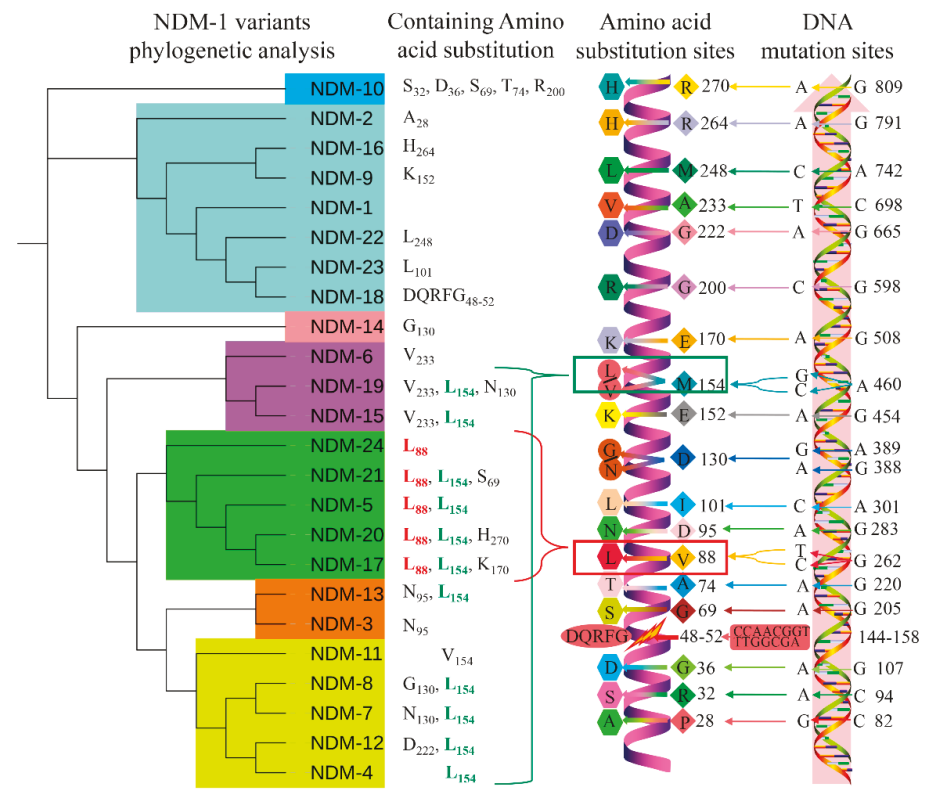

Figure 1. New Delhi metallo- $\beta$-lactamase-1 (NDM-1) variants phylogenetic analysis. Phylogenetic groups were differently coloured: For example, the NDM-24 cluster is coloured in green. 


\subsection{Functional Study}

The NDM-24 variant was obtained by a site-directed mutagenesis by using the NDM-1 as template. All genes $\left(b l a_{\mathrm{NDM}-1}, b l a_{\mathrm{NDM}-5}\right.$, and $\left.b l a_{\mathrm{NDM}-24}\right)$ were cloned into pHSG398, which were controlled by the same promoter and thus the same expression. The E. coli $\mathrm{DH} 5 \alpha$ recombinant strains were used to test susceptibility to a wide panel of $\beta$-lactams. As shown in Table 1 , the results of the susceptibility test revealed that NDM-1, NDM-5, and NDM-24 confer resistance to most $\beta$-lactams with similar MIC values, suggesting that the NDM enzymes were successfully expressed in the host cells. A different behaviour was observed for carbapenems, for which the MIC values were markedly lower than those of penicillins and cephalosporins with the exception of cefepime, as previously reported [15-20]. Concerning ertapenem, NDM-24 and NDM-5 showed an increase of the MIC values of the 4- and 8-fold with respect to NDM-1. Based on the data obtained, the V88L substitution enhances resistance toward ertapenem.

Table 1. Antimicrobial susceptibility of E. coli BL21(DE3)-DH5 $\alpha$ carrying $b l a_{\mathrm{NDM}-1}, b l a_{\mathrm{NDM}-5}$, and $b l a_{\mathrm{NDM}-24}$.

\begin{tabular}{ccccc}
\hline & \multicolumn{3}{c}{ MIC $(\mu \mathrm{g} / \mathrm{mL})$} \\
\cline { 2 - 5 } Antibiotic & E. coli & E. coli & E. coli & E. coli \\
& DH5 $\alpha$ /pHSG398 & $\begin{array}{c}\text { DH5 } \alpha / \text { pHSG398 } \\
\text {-NDM-24 }\end{array}$ & $\begin{array}{c}\text { DH5 } \alpha / \text { pHSG398 } \\
\text {-NDM-1 }\end{array}$ & $\begin{array}{c}\text { DH5 } \alpha / \text { pHSG398 } \\
\text {-NDM-5 }\end{array}$ \\
\hline Ampicillin & 2 & $>256$ & $>256$ & $>256$ \\
Penicillin G & 16 & $>256$ & $>256$ & $>256$ \\
Aztreonam & 0.031 & 0.031 & 0.031 & 0.031 \\
Cefepime & 0.031 & 2 & 1 & 2 \\
Cefotaxime & 0.062 & 32 & 64 & 64 \\
Cefoxitin & 2 & 128 & 128 & 28 \\
Ceftazidime & 0.125 & 256 & 256 & 256 \\
Cefazolin & 2 & 128 & 128 & 2 \\
Ertapenem & 0.015 & 1 & 0.25 & 2 \\
Imipenem & 0.062 & 2 & 2 & 2 \\
Meropenem & 0.031 & 1 & 1 & 25 \\
\hline
\end{tabular}

\subsection{Characteristics of Enzyme Activity}

In order to obtain soluble and active enzymes, the recombinant plasmids were successfully expressed in the E. coli BL21 (DE3) cells as described in the methods section. After purification, the enzymes were checked on SDS-PAGE to confirm the solubility and purity (>90\%) (Figure S1). The MALDI-TOF mass spectrometry was used to confirm the molecular mass of the three enzymes, which corresponds to 24884,024 Da (Figure S2). To investigate the enzyme activity, the kinetic parameters for NDM-1, NDM-5, and NDM-24 were determined (Table 2).

All the NDM variants of this study were able to hydrolyse all the $\beta$-lactams tested. Compared with NDM-1, NDM-24 showed lower $K_{m}$ values for penicillins and ceftazidime whereas for carbapenems they are quite similar. Comparing the $k_{\text {cat }}$ values, NDM-24 hydrolyses all $\beta$-lactams, except penicillins, better than NDM-1 and NDM-5. In particular, the $k_{\text {cat }}$ values of NDM-24 are 2.26-, 1.61-, 2.73-, 2.02-, 2.17-, and 1.75-fold higher than NDM-1 towards penicillin G, ceftazidime, cefepime, imipenem, meropenem, and ertapenem, respectively. This was also confirmed by a slight increase of catalytic efficiency. This result stated the important role of V88L in the substrate hydrolysis. The contribution of V88L is likely that of M154L as demonstrated by the calculation of the $k_{\text {cat }} / K_{\mathrm{m}}$ rates (Table 2$)$. This was possibly due to differences in the intrinsic properties, such as the enzyme stability, protein expression, and adaptability [21-24], and nutritional conditions of bacteria in vivo/vitro. Comparing the $k_{\mathrm{cat}} / K_{\mathrm{m}}$ values of carbapenems, the carbapenemase activity of NDM-5 was similar to NDM-24, but higher than NDM-1. A recent study showed that an increase of the catalytic efficiency $\left(k_{\mathrm{cat}} / K_{\mathrm{m}}\right)$ for meropenem has been ascertained in NDM-5 (V88L and M154L). In NDM-4, which contains only M154L, no significant change has been observed, suggesting that V88L might play a role in enhancing the NDM enzymes activity rather than M154L. Moreover, an increase of the carbapenemase activity was also observed in the evolutionary NDM variants, such as NDM-17 (V88L, M154L, and E170K) and NDM-20 (V88L, M154L, and R270H) [10,15,16]. 


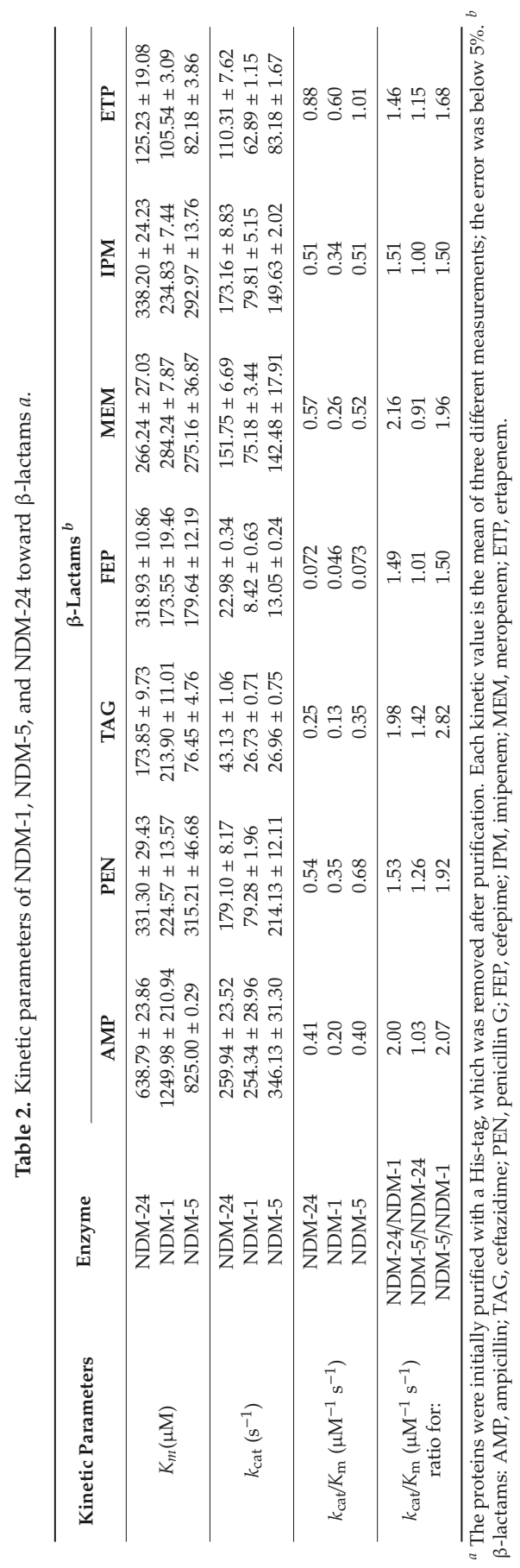




\subsection{Thermal Stability}

As previously reported, mutations in the NDM variants can affect the enzymes stability, resulting in changing the persistence lifetime in the bacterial host, and consequent antibiotics resistance [25]. For determining whether the V88L substitution influences the NDM-24 stability property, circular dichroism $C D$ was used to assay the protein stability by recording signal changes. NDM- 5 was used as reference to analyze the effect of M154L. Compared with NDM-1 and NDM-5, NDM-24 $\left(59.41 \pm 0.06^{\circ} \mathrm{C}\right)$ possessed the lowest melting temperature (Figure 2). Notably, the V88L destabilized effect was compensated by M154L in NDM- 5 with a remarkable higher thermal temperature than NDM-24 $\left(69.13 \pm 3.6^{\circ} \mathrm{C}\right.$ compared to $\left.59.41 \pm 0.06^{\circ} \mathrm{C}\right)$. Moreover, NDM- 5 showed a higher stability than NDM-1 suggesting the destabilized role of M154L. This was in agreement with a previous document that the M154L mutation would be a turning point for the NDM variants, in which combing M154L with additional substitutions benefit for the NDM enzymes exhibiting increased thermostability [10]. In the NDM-24 group there are four variants (NDM-5, -17, -20, and -21) in which the combination of the V88L and M154L substitutions takes favorable results in terms of the stability and environmental selection.

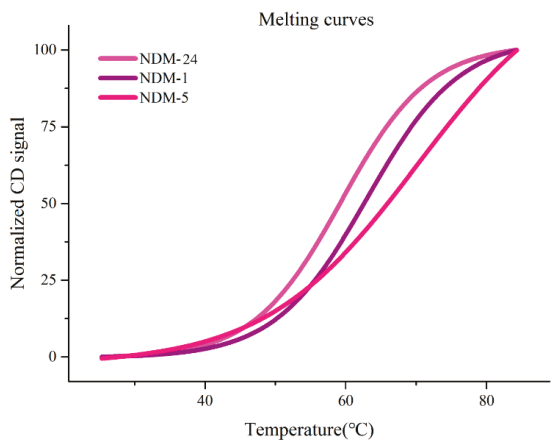

$\mathrm{A}$

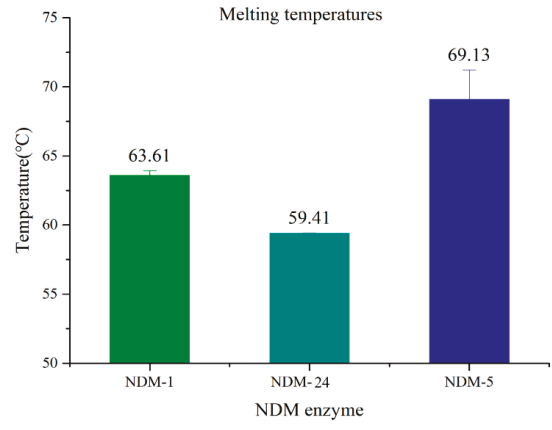

B

Figure 2. (A) Thermal stability melting curves. (B) Melting temperatures of the NDM enzymes as determined by the circular dichroism analysis: NDM-1, $63.61 \pm 0.57{ }^{\circ} \mathrm{C}$; NDM-V88L, $59.41 \pm 0.06{ }^{\circ} \mathrm{C}$; and NDM-5, $69.13 \pm 3.6^{\circ} \mathrm{C}$. Data are the means of triplicate experiments, with error bars showing the standard deviation $( \pm \mathrm{SD})$.

\subsection{Structure Analysis}

Previous reports indicated that mutations in the NDM influence the $\alpha$-helical, $\beta$-sheets content, and loop flexibility [26]. For example, the Q123A substitution in NDM-1 leads to a decrease of the $\alpha$-helical content [27]. To know if the V88L substitution could modify the NDM-24 structure, a secondary structure was determined by the Far-UV CD spectrum. All NDM variants CD spectrum data were fitted and shown in Figure 3. The spectrum signals were superimposable at most wavelengths, and showed characteristics of $\alpha \beta / \beta \alpha$ fold, a typical and conservative protein structure in MBLs [28]. The presence of positive bands at $192 \mathrm{~nm}$ and two negative peaks at $208 \mathrm{~nm}$, a minimum peak, and $220 \mathrm{~nm}$, suggesting the dominance of the $\beta$-sheets and $\alpha$-helical content. The major differences were observed in the nearby $192 \mathrm{~nm}$, symbolizing $\alpha$-helical peak, and 208-220 nm, a $\alpha$-helical and $\beta$-sheets bonds. Overall, the $\alpha$-helical content was found ranging between $13 \%-20 \%$ in NDM-1, NDM-5, and NDM-24 (Table 3), in agreement with previous reports and the content of the $\beta$-sheet was high around $30 \%$ [27]. Compared to NDM-1, NDM-24 possesses a higher $\alpha$-helical content and lower $\beta$-sheet content, suggesting that V88L was responsible for the secondary structure content changes of NDM-24. Furthermore, the secondary predicted result (Figure S3) confirmed that the V88L substitution occurred in the $\beta$-strand terminal, which may be prematurely terminated, leading to a decrease in the $\beta$-sheet content. Kumar et al. claimed that $152 \mathrm{~A}$, located in the $\beta$-strand, drastically influenced the NDM- 5 
activity and protein thermolability, by reducing the $\beta$-sheet content [26]. Our analysis demonstrates that the emergence of M154L (in NDM-5) caused the $\alpha$-helical to decrease and the $\beta$-sheet to increase relative to NDM-24, while the $\alpha$-helical and $\beta$-sheet content of NDM- 5 were between NDM- 1 and NDM-24. In addition, the 3D model of NDM-24 (Figure 4) was generated by using NDM-1 (PDB accession: 5N0H, 4RBS, 4HKY, and 4EYL) and NDM-5 (PDB accession: 6MGY, and 4TZE) as a template. Although the residue $88 \mathrm{~L}$ is away from the active site groove and far to the active loops (Loop 3 and Loop 10), differences in the structure content, stability, and enzyme activity were ascertained. Several studies confirmed that non-activity sites substitution can influence the NDM catalytic efficiency [29], and our results about the V88L substitution support this theory.

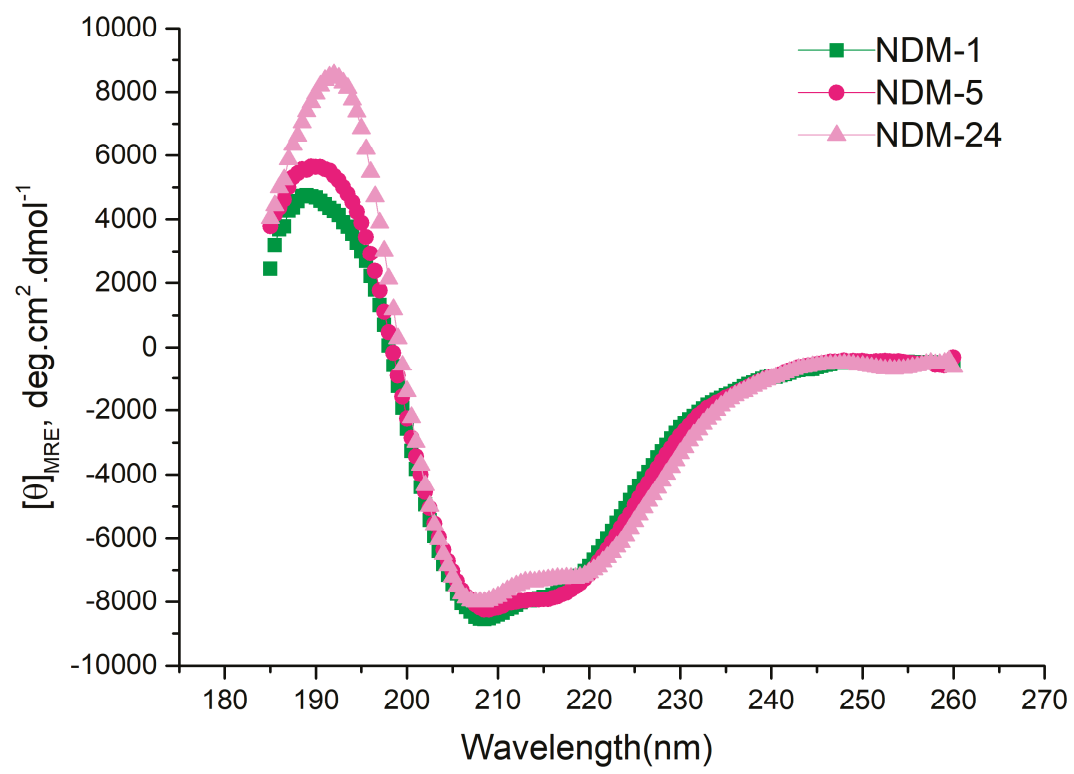

Figure 3. Normalized circular dichroism (CD) spectra of the NDM enzymes tested. MRE: Mean residue ellipticity.

Table 3. Proportions of various secondary structural elements in the NDM-1, NDM-5, and NDM-24 enzymes.

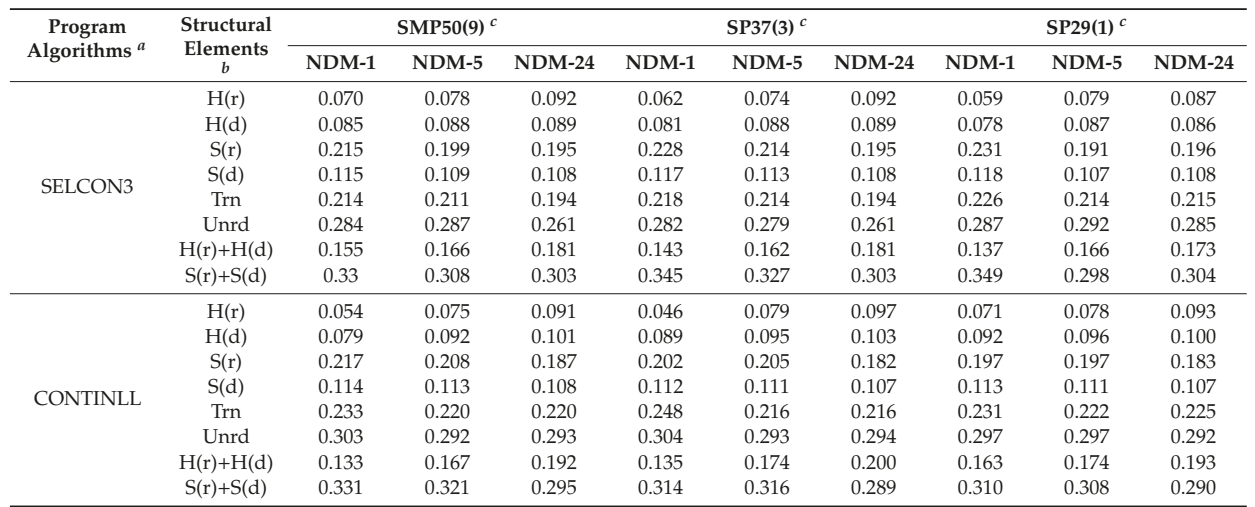

${ }^{a}$ The CDPro program package was used to analyse the data using two algorithms: CONTINLL and SELCON3.

${ }^{b} \mathrm{H}(\mathrm{r})$, regular $\alpha$-helix; $\mathrm{H}(\mathrm{d})$, distorted $\alpha$-helix; $\mathrm{S}(\mathrm{r})$, regular $\beta$-strand; $\mathrm{S}(\mathrm{d})$, distorted $\beta$-strand; Trn, turns; Unrd,

unordered. ${ }^{c}$ The reference protein sets (IBasis sets) were adopted. 


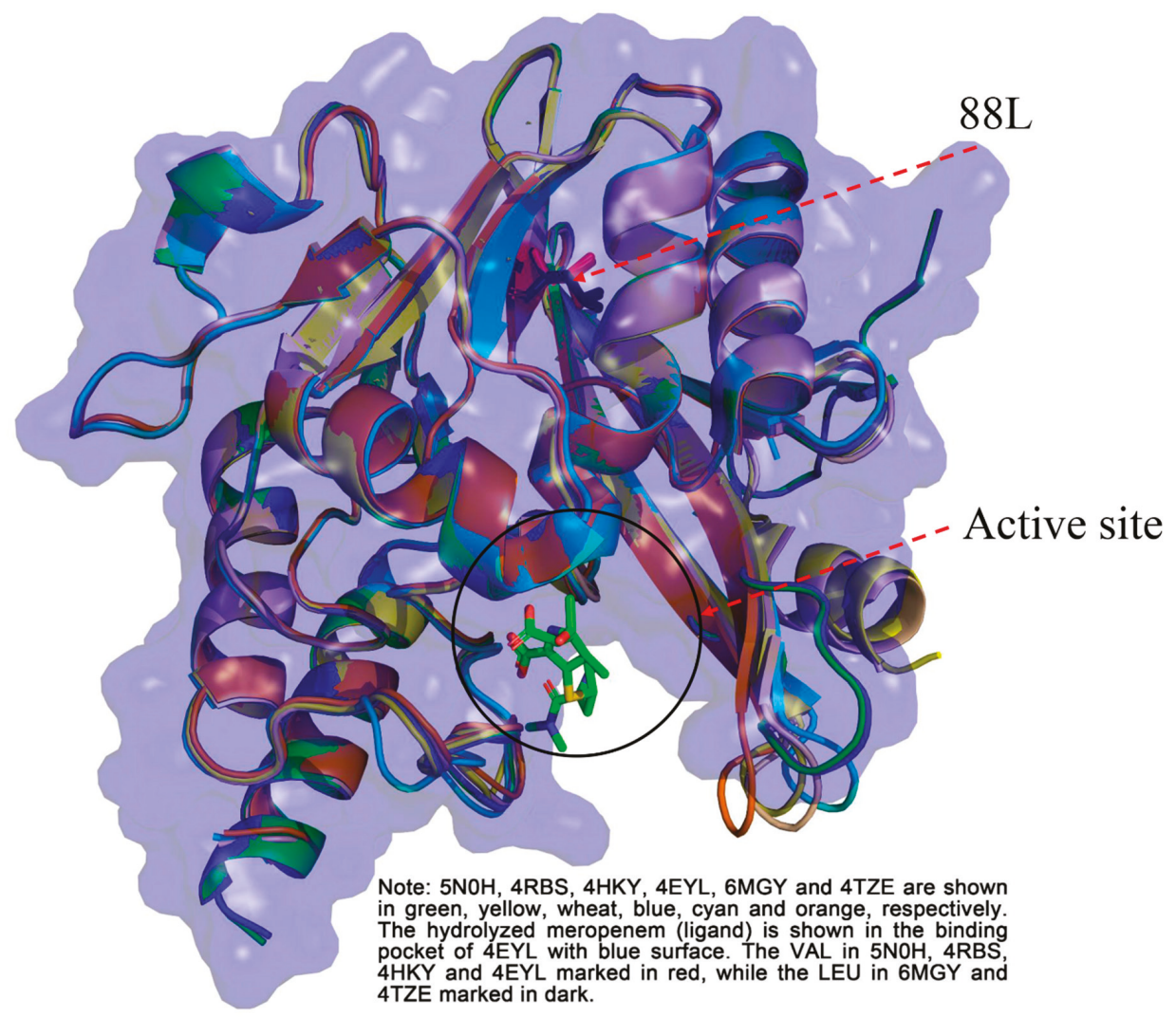

Figure 4. Cartoon model of NDM-24. To acquire a credible model, the $6 \mathrm{NDM}$ crystal structure (NDM-1(5NOH, 4RBS, 4HKY, and 4EYL) and NDM-5(6MGY, and 4TZE)) were adopted. The residue $88 \mathrm{~L}$ and active pocket were labelled.

\section{Material and Methods}

\subsection{Site-Directed Mutagenesis, Cloning and Expression of NDM Variants}

The $b l a_{\mathrm{NDM}-1}$ and $b l a_{\mathrm{NDM}-5}$ encoding genes were obtained from clinical Escherichia coli strains as previously described $[15,16]$. Site-directed mutagenesis was performed to generate $b l a_{\mathrm{NDM}-24}$ using the pHSG398/NDM-1 plasmid as template and primers listed in Table S1, as previously described [30].

First, the bla $a_{\mathrm{NDM}}$-genes were cloned into a pHSG398 vector (TaKaRa Bio, Dalian, China) using the $\mathrm{BamHI}$ and XhoI restriction sites. In a second PCR experiment, the $b l a_{\mathrm{NDM}}$ variants were amplified without a signal peptide introducing the Tobacco Etch Virus (TEV) at the N-terminal sequence. In order to obtain enzymes overexpression, the amplicons were inserted into a pET-28a(+) plasmid. The E. coli DH5 $\alpha$ competent cells were used as a non-expression host. E. coli BL21(DE3) was used for enzymes overexpression. The authenticity of recombinant plasmids was verified by PCR and sequencing was with Sanger.

\subsection{Antimicrobial Susceptibility Tests}

The phenotypic profile has been characterized by a microdilution method using a bacterial inoculum of $5 \times 10^{5} \mathrm{CFU} / \mathrm{ml}$ according to the Clinical Laboratory and Standards Institute [31,32]. E. coli ATCC25922 was used as a negative control. 


\subsection{Production and Purification of NDM-1, NDM-5, and NDM-24}

NDM-1, NDM-5, and NDM-24 were extracted from 0.5 L of culture of E. coli BL21(DE3)/pETNDM-1, E. coli BL21 (DE3) /pETNDM-5, and E. coli BL21 (DE3)/pETNDM-24, respectively. The cultures were grown at $37^{\circ} \mathrm{C}$ to achieve an $\mathrm{A}_{600}$ of $0.5 \mathrm{~L}$, and $0.4 \mathrm{mM}$ of IPTG was added. After addition of the IPTG, the cultures were incubated at $20{ }^{\circ} \mathrm{C}$ for $16 \mathrm{~h}$, under aerobic conditions. Thereafter, a cell supernatant containing the soluble NDM protein was obtained from the lytic bacteria by centrifuging at $10^{4} \mathrm{rpm}$. Proteins purification followed the manufacturer's instructions (Qiagen, Hilden, Germany) by using the Ni-nitrilotriacetic acid (NTA) agarose. The turbo tobacco etch virus (TEV) protease (Accelagen, San Diego, CA, USA) was used to gain the untagged protein without the His tags. The SDS-PAGE was performed to estimate the NDM purity enzymes. The protein concentration was determined using a BCA Protein Quantification Kit (Vazyme Biotech Co., Ltd, Nanjing, China). The $\beta$-lactamase activity was monitored at each purification step using the colour change of nitrocefin $1 \mathrm{mg} / \mathrm{mL}$, a chromogenic cephalosporin, according to the previous report [20].

\subsection{Determination of Kinetic Parameters}

Steady-state kinetic experiments were performed following the hydrolysis of each substrate at $25^{\circ} \mathrm{C}$ in a $50 \mathrm{mM}$ phosphate buffer, $\mathrm{pH} 7.0$ in the presence of $20 \mu \mathrm{M} \mathrm{Zn} \mathrm{SO}$. The data were collected with a SpectraMax M5 multi-detection microplate reader (Molecular Devices, Sunnyvale, CA, USA) as previously described [33]. Kinetic parameters were determined under initial-rate conditions using the GraphPad Prism ${ }^{\circledR}$ version 5.01 (San Diego, CA, USA) to generate the Michaelis-Menten curves, or by analysing the complete hydrolysis time courses [34,35]. Each kinetic value is the mean of the results of three different measurements. The error was below 5\%. NDM-5 was used as a reference to normalize.

\subsection{Circular Dichroism and Structure Analysis}

The circular dichroism (CD) spectra (185 to $260 \mathrm{~nm}$ ) were determined with a Chirascan Plus CD spectrophotometer (Applied Photophysics Ltd, Leatherhead, UK) equipped with a Peltier temperature-controlled cell holder, at $25^{\circ} \mathrm{C}$ using a 1-mm pathlength cuvette and the Savitzky-Golay filter was explored to the baseline-correct spectra data. Protein concentrations were diluted to 0.05-0.2 $\mathrm{mg} / \mathrm{mL}$ with a $5 \mathrm{mM}$ sodium phosphate buffer $\mathrm{pH} 7.0$ [36]. $207 \mathrm{~nm}$ spectrum data was used as the baseline to normalize and calibrate data for eliminating minor errors due to different concentrations [37]. The analysis was performed using the CONTINLL and SELCON3 algorithms with reference data sets three and nine, respectively [38]. The super-secondary (tertiary) structures of the proteins were analysed by the CDPro software package, which is available at the CDPro website: https://sites.bmb.colostate.edu/sreeram/CDPro/ [38,39]. To assay the location of the V88L substitution and analyse its effect on the structure, the pharmacophore modeling and screening software program Discovery Studio (version 2018) was employed to generate a three-dimensional (3D) interconnected model of NDM-24 using NDM-1 and NDM-5 as a template, in which reliable data of the crystal structure were collected from the PDB database.

\subsection{Thermal Stability Testing}

The melting temperature $\left(T_{m}\right)$ was used to show the protein stability. The determination of $T_{m}$ was performed by recording the $\mathrm{CD}$ signal change at $222 \mathrm{~nm}$. Data were collected at a ramp of $1^{\circ} \mathrm{C} / \mathrm{min}$ with a temperature range from $20-90^{\circ} \mathrm{C}$. The two-state model using nonlinear regression (Boltzmann) in the OriginPro 9.1.64 (OriginLab, Northampton, MA, USA) was applied to analyse the data. When 50\% of the protein melts, the temperature is defined as the Tm, representing thermal stability.

\section{Conclusions}

Our study explored the NDM-24 biological function and probed the V88L substitution role on the structure, enzyme activity, and stability. In brief, this non-active site change enhances the 
enzyme activity by increasing the turnover rate, related with an indirect effect on conformation. However, the loss cost caused by V88L significantly decreased the protein stability, and would shorten the persistence lifetime in the cell, so that the resistance to antibiotics hardly exhibits an outstanding elevation for the NDM-24-producing transformants. Meanwhile, alterations in the secondary content, such as lowering the $\beta$-sheet, have an interesting role in the NDM instability, being relevant to the V88L substitution occurring in the $\beta$-strand. According to previous data, the V88L/M154L combination appears to be favorable in the NDM evolution under an environmental pressure selection [14]. Further analysis about the significance of non-active-site residues will help in the comprehension of the resistance mechanism and broaden insight in the development of inhibitors, such as potential antibiotics candidate by reducing the protein stability lifetime.

Supplementary Materials: The following are available online at http://www.mdpi.com/2073-4344/9/9/744/s1. Figure S1: SDS-PAGE of NDM-24. Lane 1: NDM-24 containing His Tags, Figure S2: Molecular mass spectrometry of NDM-24 estimated by MALDI-TOF, Figure S3: Predicted secondary structure of NDM-24, Lane 2: NDM was cleaved by using Turbo tobacco etch virus (TEV) protease to remove His Tags (Accelagen, San Diego, CA, USA): tagged protein (2a) and untagged protein (2b); Lane 3: untagged protein; Lane M: Marker, Table S1. Oligonucleotides used in this study.

Author Contributions: J.S. designed the study. Z.L., D.L., and W.L. collected the data. Z.L., Y.W., and D.L. analyzed and interpreted the data. Z.L., A.P., D.L., Y.W., and J.S. wrote the report. All authors revised, reviewed and approved the final report.

Funding: The study was supported by grants from the National Key Research and Development Program of China (2018YFD0500300), and the National Natural Science Foundation of China (81861138051 and 81661138002).

Conflicts of Interest: The author declares no conflict of interest.

\section{References}

1. Palzkill, T. Metallo-beta-lactamase structure and function. Ann. N. Y. Acad. Sci. 2013, 1277, 91-104. [CrossRef] [PubMed]

2. Garau, G.; García-Sáez, I.; Bebrone, C.; Anne, C.; Mercuri, P.; Galleni, M.; Frère, J.M.; Dideberg, O. Update of the standard numbering scheme for class B beta-lactamases. Antimicrob. Agents Chemother. 2004, 48, 2347-2349. [CrossRef] [PubMed]

3. Yong, D.; Toleman, M.A.; Giske, C.G.; Cho, H.S.; Sundman, K.; Lee, K.; Walsh, T.R. Characterization of a New Metallo- $\beta$-Lactamase Gene, blaNDM-1, and a Novel Erythromycin Esterase Gene Carried on a Unique Genetic Structure in Klebsiella pneumoniae Sequence Type 14 from India. Antimicrob. Agents Chemother. 2009, 53, 5046-5054. [CrossRef] [PubMed]

4. Bonnin, R.A.; Poirel, L.; Carattoli, A.; Nordmann, P. Characterization of an IncFII Plasmid Encoding NDM-1 from Escherichia coli ST131. PLoS ONE 2012, 7, 34752. [CrossRef] [PubMed]

5. Dolejska, M.; Villa, L.; Poirel, L.; Nordmann, P.; Carattoli, A. Complete sequencing of an IncHI1 plasmid encoding the carbapenemase NDM-1, the ArmA 16S RNA methylase and a resistance-nodulation-cell division/multidrug efflux pump. J. Antimicrob. Chemother. 2013, 68, 34-39. [CrossRef] [PubMed]

6. King, D.; Strynadka, N. Crystal structure of New Delhi metallo-betalactamase reveals molecular basis for antibiotic resistance. Protein Sci. 2011, 20, 1484-1491. [CrossRef] [PubMed]

7. Gonzalez, L.J.; Bahr, G.; Nakashige, T.G.; Nolan, E.M.; Bonomo, R.A.; Vila, A.J. Membrane anchoring stabilizes and favors secretion of New Delhi metallo-beta-lactamase. Nat. Chem. Biol. 2016, 12, 516-522. [CrossRef] [PubMed]

8. Gonzalez, L.J.; Bahr, G.; Vila, A.J. Lipidated beta-lactamases: From bench to bedside. Future Microbiol. 2016, 11, 1495-1498. [CrossRef]

9. Khan, A.U.; Maryam, L.; Zarrilli, R. Structure, genetics and worldwide spread of New Delhi metallo-beta-lactamase (NDM): A threat to public health. BMC Microbiol. 2017, 17, 101. [CrossRef]

10. Cheng, Z.; Thomas, P.W.; Ju, L.; Bergstrom, A.; Mason, K.; Clayton, D.; Miller, C.; Bethel, C.R.; Vanpelt, J.; Tierney, D.L.; et al. Evolution of New Delhi metallo- $\beta$-lactamase (NDM) in the clinic: Effects of NDM mutations on stability, zinc affinity, and mono-zinc activity. J. Biol. Chem. 2018, 293, 12606-12618. [CrossRef] 
11. Zhang, H.O.; Hau, Q. Crystal structure of NDM-1 reveals a common $\beta$-lactam hydrolysis mechanism. FASEB J. 2011, 25, 2574-2582. [CrossRef] [PubMed]

12. Kim, Y.; Cunningham, M.A.; Mire, J.; Tesar, C.; Sacchettini, J.; Joachimiak, A. NDM-1, the ultimate promiscuous enzyme: Substrate recognition and catalytic mechanism. FASEB J. 2013, 27, 1917-1927. [CrossRef] [PubMed]

13. Liu, L.; Feng, Y.; McNally, A.; Zong, Z. bla NDM-21, a new variant of blaNDM in an Escherichia coli clinical isolate carrying blaCTX-M-55 and rmtB. J. Antimicrob. Chemother. 2018, 73, 2336-2339. [CrossRef] [PubMed]

14. Bahr, G.; Vitor-Horen, L.; Bethel, C.R.; Bonomo, R.A.; González, L.J.; Vila, A.J. Clinical evolution of New Delhi Metallo- $\beta$-lactamase (NDM) optimizes resistance under $\mathrm{Zn}(\mathrm{II})$ deprivation. Antimicrob. Agents Chemother. 2018, 62, 1817-1849. [CrossRef] [PubMed]

15. Liu, Z.; Li, J.; Wang, X.; Liu, D.; Ke, Y.; Wang, Y.; Shen, J. Novel Variant of New Delhi Metallo- $\beta$-lactamase, NDM-20, in Escherichia coli. Front. Microbiol. 2018, 9, 248. [CrossRef] [PubMed]

16. Liu, Z.; Wang, Y.; Walsh, T.R.; Liu, D.; Shen, Z.; Zhang, R.; Yin, W.; Yao, H.; Li, J.; Shen, J. Plasmid-mediated novel bla $a_{\mathrm{NDM}-17}$ gene encoding a carbapenemase with enhanced activity in a ST48 Escherichia coli strain. Antimicrob. Agents Chemother. 2017, 61, 2216-2233. [CrossRef] [PubMed]

17. Nordmann, P.; Boulanger, A.E.; Poirel, L. NDM-4 Metallo- $\beta$-Lactamase with Increased Carbapenemase Activity from Escherichia coli. Antimicrob. Agents Chemother. 2012, 56, 2184-2186. [CrossRef]

18. Zou, D.; Huang, Y.; Zhao, X.; Liu, W.; Dong, D.; Li, H.; Wang, X.; Huang, S.; Wei, X.; Yan, X.; et al. A Novel New Delhi Metallo- $\beta$-Lactamase Variant, NDM-14, Isolated in a Chinese Hospital Possesses Increased Enzymatic Activity against Carbapenems. Antimicrob. Agents Chemother. 2015, 59, 2450-2453. [CrossRef]

19. Tada, T.; Miyoshi-Akiyama, T.; Dahal, R.K.; Sah, M.K.; Ohara, H.; Kirikae, T.; Pokhrel, B.M. NDM-8 Metallo- $\beta$-Lactamase in a Multidrug-Resistant Escherichia coli Strain Isolated in Nepal. Antimicrob. Agents Chemother. 2013, 57, 2394-2396. [CrossRef]

20. Tada, T.; Shrestha, B.; Miyoshi-Akiyama, T.; Shimada, K.; Ohara, H.; Kirikae, T.; Pokhrel, B.M. NDM-12, a Novel New Delhi Metallo- $\beta$-Lactamase Variant from a Carbapenem-Resistant Escherichia coli Clinical Isolate in Nepal. Antimicrob. Agents Chemother. 2014, 58, 6302-6305. [CrossRef]

21. Ines, S.; Emma, K.; Rudolf, R.; Rumyana, M.; Anne Marie, Q.; Adolf, B. VIM-15 and VIM-16, two new VIM-2-like metallo-beta-lactamases in Pseudomonas aeruginosa isolates from Bulgaria and Germany. Antimicrob. Agents Chemother. 2008, 52, 2977.

22. Patricia, M.; Tomatis, P.E.; Mussi, M.A.; Fernando, P.; Viale, A.M.; Limansky, A.S.; Vila, A.J. Biochemical characterization of metallo-beta-lactamase VIM-11 from a Pseudomonas aeruginosa clinical strain. Antimicrob. Agents Chemother. 2008, 52, 2250.

23. Jose-Manuel, R.M.; Patrice, N.; Nicolas, F.; Laurent, P. VIM-19, a metallo-beta-lactamase with increased carbapenemase activity from Escherichia coli and Klebsiella pneumoniae. Antimicrob. Agents Chemother. 2010, 54, 471-476.

24. Pierre, B.; Carine, B.; Te-Din, H.; Warda, B.; Yves, D.; Ariane, D.; Kurt, H.; Youri, G. Detection and characterization of VIM-31, a new variant of VIM-2 with Tyr224His and His252Arg mutations, in a clinical isolate of Enterobacter cloacae. Antimicrob. Agents Chemother. 2012, 56, 3283.

25. Corbin, B.D.; Seeley, E.H.; Raab, A.; Feldmann, J.; Miller, M.R.; Torres, V.J.; Anderson, K.L.; Dattilo, B.M.; Dunman, P.M.; Gerads, R.; et al. Metal Chelation and Inhibition of Bacterial Growth in Tissue Abscesses. Science 2008, 319, 962-965. [CrossRef] [PubMed]

26. Kumar, G.; Issa, B.; Kar, D.; Biswal, S.; Ghosh, A.S. E152A substitution drastically affects NDM-5 activity. FEMS Microbiol. Lett. 2017, 364. [CrossRef] [PubMed]

27. Ali, A.; Azam, M.W.; Khan, A.U. Non-active site mutation (Q123A) in New Delhi metallo- $\beta$-lactamase (NDM-1) enhanced its enzyme activity. Int. J. Biol. Macromol. 2018, 112, 1272-1277. [CrossRef] [PubMed]

28. Carfi, A.; Pares, S.; Duée, E.; Galleni, M.; Duez, C.; Frère, J.M.; Dideberg, O. The 3-D structure of a zinc metallo-beta-lactamase from Bacillus cereus reveals a new type of protein fold. EMBO J. 1995, 14, 4914-4921. [CrossRef] [PubMed]

29. Piccirilli, A.; Brisdelli, F.; Aschi, M.; Celenza, G.; Amicosante, G.; Perilli, M. Kinetic Profile and Molecular Dynamic Studies Show that Y229W Substitution in an NDM-1/L209F Variant Restores the Hydrolytic Activity of the Enzyme toward Penicillins, Cephalosporins, and Carbapenems. Antimicrob. Agents Chemother. 2019, 63, e02270-18. [CrossRef]

30. Meini, M.-R.; Tomatis, P.E.; Weinreich, D.M.; Vila, A.J. Quantitative Description of a Protein Fitness Landscape Based on Molecular Features. Mol. Boil. Evol. 2015, 32, 1774-1787. [CrossRef] 
31. Clinical and Laboratory Standards Institute. Methods for Dilution Antimicrobial Susceptibility Tests for Bacteria that Grow Aerobically: Approved Standard, 11th ed.; CLSI document M07; Clinical and Laboratory Standards Institute: Wayne, PA, USA, 2018.

32. Clinical and Laboratory Standards Institute. Performance Standards for Antimicrobial Susceptibility Testing, 28th ed.; CLSI document M100; Clinical and Laboratory Standards Institute: Wayne, PA, USA, 2018.

33. Crowder, M.W.; Walsh, T.R.; Banovic, L.; Pettit, M.; Spencer, J. Overexpression, purification, and characterization of the cloned metallo-beta-lactamase L1 from Stenotrophomonas maltophilia. Antimicrob. Agents Chemother. 1998, 42, 921. [CrossRef] [PubMed]

34. De Meester, F.; Joris, B.; Reckinger, G. Automated analysis of enzyme inactivation phenomena. Application to $\beta$-lactamases and DD-peptidases. Biochem. Pharmacol. 1987, 36, 2393-2403. [CrossRef]

35. Segel, I.H. Biochemical Calculations, 2nd ed.; John Wiley \& Sons: New York, NY, USA, 1976; pp. $236-241$.

36. Liu, Z.; Zhang, R.; Li, W.; Yang, L.; Liu, D.; Wang, S.; Shen, J.; Wang, Y. Amino acid changes at the VIM-48 C-terminus result in increased carbapenem resistance, enzyme activity and protein stability. J. Antimicrob. Chemother. 2018, 74, 885-893. [CrossRef] [PubMed]

37. Raussens, V.; Ruysschaert, J.-M.; Goormaghtigh, E. Protein concentration is not an absolute prerequisite for the determination of secondary structure from circular dichroism spectra: A new scaling method. Anal. Biochem. 2003, 319, 114-121. [CrossRef]

38. Sreerama, N.; Venyaminov, S.Y.; Woody, R.W. Estimation of the number of $\alpha$-helical and $\beta$-strand segments in proteins using circular dichroism spectroscopy. Protein Sci. 1999, 8, 370-380. [CrossRef] [PubMed]

39. Sreerama, N.; Venyaminov, S.Y.; Woody, R.W. Analysis of Protein Circular Dichroism Spectra Based on the Tertiary Structure Classification. Anal. Biochem. 2001, 299, 271-274. [CrossRef] [PubMed]

(C) 2019 by the authors. Licensee MDPI, Basel, Switzerland. This article is an open access article distributed under the terms and conditions of the Creative Commons Attribution (CC BY) license (http://creativecommons.org/licenses/by/4.0/). 

Article

\title{
Decoding Essential Amino Acid Residues in the Substrate Groove of a Non-Specific Nuclease from Pseudomonas syringae
}

\author{
Lynn Sophie Schwardmann, Sarah Schmitz, Volker Nölle and Skander Elleuche * \\ Miltenyi Biotec B.V. \& Co. KG, Friedrich-Ebert-Straße 68, 51429 Bergisch Gladbach, Germany; \\ l.schwardmann@web.de (L.S.S.); sarahs@miltenyibiotec.de (S.S.); VolkerN@miltenyibiotec.de (V.N.) \\ * Correspondence: skander.elleuche@miltenyibiotec.de; Tel.: +49-2204-8306-4452
}

Received: 17 October 2019; Accepted: 6 November 2019; Published: 9 November 2019

\begin{abstract}
Non-specific nucleases (NSN) are of interest for biotechnological applications, including industrial downstream processing of crude protein extracts or cell-sorting approaches in microfabricated channels. Bacterial nucleases belonging to the superfamily of phospholipase D (PLD) are featured for their ability to catalyze the hydrolysis of nucleic acids in a metal-ion-independent manner. In order to gain a deeper insight into the composition of the substrate groove of a NSN from Pseudomonas syringae, semi-rational mutagenesis based on a structure homology model was applied to identify amino acid residues on the protein's surface adjacent to the catalytic region. A collection of 12 mutant enzymes each with a substitution to a positively charged amino acid (arginine or lysine) was produced in recombinant form and biochemically characterized. Mutations in close proximity to the catalytic region (inner ring) either dramatically impaired or completely abolished the enzymatic performance, while amino acid residues located at the border of the substrate groove (outer ring) only had limited or no effects. A K119R substitution mutant displayed a relative turnover rate of $112 \%$ compared to the original nuclease. In conclusion, the well-defined outer ring of the substrate groove is a potential target for modulation of the enzymatic performance of NSNs belonging to the PLD superfamily.
\end{abstract}

Keywords: DNase; kinetic profiles; RNase; semi-rational mutagenesis; substrate specificity

\section{Introduction}

Non-specific nucleases (NSN) are a group of enzymes that hydrolyze deoxyribonucleic acid (DNA) and ribonucleic acid (RNA) in all conformations, including single-stranded and double-stranded or linear and circularized substrates, without sequence specificity [1]. NSNs are ubiquitously distributed among all organisms and are of great potential for versatile biotechnological and clinical applications [2-4].

Enzymes that are highly indiscriminate towards different substrates are generally considered as potential evolutionary starting points for developing novel or more specific catalytic activities [5-7]. Members of the phospholipase D (PLD; Enzyme Commission number (EC) 3.1.4.4) superfamily are known to accept a wide range of ester substrates, including nucleic acids [8-10]. PLDs are mainly represented in eukaryotes and predominately catalyze the hydrolysis of phosphatidylcholine to produce choline and phosphatidic acid [11]. Moreover, PLDs act as important key players in various physiological processes, including cell migration and membrane trafficking [10]. This family of enzymes usually encodes two copies of the conserved $\mathrm{HxK}(\mathrm{x})_{4} \mathrm{D}(\mathrm{x})_{6} \mathrm{GSxN}$ motif in one gene.

A structurally related bacterial enzyme (Nuc) has been initially described from the human pathogenic microorganism Salmonella enterica subsp. enterica serovar Typhimurium. Nuc contains a single $\mathrm{HxK}(\mathrm{x})_{4} \mathrm{D}(\mathrm{x})_{6} \mathrm{GSxN}$ motif, but forms a homodimer, and is capable of degrading nucleic acids in a 
non-specific manner [12,13]. This enzyme is among the very few known nucleases that are not dependent on a metal ion in its catalytic region, and is therefore of potential interest for biotechnological applications that take place in buffers supplemented with metal ion chelators, such as ethylenediaminetetraacetic acid (EDTA) or ethylene glycol-bis( $\beta$-aminoethyl ether)- $\mathrm{N}, \mathrm{N}, \mathrm{N}^{\prime}, \mathrm{N}^{\prime}$-tetraacetic acid (EGTA). The group of metal-ion-independent nucleases mainly consists of two PLD-like, site-specific restriction endonucleases from Bacillus firmus and Bacillus megaterium, WSV191 from the white spot syndrome virus and GBSV1-NSN from a thermophilic bacteriophage, as well as the restriction glycosylase R.PabI from the hyperthermophilic archeon Pyrococcus abyssi [14-18].

So far, only three isozymes of bacterial PLD-like NSNs, beside Nuc from S. enterica subsp. enterica serovar Typhimurium, have been investigated and described in detail with regard to their biochemical and biophysical properties: (1) EcNuc from Escherichia coli has been shown to be applicable during cell lysis and protein purification in EDTA-containing buffers; and (2) two isozymes from the plant pathogenic competitor bacterium Pantoea agglomerans were shown to be the result of an ancient gene duplication event followed by diversification $[19,20]$. These enzymes are completely devoid of catalytic performance towards lipids and exclusively degrade nucleic acids in a non-specific manner.

In this study, another metal-ion-independent NSN (DNase/D157G) from Pseudomonas syringae was mutagenized using a semi-rational strategy to gain a deeper insight into the composition of the substrate groove. Homology modeling was applied to identify amino acid residues on the surface of the NSN in the surrounding of the catalytic site, which is buried at the bottom of the putative substrate groove. It has been shown before that positively charged amino acid residues that can interact with the proximal negatively charged phosphate groups in nucleic acids had a stimulating impact on the catalytic activity of human DNase I [21]. Therefore, positively charged amino acids were introduced at positions on the surface of DNase/D157G within the substrate groove. Two regions were defined that were either directly adjacent to the catalytic site (inner ring) or at the border of the substrate groove (outer ring). Substitutions in the inner ring dramatically impaired or completely abolished the catalytic activity, while mutagenesis in the outer ring had no or little effect. DNase variant K119R/D157G displayed increased activity, the temperature optimum of variant S143R/D157G was shifted from $50{ }^{\circ} \mathrm{C}$ to $40{ }^{\circ} \mathrm{C}$, and N95K/D157G and S143K/D157G exhibited an increased tolerance towards $50 \mathrm{mM}$ of EDTA.

\section{Results}

\subsection{Identification of Amino Acid Residues within the Substrate Groove of a NSN from Pseudomonas sp.}

Phylogenetic analyses revealed a highly conserved NSN within the genomes of Pseudomonas species. These enzymes are related to Nuc from S. enterica subsp. enterica serovar Typhimurium ( 57\% identity in 159 amino acids overlap) and are highly active at neutral $\mathrm{pH}$, in the presence of salt concentrations up to $250 \mathrm{mM}$, and in a temperature range between 4 and $50{ }^{\circ} \mathrm{C}$ (Supplementary Materials Figure S1). It has been shown that amino acid residues D157, E157, and G157 occur naturally in homologues from the genus Pseudomonas. A comparison of the catalytic activities in our laboratory revealed that an enzyme variant containing G157 is superior over a variant with a negatively charged amino acid at position 157 (unpublished results). Therefore, the natural amino acid sequence from a NSN of $P$. syringae containing a single amino acid substitution at position 157 (DNase/D157G) was used in our study as the starting variant for semi-rational mutagenesis to generate double-mutants.

A homology model of the enzyme DNase/D157G was produced based on the crystal structure from S. enterica subsp. enterica serovar Typhimurium (Figure 1). The enzyme is modelled as a hypothetical homodimer, with the catalytic site buried within a putative substrate groove at the dimeric interface. The catalytic site is composed of amino acids H122, K124, G136, S137, and N139, that are part of the $\mathrm{HxK}(\mathrm{x})_{4} \mathrm{D}(\mathrm{x})_{6} \mathrm{GSxN}$ motif, while D129 has been proposed to be of structural relevance [12]. Fifteen different amino acid residues were identified that are present on the protein surface within the substrate groove. These amino acid residues were either assigned to be part of an inner ring that is directly 
adjacent to the catalytic site or to an outer ring that surrounded the inner ring amino acid residues. The following amino acids were identified as being located on the protein surface close to the catalytic site: Y63, S64, T66, I120, and S141, while P68, H91, G92 D94, N95, A97, A101, K119, A142, and S143 are defined as being part of the outer ring (Figure A1 Appendix A).

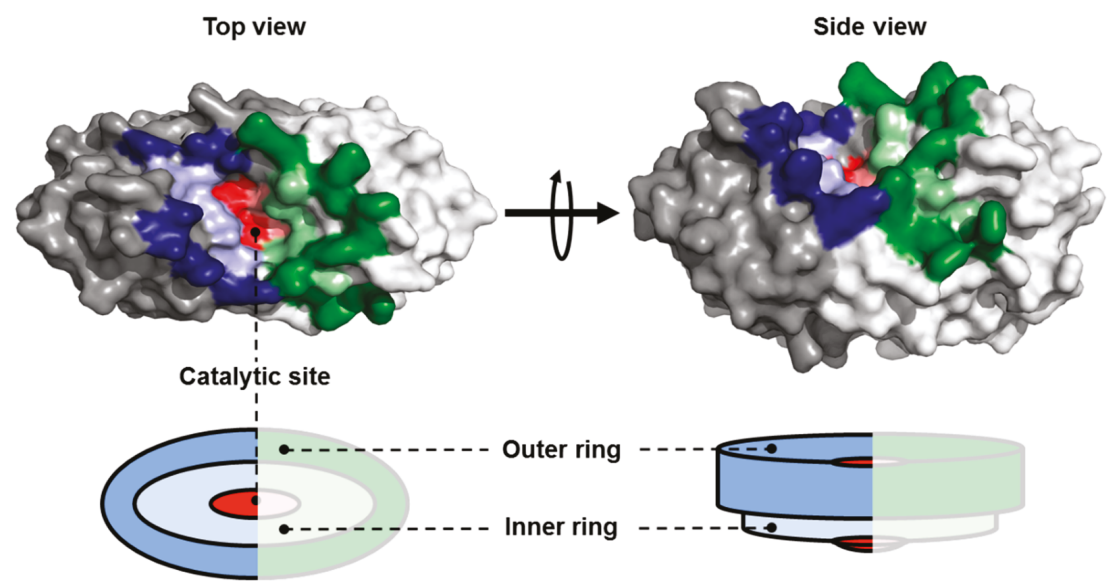

Figure 1. Homology model of non-specific nucleases (NSNs) from Pseudomonas syringae in top and side views. Low resolution model of DNase/D157G using Nuc (PDB: 1BYS_A) as a template. PyMOL was used to highlight a hypothetical dimeric structure with dark and light grey monomers. The conserved residues of the $\mathrm{HxK}(\mathrm{x})_{4} \mathrm{D}(\mathrm{x})_{6} \mathrm{GSxN}$ motif are given in dark and light red. Naturally occurring amino acids of the outer and inner rings are highlighted in dark and light blue, while substituted positively charged amino acid residues are indicated in dark and light green. Cartoon illustrations at the bottom are used to simplify the orientation of amino acid residues of the inner and outer ring within the potential substrate groove surrounding the catalytic site.

Surface-presented amino acid residues were exchanged for lysine or asparagine to improve substrate binding and modulate the enzymatic performance or to identify amino acids essential for catalytic activity. Histidine was not considered due to its bulkiness, aggravating the risk for interference with the structure of the protein. Potential steric hindrance was determined by in silico mutagenesis, and the following substitutions were selected: Y63K, S64K, T66R, P68R, H91R, D94K, N95K, K119R, I120K, S141K, A142R, and S143R. Due to the fact that K119 is the only positively charged amino acid within the substrate groove, this lysine was replaced with asparagine. Amino acid residues G92, A97, and A101 were not mutagenized due to expected clashes with adjacent amino acids.

\subsection{Production and Purification of Recombinant Nuclease Mutants}

Recombinant DNase/D157G double-mutants were produced in Escherichia coli Veggie BL21 (DE3), except for mutant P68R/D157G, because this expression strain could not be transformed with the corresponding expression plasmid. Therefore, Escherichia coli Veggie BL21 (DE3) pLysS was used for the production of this mutant. All recombinant mutant enzymes were produced in soluble form and could be purified using a two-step approach combining affinity and ion exchange chromatography. Purification strategy was optimized using the Äkta purifier (Figure 2). The purification level of all recombinant nucleases was visualized with sodium dodecyl sulfate polyacrylamide gel electrophoresis (SDS-PAGE) and Western blotting analyses using an anti-HIS antibody. 


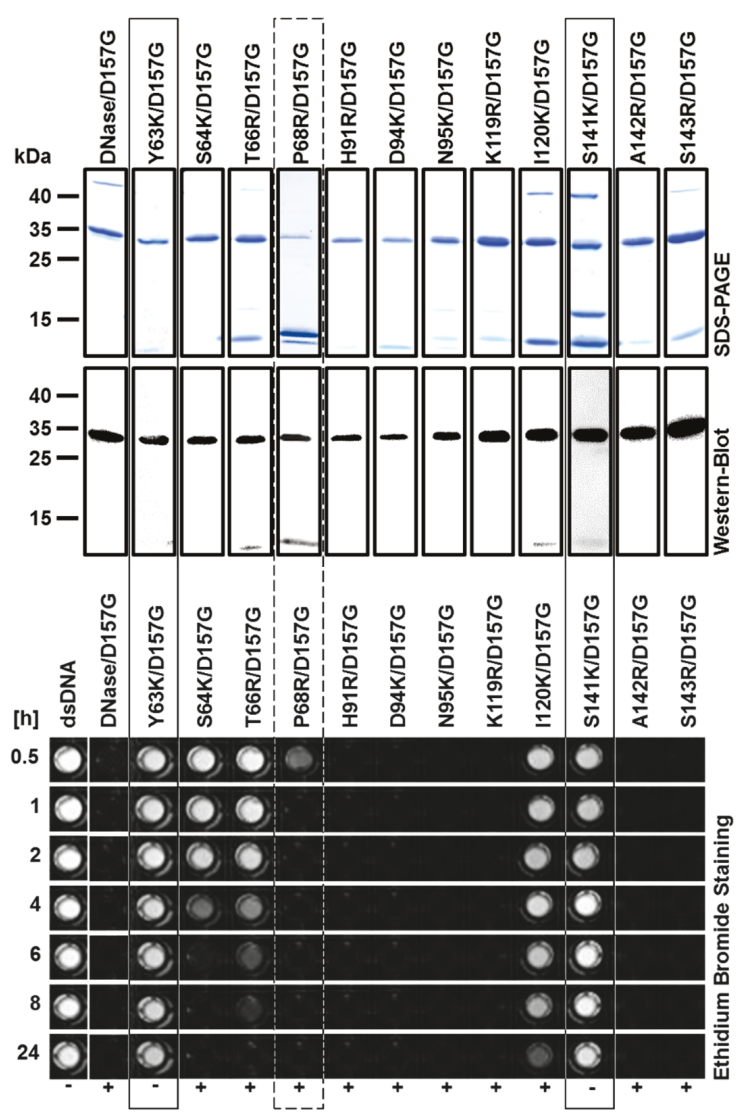

Figure 2. Biochemical and enzymatical analysis of purified nuclease mutants. SDS-PAGE results showed the purity of HIS-tagged nucleases $(29 \mathrm{kDa})$ after a two-step purification approach composed of affinity and ion exchange chromatography (upper row). Western blotting analyses confirmed the presence of HIS-tagged nucleases (middle row). Qualitative activity assays used ethidium bromide staining in 96-well plates (lower row): white colored dots indicate the presence of ethidium bromide intercalating into DNA and grey dots indicate incomplete degradation, while a complete loss of fluorescence is due to complete DNA degradation. Solid line boxes_inactive variants Y63K/D157G and S141K/D157G were purified in non-optimized gravity flow experiments. Dashed line box-variant P68K/D157G was produced in expression strain E. coli Veggie BL21(DE3) pLysS. Note: " +" indicates activity and "-" indicates inactivity. SDS-PAGE results, including all purification steps, are shown in Figure A2 Appendix A.

A qualitative assay using ethidium bromide to visualize non-degraded, double-stranded DNA (dsDNA) was applied to demonstrate that mutants Y63K/D157G and S141K/D157G were inactive, while mutant S64K/D157G completely degraded dsDNA after $6 \mathrm{~h}$, mutant T66R/D157G after $24 \mathrm{~h}$, and mutant I120K/D157G partly hydrolyzes DNA after $24 \mathrm{~h}$. These five mutants contain amino acid substitutions within the inner ring of the substrate groove. The remaining mutants as well as the positive control DNase/D157G completely hydrolyzed dsDNA after 30 min (Figure 2).

To ensure that the correct mutants were purified and characterized, the molecular masses of the purified enzymes were determined by mass spectrometry in addition to sequence verification of generated plasmids. Measured molecular weights are in accordance with predicted masses (Table 1). Variant P68R/D157G could not be properly identified due to impurities. 
Table 1. Molecular masses of nuclease variants.

\begin{tabular}{|c|c|c|}
\hline Variant & Theoretical MW (Da) $^{1}$ & Measured MW (Da) \\
\hline DNase/D157G & $28,900.30$ & $28,900.61$ \\
\hline Y63K/D157G & $28,780.19$ & $28,780.30$ \\
\hline S64K/D157G & $28,856.29$ & $28,856.19$ \\
\hline T66R/D157G & $28,870.28$ & $28,871.01$ \\
\hline P68R/D157G & $28,874.27$ & n.d. ${ }^{2}$ \\
\hline H91R/D157G & $28,834.24$ & $28,834.07$ \\
\hline D94K/D157G & $28,828.28$ & $28,828.56$ \\
\hline N95K/D157G & $28,829.26$ & $28,829.40$ \\
\hline K119R/D157G & $28,843.21$ & $28,842.25$ \\
\hline I120K/D157G & $28,830.21$ & $28,829.26$ \\
\hline S141K/D157G & $28,856.29$ & $28,856.10$ \\
\hline A142R/D157G & $28,900.30$ & $28,900.58$ \\
\hline S143R/D157G & $28,884.30$ & $28,884.27$ \\
\hline
\end{tabular}

\subsection{Biochemical Properties of Nucleases}

In vitro activity assays using dsDNA at $25^{\circ} \mathrm{C}$ without the addition of ethidium bromide were conducted to confirm the qualitative plate assays. The reaction was stopped after $1 \mathrm{~h}$ of incubation and samples were loaded onto an agarose gel to investigate the level of hydrolysis of sheared dsDNA (Figure 3). As expected, inactive mutant enzymes Y63K/D157G and S141K/D157G were not capable of degrading dsDNA, while recombinant enzymes S64K/D157G, T66R/D157G, and I120K/D157G, respectively, exhibited reduced activity levels compared to the initial nuclease variant DNase/D157G and the remaining mutants.

dsDNA, sheared

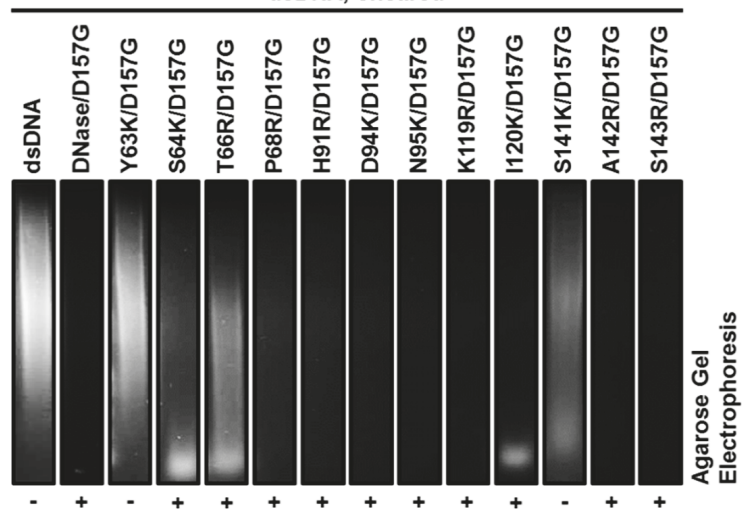

Figure 3. Digestion of sheared dsDNA by nuclease mutants. Sheared dsDNA (UltraPure ${ }^{\mathrm{TM}}$ Salmon Sperm DNA Solution) exhibited an average size of $\leq 2000$ bps. Negative control containing substrate without enzymes is indicated as "dsDNA". The positive control DNase/D157G and mutants S64K/D157G, H91R/D157G, D94K/D157G, N95K/D157G, K119R/D157G, I120K/D157G, A142R/D157G, and S143R/D157G were able to completely hydrolyze sheared dsDNA. S64K/D157G, T66R/D157G, and I120K/D157G partially degraded sheared dsDNA within $1 \mathrm{~h}$ at $25^{\circ} \mathrm{C}$. Y63K/D157G and S141K/D157G did not exhibit activity towards sheared dsDNA. Note: "+" indicates activity and "-" indicates inactivity, without any quantification of the activity level.

After $1 \mathrm{~h}$ of incubation, mutant enzyme T66R/D157G only initiated the hydrolysis of dsDNA with some low molecular weight fragments visible at the bottom of the agarose gel. Therefore, the catalytic activity of this mutant was investigated with regard to its degradation velocity. Identical concentrations 
of mutant enzyme T66R/D157G were incubated with substrate for $30 \mathrm{~min}, 1 \mathrm{~h}, 2, \mathrm{~h}, 4 \mathrm{~h}$, and $24 \mathrm{~h}$, respectively. Reactions were stopped and the samples were loaded onto an agarose gel, revealing that the substrate becomes slowly degraded and is still not completely digested after $4 \mathrm{~h}$ of incubation (Figure 4).

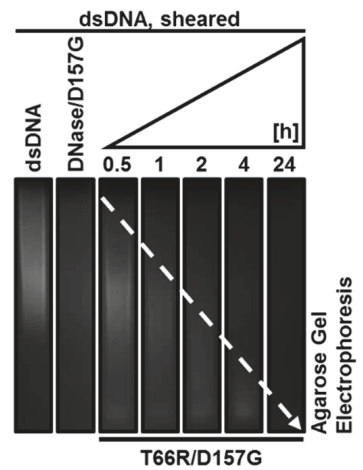

Figure 4. Degradation of sheared dsDNA by mutant T66R/D157G over time. Sheared dsDNA (UltraPureTM Salmon Sperm DNA Solution) exhibited an average size of $\leq 2000$ bps. Reaction was stopped after indicated times (between 0.5 and $24 \mathrm{~h}$ ). White dashed arrow indicates level of nucleic acid molecular weights. The dsDNA is completely hydrolyzed after $24 \mathrm{~h}$ of incubation at $25^{\circ} \mathrm{C}$.

To investigate the substrate promiscuity of active recombinant nuclease mutants, the enzymatic hydrolysis was studied towards the following substrates: unsheared dsDNA, single-stranded genomic DNA (ssDNA), circularized DNA, and RNA from bacteriophage MS2. Mutant enzymes with amino acid substitutions in the outer ring of the substrate groove that were active towards sheared dsDNA (Figure 3) also degraded unsheared dsDNA, ssDNA, circularized DNA, and RNA (Figure 5, Figure A3).

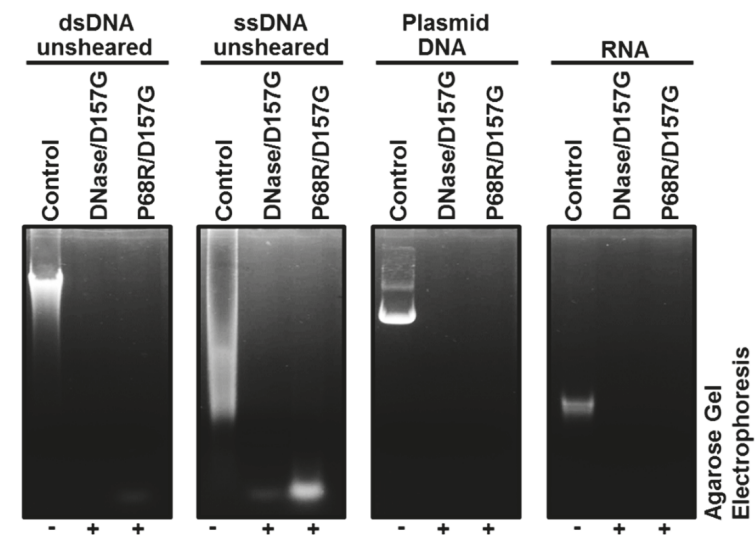

Figure 5. Substrate specificity of mutants with amino acid substitutions in the outer ring. Positive control DNase/D157G and mutant P68R/D157G were incubated for $1 \mathrm{~h}$ at $25^{\circ} \mathrm{C}$ with different types of DNA and RNA. Further outer ring mutants H91R/D157G, D94K/D157G, N95K/D157G, K119R/D157G, A142R/D157G, and S143R/D157G were also able to degrade all types of nucleic acids (Figure A3 Appendix A). "Control" indicates negative controls containing substrate but no enzyme in the reaction mixture.

Nuclease mutant enzyme Y63K/D157G was also inactive towards unsheared dsDNA, ssDNA, and circularized DNA, while S141K/D157G showed some activity on all substrates except sheared 
dsDNA (Figures 3 and 6). However, mutant Y63K/D157G exhibited some activity towards RNA. In good agreement with previous results, mutant enzyme T66R/D157G exhibited reduced activity compared to control DNase/D157G and active mutant enzymes when incubated with both DNA and RNA (Figure 6). In contrast to sheared dsDNA, mutant S64K/D157G completely digested unsheared dsDNA, ssDNA, and circularized DNA, and partially digested RNA, while I120K/D157G was also active on every substrate, but only completely degraded RNA within $1 \mathrm{~h}$ at $25^{\circ} \mathrm{C}$ (Figure 6).
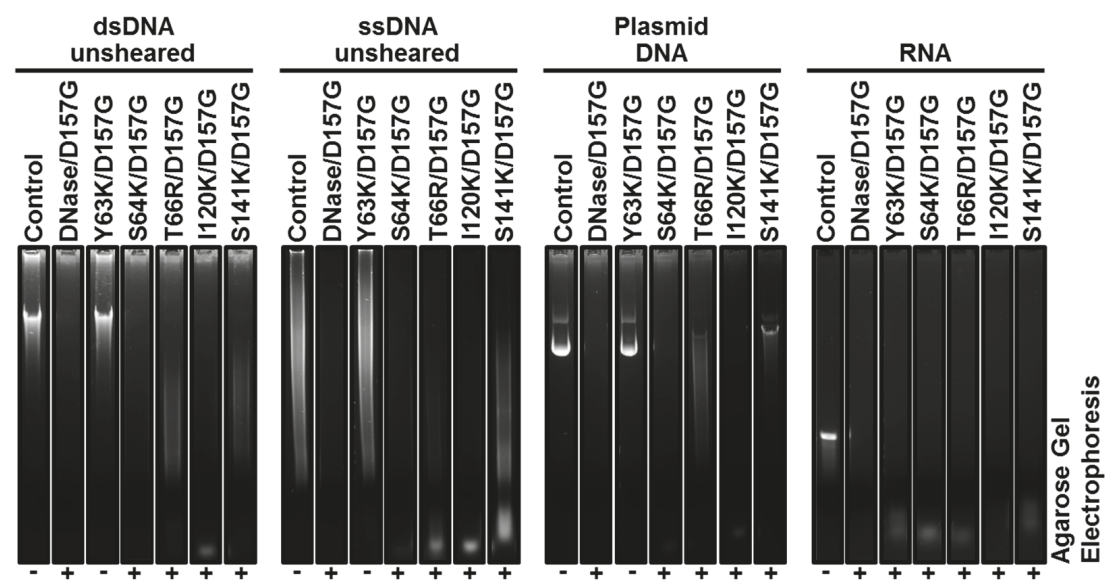

Figure 6. Substrate specificity of mutants with amino acid substitutions in the inner ring. Mutant Y63K/D157G was not able to degrade any type of nucleic acid. Mutants S64K/D157G, T66R/D157G, and I120K/D157G partially degraded all types of nucleic acids within $1 \mathrm{~h}$ at $25^{\circ} \mathrm{C}$, while mutant S141K/D157G exhibited low levels of degradation activity. "Control" indicates negative controls containing substrate but no enzyme in the reaction mixture.

Furthermore, $\mathrm{pH}$ and temperature optima of active mutants were determined. Every mutant as well as the initial variant DNase/D157G displayed optimal activity at $\mathrm{pH} 7.0$. The temperature optima were around $50{ }^{\circ} \mathrm{C}$ for the initial variant DNase/D157G and all active mutants, except for mutants S64K/D157G and S143R/D157G, which showed optimal activities at $60-70{ }^{\circ} \mathrm{C}$ and $40{ }^{\circ} \mathrm{C}$, respectively.

\subsection{Enzyme Kinetics}

Michaelis-Menten kinetics using sheared dsDNA confirmed the result of the quality activity assays: mutant enzymes Y63K/D157G and S141K/D157G did not exhibited any activity in these assays towards sheared dsDNA and the catalytic performances of mutant enzymes S64K/D157G, T66R/D157G, and I120K/D157G were lower compared to the initial nuclease variant DNase/D157G and remaining active mutant enzymes at $25^{\circ} \mathrm{C}$. Relative turnover rates were below $10 \%$ compared with DNase/D157G and the catalytic efficiency $\left(\mathrm{k}_{\mathrm{cat}} / \mathrm{K}_{\mathrm{M}}\right)$ was below $0.2 \mathrm{~s}^{-1} \mu \mathrm{M}^{-1}$ (Table 2). The turnover number of mutant enzyme K119R/D157G (1034 s $\left.{ }^{-1}\right)$ exclusively surpassed the catalytic activity of DNase/D157G $\left(924 \mathrm{~s}^{-1}\right)$, but the latter mutant enzyme also exhibited the lowest substrate affinity of all mutants ( $\left.\mathrm{K}_{\mathrm{M}}=428 \mu \mathrm{M}\right)$. 
Table 2. Kinetic characteristics of nuclease mutants ${ }^{1}$

\begin{tabular}{lcccc}
\hline \multicolumn{1}{c}{ Variant } & $\mathbf{K}_{\mathbf{M}}(\boldsymbol{\mu} \mathbf{M})$ & $\mathbf{k}_{\mathbf{c a t}}\left(\mathbf{s}^{-\mathbf{1}}\right)$ & $\mathbf{k}_{\mathbf{c a t}} / \mathbf{K}_{\mathbf{M}}\left(\mathbf{s}^{-\mathbf{1}} \boldsymbol{\mu \mathbf { M } ^ { - \mathbf { 1 } } )}\right.$ & Relative Turnover Rate (\%) \\
\hline DNase/D157G & 357 & 924 & 2.58 & 100 \\
Y63K/D157G & n.d. ${ }^{2}$ & n.d. & n.d. & - \\
S64K/D157G & 115 & 8.0 & 0.07 & 0.9 \\
T66R/D157G & 335 & 62 & 0.19 & 6.7 \\
P68R/D157G & 358 & 106 & 0.3 & 11 \\
H91R/D157G & 284 & 290 & 1.02 & 31 \\
D94K/D157G & 224 & 170 & 0.76 & 18 \\
N95K/D157G & 273 & 455 & 1.66 & 49 \\
K119R/D157G & 428 & 1034 & 2.42 & 112 \\
I120K/D157G & 115 & 3.0 & 0.03 & - \\
S141K/D157G & n.d. & n.d. & n.d. & 77 \\
A142R/D157G & 352 & 707 & 2.01 & 17 \\
S143R/D157G & 83 & 153 & 1.84 & \\
\hline
\end{tabular}

${ }^{1}$ All experiments were done at $25{ }^{\circ} \mathrm{C} .{ }^{2}$ Not detectable, below the detection limit.

\subsection{EDTA Tolerance of Nuclease Mutants}

As metal-ion-independent proteins, NSNs of the PLD-like family are known to be tolerant in the presence of chelating agents, such as EDTA. DNase/D157G displayed $>80 \%$ relative activity at a concentration of $20 \mathrm{mM}$ EDTA and still preserved $>60 \%$ residual activity in the presence of $50 \mathrm{mM}$ EDTA. Active positively charged mutant enzymes were also tested in the presence of EDTA in concentrations between $1 \mathrm{mM}$ and $50 \mathrm{mM}$, without any abnormalities, except that mutant enzymes P68R/D157G, N95K/D157G, I120K/D157G, and S143K/D157G were almost not affected by any concentration of EDTA ( $>80 \%$ residual activity at concentrations up to $50 \mathrm{mM}$ ), while mutant enzymes T66R/D157G and K119R/D157G only showed residual activities of $25 \%$ and $34 \%$ in the presence of $50 \mathrm{~mm}$ EDTA, respectively.

\section{Discussion}

Commercially available NSNs are of high potential for the elimination of nucleic acids during protein downstream processing, to reduce the viscosity, or for prevention of cell clumping in cell sorting approaches $[1,20,22]$. The prototype non-specific nuclease is the metal-ion-dependent NSN from Serratia marcescens that is commercially sold under the trademark "Benzonase ${ }^{\circledR}$ Nuclease" (Merck KGaA, Darmstadt, Germany). This enzyme has been investigated in detail with regard to protein maturation, secretion, catalytic mechanism, and biotechnological applications [2]. Further NSNs, especially metal-ion-independent enzymes, have only been rarely investigated to date $[13,16,18-20,23]$.

In this study, a semi-rational approach was used to select suitable mutation sites within the substrate groove of an NSN from Pseudomonas syringae, which were substituted by site-directed mutagenesis against positively charged amino acid residues to modulate the affinity for negatively charged substrates. Critical amino acid residues for the enzymatic performance of different nucleases were routinely identified by site-directed mutagenesis in previous studies [21,24-26].

Under natural conditions, it has been hypothesized that either positive mutations are first installed in a protein, while negative and neutral mutations are accumulated over time (Neo-Darwinian hypothesis), or neutral mutations pave the way for a flexible evolution and positive or negative mutations are installed as a response to certain conditions (competing hypothesis) [27]. By comparing homology models of proteins with singular amino acid substitutions, it is difficult to determine which of the specific mutations evokes an advantageous, neutral, or even deleterious effect on the protein performance, with certain effects on secondary and tertiary structures often being totally unpredictable [28]. Therefore, in silico mutagenesis was exclusively used to predict steric hindrance between introduced charged amino acid residues and amino acids of the catalytic site, or the predicted substrate groove followed by experimental testing of produced mutants. 
Fifteen amino acid residues on the protein surface near the catalytic site were identified in a NSN that is highly conserved within the genus Pseudomonas. In silico mutagenesis revealed that twelve amino acids could be substituted against either arginine or lysine, without any steric effects in the molecular model. Eleven mutants could be produced in recombinant form in E. coli Veggie BL21 (DE3). However, transformation of E. coli Veggie BL21 (DE3), with an expression plasmid encoding for mutant P68R/D157G, did not result in any clones, but the recombinant enzyme could be produced in expression strain E. coli Veggie BL21 (DE3) pLysS with a very low yield. The additional plasmid pLysS encodes for T7 lysozyme to lower the background expression level of genes under the control of the T7 promoter. Therefore, it can be hypothesized that background expression of the gene-encoding mutant P68R/D157G in pLysS-less expression strains leads to lethality of the host strain. It is worth mentioning that in another experiment, the same results were monitored when proline at position 68 was replaced with negatively charged aspartate in our control. Nevertheless, mutant P68R/D157G only exhibited a turnover rate of $11 \%$ compared with the original variant DNase/D157G. However, the reduced activity may also be dependent on protein impurities that were still present after application of a two-step purification approach.

Artificially increasing the positive charge of the putative substrate groove in the NSN did not accelerate the catalytic performance of the enzyme. In another study, the activity of human DNase I also dropped with the addition of basic amino acids compared with the wild-type enzyme. However, suboptimal conditions for the wild-type enzyme, such as increased salt concentrations, accelerated the performance of the mutated enzyme variants [21]. Eleven out of twelve mutants in our portfolio displayed reduced activity at optimal conditions, while K119R/D157G was the only variant exhibiting an increased turnover number compared with DNase/D157G. However, this enzyme was the sole exception with a basic amino acid replaced by another basic amino acid. Two mutations within the inner ring of the substrate groove, namely Y63K and S141K, completely abolished the ability to hydrolyze sheared dsDNA, while mutant S141K/D157G was still capable of partially hydrolyzing unsheared dsDNA and circular plasmid DNA. Both mutants were also active towards RNA, but it is important to note that although all buffers were prepared under sterile conditions, the possibility that the observed activity is an artefact due to contamination with RNase cannot be excluded. Interestingly, asparagine at position 95 within the outer ring of the substrate groove was slightly impaired with regard to $\mathrm{k}_{\mathrm{cat}}$. A comparable effect has also been observed in another mutant, in which asparagine was replaced by serine. The latter amino acid occurs naturally in the homologous NSN in some members of the genus Pseudomonas.

Mutants were also probed for stability and activity effects in the presence of chelating agents. A slight performance improvement was detected for mutants N95K/D157G and S143K/D157G with regard to the tolerance of high concentrations of EDTA, which were not affected by concentrations up to $50 \mathrm{mM}$. Metal-ion-dependent DNases are usually completely inhibited by low concentrations of EDTA (1-5 mM), and even some metalloproteins that tolerate EDTA are dramatically impaired by concentrations of $50 \mathrm{mM}[29,30]$. However, the related NSNs from Escherichia coli and Pantoea agglomerans were already inhibited at concentrations above $20 \mathrm{mM}$ of EDTA, which is similar to the results obtained with mutant enzymes T66R/D157G and K119R/D157G [19,20]. Nevertheless, these data are in line with the crystal structure of Nuc from S. enterica subsp. enterica serovar Typhimurium, demonstrating that NSNs of the superfamily of PLD proteins are not metal-ion-dependent [12].

The optimal growth temperature of Pseudomonas syringae is at $28^{\circ} \mathrm{C}$, but the highest activity of the nuclease and its mutants was determined to take place between 40 and $70{ }^{\circ} \mathrm{C}$ [31], These results are in line with previous observation of enzymes derived from psychro-, meso-, and thermophiles that displayed a temperature optimum, which is above their preferred growth temperatures $[19,20,29,32,33]$.

Detailed enzyme characterizations are always a prerequisite for understanding the functionality of enzymes and to enable the modulation of their catalytic performances [34]. It has been shown that the enzyme family of NSNs from the genus Pseudomonas is a promising model protein for modifying the catalytic performance with regard to turnover number, temperature optimum, or EDTA tolerance 
by single amino acid substitutions. Due to their enzymatic properties, PLD-like NSNs from bacteria are of great potential for versatile biotechnological applications, and for this reason the discovery of novel enzymes, the optimization of available candidates, and the development of further applications are all highly needed [4,20,35-37]. Finally, the discovery of novel candidates and the extensive characterization in combination with straight-forward protein engineering techniques will lead to the production of more tailor-made enzymes for specific biotechnological applications.

\section{Materials and Methods}

\subsection{Strain and Culture Conditions}

Escherichia coli strains Veggie BL21 (DE3) and Veggie BL21(DE3) pLysS (both from Merck KGaA, Darmstadt, Germany) were used for gene expression and protein production. E. coli strain NEB ${ }^{\circledR}$ 5-alpha (New England Biolabs, Frankfurt/Main, Germany) was used for plasmid propagation and maintenance.

\subsection{Computational Sequence Analysis and Structure Modelling}

Protein sequence data of a non-specific nuclease (WP_050543862.1) from the gram-negative, ice-nucleating bacterium Pseudomonas syringae was identified and biochemically characterized in our laboratory (unpublished results). The naturally occurring amino acid substitution D157G in related homologous sequences was shown to be beneficial for catalytic activity of the enzyme compared to the wild-type polypeptide sequence. The three-dimensional model of the bacterial nuclease DNase/D157G was generated by the SWISS-MODEL online server, using the crystal structure of a homologous nuclease (PDB ID:1BYS_A) from Salmonella enterica subsp. enterica serovar Typhimurium as a template. The structure model was analyzed and visualized using the PyMOL software package (PyMOL Molecular Graphics System, Version 2.0 Schrödinger, LLC, New York, NY, USA). Amino acid residues that are located on the surface of the predicted substrate groove were identified and chosen to be substituted against positively charged amino acids (lysine or asparagine). Fifteen amino acid residues were identified to be orientated towards the protein surface close to the catalytic region. These amino acids were assigned to two groups: (1) inner ring (closely located to the catalytic site): Y63, S64, T66, I120, S141, and S143; (2) outer ring (distantly located to the catalytic region): P68, H91, G92, D94, N95, A97, A101, K119, and A142 (Figure A1 Appendix A). In silico mutagenesis was performed to discriminate between lysine and asparagine residue, replacing amino acid residues that are located on the surface of the predicted substrate groove. The substitution with the preferred amino acid residue, either asparagine or lysine, did not result in any steric clashes with adjacent amino acids in the protein for 12 out of 15 amino acids. Therefore, amino acid residues G92, A97, and A101 were excluded from site-directed mutagenesis.

\subsection{Cloning of Nuclease Variants}

Genes-encoding nuclease variants with amino acid substitutions were codon-optimized for expression in E. coli and synthesized by ATUM (Newark, CA, USA). Flanking NcoI and AatII restriction sites were used for unidirectional ligation into linearized vector pET24d(+) (Merck KGaA, Darmstadt, Germany), equipped with a double HIS tag. Sequence verification of inserted genes was done by Eurofins Genomics (Ebersberg, Germany).

\subsection{Gene Expression and Protein Purification}

Expression of genes in E. coli Veggie BL21 (DE3) was performed as described earlier [20]. In brief, nuclease variants were produced with E. coli Veggie BL21(DE3) in 1 L cultures in 2 L Erlenmeyer shaking flasks. It was not possible to transform E. coli Veggie BL21 (DE3) with a plasmid coding for the P68K/D157G mutant in our control. Therefore, E. coli BL21 (DE3) pLys was used as an alternative expression host for this NSN variant. Cells were grown under constant shaking $(250 \mathrm{rpm})$ at $37^{\circ} \mathrm{C}$ until an optical density at $600 \mathrm{~nm}\left(\mathrm{OD}_{600}\right)$ of $0.6-0.8$ was reached. Afterwards, gene expression was induced 
by the addition of $0.4 \mathrm{mM}$ isopropyl $\beta$-d-1-thiogalactopyranoside (IPTG). Cells were harvested $4 \mathrm{~h}$ post-induction by centrifugation for $15 \mathrm{~min}$ at $4{ }^{\circ} \mathrm{C}$ and $2880 \times g$.

Cells were disrupted by high-pressure homogenization (constant cell disruption systems, Constant Systems Limited, Northants, UK) at $5{ }^{\circ} \mathrm{C}$ and 1250 bar. Pelleted cells were dissolved in lysis buffer ( $50 \mathrm{mM} \mathrm{NaPO}_{4}, \mathrm{pH} 7.3$ ): $1 \mathrm{~g}$ per $5 \mathrm{~mL}$ with a minimal volume of $20 \mathrm{~mL}$. Crude protein extract was incubated for $30 \mathrm{~min}$ at $37^{\circ} \mathrm{C}$ to enable digestion of nucleic acids by the recombinantly expressed nuclease. Afterwards, the sample was centrifuged at $4000 \times \mathrm{g}$ for $30 \mathrm{~min}$ at $4{ }^{\circ} \mathrm{C}$. HIS-tagged fusion enzymes were purified in a two-step approach using a combination of affinity (AC) and ion-exchange chromatography (IEX). Initially, gravity flow experiments using Ni sepharose 6 Fast Flow and SP Sepharose Fast Flow cation exchange chromatography resins (both GE Healthcare, Munich, Germany) were done to test activity of partly purified mutant enzymes. Afterwards, the Äkta purifier (GE Healthcare, Munich, Germany) was used to optimize the purification strategy. Supernatant from cell disruption was loaded onto a HisTrap FF Crude histidine-tagged protein purification column (GE Healthcare, Munich, Germany) equilibrated with $50 \mathrm{mM} \mathrm{NaPO}_{4}, 50 \mathrm{mM} \mathrm{NaCl}, 5 \mathrm{mM}$ imidazole, $\mathrm{pH}$ 7.3. The loaded column was connected to an Äkta protein purifier system and washed with 10 column volumes of $50 \mathrm{mM} \mathrm{NaPO}_{4}, 50 \mathrm{mM} \mathrm{NaCl}, 50 \mathrm{mM}$ imidazole, $\mathrm{pH} 7.3$, prior to the elution with $50 \mathrm{mM} \mathrm{NaPO}_{4}, 50 \mathrm{mM} \mathrm{NaCl}, 500 \mathrm{mM}$ imidazole, $\mathrm{pH}$ 7.3. For the purification by IEX, the eluate from the Ni sepharose affinity purification was diluted 1:4 with IEX running buffer $\left(25 \mathrm{mM} \mathrm{NaPO}_{4}, \mathrm{pH}\right.$ 6.0) to reach a conductivity of 7-8 mS/cm. A HiTrap-SP FF column (GE Healthcare, Munich, Germany) was equilibrated with 10 column volumes of IEX running buffer, before the sample was loaded and washed with 10 column volumes of $50 \mathrm{mM}$ sodium phosphate, $300 \mathrm{mM} \mathrm{NaCl}, \mathrm{pH}$ 6.0, prior to the elution with $50 \mathrm{mM}$ sodium phosphate, $700 \mathrm{mM} \mathrm{NaCl}, \mathrm{pH}$ 6.0. All steps were performed at a flow velocity of $1 \mathrm{~mL} / \mathrm{min}$. Finally, a PD-10 desalting column (GE Healthcare, Munich, Germany) was used to replace the IEX elution buffer with storage buffer $\left(50 \mathrm{mM} \mathrm{NaPO}_{4}, 25 \mathrm{mM} \mathrm{NaCl}, \mathrm{pH}\right.$ 7.3). SDS-PAGE (ProGel Tris Glycin 4-20\%, Anamed Elektrophorese GmbH, Groß-Bierberau/Rodau, Germany) in combination with a Western blot using a nitrocellulose blotting membrane (GE Healthcare, Munich, Germany) was used for visualization of recombinant nuclease mutants. An anti-HIS horseradish peroxidase (HRP) antibody (Miltenyi Biotec B.V. \& Co. KG, Bergisch Gladbach, Germany) and the Immobilon ${ }^{\mathrm{TM}}$ Western HRP substrate (Merck, Darmstadt, Germany) were used to detect HIS-tagged proteins.

Enzyme concentrations were measured using a (micro-) Bradford approach in 96-well plate format. A plate reader (EMax, Molecular Devices, San Jose, CA, USA) was used to determine absorbances at $590 \mathrm{~nm}$, which were evaluated with the software SoftmaxPro V5 (Molecular Devices, San Jose, CA, USA). The identities of the nuclease mutants based on their molecular masses were verified with the micrOTOF-Q II Benchtop Mass Spectrometer (Bruker, Billerica, MA, USA).

\subsection{Enzyme Activity Assays}

Enzyme activity was determined both qualitatively and quantitatively based on the depolymerization of nucleic acids. All activity assays were done at $\mathrm{pH} 7$, which has been determined to be the optimal $\mathrm{pH}$. Due to the limited stability of nuclease mutants at elevated temperatures, all assays were done at $25^{\circ} \mathrm{C}$. No thermal effect on the stability was observed for any mutant at this temperature. (1) Qualitative ethidium bromide staining: this assay was adopted from [4]. Recombinant enzyme was incubated with $5 \mu \mathrm{g}$ sheared double-stranded genomic DNA (dsDNA), namely UltraPure ${ }^{\mathrm{TM}}$ Salmon Sperm DNA Solution (Thermo Fisher Scientific, Darmstadt, Germany). This method is based on quenching of fluorescence of ethidium bromide intercalated into DNA. Repeated fluorescence recordings were taken using a VWR ${ }^{\circledR}$ imager (VWR international, Radnor, PA, USA) over a duration of up to $24 \mathrm{~h}$. (2) Qualitative visualization by agarose gel electrophoresis: this assay was adopted from [20]. Substrate specificity was tested with sheared dsDNA, unsheared dsDNA, namely deoxyribonucleic acid from calf thymus (Sigma-Aldrich, St. Louis, MO, USA), single-stranded genomic DNA (ssDNA) from calf thymus (Sigma-Aldrich, St. Louis, USA), RNA from bacteriophage MS2 (Sigma-Aldrich, St. Louis, USA), and circularized plasmid DNA. Qualitative levels of activity are exclusively interpreted 
as "+" (active enzyme) and "-" (inactive enzyme) in Figure 3, Figure 5, and Figure 6, and do not allow any quantification of activities. (3) Quantitative measurements were done in Corning ${ }^{\circledR}$ 96-well UV-transparent plates (Merck KGaA, Darmstadt, Germany) using the Victor ${ }^{\mathrm{TM}}$ X4 Multilabel Plate Reader (PerkinElmer, Rodgau, Germany), as described previously [20]. Standard activity assays were conducted in $50 \mathrm{mM}$ sodium phosphate buffer at $\mathrm{pH}$ 7.3. For the generation of $\mathrm{pH}$ profiles, reactions were performed in $50 \mathrm{mM}$ sodium acetate buffer at $\mathrm{pH} 5$ and 6 , in $50 \mathrm{mM}$ sodium phosphate buffer at $\mathrm{pH} 6,7$, and 8 , and in Tris/ $\mathrm{HCl}$ buffer at $\mathrm{pH} \mathrm{7,} \mathrm{8,} \mathrm{and} \mathrm{9.} \mathrm{Temperature} \mathrm{profiles} \mathrm{were} \mathrm{conducted}$ in the range of 10 to $90{ }^{\circ} \mathrm{C}$. EDTA tolerance was tested at the following concentrations: $0,1,2$, 5, 10, 20, and $50 \mathrm{mM}$. (4) Kinetic parameters were determined with $V_{\max }$ and $K_{M}$ obtained from Michaelis-Menten technique by non-linear regression, as described previously [20,38]. It has been speculated that the initial reaction rate of high molecular weight substrates is reduced at high substrate concentrations due to the extension of the lag phase [39]. Therefore, maximum reaction rates were evaluated for each substrate concentration to determine defined kinetic parameters. All experiments were done in triplicate. The error level was below $10 \%$.

\section{Conclusions}

The composition of the substrate groove was investigated by a combination of structural modelling, multiple sequence alignment, and site-directed mutagenesis. Amino acid residues that are in close proximity to the catalytic site (inner ring of the substrate groove) are of tremendous importance for proper activity of NSN, while amino acids at the border of the substrate groove (outer ring) are promising targets for modulation of the enzymatic properties with regard to turnover number, EDTA tolerance, and temperature preference.

\section{Patents}

A patent application describing the utilization of non-specific nucleases from the genus Pseudomonas and their application potential in cell-sorting approaches has been submitted by Miltenyi Biotec B.V. \& Co. KG.

Supplementary Materials: The following are available online at http://www.mdpi.com/2073-4344/9/11/941/s1. Figure S1: Sequence alignment of DNase/D157G vs. Nuc from S. enterica subsp. enterica serovar Typhimurium.

Author Contributions: Conceptualization, S.E.; methodology, L.S.S. and S.S.; validation, L.S.S., S.S., V.N., and S.E.; resources, V.N.; visualization, L.S.S. and S.E.; writing—original draft preparation, S.E.; writing一review and editing, S.E. and V.N.; All authors approved the final manuscript.

Funding: This research received no external funding.

Acknowledgments: The authors thank Jens Hellmer (Miltenyi Biotec B.V. \& Co. KG) for mass spectrometry analyses and Marek Wieczorek (Miltenyi Biotec B.V. \& Co. KG) for discussion.

Conflicts of Interest: The authors declare no conflict of interest. The funders had no role in the design of the study; in the collection, analyses, or interpretation of data; in the writing of the manuscript, or in the decision to publish the results. 


\section{Appendix A}

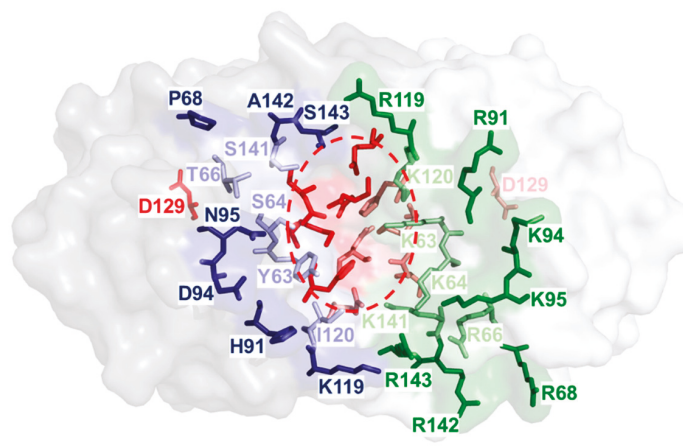

Figure A1. Homology model of NSN from Pseudomonas syringae in top view. Amino acid residues of the conserved $\mathrm{HxK}(\mathrm{x})_{4} \mathrm{D}(\mathrm{x})_{6} \mathrm{GSxN}$ motif are given as sticks in dark and light red in the respective monomer. Numbering of amino acids that are part of the catalytic site was omitted for clarity (encircled in red, dashed line), except for amino acid residue D129, which is part of the $\operatorname{HxK}(x)_{4} \mathrm{D}(\mathrm{x})_{6} \mathrm{GSxN}$ motif, but not part of the catalytic site. Naturally occurring amino acids of the outer and inner rings are also given as sticks and highlighted in dark and light blue, while substituted positively charged amino acid residues are indicated in dark and light green.

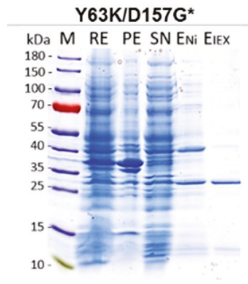

H91R/D157G

KDa M RE PE SN ENi EIEX

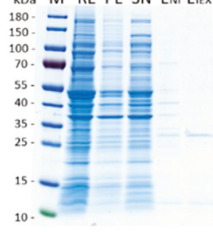

10.

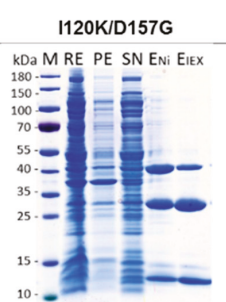

\section{S64KID157G}

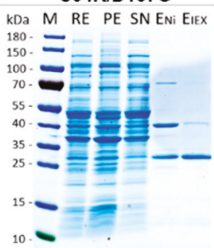

D94K/D157G

KDa M RE PE SN ENi EIEX

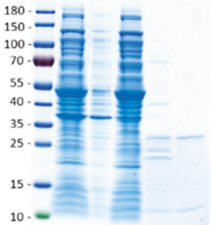

S141K/D157G*

KDa M RE PE SN ENi EIEX

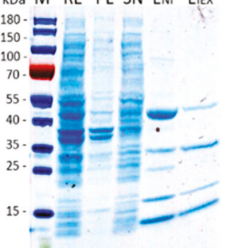

T66R/D157G

kDa M RE PE SN ENi EIEx

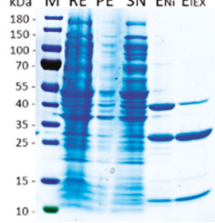

N95K/D157G

kDa M RE PE SN EniEIEx

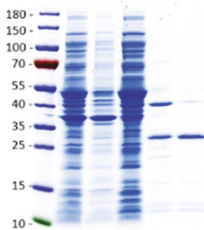

A142R/D157G

kDaM RE PE SN Eni EIEX

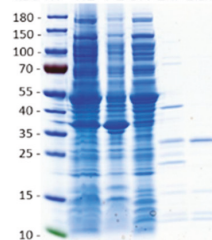

P68R/D157G

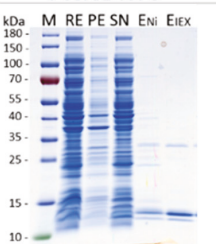

K119R/D157G

kDa M RE PE SN ENi EIEX

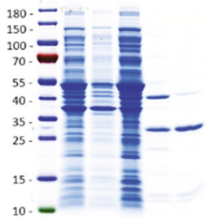

S143R/D157G

KDa M RE PE SN ENi EIEX

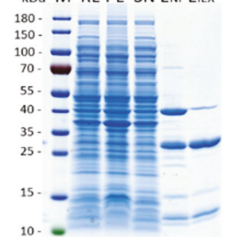

Figure A2. SDS-PAGE results illustrating the purification of all mutant enzymes. M-protein marker, RE-crude extract, $\mathrm{PE}$ - pellet, $\mathrm{SN}$ - supernatant, $\mathrm{E}_{\mathrm{Ni}}$ - elution fraction Ni-agarose, $\mathrm{E}_{\mathrm{IEX}}$ - elution fraction ion exchange chromatography. Asterisks $\left(^{*}\right)$ indicate that inactive mutants Y63K/D157G and S141K/D157G were purified using non-optimized gravity flow purification approaches, resulting in lower purities. 


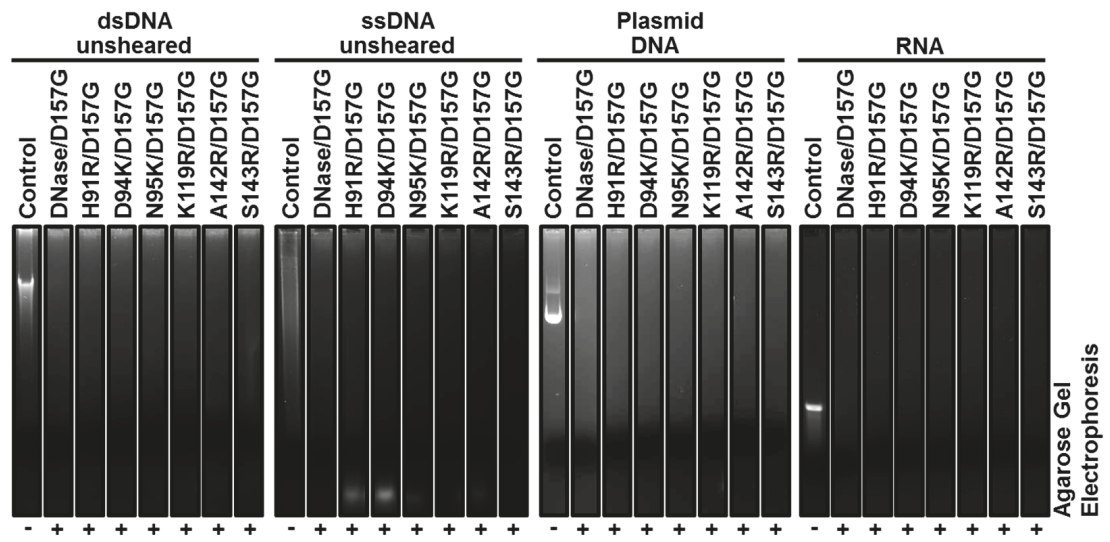

Figure A3. Substrate specificity of mutants with amino acid substitutions in the outer ring. All incubations were done for $1 \mathrm{~h}$ at $25^{\circ} \mathrm{C}$. "Control" indicates negative controls containing substrate but no enzyme in the reaction mixture.

\section{References}

1. Rangarajan, E.S.; Shankar, V. Sugar non-specific endonucleases. FEMS Microbiol. Rev. 2001, 25, 583-613. [CrossRef]

2. Benedik, M.J.; Strych, U. Serratia marcescens and its extracellular nuclease. FEMS Microbiol. Lett. 1998, 165, 1-13. [CrossRef] [PubMed]

3. Dang, G.; Cui, Y.; Wang, L.; Li, T.; Cui, Z.; Song, N.; Chen, L.; Pang, H.; Liu, S. Extracellular sphingomyelinase Rv0888 of Mycobacterium tuberculosis contributes to pathological lung injury of Mycobacterium smegmatis in mice via inducing formation of neutrophil extracellular traps. Front. Immunol. 2018, 9, 677. [CrossRef] [PubMed]

4. Vafina, G.; Zainutdinova, E.; Bulatov, E.; Filimonova, M.N. Endonuclease from gram-negative Bacteria Serratia marcescens is as effective as Pulmozyme in the hydrolysis of DNA in sputum. Front. Pharmacol. 2018, 9, 114. [CrossRef] [PubMed]

5. Khersonsky, O.; Tawfik, D.S. Enzyme promiscuity: A mechanistic and evolutionary perspective. Annu. Rev. Biochem. 2010, 79, 471-505. [CrossRef] [PubMed]

6. Yan, X.; Wang, J.; Sun, Y.; Zhu, J.; Wu, S. Facilitating the evolution of esterase activity from a promiscuous enzyme (Mhg) with catalytic functions of amide hydrolysis and carboxylic acid perhydrolysis by engineering the substrate entrance tunnel. Appl. Environ. Microbiol. 2016, 82, 6748-6756. [CrossRef]

7. Rao, S.J.; Shukla, E.; Bhatia, V.; Lohiya, B.; Gaikwad, S.M.; Kar, A.; Pal, J.K. The Leishmania donovani IMPACT-like protein possesses non-specific nuclease activity. Int. J. Biol. Macromol. 2018, 119, 962-973. [CrossRef] [PubMed]

8. Ponting, C.P.; Kerr, I.D. A novel family of phospholipase D homologues that includes phospholipid synthases and putative endonucleases: Identification of duplicated repeats and potential active site residues. Protein Sci. A Publ. Protein Soc. 1996, 5, 914-922. [CrossRef]

9. Rudolph, A.E.; Stuckey, J.A.; Zhao, Y.; Matthews, H.R.; Patton, W.A.; Moss, J.; Dixon, J.E. Expression, characterization, and mutagenesis of the Yersinia pestis murine toxin, a phospholipase D superfamily member. J. Biol. Chem. 1999, 274, 11824-11831. [CrossRef]

10. Nelson, R.K.; Frohman, M.A. Physiological and pathophysiological roles for phospholipase D. J. Lipid Res. 2015, 56, 2229-2237. [CrossRef]

11. Liscovitch, M.; Czarny, M.; Fiucci, G.; Tang, X. Phospholipase D: Molecular and cell biology of a novel gene family. Biochem. J. 2000, 345, 401-415. [CrossRef] [PubMed]

12. Stuckey, J.A.; Dixon, J.E. Crystal structure of a phospholipase D family member. Nat. Struct. Biol. 1999, 6, 278-284. [CrossRef] [PubMed] 
13. Zhao, Y.; Stuckey, J.A.; Lohse, D.L.; Dixon, J.E. Expression, characterization, and crystallization of a member of the novel phospholipase D family of phosphodiesterases. Protein Sci. 1997, 6, 2655-2658. [CrossRef] [PubMed]

14. Bao, Y.; Higgins, L.; Zhang, P.; Chan, S.H.; Laget, S.; Sweeney, S.; Lunnen, K.; Xu, S.Y. Expression and purification of BmrI restriction endonuclease and its $\mathrm{N}$-terminal cleavage domain variants. Protein Expr. Purif. 2008, 58, 42-52. [CrossRef] [PubMed]

15. Grazulis, S.; Manakova, E.; Roessle, M.; Bochtler, M.; Tamulaitiene, G.; Huber, R.; Siksnys, V. Structure of the metal-independent restriction enzyme Bfil reveals fusion of a specific DNA-binding domain with a nonspecific nuclease. Proc. Natl. Acad. Sci. USA 2005, 102, 15797-15802. [CrossRef] [PubMed]

16. Song, Q.; Zhang, X. Characterization of a novel non-specific nuclease from thermophilic bacteriophage GBSV1. BMC Biotechnol. 2008, 8, 43. [CrossRef] [PubMed]

17. Wang, D.; Miyazono, K.I.; Tanokura, M. Tetrameric structure of the restriction DNA glycosylase R.PabI in complex with nonspecific double-stranded DNA. Sci. Rep. 2016, 6, 35197. [CrossRef]

18. Li, L.; Lin, S.; Yanga, F. Functional identification of the non-specific nuclease from white spot syndrome virus. Virology 2005, 337, 399-406. [CrossRef]

19. Schmitz, S.; Börner, P.; Nölle, V.; Elleuche, S. Comparative analysis of two non-specific nucleases of the phospholipase D family from the plant pathogen competitor bacterium Pantoea Agglomerans. Appl. Microbiol. Biotechnol. 2019, 103, 2635-2648. [CrossRef]

20. Schmitz, S.; Nölle, V.; Elleuche, S. A non-specific nucleolytic enzyme and its application potential in EDTA-containing buffer solutions. Biotechnol. Lett. 2019, 41, 129-136. [CrossRef]

21. Pan, C.Q.; Lazarus, R.A. Hyperactivity of human DNase I variants. Dependence on the number of positively charged residues and concentration, length, and environment of DNA. J. Biol. Chem. 1998, 273, 11701-11708. [CrossRef] [PubMed]

22. Miltenyi, S.; Hübel, T.; Nölle, V. Process for Sorting Cells by Microfabricated Components Using a Nuclease. US Patant 10,018,541 B2, 10 July 2018.

23. Belkebir, A.; Azeddoug, H. Characterization of LlaKI, a new metal ion-independent restriction endonuclease from Lactococcus lactis KLDS4. ISRN Biochem. 2012, 2012, 287230. [CrossRef] [PubMed]

24. Friedhoff, P.; Kolmes, B.; Gimadutdinow, O.; Wende, W.; Krause, K.L.; Pingoud, A. Analysis of the mechanism of the Serratia nuclease using site-directed mutagenesis. Nucleic Acids Res. 1996, 24, 2632-2639. [CrossRef] [PubMed]

25. Zhang, Y.; Li, Z.H.; Zheng, W.; Tang, Z.X.; Shi, L.E. Enzyme activity and thermostability of a non-specific nuclease from Yersinia enterocolitica supsp. palearctica by site-directed mutagenesis. Electron. J. Biotechnol. 2016, 24, 32-37. [CrossRef]

26. Franke, I.; Meiss, G.; Pingoud, A. On the advantage of being a dimer, a case study using the dimeric Serratia nuclease and the monomeric nuclease from Anabaena sp. strain PCC 7120. J. Biol. Chem. 1999, 274, 825-832. [CrossRef] [PubMed]

27. Bommarius, A.S.; Paye, M.F. Stabilizing biocatalysts. Chem. Soc. Rev. 2013, 42, 6534-6565. [CrossRef] [PubMed]

28. Schaefer, C.; Rost, B. Predict impact of single amino acid change upon protein structure. BMC Genom. 2012, 13, S4. [CrossRef]

29. Elleuche, S.; Fodor, K.; Klippel, B.; von der Heyde, A.; Wilmanns, M.; Antranikian, G. Structural and biochemical characterisation of a $\mathrm{NAD}(+)$-dependent alcohol dehydrogenase from Oenococcus oeni as a new model molecule for industrial biotechnology applications. Appl. Microbiol. Biotechnol. 2013, 97, 8963-8975. [CrossRef]

30. Marcal, D.; Rego, A.T.; Fogg, M.J.; Wilson, K.S.; Carrondo, M.A.; Enguita, F.J. Crystallization and preliminary X-ray characterization of 1,3-propanediol dehydrogenase from the human pathogen Klebsiella pneumoniae. Acta Crystallogr. Sect. F Struct. Biol. Cryst. Commun. 2007, 63, 249-251. [CrossRef]

31. Xin, X.F.; Kvitko, B.; He, S.Y. Pseudomonas syringae: What it takes to be a pathogen. Nat. Rev. Microbiol. 2018, 16, 316-328. [CrossRef]

32. Daniel, R.M.; Danson, M.J.; Eisenthal, R.; Lee, C.K.; Peterson, M.E. The effect of temperature on enzyme activity: New insights and their implications. Extremophiles 2008, 12, 51-59. [CrossRef] [PubMed] 
33. Feller, G.; Narinx, E.; Arpigny, J.L.; Zekhnini, Z.; Swings, J.; Gerday, C. Temperature dependence of growth, enzyme secretion and activity of psychrophilic Antarctic bacteria. Appl. Microbiol. Biotechnol. 1994, 41, 477-479. [CrossRef]

34. Erb, T.J. Back to the future: Why we need enzymology to build a synthetic metabolism of the future. Beilstein J. Org. Chem. 2019, 15, 551-557. [CrossRef] [PubMed]

35. Fang, X.J.; Tang, Z.X.; Li, Z.H.; Zhang, Z.L.; Shi, L.E. Production of a new non-specific nuclease from Yersinia enterocolitica subsp. palearctica: Optimization of induction conditions using response surface methodology. Biotechnol. Biotechnol. Equip. 2014, 28, 559-566. [CrossRef] [PubMed]

36. Maciejewska, N.; Walkusz, R.; Olszewski, M.; Szymanska, A. New nuclease from extremely psychrophilic microorganism Psychromonas ingrahamii 37: Identification and characterization. Mol. Biotechnol. 2019, 61, 122-133. [CrossRef] [PubMed]

37. Anisimova, V.E.; Shcheglov, A.S.; Bogdanova, E.A.; Rebrikov, D.V.; Nekrasov, A.N.; Barsova, E.V.; Shagin, D.A.; Lukyanov, S.A. Is crab duplex-specific nuclease a member of the Serratia family of non-specific nucleases? Gene 2008, 418, 41-48. [CrossRef] [PubMed]

38. MacLellan, S.R.; Forsberg, C.W. Properties of the major non-specific endonuclease from the strict anaerobe Fibrobacter succinogenes and evidence for disulfide bond formation in vivo. Microbiology 2001, 147, 315-323. [CrossRef]

39. Friedhoff, P.; Meiss, G.; Kolmes, B.; Pieper, U.; Gimadutdinow, O.; Urbanke, C.; Pingoud, A. Kinetic analysis of the cleavage of natural and synthetic substrates by the Serratia nuclease. Eur. J. Biochem. 1996, 241, 572-580. [CrossRef]

(C) 2019 by the authors. Licensee MDPI, Basel, Switzerland. This article is an open access article distributed under the terms and conditions of the Creative Commons Attribution (CC BY) license (http://creativecommons.org/licenses/by/4.0/). 


\title{
Article \\ Effects of Random Mutagenesis and In Vivo Selection on the Specificity and Stability of a Thermozyme
}

\author{
Giuseppe Perugino ${ }^{1,+}$, Andrea Strazzulli ${ }^{2,3, \dagger}$, Marialuisa Mazzone ${ }^{1}$, Mosè Rossi ${ }^{1}$ and \\ Marco Moracci ${ }^{1,2,3, *}$ \\ 1 Institute of Biosciences and BioResources - National Research Council of Italy, Via P. Castellino 111, \\ 80131 Naples, Italy; giuseppe.perugino@ibbr.cnr.it (G.P.); marialuisam76@yahoo.it (M.M.); \\ mose.rossi@ibbr.cnr.it (M.R.) \\ 2 Department of Biology, University of Naples "Federico II", Complesso Universitario di Monte S. Angelo, \\ Via Cintia 21, 80126 Napoli, Italy; andrea.strazzulli@unina.it \\ 3 Task Force on Microbiome Studies, University of Naples Federico II, 80126 Naples, Italy \\ * Correspondence: marco.moracci@unina.it; Tel.: +39-081-679046; Fax: +39-081-679233 \\ + These authors contributed equally to the paper as First Authors.
}

Received: 18 April 2019; Accepted: 9 May 2019; Published: 11 May 2019

\begin{abstract}
Factors that give enzymes stability, activity, and substrate recognition result from the combination of few weak molecular interactions, which can be difficult to study through rational protein engineering approaches. We used irrational random mutagenesis and in vivo selection to test if a $\beta$-glycosidase from the thermoacidophile Saccharolobus solfataricus ( $S$ s $\beta$-gly) could complement an Escherichia coli strain unable to grow on lactose. The triple mutant of $S s \beta$-gly (S26L, P171L, and A235V) was more active than the wild type at $85^{\circ} \mathrm{C}$, inactivated at this temperature almost 300 -fold quicker, and showed a 2-fold higher $\mathrm{k}_{\text {cat }}$ on galactosides. The three mutations, which were far from the active site, were analyzed to test their effect at the structural level. Improved activity on galactosides was induced by the mutations. The S26L and P171L mutations destabilized the enzyme through the removal of a hydrogen bond and increased flexibility of the peptide backbone, respectively. However, the flexibility added by S26L mutation improved the activity at $\mathrm{T}>60^{\circ} \mathrm{C}$. This study shows that random mutagenesis and biological selection allowed the identification of residues that are critical in determining thermal activity, stability, and substrate recognition.
\end{abstract}

Keywords: carbohydrate active enzymes; archaea; glycosidase; Sulfolobus solfataricus; Saccharolobus solfataricus

\section{Introduction}

The ability of enzymes to recognize specific substrates and catalyzing reactions remaining stable even at extreme conditions is driven by molecular factors that are only poorly understood. In this regard, enzymes from thermophiles and hyperthermophiles, microorganisms growing at temperatures up to $80^{\circ} \mathrm{C}$ or above, respectively, have been of long standing research interest, because of their ability to promote chemical reactions at temperatures close to the boiling point of water when the majority of enzymes from mesophiles are denatured. Consequently, extensive biochemical and structural studies on thermozymes (enzymes that function at high temperatures) have shown that their stability is not governed by peculiar amino acids, covalent modifications, or structural motifs, but rather by subtle redistributions of the same intramolecular interactions that are required to stabilize proteins from mesophiles (for reviews, see the literature [1-5]).

In thermozymes, these interactions allow both a balance between molecular stability to avoid unfolding at very high temperatures and the flexibility to promote catalysis at a metabolically appropriate rate. However, thermozymes persist for a long time during incubation at high temperatures 
(thermal stability), and increase their catalytic rate with temperature (thermal activity or thermophilicity). In particular, thermozymes need high temperatures to have specific activity comparable to that of mesozymes at $37^{\circ} \mathrm{C}$. Comparisons of homologous enzymes from organisms spanning a wide range of thermal habitats show that adaptive mutations maintain a balance between thermal stability and activity, regardless of the temperature at which the enzyme operates [1].

Despite extensive studies, the identification of the molecular interactions that are responsible for these properties remained elusive. Most studies aimed to increase the thermal stability of mesozymes through rational design and enzyme engineering or random mutagenesis and appropriate selection methods to obtain new catalysts for biotechnological applications [6-9]. Even fewer examples exist of the laboratory evolution of thermozymes adapted to operational temperatures lower than their normal range of physiological conditions $[10,11]$.

The objective of this work was to analyze whether and how the substrate specificity, thermal activity, and resistance to heat of a thermozyme are bound at the molecular level by combining random mutagenesis and in vivo selection of mutants in a mesophilic host. Thus, the selective pressure might mimic that encountered during natural evolution more closely. To this aim, we focused on a glycoside hydrolase from an Archaeon, as these thermozymes are easy to assay and have interesting biotechnological applications [12-15].

The model system in this study is the $\beta$-glycosidase from Saccharolobus solfataricus-previously Sulfolobus solfataricus_-(Ss $\beta$-gly). This enzyme, belonging to family 1 (GH1) of carbohydrate active enzymes (CAZy) classification (www.cazy.org [16]), which was firstly discovered by our group and extensively characterized [17-20], is a well-known model system for studies of molecular stabilization and catalysis engineering. In fact, studies on this enzyme allowed the identification of general structural and functional elements that make thermozymes more stable than mesozymes [21,22]. In particular, ion-pair networks between protein domains and subunits were identified as major players of the molecular stabilization and resilience of thermozymes [23-28]. In addition, studies on Ss $\beta$-gly allowed us to demonstrate that the activity and stability of enzymes can be restored by small molecules that bind to allosteric sites $[29,30]$.

Ss $\beta$-Gly catalyzes a single-substrate reaction by promoting the hydrolysis of $\beta$-D-O-glycosides, including disaccharides (laminaribiose, cellobiose, and lactose) and aryl-glycosides (substituted nitrophenyl- $\beta$-D-gluco-, galacto-, fuco, and xylosides), thereby showing wide substrate specificity [31]. The simple retaining reaction mechanism followed by this enzyme and its versatility has allowed for extensive protein engineering studies that have led to mutants with different substrate specificity $[32,33]$. The modification of Ss $\beta$-gly active site residues changed the reaction mechanism [34] and allowed the production of a novel class of enzymes, named glycosynthases, that promote the synthesis, rather than then hydrolysis, of oligosaccharides [35-37]. These fundamental studies led to the development of many other glycosynthases of technological interest [38-43].

The number of catalytic studies on $S s \beta$-gly, its well-known reaction mechanism, and the availability of mutants and of several three-dimensional (3D) structures at a high resolution [22,23,34,44,45] prompted us to study the relationship between substrate specificity, catalysis at a high temperature, and structural stability. We addressed this issue by following a non-rational approach exploiting random mutagenesis and in vivo selection of mutants. This was made possible because the lacS gene, encoding for $S s \beta$-gly, cannot promote the growth on lactose minimal medium of an Escherichia coli strain lacking the endogenous lac $Z$ gene. We wanted to test whether random mutations on a thermozyme from a hyperthermophilic Archaeon $\left(\mathrm{T}_{\text {growth }}=80^{\circ} \mathrm{C}\right)$, easily and quickly produced by a chemical mutagen, could lead to novel functional $\beta$-galactosidase(s) able to promote growth of a bacterium at $37^{\circ} \mathrm{C}$ on lactose as a unique carbon source. The in vivo selection is expected to affect, simultaneously, the substrate specificity and thermal activity of the enzyme, as lactose is a non-preferred substrate of Ss $\beta$-gly, the catalyze reaction of which occurs at $\mathrm{T}>80^{\circ} \mathrm{C}[20,31]$. The remarkable $S s \beta$-gly stability, about 500 min half-life at $75^{\circ} \mathrm{C}$ [20], should not be directly affected by the selection method, but may be a side effect if thermal activity and stability are interconnected. 
By following this approach, we report here that the selection of a $S s \beta$-gly mutant library led to a triple mutant, named H7, able to complement a deficient strain of E. coli. The three mutations, S26L, $\mathrm{P} 171 \mathrm{~L}$, and $\mathrm{A} 235 \mathrm{~V}$, were in regions of the enzyme far from the active site, which could not be planned if one would rationally design an improved $\beta$-galactosidase activity. H7 catalyzed the hydrolysis of lactose 1.8-fold faster than the wild type, and, surprisingly, at $85^{\circ} \mathrm{C}$, was 2 -fold more active than the wild type and less stable at $75^{\circ} \mathrm{C}$ and $85^{\circ} \mathrm{C}$ by 23 -fold and 283 -fold, respectively. The characterization of single and double mutants and the inspection of $S s \beta$-gly $3 \mathrm{D}$-structure models allowed hypothesizing some explanations to rationalize the effect of the mutations. The results are also discussed in term of the selective pressure produced by the molecular evolution method used.

\section{Results and Discussion}

\subsection{Production of Ss $\beta$-gly Complementing Growth on Lactose at $37^{\circ} \mathrm{C}$}

The pGEX-K-Gly plasmid containing the Saccharolobus solfataricus $\beta$-glycosidase gene (lacS) was subjected to a reaction of chemical mutagenesis with hydroxylamine. This mutagen is known to cause transitions on the type $\mathrm{C} \rightarrow \mathrm{T}$ DNA [46]. The set of mutated genes was isolated from the plasmid and inserted in an untreated plasmid to avoid any mutagenic affects to the other regions (promoter, antibiotic resistance, replication origin, etc.).

This random library was used to transform the E. coli M5154 strain, which has a large deletion on the lactose operon that, unlike the commercial E. coli strains, affects only the $\beta$-galactosidase gene (lacZ) and not the sugar permease ( $(a c Y)$. This makes this strain unable to metabolize lactose as a sole carbon source, even in the presence of the sugar in the cytoplasm. Thus, E. coli M5154 can grow in lactose minimal medium, only if an active $\beta$-galactosidase is also expressed. The selection thus concerned only the clones bearing $S s \beta$-gly mutants able to promote growth faster than the wild type enzyme that complemented this $E$. coli strain after 10 days at $37^{\circ} \mathrm{C}$ in a lactose minimal medium.

The cells transformed with the plasmid library were plated on rich solid medium containing 5 -bromo-4-chloro-3-indolyl- $\beta$-D-glucopyranoside (X-Glc) chromogenic substrate to verify the efficiency of the random mutagenesis. The presence of blue and white colonies ensured that the mutagen had an effect resulting in inactive $S s \beta$-gly mutants. Then, the same cells transformed with the mutant library were plated on minimal solid medium containing lactose as the sole carbon source and incubated at $37^{\circ} \mathrm{C}$. The colonies appearing before the wild type control were identified and chosen. The screening of $>6000$ clones led to the selection of 39 colonies that were isolated and grown on rich liquid medium. Cells were assayed for $\beta$-galactosidase activity on 2-nitrophenyl- $\beta$-D-galacto- and glucopyranoside substrates (2Np-Gal and $2 \mathrm{~Np}-\mathrm{Glc}$, respectively), and the calculated enzymatic units were compared to those of the wild type enzyme in the same conditions (see Section 3). This analysis led to a further selection of six clones from the starting 39, and one specific mutant, called Ss $\beta$-gly-H7, hereinafter H7, was characterized in detail.

The H7 gene was completely sequenced: as expected, using the hydroxylamine mutagenic agent, three $\mathrm{C} \rightarrow \mathrm{T}$ transitions were found, leading to three aminoacid substitutions; namely, S26L, P171L, and A235V. From the analysis of the three-dimensional structure of $S s \beta$-gly, all of them were located far from the active site at $23 \AA$ (S26), $25 \AA$ (P171), and $18 \AA$ (A235), respectively (Figure 1). S26L and P171L were on the surface of the protein, while A235V was completely buried. Wild type lacS and H7 genes were expressed in E. coli strain BL21(DE3)RIL, fused to glutathione S-transferase, as described in Materials and Methods, and the purified enzymes were characterized in detail. Similarly, S26L, P171L, and A235V single mutants, as well as S26L/P171L, S26L/A235V, and P171L/A235V double mutants, were prepared by subcloning procedures. The corresponding genes were expressed and the recombinant enzymes purified to determine the single contribution of each identified mutation (see Materials and Methods). 


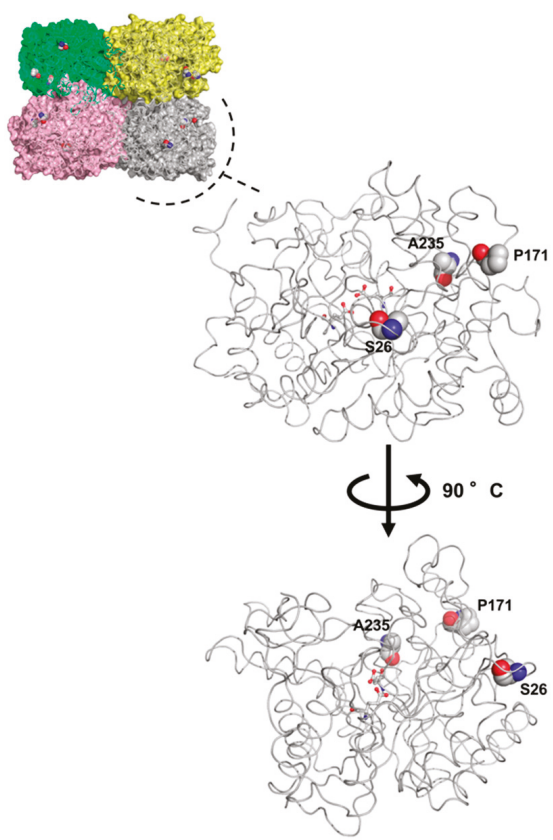

Figure 1. The aminoacid residues mutated in the Saccharolobus solfataricus (Ss $\beta$-Gly) H7 enzyme. The position of S26, P171, and A235 residues (in spherical format) are shown on the tetrameric and monomeric 3D structures of $S s \beta$-Gly, represented in ribbon format. Catalytic residues in the active site are highlighted in ball and stick format, and all atoms are colored by the CPK convention.

\subsection{Steady State Kinetic Constants of the $H 7$ and Relative Single and Double Mutants}

The kinetic parameters at $65^{\circ} \mathrm{C}$ reported in Table 1 show an increase of activity $\left(\mathrm{k}_{\text {cat }}\right)$ by about 2-fold toward the galactose-derived substrates for the $\mathrm{H} 7$ mutant. With $4 \mathrm{~Np}$-Gal, the $\mathrm{K}_{\mathrm{M}}$ values are moderately affected with respect to the wild type; consequently, a relative increase in the catalytic efficiency $\left(k_{\text {cat }} / K_{M}\right)$ is also observed. The turnover number values of the mutant on $4 \mathrm{~Np}-\mathrm{Glc}$ and cellobiose were similar to the wild type. However, the $\mathrm{k}_{\mathrm{cat}} / \mathrm{K}_{\mathrm{M}}$ on $4 \mathrm{~Np}$-Glc substrate was 3.5-fold higher than the wild type. By contrast, the increased catalytic efficiency observed on $4 \mathrm{~Np}$-Glc is mainly attributable to the $\mathrm{K}_{\mathrm{M}}$, which is 4 -fold lower than that of the wild type. The H7 mutant shows an almost 2-fold decreased affinity toward lactose; consequently, $\mathrm{k}_{\mathrm{cat}} / \mathrm{K}_{\mathrm{M}}$ values are unchanged. Therefore, H7 offered to E. coli M5154 strain the ability of growing faster on lactose thanks to an enhanced turnover number rather than catalytic efficiency. Similar results have been obtained with an evolved indoleglycerol phosphate synthase (IGPS), also from Sulfolobus solfataricus, yielding mutants that complemented E. coli growth thanks to an improved turnover number [10].

As shown in Table 1, only the S26L mutant showed properties comparable to the $\mathrm{H} 7$ triple mutant, with both $\mathrm{k}_{\text {cat }}$ and $\mathrm{k}_{\text {cat }} / \mathrm{K}_{\mathrm{M}}$ values for $4 \mathrm{~Np}$-Gal being 2 -fold higher than the wild type and specificity constants for $4 \mathrm{~Np}$-Glc, and cellobiose improved by 2.5 -fold and 1.6-fold, respectively. The other single mutants showed catalytic constant values on all substrates tested similar to or lower than the wild type. Among the single mutants, S26L showed the highest catalytic efficiency on disaccharides, although the $\mathrm{k}_{\text {cat }} / \mathrm{K}_{\mathrm{M}}$ value on lactose is comparable to that of the wild type. 
Table 1. Steady state kinetic constants at $65{ }^{\circ} \mathrm{C}$ of Saccharolobus solfataricus (Ss $\beta$-gly) wild type and mutants.

\begin{tabular}{|c|c|c|c|c|c|c|}
\hline & \multicolumn{3}{|c|}{$4 \mathrm{~Np}-\mathrm{Gal}$} & \multicolumn{3}{|c|}{ 4Np-Glc } \\
\hline & $\mathrm{K}_{\mathrm{M}}(\mathrm{mM})$ & $k_{\text {cat }}\left(\mathrm{s}^{-1}\right)$ & $\begin{array}{c}k_{\text {cat }} / \mathrm{K}_{\mathrm{M}}\left(\mathrm{s}^{-1}\right. \\
\left.\mathrm{mM}^{-1}\right)\end{array}$ & $\mathrm{K}_{\mathrm{M}}(\mathrm{mM})$ & $k_{\text {cat }}\left(\mathrm{s}^{-1}\right)$ & $\begin{array}{c}k_{\text {cat }} / \mathrm{K}_{\mathrm{M}}\left(\mathrm{s}^{-1}\right. \\
\left.\mathrm{mM}^{-1}\right)\end{array}$ \\
\hline Wild type (S26/P171/A235) & $1.17 \pm 0.15$ & $389.8 \pm 13.25$ & 333.16 & $0.94 \pm 0.22$ & $437.2 \pm 23.4$ & 465.1 \\
\hline$H 7(S 26 L / P 171 L / A 235 V)$ & $1.71 \pm 0.32$ & $908.7 \pm 43.3$ & 530.0 & $0.23 \pm 0.03$ & $376.8 \pm 13.9$ & 1629.0 \\
\hline$S 26 L$ & $1.56 \pm 0.23$ & $938.9 \pm 33.9$ & 601.8 & $0.36 \pm 0.09$ & $423.8 \pm 20.1$ & 1177.2 \\
\hline P171L & $1.39 \pm 0.25$ & $444.5 \pm 18.8$ & 319.8 & $0.44 \pm 0.11$ & $221.6 \pm 10.8$ & 503.6 \\
\hline A235V & $1.00 \pm 0.11$ & $310.1 \pm 7.9$ & 310.0 & $0.41 \pm 0.08$ & $168.5 \pm 6.1$ & 414.9 \\
\hline$S 26 L / P 171 L$ & $2.85 \pm 0.23$ & $93.2 \pm 2.2$ & 32.8 & $0.31 \pm 0.10$ & $34.3 \pm 2.0$ & 109.0 \\
\hline S26L/A235V & $1.20 \pm 0.18$ & $795.7 \pm 27.2$ & 662.0 & $0.44 \pm 0.11$ & $393.1 \pm 19.2$ & 885.7 \\
\hline \multirow[t]{3}{*}{ P171L/V235V } & $1.46 \pm 0.13$ & $150.5 \pm 3.2$ & 102.9 & $0.47 \pm 0.11$ & $75.7 \pm 3.6$ & 159.0 \\
\hline & \multicolumn{3}{|c|}{ Lactose } & \multicolumn{3}{|c|}{ Cellobiose } \\
\hline & $\mathrm{K}_{\mathrm{M}}(\mathrm{mM})$ & $k_{\text {cat }}\left(\mathrm{s}^{-1}\right)$ & $\begin{array}{c}k_{\text {cat }} / \mathrm{K}_{\mathrm{M}}\left(\mathrm{s}^{-1}\right. \\
\left.\mathrm{mM}^{-1}\right)\end{array}$ & $\mathrm{K}_{\mathrm{M}}(\mathrm{mM})$ & $k_{\text {cat }}\left(\mathrm{s}^{-1}\right)$ & $\begin{array}{c}k_{\text {cat }} / \mathrm{K}_{\mathrm{M}}\left(\mathrm{s}^{-1}\right. \\
\left.\mathrm{mM}^{-1}\right)\end{array}$ \\
\hline Wild type (S26/P171/A235) & $137.7 \pm 6.2$ & $710.8 \pm 9.6$ & 5.2 & $33.2 \pm 5.12$ & $274.7 \pm 12.9$ & 8.3 \\
\hline$H 7(S 26 L / P 171 L / A 235 V)$ & $245.5 \pm 20.4$ & $1270.8 \pm 40.7$ & 5.2 & $33.6 \pm 6.7$ & $372.5 \pm 22.1$ & 11.1 \\
\hline$S 26 L$ & $118.2 \pm 5.1$ & $505.0 \pm 7.2$ & 4.3 & $18.3 \pm 3.2$ & $252.2 \pm 11.0$ & 13.8 \\
\hline$P 171 L$ & $140.4 \pm 20.4$ & $308.6 \pm 15.7$ & 2.2 & $20.6 \pm 2.7$ & $122.2 \pm 4.0$ & 5.9 \\
\hline$A 235 \mathrm{~V}$ & $149.6 \pm 10,3$ & $226.6 \pm 5,5$ & 1.5 & $18.3 \pm 1.0$ & $95.1 \pm 1.4$ & 5.2 \\
\hline S26L/P171L & $144.8 \pm 7.6$ & $84.2 \pm 1.5$ & 0.6 & $30.7 \pm 4.2$ & $36.5 \pm 1.4$ & 1.2 \\
\hline S26L/A235V & $120.0 \pm 12.6$ & $510.2 \pm 17.6$ & 4.3 & $80.4 \pm 21.4$ & $374.8 \pm 36.5$ & 4.7 \\
\hline$P 171 L / V 235 \mathrm{~V}$ & $161.9 \pm 8.7$ & $119.0 \pm 2.3$ & 0.7 & $55.6 \pm 10.0$ & $68.0 \pm 4.4$ & 1.2 \\
\hline
\end{tabular}

The $\beta$-glycosidase from the hyperthermophilic archaeon Pyrococcus furiosus (CelB), also belonging to family GH1, once evolved on $4 \mathrm{~Np}$-Glc at room temperature, showed a three-fold improved rates of hydrolysis by single mutations in the active site [11]. In the $S s \beta$-gly H7 mutant, instead, S26L, P171L, and A235V mutations were all far from the active site. The superimposition of the 3D-structure of Ss $\beta$-gly and the derived model of the triple mutant did not show any difference in the residues of the active site (not shown). The distance from the active site did not allow us to find easy explanations on the molecular reasons of the ability of $\mathrm{H7}$ to promote lactose hydrolysis faster than the wild type. Potentially, increasing the flexibility of the structure in the mutation sites led to conformational changes that were transferred to the active site and improved the conversion of galactose-derived substrates. Mutations influencing enzyme function even at a distance from the catalytic residues may be not uncommon, as proteins often undergo conformational changes during the reaction [47] and long distance effects play important roles in enzyme function, as recently reviewed in the work of [48]. Rational protein engineering experiments on the amino acids located in the active site region broadened the substrate specificity of $S s \beta$-gly [32,33], suggesting that active site modifications would be needed to change the substrate specificity of the enzyme. Therefore, it would be easy to predict that further mutations for improved activity could be found in the same area. Instead, we showed here that substitutions not restricted to the active site had also some influence, allowing in vivo complementation and significantly enhancing the turnover number and the catalytic efficiency of the enzyme on galactose-derived substrates and 4-Np-Glc, respectively. The different effect observed for $S s \beta$-gly and CelB could be the result of the different approaches used: in vivo selection instead of in vitro screening, respectively. In the former approach, biology exerts a combination of forces not determined only by kinetic and chemical recognition. Our study demonstrates that, at the in vivo selection conditions used, enzyme catalysis of $S s \beta$-gly was determined by the enzyme as a whole.

\subsection{Temperature Dependence of the H7 and Relative Single and Double Mutants}

The effect of temperature on the specific activity on $4 \mathrm{~Np}-\mathrm{Gal}$ by all the mutants followed the same trend of the wild type, increasing continuously up to the maximum of $85^{\circ} \mathrm{C}$, with S26L and the $\mathrm{H} 7$ mutants showing the highest $\mathrm{U} \mathrm{mg}^{-1}$ at all temperatures (Figure $2 \mathrm{a}, \mathrm{b}$ ). The specific activity of the S26L mutant, as single or in combination with $\mathrm{A} 235 \mathrm{~V}$, was maximal at $85^{\circ} \mathrm{C}$, as observed in the triple mutant. Instead, at this temperature, the specific activity values were similar or lower than 
those of the wild type, for the single mutants A235V and P171L and the double mutants P171L/A235V and P26L/P171L, respectively (Figure 2a,b). This is someway surprising. For the known rule 'you get what you screen for [49], and based on previous studies on CelB [11], it might be expected that the selection at $37^{\circ} \mathrm{C}$ could result in increasing specific activity at mesophilic temperatures, possibly reducing the activity at $85^{\circ} \mathrm{C}$. Instead, selective pressure increased the specific activity of the mutant at temperatures $>50{ }^{\circ} \mathrm{C}$, where the upward shift of the curve was not constant, but increased with temperature (Figure 2a). This resembles the behaviour of the mutants of a thermophilic esterase after several directed evolution generations [50].

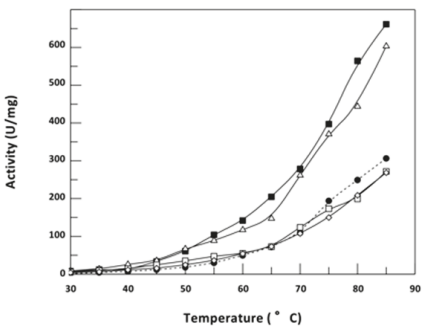

C
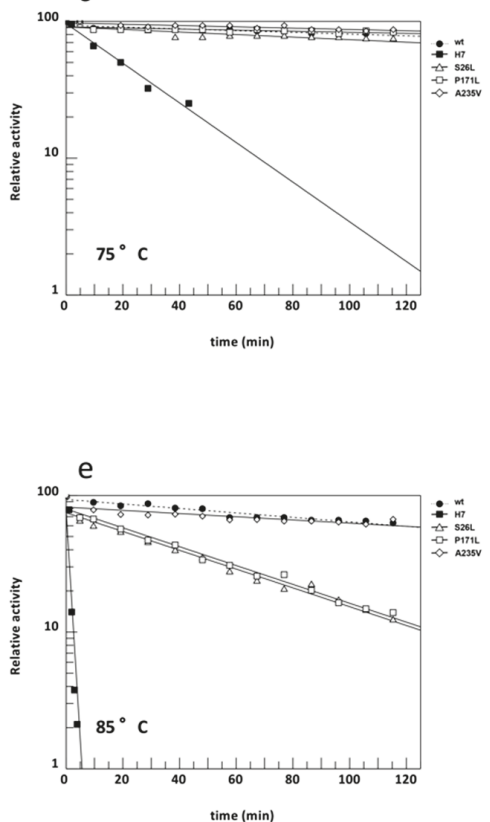

b
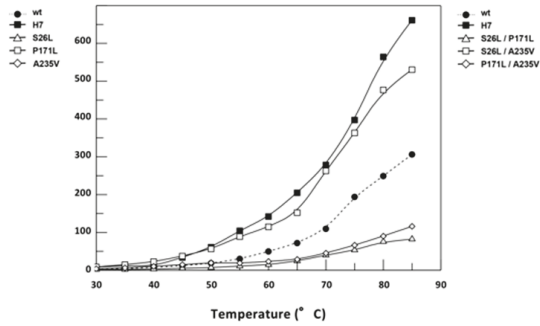

$\mathrm{d}$

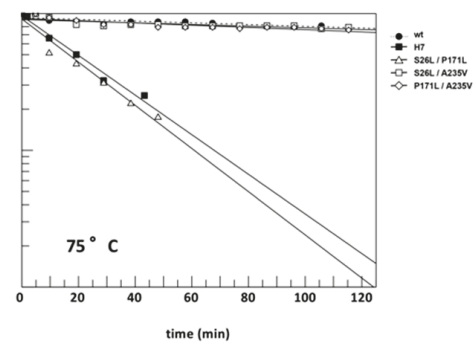

$f$

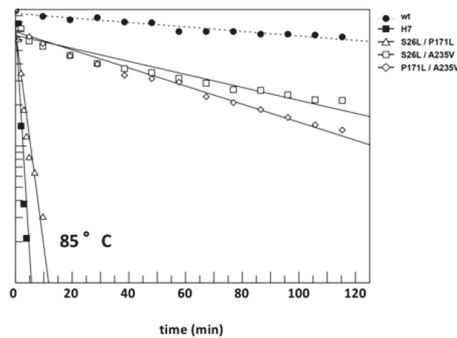

Figure 2. Thermal activity and stability of $S_{s} \beta-G l y H 7$ and relative single and double mutants. The dependence on temperature of the wild type is compared with the H7 mutant; single (a) and double mutants (b). Similarly, the residual activity at $75{ }^{\circ} \mathrm{C}$ and $85^{\circ} \mathrm{C}$ of the wild type, in comparison with $\mathrm{H} 7$ mutant, single (c,e) and double mutants $(\mathbf{d}, \mathbf{f})$, is reported. $S s \beta$-Gly (closed circles on dotted line); Ss $\beta$-Gly H7 (closed squares); L26 (open triangles); L171 (open squares); V235 (open diamonds); L26/L171 (open triangles); L26/V235 (open squares); L171/V235 (open diamonds). 
The effect of the mutations on $S s \beta$-gly was detrimental on the thermal stability. The H7 mutant was as stable as the wild type at $\mathrm{T} \leq 65^{\circ} \mathrm{C}$ (data not shown), but 23 -fold and 283 -fold less stable at $75^{\circ} \mathrm{C}$ and $85^{\circ} \mathrm{C}$, respectively (Figure 2c-f, Table 2). The half-lives measured at $75^{\circ} \mathrm{C}$ showed that all single mutations did not significantly alter the enzyme stability with the exception of S26L, which was inactivated 1.5-fold faster than the wild type (Table 2). This is even clearer in the S26L/P171L double mutant, showing the same low stability of $\mathrm{H7}$ (Figure 2c,d). Instead, the same analysis at $85^{\circ} \mathrm{C}$ revealed that only the A235V mutant was as stable as the wild type (Figure 2e). All the other mutants showed a $\mathrm{t}_{\frac{1}{2}}$ from 5.5 -fold to 284 -fold lower than the wild type $S s \beta$-gly under these conditions (Table 2). Again, the S26L/P171L double mutant is similar to H7 (Figure 2f).

Table 2. Half-life of $S s \beta$-gly wild type and mutants at $75^{\circ} \mathrm{C}$ and $85^{\circ} \mathrm{C}$.

\begin{tabular}{cccc}
\hline \multirow{2}{*}{ Mutants } & \multicolumn{2}{c}{$\mathbf{t}_{\frac{1}{2}}(\mathbf{m i n})$} & Symbols Used in Figure 2 \\
\cline { 2 - 3 } & $\mathbf{7 5}{ }^{\circ} \mathbf{C}$ & $85^{\circ} \mathbf{C}$ & $\cdots$ \\
Wild type & $461.3 \pm 78.0$ & $170.4 \pm 10.7$ & $\cdots$ \\
H7 (S26L/P171/A235) & $20.5 \pm 1.5$ & $0.6 \pm 0.1$ & \\
S26L & $299.4 \pm 68.2$ & $26.6 \pm 1.2$ & \\
P171L & $681.1 \pm 175.7$ & $30.7 \pm 1.4$ & \\
S26L/P171L & $580.8 \pm 10.5$ & $200.9 \pm 37.1$ & \\
S26L/A235V & $17.4 \pm 2.4$ & $0.9 \pm 0.1$ & \\
P171L/A235V & $365.7 \pm 164.2$ & $24.4 \pm 2.7$ & \\
\hline
\end{tabular}

The inspection of the $\mathrm{H} 7$ mutant 3D-model (Figure 3) allowed the explanation of these results. The mutations increased the entire hydrophobicity of the protein and removed specific stabilizing interactions. Residues with low hydrophobicity index (Ser $=-0.8$; Pro $=-1.8$; Ala $=1.8$ ) were substituted with amino acids that are highly hydrophobic $(\mathrm{Leu}=3.8 ; \mathrm{Val}=4.2)$ [51]. The substitution of Ser26 with a leucine increased the hydrophobicity in the loop region encompassing Met21 and Gly22 (Figure 3a,b) and removed a hydrogen-bond with the peptide nitrogen of Gly22 and the carbonyl oxygen of Thr23. In addition, the replacement of the polar S26 residue exposed to the solvent with a non-polar leucine led to a local destabilization of the protein structure, observable at temperatures $>80^{\circ} \mathrm{C}$. However, interestingly, this increased flexibility explains the high thermophilicity of the S26L mutant (Figure 2a). 


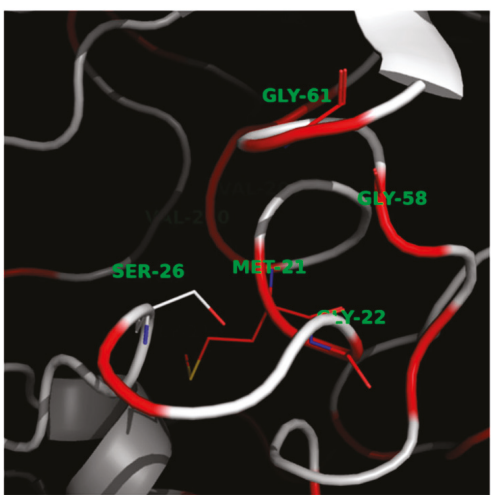

C

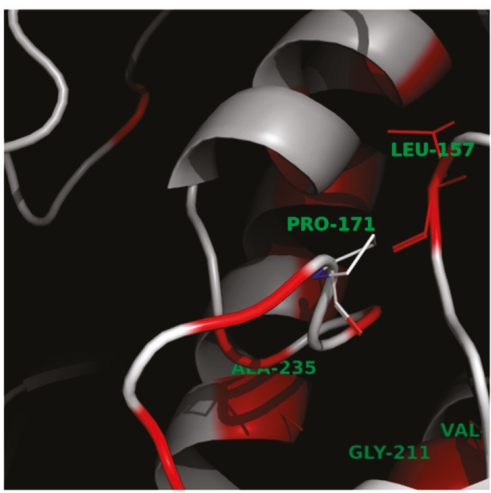

e

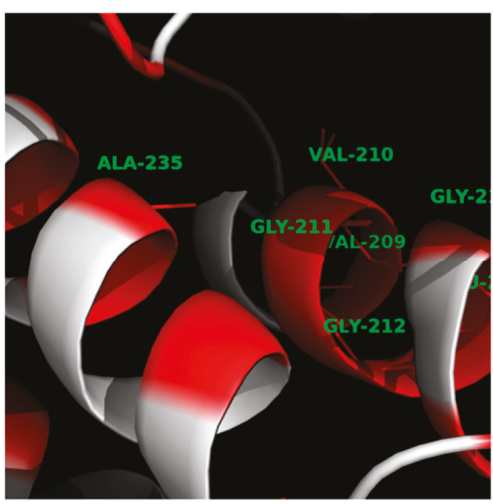

b

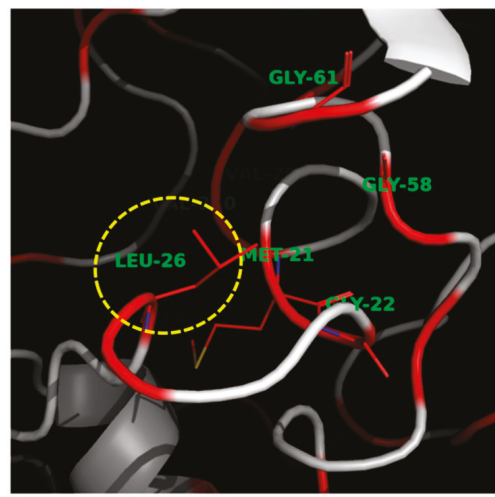

d

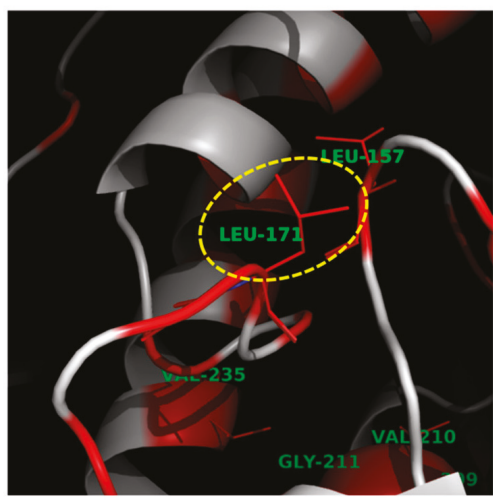

f

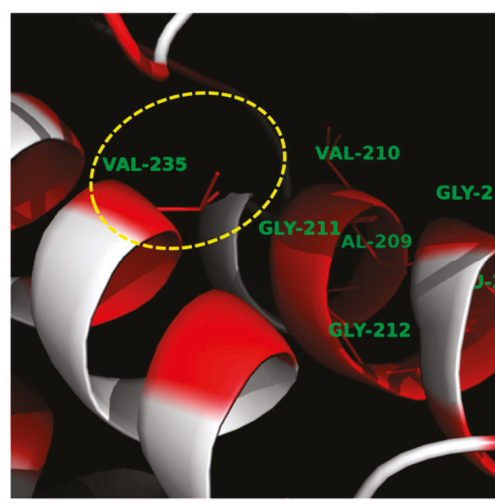

Figure 3. Ss $\beta$-Gly 3D structure in comparison with the H7 mutant model. Close-up of Ss $\beta$-Gly wild type structure (PDB ID: 1GOW) (a,c,e) and $S s \beta$-Gly single mutations in the H7 mutant, S26L, P171L, and $\mathrm{A} 235 \mathrm{~V}$ in $(\mathbf{b}, \mathbf{d}, \mathbf{f})$, respectively. The hydrophobic residues are indicated in red. The mutant residues are highlighted in yellow.

The substitution of the Pro171 with a leucine residue (P171L) in the extended loop Arg165-Thr177 exposed to the solvent (Figure 3c,d) explained the destabilizing effect in the nearby hydrophobic environment involving the $\alpha 4$-helix (Ser228-Lys255), the small $\alpha$-helix (Pro207-Val206), and the loop Asn147-Pro160 (Figure 3e,f). When we modelled in the structure the substituting leucine, the proline cis configuration was removed (Figure $3 \mathrm{~d}$ ) and the local flexibility increased, thus destabilizing the 
structure at $85^{\circ} \mathrm{C}$ (Figure 2e). Interestingly, the destabilizing effect of the S26L and P171L mutations is additive, indicating that they are responsible for the instability of the triple mutant H7 (Figure 2f).

According to the $S s \beta$-gly 3D structure, A235 is located inside of the $\alpha 4$-helix and is very close to the small $\alpha$-helix Pro207-Val216 [23]. The lack of destabilization by the A235V mutation could be explained by the similarity between these two residues, which does not affect the formation of the $\alpha$-helix despite the greater steric hindrance of a valine residue. On the other hand, V235, showing a longer side chain when compared with the wild type alanine, might affect the optimal packing by protruding on the side of the helix. However, the increased local hydrophobicity could, in part, balance this negative effect, explaining why A235V showed the same thermostability at $85^{\circ} \mathrm{C}$ as the wild type (Figure 3e).

The instability of the A235V-containing double mutants is clearly attributable to the detrimental contribution of the other mutations (Table 2; Figure 2d,f). The presence of the three mutations on the surface of $S s \beta$-gly, and the fact that they do not seem to interact with each other, may indicate that the mutations act independently on different regions of the protein promoting the unfolding at $\mathrm{T}>75^{\circ} \mathrm{C}$, thereby affecting the overall stability. In the case of P171L mutation, possibly, an increased flexibility may have made the $\mathrm{H} 7$ triple mutant more active than the wild type at all temperatures tested.

It is worth noting that the triple mutant is more active than its wild-type progenitor at all temperatures, but rapidly became inactivated at $85^{\circ} \mathrm{C}$. Directed evolution studies in which enzymes were adapted to different temperatures often led to the conclusion that there is a trade-off between catalytic activity at low temperatures and thermostability, explained as the balance to maintain the rigidity necessary for stability and the flexibility required for enzyme activity. However, this is not always the case; indeed, the evolved CelB with optimized substrate specificity and gained catalytic activity at $20^{\circ} \mathrm{C}$ showed reduced activity at $\mathrm{T}>80{ }^{\circ} \mathrm{C}$ and destabilization [11], and an evolved glucokinase from a thermophilic fungus showed both improved stability under heat and thermophilicity when compared with the wild type [52]. Laboratory evolution experiments can identify different adaptive mechanisms, but these can be achieved by exploring a limited number of protein fitness pathways often dependent on the selection method used [49,53]. In this study, we applied an in vivo selection, in which mutants complementing an E. coli mutant were isolated. The same approach on IGPS from S. solfataricus yielded mutants that improved growth appreciably, with activity increasing with temperature and accelerated thermal denaturation as observed here for evolved $S s \beta$-gly [10]. Selecting enzyme properties through survival and growth of the host organism, unlike in vitro screenings, exerts a biological function that could be dictated not only by physical and chemical laws, but also by biological natural selection [53]. Possibly, the reduced stability observed for evolved $S s \beta$-gly may allow its quicker protein turnover within the E. coli mesophilic cell that could be required to complement the lacking $\beta$-galactosidase activity. Conversely, the improved activity of the $\mathrm{H} 7$ mutant at temperatures where $\mathrm{S}$. solfataricus grows optimally $\left(85^{\circ} \mathrm{C}\right)$ could merely be the consequence of $E$. coli being more active at $37^{\circ} \mathrm{C}$ and might not fit in archaeal cells by interfering with the normal physiology of this organism.

\section{Materials and Methods}

\subsection{Reagents}

All commercially available substrates were purchased from Sigma. Restriction endonucleases and T4 DNA ligase were from New England BioLabs, USA. Synthetic oligonucleotides were from PRIMM (Milan, Italy). Escherichia coli M5154 strain was from the Coli Genetic Stock Center (Yale University, USA).

\subsection{Random Mutagenesis}

The pGEX-2TK-derivative (GE Healthcare, USA) plasmid (pGEX-K-Gly) containing the wild type S. solfataricus $\beta$-glycosidase gene (lacS) was described previously [54]. Random mutagenesis was performed by chemical treatment of the pGEX-K-Gly plasmid with hydroxylamine. In particular, 
$\sim 15.0 \mu \mathrm{g}$ of the plasmid was denatured with $\mathrm{NaOH} 0.2 \mathrm{M}$ at room temperature for $5 \mathrm{~min}$, followed by a fast neutralization step with ammonium acetate at $\mathrm{pH}$ 7.5. Finally, the plasmid was exposed to hydroxylamine $\left(\mathrm{H}_{3} \mathrm{NO}\right) 0.5 \mathrm{M}$ at $37^{\circ} \mathrm{C}$ for $8.0 \mathrm{~h}$ in phosphate buffer $50.0 \mathrm{mM} \mathrm{pH}$ 6.5. The $\sim 1500 \mathrm{bp}$ DNA fragment relative to the lacS gene was purified by gel extraction, after digestion of the treated pGEX-K-Gly plasmid using the Bam HI and Sma I restriction enzymes. A library of random mutants was obtained by a ligation of the lacS gene with a Bam HI-Sma I linearized pGEX-2TK plasmid.

\subsection{Selection of Ss $\beta$-gly Mutants for Enhanced Lactose Hydrolysis}

A ligation mixture was utilized for the transformation of the E. coli M5154 strain, which harbours a deletion of almost one-third of the lacZ gene ( $\triangle$ lacZ39 deletion), making this strain completely inactive for the hydrolysis of galactose-derived $\beta$-substrates. For the screening, we exploited the $\beta$-glucosidase activity of the product of the lacS gene. E. coli M5154 cells transformed with the library of random mutants were first plated on $50 \mu \mathrm{g} / \mathrm{mL}$ ampicillin (Amp) LB Agar medium containing the 5 -bromo-4-chloro-3-indolyl- $\beta$-D-glucopyranoside (X-Glc) chromogenic substrate, and the mutagenic impact of the hydroxylamine treatment was thus determined by calculating the blue/white colony ratio. Afterwards, transformed cells were plated on M9 Amp Trp minimal medium, containing lactose as the sole carbon source, and incubated at $37^{\circ} \mathrm{C}$. Wild type lacS expressing clones led to colonies after about 10 days of incubation because of the basal $\beta$-galactosidase activity of the enzyme. All colonies appearing before, namely after six to seven days of incubation, were identified and picked. Selected colonies were grown in rich medium and analyzed for their $\beta$-galacto- and $\beta$-glucosidase activity, by using a colorimetric enzymatic assay and $2 \mathrm{~Np}-\mathrm{Gal}$ and $2 \mathrm{~Np}$-Glc, respectively, as substrates [55].

\subsection{Production of H7-Derived Single and Double Mutants}

The in vivo selected H7 clone was sequenced and three mutations were identified (S26L, P171L, and $\mathrm{A} 235 \mathrm{~V})$. The opportunity that unique restriction sites in the lacS gene separate these mutations allowed for the preparation of specific DNA fragments containing single and/or double mutations. These were combined and ligated with the opportunely digested pGEX-K-Gly plasmids to finally achieve the $S s \beta$-gly single and double mutants.

\subsection{Enzyme Expression and Purification}

Wild-type $S s \beta$-gly and relative mutants were expressed and purified as fusions of glutathione S-transferase (GST), as previously reported $[36,54,56]$. Briefly, transformed E. coli BL21(DE3)RIL, carrying extra copies of the $\arg U$, ileY, and leuW tRNA genes cells, were grown in SB medium at $37^{\circ} \mathrm{C}$ and induced by the addition of $1.0 \mathrm{mM}$ IPTG, when cultures reached an $\mathrm{OD}_{600}$ of 1.0. After $16 \mathrm{~h}$ of incubation, cells were harvested by centrifugation at $5000 \times \mathrm{g}$ and stored at $-20^{\circ} \mathrm{C}$. Then, the pellet was thawed and resuspended in $2.0 \mathrm{~mL} / \mathrm{g}$ cells of PBS buffer $(50.0 \mathrm{mM}$ sodium phosphate buffer, $150.0 \mathrm{mM} \mathrm{NaCl} ; \mathrm{pH}$ 7.4). After French press cell disruption and centrifugation at $4{ }^{\circ} \mathrm{C}$ for $30 \mathrm{~min}$ at $30,000 \times \mathrm{g}$ to discard cell debris, free cell crude extract containing the fusion protein was subjected to an affinity chromatography on a glutathione-Sepharose $4 \mathrm{~B}^{\mathrm{TM}}$ resin (GE Healthcare, USA), followed by an incubation with thrombin protease in order to separate GST and Ss $\beta$-gly.

Aliquots of pure proteins ( $>95.0 \%$, as judged by SDS-PAGE analysis) were stored at $-20{ }^{\circ} \mathrm{C}$ in PSB $1 \mathrm{X}$ containing $20.0 \%$ glycerol. The samples stored in these conditions are stable for several months. The protein concentration was determined with the method of Bradford, using bovine serum albumin as the standard [57].

\subsection{Enzyme Characterization}

All kinetic studies were performed by following spectrophotometrically the hydrolytic activity with a Cary 100 Scan spectrophotometer (Varian, Australia), coupled with a thermally controlled Peltier system. A total of $1.0 \mathrm{~mL}$ of reaction solution was preheated for $2.0 \mathrm{~min}$, keeping the temperature constant during all measurements. $\beta$-glycosidase activity performed at $65^{\circ} \mathrm{C}$ in $50 \mathrm{mM}$ sodium 
phosphate buffer at $\mathrm{pH} 6.5$ was conventionally defined as the standard reaction. Kinetic parameters at standard conditions were determined using artificial and natural substrates, whose concentration ranged from 0.1 to 30.0 and from 1.25 to $750.0 \mathrm{mM}$, respectively. In order to correct the spontaneous hydrolysis of the substrates, mixtures containing all the reactants except enzymes were prepared and referred to as blank reactions. Steady-state kinetic constants were obtained by plotting initial velocity values versus 15 different substrate concentrations for each substrate. In each assay, amounts ranging from 0.5 to $20.0 \mu \mathrm{g}$ of wild type $S s \beta$-gly and mutants were used. Measuring the hydrolytic activity on 4-nitrophenol based substrates at standard conditions, a molar extinction coefficient $\left(\varepsilon_{\mathrm{M}}\right)$ value of $9340 \mathrm{M}^{-1} \mathrm{~cm}^{-1}$ at $405 \mathrm{~nm}$ was used, whereas the activity on lactose and cellobiose was determined by measuring the released glucose with the glucose oxidase-peroxidase enzymatic assay GOPOD (Megazyme, Chicago, Illinois, USA), taking into account that one molecule of cellobiose leads to the release of two glucose units. One unit of enzyme activity was conventionally defined as the amount of the enzyme that hydrolyses $1.0 \mu \mathrm{mol}$ of substrate in $1.0 \mathrm{~min}$ under standard conditions. All data were plotted and refined using the program GraFit 5.0 (Erithacus Software Ltd., Horley, U.K.), in order to determine the steady-state kinetic parameters.

\subsection{Thermal Stability and Temperature Dependence}

The thermal stability was analyzed by incubating all the enzymes at the concentration of $0.01 \mu \mathrm{g} / \mathrm{mL}$ in $50.0 \mathrm{mM}$ phosphate buffer $\mathrm{pH} 6.5$, at the indicated temperatures and times. The hydrolytic activity of each sample was determined at $405 \mathrm{~nm}$ in standard conditions, using a molar extinction coefficient $\left(\varepsilon_{\mathrm{M}}\right)$ value of $9340 \mathrm{M}^{-1} \mathrm{~cm}^{-1}$ for the release of 4-nitrophenol. The activity of the sample measured without any incubation was taken as $100 \%$.

Enzymes were assayed in standard conditions from 30 to $85^{\circ} \mathrm{C}$, in order to evaluate their temperature dependence. Enzymatic units were measured using different molar extinction coefficient values, as follows: $6130 \mathrm{M}^{-1} \mathrm{~cm}^{-1}\left(30^{\circ} \mathrm{C}\right) ; 6570 \mathrm{M}^{-1} \mathrm{~cm}^{-1}\left(35^{\circ} \mathrm{C}\right) ; 6910 \mathrm{M}^{-1} \mathrm{~cm}^{-1}\left(40^{\circ} \mathrm{C}\right) ; 7530 \mathrm{M}^{-1} \mathrm{~cm}^{-1}$ $\left(45^{\circ} \mathrm{C}\right) ; 7970 \mathrm{M}^{-1} \mathrm{~cm}^{-1}\left(50^{\circ} \mathrm{C}\right) ; 8420 \mathrm{M}^{-1} \mathrm{~cm}^{-1}\left(55^{\circ} \mathrm{C}\right) ; 8890 \mathrm{M}^{-1} \mathrm{~cm}^{-1}\left(60^{\circ} \mathrm{C}\right) ; 9340 \mathrm{M}^{-1} \mathrm{~cm}^{-1}\left(65^{\circ} \mathrm{C}\right) ;$ $9700 \mathrm{M}^{-1} \mathrm{~cm}^{-1}\left(70^{\circ} \mathrm{C}\right) ; 10120 \mathrm{M}^{-1} \mathrm{~cm}^{-1}\left(75^{\circ} \mathrm{C}\right) ; 10610 \mathrm{M}^{-1} \mathrm{~cm}^{-1}\left(80^{\circ} \mathrm{C}\right) ; 10900 \mathrm{M}^{-1} \mathrm{~cm}^{-1}\left(85^{\circ} \mathrm{C}\right)$.

\subsection{D-Model of Ss $\beta$-gly H7 Mutant}

Homology modeling of Ss $\beta$-gly H7 mutant structure was performed by SWISS-MODEL server [58] using the $S s \beta$-gly wild type structure (PDB entry 1 gow) as a template. Stereochemical quality of the model was analyzed by the PROCHECK program and PyMol 1.0 was used to analyze and visualize the structure [59].

\section{Conclusions}

In this study, we identified residues that are critical in determining the thermostability, thermal activity, and substrate specificity of the studied thermozyme $S_{s} \beta$-gly. In previous rationally designed protein engineering studies on $S s \beta$-gly, mutants in the active site showed broadened substrate specificity. Here, three mutations far from the active site obtained randomly after an in vivo selection produced a more than two-fold enhancement of the specific activity at $85{ }^{\circ} \mathrm{C}$ and of the $\mathrm{k}_{\text {cat }}$ on galactoside substrates. Interestingly, the activity of the enzyme on cellobiose remained the same as the wild type or was even enhanced on 4-Np-Glc. This remarkable result was paid off with a 283-fold reduced thermal stability, when compared with the wild type. The change of Ser26 into Leu enhanced the thermophilicity because of the disruption of stabilizing interactions that, by increasing the flexibility of the enzyme, facilitated catalysis at a high temperature, but also weakened its resistance to heat. Our study shows that it is not always successful to improve the enzyme activity following a "rational" approach based on the known and understood physicochemical laws that determine the conformations and interactions of the amino acids and enzyme catalysis. When possible, "irrational" approaches, which exploit in vivo selection, can produce enzyme mutants of interest. 
Author Contributions: G.P. contributed to conceptualization, investigation, and writing-review and editing; A.S. contributed to formal analysis, data curation, and writing-review and editing; M.M. (Marialuisa Mazzone) contributed to formal analysis; M.R. contributed to supervision; M.M. (Marco Moracci) contributed to conceptualization; funding acquisition, and writing—original draft preparation.

Funding: This research was funded by a grant from the Ministero dell'Università e della Ricerca Scientifica Industrial Research Project "Development of green technologies for production of BIOchemicals and their use in preparation and industrial application of POLImeric materials from agricultural biomasses cultivated in a sustainable way in Campania region-BioPoliS" PON03PE_00107_1/1, funded in the frame of Operative National Programme Research and Competitiveness 2007-2013 D. D. Prot. n. 713/Ric. 29.10.2010.

Acknowledgments: We are grateful to Chiara Nobile and Marco Petruzziello at the Institute of Biosciences and BioResources (IBBR) from the National Research Council of Italy for administrative and technical assistance, as well as to Karl Joseph Duffy (PhD) of the Department of Biology, University of Naples "Federico II" for the editing of the manuscript.

Conflicts of Interest: The authors declare no conflict of interest.

\section{References}

1. Fields, P.A. Review: Protein function at thermal extremes: Balancing stability and flexibility. Comp. Biochem. Physiol. A: Mol. Integr. Physiol. 2001, 129, 417-431. [CrossRef]

2. Littlechild, J.A.; Guy, J.; Connelly, S.; Mallett, L.; Waddell, S.; Rye, C.A.; Line, K.; Isupov, M. Natural methods of protein stabilization: Thermostable biocatalysts. Biochem. Soc. Trans. 2007, 35, 1558-1563. [CrossRef]

3. Imanaka, T. Molecular bases of thermophily in hyperthermophiles. Proc. Jpn. Acad. Ser. B Phys. Biol. Sci. 2011, 87, 587-602. [CrossRef] [PubMed]

4. Pica, A.; Graziano, G. Shedding light on the extra thermal stability of thermophilic proteins. Biopolymers 2016, 105, 856-863. [CrossRef]

5. Vieille, C.; Zeikus, G.J. Hyperthermophilic enzymes: Sources, uses, and molecular mechanisms for thermostability. Microbiol. Mol. Biol. Rev. 2001, 65, 1-43. [CrossRef]

6. Ito, Y.; Ikeuchi, A.; Imamura, C. Advanced evolutionary molecular engineering to produce thermostable cellulase by using a small but efficient library. Protein Eng. Des. Sel. 2013, 26, 73-79. [CrossRef]

7. Ruller, R.; Alponti, J.; Deliberto, L.A.; Zanphorlin, L.M.; Machado, C.B.; Ward, R.J. Concommitant adaptation of a gh11 xylanase by directed evolution to create an alkali-tolerant/thermophilic enzyme. Protein Eng. Des. Sel. 2014, 27, 255-262. [CrossRef]

8. Morais, S.; Stern, J.; Kahn, A.; Galanopoulou, A.P.; Yoav, S.; Shamshoum, M.; Smith, M.A.; Hatzinikolaou, D.G.; Arnold, F.H.; Bayer, E.A. Enhancement of cellulosome-mediated deconstruction of cellulose by improving enzyme thermostability. Biotechnol. Biofuels 2016, 9, 164. [CrossRef]

9. Ribeiro, A.L.; Sanchez, M.; Hidalgo, A.; Berenguer, J. Stabilization of enzymes by using thermophiles. Methods Mol. Biol. 2017, 1645, 297-312.

10. Merz, A.; Yee, M.C.; Szadkowski, H.; Pappenberger, G.; Crameri, A.; Stemmer, W.P.; Yanofsky, C.; Kirschner, K. Improving the catalytic activity of a thermophilic enzyme at low temperatures. Biochemistry 2000, 39, 880-889. [CrossRef] [PubMed]

11. Lebbink, J.H.; Kaper, T.; Bron, P.; van der Oost, J.; de Vos, W.M. Improving low-temperature catalysis in the hyperthermostable pyrococcus furiosus beta-glucosidase celb by directed evolution. Biochemistry 2000, 39, 3656-3665. [CrossRef]

12. Sunna, A.; Moracci, M.; Rossi, M.; Antranikian, G. Glycosyl hydrolases form hyperthermophiles. Extremophiles 1997, 1, 2-13. [CrossRef]

13. Elleuche, S.; Schroder, C.; Sahm, K.; Antranikian, G. Extremozymes-biocatalysts with unique properties from extremophilic microorganisms. Curr. Opin. Biotechnol. 2014, 29, 116-123. [CrossRef]

14. Blumer-Schuette, S.E.; Brown, S.D.; Sander, K.B.; Bayer, E.A.; Kataeva, I.; Zurawski, J.V.; Conway, J.M.; Adams, M.W.W.; Kelly, R.M. Thermophilic lignocellulose deconstruction. FEMS Microbiol. Rev. 2014, 38, 393-448. [CrossRef] [PubMed]

15. Botha, J.; Mizrachi, E.; Myburg, A.A.; Cowan, D.A. Carbohydrate active enzyme domains from extreme thermophiles: Components of a modular toolbox for lignocellulose degradation. Extremophiles 2018, 22, 1-12. [CrossRef] [PubMed] 
16. Lombard, V.; Golaconda Ramulu, H.; Drula, E.; Coutinho, P.M.; Henrissat, B. The carbohydrate-active enzymes database (cazy) in 2013. Nucleic Acids Res. 2014, 42, D490-D495. [CrossRef] [PubMed]

17. Pisani, F.M.; Rella, R.; Raia, C.A.; Rozzo, C.; Nucci, R.; Gambacorta, A.; De Rosa, M.; Rossi, M. Thermostable beta-galactosidase from the archaebacterium sulfolobus solfataricus. Purification and properties. Eur. J. Biochem. 1990, 187, 321-328. [CrossRef] [PubMed]

18. Moracci, M.; Lavolpe, A.; Pulitzer, J.F.; Rossi, M.; Ciaramella, M. Expression of the thermostable beta-galactosidase gene from the archaebacterium sulfolobus-solfataricus in saccharomyces-cerevisiae and characterization of a new inducible promoter for heterologous expression. J. Bacteriol. 1992, 174, 873-882. [CrossRef] [PubMed]

19. Moracci, M.; Ciaramella, M.; Nucci, R.; Pearl, L.H.; Sanderson, I.; Trincone, A.; Rossi, M. Thermostable $\beta$-glycosidase from sulfolobus-solfataricus. Biocatalysis 1994, 11, 89-103. [CrossRef]

20. Moracci, M.; Nucci, R.; Febbraio, F.; Vaccaro, C.; Vespa, N.; Lacara, F.; Rossi, M. Expression and extensive characterization of a beta-glycosidase from the extreme thermoacidophilic archaeon sulfolobus-solfataricus in escherichia-coli - authenticity of the recombinant enzyme. Enzyme Microb. Tech. 1995, 17, 992-997. [CrossRef]

21. Pouwels, J.; Moracci, M.; Cobucci-Ponzano, B.; Perugino, G.; van der Oost, J.; Kaper, T.; Lebbink, J.H.G.; de Vos, W.M.; Ciaramella, M.; Rossi, M. Activity and stability of hyperthermophilic enzymes: A comparative study on two archaeal beta-glycosidases. Extremophiles 2000, 4, 157-164. [CrossRef]

22. Leon, M.; Isorna, P.; Menendez, M.; Sanz-Aparicio, J.; Polaina, J. Comparative study and mutational analysis of distinctive structural elements of hyperthermophilic enzymes. Protein J. 2007, 26, 435-444. [CrossRef] [PubMed]

23. Aguilar, C.F.; Sanderson, I.; Moracci, M.; Ciaramella, M.; Nucci, R.; Rossi, M.; Pearl, L.H. Crystal structure of the beta-glycosidase from the hyperthermophilic archeon sulfolobus solfataricus: Resilience as a key factor in thermostability. J. Mol. Biol. 1997, 271, 789-802. [CrossRef]

24. Cobucci-Ponzano, B.; Moracci, M.; Di Lauro, B.; Ciaramella, M.; D’Avino, R.; Rossi, M. Ionic network at the c-terminus of the beta-glycosidase from the hyperthermophilic archaeon sulfolobus solfataricus: Functional role in the quaternary structure thermal stabilization. Proteins 2002, 48, 98-106. [CrossRef]

25. Ausili, A.; Di Lauro, B.; Cobucci-Ponzano, B.; Bertoli, E.; Scire, A.; Rossi, M.; Tanfani, F.; Moracci, M. Two-dimensional ir correlation spectroscopy of mutants of the beta-glycosidase from the hyperthermophilic archaeon sultolobus soltataricus identifies the mechanism of quaternary structure stabilization and unravels the sequence of thermal unfolding events. Biochem. J. 2004, 384, 69-78. [CrossRef]

26. Tehei, M.; Franzetti, B.; Madern, D.; Ginzburg, M.; Ginzburg, B.Z.; Giudici-Orticoni, M.T.; Bruschi, M.; Zaccai, G. Adaptation to extreme environments: Macromolecular dynamics in bacteria compared in vivo by neutron scattering. Embo. Rep. 2004, 5, 66-70. [CrossRef] [PubMed]

27. Kalimeri, M.; Rahaman, O.; Melchionna, S.; Sterpone, F. How conformational flexibility stabilizes the hyperthermophilic elongation factor g-domain. J. Phys. Chem. B 2013, 117, 13775-13785. [CrossRef] [PubMed]

28. Matsuura, Y.; Takehira, M.; Joti, Y.; Ogasahara, K.; Tanaka, T.; Ono, N.; Kunishima, N.; Yutani, K. Thermodynamics of protein denaturation at temperatures over 100 degrees c: Cuta1 mutant proteins substituted with hydrophobic and charged residues. Sci. Rep. 2015, 5, 15545. [CrossRef]

29. Deckert, K.; Budiardjo, S.J.; Brunner, L.C.; Lovell, S.; Karanicolas, J. Designing allosteric control into enzymes by chemical rescue of structure. J. Am. Chem. Soc. 2012, 134, 10055-10060. [CrossRef]

30. Budiardjo, S.J.; Licknack, T.J.; Cory, M.B.; Kapros, D.; Roy, A.; Lovell, S.; Douglas, J.; Karanicolas, J. Full and partial agonism of a designed enzyme switch. ACS Synth. Biol. 2016, 5, 1475-1484. [CrossRef]

31. Nucci, R.; Moracci, M.; Vaccaro, C.; Vespa, N.; Rossi, M. Exo-glucosidase activity and substrate-specificity of the beta-glycosidase isolated from the extreme thermophile sulfolobus-solfataricus. Biotechnol. Appl. Bioc. 1993, 17, 239-250.

32. Corbett, K.; Fordham-Skelton, A.P.; Gatehouse, J.A.; Davis, B.G. Tailoring the substrate specificity of the beta-glycosidase from the thermophilic archaeon sulfolobus solfataricus. Febs. Lett. 2001, 509, 355-360. [CrossRef]

33. Hancock, S.M.; Corbett, K.; Fordham-Skelton, A.P.; Gatehouse, J.A.; Davis, B.G. Developing promiscuous glycosidases for glycoside synthesis: Residues w433 and e432 in sulfolobus solfataricus beta-glycosidase are important glucoside- and galactoside-specificity determinants. Chembiochem 2005, 6, 866-875. [CrossRef] [PubMed] 
34. Iglesias-Fernandez, J.; Hancock, S.M.; Lee, S.S.; Khan, M.; Kirkpatrick, J.; Oldham, N.J.; McAuley, K.; Fordham-Skelton, A.; Rovira, C.; Davis, B.G. A front-face 'sni synthase' engineered from a retaining 'double-sn2' hydrolase. Nat. Chem. Biol. 2017, 13, 874-881. [CrossRef]

35. Mackenzie, L.F.; Wang, Q.P.; Warren, R.A.J.; Withers, S.G. Glycosynthases: Mutant glycosidases for oligosaccharide synthesis. J. Am. Chem. Soc. 1998, 120, 5583-5584. [CrossRef]

36. Moracci, M.; Trincone, A.; Perugino, G.; Ciaramella, M.; Rossi, M. Restoration of the activity of active-site mutants of the hyperthermophilic beta-glycosidase from sulfolobus solfataricus: Dependence of the mechanism on the action of external nucleophiles. Biochemistry 1998, 37, 17262-17270. [CrossRef] [PubMed]

37. Trincone, A.; Perugino, G.; Rossi, M.; Moracci, M. A novel thermophilic glycosynthase that effects branching glycosylation. Bioorg. Med. Chem. Lett. 2000, 10, 365-368. [CrossRef]

38. Moracci, M.; Trincone, A.; Rossi, M. Glycosynthases: New enzymes for oligosaccharide synthesis. J. Mol. Catal. B-Enzym 2001, 11, 155-163. [CrossRef]

39. Cobucci-Ponzano, B.; Strazzulli, A.; Rossi, M.; Moracci, M. Glycosynthases in biocatalysis. Adv. Synth. Catal. 2011, 353, 2284-2300. [CrossRef]

40. Cobucci-Ponzano, B.; Moracci, M. Glycosynthases as tools for the production of glycan analogs of natural products. Nat. Prod. Rep. 2012, 29, 697-709. [CrossRef] [PubMed]

41. Wei, J.H.; Lv, X.; Lu, Y.; Yang, G.Z.; Fu, L.F.; Yang, L.; Wang, J.J.; Gao, J.H.; Cheng, S.H.; Duan, Q.; et al. Glycosynthase with broad substrate specificity-an efficient biocatalyst for the construction of oligosaccharide library. Eur. J. Org. Chem. 2013, 2414-2419. [CrossRef]

42. Planas, A. Glycosynthase technology for enzymatic synthesis of functional polysaccharides. Abstr. Pap. Am. Chem. Soc. 2015, 249.

43. Goddard-Borger, E.D.; Tysoe, C.; Withers, S.G. Glycosynthase mediated synthesis of psychosine. Carbohydr. Res. 2016, 435, 97-99. [CrossRef]

44. Gloster, T.M.; Roberts, S.; Ducros, V.M.A.; Perugino, G.; Rossi, M.; Hoos, R.; Moracci, M.; Vasella, A.; Davies, G.J. Structural studies of the beta-glycosidase from sulfolobus solfataricus in complex with covalently and noncovalently bound inhibitors. Biochemistry 2004, 43, 6101-6109. [CrossRef]

45. Gloster, T.M.; Roberts, S.; Perugino, G.; Rossi, M.; Moracci, M.; Panday, N.; Terinek, M.; Vasella, A.; Davies, G.J. Structural, kinetic, and thermodynamic analysis of glucoimidazole-derived glycosidase inhibitors. Biochemistry 2006, 45, 11879-11884. [CrossRef]

46. Hill, C.M.; Duggleby, R.G. Mutagenesis of escherichia coli acetohydroxyacid synthase isoenzyme ii and characterization of three herbicide-insensitive forms. Biochem. J. 1998, 335, 653-661. [CrossRef]

47. Shimotohno, A.; Oue, S.; Yano, T.; Kuramitsu, S.; Kagamiyama, R. Demonstration of the importance and usefulness of manipulating non-active-site residues in protein design. J. Biochem. 2001, 129, 943-948. [CrossRef] [PubMed]

48. Agarwal, P.K. A biophysical perspective on enzyme catalysis. Biochemistry 2019, 58, 438-449. [CrossRef]

49. Romero, P.A.; Arnold, F.H. Exploring protein fitness landscapes by directed evolution. Nat. Rev. Mol. Cell Biol. 2009, 10, 866-876. [CrossRef]

50. Giver, L.; Gershenson, A.; Freskgard, P.O.; Arnold, F.H. Directed evolution of a thermostable esterase. Proc. Natl. Acad. Sci. USA 1998, 95, 12809-12813. [CrossRef]

51. Kyte, J.; Doolittle, R.F. A simple method for displaying the hydropathic character of a protein. J. Mol. Biol. 1982, 157, 105-132. [CrossRef]

52. Zhou, W.; Huang, R.; Zhu, Z.; Zhang, Y.P.J. Coevolution of both thermostability and activity of polyphosphate glucokinase from thermobifida fusca yx. Appl. Environ. Microbiol. 2018, 84, e01224-18. [CrossRef]

53. Arnold, F.H.; Wintrode, P.L.; Miyazaki, K.; Gershenson, A. How enzymes adapt: Lessons from directed evolution. Trends Biochem. Sci 2001, 26, 100-106. [CrossRef]

54. Moracci, M.; Capalbo, L.; Ciaramella, M.; Rossi, M. Identification of two glutamic acid residues essential for catalysis in the beta-glycosidase from the thermoacidophilic archaeon sulfolobus solfataricus. Protein Eng. 1996, 9, 1191-1195. [CrossRef]

55. Griffith, K.L.; Wolf, R.E., Jr. Measuring beta-galactosidase activity in bacteria: Cell growth, permeabilization, and enzyme assays in 96-well arrays. Biochem. Biophys. Res. Commun. 2002, 290, 397-402. [CrossRef] [PubMed] 
56. Perugino, G.; Trincone, A.; Giordano, A.; van der Oost, J.; Kaper, T.; Rossi, M.; Moracci, M. Activity of hyperthermophilic glycosynthases is significantly enhanced at acidic ph. Biochemistry 2003, 42, 8484-8493. [CrossRef] [PubMed]

57. Bradford, M.M. A rapid and sensitive method for the quantitation of microgram quantities of protein utilizing the principle of protein-dye binding. Anal. Biochem. 1976, 72, 248-254. [CrossRef]

58. Arnold, K.; Bordoli, L.; Kopp, J.; Schwede, T. The swiss-model workspace: A web-based environment for protein structure homology modelling. Bioinformatics 2006, 22, 195-201. [CrossRef] [PubMed]

59. Laskowski, R.A.; Macarthur, M.W.; Moss, D.S.; Thornton, J.M. Procheck: a program to check the stereochemical quality of protein structures. J. Appl. Crystallogr. 1993, 26, 283-291. [CrossRef]

(C) 2019 by the authors. Licensee MDPI, Basel, Switzerland. This article is an open access article distributed under the terms and conditions of the Creative Commons Attribution (CC BY) license (http://creativecommons.org/licenses/by/4.0/). 



\title{
Article \\ Change of the Product Specificity of a Cyclodextrin Glucanotransferase by Semi-Rational Mutagenesis to Synthesize Large-Ring Cyclodextrins
}

\author{
Christian Sonnendecker and Wolfgang Zimmermann * \\ Department of Microbiology and Bioprocess Technology, Institute of Biochemistry, Leipzig University, \\ Johannisallee 23, 04103 Leipzig, Germany; christian.sonnendecker@uni-leipzig.de \\ * Correspondence: wolfgang.zimmermann@uni-leipzig.de; Tel.: +49-341-97-36781
}

Received: 11 February 2019; Accepted: 1 March 2019; Published: 6 March 2019

\begin{abstract}
Cyclodextrin glucanotransferases (CGTases) convert starch to cyclodextrins (CD) of various sizes. To engineer a CGTase for the synthesis of large-ring CD composed of 9 to 12 glucose units, a loop structure of the protein involved in substrate binding was targeted for semi-rational mutagenesis. Based on multiple protein alignments and protein structure information, a mutagenic megaprimer was designed to encode a partial randomization of eight amino acid residues within the loop region. The library obtained encoding amino acid sequences occurring in wild type CGTases in combination with a screening procedure yielded sequences displaying a changed CD product specificity. As a result, variants of the CGTase from the alkaliphilic Bacillus sp. G825-6 synthesizing mainly CD9 to CD12 could be obtained. When the mutagenesis experiment was performed with the CGTase G825-6 variant $Y 183 R$, the same loop alterations that increased the total $C D$ synthesis activity resulted in lower activities of the variant enzymes created. In the presence of the amino acid residue R183, the synthesis of CD8 was suppressed and larger CD were obtained as the main products. The alterations not only affected the product specificity, but also influenced the thermal stability of some of the CGTase variants indicating the importance of the loop structure for the stability of the CGTase.
\end{abstract}

Keywords: cyclodextrin glucanotransferases; large-ring cyclodextrins; semi rational mutagenesis

\section{Introduction}

Evolutionary methods can be applied to change amino acid residues of proteins to alter their properties as desired [1]. Iterative rounds of diversification and selection thereby mimic an evolutionary process in vitro [2]. Such directed evolution approaches on a molecular level are in in contrast to site-directed mutagenesis techniques, where rational considerations lead to specific and targeted alterations of the target protein [3]. A combination of both approaches can be described as semi-rational protein engineering where the size of the library of the created protein variants is reduced and its fitness is increased [4]. Libraries with higher fitness can be constructed using mutagenic primers [5-7]. Their design requires information obtained from multiple sequence alignments, consensus sequences, and from the structure and function of the protein [5-7]. By selecting distinct amino acid residues instead of total randomization, which would lead to an incongruous number of combinations, a drastic decrease of the size of the variant library can be achieved allowing the alteration of further residues of the target protein without increasing its size [8].

Cyclodextrin glucanotransferases (CGTases), a part of the GH13 $\alpha$-amylase superfamily, are starch-degrading enzymes produced by many bacteria $[9,10]$. They catalyze an intramolecular transglycosylation reaction resulting in the formation of cyclic $\alpha$-1,4-linked glucans, cyclodextrins (CD) [11]. Due to their ability to form reversible complexes with guest molecules thereby increasing their solubility and stability, $\mathrm{CD} 6$ to $\mathrm{CD} 8$ composed of 6 to 8 glucose units have found many industrial 
applications [12]. In contrast, limited information is available on the potential of larger ring CD as host compounds [13-15]. In particular, CD9 to CD12 could be of interest as hosts for the formation of complexes with bulky guest compounds or with pharmaceuticals not able to form complexes with CD6 to CD8 [16-18]. Although a mixture of CD with a degree of polymerization of 6 up to more than 60 is initially synthesized by the CGTase, the larger CD are rapidly reused as substrates in further intermolecular transglycosylation reactions [19]. Therefore, mostly CD6, CD7 and some CD8 with only small amounts of large-ring CD of more than eight glucose units are obtained as products of a reaction of CGTases with starch $[20,21]$. While efforts to engineer CGTases to increase the yield of CD 6 to CD8 have been published previously [22], only recently attempts to increase the yield of larger CD by site-directed mutagenesis and domain shuffling of CGTases have been reported [23,24].

In this paper, we engineered a CGTase to synthesize large-ring CD in high amounts. We used a semi-rational mutagenesis approach to generate a diverse library of enzyme variants with high fitness. Based on multiple sequence alignments and protein structure information, a loop region of the enzyme was selected for mutagenesis using a partially randomized megaprimer. A library adjusted to reduce sequence space and increase its fitness was designed using degenerated codons, followed by fitness screening of the obtained recombinant E. coli clones.

\section{Results}

\subsection{Construction of Vector Libraries}

A low-conserved loop region of the CGTase G825-6 (amino acid residues 81-89) representing the binding site for the glucan substrate at the subsite-3 (three glucose residues downstream from the glucan chain cleavage site towards the non-reducing end) was selected as the target for mutagenesis. Based on a multiple sequence alignment of 31 CGTases (Table S1), degenerated codons were used to design a DNA library encoding for a partially randomized loop sequence (Figure S1, Figure 1a). The mutagenic megaprimer with conserved flanking regions was amplified and used in a further PCR with CGTase G825-6 and the variant Y183R as templates. The obtained vector library displayed the desired randomization and was subsequently used for expression and activity screening in E. coli BL21(DE3) as host (Figure 1a). The constructs were designated Loop-3 (L3) with the CGTase G825-6 as a template and Loop-3 Y183R (L3YR) with the corresponding CGTase encoding the mutation Y183R as a template.

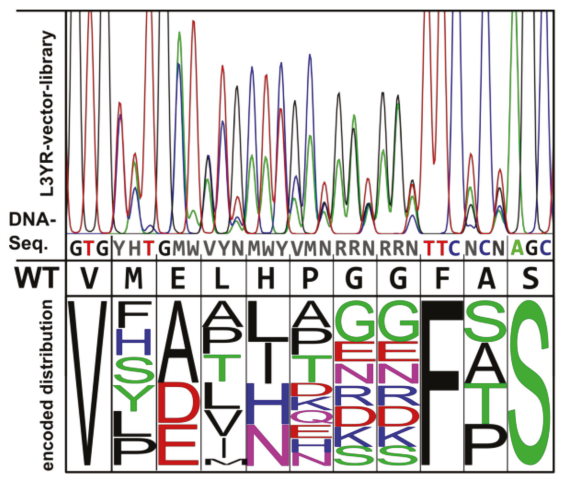

(a)

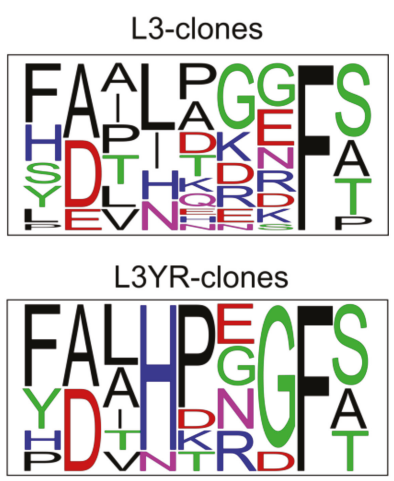

(b)

Figure 1. Cyclodextrin glucanotransferases (CGTase) library design and screening process. (a) Sequencing of the generated L3YR vector library. The protein sequence 80-90 of the CGTase G825-6 and the library of encoded residues and codon distributions are shown as the frequency of the sequences. (b) Logos of the sequence frequency of 22 variants from the L3, and of eight variants from the L3YR experiment. 


\subsection{Agar Plate Sceening of the CGTase Variants}

About 1350 E. coli BL21 clones of the L3 and 1550 clones of the L3YR experiment were screened plates for the specific detection of CD7, CD8, and starch-degrading activity (Figure S2). The majority of the L3 clones ( $>80 \%)$ synthesized CD7 and CD8 and about $10 \%$ of them in larger amounts as compared to the wild type (WT) CGTase indicated by the formation of larger halos around the colonies. Twenty-two clones from the L3 and eight clones from the L3YR experiments were selected and further characterized by isolating and sequencing the vector DNA followed by the recombinant expression and purification of the CGTase variants. SDS-PAGE analysis confirmed the high purity of the CGTase (Figure S3).

\subsection{Comparison of the CD Synthesis by the CGTase Variants}

To compare the synthesis of CD by the created L3 variants, their cyclic glucan products up to a size of CD12 were analyzed after $1 \mathrm{~h}$ and $24 \mathrm{~h}$ of reaction at $40^{\circ} \mathrm{C}$ and $50{ }^{\circ} \mathrm{C}$ (Figure 2). At a reaction time of $24 \mathrm{~h}$, the WT CGTase produced the maximum yield of the larger CD. After $1 \mathrm{~h}$ of reaction at $50{ }^{\circ} \mathrm{C}, 20$ of the $22 \mathrm{~L} 3$-variants showed higher yields of total CD (CD7 to CD12) compared to the WT CGTase. All variants except L3-8 also synthesized larger amounts of CD9 to CD12 (Figure 2a). After $24 \mathrm{~h}$ of reaction at $50{ }^{\circ} \mathrm{C}$, nine variants (L3-1 to L3-9) produced between 6.9 to $11.5 \mathrm{mg}$ CD7 to $\mathrm{CD} 12$, with a higher yield as the WT enzyme ( $6.4 \mathrm{mg}$ total $\mathrm{CD})$ corresponding to a substrate conversion of up to $58 \%$ (Figure $2 \mathrm{~b}$ ). While CD9 to CD12 made up $22 \%$ of the total CD synthesized by the WT enzyme, the variants L3-1, L3-3, L3-5 and L3-9 synthesized 38\%, 43\%, 47\% and 51\% CD9 to CD12 at $50{ }^{\circ} \mathrm{C}$, respectively. The loop randomization step was repeated with the CGTase G825-6 variant Y183R, which synthesized CD8 as the smallest $\mathrm{CD}$. The CD products were analyzed after $1 \mathrm{~h}$ (Figure 2c) and $24 \mathrm{~h}$ (Figure 2d) of reaction. The L3YR variants synthesized between $76 \%$ and $97 \%$ CD9 to CD12 after $1 \mathrm{~h}$ of reaction. CD9 to CD12 made up 58\% of its products after $24 \mathrm{~h}$ of reaction (Figure $2 \mathrm{~d}$ ). In contrast, the variants L3YR-6, L3YR-7 and L3YR-8 synthesized between $91 \%$ to $94 \%$ CD9 to CD12 at the same reaction conditions, however with a concomitant very low total $C D$ yield of 0.7 to $1.5 \mathrm{mg}$. At a reaction temperature of $40^{\circ} \mathrm{C}$, these three L3YR variants showed a similar total CD yield as Y183R after $1 \mathrm{~h}$ of reaction, but with a higher proportion of CD9 to CD12 (Figure 2e). After $24 \mathrm{~h}$ of reaction, the total amount of $\mathrm{CD}$ produced by L3YR- 8 at $40^{\circ} \mathrm{C}$ was three times higher compared to a synthesis performed at $50{ }^{\circ} \mathrm{C}$ indicating a destabilizing effect of the alterations at the loop structure of the enzyme (Figure 2f). The variant L3-2-M constructed by incorporating the mutation Y183R in the highly active variant L3-2 resulted in similar CD synthesis properties as displayed by L3YR-6, L3YR-7 and LRYR-8 (Figure 2d). 

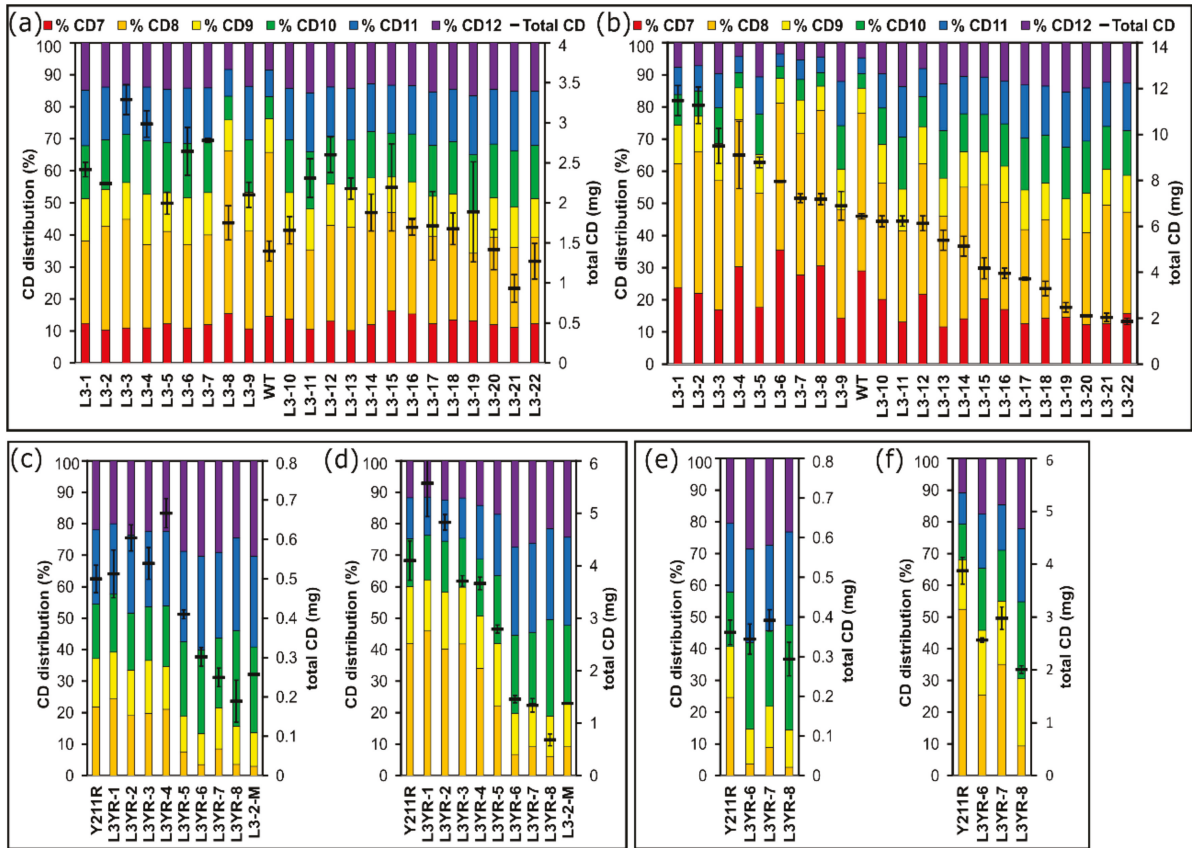

Figure 2. Synthesis of CD by the CGTase variants. The distribution of synthesized CD7 to CD12 is shown at the primary y-axis. The total amount of CD synthesized (CD6 to CD12) is shown at the secondary y-axis. The CD products of the CGTase G825-6 and the L3 variant enzymes obtained after $1 \mathrm{~h}$ (a) and $24 \mathrm{~h}$ (b) of reaction are shown. The CD products of the Y183R variant and of eight L3YR variant CGTases obtained after $1 \mathrm{~h} \mathrm{(c)} \mathrm{and} 24 \mathrm{~h} \mathrm{(d)} \mathrm{of} \mathrm{reaction} \mathrm{at} 50{ }^{\circ} \mathrm{C}$ are also shown. Selected enzymes were compared to $\mathrm{Y} 183 \mathrm{R}$ in a synthesis reaction at $40^{\circ} \mathrm{C}$ for $1 \mathrm{~h}(\mathbf{e})$ and $24 \mathrm{~h}(\mathbf{f})$. Mean values $(n=3) \pm$ S.D. are presented.

\subsection{Thermostability of the CGTase Variants}

The WT CGTase and the L3-6, L3-8 and L3-18 variants showed a temperature optimum for starch-degrading activity at $60{ }^{\circ} \mathrm{C}$ while L3-1, L3-2, L3-21, L3-22 displayed a lower temperature optimum at $50{ }^{\circ} \mathrm{C}$ (Figure 3a). The L3YR variants L3YR-2 and L3YR-5 had a similar temperature optimum compared to $\mathrm{Y} 183 \mathrm{R}$ at $60^{\circ} \mathrm{C}$, while the other L3YR variants showed an optimum temperature of $50{ }^{\circ} \mathrm{C}$ (Figure $3 \mathrm{~b}$ ). Among those, L3YR-6 displayed a residual activity of $81 \%$ after $2 \mathrm{~h}$ of incubation at $50{ }^{\circ} \mathrm{C}$ while no activity loss was observed for Y183R (Figure S4). A determination of the protein melting temperature by nano-DSF confirmed the significant lower thermostability of the L3 variants with a low total CD yield in contrast to highly active variants (L3-1) (Figure S5) (Table 1). While L3YR-1 displayed a similar thermostability as the Y183R CGTase, it was reduced in L3YR6, L3YR-7, L3YR-8 and L3-2M. 


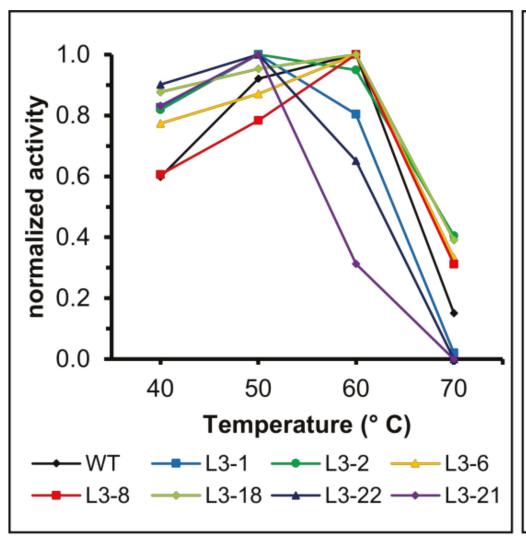

(a)

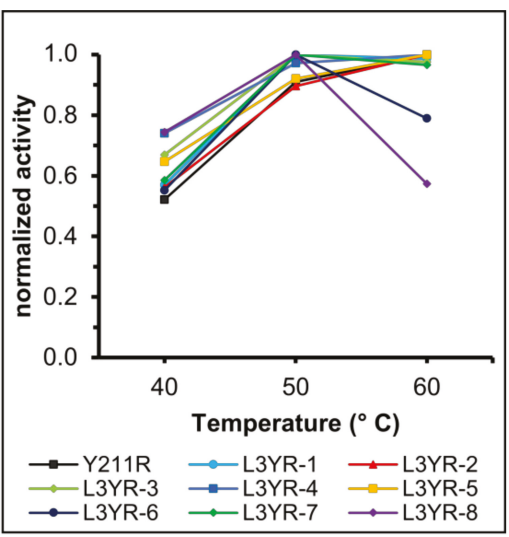

(b)

Figure 3. Temperature optimum of the CGTase variants. The starch-degrading activity of L3 variant enzymes (a) and L3YR variant enzymes (b) was determined between $40{ }^{\circ} \mathrm{C}$ and $70{ }^{\circ} \mathrm{C}$. Data represent mean values, $n=3$.

Table 1. Melting temperature ( $\left.T_{\mathrm{m}}\right)$ of L3 and L3YR CGTase variants determined by nano-DSF. Mean values $(n=3)$ are shown.

\begin{tabular}{cc}
\hline CGTase & Tm $\left({ }^{\circ} \mathbf{C}\right)$ \\
\hline WT & $58.7 \pm 0.19$ \\
L3-1 & $59.7 \pm 0.06$ \\
L3-18 & $58.3 \pm 0.08$ \\
L3-21 & $52.5 \pm 0.08$ \\
Y211R & $67.3 \pm 0.04$ \\
L3YR-1 & $66.3 \pm 0.08$ \\
L3YR-6 & $64.8 \pm 0.05$ \\
L3YR-7 & $62.7 \pm 0.05$ \\
L3YR-8 & $63.5 \pm 0.03$ \\
L3-2M & $59.9 \pm 0.14$ \\
\hline
\end{tabular}

\section{Discussion}

Previously we had engineered the CGTase G825-6 variant Y183R, which produced a high yield of large-ring CD without concomitant formation of CD6 and CD7 [23]. However, its total CD synthesis activity was strongly decreased. To reconstitute its activity, we aimed to modify the enzyme near its substrate binding site by a semi-rational mutagenesis approach. We focused on a loop structure of the protein involved in substrate binding composed of the amino acid residues 81-89 (Figure 4). This region has been previously suggested to control the CD product specificity of CGTases $[25,26]$. Indeed, the loop structure of CGTases mainly synthesizing CD6 or CD7 (Figure 4a) was different from CGTases with CD8 as the main product (Figure 4b,c). Since the residue F88 in the CGTase G825-6 plays an important role in its product specificity for CD8, it was kept constant while the surrounding residues were targeted for mutagenesis (Figure S6). 


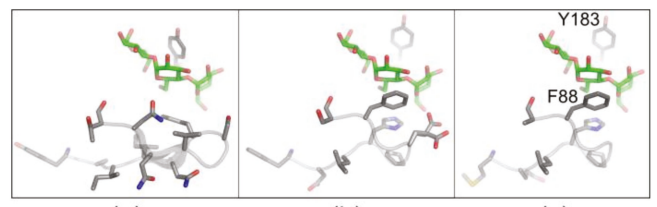

(a)

(b)

(c)

Figure 4. Structure of the L3 loop in different CGTases. X-ray structures from (a) B. circulans 251 CGTase (PDB: 1CXK), (b) B. clarkii CGTase (PDB: 4JCM) and (c) a model of the CGTase G825-6 based on the PDB structure 4JCM are shown.

\subsection{High Fitness of the CGTase Variant Library}

Based on the multiple sequence alignments performed, the limited selection of residues used for the design of the variant library reduced the number of possibly translated protein sequences by a factor of $\sim 6 \times 10^{5}$ to 0.9 million sequences. The resulting library not only encoded for the majority of amino acid residues occurring in WT CGTases, but also included a set of residues not found in CGTases within the corresponding loop structure (Figure S1, Figure 1a). The residues D, E, K and R were encoded to allow for the formation of salt bridges with other loop regions to stabilize the binding pocket, since previous studies have shown that a crosslinking of CGTases increases their catalytic efficiency [27-29]. The residues D, E and P were encoded to destabilize a $\beta$-sheet formation of the loop (Figure 5) with the aim to increase its flexibility [30,31]. Since stabilizing the loop or making it more flexible was expected to influence the CD product specificity, the library was designed to allow both possibilities.

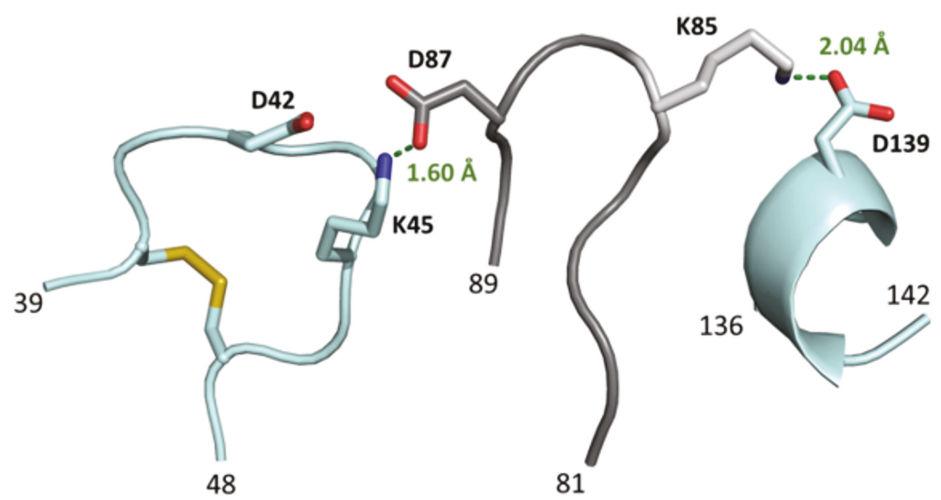

Figure 5. Potential salt bridges between loop elements in the CGTase variants. A model of residues encoded in the L3 library (positions 81-89) predicted to form salt bridges with residues from the adjacent loops $39-48$ and $136-142$ is shown. The residues D, E, R and K encoded in the library design at position 87 are in close range to K45 and D42 and could form a salt bridge between these loops. K85 may form a salt bridge with D139, located on a neighboring loop.

Instead of a classical directed evolution approach performing small adaptive walks in an imaginary fitness landscape [32], the library design set a high mutation frequency within a narrow sequence window to cover a large sequence space simultaneously. By this strategy, a large set of combinations could be tested for a small sequence element like a loop, while keeping the remaining structure intact. This allowed screening for combinatorial effects that had a beneficial outcome regarding the catalytic activity or product specificity of the CGTase.

In comparison to other loop saturation experiments [33,34], the high fitness of the L3 semi-randomized library can be attributed to several factors, which ensured loop compositions with a 
high proportion of active variants: (i) The sufficient distance of the mutagenesis target site to avoid a direct interference with the catalytic triad, (ii) the choice of encoded residues deduced from multiple sequence alignments and (iii) the low conservation of this loop. Furthermore, the introduction of ionic residues should promote synergistic effects by electrostatic interactions between different residues of the loop [35]. Three of the randomized codons encoded amino acid residues with an equal distribution (YHT, MWY, NCN), while for the other randomized codons the ratio of the most abundant to the rarest amino acid encoded was 2:1, except for VYN (4:1). Therefore, only a minor encoded bias occurred in the library.

\subsection{Selection of CGTase Variants with Changed CD Product Specificity}

By screening for either CD7 or CD8 and of starch-degrading activity in a semi-quantitative agar plate assay, CGTase variants synthesizing CD7 or CD8 in amounts relative to their starch-degrading activity could be selected in parallel (Figure S2). Despite coverage of less than $0.1 \%$ of the L3 library, this screening method resulted in the identification of variants with a changed CD product specificity demonstrating the validity of the library design. The L3 variants showed a distribution of amino acid residues similar to the encoded library indicating that certain residues were not preferred among the 22 L3 variants (Figure 1a,b). In the L3YR clones $(n=8)$, residues H84 and G87 occurred in 7 out of 8 protein sequences of the variants, indicating their importance for the synthesis of CD in the presence of the substitution Y183R. Interestingly, L3YR-1, L3YR-2 and L3YR-3 had the sequence 83-LHPXG-87 with $\mathrm{X}=\mathrm{E}$ or G, similar to the CGTase G825-6 and a CGTase of Bacillus clarkii. In fact, the sequences of the variants L3YR-1 and L3-8 were identical to the CGTase from B. clarkii (Figure S1). The sequence 81-YALHP of variant L3YR-2 was also found in the protein sequences of other WT CGTases (Figure S1). This suggests that the naturally evolved loop sequence efficiently compensated alterations of the centrally located Y183 residue resulting in active enzyme variants. While the number of investigated variants was too small to draw definitive conclusions, we consider these sequences as interesting targets for further site-directed mutagenesis experiments.

\subsection{Variants Synthesizing High Yields of Large-Ring CD}

The incorporated mutations resulted in a set of variants, which produced high proportions of CD9 to CD12 (Figure 2). The variant L3-8, carrying the B. clarkii CGTase/G825-6 CGTase loop consensus sequence 83-LHP-85 showed the same composition of its CD products as the WT enzyme, indicating that this sequence could be involved in the suppression of the synthesis of larger CD. L3YR variants with the composition 83-LHPGG or LHPEG, corresponding to the sequences of the $B$. clarkii CGTase/G825-6, synthesized a similar proportion of large-ring CD compared to Y183R. In contrast, L3YR-6, L3YR-7, L3YR 8 and L3-2M showed a strongly decreased synthesis of CD8. Whether these changes were caused by the alteration of the sequence $83-\mathrm{LHP}$, the position 86 or by a combination of both remains ambiguous. The CD yield of these variants increased at lower reaction temperatures, indicating that they were less thermostable compared to the WT CGTase.

From 18 possible combinations of FA, FD and YA of the loop amino acid residues 81 and 82, 16 were present in the 30 variant sequences and represent combinations also found in WT CGTases (Table S1, Figure S1). When the altered sequence of variant L3-2 was cloned into Y183R, the resulting variant L3-2M showed similar properties as L3YR-6, L3YR-7 and L3YR-8 (Figure 2d). The replacement of $Y$ at position 183 with $R$ resulted in the synthesis of almost only large-ring CD composed of CD9 to CD12, however concomitant with a decreased overall CD yield.

The most efficient variants from the L3 experiment displayed $\mathrm{E}, \mathrm{R}$ or $\mathrm{K}$ at position 87, amino acids able to electrostatic interaction with D42 and K45 of the nearby loop. Variant L3-3 with K85 and E87 possibly formed salt bridges between loop 81-89, loop 39-48 and loop 136-142 (Figure 5). All three loops were positioned near the binding site and have been reported to contribute to the activity and CD product specificity of the CGTase $[11,36,37]$. Accordingly, our results also indicate that a stabilization of the loop resulted in an increased synthesis of large-ring CD. However, less efficient L3 variants 
likewise had E, D and $\mathrm{K}$ at position 87 , indicating that surrounding residues also contribute to the observed changes in CD synthesis and enzyme stability.

\subsection{The L3 Loop Contributes to the Thermal Stability of the CGTase}

Several L3YR variants showed high CD synthesis activities within $1 \mathrm{~h}$ of reaction, which were significantly lower after $24 \mathrm{~h}$, suggesting a thermal inactivation of the enzyme during longer reaction times, due to the altered loop (Figure S4). A determination of the thermal stability and optimum temperature of the variant enzymes confirmed this assumption. The variants L3YR-6, L3YR-7 and L3YR-8 showed a lower $T_{M}$ and optimum temperature compared to the WT enzyme (Figure 3). When the $\mathrm{CD}$ synthesis reaction with these variants was performed at $40{ }^{\circ} \mathrm{C}$, these L3YR variants indeed showed a 1.8 to 2.9 -fold higher yield of total $\mathrm{CD}$ compared to $50^{\circ} \mathrm{C}$ (Figure 2e,f).

\section{Materials and Methods}

\subsection{Generation of the Vector Library}

A CGTase expression system in E. coli based on a pET20b+ vector harboring an expression cassette encoding for a mature CGTase from the alkaliphilic Bacillus sp. G825-6 with an N-terminal DacD signal peptide was used [38]. A partially randomized megaprimer 5'-agc ccg ccg att gaa aat gtg yht gmw vyn nmy vmn rrn rrn ttc ncn age tat cat gge tat tgg gge was amplified by PCR (Phusion HF Kit, New England Biolabs, Frankfurt, Germany,) using primers hybridizing to the flanking sites to generate a dsDNA megaprimer. The randomized ssDNA primer $(1 \mathrm{pmol})$ was added as a template for a $50 \mu \mathrm{L}$ PCR reaction for 30 cycles according to the supplier's manual. The product was purified by agarose gel electrophoresis. The megaprimer DNA and the template vector pET20b(+):dacD-cgt was used in a molar ratio of 10:1 in a second PCR reaction (18 cycles, $\left.\mathrm{T}_{\text {Anneal }}: 60^{\circ} \mathrm{C}\right)$. The product designated pET20b(+):dacD-cgt-L3 was digested with DpnI and ultracompetent E. coli XL10-Gold cells (New England Biolabs, Frankfurt, Germany) were used for transformation [39]. After $1 \mathrm{~h}$, an aliquot $\left(50 \mu \mathrm{L}\right.$ ) was plated on LB agar plates containing $70 \mu \mathrm{g} \mathrm{mL} \mathrm{m}^{-1}$ ampicillin (LB-amp), and the residual cells were further incubated for $12 \mathrm{~h}$ before harvesting the cells. Plasmids were extracted to obtain the L3 vector library and used for the transformation of E. coli BL21 (DE3). The procedure was repeated with a mutated version of the vector encoding the CGTase G825-6 with the substitution Y183R to generate the L3YR vector library.

\subsection{Agar Plate Screening}

Single colonies of E. coli BL21(DE3) pET20b(+):dacD-cgt-L3 were transferred to LB-amp, congo red [40], and phenolphthalein (LB agar pH 7.4, $40 \mathrm{mg} \mathrm{L}^{-1}$ phenolphthalein) agar plates [41]. Both congo red and phenolphthalein agar plates were supplemented with $10 \mathrm{~g} \mathrm{~L}^{-1}$ soluble starch and $70 \mu \mathrm{g} \mathrm{mL} \mathrm{m}^{-1}$ ampicillin. Plates for the L3 experiment were incubated at $37^{\circ} \mathrm{C}$ for $24 \mathrm{~h}$. For the screening of the L3YR clones the congo red plates were transferred after $14 \mathrm{~h}$ from $37^{\circ} \mathrm{C}$ to $50^{\circ} \mathrm{C}$ and further incubated for $8 \mathrm{~h}$. The size of the halos formed on the congo red plates was estimated after 14 $\mathrm{h}$ and $24 \mathrm{~h}$ of incubation. Subsequently, starch-degrading activity was visualized by covering the congo red plates with $1 \%(w / w)$ Lugol's solution and halo formation were estimated after $1 \mathrm{~min}$. After $24 \mathrm{~h}$ of incubation, the phenolphthalein plates were overlayed with a solution containing $1 \mathrm{M}$ $\mathrm{NaOH}, 0.1 \mathrm{M}$ glycine, $1 \mathrm{M} \mathrm{NaCl}$. After $1 \mathrm{~min}$ of incubation the size of the halos was estimated. 28 clones were picked per plate. Each plate contained two clones for the positive control E. coli BL21(DE3) pET20b(+):dacD-cgt, a second positive control encoding the G825-CGTase variant D358R with low CD7and CD8-synthesizing activity, and a negative control (E. coli BL21(DE3) pET20b(+):tfcut, encoding a cutinase [42]). 


\subsection{Recombinant Protein Production and Analysis}

Positive clones were repeatedly screened, and selected clones were used for expression of the proteins in $50 \mathrm{~mL}$ cultures. The enzyme in the extracellular fraction was purified by starch adsorption [38]. The starch-degrading activity and the protein concentration of the purified enzyme variants were determined, as previously described [38].

\subsection{Synthesis and Analysis}

For the determination of the product spectrum synthesized by the CGTase variants, $0.2 \mu \mathrm{g}$ purified protein $\left(0.4 \mu \mathrm{g}\right.$ for the L3YR variants) was added to a $20 \mathrm{~g} \mathrm{~L}^{-1}$ soluble starch substrate (soluble potato starch, CAS9005-84-9; Merck KGaA, Darmstadt, Germany) in a total volume of $1 \mathrm{~mL}$. Reactions were performed at $40{ }^{\circ} \mathrm{C}$ and $50{ }^{\circ} \mathrm{C}$ in $25 \mathrm{mM}$ Tris- $\mathrm{HCl} \mathrm{pH} 8.5$ containing $10 \mathrm{mM} \mathrm{KCl}$ and $5 \mathrm{mM} \mathrm{MgCl}_{2}$. Samples were analyzed by high pressure anion exchange chromatography with pulsed amperometric detection after $1 \mathrm{~h}$ and $24 \mathrm{~h}$ of reaction [23].

\subsection{Determination of Temperature Optimum and Thermostability of the Variants}

The temperature optimum of the variants was determined by measuring their starch-degrading activity between $40{ }^{\circ} \mathrm{C}$ and $70{ }^{\circ} \mathrm{C}$ [38]. The thermostability of Y211R and L3YR-6 was analyzed by determining its residual activity after incubation of the enzyme solution at $50{ }^{\circ} \mathrm{C}$ for $2 \mathrm{~h}$. Nano differential scanning fluorimetry (nano-DSF) (Prometheus NT.48, Nanotemper Technologies, Munich, Germany) based on the tryptophan fluorescence ratio $350 / 330 \mathrm{~nm}\left(20^{\circ} \mathrm{C}\right.$ to $95{ }^{\circ} \mathrm{C}$ with $\left.1{ }^{\circ} \mathrm{C} / \mathrm{min}\right)$ was used to determine the melting temperature $\left(\mathrm{T}_{\mathrm{m}}\right)$ of the proteins, which were calculated by first derivative analysis.

\subsection{Protein Sequence Alignments and Molecular Modeling}

Protein sequences from 30 CGTases were obtained from the National Center of Biotechnology Information (www.ncbi.nlm.nih.gov; accession numbers in Table S1) and compared to the CGTase G825-6 sequence [43] using a clustalW algorithm implemented in the homology software MEGA, version 6.06 [44]. Based on the X-ray structure of the CGTase from Bacillus clarkii (PDB:4JCM), obtained from the Protein Data Bank (PDB) (www.rcsb.org), structure homology modeling was performed using the SWISS-MODEL platform [45,46]. The PyMOL molecular graphic system (v0.99, Schrödinger, LCC) was used to model amino acid substitutions. The superimposed structure of a maltononaose substrate was derived from PDB:1CXK [47].

\section{Conclusions}

A strongly compressed library with high fitness was constructed using a semi-rational design for the alteration of the CD synthesis activity of a CGTase. The screening method based on three different markers allowed both the selection for variants with changed CD synthesis activity and CD product specificity. With this approach, we were able to screen a reasonable small number of clones to obtain CGTase variants synthesizing preferentially large-ring CD. This approach resulted in enzyme variants producing three times higher total amounts of CD7 to CD12 with a high proportion of CD9 and CD12. Some of the variants even synthesized almost solely CD10, CD11 and CD12. The results demonstrate that by semi-rational design, CGTase variants specifically producing these large-ring $\mathrm{CD}$ can be generated providing a previously difficult to access group of novel host molecules in supramolecular complexing reactions.

Supplementary Materials: Supplementary Materials are available online at http:/ / www.mdpi.com/2073-4344/ 9/3/242/s1, Table S1: Accession numbers for the sequences used in the multiple protein alignment, Figure S1: Multiple sequence alignment of CGTases and library design, Figure S2: Agar plate screening of L3 clones for CD7 and CD8 synthesis activity, and starch-degrading activity, Figure S3: SDS-PAGE of purified L3 and L3YR variants, Figure S4: Thermal stability of variant Y183R and L3YR-6, Figure S5: Nano-DSF melting curves. Figure S6: Influence of residue 88 on the CD product share. 
Author Contributions: Conceptualization, C.S. and W.Z.; Funding acquisition, C.S. and W.Z.; Methodology, C.S.; Supervision, W.Z.; Validation, C.S.; Writing—original draft, C.S.; Writing—review and editing, W.Z.

Funding: C.S. was supported by the European Social Fund (project nr. 100234741).

Acknowledgments: Norbert Sträter from Leipzig University is acknowledged for his support in the determination of the melting points of the enzymes.

Conflicts of Interest: The authors declare no conflict of interest.

\section{References}

1. Cobb, R.E.; Chao, R.; Zhao, H. Directed evolution: Past, present and future. AIChE J. 2013, 59, 1432-1440. [CrossRef] [PubMed]

2. Dalby, P.A. Strategy and success for the directed evolution of enzymes. Curr. Opin. Struct. Biol. 2011, 21, 473-480. [CrossRef] [PubMed]

3. Hsieh, P.-C.; Vaisvila, R. Protein engineering: Single or multiple site-directed mutagenesis. Methods Mol. Biol. 2013, 978, 173-186. [CrossRef] [PubMed]

4. Chica, R.A.; Doucet, N.; Pelletier, J.N. Semi-rational approaches to engineering enzyme activity: Combining the benefits of directed evolution and rational design. Curr. Opin. Biotechnol. 2005, 16, 378-384. [CrossRef] [PubMed]

5. Patrick, W.M.; Firth, A.E. Strategies and computational tools for improving randomized protein libraries. Biomol. Eng. 2005, 22, 105-112. [CrossRef] [PubMed]

6. Lutz, S. Beyond directed evolution-semi-rational protein engineering and design. Curr. Opin. Biotechnol. 2010, 21, 734-743. [CrossRef] [PubMed]

7. Chen, M.M.Y.; Snow, C.D.; Vizcarra, C.L.; Mayo, S.L.; Arnold, F.H. Comparison of random mutagenesis and semi-rational designed libraries for improved cytochrome P450 BM3-catalyzed hydroxylation of small alkanes. Protein Eng. Des. Sel. 2012, 25, 171-178. [CrossRef] [PubMed]

8. Tang, L.; Gao, H.; Zhu, X.; Wang, X.; Zhou, M.; Jiang, R. Construction of "small-intelligent" focused mutagenesis libraries using well-designed combinatorial degenerate primers. BioTechniques 2012, 52, 149-158. [CrossRef] [PubMed]

9. DePinto, J.A.; Campbell, L.L. Purification and properties of the amylase of Bacillus macerans. Biochemistry 1968, 7, 114-120. [CrossRef] [PubMed]

10. Qi, Q.; Zimmermann, W. Cyclodextrin glucanotransferase: From gene to applications. Appl. Microbiol. Biotechnol. 2005, 66, 475-485. [CrossRef] [PubMed]

11. Uitdehaag, J.C.; Kalk, K.H.; van der Veen, B.A.; Dijkhuizen, L.; Dijkstra, B.W. The cyclization mechanism of cyclodextrin glycosyltransferase (CGTase) as revealed by a gamma-cyclodextrin-CGTase complex at 1.8-A resolution. J. Biol. Chem. 1999, 274, 34868-34876. [CrossRef] [PubMed]

12. Del Valle, E. Cyclodextrins and their uses: A review. Process Biochem. 2004, 39, 1033-1046. [CrossRef]

13. Endo, T.; Nagase, H.; Ueda, H.; Kobayashi, S.; Nagai, T. Isolation, purification, and characterization of cyclomaltodecaose (.EPSILON.-Cyclodextrin), cyclomaltoundecaose (.ZETA.-Cyclodextrin) and cyclomaltotridecaose (.THETA.-Cyclodextrin). Chem. Pharm. Bull. 1997, 45, 532-536. [CrossRef]

14. Larsen, K.L.; Endo, T.; Ueda, H.; Zimmermann, W. Inclusion complex formation constants of $\alpha_{--}, \beta_{-}^{-}, \gamma_{-}^{-}, \delta_{-}^{-,} \varepsilon_{-}^{-}$, $\zeta-, \eta$ - and $\theta$-cyclodextrins determined with capillary zone electrophoresis. Carbohydr. Res. 1998, 309, 153-159. [CrossRef]

15. Ueda, H.; Endo, T. Large-ring cyclodextrins. In Cyclodextrins and Their Complexes: Chemistry, Analytical Methods, Applications; Dodziuk, H., Ed.; Wiley-VCH: Weinheim, Germany, 2006; pp. 370-380. ISBN 9783527608980.

16. Akasaka, H.; Endo, T.; Nagase, H.; Ueda, H.; Kobayashi, S. Complex formation of cyclomaltononaose delta-cyclodextrin (delta-CD) with macrocyclic compounds. Chem. Pharm. Bull. 2000, 48, 1986-1989. [CrossRef] [PubMed]

17. Dodziuk, H.; Ejchart, A.; Anczewski, W.; Ueda, H.; Krinichnaya, E.; Dolgonos, G.; Kutner, W. Water solubilization, determination of the number of different types of single-wall carbon nanotubes and their partial separation with respect to diameters by complexation with $\eta$-cyclodextrin. Chem. Commun. 2003, 9, 986-987. [CrossRef]

18. Assaf, K.I.; Gabel, D.; Zimmermann, W.; Nau, W.M. High-affinity host-guest chemistry of large-ring cyclodextrins. Org. Biomol. Chem. 2016, 14, 7702-7706. [CrossRef] [PubMed] 
19. Terada, Y.; Yanase, M.; Takata, H.; Takaha, T.; Okada, S. Cyclodextrins are not the major cyclic alpha-1,4-glucans produced by the initial action of cyclodextrin glucanotransferase on amylose. J. Biol. Chem. 1997, 272, 15729-15733. [CrossRef] [PubMed]

20. Li, Z.; Wang, M.; Wang, F.; Gu, Z.; Du, G.; Wu, J.; Chen, J. Gamma-cyclodextrin: A review on enzymatic production and applications. Appl. Microbiol. Biotechnol. 2007, 77, 245-255. [CrossRef] [PubMed]

21. Terada, Y.; Sanbe, H.; Takaha, T.; Kitahata, S.; Koizumi, K.; Okada, S. Comparative study of the cyclization reactions of three bacterial cyclomaltodextrin glucanotransferases. Appl. Environ. Microbiol. 2001, 67, 1453-1460. [CrossRef] [PubMed]

22. Han, R.; Li, J.; Shin, H.-D.; Chen, R.R.; Du, G.; Liu, L.; Chen, J. Recent advances in discovery, heterologous expression, and molecular engineering of cyclodextrin glycosyltransferase for versatile applications. Biotechnol. Adv. 2014, 32, 415-428. [CrossRef] [PubMed]

23. Sonnendecker, C.; Melzer, S.; Zimmermann, W. Engineered cyclodextrin glucanotransferases from Bacillus sp. G-825-6 produce large-ring cyclodextrins with high specificity. Microbiologyopen 2018, e757. [CrossRef] [PubMed]

24. Sonnendecker, C.; Zimmermann, W. Domain shuffling of cyclodextrin glucanotransferases for tailored product specificity and thermal stability. FEBS Open Bio 2019, 9, 384-395. [CrossRef] [PubMed]

25. Kim, Y.H.; Bae, K.H.; Kim, T.J.; Park, K.H.; Lee, H.S.; Byun, S.M. Effect on product specificity of cyclodextrin glycosyltransferase by site-directed mutagenesis. Biochem. Mol. Biol. Int. 1997, 41, 227-234. [CrossRef] [PubMed]

26. Goh, K.M.; Mahadi, N.M.; Hassan, O.; Rahman, R.N.Z.R.A.; Illias, R.M. A predominant $\beta$-CGTase G1 engineered to elucidate the relationship between protein structure and product specificity. J. Mol. Catal. B Enzym. 2009, 57, 270-277. [CrossRef]

27. Kumar, S.; Nussinov, R. Close-range electrostatic interactions in proteins. ChemBioChem 2002, 3, 604. [CrossRef]

28. Kaulpiboon, J.; Pongsawasdi, P.; Zimmermann, W. Molecular imprinting of cyclodextrin glycosyltransferases from Paenibacillus sp. A11 and Bacillus macerans with gamma-cyclodextrin. FEBS J. 2007, 274, 1001-1010. [CrossRef] [PubMed]

29. Kaulpiboon, J.; Pongsawasdi, P.; Zimmermann, W. Altered product specificity of a cyclodextrin glycosyltransferase by molecular imprinting with cyclomaltododecaose. J. Mol. Recognit. 2010, 23, 480-485. [CrossRef] [PubMed]

30. Chou, P.Y.; Fasman, G.D. Prediction of the secondary structure of proteins from their amino acid sequence. Adv. Enzymol. Relat. Areas Mol. Biol. 1978, 47, 45-148. [CrossRef] [PubMed]

31. Leemhuis, H.; Rozeboom, H.J.; Dijkstra, B.W.; Dijkhuizen, L. Improved thermostability of bacillus circulans cyclodextrin glycosyltransferase by the introduction of a salt bridge. Proteins 2004, 54, 128-134. [CrossRef] [PubMed]

32. Gillespie, J.H. Molecular evolution over the mutational landscape. Evolution 1984, 38, 1116-1129. [CrossRef] [PubMed]

33. Hörtnagel, K.; Voloshin, O.N.; Kinal, H.H.; Ma, N.; Schaffer-Judge, C.; Camerini-Otero, R.D. Saturation mutagenesis of the E. coli RecA loop L2 homologous DNA pairing region reveals residues essential for recombination and recombinational repair. J. Mol. Biol. 1999, 286, 1097-1106. [CrossRef] [PubMed]

34. Duenas-Decamp, M.; Jiang, L.; Bolon, D.; Clapham, P.R. Saturation mutagenesis of the HIV-1 envelope CD4 binding loop reveals residues controlling distinct trimer conformations. PLoS Pathog. 2016, 12, e1005988. [CrossRef] [PubMed]

35. Lehmann, M.; Wyss, M. Engineering proteins for thermostability: The use of sequence alignments versus rational design and directed evolution. Curr. Opin. Biotechnol. 2001, 12, 371-375. [CrossRef]

36. Parsiegla, G.; Schmidt, A.K.; Schulz, G.E. Substrate binding to a cyclodextrin glycosyltransferase and mutations increasing the gamma-cyclodextrin production. Eur. J. Biochem. 1998, 255, 710-717. [CrossRef] [PubMed]

37. Leemhuis, H.; Kelly, R.M.; Dijkhuizen, L. Engineering of cyclodextrin glucanotransferases and the impact for biotechnological applications. Appl. Microbiol. Biotechnol. 2010, 85, 823-835. [CrossRef] [PubMed]

38. Sonnendecker, C.; Wei, R.; Kurze, E.; Wang, J.; Oeser, T.; Zimmermann, W. Efficient extracellular recombinant production and purification of a Bacillus cyclodextrin glucanotransferase in E. coli. Microb. Cell. Fact. 2017, 16, 87. [CrossRef] [PubMed] 
39. Sambrook, J.; Russell, D.W. The inoue method for preparation and transformation of competent e. Coli: "ultra-competent" cells. CSH Protoc. 2006, 2006. [CrossRef] [PubMed]

40. Hamaker, K.; Tao, B.Y. Screening of Gamma Cyclodextrin-Producing Recombinant E. coli using congo red dye on solid complex media. Starch/Stärke 1993, 45, 181-182. [CrossRef]

41. Park, C.S.; Park, K.H.; Kim, S.H. A rapid screening method for alkaline BETA-cyclodextrin glucanotransferase using phenolphthalein-methyl orange-containing-solid medium. Agric. Niol. Chem. 1989, 53, 1167-1169. [CrossRef]

42. Oeser, T.; Wei, R.; Baumgarten, T.; Billig, S.; Föllner, C.; Zimmermann, W. High level expression of a hydrophobic poly (ethylene terephthalate)-hydrolyzing carboxylesterase from Thermobifida fusca KW3 in E. coli BL21(DE3). J. Biotechnol. 2010, 146, 100-104. [CrossRef] [PubMed]

43. Melzer, S.; Sonnendecker, C.; Föllner, C.; Zimmermann, W. Stepwise error-prone PCR and DNA shuffling changed the $\mathrm{pH}$ activity range and product specificity of the cyclodextrin glucanotransferase from an alkaliphilic Bacillus sp. FEBS Open Bio 2015, 5, 528-534. [CrossRef] [PubMed]

44. Tamura, K.; Stecher, G.; Peterson, D.; Filipski, A.; Kumar, S. MEGA6: Molecular evolutionary genetics analysis version 6.0. Mol. Biol. Evol. 2013, 30, 2725-2729. [CrossRef] [PubMed]

45. Guex, N.; Peitsch, M.C.; Schwede, T. Automated comparative protein structure modeling with SWISS-MODEL and Swiss-PdbViewer: A historical perspective. Electrophoresis 2009, 30, S162-S173. [CrossRef] [PubMed]

46. Biasini, M.; Bienert, S.; Waterhouse, A.; Arnold, K.; Studer, G.; Schmidt, T.; Kiefer, F.; Gallo Cassarino, T.; Bertoni, M.; Bordoli, L.; et al. SWISS-MODEL: Modelling protein tertiary and quaternary structure using evolutionary information. Nucleic Acids Res. 2014, 42, W252-W258. [CrossRef] [PubMed]

47. Uitdehaag, J.C.; Mosi, R.; Kalk, K.H.; van der Veen, B.A.; Dijkhuizen, L.; Withers, S.G.; Dijkstra, B.W. X-ray structures along the reaction pathway of cyclodextrin glycosyltransferase elucidate catalysis in the alpha-amylase family. Nat. Struct. Biol. 1999, 6, 432-436. [CrossRef] [PubMed]

(C) 2019 by the authors. Licensee MDPI, Basel, Switzerland. This article is an open access article distributed under the terms and conditions of the Creative Commons Attribution (CC BY) license (http:/ / creativecommons.org/licenses/by/4.0/). 
Article

\title{
Low-Level Organic Solvents Improve Multienzyme Whole-Cell Catalytic Synthesis of Myricetin-7-O-Glucuronide
}

\author{
Yan Yang ${ }^{1,2}$, Min-Zhi Liu ${ }^{2}$, Yun-Song Cao ${ }^{2}$, Chang-Kun Li $^{3}$ and Wei Wang ${ }^{1,2, *}$ \\ 1 State Key Laboratory of Bioactive Substance and Function of Natural Medicines, Institute of Materia Medica, \\ Chinese Academy of Medical Sciences \& Peking Union Medical College, Beijing 100050, China; \\ yangyan@imm.ac.cn \\ 2 Key Laboratory of Biosynthesis of Natural Products of National Health Commission of the People's Republic \\ of China, Institute of Materia Medica, Chinese Academy of Medical Sciences \& Peking Union Medical \\ College, Beijing 100050, China; lmzluoxue@imm.ac.cn (M.-Z.L.); caoyunsong@imm.ac.cn (Y.-S.C.) \\ 3 Beijing Branch, Shimadzu (China) Co. Ltd., Beijing 100020, China; fxlck@shimadzu.com.cn \\ * Correspondence: wwang@imm.ac.cn; Tel.: +86-10-631-65196
}

Received: 18 October 2019; Accepted: 15 November 2019; Published: 18 November 2019

\begin{abstract}
Multienzyme whole-cell biocatalysts are preferred in industrial applications, and two major concerns regarding the use of these biocatalysts, cell viability and cell membrane integrity, must be addressed. In this work, the transformation of myricetin to myricetin-7-O-glucuronide catalyzed by an engineered Escherichia coli strain was taken as the model reaction to examine the impacts of low-level organic solvents on whole-cell biocatalysis. Low-level organic solvents $(2 \%, v / v)$ showed a significant increase (roughly 13-fold) in myricetin-7-O-glucuronide yields. No obvious compromises of cellular viability and integrity were observed by a flow cytometry assay or in the determination of extracellular protein leakage, suggesting the addition of low-level organic solvents accommodates whole E. coli cells. Furthermore, a scaled-up reaction was conducted to test the capability and efficiency of whole-cell catalysis in the presence of organic solvents. This study presents a promising and simple means to enhance the productivity of multienzyme whole-cell catalysis without losing the barrier functions of the cell membrane.
\end{abstract}

Keywords: engineered Escherichia coli; flavonoid glucuronides; multienzyme whole-cell biocatalyst; organic solvents

\section{Introduction}

Multistep whole-cell catalysis is becoming a fast-developing area in the field of biocatalysis [1,2]. A single, tailored, whole-cell biocatalyst containing all of the required enzymes not only offers a high degree of selectivity, including regio-, stereo-and enantio-selectivity [3,4], but is also superior to in vitro enzyme biotransformation, as it circumvents cell lysis, enzyme purification, and the addition of external cofactors (e.g., $\mathrm{NAD}(\mathrm{P}) \mathrm{H}$ and ATP). In addition to these capacities, microbial cells provide a protective environment for enzymes, preventing conformational changes from occurring in the protein structure in non-conventional media or under harsh reaction conditions $[1,5]$.

Whole-cell biocatalysts have been widely used as an excellent alternative means to directly convert different substrates into fine chemicals [2,6], but they are generally less efficient than reactions catalyzed by isolated enzymes by a factor of one or two orders of magnitude [7,8]. The most prominent limitations are unimpeded transport of the substrate into and the final product out of the cell [8]. Since hydrophobic substrates can enter cells through passive diffusion [9], the solubility of substrates is generally considered a limiting factor, and the permeability of the cell membrane as a 
mass transfer barrier is a most common concern for whole-cell bioprocesses. Although many chemical (e.g., by adding detergents or solvents) and physical (e.g., temperature shock) treatments are used to improve the permeability of cell membranes, they may compromise cell integrity, spur the leakage of cellular components (e.g., diffusional loss of NAD(P)H), and affect downstream processes [10]. Given the attractive advantages of conventional water-miscible organic solvents, including their simple management, high solubility for various organic substances, and capacities to improve the enantio-selectivity and activity of biocatalysts [11,12], organic solvents have been used as "cosolvents" and "permeability enhancers" to stimulate substrate transfer across cells [7,10], but the choice and amount of added organic solvent are highly empirical and generally undesirable for large-scale applications [13]. In most single-enzyme whole-cell catalytic processes, dimethyl sulfoxide (DMSO) and methanol $(\mathrm{MeOH})$ are commonly used as solubility enhancers to promote the biosynthesis of glycosides and hydrophobic compounds [14,15]. The use of a recombinant single enzyme overexpressed in Escherichia coli is employed as a whole-cell biocatalyst treated with $60 \%$ acetone $(v / v)$ [16] or $10 \%$ ethanol (EtOH) [11] to enhance the permeabilization of cell membranes and, further, to promote high yields of L-phenylalanine and L-menthol.

Although the above studies have demonstrated that organic solvents are effective in enhancing the yields of whole-cell reactions by affecting substrate solubility or cellular permeability, a widespread means to balance the contradiction between reducing barrier-like actions and maintaining the integrity of the cell membrane remain elusive. In addition, the presence of an intact cell is required for whole-cell catalysis, and especially for multienzyme whole-cell reactions coupled with the (re)generation of cofactors and energy molecules. While adaptation of bacterial cells to the organic solvent is an important issue to be addressed $[17,18]$, little attention has been paid to the lesser negative effects on cell survival and membrane integrity resulting from the use of low-level organic solvents that can affect bioconversion efficiency. Indeed, biocatalytic systems, especially whole-cell ones, can be very sensitive to organic solvents.

In this study, an engineered E. coli BPGUT [19] performing the multienzyme cascade biosynthesis of a uridine diphosphate (UDP) sugar donor, which requires the (re)generation of redox (NAD $(\mathrm{P}) \mathrm{H})$ and energy ATP, was used as a multienzyme whole-cell model biocatalyst to test the effects of organic solvents on the conversion of myricetin into myricetin-7-O-glucuronide (M7GA) (Scheme 1). Myricetin is a natural plant-derived flavonoid that has been well recognized for its nutraceutical value, but which exhibits limited aqueous solubility [20]. M7GA, a structural analogue of scutellarein-7-O-glucuronide [21], exhibits the potential capacity to treat cardio-cerebral vascular diseases. Herein, we focused on the influence of different organic solvents on the one-pot whole-cell reaction. The effects of the addition of low-level water-miscible organic solvents on solubility and bioconversion rates and on microbial cellular viability and membrane integrity were investigated. Additionally, the whole-cell reaction for producing M7GA with the use of optimal organic solvent was scaled up.

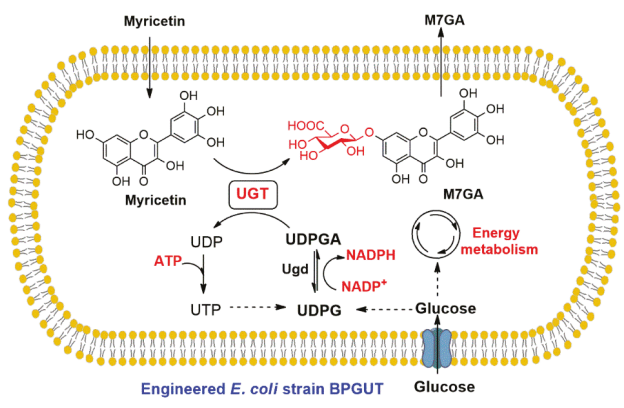

Scheme 1. Production of myricetin-7-O-glucuronide (M7GA) from myricetin with engineered Escherichia coli BPGUT cells used as the whole-cell biocatalyst. 


\section{Results and Discussion}

\subsection{Effects of the Organic Solvents on Bioconversion}

As many flavonoid aglycones have been suggested to be able to move into cells through passive diffusion [22-24], a high concentration gradient of flavonoid aglycones in a metabolic cell aqueous system may allow for a higher level of cross-membrane uptake. The screening test involving the addition of $2 \%-10 \%$ organic solvents to the reaction system (Figure 1A and Table S1) showed that all of the organic solvents tested (except for 10\% acetone and 10\% EtOH) triggered higher degrees of yield, with the highest value observed following the addition of $2 \%$ acetone, $2 \% \mathrm{EtOH}$ and $2 \% \mathrm{MeOH}$ (over 13-fold increase). M7GA yields underwent a steep decline when acetone and EtOH concentrations reached $10 \%$, exhibiting $10 \%-27 \%$ decreases relative to the control. The conversion rate underwent an approximate 9 -fold increase relative to the control when the $N, N$-dimethylformamide (DMF) and DMSO concentrations were $2 \%$, and the product yield decreased slowly as the content of DMF and DMSO sequentially increased.

The solubilities of myricetin and M7GA coupled with working concentrations of organic solvent were evaluated. As shown in Figure 1B and Table S1, the addition of organic solvents can induce minor improvements (ranging from $16 \%$ to $200 \%$ ) in the solubility of myricetin in the presence of DMF and DMSO $(2 \%, v / v)$, of acetone and $\mathrm{EtOH}(2 \%$ or $5 \%, v / v)$ or of $\mathrm{MeOH}$ (below $10 \%, v / v)$ relative to the control. However, the solubility of myricetin with acetone or DMF or DMSO $(10 \%, v / v)$ was dramatically stimulated by approximately 22- to 48-fold relative to the one obtained from the control. In contrast to the substrate myricetin, the product M7GA showed good solubility in modified M9 medium and those with low-level organic solvents (Figure 1C and Table S1). Almost 68\% of M7GA dissolved in modified M9 medium, with only minor differences in the solubility of M7GA (less than $31 \%$ ) among the tested solutions, which indicated that the inherent hydrophilic property of M7GA rather than the presence of organic solvent improved the solubility or the transport pace of the product.

A step-down relationship was found between yields and organic solvent content levels in the reaction system, with an optimal value attained when the volume of organic solvents was only 2\% (Figure 1A). A step-up relationship was found between solubility levels and organic solvent content, with an optimal value obtained when the volumes of certain organic solvents reached $10 \%$ $(v / v)$ (Figure 1B). Low concentrations of organic solvents exhibited accelerating potential during the biocatalytic conversion of myricetin into M7GA, with a slight increase in solubility. Moreover, when plotting production yields against the solubility of myricetin for the respective M9 solution with organic solvents, an obvious decrease in yields accompanied by an increase in myricetin solubility was found (Figure S1), possibly related to interactions between the cells and added organic solvents, which may have affected the surface tension, fluidity, permeability, or integrity of cellular membranes or further caused the leakage of intracellular small molecules (e.g., UDP-sugars, NAD(P)H, or ATP). DMSO can increase membrane fluidity, reduce membrane thickness, form transient water pores, or destroy the membrane structure with increases in concentrations [13,25]. Short-chain alkanols (MeOH and EtOH) can partition into cell membranes and reduce surface tension. As concentrations increase, the membrane becomes overly fluid, which further damages its integrity [26-28]. Thus, a low concentration of organic solvent reduces mass-transfer resistance from the membranes of whole cells, and a high concentration of organic solvent damages the membrane structure and integrity. Certainly, low or high concentrations of organic solvent should be correlated with cell density $\left(\mathrm{OD}_{600}=6.0,12 \mathrm{~g}_{\text {cells L }}{ }^{-1}\right.$ in this study). 

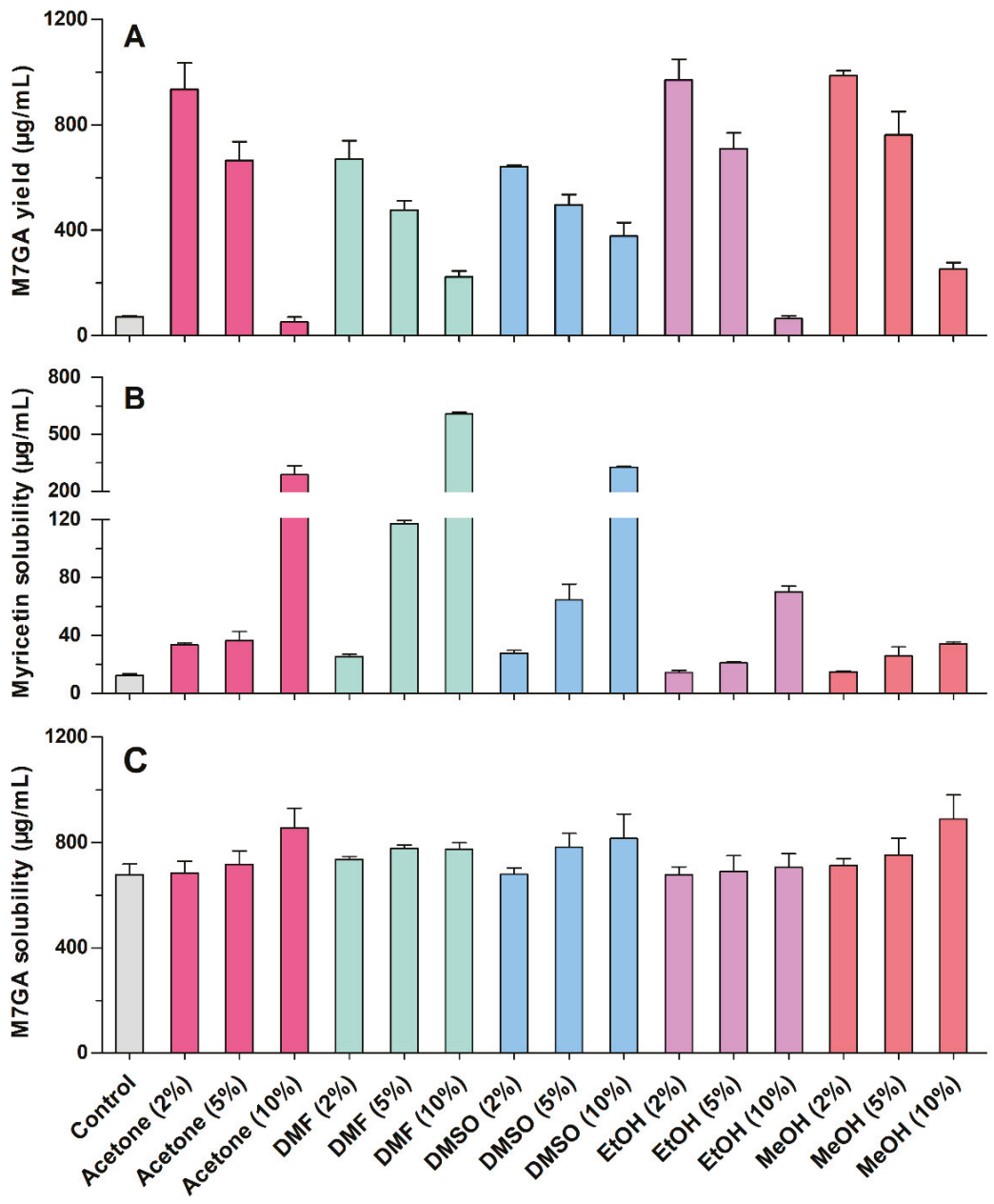

Figure 1. Effects of different organic solvents on the whole-cell reaction and the substrate and product solubilities. (A) Bioconversion of myricetin to myricetin-7-O-glucuronide (M7GA) catalyzed by E. coli BPGUT cells in the presence of organic solvents; (B) The solubility of myricetin and (C) the solubility of M7GA obtained in the modified M9 medium containing different concentrations of organic solvents.

\subsection{Cell Viability and Its Impacts on Bioconversion}

To clarify the effects of the addition of organic solvents on the catalytic activity of E. coli BPGUT in converting myricetin into M7GA, we assumed that these additives may primarily affect bioconversion through their interactions with cell membranes. Whether cell membranes are damaged or not can be determined from cell viability. In this study, the viability of the treated cells was assessed through the flow cytometry (FCM) test, as dead cells with damaged cytoplasmic membranes exhibit red fluorescence (due to propidium iodide (PI) staining), and live cells with intact membranes appear green (due to SYTO9 staining).

As can be observed from the FCM micrographs (Figure 2 and Table S2), the addition of $20 \%$ acetone and $20 \% \mathrm{EtOH}$ seriously disrupted cell membranes, leading to cell death; the disruptions became much more severe when cells suffered from $20 \%$ concentrations of acetone and EtOH than from $2 \%$ concentrations, reflecting a result distinct from that observed for cells treated with DMSO 
and DMF (Figure 2). Interestingly, although the distinction in production yield was obvious when different organic solvents $(2 \%-10 \%)$ were added, the FCM test for cell viability did not show obvious differences (Figure 2). However, when the cells were treated with 20\% acetone and 20\% EtOH, the damage was the most severe, and coincidently, the yields of M7GA were the lowest when 10\% acetone and $10 \%$ EtOH were used.
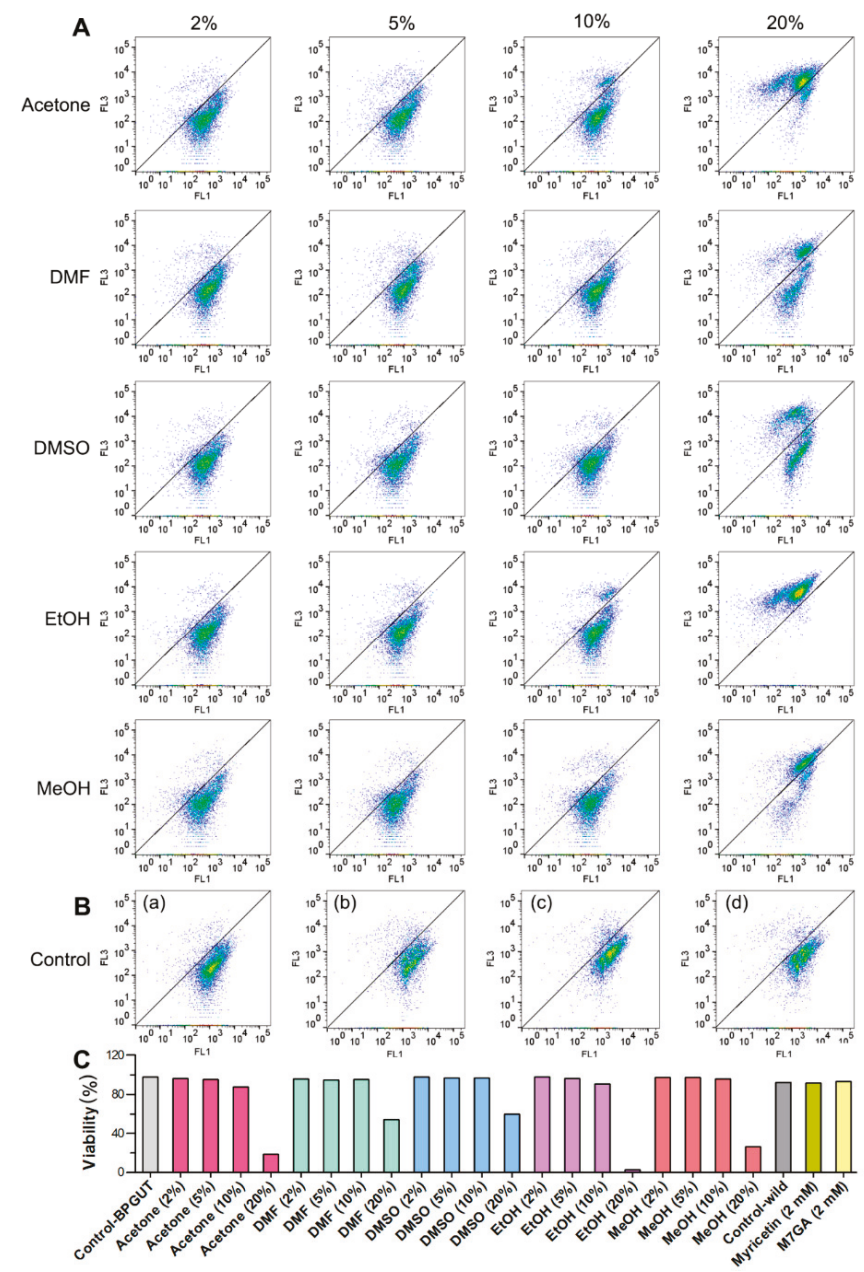

Figure 2. Viability of E. coli BPUGT cells or wild-type cells after being treated for $6 \mathrm{~h}$ at $30{ }^{\circ} \mathrm{C}$ in a modified M9 solution containing 2\% (v/v), $5 \%(v / v), 10 \%(v / v)$, and 20\% $(v / v)$ of organic solvents, or $2 \mathrm{mM}$ of myricetin and M7GA, respectively. (A) Flow cytometry (FCM) images of organic solvent-treated $E$. coli BPUGT cells; (B) FCM images of untreated E. coli BPUGT cells (a), untreated E. coli wild type cells (b), myricetin-treated E. coli wild type cells (c), and M7GA-treated E. coli wild type cells (d); (C) The cell viability as determined by FCM.

Cell protein leakage was observed after the removal of the treated cells, which serves as another indication of damage to the cell membrane on one hand and reflects the leakage of intracellular small molecules on the other. The levels of protein leakage increased with the increase of organic solvents, especially for acetone and EtOH (Figure 3 and Table S3). The $2 \%-10 \%$ organic solvents (DMF and 
DMSO) only spurred a less than twofold increase with respect to the control reaction system, which might be due to the E. coli surface protein. Extracellular protein leakage resulted in a sharp increase when the cells were exposed to acetone (20\%) and EtOH (20\%)—containing aqueous solution. This finding was in accordance with that of the FCM tests showing a decrease in the viability of the E. coli cells. These results suggest that the reduced barrier function of cell membranes accompanied by an increase in organic solvents can result in the further leakage of intracellular components essential to multienzyme whole-cell biocatalysts.

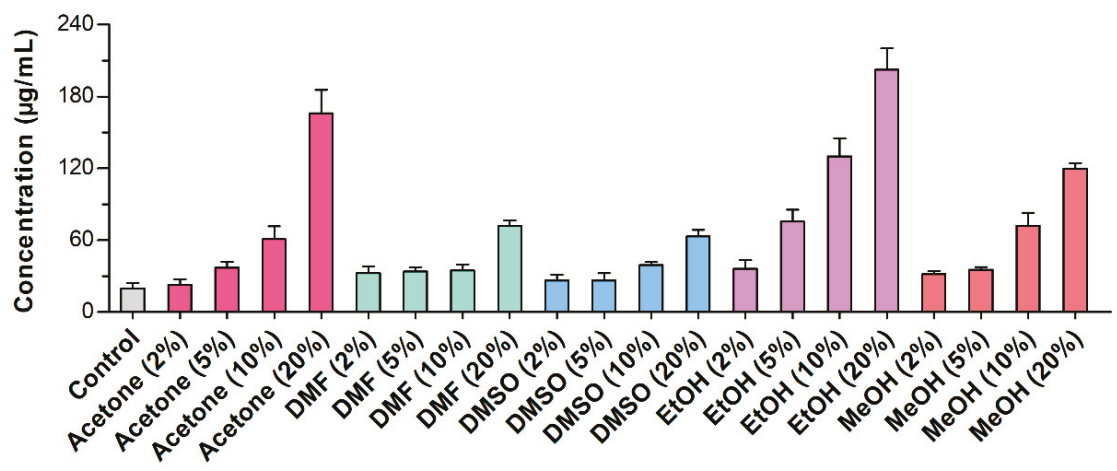

Figure 3. Concentrations of proteins released from E. coli BPGUT cells after the cells were exposed to $2 \%$ $(v / v), 5 \%(v / v), 10 \%(v / v)$ and $20 \%(v / v)$ of acetone, DMF, DMSO, EtOH, and MeOH for $6 \mathrm{~h}$, respectively.

Therefore, the above experiments demonstrate that organic solvents (for the type and concentration domains of organic solvents explored in this work) supported mild interactions with cells, especially in regard to DMSO. The minor improvement in solubility in the presence of low-level organic solvent $(2 \%)$ led to an outstanding increase in yield, and no obvious compromises to cellular viability or integrity were observed from the FCM and protein leakage assay. It is reasonable to speculate that low-level organic solvents probably affected the membrane structure (including fluidity, tension, thickness, permeability, or water pore formation, and so on), which may be referred to as "micro-permeabilization", and the tiny change improved the transport pace of the myricetin. In contrast, the major improvement in solubility in the presence of $10 \%$ of organic solvent led to a major decrease in yield and no prominent compromises to cellular viability or integrity. The explanation for this finding might be the toxicity of organic solvents in the whole-cell reaction system.

\subsection{Scaled-Up Synthesis of M7GA in a Fermenter System}

To further evaluate the industrial potential of the whole-cell strategies, the one-pot bioconversion system was further scaled up to $1 \mathrm{~L}$ in a 3-L fermenter, in which some factors involved in the growth of E. coli, such as $\mathrm{pH}$ and dissolved oxygen, could be controlled. Based on the effects of organic solvents on cell integrity, viability, and stability, DMSO was selected as the co-solvent. A kinetic analysis of M7GA production over time is shown in Figure 4. The M7GA production dramatically increased within $12 \mathrm{~h}$, and the production then incrementally leveled off over time. Finally, approximately $1322 \pm 106 \mathrm{mg} / \mathrm{L}$ (roughly $2.7 \mathrm{mM}$ ) M7GA was produced after $48 \mathrm{~h}$, and a $67 \%$ conversion yield was achieved. 


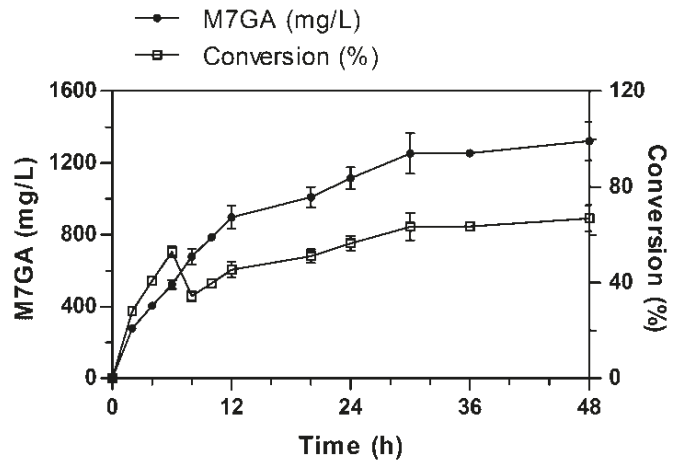

Figure 4. Time course for the production and conversion of myricetin-7-O-glucuronide (M7GA) obtained in a 3-L fermenter system containing $1 \mathrm{~L}$ of whole-cell catalyst. Two volumes of $20 \mathrm{~mL}$ myricetin stock solution (100 mM, dissolved in DMSO) was supplied in the reaction system at $0 \mathrm{~h}$ and $6 \mathrm{~h}$, respectively.

\section{Materials and Methods}

\subsection{Materials}

Myricetin and M7GA were purchased from BioBioPha (Kunming, Yunnan, China). Organic solvents, acetone, DMF, DMSO, EtOH, MeOH, and all other reagents of analytical grade were purchased from local manufacturers (Beijing Chemical Factory, Beijing, China). The LIVE/DEAD BacLight Bacterial Viability Kit (\# L7012), including solutions of $3.34 \mathrm{mM}$ SYTO9 dye and $20 \mathrm{mM}$ propidium iodide (PI) (both dissolved in DMSO), was purchased from Thermo Fisher Scientific (Waltham, MA, USA).

Transformed E. coli cells were grown on Luria-Bertani (LB) medium supplemented with antibiotics (100 mg/L ampicillin, $50 \mathrm{mg} / \mathrm{L}$ kanamycin and $25 \mathrm{mg} / \mathrm{L}$ chloramphenicol). The standard reaction system used for all shake-flask or fermenter production studies consisted of a modified M9 medium ( $\mathrm{pH} 7.0$, $\left.\mathrm{Na}_{2} \mathrm{HPO}_{4} 6.8 \mathrm{~g} / \mathrm{L} ; \mathrm{KH}_{2} \mathrm{PO}_{4} 2.7 \mathrm{~g} / \mathrm{L} ; \mathrm{NaCl} 0.5 \mathrm{~g} / \mathrm{L} ; \mathrm{NH}_{4} \mathrm{Cl} 1.0 \mathrm{~g} / \mathrm{L} ; \mathrm{MgSO}_{4} 0.24 \mathrm{~g} / \mathrm{L} ; \mathrm{CaCl}_{2} 0.01 \mathrm{~g} / \mathrm{L}\right)$ supplemented with glucose $(10 \mathrm{~g} / \mathrm{L})$.

\subsection{Preparation of a Certain Concentration of Organic Solvent}

Myricetin was dissolved in the organic solvents such as acetone, DMF, DMSO, EtOH, and MeOH to form specific concentrations of myricetin stock solutions (100 mM, $40 \mathrm{mM}$, and $20 \mathrm{mM})$. Certain volumes of liquid solvents (acetone, DMF, DMSO, EtOH, and $\mathrm{MeOH}$ ) were mixed with modified M9 medium to form final volumes of $4 \%, 20 \%$, and $40 \%(v / v)$ (as $2 \times$ stocks used for the extracellular protein leakage assay).

\subsection{General Procedure for the Whole-Cell Biocatalytic Conversion of Myricetin into M7GA}

The engineered E. coli strain BPGUT was constructed as described in our previous work [19]. Transformed BPGUT cells were activated in LB medium, and the recombinant proteins were induced to express by the addition of $0.5 \mathrm{mM}$ IPTG, and then incubated for an additional $15 \mathrm{~h}$ at $16{ }^{\circ} \mathrm{C}$. To obtain the whole-cell biocatalyst, the bacterial cells were harvested by centrifugation, and the pellets were washed twice with modified M9 medium to remove the residual medium from the cell pellets. The washed pellets were resuspended in $10 \mathrm{~mL}$ of modified $\mathrm{M} 9$ medium, and the cell density was adjusted to an $\mathrm{OD}_{600}$ of 6 (12 $\mathrm{g}$ of cells per liter). Myricetin solid powder or stock solution was added to the above whole-cell biocatalyst system to form a working concentration of $2 \mathrm{mmol} / \mathrm{L}$, which was then kept shaking at $30^{\circ} \mathrm{C}$ for $6 \mathrm{~h}$. The reaction mixture including cells was collected and lyophilized. 
The dried mixture was dissolved in $\mathrm{MeOH}$ and analyzed by HPLC. All of the reactions were carried out in triplicate.

\subsection{Determination of Myricetin and M7GA Solubility}

Myricetin $(0.64 \mathrm{mg})$ or M7GA $(0.99 \mathrm{mg})$ solid powder or stock solution was added to $1 \mathrm{~mL}$ of modified M9 medium and then incubated in a shaker at $30^{\circ} \mathrm{C}$ for $6 \mathrm{~h}$. After centrifugation, the supernatant was analyzed by HPLC to determine the solubility of myricetin or M7GA. All assays were conducted in triplicate.

\subsection{HPLC Analysis}

A 20- $\mu \mathrm{L}$ sample of supernatant was used for analysis using a Thermo HPLC system (Thermo Fisher, Germering, Germany) equipped with a GL AQ-C18 reverse-phase column (GL Sciences Inc., Tokyo, Japan, $4.60 \times 250 \mathrm{~mm}, 5 \mu \mathrm{m}$ particle size). The mobile phase was composed of water with $0.05 \%$ TFA (A) and acetonitrile (B) with a gradient program. The analysis of myricetin and M7GA was conducted with a 20 -min linear gradient of $20 \%-45 \%$ B. This was followed by isocratic flow with $100 \%$ $\mathrm{B}$ for $5 \mathrm{~min}$ to rinse off hydrophobic compounds and by isocratic development with $20 \% \mathrm{~B}$ for $5 \mathrm{~min}$ to equilibrate the column. The solubility of myricetin $(\mu \mathrm{g} / \mathrm{mL})$ or M7GA $(\mu \mathrm{g} / \mathrm{mL})$ and yields of M7GA $(\mu \mathrm{g} / \mathrm{mL})$ were calculated using the external standard curve method.

\subsection{Flow Cytometry (FCM) Tests}

The whole-cell biocatalyst cells or E. coli wild type cells were incubated in $1 \mathrm{~mL}$ of modified M9 medium containing a certain concentration of liquid organic solvents at $30^{\circ} \mathrm{C}$ for $6 \mathrm{~h}$. After being rinsed and appropriately diluted in $0.85 \%(\mathrm{w} / \mathrm{v}) \mathrm{NaCl}$ solution to reach a final density of $1 \times 10^{7}$ cells $/ \mathrm{mL}$, $600 \mu \mathrm{L}$ of the cell suspension was sampled and stained with $2 \mu \mathrm{L}$ of the premixed dye solution (a 2:1 mixture of SYTO9 and PI stains generated by the LIVE/DEAD BacLight bacterial viability kit) for $15 \mathrm{~min}$ at room temperature in the dark before being subjected to FCM tests using a BD FACS melody flow cytometer (BD Biosciences, Franklin Lakes, NJ, USA). For FCM tests, the sample was excited at $488 \mathrm{~nm}$, and the emission wavelengths were $515-545 \mathrm{~nm}$ for the SYTO9 stain and $>650 \mathrm{~nm}$ for the PI stain, and data were analyzed using FlowJo software (Version 10, BD Biosciences, Franklin Lakes, NJ, USA, 2019).

\subsection{Extracellular Protein Leakage Assay}

The whole-cell biocatalyst was prepared as described above, and the final cell concentration was adjusted to $\mathrm{OD}_{600}=12$. The above cell suspension and different concentrations of organic solvents $(2 \times$ stock) were then separately mixed at a volume ratio of $1: 1$. The mixture was then incubated at $30{ }^{\circ} \mathrm{C}$ for $6 \mathrm{~h}$ followed by a $16,000 \mathrm{~g}$ centrifugation for $20 \mathrm{~min}$. The total content of extracellular proteins leaked from the treated cells in the supernatants was estimated using a protein quantitative kit (Bradford) (Bio-Rad, Hercules, CA, USA). The tests were conducted three separate times.

\subsection{Scale-Up Synthesis of M7GA}

To assess the scale-up whole-cell synthesis of M7GA with low-level organic solvent, two volumes of $20 \mathrm{~mL}$ of DMSO containing $100 \mathrm{mM}$ myricetin were added at $0 \mathrm{~h}$ and $6 \mathrm{~h}$. The scale-up reaction was carried out in a 3-L glass fermenter system (Biotech, Shanghai, China) containing $1 \mathrm{~L}$ of the $12 \mathrm{~g} / \mathrm{L}$ whole-cell catalyst $\left(\mathrm{OD}_{600}=6.0\right)$ at $30{ }^{\circ} \mathrm{C}$ and $350 \mathrm{rpm}$ for $48 \mathrm{~h}$. The $\mathrm{pH}$ was maintained at 6.8-7.0 throughout the process using ammonium hydroxide (28\%) and phosphoric acid (4 M). Dissolved oxygen (DO) was maintained above 50\% during the experiment. Samples were collected at given time points and lyophilized and dissolved in MeOH for quantification by HPLC. 


\section{Conclusions}

In summary, the effects of five kinds of commonly used water-miscible organic solvents on the transformation of myricetin into M7GA were examined using engineered E. coli BPGUT as a multienzyme whole-cell biocatalyst. Higher M7GA yields were obtained from low-level organic solvents $(2 \%, v / v)$, and in further correlating cell viability and bioconversion yields together with cell membrane integrity, we can conclude that the addition of low-level organic solvents accommodates whole E. coli cells. The fine physical or structural property changes to the cell membrane induced by low-level organic solvent, not the solubility of the substrate or product, were the main causes to improve the yields of the product. However, in spite of the encouraging results of the M7GA yields and cell viability, we have not gained enough information for cell membrane micro-permeabilization induced by low-level organic solvents and their corresponding molecular mechanisms. The application of organic solvents in multistep whole-cell catalysis should be a compromise between two factors: solvent properties and toxic effects. From the results of this research, the former aspect dealing with the solubility of substrates may be neglected. The majority of attention should be paid to the viability and integrity of the cells. Furthermore, whole-cell reactions involve a complex reaction system; other important factors, including the inhibition or denaturation of enzymes, the cellular tolerance to organic solvents, and the density of E. coli cells, may also have effects. Thus, the ways in which low-level organic solvents contribute to the biotransformation of a multienzyme whole-cell biocatalyst must be further investigated. This study highlights the relationships among solubility, cell viability, and performance of the whole-cell catalyst. To further increase stability, the catalytic capability of whole-cell catalysts for modification of other hydrophobic substrates with structure similar to myricetin can be tested.

Supplementary Materials: The following are available online at http://www.mdpi.com/2073-4344/9/11/970/s1. Table S1: the yields of M7GA and the solubilities of myricetin or M7GA obtained in the modified M9 reaction system containing different concentrations of organic solvents; Table S2: the proportion of the live and dead cells as determined by FCM; Table S3: concentrations of proteins released from E. coli BPGUT cells after being exposed to organic solvents for $6 \mathrm{~h}$; Table S4: concentrations of proteins released from E. coli BPGUT cells after being exposed to organic solvents for $12 \mathrm{~h}$; Figure S1: correlations between the M7GA yield and the solubility of myricetin obtained in the modified M9 reaction system containing different concentrations of organic solvents; Figure S2: FCM images of E. coli BPUGT cells or wild type cells after being treated for $6 \mathrm{~h}$ at $30^{\circ} \mathrm{C}$ in a modified M9 solution containing $2 \%(v / v), 5 \%(v / v), 10 \%(v / v)$, and $20 \%(v / v)$ organic solvents, or myricetin $(2 \mathrm{mM})$ and M7GA $(2 \mathrm{mM})$; Figure S3: viability of E. coli BPUGT cells after being treated for $12 \mathrm{~h}$ at $30^{\circ} \mathrm{C}$ in a modified M9 solution containing $2 \%(v / v)$ organic solvents; Figure S4: concentrations of proteins released from E. coli BPGUT cells after the cells were exposed to $2 \%(v / v), 5 \%(v / v), 10 \%(v / v)$ and 20\% $(v / v)$ organic solvents for $12 \mathrm{~h}$; Figure S5: time course for the production of M7GA obtained in a 100-mL shake-flask system containing $10 \mathrm{~mL}$ of whole-cell catalyst.

Author Contributions: Conceptualization, Y.Y. and W.W.; data curation, Y.Y.; formal analysis, Y.Y.; funding acquisition, W.W.; investigation, Y.Y.; methodology, Y.Y., and M.-Z.L.; project administration, W.W.; resources, W.W.; software, Y.Y. and C.-K.L.; validation, Y.Y., and Y.-S.C.; writing-original draft preparation, Y.Y., and M.-Z.L.; writing-review and editing, Y.Y. and W.W.

Funding: This research was funded by the CAMS Innovation Fund for Medical Science (CAMS-2016-I2M-3-012, CAMS-2017-I2M-1-011) and National Mega-project for Innovative Drugs (2018ZX09711001-006-001).

Acknowledgments: We are grateful to Liu Yang (Institute of Materia Medica, Chinese Academy of Medical Sciences) for providing technical assistance.

Conflicts of Interest: The authors declare no conflict of interest.

$\begin{array}{ll}\text { Abbreviations } \\ \text { DMF } & N, N \text {-dimethylformamide } \\ \text { DMSO } & \text { Dimethyl sulfoxide } \\ \text { EtOH } & \text { Ethanol } \\ \text { FCM } & \text { Flow cytometry } \\ \text { MeOH } & \text { Methanol } \\ \text { M7GA } & \text { Myricetin-7-O-glucuronide } \\ \text { PI } & \text { Propidium iodide }\end{array}$




\section{References}

1. Lin, B.; Tao, Y. Whole-cell biocatalysts by design. Microb. Cell Fact. 2017, 16, 106. [CrossRef] [PubMed]

2. Wu, S.; Li, Z. Whole-cell cascade biotransformations for one-pot multistep organic synthesis. ChemCatChem 2018, 10, 2164-2178. [CrossRef]

3. Ricca, E.; Brucher, B.; Schrittwieser, J.H. Multi-enzymatic cascade reactions: Overview and perspectives. Adv. Synth. Catal. 2011, 353, 2239-2262. [CrossRef]

4. Shi, J.; Wu, Y.; Zhang, S.; Tian, Y.; Yang, D.; Jiang, Z. Bioinspired construction of multi-enzyme catalytic systems. Chem. Soc. Rev. 2018, 47, 4295-4313. [CrossRef] [PubMed]

5. De Carvalho, C.C. Whole cell biocatalysts: Essential workers from nature to the industry. Microb. Biotechnol. 2017, 10, 250-263. [CrossRef] [PubMed]

6. Kadisch, M.; Willrodt, C.; Hillen, M.; Bühler, B.; Schmid, A. Maximizing the stability of metabolic engineering-derived whole-cell biocatalysts. Biotechnol. J. 2017, 12, 1600170. [CrossRef] [PubMed]

7. Wachetmeister, J.; Rother, D. Recent advances in whole cell boicatalsysis. Curr. Opin. Biotech. 2016, 42, 169-177. [CrossRef]

8. Rudroff, F. Whole-cell based synthetic enzyme cascades-light and shadow of a promising technology. Curr. Opin. Chem. Biol. 2019, 49, 84-90. [CrossRef]

9. McAuliffe, J.C. Industrial enzymes and biocatalysis. In Handbook of Industrial Chemistry and Biotechnology; Kent, J.A., Ed.; Springer: Boston, MA, USA, 2012; pp. 1183-1227. ISBN 978-1-4614-4259-2.

10. Krauser, S.; Weyler, C.; Blaß, L.K.; Heinzle, E. Directed multistep biocatalysis using tailored permeabilized cells. Adv. Biochem. Eng. Biotechnol. 2013, 137, 185-234. [CrossRef]

11. Zheng, G.W.; Pan, J.; Yu, H.L.; Ngo-Thi, M.T.; Li, C.X.; Xu, J.H. An efficient bioprocess for enzymatic production of L-menthol with high ratio of substrate to catalyst using whole cells of recombinant E. coli. J. Biotechnol. 2010, 150, 108-114. [CrossRef]

12. Li, X.F.; Yuan, T.; Xu, H.; Xin, X.; Zhao, G.; Wu, H.; Xiao, X. Whole-cell catalytic synthesis of puerarin monoesters and analysis of their antioxidant activities. J. Agric. Food Chem. 2019, 67, 299-307. [CrossRef] [PubMed]

13. Gurtovenko, A.A.; Anwar, J. Modulating the structure and properties of cell membranes: The molecular mechanism of action of dimethyl sulfoxide. J. Phys. Chem. B 2007, 111, 10453-10460. [CrossRef] [PubMed]

14. Kim, M.J.; Seo, M.J.; Shin, K.C.; Oh, D.K. Production of 10S-hydroxy-8(E)-octadecenoic acid from oleic acid by whole recombinant Escherichia coli cells expressing 10S-dioxygenase from Nostoc punctiforme PCC 73102 with the aid of a chaperone. Biotechnol. Lett. 2017, 39, 133-139. [CrossRef] [PubMed]

15. Ma, L.; Du, L.; Chen, H.; Sun, Y.; Huang, S.; Zheng, X.; Kim, E.S.; Li, S. Reconstitution of the in vitro activity of the cyclosporine-specific P450 hydroxylase from Sebekia benihana and development of a heterologous whole-cell biotransformation system. Appl. Environ. Microbiol. 2015, 81, 6268-6275. [CrossRef]

16. Cui, J.D.; Jia, S.R.; Sun, A.Y. Influence of amino acids, organic solvents and surfactants for phenylalanine ammonia lyase activity in recombinant Escherichia coli. Lett. Appl. Microbiol. 2008, 46, 631-635. [CrossRef]

17. Janardhan Garikipati, S.V.; Peeples, T.L. Solvent resistance pumps of Pseudomonas putida S12: Applications in 1-naphthol production and biocatalyst engineering. J. Biotechnol. 2015, 210, 91-99. [CrossRef]

18. Honda, K.; Inoue, M.; Ono, T.; Okano, K.; Dekishima, Y.; Kawabata, H. Improvement of operational stability of Ogataea minuta carbonyl reductase for chiral alcohol production. J. Biosci. Bioeng. 2017, 123, 673-678. [CrossRef]

19. Yang, Y.; Wang, H.M.; Tong, Y.F.; Liu, M.Z.; Cheng, K.D.; Wu, S.; Wang, W. Systems metabolic engineering of Escherichia coli to enhance the production of flavonoid glucuronides. RSC Adv. 2016, 6, 33622-33630. [CrossRef]

20. Semwal, D.K.; Semwal, R.B.; Combrinck, S.; Viljoen, A. Myricetin: A dietary molecule with diverse biological activities. Nutrients 2016, 8, 90. [CrossRef]

21. Guo, C.; Zhu, Y.; Weng, Y.; Wang, S.; Guan, Y.; Wei, G.; Yin, Y.; Xi, M.; Wen, A. Therapeutic time window and underlying therapeutic mechanism of breviscapine injection against cerebral ischemia/reperfusion injury in rats. J. Ethnopharmacol. 2014, 151, 660-666. [CrossRef]

22. Ishisaka, A.; Kawabata, K.; Miki, S.; Shiba, Y.; Minekawa, S.; Nishikawa, T.; Mukai, R.; Terao, J.; Kawai, Y. Mitochondrial dysfunction leads to deconjugation of quercetin glucuronides in inflammatory macrophages. PLoS ONE 2013, 8, e80843. [CrossRef] [PubMed] 
23. Spencer, J.P.; Abd-el-Mohsen, M.M.; Rice-Evans, C. Cellular uptake and metabolism of flavonoids and their metabolites: Implications for their bioactivity. Arch. Biochem. Biophys. 2004, 423, 148-161. [CrossRef] [PubMed]

24. Wong, C.C.; Barron, D.; Orfila, C.; Dionisi, F.; Krajcsi, P.; Williamson, G. Interaction of hydroxycinnamic acids and their conjugates with organic anion transporters and ATP-binding cassette transporters. Mol. Nutr. Food Res. 2011, 55, 979-988. [CrossRef] [PubMed]

25. Notman, R.; Noro, M.; O’Malley, B.; Anwar, J. Molecular basis for dimethylsulfoxide (DMSO) action on lipid membranes. J. Am. Chem. Soc. 2006, 128, 13982-13983. [CrossRef] [PubMed]

26. Sandoval, N.R.; Papoutsakis, E.T. Engineering membrane and cell-wall programs for tolerance to toxic chemicals: Beyond solo genes. Curr. Opin. Microbiol. 2016, 33, 56-66. [CrossRef] [PubMed]

27. Marquês, J.T.; Viana, A.S.; De Almeida, R.F. Ethanol effects on binary and ternary supported lipid bilayers with gel/fluid domains and lipid rafts. Biochim. Biophys. Acta 2011, 1808, 405-414. [CrossRef]

28. Weber, F.J.; de Bont, J.A. Adaptation mechanisms of microorganisms to the toxic effects of organic solvents on membranes. Biochim. Biophys. Acta 1996, 1286, 225-245. [CrossRef]

(C) 2019 by the authors. Licensee MDPI, Basel, Switzerland. This article is an open access article distributed under the terms and conditions of the Creative Commons Attribution (CC BY) license (http://creativecommons.org/licenses/by/4.0/). 



\title{
Article \\ An Innovative Biocatalyst for Continuous 2G Ethanol Production from Xylo-Oligomers by Saccharomyces cerevisiae through Simultaneous Hydrolysis, Isomerization, and Fermentation (SHIF)
}

\author{
Thais S. Milessi-Esteves ${ }^{1,+}{ }^{,}$, Felipe A.S. Corradini ${ }^{2,+}{ }^{\dagger}$, Willian Kopp ${ }^{1}$, Teresa C. Zangirolami ${ }^{1,2}$, \\ Paulo W. Tardioli ${ }^{1,2}$, Roberto C. Giordano ${ }^{1,2}$ and Raquel L.C. Giordano ${ }^{1,2, *}$ \\ 1 Department of Chemical Engineering, Federal University of São Carlos, Rodovia Washington Luiz, km 235, \\ 13565-905, São Carlos, SP, Brazil; thais.milessi@gmail.com (T.S.M.-E.); willkopp@gmail.com (W.K.); \\ teresacz@ufscar.br (T.C.Z.); pwtardioli@ufscar.br (P.W.T.); roberto@ufscar.br (R.C.G.) \\ 2 Graduate Program of Chemical Engineering, Federal University of São Carlos (PPGEQ-UFSCar), \\ Rodovia Washington Luiz, km 235, 13565-905, São Carlos, SP, Brazil; eq.felipe.silva@gmail.com \\ * Correspondence: raquel@ufscar.br; Tel.: +55-16-3351-8264 \\ + Both authors contributed equally to this work
}

Received: 3 February 2019; Accepted: 24 February 2019; Published: 1 March 2019

\begin{abstract}
Many approaches have been considered aimed at ethanol production from the hemicellulosic fraction of biomass. However, the industrial implementation of this process has been hindered by some bottlenecks, one of the most important being the ease of contamination of the bioreactor by bacteria that metabolize xylose. This work focuses on overcoming this problem through the fermentation of xylulose (the xylose isomer) by native Saccharomyces cerevisiae using xylo-oligomers as substrate. A new concept of biocatalyst is proposed, containing xylanases and xylose isomerase (XI) covalently immobilized on chitosan, and co-encapsulated with industrial baker's yeast in Ca-alginate gel spherical particles. Xylo-oligomers are hydrolyzed, xylose is isomerized, and finally xylulose is fermented to ethanol, all taking place simultaneously, in a process called simultaneous hydrolysis, isomerization, and fermentation (SHIF). Among several tested xylanases, Multifect CX XL A03139 was selected to compose the biocatalyst bead. Influences of $\mathrm{pH}, \mathrm{Ca}^{2+}$, and $\mathrm{Mg}^{2+}$ concentrations on the isomerization step were assessed. Experiments of SHIF using birchwood xylan resulted in an ethanol yield of $0.39 \mathrm{~g} / \mathrm{g}$, (76\% of the theoretical), selectivity of $3.12 \mathrm{~g}_{\text {ethanol }} / \mathrm{g}_{x y l i t o l}$, and ethanol productivity of $0.26 \mathrm{~g} / \mathrm{L} / \mathrm{h}$.
\end{abstract}

Keywords: 2G ethanol; hemicellulose usage; S. cerevisiae; enzyme immobilization; cell immobilization; SHIF

\section{Introduction}

Biofuels will have a significant role in the energetic matrix of the low-carbon economy, helping to meet the goals established at Conference of the Parties (COP 21) [1,2]. Among biofuels, bioethanol production from lignocellulosic materials has been intensively studied once it was shown that these byproducts had high availability, had a low cost, and did not compete with the production of food [3]. Lignocellulosic raw materials are mainly composed of cellulose and hemicellulose (up to $70 \%$ ), which are polysaccharides that, after a hydrolysis step, generate fermentable sugars, mostly xylose from hemicellulose and glucose from cellulose [4]. The use of these two polysaccharides is important for the economic feasibility of the biofuel production process.

Some microorganisms that naturally ferment pentoses to ethanol have been tested for industrial use, such as Scheffersomyces stipitis and Pachysolen tannophilus [5,6]. However, these microorganisms 
have a low tolerance to ethanol and slow fermentation rates and are inhibited by compounds generated during the biomass pretreatment step, such as furfural [7].

Saccharomyces cerevisiae is the most common microorganism used for ethanol production from hexoses, due to its high rate of fermentation and superior ethanol yield. In addition, this yeast exhibits unbeatable tolerance to ethanol, to inhibitors, and to high concentrations of sugar $[8,9]$. However, in its wild form S. cerevisiae is unable to efficiently metabolize D-xylose.

The genetic modification of $S$. cerevisiae aimed at xylose fermentation has been extensively studied [8,10-12]. However, the low specific growth rate, high xylitol production, reduced yeast tolerance, and possible genetic instability are still hindrances for the application of recombinant strains on an industrial scale [7].

In spite of the inability of $S$. cerevisiae to metabolize xylose, it is capable of fermenting its isomer, xylulose, to ethanol. Hence, an alternative for the utilization of the hemicellulose fraction for bioethanol production would be to isomerize xylose to xylulose ex vivo, followed by fermentation by S. cerevisiae [7]. The enzyme xylose isomerase (XI) (EC 5.3.1.5) is widely used in the industry for the production of fructose syrup from corn starch and also catalyzes the reversible isomerization of xylose to xylulose [13]. Although the xylose/xylulose chemical equilibrium is unfavorable $\left(3.5: 1\right.$ at $\left.60{ }^{\circ} \mathrm{C}\right)$ [14], the reaction can be displaced by the simultaneous isomerization and fermentation (SIF) process, where the continuous conversion of xylulose to ethanol might allow the complete depletion of the available xylose [15].

The use of catalysts with immobilized enzymes may be crucial for the application of multi-enzymatic processes on an industrial scale. This approach allows the continuous operation of the reactor and facilitates the product recovery as well as the use of high loads of cells and enzymes [16]. The production of an active and stable enzyme derivative using a non-expensive support is also an important issue in enzyme immobilization [17]. The literature reports successful applications of immobilized enzymes on an industrial scale $[18,19]$ and immobilized XI is one of the most successful and established examples [13]. Silva et al. [7] developed a biocatalyst containing chitosan-immobilized XI, co-immobilized with $S$. cerevisiae in calcium alginate gel. Calcium alginate gel was chosen for being a natural polymer widely studied as a support for the immobilization of viable cells [20]. However, this system showed to be susceptible to contamination by xylose-consuming bacteria. High concentrations of xylose in the medium disfavored the $S$. cerevisiae population, due to its low uptake rates of xylulose.

An alternative to tackling the contamination problem is to use a cultivation medium containing non-readily fermentable substrates, such as xylo-oligomers obtained by the solubilization of hemicellulose under mild conditions [21]. The hetero-polysaccharides that compose hemicellulose are polymers with about 100 units of monomers, mainly xylose, and their solubility depends on the number of monomeric units in the chain [22]. Thus, the extraction of xylan in the form of large oligomers must be carried out under conditions that allow a sufficient number of glycosidic bonds to be broken, so that soluble polymers with lower molecular weight (xylo-oligomers) are released.

Xylanases ( $\beta-1,4$-D-xylanase) are enzymes that catalyze the hydrolysis of the glycosidic bonds between xylose units. The enzymatic complex is commonly composed of endoxylanases, exoxylanases, $\beta$-D-xylosidases as well as accessory enzymes such as glucuronidase and arabinofuranosidase that act on the ramifications of the xylan chain [23]. The addition of these enzymes to the biocatalyst proposed by Silva et al. [7] would allow the feeding of xylo-oligomers to the bioreactor. This substrate might decrease the probability of contamination during the operation of the bioreactor for long periods, which are typical in industry. Preliminary results showed the technical viability of this process [24].

The development of viable processes to increase ethanol yields from lignocellulosic materials is crucial, despite the challenges that still remain for the production of $2 \mathrm{G}$ ethanol from xylose. Considering the higher production cost of $2 \mathrm{G}$ ethanol (compared to $1 \mathrm{G}$ ethanol), the use of pentoses as raw material could make its production more profitable and might overcome the costs of $2 \mathrm{G}$ ethanol extra steps [25]. The integration of several biocatalytic transformations in a multi-enzymatic cascade system is particularly appealing to the development of cleaner and more efficient biochemical processes. 
Multi-enzymatic cascade reactions offer advantages such as lower demand of time, reduced costs, easier recovery of products, completion of reversible reactions as well as concentrations of inhibitory compounds restrained to a minimum [26].

In this context, the simultaneous hydrolysis, isomerization, and fermentation (SHIF) process stands out for $2 \mathrm{G}$ ethanol production since unmodified $S$. cerevisiae remains the preferred microorganism in industry, due to its robustness, high ethanol tolerance, and production rates. The use of wild strains to produce ethanol from xylose is an important issue in countries like Brazil, where biosafety regulations are strict [15]. In addition, one advantage of this approach is that XI, along with amylases and proteases, is among the most widely and cheaply available commercial enzymes [27]. The present work reports the results of using this new biocatalyst for the simultaneous hydrolysis, isomerization, and fermentation of xylan derived from the hemicellulose fraction of biomass, aimed at the production of ethanol (Figure 1).

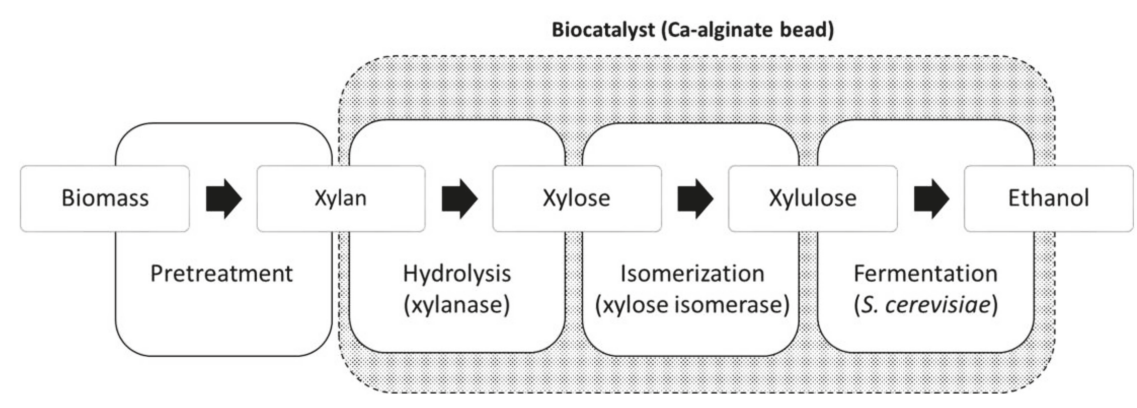

Figure 1. Xylan biomass simultaneous hydrolysis, isomerization, and fermentation (SHIF). Biocatalyst composed of xylanases, xylose isomerase, and co-immobilized S. cerevisiae.

\section{Results}

\subsection{Application of the New Biocatalyst in the SHIF Process}

The biocatalyst is designed for the industrial production of second-generation ethanol in continuous, fixed-bed reactors through long-term operation, by applying simultaneous hydrolysis, isomerization, and fermentation (SHIF) of the hemicellulosic fraction of biomass. First, xylanase and xylose isomerase were covalently immobilized on chitosan. The obtained XI derivative presented an activity of $252.5 \pm 1.6 \mathrm{IU} / \mathrm{g}$ (immobilization yield of $93 \%$ and recovered activity of $91 \%$ ), whereas the Accellerase derivative exhibited $346.3 \pm 9.2 \mathrm{IU} / \mathrm{g}$ (immobilization yield of $54 \%$ and recovered activity of $12 \%$ ). Both derivatives were co-encapsulated with $S$. cerevisiae in Ca-alginate gel and this biocatalyst was used to produce ethanol from commercial birchwood xylan.

Birchwood xylan, which is a heteropolymer composed of long chains, was first hydrolyzed to smaller xylo-oligomers by the action of recombinant endoxylanase of Bacillus subtilis (XynA) in order to increase the concentration of xylo-oligomers with smaller chains that may diffuse into the catalyst beads [28]. This step was carried out to make xylan more similar to lignocellulosic hydrolysates obtained from the pretreatment of biomass (data not shown). The composition of the substrate after xylan pre-hydrolysis is shown in Table 1.

As expected, there was no xylose production since XynA is a strict endoxylanase [28]. The solubilized fraction corresponded to $67 \%$ (w/w) of the offered xylan. According to Gray et al. [22], the solubility of the xylan oligomers depends on the degree of polymerization of each compound. Under the used conditions, 33\% (w/w) of birchwood xylan is insoluble. Therefore, the substrate obtained for the SHIF process had $73 \mathrm{~g} / \mathrm{L}$ of xylo-oligomers. 
Table 1. Characterization of SHIF substrate: birchwood xylan, $108 \mathrm{~g} / \mathrm{L}$ after $24 \mathrm{~h}$ hydrolysis by endoxylanase XynA (150 IU/gxylan $)$ at $50{ }^{\circ} \mathrm{C}$ and $\mathrm{pH} 5.6$.

\begin{tabular}{ccc}
\hline Component & \multicolumn{2}{c}{ Hydrolyzed Birchwood Xylan } \\
& $(\mathrm{g} / \mathrm{L})$ & $\mathbf{( \% )}$ \\
\hline Xylohexaose (X6) or bigger & 62.3 & 57.4 \\
Xylopentaose (X5) & 0.0 & 0.0 \\
Xylotetraose (X4) & 1.2 & 1.1 \\
Xylotriose (X3) & 2.5 & 2.2 \\
Xylobiose (X2) & 7.1 & 6.5 \\
Xylose & 0.0 & 0.0 \\
Total Soluble & 73.0 & 67.2 \\
Total Insoluble & 35.6 & 32.8 \\
Total & 108.6 & 100.0 \\
\hline
\end{tabular}

For the SHIF assays, the offered enzyme activity in the reactor was $1.7 \times 10^{4} \mathrm{IU} / \mathrm{L}_{\text {reactor }}$ for xylanase (Accellerase $\mathrm{XY}$ ) and $3.7 \times 10^{4} \mathrm{IU} / \mathrm{L}_{\text {reactor }}$ of xylose isomerase. Accellerase $\mathrm{XY}$ was used due to the presence of $\beta$-xylosidase, which is necessary to xylose formation. Commercial baker's yeast (Itaiquara ${ }^{\circledR}$ ) concentration was $50 \mathrm{~g}_{\text {dry mass }} / \mathrm{L}_{\text {reactor }}$ at the beginning of the SHIF assays. Results in Figure 2 show the production of ethanol through SHIF using the developed biocatalyst. Ethanol production was higher compared to xylitol, presenting a selectivity of $2.61(2.2 \mathrm{~g} / \mathrm{L}$ ethanol and $0.84 \mathrm{~g} / \mathrm{L} x y l i t o l)$. Ethanol productivity of $0.092 \mathrm{~g} / \mathrm{L} / \mathrm{h}$ and yield $\left(\mathrm{Y}_{\mathrm{P} / \mathrm{S}}\right)$ of $0.160 \mathrm{~g}_{\text {ethanol }} / \mathrm{g}_{\text {potentialxylose }}$ ( $32 \%$ of theoretical, calculated on the basis of potential xylose in the xylan) were achieved at the end of the SHIF run.

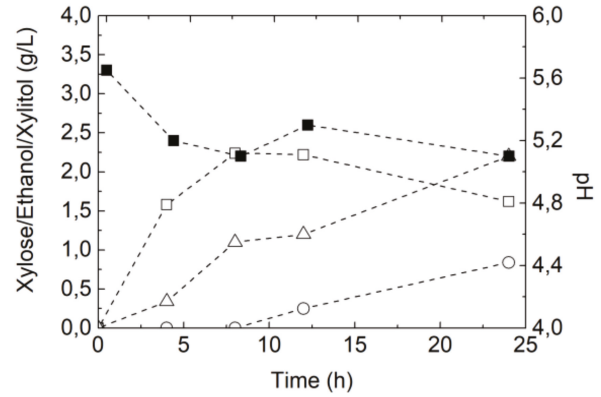

(a)

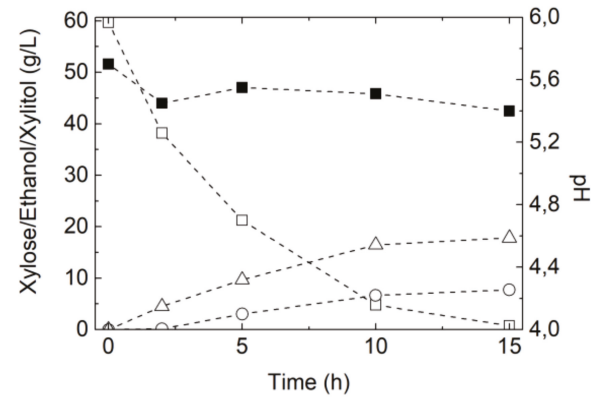

(b)

Figure 2. (a) SHIF of pre-hydrolyzed birchwood xylan using a biocatalyst containing $5 \mathrm{w} \%$ of Accellerase XY, $15 \mathrm{w} \%$ of XI, and $10 \mathrm{w} \%$ dry mass yeast $\left(1.7 \times 10^{4} \mathrm{IU} / \mathrm{L}, 3.7 \times 10^{4} \mathrm{IU} / \mathrm{L}\right.$, and $50 \mathrm{~g} / \mathrm{L}$, respectively), $\mathrm{pH} 5.6,150 \mathrm{rpm}$ stirring, and $32{ }^{\circ} \mathrm{C}$; (b) control experiment using xylose as substrate (SIF): $\mathrm{pH}(\square)$, xylose $(\square)$, ethanol $(\Delta)$, and xylitol $(\bigcirc)$.

Figure 2 shows that ethanol is produced from xylo-oligomers. The slower velocity of SHIF compared to the control experiment (where the substrate is xylose, resulting in a simultaneous isomerization, and fermentation (SIF) process) was expected since xylose concentration in SHIF depends on the velocity of hydrolysis of the xylo-oligomers. However, a decrease in the xylose consumption was observed after eight hours of SHIF (Figure 2a), which indicates that the xylose isomerization was impaired. There are two possible reasons for this occurrence: XI is not catalyzing isomerization of xylose in the required velocity; or the yeast is not consuming the generated xylulose, which would be accumulating and consequently stopping the isomerization due to the xylose:xylulose equilibrium ratio. Since the yeast remained viable (initial and final cell viability unchanged: $96 \%$ ) and there was no accumulation of xylulose in the medium, the accumulation of xylose seemed to be related to the isomerization step. 
In the control experiment, using only xylose as substrate, XI catalyzed the isomerization reaction effectively, almost until depletion of the pentose $(60 \mathrm{~g} / \mathrm{L}$ of xylose were consumed in $12 \mathrm{~h}$, a productivity of $1.2 \mathrm{~g} / \mathrm{L} / \mathrm{h}$, with $\mathrm{Y}_{\mathrm{P} / \mathrm{S}}$ of $0.303 \mathrm{~g} / \mathrm{g}$ and selectivity of 2.3 with respect to xylitol). Thus, an increase of the isomerization velocity must be sought. Some of the possible causes for the hindrance of the isomerization step were then investigated. High calcium concentrations are known to inhibit XI action [29], and the hydrolysis reaction could be demanding a higher release of the calcium ion (increased hydrolysis of $\mathrm{CaCO}_{3}$ to control the $\mathrm{pH}$ ). However, even with a higher release of calcium, the results shown in Figure 2 indicate that the hydrolysis step led to a drop of $\mathrm{pH}$ to approximately 5.1. $\mathrm{XI}$ shows maximum activity at $\mathrm{pH}$, being highly sensitive to a drop of $\mathrm{pH}$ to this range [15]. On the other hand, it is known that the magnesium ion is an important cofactor for XI, as an activator of this enzyme [30]. The influence of $\mathrm{pH}$ and $\mathrm{Ca}^{2+}$ and $\mathrm{Mg}^{2+}$ ions in the isomerization step was then investigated.

\subsection{Influence of $\mathrm{pH}, \mathrm{Ca}^{2+}$, and $\mathrm{Mg}^{2+}$ on XI Activity}

In order to investigate the influence of calcium and magnesium ions on XI, the activity of this enzyme to catalyze fructose-glucose isomerization was measured at different pHs (5.0 to 8.0) in the presence of different concentrations of $\mathrm{Ca}^{2+}$ and $\mathrm{Mg}^{2+}$ ions. The standard medium for assessing activity was $2 \mathrm{M}$ fructose, $\mathrm{pH} 8.0$ (50 mM tris-maleate buffer) supplemented with $50 \mathrm{mM}$ of $\mathrm{MgSO}_{4}$ and $2.5 \mathrm{mM}$ of $\mathrm{CoCl}_{2}$ at $60^{\circ} \mathrm{C}$. Both $\mathrm{Co}^{2+}$ and $\mathrm{Mg}^{2+}$ are essential for the activity of $\mathrm{XI}$, however they play differentiated roles. $\mathrm{Mg}^{2+}$ is superior to $\mathrm{Co}^{2+}$ as an activator, while the latter is responsible for the stabilization of the enzyme and maintenance of its conformation, especially the quaternary structure [31]. Table 2 shows the measured activities of XI in each condition studied, referred to the test performed with the standard medium at $\mathrm{pH} 8.0$ as $100 \%$.

Table 2. Influence of $\mathrm{Mg}^{2+}$ and $\mathrm{Ca}^{2+}$ on XI activity at different $\mathrm{pHs}$ (isomerization of fructose 2M, $\left.60{ }^{\circ} \mathrm{C}\right)$. The activity measured in standard medium $\left(\mathrm{pH} 8.0,50 \mathrm{mM} \mathrm{MgSO} 4,2.5 \mathrm{mM} \mathrm{CoCl}_{2}\right.$ ) was taken as $100 \%$.

\begin{tabular}{|c|c|c|c|c|c|c|c|c|c|}
\hline & \multirow[t]{2}{*}{ Medium } & \multicolumn{2}{|c|}{ pH 8.0} & \multicolumn{2}{|c|}{$\mathrm{pH} 7.0$} & \multicolumn{2}{|c|}{ pH 6.0} & \multicolumn{2}{|c|}{ pH 5.0} \\
\hline & & $\mathrm{IU} / \mathrm{mL}$ & $\%$ & $\mathrm{IU} / \mathrm{mL}$ & $\%$ & $\mathrm{IU} / \mathrm{mL}$ & $\%$ & $\mathrm{IU} / \mathrm{mL}$ & $\%$ \\
\hline 1 & Standard & $1896 \pm 68$ & 100.0 & $1590 \pm 23$ & 83.9 & $1466 \pm 12$ & 77.4 & $442 \pm 21$ & 23.4 \\
\hline 2 & $2 \times \mathrm{Mg}^{2+}$ & $2041 \pm 31$ & 107.7 & $1890 \pm 7$ & 99.7 & $1820 \pm 3$ & 96.9 & $940 \pm 24$ & 49.6 \\
\hline 3 & $5 \times \mathrm{Mg}^{2+}$ & $2202 \pm 67$ & 116.2 & $2287 \pm 43$ & 120.6 & $2333 \pm 12$ & 123.1 & $1166 \pm 35$ & 61.5 \\
\hline 4 & Standard $+\mathrm{Ca}^{2+*}$ & $1454 \pm 97$ & 76.7 & $1312 \pm 20$ & 69.2 & $572 \pm 85$ & 30.2 & $380 \pm 45$ & 20.1 \\
\hline 5 & $2 \times \mathrm{Ca}^{2+}$ & $1366 \pm 72$ & 72.1 & $944 \pm 69$ & 49.8 & $503 \pm 94$ & 26.6 & $352 \pm 45$ & 18.6 \\
\hline 6 & $5 \times \mathrm{Ca}^{2+}$ & $1063 \pm 56$ & 56.1 & $797 \pm 56$ & 42.1 & $356 \pm 31$ & 18.8 & $255 \pm 44$ & 13.5 \\
\hline 7 & $\mathrm{Ca}^{2+*}+2 \times \mathrm{Mg}^{2+}$ & $1542 \pm 81$ & 81.3 & $1673 \pm 27$ & 88.3 & $1073 \pm 56$ & 56.6 & $803 \pm 20$ & 42.4 \\
\hline 8 & $\mathrm{Ca}^{2+*}+5 \times \mathrm{Mg}^{2+}$ & $1672 \pm 88$ & 88.2 & $2236 \pm 39$ & 117.9 & $1250 \pm 16$ & 65.9 & $966 \pm 17$ & 51.0 \\
\hline
\end{tabular}

The $\mathrm{Ca}^{2+}$ ion proved to be an inhibitor of this enzyme, since a significant decrease in the XI activity occurred when the $\mathrm{Ca}^{2+}$ concentration in the medium increased. The $\mathrm{Mg}^{2+}$ ion, in turn, was able to activate the enzyme, increasing its activity in $16.2 \%$ at $\mathrm{pH} 8.0$ and $163 \%$ at $\mathrm{pH} 5.0$, both in calcium-free medium. This cofactor was still able to bypass the inhibition caused by calcium, since it reactivated the enzyme in the presence of this ion, increasing its catalytic activity in all studied pHs.

Xylose isomerization catalyzed by XI is initiated by opening the sugar ring, followed by isomerization through the exchange of hydride and finally stabilization of the product by ring closure [32]. Although there is no relationship between the presence of magnesium and the ring opening step, this cation is essential for the isomerization [33]. According to Kasumi et al. [34], the reaction mechanism demands the formation of a binary divalent enzyme-cation complex, since the substrate will bind only to the active site of this complex. Xylose isomerase has two active sites, each containing two divalent cations [33]. Thus, the presence of higher concentrations of magnesium in the reaction medium, improving the probability of the presence of this ion in the active sites of the enzyme, would increase the rates of the isomerization reaction. 
Although calcium is a divalent cation and belongs to the same family as magnesium (same configuration in the valence layer) in the periodic table, $\mathrm{Ca}^{2+}$ has a larger ionic radius than $\mathrm{Mg}^{2+}$. This fact could be the reason why $\mathrm{Mg}^{2+}$ is an activator of the enzyme while $\mathrm{Ca}^{2+}$ inhibits $\mathrm{XI}$, that is, the difference in their atomic radii would cause a different interaction with the active site of the enzyme.

In addition to the significant influence of $\mathrm{Ca}^{2+}$ and $\mathrm{Mg}^{2+}, \mathrm{XI}$ showed great sensitivity to $\mathrm{pH}$, losing activity significantly at $\mathrm{pH}$ 5.0. The sensitivity of $\mathrm{XI}$ to $\mathrm{pH}$ was previously observed by Milessi et al. [15], who emphasized the importance of $\mathrm{pH}$ control during the simultaneous isomerization and fermentation (SIF) of xylose. However, the activation provided by $\mathrm{Mg}^{2+}$ is potentiated at lower $\mathrm{pHs}$. When $\mathrm{Ca}^{2+}(4 \mathrm{~g} / \mathrm{L})$ was added, the magnesium ion was able to recover XI activity more effectively at $\mathrm{pH} 5.0$ than at $\mathrm{pH} 8.0$ (Table 2, media 4 and 7).

Data presented in Table 2 also prove that XI activity was greatly reduced at the SHIF pH range (5.0 to 6.0). The quaternary structure of this enzyme is composed of four subunits that are delicately folded and associated with noncovalent links and without interchain disulfide bonds [31,32]. At $\mathrm{pH}$ 8.0, the enzyme structure is composed of all four subunits combined, resulting in the maximum catalytic activity. However, as the $\mathrm{pH}$ of the reaction medium lowers, the enzyme is more likely to suffer structure distortions, unfolding and dissociating its tetrameric structure. The presence of $\mathrm{Ca}^{2+}$ ions at the low $\mathrm{pH}$ of the reaction medium results in a combined effect, acting both on the 3D structure and on the active site. Therefore, the performance of the SHIF process will certainly benefit from a $\mathrm{pH}$ control system ( $\mathrm{pH}$ 5.6). Unfortunately, the substitution of calcium chloride by magnesium chloride in the coagulation solution during sodium alginate gelation was not possible since the resulting beads were not stable. For this reason, SHIF experiments with $\mathrm{pH}$ control and excess of magnesium were run, in order to minimize the inhibition of XI caused by the hydrolysis reactions, which release acids from the structures of the xylo-oligomers [35].

\subsection{Xylanase Selection}

Xylan hydrolysis has to occur efficiently to enable the cascade SHIF process. Hydrolysis cannot be the rate-determining step of these reactions in series: due to the unfavorable equilibrium of xylose to xylulose isomerization, the supply of xylose must not control the reaction [7]. Considering that the composition of each xylanase complex influences the hydrolysis efficiency, different xylanases were evaluated with the purpose of selecting the most efficient for the SHIF process.

The xylanase family is strongly related to the profile of products generated in the process [36]. A xylanase capable of depolymerizing xylan into xylose efficiently is required to ensure that the SHIF process will proceed as expected. Thus, besides Accellerase XY A03304, used in previous SHIF tests, two additional xylanases were evaluated: recombinant B. subtilis endoxylanase (XynA) and Multifect CX XL A03139.Hydrolysis profiles and xylooligosaccharide (XOS) composition are reported in Table 3 and Figure 3, respectively.

Table 3. Composition of xylooligosaccharides (XOS) after enzymatic hydrolysis ofbirchwood xylan $\left(25.4 \mathrm{~g} / \mathrm{L}, 3.8 \mathrm{IU} / \mathrm{mL}, 24 \mathrm{~h}\right.$ of reaction at $\left.50^{\circ} \mathrm{C}, \mathrm{pH} 5.6\right)$.

\begin{tabular}{cccccccc}
\hline Xylanase & X6 (g/L) & X5 (g/L) & X4 (g/L) & X3 (g/L) & X2 (g/L) & Xylose $(\mathrm{g} / \mathrm{L})$ & Conversion $(\%)$ \\
\hline XynA & 0 & 0.20 & 1.22 & 4.43 & 3.49 & 0.00 & 44.8 \\
Multifect & 0 & 0.18 & 0.31 & 1.85 & 6.48 & 13.24 & 78.7 \\
Accellerase & 0 & 0.00 & 0.34 & 1.51 & 6.45 & 8.08 & 58.8 \\
\hline
\end{tabular}




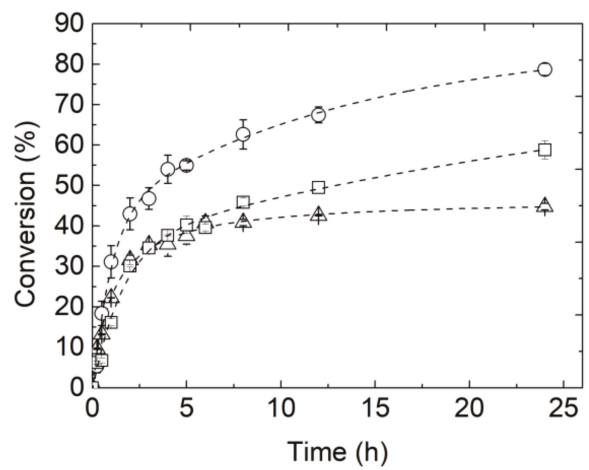

Figure 3. Hydrolysis of birchwood xylan soluble fraction $(25,4 \mathrm{~g} / \mathrm{L})$ by the studied xylanases (150 $\left.\mathrm{IU} / \mathrm{g}_{\text {xylan }}=3810 \mathrm{IU} / \mathrm{L}\right)$ at $50{ }^{\circ} \mathrm{C}, 24 \mathrm{~h}, \mathrm{pH}$ 5.6. XynA ( $\Delta$ ); Multifect $(\bigcirc)$, and Accellerase $(\square)$. Bars are standard errors of triplicates.

Figure 3 shows that Multifect stands out, with a xylan conversion of $78.7 \%$. Moreover, the higher xylose concentration achieved with this enzyme at the end of the experiments indicates that this xylanase complex has a more stable $\beta$-xylosidase enzyme, responsible for catalyzing the hydrolysis of xylobiose, the essential final step for the complete xylan hydrolysis. Hence, this xylanase seems to be the most suitable for the production of xylose in the SHIF process, among the studied enzymes.

Accellerase has the highest enzymatic activity under standard conditions. However, in long-term reaction it was able to convert only $58.8 \%$ of the available xylan. Several factors may have contributed to Accellerase's inferior performance, such as the amount of each enzyme in the complex, thermal inactivation, substrate affinity, and inhibitory effects.

XynA was already known to have a strictly endoxylanase action, lacking $\beta$-xylosidase activity and consequently not producing xylose when hydrolyzing xylan [28]. Accordingly, it presented the lowest conversion $(44.8 \%)$, probably due to the absence of debranching enzymes.

None of the tested xylanases reached $100 \%$ of xylan conversion. Indeed, the incapacity of xylanases to completely hydrolyze xylan has been previously reported. Akpinar et al. [37] observed a yield of $13.8 \%$ for tobacco xylan using Aspergillus niger xylanase (200 IU /g) at $50{ }^{\circ} \mathrm{C}$ after $24 \mathrm{~h}$. Aragon et al. [38] achieved $13 \%$ of conversion in the hydrolysis of birch xylan $(18 \mathrm{~g} / \mathrm{L})$ using Aspergillus versicolor endoxylanase immobilized on agarose-glyoxyl at $25{ }^{\circ} \mathrm{C}$ and $\mathrm{pH}$ 5.0. In fact, since xylan is not a linear polymer of pure xylose, its complete depolymerization requires the use of a varied pool of enzymes [21,23,39]. In this context, the xylanase Multifect CX XL A03139 was selected to be co-immobilized with XI and S. cerevisiae in the SHIF process.

\subsection{SHIF Assay with $\mathrm{pH}$ Control and Excess of $\mathrm{Mg}^{2+}$}

In order to overcome the possible inhibition of $\mathrm{Ca}^{2+}$ in XI activity, a SHIF assay was performed with $\mathrm{pH}$ control and excess of magnesium. Beads without $\mathrm{CaCO}_{3}$ in its composition were prepared, since this salt is only necessary to sustain the $\mathrm{pH}$ at the desired range. Moreover, an isomerization free of $\mathrm{CaCO}_{3}$ would contribute to reduce the undesired $\mathrm{Ca}^{2+}$ effects. After all these modifications, the obtained derivative of xylanase Multifect presented 330.2 $\pm 8.1 \mathrm{IU} / \mathrm{g}$ (immobilization yield of $96 \%$ and recovered activity of $77 \%$ ). For the SHIF experiment, the medium supplemented with $100 \mathrm{mM}$ $\mathrm{MgSO}_{4}\left(24.6 \mathrm{~g} / \mathrm{L}\right.$ ) and $4 \mathrm{~g} / \mathrm{L}$ of $\mathrm{CaCl}_{2}$ (to maintain the integrity of the beads) was added together with the beads to the $\mathrm{pH}$-stat stirred reactor. It is important to note that the moderate agitation used during the process did not affect the integrity of the beads. According to Rahim et al. [40], damages to Ca-alginate immobilized biocatalysts due to stirring are usually observed above $200 \mathrm{rpm}$. In fact, Carvalho et al. [41], in experiments carried out at $300 \mathrm{rpm}$, noticed a $30 \%$ reduction in the size of Ca-alginate beads during experiments with immobilized Candida guilliermondii. Accordingly, in the 
present work, an agitation of $150 \mathrm{rpm}$ was employed and the structural characteristics of the biocatalyst beads were preserved.

The obtained results, showed in Figure 4, indicated a higher ethanol production in SHIF using $\mathrm{pH}$ control and excess of $\mathrm{Mg}^{2+}(3.1 \mathrm{~g} / \mathrm{L}$ of ethanol) compared to the value of $2.2 \mathrm{~g} / \mathrm{L}$, which was achieved under the original SHIF conditions (Figure 2$)$. Ethanol yield $(0.39 \mathrm{~g} / \mathrm{g}, 76 \%$ of the theoretical), selectivity (3.12), and productivity $(0.26 \mathrm{~g} / \mathrm{L} / \mathrm{h})$ were also improved.

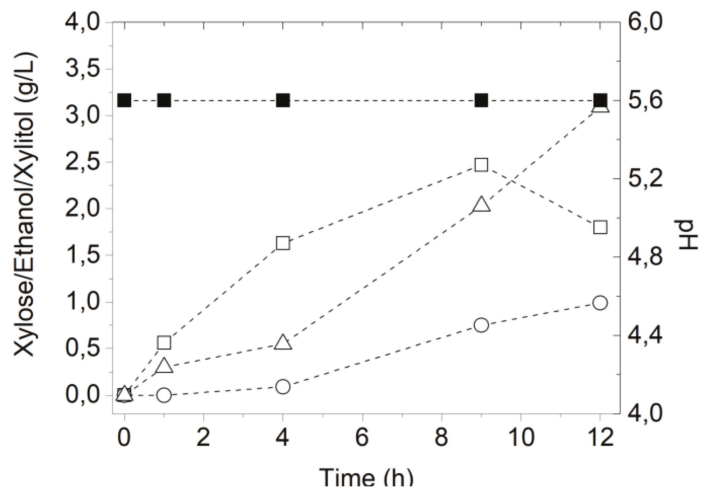

Figure 4. SHIF of previously hydrolyzed birchwood xylan with $\mathrm{pH}$ control and excess of $\mathrm{Mg}^{2+}$ using immobilized biocatalyst containing $5 \mathrm{w} \%$ Multifect xylanase derivative, $15 \mathrm{w} \%$ XI derivative, and $10 \mathrm{w} \%$ yeast $\left(1.7 \times 10^{4} \mathrm{IU} / \mathrm{L}, 3.7 \times 10^{4} \mathrm{IU} / \mathrm{L}, 50 \mathrm{~g} / \mathrm{L}\right)$, initial $\mathrm{pH} 5.6,150 \mathrm{rpm}$ stirring and $32{ }^{\circ} \mathrm{C}$; $\mathrm{pH}(\square)$, xylose $(\square)$, ethanol $(\Delta)$, and xylitol $(\bigcirc)$.

To the best of our knowledge, these are the highest yield and productivity reported in the literature for ethanol production from xylan through the simultaneous hydrolysis, isomerization, and fermentation (SHIF) process. Only a few works have studied ethanol production from pentoses using ex vivo isomerization and native $S$. cerevisiae, due to the differences in optimal $\mathrm{pH}$ and temperature ranges for each step (and none of them with co-immobilized enzymes/cells). The inclusion of the xylan hydrolysis step should not be a problem in relation to the temperature and $\mathrm{pH}$ of the process. Xylanases have the highest catalytic $\mathrm{pH}$ and temperature at approximately 5.5 and $50{ }^{\circ} \mathrm{C}$, respectively, whereas $\mathrm{XI}$ optimal conditions are $\mathrm{pH} 7.0-8.0$ and $70{ }^{\circ} \mathrm{C}$ [7]. Alcoholic fermentation, on the other hand, operates at $\mathrm{pH} 5.0$ and $30^{\circ} \mathrm{C}$. Due to these facts, the process integration for ethanol production is still a challenge. Nakata et al. [42] studied ethanol production of hot-compressed water pretreated Japanese beech using soluble $\beta$-xylosidase, XI, and S. cerevisiae. It should be stressed that in this work the absence of exo- and endoxylanases would be a restraint to the saccharification step. The best results reported $(0.62 \mathrm{~g} / \mathrm{L}$ of ethanol, corresponding to $13 \%$ of theoretical yield) were achieved at $\mathrm{pH} 5.0,30{ }^{\circ} \mathrm{C}$ after $100 \mathrm{~h}$. Hence, the immobilized biocatalyst containing enzymes and yeast co-encapsulated reported in the present work was significantly more efficient than using enzymes and microorganisms in their soluble form, leading to a better yield and productivity.

Although there are only a few studies addressing the SHIF of xylan, the simultaneous isomerization and fermentation (SIF) of xylose has been more frequently reported. Rao et al. [27] studied the xylose SIF in the presence of $0.05 \mathrm{M}$ borax to shift equilibrium concentration of xylulose/xylose and improve the isomerization step. However, although the isomerization was enhanced, only half of the available xylose was consumed. Lastick et al. [43] observed an ethanol titer of $2.1 \%(\mathrm{w} / \mathrm{v})$ from the SIF of $6 \%$ xylose using XI and Schizosaccharomyces pombe (Y-164). Silva et al. [7] studied the SIF of $65 \mathrm{~g} / \mathrm{L}$ of xylose at $30^{\circ} \mathrm{C}$, using a biocatalyst containing $32.5 \times 10^{3} \mathrm{IU} / \mathrm{L}$ of xylose isomerase and $20 \mathrm{~g} / \mathrm{L}$ of yeast co-immobilized in Ca-alginate gel, and reported an ethanol productivity of $0.25 \mathrm{~g} / \mathrm{L} / \mathrm{h}$. However, the isomerization step became a limiting factor, due to the decrease of the $\mathrm{pH}$ from 5.3 (initial) to 4.8 (final). Milessi et al. [15] incorporated $\mathrm{CaCO}_{3}$ into SIF beads to control the $\mathrm{pH}$ 
of the process. The biocatalysts were prepared with 20\% chitosan-immobilized XI and $10 \%$ fresh yeast. An ethanol yield of $0.35 \mathrm{~g} / \mathrm{g}$ ( $70 \%$ of the theoretical yield) and $2 \mathrm{~g} / \mathrm{L} / \mathrm{h}$ productivity was observed. However, the long time needed by $S$. cerevisiae to ferment xylulose makes the SIF process susceptible to contamination by bacteria capable of metabolizing the xylose.

In this context, the proposed SHIF process appears as a promising approach for $2 \mathrm{G}$ ethanol production from hemicellulose. Process conditions and enzyme loads in the biocatalyst can be optimized to achieve higher yields and productivity as well as to overcome the difference between optimal $\mathrm{pH}$ ranges for each step of the process. Despite the improvement achieved after $\mathrm{pH}$ control and supplementation with excess of $\mathrm{Mg}^{2+}$, a small accumulation of xylose was still observed, which suggests that the isomerization step may be still limiting the process. There are other factors that might be affecting the isomerization and/or the fermentation steps, such as the presence of xylooligosaccharides ( $2-8$ xylose units) or other intermediate products released during the xylan hydrolysis, which are not present in the SIF process. The understanding of the influence of these compounds as well as the optimization of the biocatalyst composition regarding the balance of the enzyme pool are important issues to be addressed in order to improve ethanol production rates.

In general, the SHIF process using co-immobilized enzymes and cells stands out for $2 \mathrm{G}$ ethanol production. Besides presenting the advantages of multi-enzymatic cascade reactions, it also enables an easy recovery of the biocatalyst, which could be applied in continuous or repeated batch ethanol production runs using a medium that inhibits contamination. In addition, it builds on the advantage of using the same native yeast, already employed in $1 \mathrm{G}$ ethanol industry, which simplifies the operation of the fermentation unit. The low genetic stability of recombinant microorganisms together with the strict Brazilian biosafety regulations for genetically modified organisms (GMO) application in the industrial environment make the $2 \mathrm{G}$ ethanol production process based on a native yeast an attractive alternative.

\section{Materials and Methods}

\subsection{Materials}

GENSWEET $^{\circledR}$ SGI $\left(3400 \mathrm{IU} / \mathrm{mL}, 127 \mathrm{mg}_{\text {protein }} / \mathrm{mL}\right.$, DuPont ${ }^{\mathrm{TM}}$ Genencor ${ }^{\circledR}$, Palo Alto, CA, USA), an enzymatic extract of commercial xylose isomerase (EC 5.3.1.5) from Streptomyces rubiginosus, and the commercial enzyme preparations Accellerase $X Y\left(3670 \mathrm{IU} / \mathrm{mL}, 9.8 \mathrm{mg}_{\text {protein }} / \mathrm{mL}\right)$ and Multifect CX XL A03139 (785 IU / mL, $35 \mathrm{mg}_{\text {protein }} / \mathrm{mL}$ ) were kindly donated by DuPont ${ }^{\mathrm{TM}}$ Genencor ${ }^{\circledR}$ (Palo Alto, CA, USA). The Bacillus subtilis recombinant endoxylanase ( $502 \mathrm{IU} / \mathrm{mL}, 9.2 \mathrm{mg}$ protein $/ \mathrm{mL}$ ) was donated by Verdartis (Ribeirão Preto, SP, Brazil). Powdered chitosan ( $85.2 \%$ deacetylation degree) was supplied by Polymar Ind. Ltda (Fortaleza, CE, Brazil) and 25\% glutaraldehyde solution was purchased from Vetec (Duque de Caxias, RJ, Brazil). Birchwood and beechwood xylans were from Sigma-Aldrich (St. Louis, MO, USA). A Saccharomyces cerevisiae industrial strain (purchased from Itaiquara ${ }^{\circledR}$, Tapiratiba, SP, Brazil) was used in all SHIF experiments. All other reagents were of analytical grade.

\subsection{Biocatalyst Production}

\subsubsection{Preparation of Chitosan-Glutaraldehyde Beads}

Chitosan gel $(2 \%$ or $4 \%, \mathrm{w} / \mathrm{v})$ was prepared as described by Budriene et al. [44], using the coagulation of the chitosan-acetic acid solution in $0.5 \mathrm{M} \mathrm{KOH}$. Activation of the support was carried out by the addition of glutaraldehyde $(5 \%, \mathrm{v} / \mathrm{v})$ in a suspension of chitosan at $\mathrm{pH} 7.0(100 \mathrm{mM}$ phosphate buffer, 1:10 $\left.\mathrm{m}_{\text {support }} / \mathrm{v}_{\text {suspension }}\right)$. After $60 \mathrm{~min}$ stirring at $25^{\circ} \mathrm{C}$, the support was filtered under vacuum, washed first with distilled water until neutrality, and then with ultrapure water. 


\subsubsection{Enzyme Immobilization}

Xylose isomerase immobilization was carried out onto $2 \%(\mathrm{w} / \mathrm{v})$ chitosan-glutaraldahyde according to Silva et al. [7]. The enzyme solution was prepared in $50 \mathrm{mM}$ Tris-maleate buffer (pH 7.0) containing $5 \mathrm{mM} \mathrm{MgSO}_{4} .7 \mathrm{H}_{2} \mathrm{O}$ and $2.5 \mathrm{mM} \mathrm{CoCl}_{2} \cdot 6 \mathrm{H}_{2} \mathrm{O}$, in order to provide $50 \mathrm{mg}_{\text {protein }} / \mathrm{g}_{\text {support }}$. The support was added to the enzyme solution at a ratio of 1:10 (w/v). After $20 \mathrm{~h}$ of immobilization at $25^{\circ} \mathrm{C}$ under $150 \mathrm{rpm}$ stirring, sodium borohydride was added $(1 \mathrm{mg} / \mathrm{mL})$ and the suspension was kept under gentle agitation for $30 \mathrm{~min}$ in an ice bath [45]. The derivatives were filtered and washed under vacuum, first with $200 \mathrm{mM}$ Tris-maleate buffer ( $\mathrm{pH}$ 7.0), then with ultrapure water, and finally with $50 \mathrm{mM}$ Tris-maleate buffer ( $\mathrm{pH}$ 7.0), in order to remove borohydride and adsorbed enzyme.

Xylanase complexes were immobilized onto $4 \%(\mathrm{w} / \mathrm{v})$ chitosan-glutaraldehyde according to Milessi et al. [28]. The immobilizations were performed at $\mathrm{pH} 7.0$ (100 mM phosphate buffer), $25^{\circ} \mathrm{C}$, and under constant stirring. A load of $20 \mathrm{mg}_{\text {protein }} / \mathrm{g}_{\text {support }}$ was offered, maintaining 1:10 (w/v) ratio of mass of support to volume of enzymatic solution. After the completion of immobilization, sodium borohydride was added $(1 \mathrm{mg} / \mathrm{mL})$ and the reduction reaction proceeded for $30 \mathrm{~min}$ at $4{ }^{\circ} \mathrm{C}$. The derivatives were extensively washed with $50 \mathrm{mM}$ citrate buffer $\mathrm{pH} 4.8$ and stored until use.

\subsubsection{Biocatalyst Co-immobilization}

The biocatalyst preparation was carried out through Ca-alginate gel entrapment according to the methodology described in Silva et al. [7]. The industrial strain, supplied as freshly compressed yeast cells, was used as purchased, without previous propagation or activation [46]. A solution of sodium alginate ( $1 \% \mathrm{w} / \mathrm{v})$, immobilized XI (15\% w/v), immobilized xylanase (5\% w/v), and fresh yeast $(10 \% \mathrm{w} / \mathrm{v})$ was gently dropped into a $0.25 \mathrm{M} \mathrm{CaCl}_{2} / 0.25 \mathrm{M} \mathrm{MgCl}_{2}$ solution. Spherical particles $(\varnothing=1-1.5 \mathrm{~mm})$ were produced using a pneumatic extruder [47]. The procedure was carried out in a laminar flow chamber (Airstream, ESCO, Horsham, PA, USA) and the sodium alginate and coagulation solutions were previously sterilized at $121^{\circ} \mathrm{C}$ for $20 \mathrm{~min}$. After immobilization, the beads were cured in a refrigerator for $12-16 \mathrm{~h}$ in cure solution $\left(4 \mathrm{~g} / \mathrm{L}\right.$ of $\mathrm{MgSO}_{4}, 10 \mathrm{~g} / \mathrm{L}$ of $\mathrm{KH}_{2} \mathrm{PO}_{4}, 3 \mathrm{~g} / \mathrm{L}$ of urea, $0.2 \mathrm{~g} / \mathrm{L}$ of $\mathrm{CoCl}_{2}$, and $4 \mathrm{~g} / \mathrm{L}$ of $\mathrm{CaCl}_{2} \cdot 2 \mathrm{H}_{2} \mathrm{O}$ ).

\subsection{Simultaneous Hydrolysis, Isomerization, and Fermentation (SHIF) of Birchwood Xylan}

First, the birchwood xylan substrate was hydrolyzed in smaller xylo-oligomers by the action of recombinant endoxylanase of B. subtilis (XynA) in order to make xylan more similar to lignocellulosic hydrolysates, since after a pretreatment step the xylo-oligomers present in the medium are smaller than those in commercial xylan [28]. Xylan pre-hydrolysis was carried out by XynA (150 IU/gxylan, $3.8 \mathrm{IU} / \mathrm{mL})$ immobilized on chitosan-glutaraldehyde $(35.0 \pm 0.8 \mathrm{IU} / \mathrm{g})$ for $24 \mathrm{~h}$ and $50{ }^{\circ} \mathrm{C}$ under $150 \mathrm{rpm}$ stirring. At the end, the immobilized enzyme was recovered by filtration and the dried xylan mass retained on the filter was quantified (xylan insoluble fraction). The $\mathrm{pH}$ of the xylan solubilized fraction (SHIF substrate) was adjusted to 5.6 with $\mathrm{HCl}$ or $\mathrm{NaOH} 1 \mathrm{M}$ and the medium was sterilized by filtration through a $0.22 \mu \mathrm{m}$ membrane. SHIF experiments were carried out in a shaker incubator $\left(32{ }^{\circ} \mathrm{C}\right.$ and $150 \mathrm{rpm}$ ), using sealed tubes with a total reaction volume of $2.4 \mathrm{~mL}$ (bead ratio of 1:1, $1.2 \mathrm{~g}$ of beads and $1.2 \mathrm{~mL}$ of medium, bead density was $\left.1 \mathrm{~g} / \mathrm{cm}^{3}\right)$. The composition of SHIF medium was $108 \mathrm{~g} / \mathrm{L}$ of birchwood xylan supplemented with $\mathrm{MgSO}_{4}(4 \mathrm{~g} / \mathrm{L}), \mathrm{KH}_{2} \mathrm{PO}_{4}(10 \mathrm{~g} / \mathrm{L})$, urea $(3 \mathrm{~g} / \mathrm{L}), \mathrm{CoCl}_{2} \cdot 6 \mathrm{H}_{2} \mathrm{O}$ $(0.2 \mathrm{~g} / \mathrm{L})$, and $\mathrm{CaCl}_{2} \cdot 2 \mathrm{H}_{2} \mathrm{O}(4 \mathrm{~g} / \mathrm{L})$. Samples were collected at regular intervals for determination of $\mathrm{pH}$, substrate consumption, and product formation.

\subsection{Influence of $\mathrm{pH}, \mathrm{Ca}^{2+}$, and $\mathrm{Mg}^{2+}$ on XI Activity}

In order to study the influence of $\mathrm{Ca}^{2+}$ and $\mathrm{Mg}^{2+}$ ions on the catalytic activity of XI, the enzyme activity was measured at different $\mathrm{pHs}$ (5.0 to 8.0) and different ion concentrations. Nine medium compositions were tested for each studied $\mathrm{pH}$. The standard medium was constituted of $2 \mathrm{M}$ fructose at pH 8.0 (50 mM Tris-maleate buffer), $50 \mathrm{mM} \mathrm{MgSO}_{4}$, and $2.5 \mathrm{mM} \mathrm{CoCl}_{2}$. 


\subsection{Enzymatic Xylan Hydrolysis for Xylanase Selection}

Xylan hydrolysis was carried out using the soluble fraction of the birchwood xylan obtained by adding $8 \mathrm{~g}$ of commercial birchwood xylan in $100 \mathrm{~mL}$ of $50 \mathrm{mM}$ citrate buffer, $\mathrm{pH} 5.5$ at $50{ }^{\circ} \mathrm{C}$. After $1 \mathrm{~h}$ at $150 \mathrm{rpm}$ stirring, the solution was centrifuged for $20 \mathrm{~min}$ at $9500 \times g$ and $5{ }^{\circ} \mathrm{C}$. The supernatant was then recovered for further use at the concentration of $25 \mathrm{~g} / \mathrm{L}$ of xylan. It was offered $150 \mathrm{IU} / \mathrm{g}_{x y l a n}$ $\left(3.8 \mathrm{IU} / \mathrm{mL}_{\text {reactor }}\right)$. The reaction was conducted at $50{ }^{\circ} \mathrm{C}$ under mechanical stirring for $24 \mathrm{~h}$.

\subsection{Analytical Methods}

\subsubsection{Xylanase Activity}

Xylanase activity was determined according to International Union of Pure and Applied Chemistry (IUPAC) [48] by calculating the initial velocity of xylan hydrolysis catalyzed by a known amount of enzyme. The standard substrate was birchwood xylan (1\% w/v) in $50 \mathrm{mM}$ citrate buffer $\mathrm{pH}$ 5.5. Enzyme was added to the reaction medium and incubated at $50^{\circ} \mathrm{C}$ for $10 \mathrm{~min}$ under $250 \mathrm{rpm}$ stirring. Aliquots were withdrawn at 2 min intervals, and the released reducing sugars were quantified by the dinitrosalicylic (DNS) acid method [49]. One unit of activity (IU) was defined as the amount of enzyme required to release $1 \mu \mathrm{mol}$ of xylose per minute under the assayed conditions.

\subsubsection{Xylose Isomerase Activity}

Xylose isomerase activity was determined according to Giordano et al. [13], by measuring the initial velocity of fructose isomerization to glucose, under the following conditions: $2 \mathrm{M}$ fructose solution prepared in $50 \mathrm{mM}$ Tris-maleate buffer containing $50 \mathrm{mM} \mathrm{MgSO} \cdot 7 \mathrm{H}_{2} \mathrm{O}$ and $2.5 \mathrm{mM}$ $\mathrm{CoCl}_{2} \cdot 6 \mathrm{H}_{2} \mathrm{O}$, at $\mathrm{pH} 7.0$ and $60^{\circ} \mathrm{C}$. The glucose concentration was determined colorimetrically using the commercial enzyme kit containing glucose oxidase and peroxidase (GOD-PAP ${ }^{\circledR}$, Bioclin, Belo Horizonte, Mg, Brazil). One international unit (IU) of xylose isomerase was defined as the amount of enzyme that released $1 \mu \mathrm{mol}$ of glucose per minute under the assayed conditions.

\subsubsection{Substrate and Product Quantification}

The concentrations of XOs, xylose, xylulose, xylitol, and ethanol were determined by high performance liquid chromatography (HPLC), equipped with a Waters Sugar-Pak I column (Milford, MA, USA) $(300 \times 6.5 \mathrm{~mm})$ coupled to a refractive index detector (W410 Waters) (Milford, MA, USA). Ultrapure water was used as eluent at a flow rate of $0.5 \mathrm{~mL} / \mathrm{min}$. The column temperature was $80^{\circ} \mathrm{C}$, the detector was set at $40^{\circ} \mathrm{C}$, and the injected volume was $20 \mu \mathrm{L}$. Before the analysis, the samples were filtered using a $0.22 \mu \mathrm{m}$ filter.

\section{Conclusions}

A new biocatalyst composed of co-immobilized xylanases, xylose isomerase, and unmodified S. cerevisiae was able to produce $2 \mathrm{G}$ ethanol from birchwood xylan in a one-spot multi-enzymatic simultaneous hydrolysis, isomerization, and fermentation (SHIF) process. Although more studies are required to increase ethanol productivity, the SHIF process showed to be promising from the point of view of its technical viability. The SHIF process brings advantages to industrial applications for easing the integration of $1 \mathrm{G}$ and $2 \mathrm{G}$ ethanol production processes (because both are based on the same native yeast strains), while reducing the contamination risk due to the use of xylo-oligomers as substrate instead of xylose.

Author Contributions: T.S.M. and F.A.S.C. performed the experiments, analyzed the data, and wrote the paper; W.K. performed the experiments; P.W.T and T.C.Z. analyzed the data and revised the paper; R.C.G. and R.L.C.G. supervised the work and reviewed the final manuscript.

Funding: This research was funded by the São Paulo Research Foundation (FAPESP), grants \#2008/56246-0 and \#2016/10636-8, the Brazilian National Council for Scientific and Technological Development (CNPq) grant 
\#140982/2013-2, and in part by the Coordenação de Aperfeiçoamento de Pessoal de Nível Superior - Brazil (CAPES), Finance Code 001.

Acknowledgments: The authors thank DuPont ${ }^{\mathrm{TM}}$ Genencor $^{\circledR}$ (USA) for the donation of xylose isomerase, Accellerase, and Multifect xylanases; and Verdartis for the donation of xylanase from B. subtilis.

Conflicts of Interest: The authors declare no conflict of interest.

\section{References}

1. Antunes, F.A.F.; Chandel, A.K.; Milessi, T.S.S.; Santos, J.C.; Rosa, C.A.; da Silva, S.S. Bioethanol Production from Sugarcane Bagasse by a Novel Brazilian Pentose Fermenting Yeast Scheffersomyces shehatae UFMG-HM 52.2: Evaluation of Fermentation Medium. Int. J. Chem. Eng. 2014, 2014, 1-8. [CrossRef]

2. UNFCC Conference of the Parties. Adoption of the Paris Agreement. Report No. FCC/CP/2015/L.9/Rev1. United Nations Framew. Conv. Clim. Chang. 2015. Available online: http://unfccc.int/resource/docs/2015/ cop21/eng/109r01.pdf (accessed on January 2019).

3. Nigam, P.S.; Singh, A. Production of liquid biofuels from renewable resources. Prog. Energy Combust. Sci. 2011, 37, 52-68. [CrossRef]

4. Canilha, L.; Chandel, A.K.; Suzane dos Santos Milessi, T.; Antunes, F.A.F.; Luiz da Costa Freitas, W.; das Graças Almeida Felipe, M.; da Silva, S.S. Bioconversion of Sugarcane Biomass into Ethanol: An Overview about Composition, Pretreatment Methods, Detoxification of Hydrolysates, Enzymatic Saccharification, and Ethanol Fermentation. J. Biomed. Biotechnol. 2012, 2012, 1-15. [CrossRef] [PubMed]

5. Dos Santos, L.V.; de Barros Grassi, M.C.; Gallardo, J.C.M.; Pirolla, R.A.S.; Calderón, L.L.; de Carvalho-Netto, O.V.; Parreiras, L.S.; Camargo, E.L.O.; Drezza, A.L.; Missawa, S.K.; et al. Second-Generation Ethanol: The Need is Becoming a Reality. Ind. Biotechnol. 2016, 12, 40-57. [CrossRef]

6. Hahn-Hägerdal, B.; Jeppsson, H.; Skoog, K.; Prior, B.A. Biochemistry and physiology of xylose fermentation by yeasts. Enzyme Microb. Technol. 1994, 16, 933-943. [CrossRef]

7. Silva, C.R.; Zangirolami, T.C.; Rodrigues, J.P.; Matugi, K.; Giordano, R.C.; Giordano, R.L.C. An innovative biocatalyst for production of ethanol from xylose in a continuous bioreactor. Enzyme Microb. Technol. 2012, 50, 35-42. [CrossRef] [PubMed]

8. $\quad$ Demeke, M.M.; Dietz, H.; Li, Y.; Foulquié-Moreno, M.R.; Mutturi, S.; Deprez, S.; Den Abt, T.; Bonini, B.M.; Liden, G.; Dumortier, F.; et al. Development of a D-xylose fermenting and inhibitor tolerant industrial Saccharomyces cerevisiae strain with high performance in lignocellulose hydrolysates using metabolic and evolutionary engineering. Biotechnol. Biofuels 2013, 6, 89. [CrossRef] [PubMed]

9. Zhang, T.; Chi, Z.; Zhao, C.H.; Chi, Z.M.; Gong, F. Bioethanol production from hydrolysates of inulin and the tuber meal of Jerusalem artichoke by Saccharomyces sp. W0. Bioresour. Technol. 2010, 101, 8166-8170. [CrossRef] [PubMed]

10. Hector, R.E.; Mertens, J.A.; Bowman, M.J.; Nichols, N.N.; Cotta, M.A.; Hughes, S.R. Saccharomyces cerevisiae engineered for xylose metabolism requires gluconeogenesis and the oxidative branch of the pentose phosphate pathway for aerobic xylose assimilation. Yeast 2011, 28, 645-660. [CrossRef] [PubMed]

11. Kuyper, M.; Winkler, A.A.; van Dijken, J.P.; Pronk, J.T. Minimal metabolic engineering of Saccharomyces cerevisiae for efficient anaerobic xylose fermentation: A proof of principle. FEMS Yeast Res. 2004, 4, 655-664. [CrossRef] [PubMed]

12. Ohgren, K.; Bengtsson, O.; Gorwa-Grauslund, M.F.; Galbe, M.; Hahn-Hägerdal, B.; Zacchi, G. Simultaneous saccharification and co-fermentation of glucose and xylose in steam-pretreated corn stover at high fiber content with Saccharomyces cerevisiae TMB3400. J. Biotechnol. 2006, 126, 488-498. [CrossRef] [PubMed]

13. Giordano, R.L.C.; Giordano, R.C.; Cooney, C.L. A study on intra-particle diffusion effects in enzymatic reactions: Glucose-fructose isomerization. Bioprocess Eng. 2000, 23, 0159-0166. [CrossRef]

14. Gong, C.S. Recent Advances in D-Xylose Conversion by Yeasts. In Annual Reports on Fermentation Processes; Tsao, G.T., Ed.; Academic Press: New York, NY, USA, 1983; Volume 6, pp. 253-297.

15. Milessi, T.S.; Aquino, P.M.; Silva, C.R.; Moraes, G.S.; Zangirolami, T.C.; Giordano, R.C.; Giordano, R.L.C. Influence of key variables on the simultaneous isomerization and fermentation (SIF) of xylose by a native Saccharomyces cerevisiae strain co-encapsulated with xylose isomerase for $2 \mathrm{G}$ ethanol production. Biomass Bioenergy 2018, 119, 277-283. [CrossRef] 
16. Silva, S.S.; Mussatto, S.I.; Santos, J.C.; Santos, D.T.; Polizel, J. Cell immobilization and xylitol production using sugarcane bagasse as raw material. Appl. Biochem. Biotechnol. 2007, 141, 215-227. [CrossRef] [PubMed]

17. Guisan, J.M. New Opportunities for Immobilization of Enzymes. In Methods in Molecular Biology; Guisan, J.M., Ed.; Springer: Clifton, NJ, USA, 2013; pp. 1-13.

18. DiCosimo, R.; McAuliffe, J.; Poulose, A.J.; Bohlmann, G. Industrial use of immobilized enzymes. Chem. Soc. Rev. 2013, 42, 6437-6474. [CrossRef] [PubMed]

19. Choi, J.-M.; Han, S.-S.; Kim, H.-S. Industrial applications of enzyme biocatalysis: Current status and future aspects. Biotechnol. Adv. 2015, 33, 1443-1454. [CrossRef] [PubMed]

20. Hernández, R.M.A.; Orive, G.; Murua, A.; Pedraz, J.L. Microcapsules and microcarriers for in situ cell delivery. Adv. Drug Deliv. Rev. 2010, 62, 711-730. [CrossRef] [PubMed]

21. Carvalho, A.F.A.; de Oliva Neto, P.; da Silva, D.F.; Pastore, G.M. Xylo-oligosaccharides from lignocellulosic materials: Chemical structure, health benefits and production by chemical and enzymatic hydrolysis. Food Res. Int. 2013, 51, 75-85. [CrossRef]

22. Gray, M.C.; Converse, A.O.; Wyman, C.E. Solubilities of Oligomer Mixtures Produced by the Hydrolysis of Xylans and Corn Stover in Water at $180^{\circ}$ C. Ind. Eng. Chem. Res. 2007, 46, 2383-2391. [CrossRef]

23. Biely, P.; Singh, S.; Puchart, V. Towards enzymatic breakdown of complex plant xylan structures: State of the art. Biotechnol. Adv. 2016, 34, 1260-1274. [CrossRef] [PubMed]

24. Giordano, R.L.C.; Giordano, R.C.; Zangirolami, T.C.; Tardioli, P.W.; Kopp, W.; Milessi, T.; Silva, C.R.; Cavalcanti-Montano, I.D.; Galeano-Suarez, C.A.; Rojas, M.J.; et al. Sistema catalítico e processo de obtenção de bioetanol 2g a partir de xilana/oligômeros de xilose. Brazilian Patent BR102014023394, 19 September 2014.

25. Macrelli, S.; Galbe, M.; Wallberg, O. Effects of production and market factors on ethanol profitability for an integrated first and second generation ethanol plant using the whole sugarcane as feedstock. Biotechnol. Biofuels 2014, 7, 26. [CrossRef] [PubMed]

26. Ricca, E.; Brucher, B.; Schrittwieser, J.H. Multi-Enzymatic Cascade Reactions: Overview and Perspectives. Adv. Synth. Catal. 2011, 353, 2239-2262. [CrossRef]

27. Rao, K.; Chelikani, S.; Relue, P.; Varanasi, S. A Novel Technique that Enables Efficient Conduct of Simultaneous Isomerization and Fermentation (SIF) of Xylose. Appl. Biochem. Biotechnol. 2008, 146, 101-117. [CrossRef] [PubMed]

28. Milessi, T.S.S.; Kopp, W.; Rojas, M.J.; Manrich, A.; Baptista-Neto, A.; Tardioli, P.W.; Giordano, R.C.; Fernandez-Lafuente, R.; Guisan, J.M.; Giordano, R.L.C. Immobilization and stabilization of an endoxylanase from Bacillus subtilis (XynA) for xylooligosaccharides (XOs) production. Catal. Today 2016, 259, 130-139. [CrossRef]

29. Fuxreiter, M.; Böcskei, Z.; Szeibert, A.; Szabó, E.; Dallmann, G.; Naray-Szabo, G.; Asboth, B. Role of electrostatics at the catalytic metal binding site in xylose isomerase action: $\mathrm{Ca}(2+)$-inhibition and metal competence in the double mutant D254E/D256E. Proteins 1997, 28, 183-193. [CrossRef]

30. Kovalevsky, A.Y.; Hanson, L.; Fisher, S.Z.; Mustyakimov, M.; Mason, S.A.; Trevor Forsyth, V.; Blakeley, M.P.; Keen, D.A.; Wagner, T.; Carrell, H.L.; et al. Metal Ion Roles and the Movement of Hydrogen during Reaction Catalyzed by D-Xylose Isomerase: A Joint X-Ray and Neutron Diffraction Study. Structure 2010, 18, 688-699. [CrossRef] [PubMed]

31. Bhosale, S.H.; Rao, M.B.; Deshpande, V. V Molecular and industrial aspects of glucose isomerase. Microbiol. Rev. 1996, 60, 280-300. [PubMed]

32. Asboth, B.; Naray-Szabo, G. Mechanism of Action of D-Xylose Isomerase. Curr. Protein Pept. Sci. 2000, 1, 237-254. [CrossRef] [PubMed]

33. Allen, K.N.; Lavie, A.; Glasfeld, A.; Tanada, T.N.; Gerrity, D.P.; Carlson, S.C.; Farber, G.K.; Petsko, G.A.; Ringe, D. Role of the divalent metal ion in sugar binding, ring opening, and isomerization by D-xylose isomerase: Replacement of a catalytic metal by an amino acid. Biochemistry 1994, 33, 1488-1494. [CrossRef] [PubMed]

34. Kasumi, T.; Hayashi, K.; Tsumura, N. Roles of Magnesium and Cobalt in the Reaction of Glucose Isomerase from Streptomyces griseofuscus S-41. Agric. Biol. Chem. 1982, 46, 21-30. [CrossRef]

35. Jacobsen, S.E.; Wyman, C.E. Xylose Monomer and Oligomer Yields for Uncatalyzed Hydrolysis of Sugarcane Bagasse Hemicellulose at Varying Solids Concentration. Ind. Eng. Chem. Res. 2002, 41, 1454-1461. [CrossRef]

36. Dodd, D.; Cann, I.C.K.O. Enzymatic deconstruction of xylan for biofuel production. GCB Bioenergy 2009, 1, 2-17. [CrossRef] [PubMed] 
37. Akpinar, O.; Erdogan, K.; Bostanci, S. Production of xylooligosaccharides by controlled acid hydrolysis of lignocellulosic materials. Carbohydr. Res. 2009, 344, 660-666. [CrossRef] [PubMed]

38. Aragon, C.C.; Santos, A.F.; Ruiz-Matute, A.I.; Corzo, N.; Guisan, J.M.; Monti, R.; Mateo, C. Continuous production of xylooligosaccharides in a packed bed reactor with immobilized-stabilized biocatalysts of xylanase from Aspergillus versicolor. J. Mol. Catal. B Enzym. 2013, 98, 8-14. [CrossRef]

39. Biely, P. Xylanolytic Enzymes. In Handbook of Food Enzymology; Whitaker, J., Voragen, A., Wong, D., Eds.; CRC Press: Boca Raton, FL, USA, 2003; pp. 879-916.

40. Rahim, S.N.A.; Alawi, S.; Hamid, K.H.K.; Edama, N.A.; Baharuddin, A.S. Effect of Agitation Speed for Enzymatic Hydrolysis of Tapioca Slurry Using Encapsulated Enzymes in an Enzyme Bioreactor. Int. J. Chem. Eng. Appl. 2015, 6, 38-41.

41. Carvalho, W.; Canilha, L.; Silva, S.S. Semi-continuous xylose-to-xylitol bioconversion by Ca-alginate entrapped yeast cells in a stirred tank reactor. Bioprocess Biosyst. Eng. 2008, 31, 493-498. [CrossRef] [PubMed]

42. Nakata, T.; Miyafuji, H.; Saka, S. Ethanol production with $\beta$-xylosidase, xylose isomerase, and Saccharomyces cerevisiae from the hydrolysate of Japanese beech after hot-compressed water treatment. J. Wood Sci. 2009, 55, 289-294. [CrossRef]

43. Lastick, S.M.; Tucker, M.Y.; Beyette, J.R.; Noll, G.B.; Grohmann, K. Simultaneous fermentation and isomerization of xylose. Appl. Microbiol. Biotechnol. 1989, 30, 574-579. [CrossRef]

44. Budriene, S.; Gorochovceva, N.; Romaskevic, T.; Yugova, L.V.; Miezeliene, A.; Dienys, G.; Zubriene, A. $\beta$-Galactosidase from Penicillium canescens. Properties and immobilization. Cent. Eur. J. Chem. 2005, 3, 95-105. [CrossRef]

45. Guisán, J. Aldehyde-agarose gels as activated supports for immobilization-stabilization of enzymes. Enzyme Microb. Technol. 1988, 10, 375-382. [CrossRef]

46. Basso, L.C.; de Amorim, H.V.; de Oliveira, A.J.; Lopes, M.L. Yeast selection for fuel ethanol production in Brazil. FEMS Yeast Res. 2008, 8, 1155-1163. [CrossRef] [PubMed]

47. Trovati, J.; Giordano, R.C.; Giordano, R.L.C. Improving the Performance of a Continuous Process for the Production of Ethanol from Starch. Appl. Biochem. Biotechnol. 2009, 156, 76-90. [CrossRef] [PubMed]

48. Ghose, T.K.; Bisaria, V.S. Measurement of hemicellulase activities: Part I Xylanases. Pure Appl. Chem. 1987, 59, 1739-1751. [CrossRef]

49. Miller, G.L. Use of dinitrosalicylic acid reagent for determination of reducing sugar. Anal. Chem. 1959, 31, 426-428. [CrossRef]

(C) 2019 by the authors. Licensee MDPI, Basel, Switzerland. This article is an open access article distributed under the terms and conditions of the Creative Commons Attribution (CC BY) license (http:/ / creativecommons.org/licenses/by/4.0/). 
Article

\title{
Highly Selective Oxidation of 5-Hydroxymethylfurfural to 5-Hydroxymethyl- 2-Furancarboxylic Acid by a Robust Whole-Cell Biocatalyst
}

\author{
Ran Cang ${ }^{1,+}$, Li-Qun Shen ${ }^{1,+}$, Guang Yang ${ }^{1}$, Zhi-Dong Zhang ${ }^{3}$, He Huang ${ }^{1,2, *}$ \\ and Zhi-Gang Zhang ${ }^{1, *}$ \\ 1 School of Pharmaceutical Sciences, Nanjing Tech University, 30 Puzhu Road(S), Nanjing 211816, China; \\ crnj123@126.com (R.C.); shenliqun163@126.com (L.-Q.S.); qwe88227518@njtech.edu.cn (G.Y.) \\ 2 State Key Laboratory of Materials-Oriented Chemical Engineering, Nanjing Tech University, \\ 30 Puzhu Road(S), Nanjing 211816, China \\ 3 Institute of Microbiology, Xinjiang Academy of Agricultural Sciences, 403 Nanchang Rd, \\ Wulumuqi 830091, China; zhangzheedong@sohu.com \\ * Correspondence: huangh@njtech.edu.cn (H.H.); zhangzg@njtech.edu.cn (Z.-G.Z.) \\ + These authors contributed equally to this work.
}

Received: 16 May 2019; Accepted: 11 June 2019; Published: 12 June 2019

\begin{abstract}
Value-added utilization of biomass-derived 5-hydroxymethylfurfural (HMF) to produce useful derivatives is of great interest. In this work, extremely radiation resistant Deinococcus wulumuqiensis R12 was explored for the first time as a new robust biocatalyst for selective oxidation of HMF to 5-hydroxymethylfuroic acid (HMFCA). Its resting cells exhibited excellent catalytic performance in a broad range of $\mathrm{pH}$ and temperature values, and extremely high tolerance to HMF and the HMFCA product. An excellent yield of HMFCA (up to 90\%) was achieved when the substrate concentration was set to $300 \mathrm{mM}$ under the optimized reaction conditions. In addition, $511 \mathrm{mM}$ of product was obtained within $20 \mathrm{~h}$ by employing a fed-batch strategy, affording a productivity of $44 \mathrm{~g} / \mathrm{L}$ per day. Of significant synthetic interest was the finding that the $D$. wulumuqiensis $\mathrm{R} 12$ cells were able to catalyze the selective oxidation of other structurally diverse aldehydes to their corresponding acids with good yield and high selectivity, indicating broad substrate scope and potential widespread applications in biotechnology and organic chemistry.
\end{abstract}

Keywords: biocatalysis; extremophile; 5-hydroxymethylfurfural; 5-hydroxymethylfuroic acid; platform chemicals; whole cells

\section{Introduction}

The production of bio-fuels and chemicals from carbon-neutral and renewable biomass is attracting increasing interest [1-5]. Biomass is regarded as a sustainable resource from which some platform chemicals can be manufactured [6,7]. 5-hydroxymethylfurfural (HMF), derived from lignocellulosic materials via dehydration of carbohydrates, is one of the most important platform chemicals [8-10]. It has been listed as one of "Top 10+4" bio-based chemicals by the U.S. Department of Energy (DOE) [11], being applied in the synthesis of a variety of value-added pharmaceutical and biomaterial intermediates [12]. Due to its high reactivity, HMF is a versatile molecule that can be converted into various useful furan derivatives [12-14]. Its structure comprises a furan ring, an aldehyde group and a hydroxymethyl group which can be subjected to upgrading processes by selective redox reactions, leading to 5-hydroxymethylfuroic acid (HMFCA), 2,5-diformylfuran (DFF), 5-formylfuroic acid (FFCA), 2,5-furandicarboxylic acid (FDCA), maleic anhydride (MA) and 2,5-bis 
(hydroxymethyl) furan (BHMF) (Scheme 1). Among these HMF derivatives, the completely oxidized product FDCA displays very promising application potential and may serve as a "greener" substitute for terephthalate in the manufacture of polyester and polyamide materials $[15,16]$. HMFCA is the oxidation product of the aldehyde group in HMF and a promising starting material for the synthesis of various polyesters [17]. It was reported that HMFCA can also be used as an antitumor agent and interleukin inhibitor [18,19].

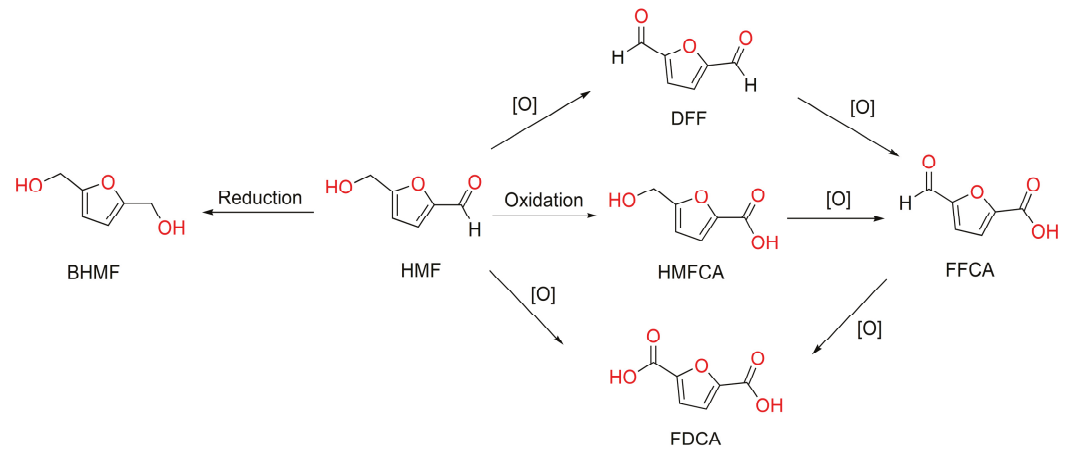

Scheme 1. Catalytic biotransformation of 5-hydroxymethylfurfural (HMF) into high value derivatives.

In order to form HMFCA, selective oxidation of the aldehyde group in HMF is required, while the alcohol group is left intact. Chemoselective oxidation methods are mainly used in the synthesis of HMFCA from HMF, in which noble metal catalysts are generally used [12,20-22]. Recently, HMF was selectively oxidized to HMFCA by an immobilized molybdenum complex in toluene within $3 \mathrm{~h}$, with a yield of approximately $87 \%$ [23]. Han et al. reported a selective and mild photocatalytic method for HMFCA synthesis from HMF under ultraviolet and visible light conditions with a yield of $90-95 \%$ [24]. In addition, the conversion of HMF to HMFCA via the Cannizzaro reaction is of great value $[25,26]$. However, the maximal selectivity of HMFCA was $50 \%$ due to the formation of an equimolar by-product.

Biocatalytic oxidation of HMF to HMFCA represents a promising alternative to chemical methods [14,27]. Biocatalysis offers many advantages, such as mild, environmentally friendly reaction conditions and often excellent selectivity, as well as high efficiency. However, compared to chemical methods, there are only a few reports on biotransformation of HMF to selectively form HMFCA in the literature [28-32]. In seminal work, Sheldon et al. reported the chloroperoxidase-catalyzed oxidation of HMF affording HMFCA with a selectivity of 25-40\% [31]. Krystof et al. reported lipase-mediated and peracid-assisted oxidation of the HMF process to produce HMFCA [32]. Recently, $\mathrm{Li}$ and co-workers made use of a molybdenum-dependent enzyme-xanthine oxidase from Escherichia coli-for the biocatalytic oxidation of HMF to form HMFCA, with 94\% yield and 99\% selectivity [29].

Relative to the use of isolated enzymes, we believe that, in HMF oxidation, whole-cell biocatalysts have advantages. They are not only inexpensive and relatively stable, but they also do not require cofactor regeneration [27,33]. Biocatalysis is more efficient when recombinant whole cells that overexpress the enzyme(s) important for catalysis are used [34]. However, employing whole-cell biocatalysts for HMF oxidation is still challenging due to the well-known toxicity of HMF to microbial cells [30]. In addition, due to the variety of enzymes in microbial cells many side reactions are likely to occur during the process of HMF oxidation with formation of HMFCA [28]. Hence, exploring highly tolerant and selective microbial strains is crucial for the biotransformation of HMF into value-added derivative. To our knowledge, there are only a few studies on whole-cell-catalyzed selective oxidation of HMF to form HMFCA in the literature [28,30]; processes that are accompanied by a certain amount of HMF derivatives as byproducts. It was reported that some Pseudomonas strains have an HMF degradation pathway, in which HMF is converted to HMFCA as an intermediate [35-37]. A careful 
literature search did not reveal any studies describing the use of this system for the production of HMFCA. In 2010, Koopman et al. reported the production of 2,5-furandicarboxylic acid (FDCA) from HMF by using recombinant P. putida S12_hmfH. As part of this biotransformation, HMFCA hardly accumulated, leading to a mixture of other metabolites [38,39]. Therefore, in the challenging quest to obtain large amounts of pure HMFCA, the use of the Pseudomonas strain metabolic pathway is not feasible. Moreover, long standing issues still exist, such as low substrate loading, substrate toxicity and insufficient selectivity, etc. Therefore, searching for new and robust biocatalytic systems with high selectivity is a demanding task.

Extremophiles are organisms that have evolved to thrive under one or more extreme adverse environmental conditions where other organisms cannot survive [40,41]. They are regarded as an ideal and valuable source of biocatalysts, allowing biotransformation under relatively harsh industrial conditions [42-44]. Nevertheless, employing whole-cells or isolated enzymes derived from extremophiles for biocatalysis in a general manner is just beginning to be implemented experimentally. Recently, a Deinococcus sp, designated as Deinococcus wulumuqiensis R12, was isolated from radiation-polluted soil [45,46]. Previous studies showed that it is phylogenetically more closely related to a prototype strain of the Deinococcus genus, namely Deinococcus radiodurans R1 [47]. It was found that this strain was capable of producing carotenoids with good yield, and related biosynthesis genes were subsequently cloned and heterogeneously expressed in E. coli. by $\mathrm{Xu}$ et al. [48]. Furthermore, its whole genome was sequenced by Huang et al. [49]. Recently, genes encoding heat shock proteins from D. wulumuqiensis R12 were introduced into Clostridium acetobutylicum ATCC824 in order to improve the robustness and butanol titers of host cells [50]. Considering the robustness of D. wulumuqiensis R12, it would be of great interest to explore the catalytic properties of its whole cells in biotransformation or bioconversion.

In this study, we report that the radiation resistant strain D. wulumuqiensis R12 that can indeed be used as a whole-cell biocatalyst in HMFCA synthesis by selective oxidation of HMF (Scheme 2). The catalytic properties of this strain were evaluated in the transformation of HMF, and the reaction conditions were optimized. In addition, the substrate scope of this new whole-cell biocatalyst was also investigated.

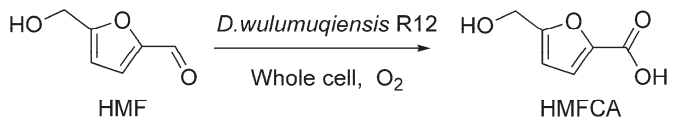

Scheme 2. Chemoselective oxidation of MF to 5-hydroxymethylfuroic acid (HMFCA) with whole D. wulumuqiensis R12 cells.

\section{Results and Discussion}

\subsection{Growing and Resting Deinococcus Cells as Catalysts in HMF Oxidation with Selective Formation of HMFCA}

Similar to the prototype strain of the Deinococcus genus, D. radiodurans $\mathrm{R} 1, D$. wulumuqiensis $\mathrm{R} 12$ is also well known for its excellent ability to resist extremely high doses of gamma and UV radiation [45]. In order to explore its potential applications in biocatalysis, growing and resting cells of this strain were applied as biocatalysts in the conversion of HMF to form HMFCA. As shown in Figure 1a, $100 \mathrm{mM}$ of the HMF substrate were converted almost completely within $12 \mathrm{~h}$ using resting cells, whereas growing cells gave only a $32 \%$ yield at a prolonged reaction time of $36 \mathrm{~h}$. Resting cells enabled a much higher yield with more than $98 \%$ of HMFCA and a trace amount of 2,5-bis (hydroxymethyl) furan (BHMF) as sole byproduct, indicating excellent chemoselectivity in this biocatalytic process. Increasing substrate concentration further did not affect the selectivity of the resting cells (Figure S2). Considering the reported degradation mechanism of HMF in microbial cells [51], it is reasonable to speculate that the intermediate HMF alcohol (from HMF reduction) was almost completely oxidized in a very 
short time to form the final HMFCA, or the HMF substrate was oxidized directly-which constitutes a different mechanistic hypothesis. However, to validate this inference, more efforts need to be invested.
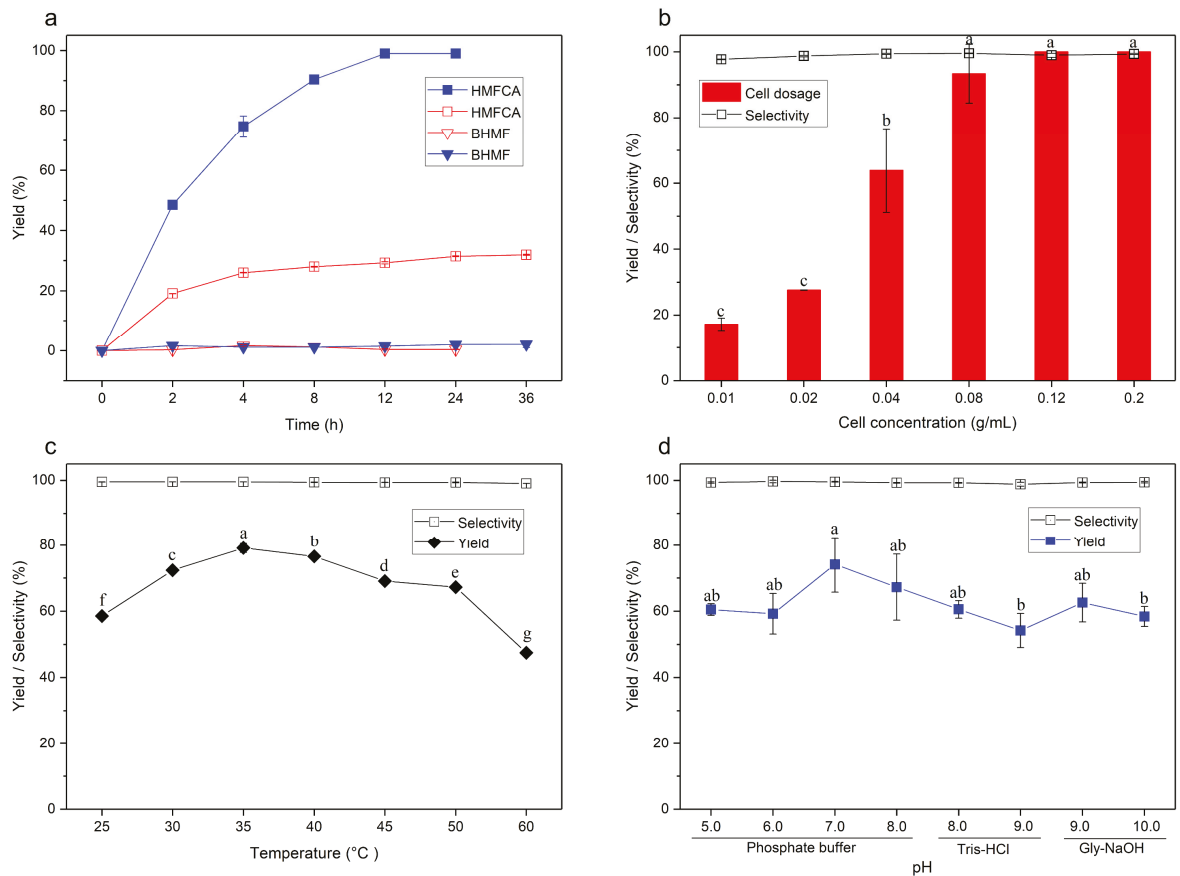

Figure 1. The influence of various factors on HMFCA synthesis by HMF. General conditions unless otherwise stated: $100 \mathrm{mM} \mathrm{HMF}, 0.12 \mathrm{~g} / \mathrm{mL}$ microbial cells, $100 \mathrm{mM}, \mathrm{pH}$ 7.4, phosphate buffer, $850 \mathrm{rpm}$, $30{ }^{\circ} \mathrm{C}$, 4 h reaction time. (a) Resting (solid symbols) and growing cells (open symbols), wherein tryptone glucose yeast extract (TGY) culture was used when growing cells were employed under $200 \mathrm{rpm}, 30^{\circ} \mathrm{C}$; (b) cell concentration; (c) temperature; and (d)pH values. Time courses of HMF biotransformation using resting (solid symbols) and growing cells (open symbols).

In addition, we were pleased to discover the performance of two other Deinococcus strains stored in our lab, D. radiodurans R1 and Deinococcus xibeiensis R13, which were also used in the biocatalytic oxidation of HMF to HMFCA. It was found that both radiation resistant strains selectively oxidized HMF with formation of HMFCA. The conversions achieved by D. radiodurans R1 and D. xibeiensis R13 were slightly lower than that of D. wulumuqiensis R12 under the same reaction conditions (Figure S3). These results suggest that the D. wulumuqiensis R12 cells act as a catalytic system with high activity and excellent chemoselectivity in the oxidation of HMF to HMFCA. Its catalytic properties were subsequently investigated in greater detail (Figure 1).

\subsection{Effect of Cell Dosage in the Reaction System for HMFCA Synthesis}

Figure $1 \mathrm{~b}$ shows the influence of microbial cell dosage on HMFCA synthesis based on selective oxidation of HMF. The yield of HMFCA increased steadily from 18\% to $99 \%$ with increasing cell dosage in the presence of $100 \mathrm{mM}$ of HMF substrate. The maximal yield of $99 \%$ was achieved when the cell dosage reached $0.12 \mathrm{~g} / \mathrm{mL}$, and further increasing did not improve the HMFCA yield, indicating that the biocatalyst was potentially saturated by substrate under the given reaction conditions. Our results imply that the conversion of HMF to HMFCA correlates with the cell dosage employed in the biocatalytic system. A small amount of cell dosage was required to reach maximal conversion 
when the substrate concentration decreased to $40 \mathrm{mM}$ under the same reaction conditions (Figure S4). In addition, cell dosage had no significant effect on the selectivity of the reactions (>98\%). A higher cell dosage may result in higher viscosity, however, which could impact mass transfer of the reaction mixture. Thus, the optimal cell dosage of $0.12 \mathrm{~g} / \mathrm{mL}$ wet cells was used in subsequent experiments.

\subsection{Effect of Temperature and $p H$ on HMFCA Synthesis}

The influence of temperature and $\mathrm{pH}$ on HMFCA synthesis in the whole-cell catalyzed oxidation of HMF was also studied. As shown in Figure 1c, the effect of reaction temperature on HMF selective oxidation was determined by performing the transformation at different temperatures. Remarkably, the microbial cell biocatalyst showed considerable activity at a broad temperature range, from 25 to $60{ }^{\circ} \mathrm{C}$. The maximal substrate conversion of $79 \%$ was obtained at $35^{\circ} \mathrm{C}$ after $4 \mathrm{~h}$ in the presence of $100 \mathrm{mM}$ HMF substrate. In addition, even at $50{ }^{\circ} \mathrm{C}, 67 \%$ of the $\mathrm{HMF}$ substrate was converted to HMFCA, which is in accord with an early report that $D$. wulumuqiensis $\mathrm{R} 12$ has a broad growth temperature range [45]. Slightly decreased conversion is possibly due to the inactivation of the enzymes in the microbial cells at $60^{\circ} \mathrm{C}$. It should be mentioned that HMFCA was obtained as essentially the only oxidative product-with a yield of $99 \%$-in the reaction within the temperature range of $25^{\circ} \mathrm{C}$ to $60^{\circ} \mathrm{C}$, indicating excellent catalytic selectivity of the whole-cell biocatalyst. Considering the thermostability of cells and energy efficiency, a temperature of $35^{\circ} \mathrm{C}$ was set for subsequent experiments.

In addition, we further studied the $\mathrm{pH}$ profile of the whole-cell catalyst in HMFCA synthesis via selective oxidation of HMF (Figure 1d). It was found that the microbial cells had a broadpH activity profile and exhibited a particularly good catalytic performance in the $\mathrm{pH}$ range of 5.0 to 10.0 . The best yield of $81 \%$ was achieved in $100 \mathrm{mM}$ phosphate buffer at a $\mathrm{pH} 7.0$ after $4 \mathrm{~h}$. Interestingly, a conversion percentage of $60 \%$ and $58 \%$ was obtained in phosphate buffer ofpH 5.0 and Gly-NaOH buffer ofpH 10.0, respectively, after a reaction time of $4 \mathrm{~h}$. In addition, it appeared that the buffer types had a moderate influence on the conversion of $\mathrm{HMF}$, as a yield of $54 \%$ was obtained in Tris- $\mathrm{HCl}$ buffer ( $\mathrm{pH} 9.0$ ), compared to $63 \%$ in Gly-NaOH buffer at the samepH . One should not be surprised that D. wulumuqiensis $\mathrm{R} 12$ cells are able to resist such harsh reaction conditions with extremepH values. In their studies, Wang et al. reported that the D. wulumuqiensis R12 strain is able to grow in a widepH range from 5.0 to 12.0 [45]. Compared to Comamonas testosterone SC1588, which has been applied in HMFCA synthesis from HMF [28], D. wulumuqiensis R12 cells showed higher tolerance to extremepH values. Therefore, the optimalpH value of 7.0 was selected for all subsequent experiments.

\subsection{Inhibitory and Toxic Effect of Substrate}

HMF is a well-known toxic inhibitor of microbial cells, inhibiting their growth and hindering their upgrading of HMF by whole-cell biocatalysis [52]. The catalytic performance of $D$. wulumuqiensis R12 cells towards HMF under varying concentrations was therefore tested. As shown in Figure 2a, HMFCA was synthesized in $99 \%$ yield within $12 \mathrm{~h}$ when the substrate concentration was $150 \mathrm{mM}$. However, the yield decreased slightly to $81 \%$ at the substrate concentration of $200 \mathrm{mM}$. The yield decreased gradually in the substrate concentration range of $250-1000 \mathrm{mM}$. Remarkably, $41 \%$ yield of HMFCA was obtained when the substrate concentration reached $500 \mathrm{mM}$, and a yield of $23 \%$ was observed at the substrate concentration of $1000 \mathrm{mM}$. The essentially complete selectivity remained almost constant at these varying substrate concentrations. 

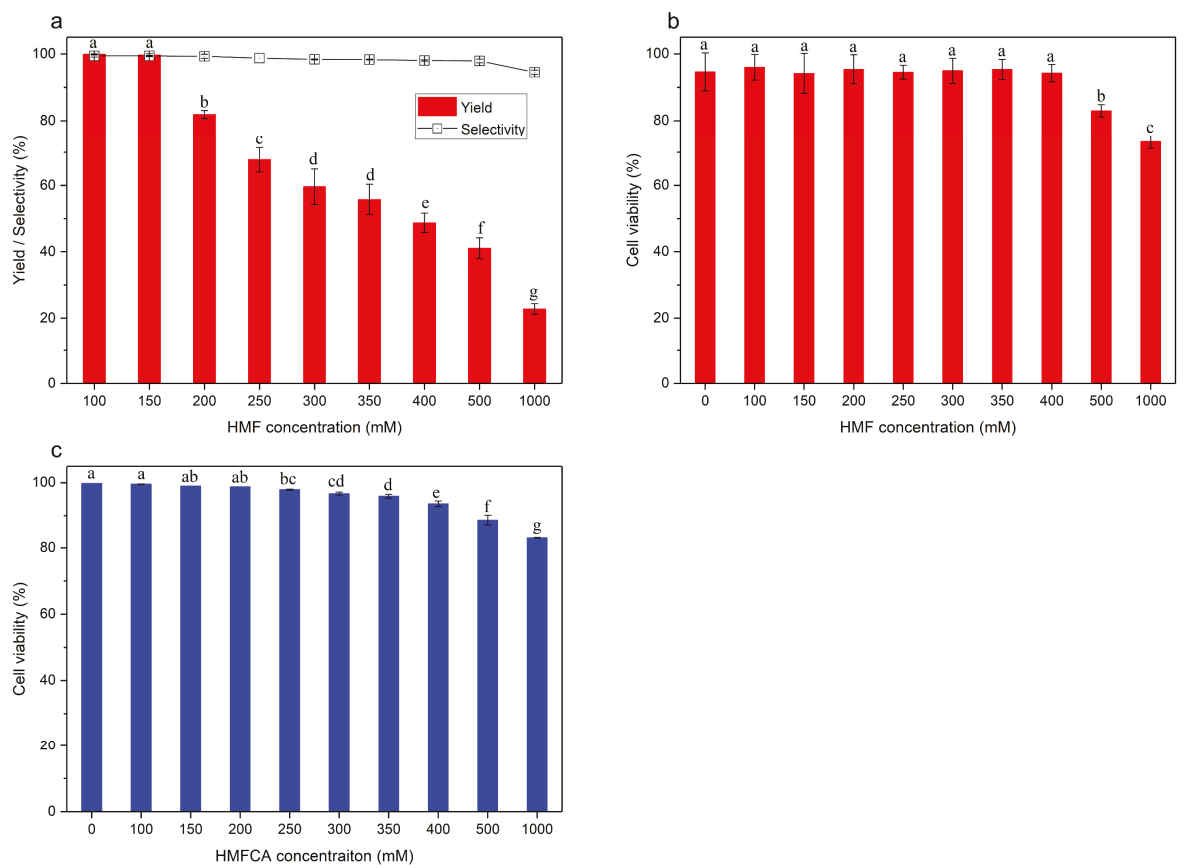

Figure 2. Effects of HMF concentration on (a) HMFCA synthesis and (b) cell viability. Reaction conditions: $0.12 \mathrm{~g} / \mathrm{mL}$ microbial cells, in phosphate buffer $(100 \mathrm{mM}, \mathrm{pH} 7.0)$ under $850 \mathrm{rpm}$ and $35^{\circ} \mathrm{C}$. Fresh harvested cells incubated without HMF/HMFCA under identical conditions were used as a control. Reaction periods: $12 \mathrm{~h}$ for $100 \mathrm{mM} 150 \mathrm{mM}$; $24 \mathrm{~h}$ for $200 \mathrm{mM}, 250 \mathrm{mM}$; and $36 \mathrm{~h}$ for $300 \mathrm{mM}, 350 \mathrm{~m}$, $400 \mathrm{mM}, 500 \mathrm{mM}, 1000 \mathrm{mM}$. (c) Effects of the product concentration on cell viability. HMFCA was incubated for $24 \mathrm{~h}$ under the same conditions.

It is well known that the cytotoxicity of HMF to microbial cells is a key parameter in whole-cell biocatalytic conversion of HMF. As shown in Figure 2b, the effect of substrate concentration on cell viability was investigated by using a cell viability assay. The microbial cells were incubated with varying concentrations of HMF under the usual reaction conditions, and the cell viability was subsequently measured using an Annexin V-FITC/PI Apoptosis Detection Kit. Microbial cells incubated in buffer without substrate under the same reaction condition were used as a control. Good cell viability $(94 \%)$ was unexpectedly obtained in the presence of $400 \mathrm{mM}$ substrate, which was not significantly different than that of the control. This result suggests that the microbial cells can tolerate as much as $400 \mathrm{mM}$ of HMF substrate without losing viability. Further increasing HMF concentration to $500 \mathrm{mM}$ led only to a slight decrease in cell viability to $83 \%$. When $1000 \mathrm{mM}$ of HMF substrate was used, $73 \%$ cell viability was still observed, indicating that $D$. wulumuqiensis R12 is extremely tolerant to HMF substrate. However, the conversion of HMF in the oxidation reaction decreased dramatically with increased substrate concentration. Since detailed toxic mechanisms of HMF to microbial cells are not completely understood, nor the reason for the extreme resistance of D. wulumuqiensis R12 cells to harsh environmental factors, the present results are not considered surprising.

\subsection{Inhibitory and Toxic Effect of the HMFCA Product}

In the oxidation of HMF to HMFCA, the product is an acidic compound harboring a carboxylic and hydroxyl group. In our work, the $\mathrm{pH}$ of the reaction system decreased over the reaction time due to the accumulation of the HMFCA product. This situation could conceivably become critical when high concentrations of substrate are produced. Thus, it would be of great interest and importance to 
investigate the possible inhibition and toxicity of the product towards microbial cells. Microbial cells incubated in phosphate buffer without the product was used as the control for such investigations. Based on the high cell viability ( $>93 \%$ ), which was comparable to that of the control, there appeared to be no significant toxicity towards the microbial cells at HMFCA product concentrations less than $400 \mathrm{mM}$, as shown in Figure 2c. However, a product amount of $500 \mathrm{mM}$ resulted in slight toxicity, as the cell viability value decreased to $87 \%$. A further increased product concentration of $1000 \mathrm{mM}$ led to significant toxicity of the microbial cells, with a viability of $84 \%$. To our surprise, the data showed that the product toxicity to the viability of microbial cells was not as high as expected, even at extremely high concentrations. Considering that D. wulumuqiensis R12 is a robust strain, able to grow in a broad range ofpH values, one should not be surprised that the microbial cells are highly resistant to HMFCA production, with excellent cell viability at extremely high product concentrations. Further product toxicity tests with still higher concentrations were not performed, as the conversion of $\mathrm{HMF}$ was already very low at the substrate concentration of $1000 \mathrm{mM}$.

\subsection{Manufacture of HMFCA Under Optimized Conditions}

Obtaining large amounts of HFMCA is highly desired in biocatalytic oxidation of HMF by whole-cell biocatalysis, with great potential applications in industrial production. Therefore, further enhancement of the catalytic performance of $D$. wulumuqiensis R12 was investigated by optimizing the biocatalytic parameters of the conversion process. It was found that the HMFCA product yields were affected significantly by increasing the substrate concentration. For example, due to the known negative effect of HMF, the yield of HMFCA decreased significantly when HMF concentrations were higher than $300 \mathrm{mM}$ (Figure 2a). Based on the catalytic properties of this strain, increasing the dosage of microbial cells in the reaction may further enhance the HMFCA yield. Recently, Zhang et al. reported that improved synthesis of HFMCA from HMF was obtained by tuning the $\mathrm{pH}$ of the reaction mixture using $\mathrm{NaOH}$ solution during the catalytic process [28]. Thus, we decided to employ the same strategy. In addition, it has been reported that adding furfural and furfural alcohol as inducers during cultivation of microbial cells for biocatalysis can trigger the expression of the enzymes responsible for HMF oxidation, which can facilitate HMFCA production. Therefore, three strategies (increasing microbial cell dosage, using inducing cells and tuningpH of reaction mixture) were applied in subsequent studies.

Increasing the dosage of microbial cells proved to be effective for enhancing the yield of HMFCA (Figure S4a). For example, in the presence of $300 \mathrm{mM} \mathrm{HMF}$, the yield of HMFCA increased considerably from $59 \%$ to $71 \%$ when the concentration of cells increased from $0.12 \mathrm{~g} / \mathrm{mL}$ to $0.2 \mathrm{~g} / \mathrm{mL}$. A further increase in cells dosage was not performed considering the negative effect of higher viscosity in the reaction mixture. On the other hand, influencing the expression of cells by the use of furfural and furfural alcohol for enhancing the yield of HMFCA proved not to be effective (Figure S4b). The reason for this might be that enzymes in D. wulumuqiensis R12 responsible for HMF oxidation are expressed constitutively. Finally,pH tuning was found to be an effective method for improving the yield of HMFCA (Figure S4c). Thus, the $\mathrm{pH}$ of the reaction mixture was tuned to approximately $7.0 \mathrm{using}$ a $\mathrm{NaOH}$ solution. Compared with the control withoutpH tuning, the HMFCA yield improved from $66 \%$ to $83 \%$ in the presence of $300 \mathrm{mM} \mathrm{HMF}$ substrate, and from $48 \%$ to $65 \%$ at an HMF concentration of $500 \mathrm{mM}$.

Therefore, both increasing the dosage of microbial cells and $\mathrm{pH}$ tuning was applied together for enhancing the production of HMFCA. As shown in Figure 3, at a high HMFCA concentration, a yield of $90 \%$ was achieved after $36 \mathrm{~h}$ when the substrate concentration was $300 \mathrm{mM}$. This demonstrates the considerable effectiveness of the combined strategy. In addition, the oxidative conversion of HMF to HMFCA reached $80 \%$ in the presence of $350 \mathrm{mM} \mathrm{HMF}$ after $48 \mathrm{~h}$. When the concentration of HMF was set to $500 \mathrm{mM}, 66 \%$ of the substrate was still converted after $48 \mathrm{~h}$, but further prolonged reaction times did not lead to an increase in HMFCA yield. 


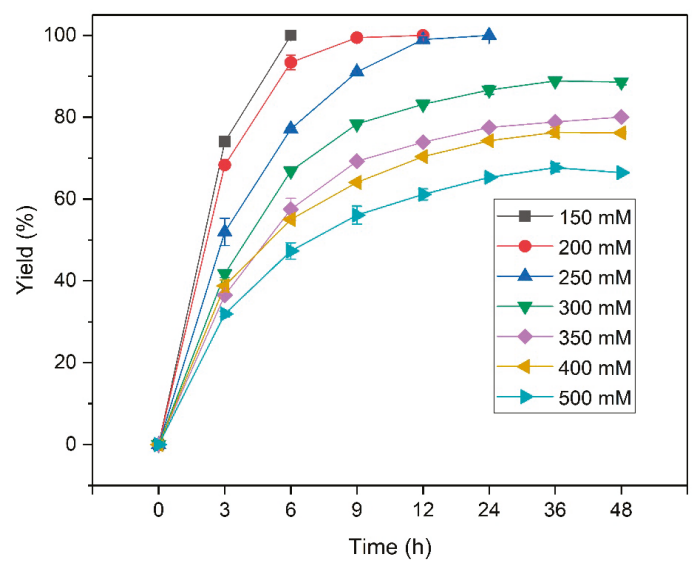

Figure 3. Synthesis of HMFCA under optimized conditions. Reaction conditions: HMF of the designated concentration, $0.2 \mathrm{~g} / \mathrm{mL}$ microbial cells, $5 \mathrm{~mL}$ phosphate buffer $(100 \mathrm{mM}, \mathrm{pH} 7.0), 35^{\circ} \mathrm{C}$, and $850 \mathrm{rpm}$. Tuning the $\mathrm{pH}$ of the reaction system to approximately 7.0 occurred every $3 \mathrm{~h}$ in the first $12 \mathrm{~h}$, and then every $12 \mathrm{~h}$ in the $36 \mathrm{~h}$ that followed.

Compared with previous reported biocatalysis results, the data obtained in this work proved to be more efficient and selective because of a higher substrate concentration and simpler catalytic process. As shown in Table 1, the substrate concentrations used in the reported biocatalytic routes were still very low and co-enzymes were usually required when isolated enzymes were applied. Although C. testosterone SC1588 cells also display good selectivity and high HMF tolerance, its catalytic performance is highly sensitive topH [28]. Thus, a considerable amount of histidine co-substrate is required for efficient selective oxidation of HMF. The extreme environment-derived $D$. wulumuqiensis $\mathrm{R} 12$ strain used in this work exhibited excellent resistance to highpH and temperatures, and proved to be a robust biocatalyst for HMFCA synthesis by way of selective oxidation of HMF.

Table 1. HMFCA synthesis via HMF oxidation by various biocatalytic systems.

\begin{tabular}{|c|c|c|c|c|}
\hline Biocatalysts & Reaction Conditions & $t(h)$ & $\begin{array}{c}\text { Yield } \\
(\%)\end{array}$ & Ref. \\
\hline Chloroperoxidase & $50 \mathrm{mM}$ HMF, 1 equiv $\mathrm{H}_{2} \mathrm{O}_{2}$ per $2 \mathrm{~h}$ & 2.5 & $25-40$ & [31] \\
\hline Serratia liquefaciens LF14 & $\begin{array}{l}10 \mathrm{mM} \text { HMF, } 18.2 \mathrm{mg} / \mathrm{mL} \text { dry cells, in phosphate buffer } \\
50 \mathrm{mM} \text { HMF, } 10 \mathrm{mg} / \mathrm{mL} \text { catalase, addition of aqueous }\end{array}$ & 1 & 97 & [30] \\
\hline Immobilized lipase B & $\begin{array}{l}\mathrm{H}_{2} \mathrm{O}_{2}(30 \% \mathrm{v} / \mathrm{v}) \text { hourly, reaction media: acyl } \\
\text { butyrate/tBuOH }(1: 1 \mathrm{v} / \mathrm{v}), 40{ }^{\circ} \mathrm{C}\end{array}$ & 24 & 76 & [32] \\
\hline Xanthine oxidase $(\mathrm{XO})$ & $\begin{array}{l}26 \mathrm{mM} \text { HMF, } 5.6 \mathrm{U} \text { E. coli } \mathrm{XO}, 1.1 \mathrm{mg} \text { catalase, } \\
\text { phosphate buffer, } 37^{\circ} \mathrm{C}, 150 \mathrm{rpm} \text {, air bubbling }\end{array}$ & 7 & 94 & [29] \\
\hline Comamonas testosterone SC1588 & $\begin{array}{l}160 \mathrm{mM} \text { HMF, } 30 \mathrm{mg} / \mathrm{mL} \text { induced microbial cells, } \\
\text { phosphate buffer, } 20 \mathrm{mM} \text { histidine, } 150 \mathrm{rpm}, 30^{\circ} \mathrm{C} \text {, } \\
\text { tuningpH of the reaction mixture to approximately } 7.0 \\
\text { every } 24 \mathrm{~h} \text {. }\end{array}$ & 36 & 98 & [28] \\
\hline Aldehyde dehydrogenases & $\begin{array}{l}20 \mathrm{mM} \text { HMF, } 10 \mu \mathrm{M} \text { catalase, } 5 \mu \mathrm{M} \text { [NOx], } 100 \mu \mathrm{g} / \mathrm{mL} \\
{[\mathrm{DTT}], 0.5 \mathrm{mM}\left[\mathrm{NAD}^{+}\right] \text {, phosphate buffer, }} \\
40^{\circ} \mathrm{C}, 180 \mathrm{rpm}\end{array}$ & 24 & 91 & [53] \\
\hline D. wulumuqiensis R12 & $\begin{array}{l}300 \mathrm{mM} H \mathrm{HF}, 200 \mathrm{mg} / \mathrm{mL} \text { microbial cells, phosphate } \\
\text { buffer, } 850 \mathrm{rpm}, 35^{\circ} \mathrm{C} \text {, tuningpH of the reaction mixture } \\
\text { to approximately } 7.0 \text { every } 3 \mathrm{~h} \text {. }\end{array}$ & 36 & 90 & This work \\
\hline
\end{tabular}

\subsection{Efficient Synthesis of HMFCA by a Fed-Batch Strategy}

As mentioned above, excellent yields of HMFCA from selective oxidation of HMF were obtained under optimized conditions. It is highly desirable to manufacture HMFCA on a large scale in an effort to create a practical biocatalytic process. Thus, by applying a fed-batch strategy, in which HMF substrate was added continuously, the accumulation of high concentrations of product was achieved. 
Figure 4 shows the results of biocatalytic synthesis of high concentrations of HMFCA. It was found that $511 \mathrm{mM}$ of product was produced within $20 \mathrm{~h}$ after three-batch feeding of HMF, affording a total yield of $85 \%$ and a productivity of approximately $44 \mathrm{~g} / \mathrm{L}$ per day. Only $4 \mathrm{mM}$ of BHMF was observed as the sole byproduct $(<1 \%)$. Chemoselectivity towards the target product reached more than $99 \%$. In addition, a decrease in yield of HMFCA in each batch feeding was observed, indicating possible substrate and/or product inhibition in the whole-cell biocatalyst. An attempt to improve the yield of HMFCA further in this fed-batch process was performed by prolonging the reaction time, but no significant improvement was observed (Data not shown).

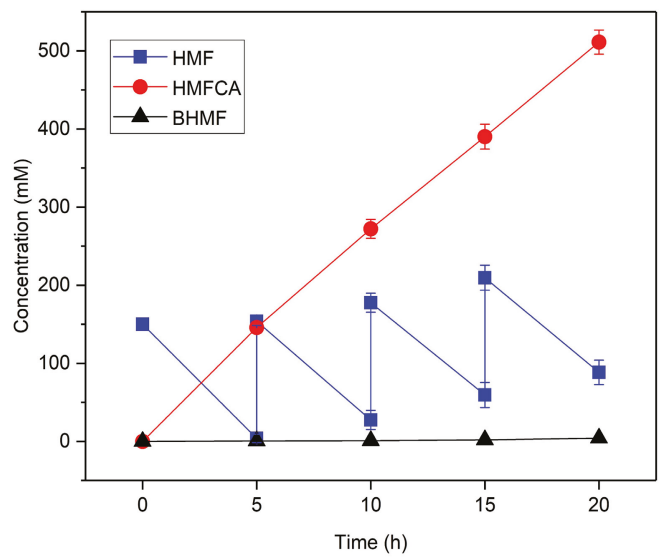

Figure 4. Synthesis of HMFCA by a fed-batch method. Reaction conditions: $150 \mathrm{mM} \mathrm{HMF}, 0.2 \mathrm{~g} / \mathrm{mL}$ microbial cells, $5 \mathrm{~mL}$ phosphate buffer $(100 \mathrm{mM}, \mathrm{pH} 7.0), 35^{\circ} \mathrm{C}$, and $850 \mathrm{rpm}$. In each cycle of $5 \mathrm{~h}$, $0.75 \mathrm{mmoL}$ of HMF was added.

\subsection{Exploring the Substrate Scope of D. wulumuqiensis R12}

In order to examine the substrate spectrum of this novel whole-cell biocatalyst, a set of structurally unique aldehyde compounds was applied in the oxidation reactions catalyzed by D. wulumuqiensis R12 cells (Scheme 3). Considering possible solubility and toxicity effects, proper concentrations of these aldehyde compounds were applied. The results showed that the whole cells of the strain readily accept furfural as a substrate, thereby enabling an efficient synthesis of furoic acid ( $>99 \%$ yield). Furoic acid can be used in the pharmaceutical, agrochemical, and flavor industries [9]. In the case of aldehydes containing an additional hydroxyl group, the microbial cells proved to be strictly chemoselective for the aldehyde group, affording the corresponding carboxylic acids with good to excellent yields (Table 2). For example, oxidation of DFF and FFCA to FDCA was achieved with $100 \%$ and $63 \%$ yields, respectively. Due to solubility issues, higher DFF substrate concentrations were not applied. We also discovered that the aldehyde group of vanillin could be selectively oxidized by the microbial cells to vanillic acid. Vanillic acid has important applications in the pharmaceutical industry, and also as a monomer in polyester synthesis [54]. In addition, terephthalic acid and p-hydroxybenzoic acid were also prepared by selective oxidation of the corresponding aldehydes. In short, the results showed that D. wulumuqiensis R12 as a biocatalyst has an amazingly broad substrate spectrum. 
<smiles>O=Cc1ccco1</smiles>

Furfural<smiles>COc1cc(C=O)ccc1O</smiles>

Vanillin<smiles>COc1cc(C(=O)O)ccc1O</smiles>

Vanillic acid<smiles>O=C(O)c1ccco1</smiles>

Furoic acid<smiles>O=Cc1ccc(O)cc1</smiles><smiles>O=Cc1ccc(C=O)cc1</smiles>

p-Hydroxybenzaldehyde Terephthaldehyde<smiles>O=C(O)c1ccc(O)cc1</smiles><smiles>O=C(O)c1ccc(C(=O)O)cc1</smiles>

Terephthalic acid

Scheme 3. Aldehyde substrates used and products obtained in biocatalytic oxidation by D. wulumuqiensis R12 whole cells.

Table 2. Whole-cell biocatalytic oxidation of aldehydes.

\begin{tabular}{ccccc}
\hline Entry & Substrate & Substrate Concentration $(\mathbf{m M})$ & Product & Yield (\%) \\
\hline 1 & Furfural & 100 & Furoic acid & $>99$ \\
2 & DFF & 30 & FDCA & $>99$ \\
3 & FFCA & 100 & FDCA & 63 \\
4 & Vanillin & 5 & Vanillic acid & $>99$ \\
5 & $p$-Hydroxybenzaldehyde & 5 & Terephthalic acid & $>99$ \\
6 & Terephthaldehyde & 2 & -Hoxybenzoic acid & 70 \\
\hline
\end{tabular}

Reaction conditions: $0.12 \mathrm{~g} / \mathrm{mL}$ microbial cells, $5 \mathrm{~mL}$ of phosphate buffer $(100 \mathrm{mM}, \mathrm{pH} 7.0), 850 \mathrm{rpm}, 35^{\circ} \mathrm{C}$ for $12 \mathrm{~h}$.

\section{Materials and Methods}

\subsection{Chemicals and Strains}

Extremely radiation resistant strains D. wulumuqiensis R12 (DSM 28115T), D. radiodurans R1 (ATCC NO.13939), and D. xibeiensis R13 (NRBC 105666T) were acquired from Zhi-Dong Zhang at the Institute of Microbiology, Xinjiang Academy of Agricultural Sciences in China and stored in our laboratory. The GenBank accession number for the $16 \mathrm{~S}$ rDNA sequence was KJ784486, while the whole genome sequence was APCS01000000.

HMF (97\%) and HMFCA (97\%) were purchased from Macklin Biochemical Co., Ltd (Shanghai, China). FDCA (98\%), DFF (98\%) and furfural (98\%) were obtained from Aladdin Biochemical Technology Co., Ltd (Shanghai, China). BHMF (98\%) was purchased from Ark Pharm, Inc (Arlington Heights, IL, USA). HMFCA (97\%) was obtained from J\&K Scientific Ltd (Beijing, China). Both furfuryl alcohol (99.5\%) and furoic acid (98\%) were obtained from TCI (Shanghai, China). Annexin V-FITC/PI Apoptosis Detection Kit was purchased from Nanjing KeyGen Biotech. Co. Ltd. (Jiangsu, China) for the cell viability assay. 


\subsection{Cultivation of D. wulumuqiensis R12 Cells}

The glycerol stock of $D$. wulumuqiensis R12 was pre-cultivated at $30{ }^{\circ} \mathrm{C}, 200 \mathrm{rpm}$ for $24 \mathrm{~h}$ in tryptone glucose yeast extract (TGY) medium containing $0.5 \%$ tryptone, $0.1 \%$ glucose, and $0.3 \%$ yeast extract. Then, $1 \%$ of the overnight preculture was transferred to fresh TGY medium. The culture was incubated at $30{ }^{\circ} \mathrm{C}, 200 \mathrm{rpm}$ for $48 \mathrm{~h}$ and was centrifugated under $5000 \mathrm{rpm}$ for $10 \mathrm{~min}$ to harvest cells. The cell pellet was washed twice with $100 \mathrm{mM}$ phosphate buffer ( $\mathrm{pH}$ 7.4) and resuspended in phosphate buffer with a final cell concentration of $0.12 \mathrm{~g} / \mathrm{mL}$ (cell wet weight).

\subsection{General Procedure for the Biocatalytic Oxidation of Aldehyde Substrates}

Five milliliters of phosphate buffer $(0.1 \mathrm{M}, \mathrm{pH} 7.0)$ containing the designated amounts of microbial cells (cell wet weight) and substrates was incubated at $35{ }^{\circ} \mathrm{C}$ and $850 \mathrm{rpm}$ for a given reaction time. Aliquots of the reaction mixture were withdrawn at specified reaction times and diluted with the phosphate buffer prior to high-performance liquid chromatography (HPLC) assays. The conversion of HMF and other aldehydes by biocatalytic oxidation was defined as the percentage of the consumed substrate amount in the initial amount. The selectivity of the reaction was defined as the ratio of HMFCA product amount to the sum of all the products. The yield was defined as the percentage of the measured product amount in the theoretical product amount based on the initial amount of HMF.

$$
\% \text { yield }=\frac{\text { Actual yield }}{\text { Theoretical yield }} \times 100 \%
$$

\subsection{Analytical Method}

The reaction products were analyzed by HPLC following a previously reported method with slight modifications [28]. Briefly, a reverse-phase HPLC (Thermo Fisher ultimate 3000), equipped with Sepax GP-C18 column $(4.6 \mathrm{~mm} \times 250 \mathrm{~mm}, 5 \mu \mathrm{m})$, was used at $25^{\circ} \mathrm{C}$. The mobile phase was the gradient of acetonitrile in $20 \mathrm{mM} \mathrm{KH}_{2} \mathrm{PO}_{4}\left(\mathrm{pH}\right.$ 6.0) at a flow of $1.0 \mathrm{~mL} \mathrm{~min}^{-1}$, increasing from $10 \%$ to $24 \%$ within $7 \mathrm{~min}$ and from $24 \%$ to $10 \%$ within $3 \mathrm{~min}$. The HPLC retention time of the HMFCA product and HMF were $2.90 \mathrm{~min}$ and $6.20 \mathrm{~min}$, respectively. All experiments were performed in triplicate and mean values are presented. Data are expressed as the mean \pm standard deviation. Duncan's multiple range test (using SPSS software 16.0, Chicago, IL, USA) was used to analyze the statistical significance of differences between the groups. A significance difference was judged to exist at a level of $p<0.05$. HPLC runs are shown in Figure S1.

\subsection{Cell Viability Assay}

Cell viability assay experiments were performed using an Annexin V-FITC/PI Apoptosis Detection Kit and flow cytometry following the manufacturers' instructions. Cell viability was determined using ACEA NovoCyte Flow Cytometer (ACEA Biosciences, Inc., San Diego, CA, USA) with the excitation light and emission light wavelengths set at $488 \mathrm{~nm}$ and $530 \mathrm{~nm}$, respectively. Data were collected and analyzed using NovoExpress software. The cell viability of D. wulumuqiensis R12 when using HMF as the substrate is presented as the percentage of living cells to the total amount of cells.

\subsection{Synthesis of HMFCA by the Substrate Fed-Batch Feeding Process}

Five milliliters of $100 \mathrm{mM}$ phosphate buffer,pH 7.0, which contained $150 \mathrm{mM}$ HMF substrate and $0.2 \mathrm{~g} / \mathrm{mL}$ of microbial cells, was incubated at $35^{\circ} \mathrm{C}$ and $850 \mathrm{rpm}$. After $5 \mathrm{~h}, 0.75 \mathrm{mmol}$ of HMF was repeatedly added to the reaction mixture. During the whole biocatalytic process, the $\mathrm{pH}$ of the reaction mixture was adjusted to the range of 7.0-8.0 with $\mathrm{NaOH}$ solution and the concentration of substrate and products was analyzed by HPLC. 


\section{Conclusions}

Herein, we successfully explored for the first time the use of a radiation resistant $D$. wulumuqiensis R12 strain as a whole-cell biocatalyst for the efficient synthesis of HMFCA from HMF. The whole cells of this strain proved to be highly tolerant to HMF and the product, HMFCA. The whole-cell system is an excellent biocatalyst for the selective oxidation of HMF. An excellent yield of HMFCA of up to $90 \%$ was achieved within $36 \mathrm{~h}$ in the presence of $300 \mathrm{mM} \mathrm{HMF}$ substrate under optimized conditions. A yield of $80 \%$ to $66 \%$ was obtained when the substrate concentration increased from $350 \mathrm{mM}$ to $500 \mathrm{mM}$, while the selectivity towards HMFCA remained at approximately $98 \%$. In addition, up to $511 \mathrm{mM}$ of HMFCA was synthesized in $20 \mathrm{~h}$ via a fed-batch method, resulting in a productivity of $44 \mathrm{~g} / \mathrm{L}$ per day. Thus, D. wulumuqiensis R12 cells are a promising catalyst in the biocatalytic process of HMF upgrading. Moreover, the cells were able to transform a set of structurally different aldehyde compounds into their corresponding carboxylic acids with good to excellent selectivity. Since the genome sequence of this strain has been sequenced, exploring the genes that encode the enzymes responsible for HMFCA synthesis from HMF has become feasible in future work. The catalytic properties of these microbial cells can also be further engineered by introduction of other oxidases to form a cell factory for HMF biotransformation. Furthermore, this strain may also have potential applications for the biodetoxification of lignocellulosic hydrolysates in the process of biofuel production. Discovery of D. wulumuqiensis R12 as an efficient biocatalyst broadens the toolbox of biocatalysts for the biotransformation of HMF into value-added derivatives and will further facilitate the utilization of biomass for the production of useful chemicals and biofuels.

Supplementary Materials: The following are available online at http://www.mdpi.com/2073-4344/9/6/526/s1, Figure S1: HPLC measurements: (A) HMF and its derivatives; (B) HMF substrate, HMFCA and BHMF products. Figure S2: Effects of reaction time on HMFCA synthesis. Figure S3: Biocatalytic oxidation of HMF to HMFCA by different Deinococcus strains. Figure S4: Effect of cell concentration on HMFCA synthesis. Figure S5: Optimizing reaction condition for HMFCA synthesis by using various strategies.

Author Contributions: Conceptualization, Z.-G.Z.; investigation, R.C., G.Y. and L.-Q.S.; funding acquisition, Z.-G.Z.; resources, Z.-G.Z.; writing-original draft preparation, Z.-G.Z.; writing-review and editing, H.H. and Z.-D.Z.

Funding: This research was funded by the National Natural Science Foundation of China (No. 21646014, 21776134 and 21776136), the program of Jiangsu Synergetic Innovation Center for Advanced Bio-Manufacture (XTE1851). and The APC was funded by the program of Jiangsu Synergetic Innovation Center for Advanced Bio-Manufacture (XTE1851).

Acknowledgments: We thank Professor Dr. Manfred T. Reetz (Max-Planck-Institut für Kohlenforschung, Germany) for critical reading of the manuscript and helpful comments.

Conflicts of Interest: The authors declare no conflict of interest.

\section{References}

1. Sheldon, R.A. Green and sustainable manufacture of chemicals from biomass: State of the art. Green Chem. 2014, 16, 950-963. [CrossRef]

2. Wu, L.; Moteki, T.; Gokhale, A.A.; Flaherty, D.W.; Toste, F.D. Production of Fuels and Chemicals from Biomass: Condensation Reactions and Beyond. Chem 2016, 1, 32-58. [CrossRef]

3. Tuck, C.O.; Pérez, E.; Horváth, I.T.; Sheldon, R.A.; Poliakoff, M. Valorization of Biomass: Deriving More Value from Waste. Science 2012, 337, 695-699. [CrossRef] [PubMed]

4. Zhang, Z.; Deng, K. Recent Advances in the Catalytic Synthesis of 2,5-Furandicarboxylic Acid and Its Derivatives. ACS Catal. 2015, 5, 6529-6544. [CrossRef]

5. Christensen, C.H.; Rass-Hansen, J.; Marsden, C.C.; Taarning, E.; Egeblad, K. The Renewable Chemicals Industry. ChemSusChem 2008, 1, 283-289. [CrossRef] [PubMed]

6. Gallezot, P. Conversion of biomass to selected chemical products. Chem. Soc. Rev. 2012, 41, 1538-1558. [CrossRef] [PubMed]

7. Isikgor, F.H.; Becer, C.R. Lignocellulosic biomass: A sustainable platform for the production of bio-based chemicals and polymers. Polym. Chem. 2015, 6, 4497-4559. [CrossRef] 
8. Chheda, J.N.; Román-Leshkov, Y.; Dumesic, J.A. Production of 5-hydroxymethylfurfural and furfural by dehydration of biomass-derived mono- and poly-saccharides. Green Chem. 2007, 9, 342-350. [CrossRef]

9. Van Putten, R.-J.; van der Waal, J.C.; de Jong, E.; Rasrendra, C.B.; Heeres, H.J.; de Vries, J.G. Hydroxymethylfurfural, A Versatile Platform Chemical Made from Renewable Resources. Chem. Rev. 2013, 113, 1499-1597. [CrossRef] [PubMed]

10. Teong, S.P.; Yi, G.; Zhang, Y. Hydroxymethylfurfural production from bioresources: Past, present and future. Green Chem. 2014, 16, 2015-2026. [CrossRef]

11. Bozell, J.J.; Petersen, G.R. Technology development for the production of biobased products from biorefinery carbohydrates—the US Department of Energy's “Top 10" revisited. Green Chem. 2010, 12, 539-554. [CrossRef]

12. Rosatella, A.A.; Simeonov, S.P.; Frade, R.F.M.; Afonso, C.A.M. 5-Hydroxymethylfurfural (HMF) as a building block platform: Biological properties, synthesis and synthetic applications. Green Chem. 2011, 13, 754-793. [CrossRef]

13. Koopman, F.; Wierckx, N.; de Winde, J.H.; Ruijssenaars, H.J. Efficient whole-cell biotransformation of 5-(hydroxymethyl)furfural into FDCA, 2,5-furandicarboxylic acid. Bioresour. Technol. 2010, 101, 6291-6296. [CrossRef] [PubMed]

14. Hu, L.; He, A.; Liu, X.; Xia, J.; Xu, J.; Zhou, S.; Xu, J. Biocatalytic Transformation of 5-Hydroxymethylfurfural into High-Value Derivatives: Recent Advances and Future Aspects. ACS Sustain. Chem. Eng. 2018, 6, 15915-15935. [CrossRef]

15. Gandini, A.; Silvestre, A.J.D.; Neto, C.P.; Sousa, A.F.; Gomes, M. The furan counterpart of poly(ethylene terephthalate): An alternative material based on renewable resources. J. Polym. Sci. Part A Polym. Chem. 2009, 47, 295-298. [CrossRef]

16. Sousa, A.F.; Vilela, C.; Fonseca, A.C.; Matos, M.; Freire, C.S.R.; Gruter, G.-J.M.; Coelho, J.F.J.; Silvestre, A.J.D. Biobased polyesters and other polymers from 2,5-furandicarboxylic acid: A tribute to furan excellency. Polym. Chem. 2015, 6, 5961-5983. [CrossRef]

17. Hirai, H. Oligomers from Hydroxymethylfurancarboxylic Acid. J. Macromol. Sci. Part A Chem. 1984, 21, 1165-1179. [CrossRef]

18. Tamura, G. Antitumor Activity of 5-Hydroxy-methyl-2-furoic Acid AU-Munekata, Masanobu. Agric. Biol. Chem. 1981, 45, 2149-2150. [CrossRef]

19. Braisted, A.C.; Oslob, J.D.; Delano, W.L.; Hyde, J.; McDowell, R.S.; Waal, N.; Yu, C.; Arkin, M.R.; Raimundo, B.C. Discovery of a Potent Small Molecule IL-2 Inhibitor through Fragment Assembly. J. Am. Chem. Soc. 2003, 125, 3714-3715. [CrossRef]

20. Casanova,O.; Iborra, S.; Corma, A. Biomass into Chemicals: Aerobic Oxidation of 5-Hydroxymethyl-2-furfural into 2,5-Furandicarboxylic Acid with Gold Nanoparticle Catalysts. ChemSusChem 2009, 2, 1138-1144. [CrossRef]

21. Gorbanev, Y.Y.; Klitgaard, S.K.; Woodley, J.M.; Christensen, C.H.; Riisager, A. Gold-Catalyzed Aerobic Oxidation of 5-Hydroxymethylfurfural in Water at Ambient Temperature. ChemSusChem 2009, 2, 672-675. [CrossRef]

22. Davis, S.E.; Houk, L.R.; Tamargo, E.C.; Datye, A.K.; Davis, R.J. Oxidation of 5-hydroxymethylfurfural over supported Pt, Pd and Au catalysts. Catal. Today 2011, 160, 55-60. [CrossRef]

23. Zhang, Z.; Liu, B.; Lv, K.; Sun, J.; Deng, K. Aerobic oxidation of biomass derived 5-hydroxymethylfurfural into 5-hydroxymethyl-2-furancarboxylic acid catalyzed by a montmorillonite K-10 clay immobilized molybdenum acetylacetonate complex. Green Chem. 2014, 16, 2762-2770. [CrossRef]

24. Zhou, B.; Song, J.; Zhang, Z.; Jiang, Z.; Zhang, P.; Han, B. Highly selective photocatalytic oxidation of biomass-derived chemicals to carboxyl compounds over $\mathrm{Au} / \mathrm{TiO}_{2}$. Green Chem. 2017, 19, 1075-1081. [CrossRef]

25. Subbiah, S.; Simeonov, S.P.; Esperança, J.M.S.S.; Rebelo, L.P.N.; Afonso, C.A.M. Direct transformation of 5-hydroxymethylfurfural to the building blocks 2,5-dihydroxymethylfurfural (DHMF) and 5-hydroxymethyl furanoic acid (HMFA) via Cannizzaro reaction. Green Chem. 2013, 15, 2849-2853. [CrossRef]

26. Kang, E.-S.; Chae, D.W.; Kim, B.; Kim, Y.G. Efficient preparation of DHMF and HMFA from biomass-derived HMF via a Cannizzaro reaction in ionic liquids. J. Ind. Eng. Chem. 2012, 18, 174-177. [CrossRef]

27. Domínguez de María, P.; Guajardo, N. Biocatalytic Valorization of Furans: Opportunities for Inherently Unstable Substrates. ChemSusChem 2017, 10, 4123-4134. [CrossRef] 
28. Zhang, X.-Y.; Zong, M.-H.; Li, N. Whole-cell biocatalytic selective oxidation of 5-hydroxymethylfurfural to 5-hydroxymethyl-2-furancarboxylic acid. Green Chem. 2017, 19, 4544-4551. [CrossRef]

29. Qin, Y.-Z.; Li, Y.-M.; Zong, M.-H.; Wu, H.; Li, N. Enzyme-catalyzed selective oxidation of 5-hydroxymethylfurfural (HMF) and separation of HMF and 2,5-diformylfuran using deep eutectic solvents. Green Chem. 2015, 17, 3718-3722. [CrossRef]

30. Mitsukura, K.; Sato, Y.; Yoshida, T.; Nagasawa, T. Oxidation of heterocyclic and aromatic aldehydes to the corresponding carboxylic acids by Acetobacter and Serratia strains. Biotechnol. Lett 2004, 26, 1643-1648. [CrossRef]

31. Van Rantwijk, F.; Sheldon, R.A. Chloroperoxidase-Catalyzed Oxidation of 5-Hydroxymethylfurfural. J. Carbohydr. Chem. 1997, 16, 299-309. [CrossRef]

32. Krystof, M.; Pérez-Sánchez, M.; Domínguez de María, P. Lipase-Mediated Selective Oxidation of Furfural and 5-Hydroxymethylfurfural. ChemSusChem 2013, 6, 826-830. [CrossRef] [PubMed]

33. Ni, Y.; Xu, J.-H. Biocatalytic ketone reduction: A green and efficient access to enantiopure alcohols. Biotechnol. Adv. 2012, 30, 1279-1288. [CrossRef] [PubMed]

34. Ku, S. Finding and Producing Probiotic Glycosylases for the Biocatalysis of Ginsenosides: A Mini Review. Molecules 2016, 21, 645. [CrossRef] [PubMed]

35. Trudgill, P.W. The metabolism of 2-furoic acid by Pseudomanas F2. Biochem. J. 1969, 113, 577-587. [CrossRef]

36. Koenig, K.; Andreesen, J.R. Xanthine dehydrogenase and 2-furoyl-coenzyme A dehydrogenase from Pseudomonas putida Fu1: Two molybdenum-containing dehydrogenases of novel structural composition. J. Bacteriol. 1990, 172, 5999-6009. [CrossRef]

37. López, M.J.; Nichols, N.N.; Dien, B.S.; Moreno, J.; Bothast, R.J. Isolation of microorganisms for biological detoxification of lignocellulosic hydrolysates. Appl. Microbiol. Biotechnol. 2004, 64, 125-131. [CrossRef]

38. Koopman, F.; Wierckx, N.; de Winde, J.H.; Ruijssenaars, H.J. Identification and characterization of the furfural and 5-(hydroxymethyl)furfural degradation pathways of Cupriavidus basilensis HMF14. Proc. Natl. Acad. Sci. USA 2010, 107, 4919-4924. [CrossRef]

39. Nikel, P.I.; Chavarría, M.; Danchin, A.; de Lorenzo, V. From dirt to industrial applications: Pseudomonas putida as a Synthetic Biology chassis for hosting harsh biochemical reactions. Curr. Opin. Chem. Biol. 2016, 34, 20-29. [CrossRef]

40. Hoover, R.B.; Tang, J. Microbial Extremophiles at the Limits of Life AU - Pikuta, Elena V. Crit. Rev. Microbiol. 2007, 33, 183-209. [CrossRef]

41. Madigan, M.T.; Orent, A. Thermophilic and halophilic extremophiles. Curr. Opin. Microbiol. 1999, 2, $265-269$. [CrossRef]

42. Schiraldi, C.; De Rosa, M. The production of biocatalysts and biomolecules from extremophiles. Trends Biotechnol. 2002, 20, 515-521. [CrossRef]

43. Van den Burg, B. Extremophiles as a source for novel enzymes. Curr. Opin. Microbiol. 2003, 6, $213-218$. [CrossRef]

44. Elleuche, S.; Schröder, C.; Sahm, K.; Antranikian, G. Extremozymes-Biocatalysts with unique properties from extremophilic microorganisms. Curr. Opin. Biotechnol. 2014, 29, 116-123. [CrossRef] [PubMed]

45. Wang, W.; Mao, J.; Zhang, Z.; Tang, Q.; Xie, Y.; Zhu, J.; Zhang, L.; Liu, Z.; Shi, Y.; Goodfellow, M. Deinococcus wulumuqiensis sp. nov., and Deinococcus xibeiensis sp. nov., isolated from radiation-polluted soil. Int. J. Syst. Evol. Microbiol. 2010, 60, 2006-2010. [CrossRef] [PubMed]

46. Hong, S.; Farrance, C.E.; Russell, A.; Yi, H. Reclassification of Deinococcus xibeiensis Wang et al. 2010 as a heterotypic synonym of Deinococcus wulumuqiensis Wang et al. 2010. Int. J. Syst. Evol. Microbiol. 2015, 65, 1083-1085. [CrossRef]

47. Battista, J.R.; Earl, A.M.; Park, M.-J. Why is Deinococcus radiodurans so resistant to ionizing radiation? Trends Microbiol. 1999, 7, 362-365. [CrossRef]

48. Xu, X.; Tian, L.; Xu, J.; Xie, C.; Jiang, L.; Huang, H. Analysis and expression of the carotenoid biosynthesis genes from Deinococcus wulumuqiensis R12 in engineered Escherichia coli. AMB Express 2018, 8, 94. [CrossRef]

49. Xu, X.; Jiang, L.; Zhang, Z.; Shi, Y.; Huang, H. Genome Sequence of a Gamma- and UV-Ray-Resistant Strain, Deinococcus wulumuqiensis R12. Genome Announc. 2013, 1, e00206-e00213. [CrossRef]

50. Liao, Z.; Zhang, Y.; Luo, S.; Suo, Y.; Zhang, S.; Wang, J. Improving cellular robustness and butanol titers of Clostridium acetobutylicum ATCC824 by introducing heat shock proteins from an extremophilic bacterium. J. Biotechnol. 2017, 252, 1-10. [CrossRef] 
51. Wierckx, N.; Koopman, F.; Ruijssenaars, H.J.; de Winde, J.H. Microbial degradation of furanic compounds: Biochemistry, genetics, and impact. Appl. Microbiol. Biotechnol. 2011, 92, 1095-1105. [CrossRef] [PubMed]

52. Palmqvist, E.; Hahn-Hägerdal, B. Fermentation of lignocellulosic hydrolysates. II: Inhibitors and mechanisms of inhibition. Bioresour. Technol. 2000, 74, 25-33. [CrossRef]

53. Knaus, T.; Tseliou, V.; Humphreys, L.D.; Scrutton, N.S.; Mutti, F.G. A biocatalytic method for the chemoselective aerobic oxidation of aldehydes to carboxylic acids. Green Chem. 2018, 20, 3931-3943. [CrossRef]

54. Pang, C.; Zhang, J.; Zhang, Q.; Wu, G.; Wang, Y.; Ma, J. Novel vanillic acid-based poly(ether-ester)s: From synthesis to properties. Polym. Chem. 2015, 6, 797-804. [CrossRef]

(C) 2019 by the authors. Licensee MDPI, Basel, Switzerland. This article is an open access article distributed under the terms and conditions of the Creative Commons Attribution (CC BY) license (http://creativecommons.org/licenses/by/4.0/). 

Article

\title{
Screening and Comparative Characterization of Microorganisms from Iranian Soil Samples Showing $\omega$-Transaminase Activity toward a Plethora of Substrates
}

\author{
Najme Gord Noshahri ${ }^{1}$, Jamshid Fooladi ${ }^{1, *}$, Christoph Syldatk ${ }^{2}$, Ulrike Engel ${ }^{2}$, \\ Majid M. Heravi ${ }^{3}$, Mohammad Zare Mehrjerdi ${ }^{4}$ and Jens Rudat ${ }^{2, *}$ \\ 1 Department of Biotechnology, Faculty of Biology Science, Alzahra University, 1993893973 Tehran, Iran \\ 2 BLT_II: Technical Biology, Karlsruhe Institute of Technology (KIT), Fritz-Haber-Weg 4, 76131 Karlsruhe, \\ Germany; christoph.syldatk@kit.edu (C.S.); ulrike.engel@kit.edu (U.E.) \\ 3 Department of Chemistry, School of Sciences, Alzahra University, 1993891176 Tehran, Iran; \\ mmheravi@alzahra.ac.ir \\ 4 Higher Education Complex of Shirvan, 9468194477 Shirvan, Iran; mzarem@um.ac.ir \\ * Correspondence: jfooladi@alzahra.ac.ir (J.F.); jens.rudat@kit.edu (J.R.); Tel.: +98-21-880-440-40 (J.F.); \\ +49-721-608-484-28 (J.R.)
}

Received: 26 September 2019; Accepted: 18 October 2019; Published: 22 October 2019

\begin{abstract}
In this study, soil microorganisms from Iran were screened for $\omega$-transaminase ( $\omega$-TA) activity based on growth on minimal media containing (rac)- $\alpha$-methylbenzylamine (rac- $\alpha$-MBA) as a sole nitrogen source. Then, for the selection of strains with high enzyme activity, a colorimetric o-xylylendiamine assay was conducted. The most promising strains were identified by $16 \mathrm{~S}$ rDNA sequencing. Five microorganisms showing high $\omega$-TA activity were subjected to determine optimal conditions for $\omega$-TA activity, including $\mathrm{pH}$, temperature, co-solvent, and the specificity of the $\omega$-TA toward different amine donors and acceptors. Among the five screened microorganisms, Bacillus halotolerans turned out to be the most promising strain: Its cell-free extract showed a highly versatile amino donor spectrum toward aliphatic, aromatic chiral amines and a broad range of $\mathrm{pH}$ activity. Transaminase activity also exhibited excellent solvent tolerance, with maximum turnover in the presence of $30 \%(v / v)$ DMSO.
\end{abstract}

Keywords: $\omega$-transaminase; $\alpha$-methylbenzylamine; biocatalysis; chiral amine; biotransformation

\section{Introduction}

Chiral amines as building blocks are prevalent in pharmaceuticals and chemical industries [1]. For instance, chiral amines are present in roughly $40 \%$ of FDA approved pharmaceuticals $[2,3]$. Furthermore, chiral $\beta$-amino acids ( $\beta$-aas) have attracted significant attention recently [4]. They are critical building blocks in highly important medicines and natural compounds such as maraviroc (HIV remedy) [5,6], taxol (cytostatic drug against breast and ovarian cancer), jaspamide (insecticidal and antifungal agent), theopalauamide (antifungal compound), and dolastatin (antitumor agent) [7]. $\beta$-aas are also employed in the production of peptidomimetics that are stable against degradation by proteolytic enzymes $[4,8]$.

The significant challenge in industry is to use optically pure amines and amino acids from cost-effective production $[1,9]$. For the mass production of such compounds, nowadays biocatalysts are frequently used to comply with green chemistry as well be economically feasible $[1,5]$. Among various enzymatic methods for producing chiral amine compounds, $\omega$-transaminases $(\omega$-TAs) are promising enzymes to synthesize chiral amines. They show high substrate spectra, 
enantioselectivity, and no requirement to regenerate external cofactors [10-13]. They belong to pyridoxal-5'-phosphate-(PLP)-dependent enzymes that transfer an amino group from an amino donor to amino accepters such as prochiral ketones or aldehydes [14,15]. In addition, $\omega$-TAs can be used for providing optically enriched chiral amino acids via the kinetic resolution of racemic amines or asymmetric synthesis from prochiral ketones [12].

A restricted substrate scope for large molecules [16], as well as rather low enzyme stability under extreme reaction conditions associated with $\mathrm{pH}$, temperature [17], and organic solvents $[5,13]$ have been major hurdles of using $\omega$-TAs. Thus, these limitations should be circumvented by additional screening approaches to fill the toolbox of industrially applicable enzymes.

Basically, there are different approaches to discover new $\omega$-TAs: metagenomic screenings $[18,19]$, site-directed mutagenesis of well-established enzymes [20], and screening new biocatalysts by identifying novel microorganisms from as-yet unexplored screening sites [21-23].

Results of several studies indicated that Iranian landscapes contain highly diverse microbial storages due to considerable variety in geographical features, including mountain range peaks with volcano activity, sandy deserts (Dasht-e Lut is one of the hottest points of the Earth), rivers [24], forest areas, hot springs, glaciers, and frequent snowing. Iran also has two coastlines to its north and south. Besides the extremely versatile environments in Iran, industries such as petroleum (oil well) and petrochemical units releasing chemical substances cause influences on the microorganism populations of the above-mentioned country. With such a variety of environments, Iran's soil can be considered a rich source for screening microorganisms, which are able to produce special extremophile biocatalysts [25-28].

The purpose of this study is to identify novel $\omega$-TA from Iranian soil microorganisms to be examined as a catalyst in the synthesis of enantiopure $\beta$-amino acid ( $\beta$-aa) and other chiral amino compounds. Relevant properties of this novel $\omega$-TA, such as the effect of temperature, $\mathrm{pH}$, and solvent and substrate spectra were also investigated.

\section{Results and Discussion}

\subsection{Microorganisms Screening and Identification}

In this study, 42 strains were isolated by enrichment culture against ( $r a c)-\alpha$-methylbenzylamine (rac-MBA) as a sole nitrogen source. Induction and amount of $\omega$-TA is affected by nitrogen source in media. In complex media such as Luria-Bertani (LB) medium, some of the microorganisms produce enzymes with lower activity [29]. Therefore, minimal media (MIM) containing (rac)- $\alpha$-MBA as a model amine compound $[22,23]$ was used in the experiment.

They were subsequently validated through $o$-xylylenediamine (o-XDA) assay, with the color changing from yellow to black after $4 \mathrm{~h}$. $o$-XDA after deamination undergoes spontaneous cyclization, tautomerization, and irreversible polymerization to form a black product [1]. Five strains showing $\omega$-TA activity were found to be promising. Four of these strains were identified by $16 \mathrm{~S}$ rDNA sequencing to be members of the genus Bacillus close to Bacillus halotolerans (BaH) (99.93\% similarity) and Bacillus endophyticus (BaE) (99.76\% similarity). Two subspecies belong to Bacillus subtilis with 99.92\% and $99.93 \%$ similarity to stercoris (BaS) and inaquosorum (BaI), respectively. The fifth bacterium is associated to Rhizobium radiobacter (RhZ) with $99.77 \%$ similarity (Table 1). All of the strains except $\mathrm{BaE}$ were isolated from first method of screening. 
Table 1. Results of 16 SrDNA sequencing.

\begin{tabular}{ccc}
\hline Isolate & Closest Relative in GenBank & \% Similarity/Sequence Length (bp) \\
\hline $\mathrm{BaH}$ & $\begin{array}{c}\text { Bacillus halotolerans } \\
\text { (LPVF01000003) }\end{array}$ & $99.9 / 1388$ \\
\hline $\mathrm{BaE}$ & Bacillus endophyticus (AF295302) & $99.7 / 1273$ \\
\hline $\mathrm{BaS}$ & $\begin{array}{c}\text { Bacillus subtilis subsp. stercoris } \\
\text { (JHCA01000027) }\end{array}$ & $99 / 1385$ \\
\hline $\mathrm{BaI}$ & $\begin{array}{c}\text { Bacillus subtilis subsp. inaquosorum } \\
\text { (AMXN01000021) }\end{array}$ & $99.9 / 1406$ \\
\hline $\mathrm{RhZ}$ & Rhizobium radiobacter (AJ389904) & $99.4 / 1338$ \\
\hline
\end{tabular}

\subsection{Enzymatic Properties and Substrate Specificity}

Appropriate temperature, $\mathrm{pH}$, and organic solvents play important roles in $\omega$-TA activity $[5,30]$. To survey such effects, the optimum reaction condition against these three factors as investigated in the screened bacteria. Several studies have been performed by applying cell and crude extract to convert different substrates [2,18,21,29,31-33], so instead of using high-priced purified protein, we applied cell-free extracts to optimize reaction parameters and to investigate substrate scope.

The relative values of $\omega$-TA activity were calculated based on producing acetophenone as a product of (S)-MBA deamination. The highest activity was considered as 100\%.

\subsubsection{Effect of Temperature on $\omega$-TA Activity}

The cell-free extracts were incubated at defined temperatures $\left(25-65^{\circ} \mathrm{C}\right)$ for one hour. The crude extracts of $\mathrm{BaH}, \mathrm{RhZ}$, and $\mathrm{BaS}$ shared similar expected mesophilic temperature profiles between 30 and $65{ }^{\circ} \mathrm{C}$, with highest activity at $35^{\circ} \mathrm{C}$, which is reported for other $\omega$-TAs [21,34]. They exhibited reasonable activity of around $70 \%$ up to $45^{\circ} \mathrm{C}$. Among all of them, $40-50 \%$ of activity remained at $50{ }^{\circ} \mathrm{C}$, which decreased to approximately $10-20 \%$ at temperatures above $60^{\circ} \mathrm{C}$ (Figure 1a).

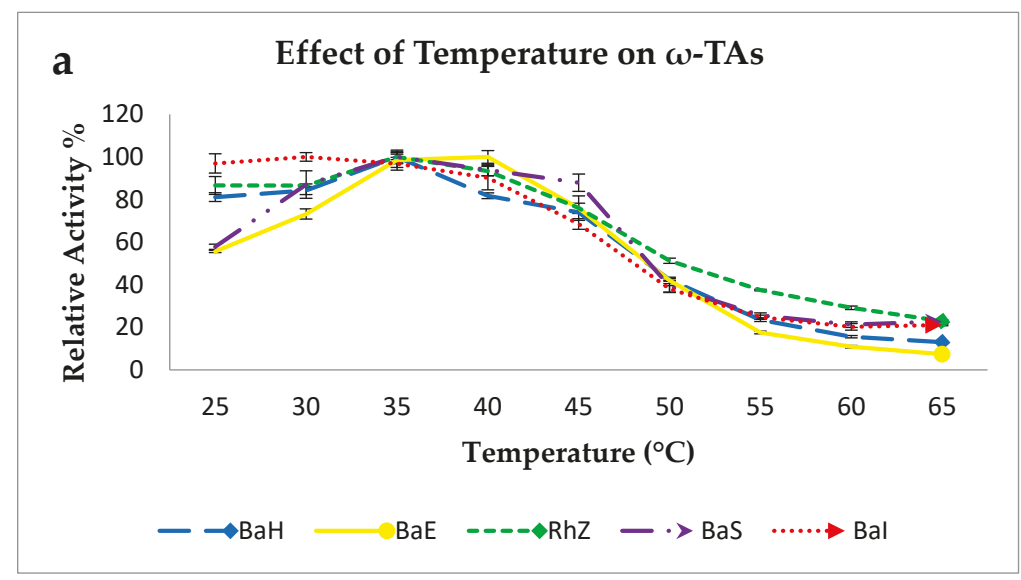

Figure 1. Cont. 


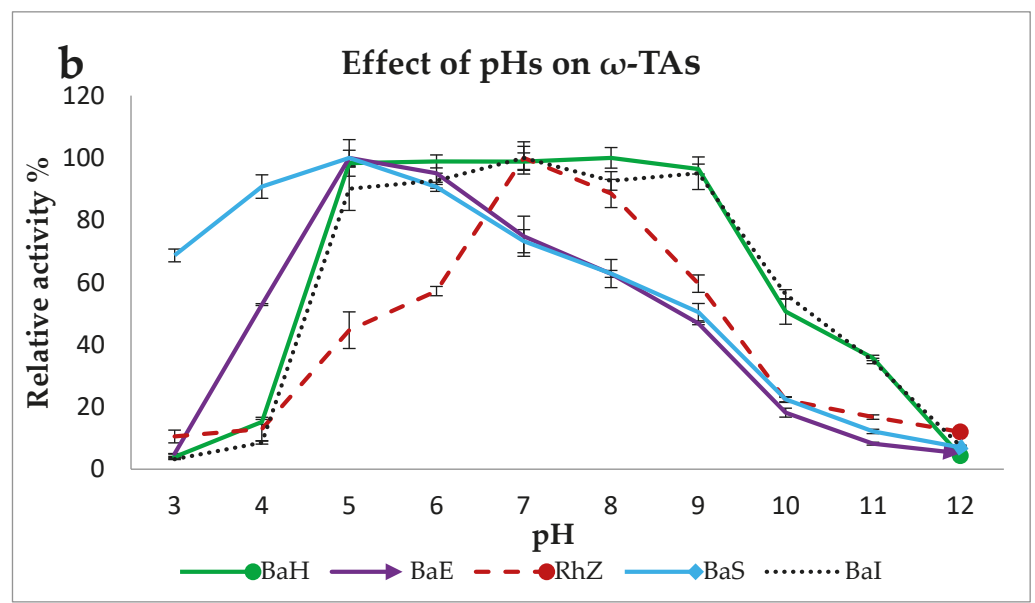

Figure 1. The effect of temperature (a) and $\mathrm{pH}(\mathbf{b})$ on the amination of pyruvate and (S)-MBA as amino donor using $1 \mathrm{mg} / \mathrm{mL}$ of cell-free extracts of screened strains: Bacillus halotolerans $(\mathrm{BaH})$, Bacillus endophyticus (BaE), Rhizobium radiobacter (RhZ), Bacillus subtilis subsp. stercoris (BaS) and Bacillus subtilis subsp. inaquosorum (BaI).Reaction conditions are given in the method section. Formation of acetophenone was detected by HPLC at $254 \mathrm{~nm}$. The value of $100 \%$ corresponded to the highest activity. Error bars represent \pm standard deviation.

For $\omega$-TABaE and $\omega$-TABaI, the optimum reaction temperature was $40{ }^{\circ} \mathrm{C}$ and $30^{\circ} \mathrm{C}$, respectively. No significant change of activity was observed at $35^{\circ} \mathrm{C}$. Thus, for surveying the effect of $\mathrm{pH}$ and solvent on enzyme activity on all crude extracts, the temperature was maintained at $35^{\circ} \mathrm{C}$. Additionally, $\omega$-TABaI showed approximately the same activity at temperatures between 20 and $30^{\circ} \mathrm{C}$ (Table S1).

\subsubsection{Effect of $\mathrm{pH}$ on $\omega$-TA Activity}

In contrast to other $\omega$-TAs that usually show their maximum activity at slightly alkaline $\mathrm{pH}[12,21,31], \omega-\mathrm{TABaI}$ and $\omega$-TABaH exhibited an almost constant activity in the $\mathrm{pH}$ range of 5 to 9 . Surprisingly, for $\omega$-TABaS and $\omega$-TABaE, the highest enzyme activity was observed under acidic conditions ( $\mathrm{pH} 5$ ). Notably, $70 \%$ of $\omega$-TABaS activity remained at $\mathrm{pH} 3$, Furthermore, $\omega$-TARhz preferred neutral conditions (Figure 1b). No enzyme activity was observed at $\mathrm{pH} 12$. In the literature data, there is no report concerning $\omega$-TA activity in acidic conditions. $\omega$-TA activity at different $\mathrm{pHs}$ was mostly tested in $\mathrm{pH}$ range from 6 to $11[4,17,18]$.

\subsubsection{Effect of Organic Solvents on $\omega$-TA Activity}

Organic solvents are often added to $\omega$-TA reactions to increase substrate solubility. However, this mostly causes negative effects on enzyme activity [10]. Therefore, the examination of the tolerance of the applied enzyme to different solvents is highly required [5]. To analyze whether solvents affect enzyme activity, four different solvents with a $0 \%-20 \%$ with the exception of DMSO which increased up to $40 \% v / v$ concentration were tested. The $\omega$-TA activity in aqueous buffer without addition of organic solvents was set as $100 \%$. The results were expressed as relative activity in \%.

Dimethyl sulfoxide (DMSO) is a common solvent that was used in concentrations ranging from $5 \%-20 \% v / v$ in different projects [5]. DMSO as co-solvent led to the highest activity, followed by methanol, N,N-Dimethylformamide (DMF), and isopropanol. In some cases (BaI and Rhz), the reactions without any co-solvent showed better activity than methanol. It is remarkable to mention that $\omega-\mathrm{TABaH}$ activity was enhanced threefold with a concentration of DMSO up to $30 \%$. The results again suggest that DMSO is the most suitable organic solvent for catalytic activation of $\omega$-TAs. However, 
methanol in some cases also increased enzyme activity (Figure 2). Methanol was mentioned as a second co-solvent after DMSO for enhancing $\omega$-TA activity in Pawer et al.'s experiment [2].

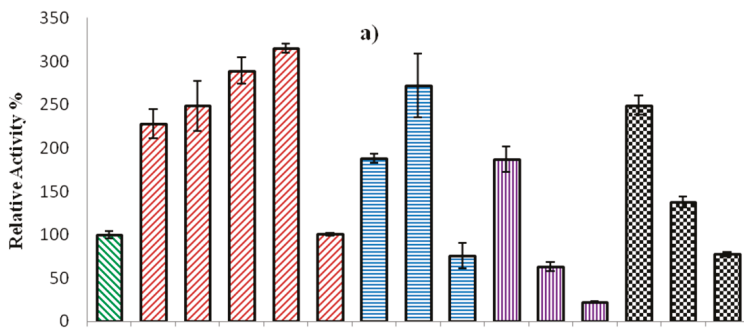

b)
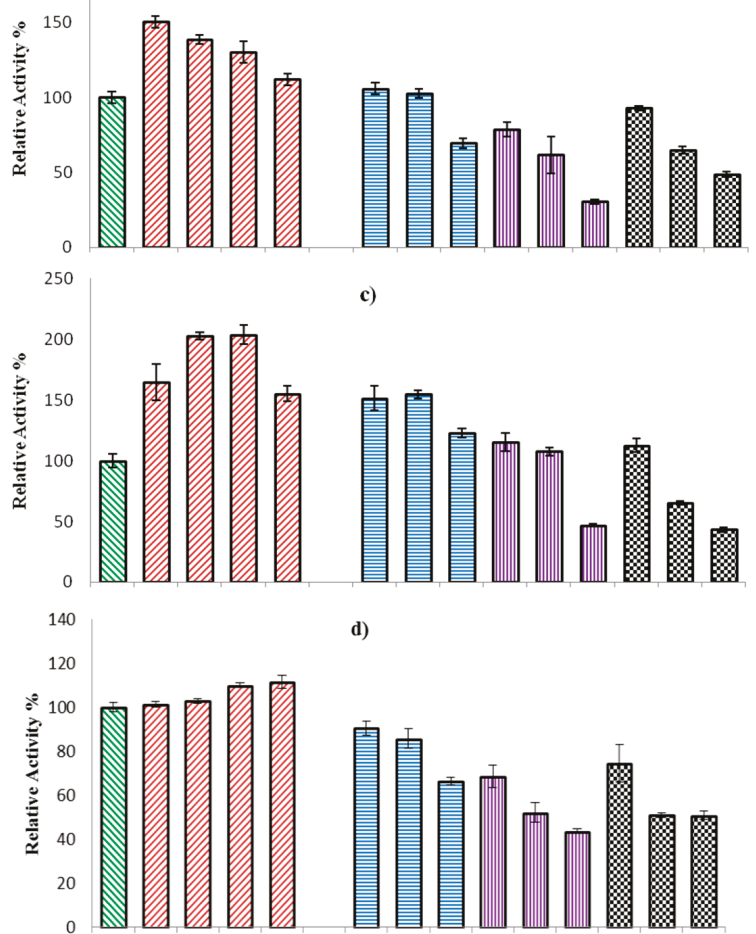

Figure 2. Cont. 


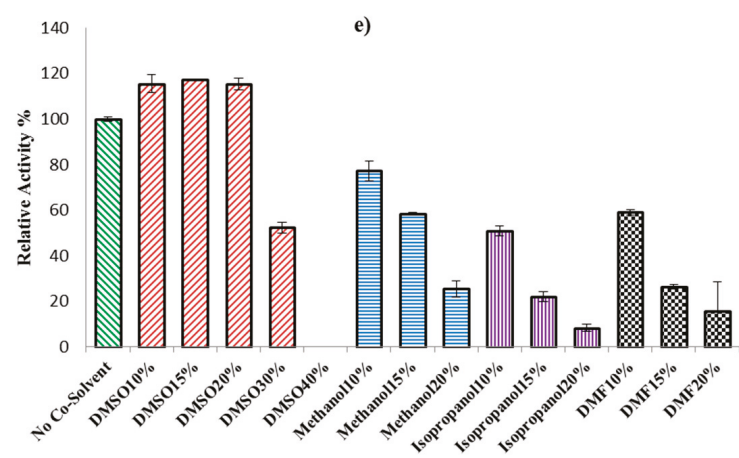

Figure 2. Effect of co-solvent on $\omega$-TA activity of screened strains. (a) BaH; (b) BaE; (c) BaS; (d) RhZ; (e) BaI. The value of $100 \%$ corresponds to enzyme activity in the no co-solvent condition. $1 \mathrm{mg} / \mathrm{mL}$ cell-free extract was added to react under the following conditions: (S)-MBA $(10 \mathrm{mM})$, pyruvate $(10 \mathrm{mM})$, PLP $(0.1 \mathrm{mM})$, and co-solvent $(0-30 \% v / v)$ in Britton-Robinson buffer ( $\mathrm{pH} 7)$ at $35^{\circ} \mathrm{C}$. Formation of acetophenone was detected by HPLC at $254 \mathrm{~nm}$. Error bars represent \pm standard deviation.

\subsubsection{Substrate Specificity and Enantioselectivity}

The substrate spectrum of all strains was investigated in order to find the most suitable amino donor and acceptor.

Regarding amino donors, 28 substrates, including aliphatic and aromatic amino compounds were reacted to pyruvate as an amino acceptor to investigate amino donor specificity, and alanine generation was monitored by the HPLC technique. Racemates as well as the pure, $(S)$ and $(R)$ enantiomers (if available) of amino donors were chosen to explore the enantioselectivity of $\omega$-TA. The results of the substrate screening are illustrated in Table 2. HPLC analysis proved that all enzymes show predominant formation of an (S)-configuration. This is in accordance with most previously reported publications in the literature indicating that $(R)$-stereoselectivity are rather rare in wild-type microorganisms [35]. All cell-free extracts showed high activity against (S)- $\alpha$-methylbenzylamine (S-MBA) $1 \mathbf{s}$.

$\mathrm{BaH}$ showed considerable activity toward a wide range of substrates, including $(S),(R)$, and racemates of aromatic and aliphatic amino donors. Although this cell-free extract also showed activity toward some tested ( $R$ )-enantiomers (1r, 2r, 4r, 5r, 7r, 8r, 13r), (S)-selectivity appeared to be not so strict in this strain. Notably, it is difficult to conclude that BaH showed $(R)$-selectivity since in this study, crude extract was applied. There is a possibility that $(R)$ converted to $(S)$-enantiomer via enzymatic racemization [36], and then the latter was subjected to $\omega$-TA activity. On the other hand, $(R)$-preference towards $13 \mathrm{r}$ in compare to $13 \mathrm{~s}$ leads to another hypothesis, in which both $\mathrm{R}$ and $\mathrm{S}$ transaminases are present in crude extract.

While the cell-free extract of $\mathrm{BaH}$ revealed varying enantiopreference toward all tested amino donors to different degrees, the substrate specificity was found to resemble what has previously been reported by Mathew et al. [5,30], as a preference to react with aromatic $\beta$-amino acids is clearly visible [5]. (S)-MBA 1s is converted with the highest activity, which therefore was set as $100 \%$. Although a few $\omega$-TAs are described with activity toward aromatic $\beta$-amino acids (56), it is remarkable that $\mathrm{BaH}$ uses $\beta$-phenylalanine (13, 13s, 13r) and (rac)- $\beta$-homophenylalanine (14) as an amino donor; both of these were inert for crude extraction from other bacteria in this experiment, which implies the presence of a broad binding pocket in the active site of $\omega$-TABaH. $\omega$-TA activity against $\mathbf{1 4}$ has been reported by Mathew et al. for $\omega$-TABG, with $50 \%$ relative activity in comparison with 13 [30]. A recent study by Buß et al. explained the lack of $\omega$-TA activity against 14 (by an $\omega$-TA that was highly active against 13) by sterice hindrance caused by the additional carbon atom located between the amino group and phenyl group [36]. Several substituted derivatives of $\beta$-phenylalanine are converted as well. 
Table 2. Amino donor screened assays were carried out in Britton-Robinson buffer, $\mathrm{pH} 7$ with amino donor $(10 \mathrm{mM})$, pyruvate $(10 \mathrm{mM})$, PLP $(0.1 \mathrm{mM})$, and 15\% $(v / v)$ DMSO. The reaction was initiated by adding crude extract to a final concentration of $1 \mathrm{mg}$ protein per $\mathrm{ml}$. Reactions were performed at $35{ }^{\circ} \mathrm{C}, 600 \mathrm{rpm}$ for $20 \mathrm{~h}$. Relative activity was measured by HPLC detection of alanine formation at $338 \mathrm{~nm}$. All reactions were conducted in triplicate, and each cell-free extract was separately analyzed for alanine content as a control.

\begin{tabular}{|c|c|c|c|c|c|c|}
\hline & \multirow{2}{*}{ Amino Donor } & \multicolumn{5}{|c|}{ Relative Activity\% } \\
\hline & & BaH & $\mathrm{BaE}$ & BaS & BaI & RhZ \\
\hline $1 \quad$ (rac) & \multirow{3}{*}{$\alpha$-methylbenzylamine } & 53 & 48 & 45 & 60 & 36 \\
\hline 1s (S) & & 100 & 100 & 100 & 100 & 100 \\
\hline $1 \mathbf{r} \quad(R)$ & & 23 & 0 & 0 & 6 & 0 \\
\hline $2 \quad(\mathrm{rac})$ & \multirow{3}{*}{ 3-amino-3-(4-chlorophenyl) propionic acid } & 19 & 0 & 0 & 0 & 0 \\
\hline $2 s \quad(S)$ & & 20 & 0 & 0 & 0 & 0 \\
\hline $2 \mathbf{r} \quad(R)$ & & 16 & 0 & 0 & 0 & 0 \\
\hline $3 \quad(\mathrm{rac})$ & 3-amino-3-(3,4-dichloro-phenyl)propionic acid & 20 & 0 & 0 & 0 & 0 \\
\hline $4 \quad(\mathrm{rac})$ & \multirow{2}{*}{ 3-amino-3-(4-nitrophenyl)propionic acid } & 51 & 0 & 0 & 0 & 0 \\
\hline $4 \mathbf{r} \quad(R)$ & & 19 & 0 & 0 & 0 & 0 \\
\hline $5 \mathbf{r} \quad(R)$ & (R)3-amino-3-(2-nitro-phenyl)-propionic acid & 16 & 0 & 0 & 0 & 0 \\
\hline $6 \quad(\mathrm{rac})$ & \multirow{2}{*}{ 3-amino-3-(4-methoxyphenyl) propionic acid } & 21 & 0 & 0 & 0 & 0 \\
\hline 6s $\quad(S)$ & & 17 & 0 & 0 & 0 & 0 \\
\hline $7 \mathbf{s} \quad(S)$ & \multirow{2}{*}{ 3-amino-3-(4-hydroxy-phenyl)propionic acid } & 18 & 0 & 0 & 0 & 0 \\
\hline $7 \mathbf{r} \quad(R)$ & & 15 & 0 & 0 & 0 & 0 \\
\hline $8 \quad(\mathrm{rac})$ & \multirow{2}{*}{ 3-amino-3-(4-bromophenyl)-propionic acid } & 21 & 0 & 0 & 0 & 0 \\
\hline $8 \mathbf{r} \quad(R)$ & & 20 & 0 & 0 & 0 & 0 \\
\hline $9 \quad$ (rac) & \multirow{2}{*}{ 3-amino-3-(4-fluorophenyl)propionic acid } & 43 & 0 & 0 & 0 & 0 \\
\hline 9s $\quad(\mathrm{S})$ & & 16 & 0 & 0 & 0 & 0 \\
\hline $10 \quad(r a c)$ & $\begin{array}{l}\text { Methyl(-3-amino-3-phenyl propanoate } \\
\text { hydrochloride) }\end{array}$ & 11 & 0 & 0 & 0 & 0 \\
\hline 11 (rac) & 3-amino-3-(4-isopropylphenyl) propionic acid & 20 & 0 & 0 & 0 & 0 \\
\hline 12 (rac) & 1-aminocyclopropane-1-carboxylic acid & 17 & 17 & 0 & 30 & 0 \\
\hline 13 (rac) & \multirow{3}{*}{$\beta$-phenylalanine } & 17 & 0 & 0 & 0 & 0 \\
\hline $13 s(S)$ & & 16 & 0 & 0 & 0 & 0 \\
\hline 13r $(R)$ & & 22 & 0 & 0 & 0 & 0 \\
\hline 14 (rac) & $\beta$-Homophenylalanine & 16 & 0 & 0 & 0 & 0 \\
\hline 15 & Isopropylamine & 20 & 0 & 0 & 21 & 0 \\
\hline 16 & Sec-butylamine & 25 & 7 & 0 & 27 & 0 \\
\hline $17 \mathrm{~s}(S)$ & 3-amino butyric acid & 91 & 59 & 54 & 20 & 135 \\
\hline
\end{tabular}

The activity against (S)-MBA was set as 100. An amount under $1 \%$ was considered as zero activity. 
BaE presented only (S)-selectivity in relation to tested substrates. Similar to BaH, the strain's crude extract exhibited activity toward 1s, almost double that of $\mathbf{1}$. $\mathrm{BaE}$ and $\mathrm{BaH}$ share the same activity toward 12, while BaI showed almost double the activity in comparison with those. The relative activity of $\omega$-TA of BaI toward ( $\mathrm{rac}$ )-MBA 1 exceeded $60 \%$, which might be related to the presence of racemase in the crude extract of bacteria [37,38].

Crude extracts of RhZ and BaS displayed (S)-selectivity toward the tested amino donors with similar preference profiles. RhZ showed more activity toward $\mathbf{1 7 s}$ as an aliphatic substrate than MBA 1s, which was not observed for other screened strains.

Amino acceptors play a critical role in $\omega$-TA activity [30]. Eight ketones were reacted with (S)-MBA to explore the amino acceptor specificities by HPLC detection of acetophenone production (Table 3). Aliphatic ketones such as sodium pyruvate $7 \mathbf{b}$ and $\alpha$-ketoglutaric acid $\mathbf{8 b}$ showed high conversion, whereas most aromatic ketones were not accepted by the investigated enzymes.

Table 3. Amino acceptor screened assays were carried out in Britton-Robinson buffer, $\mathrm{pH} 7$ with (S)-MBA (10 mM), amino acceptor (10 mM), PLP (0.1 mM), and 15\% (v/v) DMSO. The reaction was started by the addition of crude extract to a final concentration of $1 \mathrm{mg} / \mathrm{mL}$ in the following conditions: $35^{\circ} \mathrm{C}, 600 \mathrm{rpm}$ for $20 \mathrm{~h}$. Relative activity was measured by HPLC detection of acetophenone formation at $254 \mathrm{~nm}$. All reactions were conducted in triplicate, and each cell-free extract was separately analyzed as a control.

\begin{tabular}{|c|c|c|c|c|c|c|}
\hline \multirow{2}{*}{\multicolumn{2}{|c|}{ Amino Acceptors }} & \multicolumn{5}{|c|}{ Relative Activity $\%$} \\
\hline & & $\mathrm{BaH}$ & $\mathrm{BaE}$ & BaS & BaI & RhZ \\
\hline $1 b$ & Ethyl benzoylacetate & 40.95 & 0 & 20.84 & 14.87 & 0 \\
\hline $2 b$ & $\begin{array}{c}\text { Ethyl } \\
\text { 3-(4-methoxyphenyl)-3-oxopropanoate }\end{array}$ & 0 & 0 & 0 & 60.48 & 0 \\
\hline $3 b$ & Sodium 3-oxo-3-phenylpropanoate & 0 & 0 & 0 & 0 & 0 \\
\hline $4 b$ & Ethyl(4-flurobenzoyl)acetate & 0 & 0 & 0 & 0 & 0 \\
\hline $5 b$ & Ethyl(4-chlorobenzoyl)acetate & 0 & 0 & 0 & 0 & 0 \\
\hline $6 b$ & Ethyl 4-nitrobenzoylacetate & 0 & 0 & 0 & 0 & 0 \\
\hline $7 \mathrm{~b}$ & Pyruvate & 100 & 100 & 43.73 & 100 & 36.39 \\
\hline $8 b$ & $\alpha$-ketoglutarate & 17.09 & 7.31 & 100 & 0 & 100 \\
\hline
\end{tabular}

In each column, the highest activity was defined as $100 \%$. Activity less than $1 \%$ was considered zero.

Cell-free extract of $\mathrm{BaH}, \mathrm{BaS}$, and $\mathrm{BaI}$ exhibited some activity toward bulkier substrates, including $\mathbf{1 b}$ or $\mathbf{2} \mathbf{b}$. It is supposed that $\beta$-amino acid esters were produced by using these acceptors, but this needs to be investigated in further experiments. $\mathrm{BaH}, \mathrm{BaS}$, and $\mathrm{BaI}$ showed activity toward $\mathbf{1} \mathbf{b}$ as amino acceptor. BaI was the only extract to show activity toward acceptor $\mathbf{2} \mathbf{b}$.

The substrate scope of $\omega$-TA is determined by the active site, which consists of a large and a small binding pocket. The former can accommodate bulky residues, including aryl groups, whereas the latter is loaded by a small group such as a methyl substituent [14]. So most $\omega$-TAs have a limitation in accepting bulky substrates without applying protein engineering. Voss et al. reported that after double mutation on $\omega$-TA 3FCR from Ruegeria sp. TM1040, this enzyme gained activity toward bulkier substrates such as phenylpropylamine and phenylbutylamine [16]. Strain BaH showed a good 
ability to convert bulky substrates and showed different substrate spectra with known $\omega$-TAs [15,35]. Purification and further investigation of this enzyme is intended for further studies.

\section{Materials and Methods}

\subsection{Chemicals}

All solvents and chemicals used in this study were purchased from Sigma-Aldrich (St Louis, MO, USA), Carl Roth GmbH (Karlsruhe, Germany), and Peptech (Burlington, MA, USA).

\subsection{Screening and Identification}

\subsubsection{Enrichment of Microorganisms on (rac)- $\alpha$-MBA as Sole Nitrogen Source}

Due to the role of transaminase in nitrogen metabolism [29], areas enriched with nitrogen compounds were chosen as potential sites for screening novel $\omega$-transaminase. Soil samples $(2 \mathrm{~g})$ from a petrochemical site, oil well, and an agriculture field in Iran were separately suspended in $200 \mathrm{~mL}$ sterile minimal medium (MIM) in $500 \mathrm{~mL}$ Erlenmeyer flasks containing $10 \mathrm{mM}(\mathrm{rac})-\alpha$-MBA, $100 \mathrm{mM}$ glycerol, $1 \mathrm{~g} / \mathrm{L} \mathrm{MgSO}_{4} .7 \mathrm{H}_{2} \mathrm{O}, 0.02 \mathrm{mg} / \mathrm{L} \mathrm{H}_{3} \mathrm{BO}_{3}, 0.2 \mathrm{mM} \mathrm{CaCl}, 0.1 \mathrm{mg} / \mathrm{L} \mathrm{MnSO}{ }_{4} .4 \mathrm{H}_{2} \mathrm{O}$, $0.1 \mathrm{mg} / \mathrm{L} \mathrm{CuSO}{ }_{4} .5 \mathrm{H}_{2} \mathrm{O}, 0.1 \mathrm{mg} / \mathrm{L} \mathrm{NiSO}_{4} .6 \mathrm{H}_{2} \mathrm{O}, 2.0 \mathrm{mg} / \mathrm{L} \mathrm{NaMoO}, 0.05 \mathrm{mg} / \mathrm{L} \mathrm{CoCl}_{2}, 0.1 \mathrm{mg} / \mathrm{L} \mathrm{ZnCl}$, $4 \mathrm{mg} / \mathrm{L} \mathrm{FeSO}_{4} \cdot 7 \mathrm{H}_{2} \mathrm{O}$, and potassium phosphate buffer (50 mM, pH 7.0) [39]. $\mathrm{FeSO}_{4}$ and (rac)- $\alpha$-MBA were separately sterile filtrated and added to the medium. Autoclaving causes precipitation of ferric hydrate [40]. Each sample was prepared in duplicate. Enrichment went through two strategies:

In the first method, Erlenmeyer flasks were incubated for $24 \mathrm{~h}$ at $180 \mathrm{rpm}$ at $35^{\circ} \mathrm{C}$ (depending on the original temperature of the soil samples). After $24 \mathrm{~h}$ of incubation, a $100 \mu \mathrm{L}$ sample was transferred to $20 \mathrm{~mL}$ of fresh minimal medium and incubated for $24 \mathrm{~h}$ under the same conditions as described before. This serial dilution was repeated 3 times. After that, the culture was diluted with PBS buffer (10: $90 \mu \mathrm{L}$ ) and poured to MIM agar plates (mineral medium, $10 \mathrm{mM}(\mathrm{rac})-\alpha$-MBA with $1.5 \%$ agar) and incubated at $35^{\circ} \mathrm{C}$. As soon as colonies were visible, single colonies were streaked on new MIM agar plates to obtain uniform colonies under the same temperature.

In the second method, Erlenmeyer flasks were transferred to a dark place, without shaking, at $35^{\circ} \mathrm{C}$. During incubation, $1 \mathrm{~mL}$ of concentrated MIM (5X), $0.5 \%$ v/v glycerol, and $10 \mathrm{mM}(\mathrm{rac})-\alpha$-MBA were added to the flasks every week. After 3 months, the culture broth was centrifuged (1000 $g, 2 \mathrm{~min}$ ) and $100 \mu \mathrm{L}$ of supernatant was spread on MIM agar plates. The colonies were isolated after 3 days of incubation at $35^{\circ} \mathrm{C}$. This was continued until the isolation of single colonies was achieved.

\subsubsection{Selection of the Most Promising Strains}

To identify whether isolated strains use (rac)- $\alpha$-MBA as a sole nitrogen source or atmospheric nitrogen, o-Xylylenediamine was applied as a smart amino donor. Each colony was cultivated in a shake flask containing $20 \mathrm{~mL}$ MIM medium with $12 \mathrm{mM}(\mathrm{rac})-\alpha-\mathrm{MBA}$ for three days at $35^{\circ} \mathrm{C}$ at $120 \mathrm{rpm}$. The cells were harvested by centrifugation at $6000 \times g$ for $10 \mathrm{~min}$ at $4{ }^{\circ} \mathrm{C}$ and resuspended in HEPES buffer $(50 \mathrm{mM}, \mathrm{pH} 7.5)$. The cell concentration was adjusted to around $20 \mathrm{mg} / \mathrm{mL}$ by measuring dry cell mass based on Buß et al. [36]. The cells were frozen at $-80{ }^{\circ} \mathrm{C}$ and thawed at room temperature for cell disruption.

Reaction was started by adding $50 \mu \mathrm{L}$ of whole cells to $150 \mu \mathrm{L}$ reaction solution containing $7.5 \mathrm{mM}$ o-Xylylenediamine, $5 \mathrm{mM}$ pyruvate, $1 \mathrm{mM}$ PLP, and 10\% DMSO in HEPES buffer (50 mM, pH 7.5) [41] in a 96 -well plate. Each reaction was conducted in triplicate. The plate was incubated overnight at $35^{\circ} \mathrm{C}$, $150 \mathrm{rpm}$.

\subsubsection{Identification of Bacteria}

The positive strains were grown separately overnight in LB broth at $35^{\circ} \mathrm{C}, 150 \mathrm{rpm}$. DNA was extracted by ZR soil Microbe DNA Kit ${ }^{\mathrm{TM}}$. PCR was done with a Q5 high-fidelity PCR kit (NEB, 
Germany). Universal Primers (27F and 1492R) were applied to amplify $1.5 \mathrm{~kb} 16 \mathrm{~S}$ rDNA fragments. PCR was conducted following the manufacturer's instructions for Q5 polymerase. Gene sequencing was performed by Eurofins Company (Ebersberg, Germany). The resulting 16S rRNA gene sequences were compared with available gene sequences in the EZ bioCloud database [42].

\subsection{Enzymatic Properties and Substrate Specificity}

\subsubsection{Preparation of Crude Extract}

The inoculum $(3 \mathrm{~mL})$ was prepared by picking a single colony and cultivating it for three days in MIM with $12 \mathrm{mM}(\mathrm{rac})-\alpha$-MBA. The medium $(400 \mathrm{~mL})$ was inoculated by the addition of $1 \%(v / v)$ of the latter culture into $1 \mathrm{~L}$ shaking flasks containing MIM with $0.5 \mathrm{~g} / \mathrm{L}$ yeast extract and $12 \mathrm{mM}$ (rac)- $\alpha$-MBA overnight at $150 \mathrm{rpm}$ and $35^{\circ} \mathrm{C}$. Cells were harvested before reaching stationary phase by centrifugation at $6000 \times g$ for $10 \mathrm{~min}$ at $4{ }^{\circ} \mathrm{C}$. After washing the pellet with sodium phosphate buffer $(50 \mathrm{mM}, \mathrm{pH} 7)$, cells were resuspended in $10 \mathrm{~mL}$ lysis buffer (sodium phosphate $(50 \mathrm{mM}, \mathrm{pH}$ 7), $0.1 \mu \mathrm{M}$ PLP, $100 \mu \mathrm{g} / \mathrm{mL}$ lysozyme]. Afterwards, they were incubated for $1 \mathrm{~h}$ at room temperature, followed by sonification ( 3 cycles: $30 \mathrm{~s}$ pulse, $20 \mathrm{~s}$ pause; $60 \%$ amplitude) on ice. Subsequently, the cell debris was removed by centrifugation $\left(20,000 \mathrm{rpm}, 4{ }^{\circ} \mathrm{C}, 15 \mathrm{~min}\right)$ in a JA-30-50 rotor (Coulter-Beckman centrifuge). The protein concentration of crude extract was determined by using the Roti ${ }^{\circledR}$-Quant universal kit (Carl Roth, Karlsruhe, Germany) following the manufacturer's instructions. Eventually, they were mixed with $15 \%$ glycerol and preserved in $-80^{\circ} \mathrm{C}$ for further analysis.

\subsubsection{Effect of Temperature, $\mathrm{pH}$, and Co-Solvent}

The effects of temperature and $\mathrm{pH}$ on enzyme activity were examined at different temperatures $\left(25-65^{\circ} \mathrm{C}\right.$ at $\left.\mathrm{pH}\right)$ and various $\mathrm{pHs}\left(3-12\right.$ at $\left.35^{\circ} \mathrm{C}\right)$ by using Britton-Robinson buffer $\left(0.04 \mathrm{M} \mathrm{H}_{3} \mathrm{BO}_{3}\right.$, $\left.0.04 \mathrm{M} \mathrm{H}_{3} \mathrm{PO}_{4}, 0.04 \mathrm{M} \mathrm{CH}_{3} \mathrm{COOH}\right)$ containing an amino donor $(10 \mathrm{mM})$, amino acceptor (10 mM), PLP $(0.1 \mathrm{mM})$, and DMSO $(10 \%)$. The total reaction volume was set to $0.25 \mathrm{~mL}$. The reactions were initiated by adding crude extract of enzyme $(\sim 1 \mathrm{mg} / \mathrm{mL})$.

To study the effect of solvent on $\omega$-TA activity, reactions were carried out applying various organic solvents with $0-20 \%(v / v)$ (for DMSO $0-40 \%)$. (rac)- $\alpha$-MBA $(10 \mathrm{mM}$ ) was used as amino donor and pyruvate $(10 \mathrm{mM})$ as amino acceptor in the presence of PLP $(0.1 \mathrm{mM})$ and cell-free extract $(\sim 1 \mathrm{mg} / \mathrm{mL})$. The reactions were carried out in Britton-Robinson buffer (pH 7) at $35^{\circ} \mathrm{C}$ as described above.

Each reaction was conducted in triplicate and incubated (ThermoMixer, Eppendorf) at $600 \mathrm{rpm}$ for $1 \mathrm{~h}$. As a control, the reaction was conducted without adding enzyme. Furthermore, the amount of acetophenone in crude extract of enzyme was also evaluated. Reactions were stopped by heating to $95^{\circ} \mathrm{C}$ for $5 \mathrm{~min}$. After centrifugation, the supernatant was analyzed by HPLC to detect produced acetophenone according to Section 3.4. Results are shown as relative activity.

\subsubsection{Substrate Specificity and Enantioselectivity}

The reactions were carried out according to Section 3.3.2. Various amino donors (10 mM) listed in Table 1 were tested using sodium pyruvate $(10 \mathrm{mM})$ as amino acceptor in the Britton-Robinson buffer $(\mathrm{pH} 7)$ and $15 \%(v / v)$ DMSO. The reaction was carried out at $35^{\circ} \mathrm{C}, 600 \mathrm{rpm}$, for $20 \mathrm{~h}$ (ThermoMixer, Eppendorf). The produced alanine was analyzed by HPLC according to Section 3.4.

Different amino acceptors $(10 \mathrm{mM})$ were tested with (S)- $\alpha$-MBA as amino donor $(10 \mathrm{mM})$ in Britton-Robinson buffer, $\mathrm{pH} 7$, at $35{ }^{\circ} \mathrm{C}, 600 \mathrm{rpm}$, for $20 \mathrm{~h}$. The production of acetophenone was analyzed by HPLC according to Section 3.4.

Each reaction was conducted in triplicate, and the average of three independent reactions was used for evaluation. Enzyme inactivation was applied by heating to $95^{\circ} \mathrm{C}$ for $5 \mathrm{~min}$. The supernatant was used for analysis after centrifugation. In addition, the amounts of alanine and acetophenone were measured in enzyme crude extracts as blanks. 


\subsection{HPLC Analytics}

All samples were analyzed by Agilent 1100 series HPLC system (Santa Clara, CA, USA). For the analysis of alanine, derivatization by using ortho-phthalaldehyde was carried out according to Brucher et al. [43] and Buß et al. [44], with an automated precolumn derivatization. A reversed-phase $\mathrm{C}_{18}$ column $(150 \times 4.6 \mathrm{~mm}$ HyperClone $5 \mu \mathrm{m}$ ODS, Phenomenex, Germany) with isocratic elution with $35 \%(v / v)$ methanol and $65 \%(v / v)$ sodium phosphate buffer $(40 \mathrm{mM}, \mathrm{pH} 6.5)$ at a flow rate of $0.8 \mathrm{~mL} \mathrm{~min}{ }^{-1}$ and detection at $338 \mathrm{~nm}$ at $25^{\circ} \mathrm{C}$ was used.

The acetophenone concentration in the samples was determined chromatographically by isocratic elution with acetonitrile/water $(50 / 50, v / v)$ at flow rate of $0.6 \mathrm{~mL} \mathrm{~min}^{-1}$ with $\mathrm{UV}$ detection at $254 \mathrm{~nm} \mathrm{[45],}$ at $25^{\circ} \mathrm{C}$ applying a $\mathrm{C}_{18}$ Hypersil-keystone column $(250 \times 4.6 \mathrm{~mm} 5 \mu$ Hypersil). The injection volume was adjusted to $1 \mu \mathrm{L}$.

\section{Conclusions}

Our motivation for screening novel microorganisms exhibiting transaminase activity resulted from several challenges for the industrial application of $\omega$-TAs, e.g., lacking activity at acidic $\mathrm{pH}$, high temperature, unnatural substrates, $(R)$-configured molecules, and elevated concentrations of organic solvents (needed due to low substrate solubility in aqueous systems). We succeeded in finding promising new strains from a high variety of Iranian soil samples by enrichment culture using (rac)- $\alpha$-methylbenzylamine ( $\alpha$-MBA) as a sole nitrogen source.

In particular, a Bacillus halotolerans $(\mathrm{BaH})$ strain was isolated from a petroleum refinery, exhibiting $\omega$-TA activity using a broad spectrum of amino donors over a $\mathrm{pH}$ range of 5-9 at elevated concentrations of DMSO and other organic solvents up to $30 \%(v / v)$. Two other strains isolated from an agricultural field (Bacillus endophyticus, BaE) and an oilfield (Bacillus subtilis, BaS) showed the highest $\omega$-TA activity against $\alpha$-MBA at $\mathrm{pH} 5$ with $70 \%$ remaining activity at $\mathrm{pH} 3(\mathrm{BaS})$, whereas $\omega$-TAs are usually described to prefer slightly alkaline conditions. The enzymes dedicated to these extraordinary activities will be purified and subjected to in-depth studies for application-technical characterization.

Supplementary Materials: The following are available online at http://www.mdpi.com/2073-4344/9/10/874/s1, Table S1: The Effect of temperature on the amination of pyruvate and (S)-MBA as amino donor using $1 \mathrm{mg} / \mathrm{mL}$ cell-free extracts of BaI strain. Reaction conditions are given in the method section. Formation of acetophenone was detected by HPLC at $254 \mathrm{~nm}$. Every reaction was conducted in three replicates.

Author Contributions: Conceptualization, J.F. and J.R., methodology, N.G.N., M.Z.M., and U.E., validation, J.R., M.M.H., and U.E., formal analysis, N.G.N., investigation, N.G.N., data curation, N.G.N., writing—original draft preparation, N.G.N., writing—review and editing, N.G.N., J.F., J.R., U.E., M.M.H., M.Z.M., and C.S., visualization, M.Z.M., supervision, J.F., J.R., and C.S., project administration, J.F.

Funding: This research received no external funding.

Acknowledgments: This study was financially supported by grant No: 970201 of the Biotechnology Development Council of the Islamic Republic of Iran. The publication of this article was funded by Karlsruhe Institute of Technology (Helmholtz).

Conflicts of Interest: The authors declare that there is no conflict of interest.

\section{References}

1. Gomm, A.; Lewis, W.; Green, A.P.; O’Reilly, E. A New Generation of Smart Amine Donors for Transaminase-Mediated Biotransformations. Chem. A Eur. J. 2016, 22, 12692-12695. [CrossRef]

2. Pawar, S.V.; Hallam, S.J.; Yadav, V.G. Metagenomic Discovery of a Novel Transaminase for Valorization of Monoaromatic Compounds. RSC Adv. 2018, 8, 22490-22497. [CrossRef]

3. Aleku, G.A.; France, S.P.; Man, H.; Mangas-Sanchez, J.; Montgomery, S.L.; Sharma, M.; Leipold, F.; Hussain, S.; Grogan, G.; Turner, N.J. A Reductive Aminase from Aspergillus Oryzae. Nat. Chem. 2017, 9, 961. [CrossRef]

4. Kim, G.H.; Jeon, H.; Khobragade, T.P.; Patil, M.D.; Sung, S.; Yoon, S.; Won, Y.; Choi, I.S.; Yun, H. Enzymatic Synthesis of Sitagliptin Intermediate Using a Novel $\omega$-Transaminase. Enzym. Microb. Technol. 2019, 120, 52-60. [CrossRef] 
5. Mathew, S.; Nadarajan, S.P.; Chung, T.; Park, H.H.; Yun, H. Biochemical Characterization of Thermostable $\omega$-Transaminase from Sphaerobacter Thermophilus and its Application for Producing Aromatic $\beta$-and $\gamma$-Amino Acids. Enzym. Microb. Technol. 2016, 87, 52-60. [CrossRef]

6. Haycock-Lewandowski, S.J.; Wilder, A.; Åhman, J. Development of a Bulk Enabling Route to Maraviroc (UK-427,857), a CCR-5 Receptor Antagonist. Org. Process. Res. Dev. 2008, 12, 1094-1103. [CrossRef]

7. Slomka, C.; Zhong, S.; Fellinger, A.; Engel, U.; Syldatk, C.; Bräse, S.; Rudat, J. Chemical Synthesis and Enzymatic, Stereoselective Hydrolysis of a Functionalized Dihydropyrimidine for the Synthesis of $\beta$-Amino Acids. AMB Express 2015, 5, 85. [CrossRef]

8. Weiner, B.; Szymański, W.; Janssen, D.B.; Minnaard, A.J.; Feringa, B.L. Recent Advances in the Catalytic Asymmetric Synthesis of $\beta$-Amino Acids. Chem. Soc. Rev. 2010, 39, 1656-1691. [CrossRef]

9. Turner, N.J.; Truppo, M.D. Biocatalytic Routes to Nonracemic Chiral Amines. In Chiral Amine Synthesis: Methods, Developments and Applications; Nugent, T.C., Ed.; Wiley-VCH: Weinheim, Germany, 2010; pp. 431-459.

10. Mathew, S.; Jeong, S.S.; Chung, T.; Lee, S.H.; Yun, H. Asymmetric Synthesis of Aaromatic $\beta$-Amino Acids Using $\omega$-Transaminase: Optimizing the Lipase Concentration to Obtain Thermodynamically Unstable $\beta$-Keto Acids. Biotechnol. J. 2016, 11, 185-190. [CrossRef]

11. Malik, M.S.; Park, E.S.; Shin, J.S. Features and Technical Applications of $\omega$-Transaminases. Appl. Microbiol. Biotechnol. 2012, 94, 1163-1171. [CrossRef]

12. Jiang, J.; Chen, X.; Feng, J.; Wu, Q.; Zhu, D. Substrate Profile of an $\omega$-Transaminase from Burkholderia Vietnamiensis and its Potential for the Production of Optically Pure Amines and Unnatural Amino Acids. J. Mol. Catal. B Enzym. 2014, 100, 32-39. [CrossRef]

13. Cerioli, L.; Planchestainer, M.; Cassidy, J.; Tessaro, D.; Paradisi, F. Characterization of a Novel Amine Transaminase from Halomonas Elongata. J. Mol. Catal. B Enzym. 2015, 120, 141-150. [CrossRef]

14. Voss, M.; Das, D.; Genz, M.; Kumar, A.; Kulkarni, N.; Kustosz, J.; Kumar, P.; Bornscheuer, U.T.; Höhne, M. In Silico Based Engineering Approach to Improve Transaminases for the Conversion of Bulky Substrates. ACS Catal. 2018, 8, 11524-11533. [CrossRef]

15. Rudat, J.; Brucher, B.R.; Syldatk, C. Transaminases for the Synthesis of Enantiopure Beta-Amino Acids. $A M B$ Express 2012, 2, 11. [CrossRef]

16. Pavlidis, I.V.; Weiß, M.S.; Genz, M.; Spurr, P.; Hanlon, S.P.; Wirz, B.; Iding, H.; Bornscheuer, U.T. Identification of (S)-Selective Transaminases for the Asymmetric Synthesis of Bulky Chiral Amines. Nat. Chem. 2016, 8 , 1076-1082. [CrossRef]

17. Kelly, S.A.; Magill, D.J.; Megaw, J.; Skvortsov, T.; Allers, T.; McGrath, J.W.; Allen, C.C.; Moody, T.S.; Gilmore, B.F. Characterisation of a Solvent-Tolerant Haloarchaeal (R)-Selective Transaminase Isolated from a Triassic Period Salt Mine. Appl. Microbiol. Biotechnol. 2019, 103, 5727-5737. [CrossRef]

18. Leipold, L.; Dobrijevic, D.; Jeffries, J.W.; Bawn, M.; Moody, T.S.; Ward, J.M.; Hailes, H.C. The Identification and Use of Robust Transaminases from a Domestic Drain Metagenome. Green Chem. 2019, 21, 75-86. [CrossRef]

19. Ferrandi, E.E.; Previdi, A.; Bassanini, I.; Riva, S.; Peng, X.; Monti, D. Novel Thermostable Amine Transferases from Hot Spring Metagenomes. Appl. Microbiol. Biotechnol. 2017, 101, 4963-4979. [CrossRef]

20. Genz, M.; Vickers, C.; van den Bergh, T.; Joosten, H.-J.; Dörr, M.; Höhne, M.; Bornscheuer, U. Alteration of the Donor/Acceptor Spectrum of the (S)-Amine Transaminase from Vibrio Fluvialis. Int. J. Mol. Sci. 2015, 16, 26953-26963. [CrossRef]

21. Kelly, S.A.; Megaw, J.; Caswell, J.; Scott, C.J.; Allen, C.C.; Moody, T.S.; Gilmore, B.F. Isolation and Characterisation of a Halotolerant $\omega$-Transaminase from a Triassic Period Salt Mine and Its Application to Biocatalysis. ChemistrySelect 2017, 2, 9783-9791. [CrossRef]

22. Shin, J.S.; Kim, B.G. Kinetic Resolution of $\alpha$-Methylbenzylamine with o-Transaminase Screened from Soil Microorganisms: Application of a Biphasic System to Overcome Product Inhibition. Biotechnol. Bioeng. 1997, 55, 348-358. [CrossRef]

23. Pavkov-Keller, T.; Strohmeier, G.A.; Diepold, M.; Peeters, W.; Smeets, N.; Schürmann, M.; Gruber, K.; Schwab, H.; Steiner, K. Discovery and Structural Characterisation of New Fold Type IV-Transaminases Exemplify the Diversity of This Eenzyme Fold. Sci. Rep. 2016, 6, 38183. [CrossRef] [PubMed]

24. Yazdi, A.; Emami, M.H.; Shafiee, S.M. Dasht-E Lut in Iran, the Most Complete Collection of Beautiful Geomorphological Phenomena of Desert. Open J. Geol. 2014, 4, 249-261. [CrossRef]

25. Ataee, N.; Fooladi, J.; Namaei, M.H.; Rezadoost, H.; Mirzajani, F. Biocatalysts Screening of Papaver Bracteatum Flora for Thebaine Transformation to Codeine and Morphine. Biocatal. Agric. Biotechnol. 2017, 9, 127-133. [CrossRef] 
26. Ghasemi, Y.; Rasoul-Amini, S.; Ebrahiminezhad, A.; Kazemi, A.; Shahbazi, M.; Talebnia, N. Screening and Isolation of Extracellular Protease Producing Bacteria from the Maharloo Salt Lake. Iran. J. Pharm. Sci. 2011, 7, 175-180.

27. Alghabpoor, S.S.; Panosyan, H.; Trchounian, A.; Popov, Y. Purification and Characterization of a Novel Thermostable and Acid Stable $\alpha$-Amylase from Bacillus Sp. Iranian S1. Int. J. Eng. Trans. B Appl. 2013, 26, 815-820. [CrossRef]

28. Shirsalimian, M.; Amoozegar, M.; Sepahy, A.A.; Kalantar, S.; Dabbagh, R. Isolation of Extremely Halophilic Archaea from a Saline River in the Lut Desert of Iran, Moderately Resistant to Desiccation and Gamma Radiation. Microbiology 2017, 86, 403-411. [CrossRef]

29. Shin, J.S.; Kim, B.G. Comparison of the $\omega$-Transaminases from Different Microorganisms and Application to Production of Chiral Amines. Biosci. Biotechnol. Biochem. 2001, 65, 1782-1788. [CrossRef]

30. Mathew, S.; Bea, H.; Nadarajan, S.P.; Chung, T.; Yun, H. Production of Chiral $\beta$-Amino Acids Using $\omega$-Transaminase from Burkholderia Graminis. J. Biotechnol. 2015, 196, 1-8. [CrossRef]

31. Guo, F.; Berglund, P. Transaminase Biocatalysis: Optimization and Application. Green Chem. 2017, 19, 333-360. [CrossRef]

32. Dreßen, A.; Hilberath, T.; Mackfeld, U.; Billmeier, A.; Rudat, J.; Pohl, M. Phenylalanine Ammonia Lyase from Arabidopsis Thaliana (AtPAL2): A Potent MIO-Enzyme for the Synthesis of Non-Canonical Aromatic Alpha-Amino Acids: Part I: Comparative Characterization to the Enzymes from Petroselinum Crispum (PcPAL1) and Rhodosporidium Toruloides (RtPAL). J. Biotechnol. 2017, 258, 148-157.

33. Schätzle, S.; Höhne, M.; Robins, K.; Bornscheuer, U.T. Conductometric Method for the Rapid Characterization of the Substrate Specificity of Amine-Transaminases. Anal. Chem. 2010, 82, 2082-2086. [CrossRef]

34. Schätzle, S.; Höhne, M.; Redestad, E.; Robins, K.; Bornscheuer, U.T. Rapid and Sensitive Kinetic Assay for Characterization of $\omega$-Transaminases. Anal. Chem. 2009, 81, 8244-8248. [CrossRef] [PubMed]

35. Koszelewski, D.; Tauber, K.; Faber, K.; Kroutil, W. $\omega$-Transaminases for the Synthesis of Non-Racemic $\alpha$-Chiral Primary Amines. Trends Biotechnol. 2010, 28, 324-332. [CrossRef] [PubMed]

36. Buß, O.; Dold, S.M.; Obermeier, P.; Litty, D.; Muller, D.; Grüninger, J.; Rudat, J. Enantiomer Discrimination in $\beta$-Phenylalanine Degradation by a Newly Isolated Paraburkholderia Strain BS115 and Type Strain PsJN. AMB Express 2018, 8, 149. [CrossRef] [PubMed]

37. Conti, E.; Stachelhaus, T.; Marahiel, M.A.; Brick, P. Structural Basis for the Activation of Phenylalanine in the Non-Ribosomal Biosynthesis of Gramicidin S. EMBO J. 1997, 16, 4174-4183. [CrossRef] [PubMed]

38. Yamada, M.; Kurahashi, K. Further Purification and Properties of Adenosine Triphosphate-Dependent Phenylalanine Racemase of Bacillus Brevis Nagano. J. Biochem. 1969, 66, 529-540. [CrossRef]

39. Yun, H.; Lim, S.; Cho, B.K.; Kim, B.G. w-Amino Acid: Pyruvate Transaminase from Alcaligenes Denitrificans Y2k-2: A New Catalyst for Kinetic Resolution of $\beta$-Amino Acids and Amines. Appl. Environ. Microbiol. 2004, 70, 2529-2534. [CrossRef]

40. Temple, K.L.; Colmer, A.R. The Autotrophic Oxidation of Iron by a New Bacterium: Thiobacillus Ferrooxidans. J. Bacteriol. 1951, 62, 605.

41. Buß, O.; Voss, M.; Delavault, A.; Gorenflo, P.; Syldatk, C.; Bornscheuer, U.; Rudat, J. $\beta$-Phenylalanine Ester Synthesis from Stable $\beta$-Keto Ester Substrate Using Engineered $\omega$-Transaminases. Molecules 2018, 23, 1211. [CrossRef]

42. Yoon, S.H.; Ha, S.M.; Kwon, S.; Lim, J.; Kim, Y.; Seo, H.; Chun, J. Introducing EzBioCloud: A taxonomically united database of $16 \mathrm{~S}$ rRNA gene sequences and whole-genome assemblies. Int. J. Syst. Evol. Microbiol. 2017, 67, 1613. [PubMed]

43. Brucher, B.; Rudat, J.; Syldatk, C.; Vielhauer, O. Enantioseparation of Aromatic $\beta^{3}$-Amino Acid by Precolumn Derivatization with o-Phthaldialdehyde and N-Isobutyryl-1-Cysteine. Chromatographia 2010, 71, 1063-1067. [CrossRef]

44. Buß, O.; Muller, D.; Jager, S.; Rudat, J.; Rabe, K.S. Improvement in the Thermostability of a $\beta$-Amino Acid Converting $\omega$-Transaminase by Using FoldX. ChemBioChem 2018, 19, 379-387. [CrossRef] [PubMed]

45. Gao, S.; Su, Y.; Zhao, L.; Li, G.; Zheng, G. Characterization of a (R)-Selective Amine Transaminase from Fusarium Oxysporum. Process Biochem. 2017, 63, 130-136. [CrossRef]

(C) 2019 by the authors. Licensee MDPI, Basel, Switzerland. This article is an open access article distributed under the terms and conditions of the Creative Commons Attribution (CC BY) license (http://creativecommons.org/licenses/by/4.0/). 

MDPI

St. Alban-Anlage 66

4052 Basel

Switzerland

Tel. +41616837734

Fax +41 613028918

www.mdpi.com

Catalysts Editorial Office

E-mail: catalysts@mdpi.com

www.mdpi.com/journal/catalysts

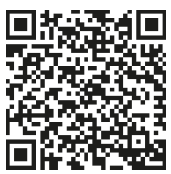



MDPI

St. Alban-Anlage 66

4052 Basel

Switzerland

Tel: +41 616837734

Fax: +41 613028918

www.mdpi.com 